
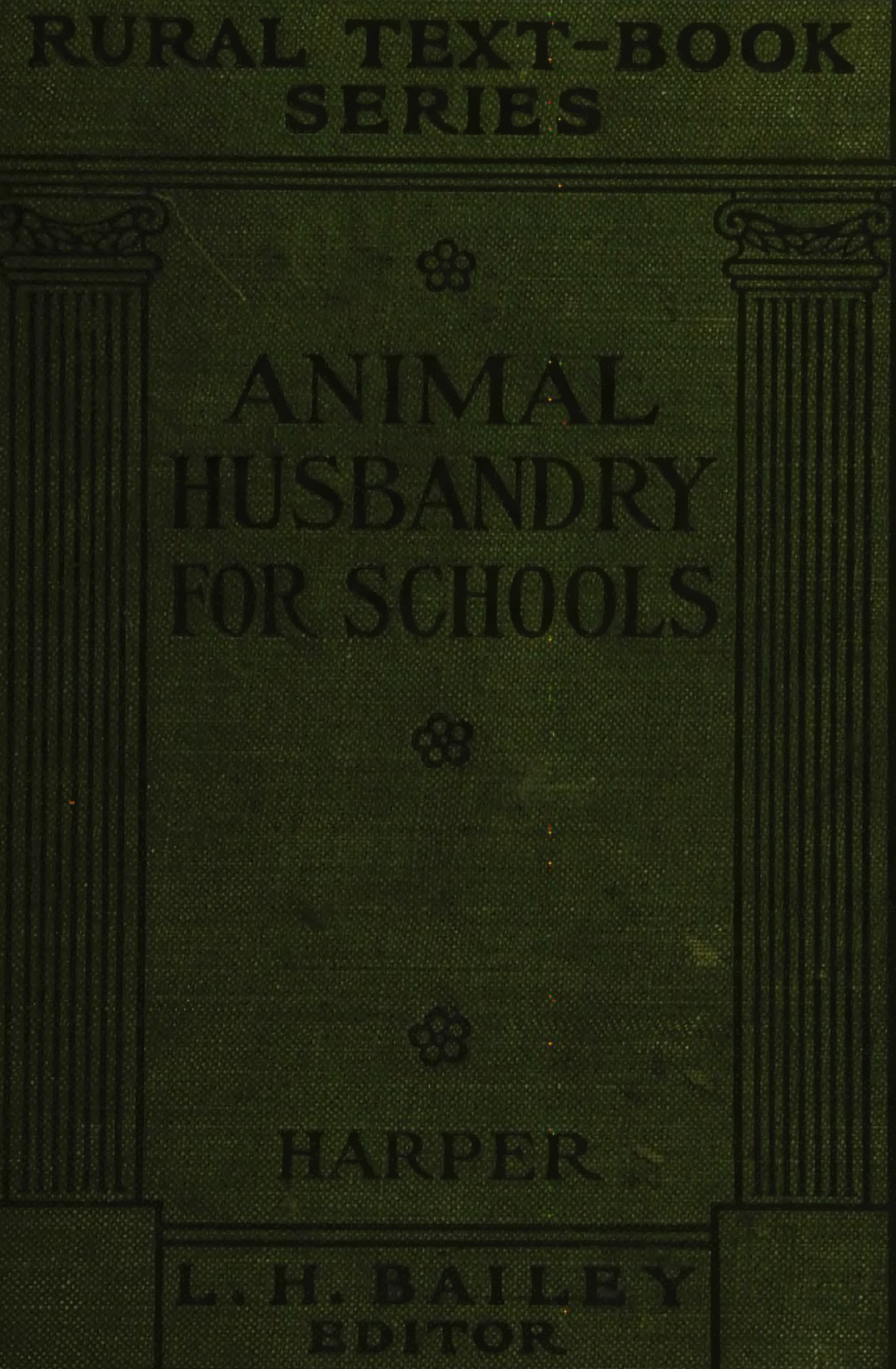


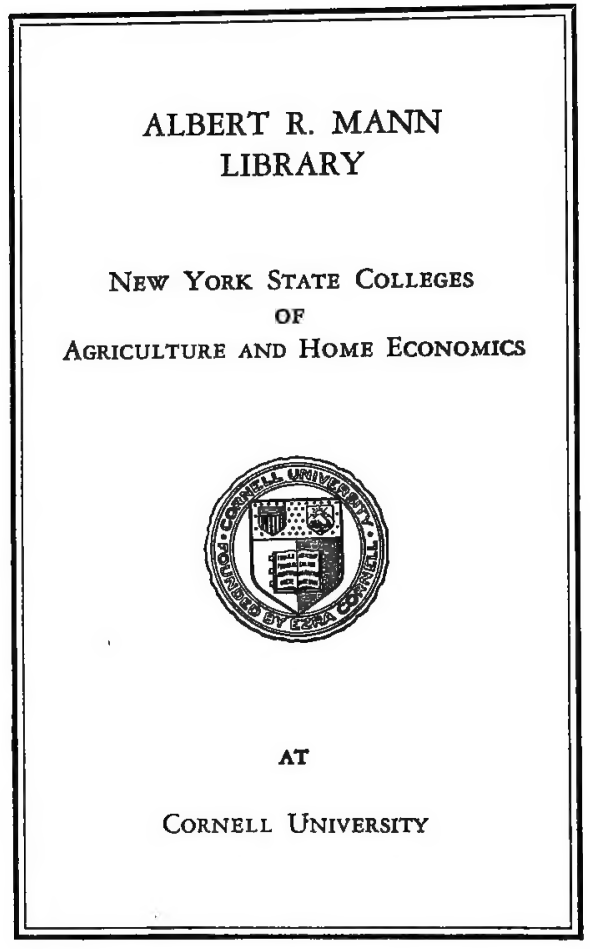




\section{SF $65 . \mathrm{H} 33^{\text {Cornell University Library }}$}

Animal husbandry for schools,

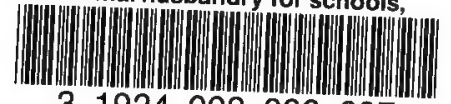

31924003080607 


\section{Cornell University Library}

The original of this book is in the Cornell University Library.

There are no known copyright restrictions in the United States on the use of the text.

http://www.archive.org/details/cu31924003080607 


\section{Tbe tRural Text=\$Book \$eries}

Edited by L. H. BAILEY

ANIMAL HUSBANDRY FOR SCHOOLS 


\section{The $\mathfrak{R u r a l}$ Text=ßBook Žries}

Lyon and Fippin, Principies of Soll ManAGEMENT.

G. F. Warren, Elements of Agriculture.

A. R. Mann, Beginnings in Agriculture.

J. F. Duggar, Southern Field Crops.

B. M. Duggar, Plant Physiblogt, with Special Reference to Plant Production. G. F. Warren, Fairm Management,

M. W. Harper, Antmal Hugbandry for Schools.

W. G. Montgomery, The Corn Crops.

H. J. Wheeler, Manures and Fertilizers. 


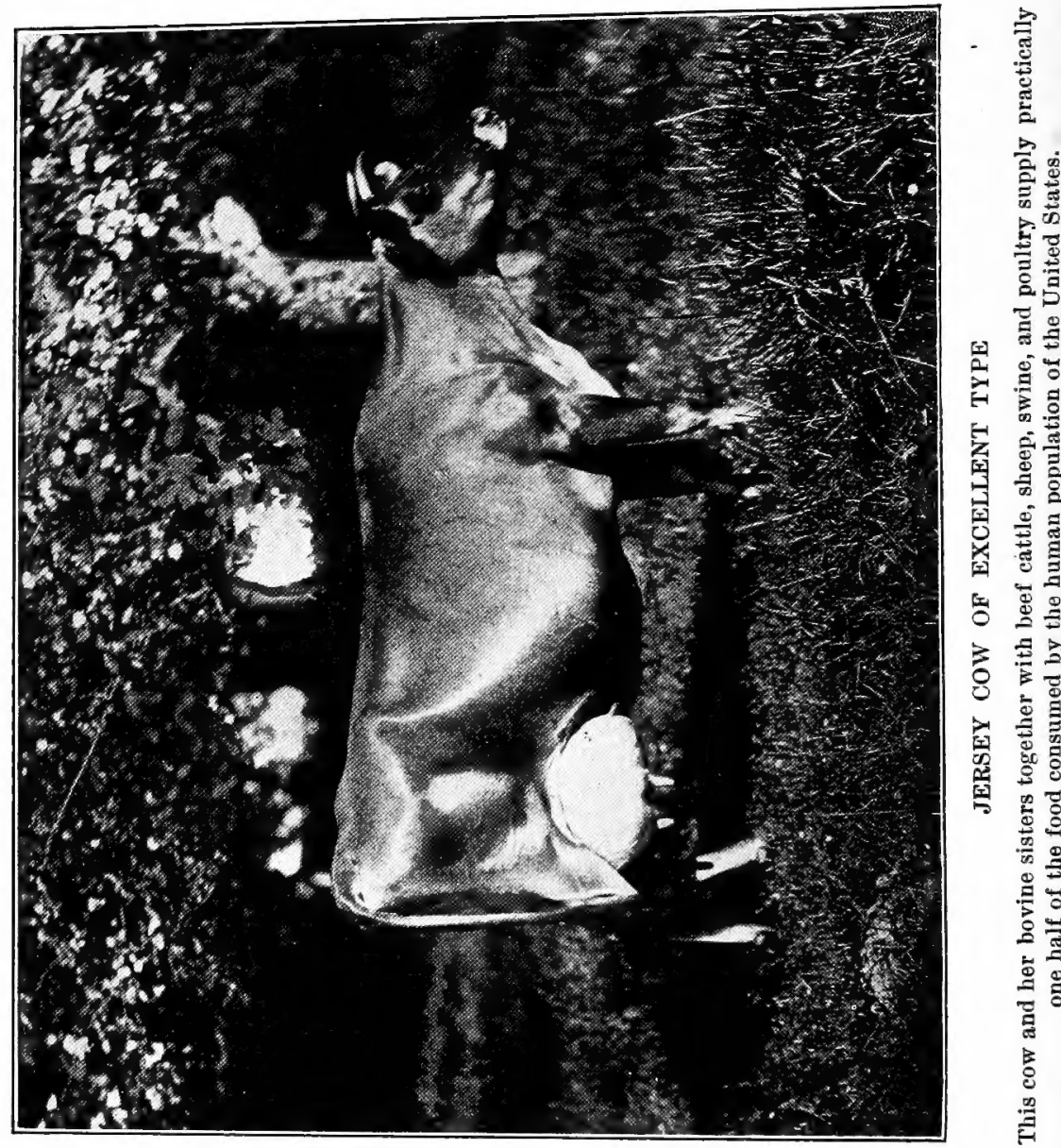


\author{
BY \\ MERRITT W. HARPER \\ ASSISTANT PROFESSOR OF ANIMAL HUSBANDRY IN THE \\ NEW YORK STATE COLLEGE OF AGRICULTURE \\ AT CORNELL UNIVERSIYY
}

Nefo 㷅ork THE MACMILLAN COMPANY 1915 


\section{8}

COPYRIGHT, 1913,

BT THE MACMILIAN COMPANT.

Set up and electrotyped. Published June, 1913. Reprinted September, 1913; March, I914; January, 19r5. 


\section{PREFACE}

THrs book is designed to introduce students to the study of Animal Husbandry in the schools, and also in colleges when only a short time can be given to the subject. Possibly it may be useful to the farmer or general reader who desires a book treating of the several classes of farm animals.

Now that agriculture is becoming recognized as an educational subject, there is an increasing demand for the subject-matter involved. Especially is there a demand for knowledge concerning the farm animals. It has been the aim of the author to cover the work very largely from a practical point of view. This is done with the thought that the pupils should be brought into close touch with actual farm affairs. In all courses of study involving the consideration of material objects, it is important to recognize that the pupil should study not only about the thing, but should study the object itself. In Animal Husbandry, especially, the importance of studying animals in all their circumstances cannot be too strongly recommended. Unfortunately this is not always possible, since many of the schools lack facilities and are far removed from the farms.

The arrangement of the subject-matter in a textbook of this class is important. There is utter lack of agreement anong Animal Husbandry instructors as to the method of presenting the subject. The method here employed was chosen after careful consideration as the most adaptable for beginners. Each class of farm animals is considered separately, the subject-matter being arranged under similar chapter headings. This has been done to clarify the text, and to make it possible for the teacher to consider the types and breeds of the several classes, the judging, feeding, management, and the like, without respect to a particular class, if he so desires.

The author realizes that it is often difficult to introduce Animal Husbandry into the schools, largely because of the lack of facilities. 
With this difficulty in mind, many exercises or practicums are sug. gested in the Appendix, in order that the teacher may choose such as he requires, or as his facilities permit. At least one exercise should be used each week. The exercises may be considered in any order to suit the convenience of the teacher. Neither the substance nor the form here proposed is vital. The teacher can modify them to suit his needs or plan others along similar lines.

When at all convenient, the teacher and pupils should visit stables, where animals are housed. This will provide an opportunity to study at first hand the subject-matter discussed in the text, and will add greatly to the interest and value of the work.

Realizing the difficulties of presenting Animal Husbandry in the schools, the author will be glad to correspond with teachers concerning their work, and also to receive criticisms or suggestions as to changes they find desirable in the text.

M. W. HARPER.

ITHACA, N. Y.

April 30, 1913. 


\section{CONTENTS}

\section{PART ONE - HORSES}

\section{CHAPTER I}

The Breeds of Horses .

The light type - The heavy type.

The Light Breeds of Horses

The Thoroughbred horse-History of the Thoroughbred horse - Description of the Thoroughbred horse - Famous Thoroughbred races - English track records - American track records - The Arabian horse - The Arabian compared with the Thoroughbred - The American Saddle horse - The American Saddle horse compared with the Thoroughbred - The Standardbred horse - History of the Standardbred horse - Hambletonian 10 - The Standardbred compared with the Thoroughbred Trotting and pacing records.

The Coach Breeds of Horses

The Hackney Coach horse - Description of the Hackney The French Coach horse - Classes of horses in France - The French Coach compared with the Hackney - The German Coach horse-German Coach compared with the Hackney-The Cleveland Bay Coach horse - Cleveland Bay compared with the Hackney.

The Draft Breeds of Horses .
The Percheron draft horse - Description of the PercheronThe French draft horse - The Clydesdale draft horse-Clydesdale compared with the Percheron - The Shire draft horse Shire compared with the Percheron - The Belgian draft horse - Belgian compared with the Percheron - The Suffolk draft horse - Suffolk compared with the Percheron.

The Pony Breeds of Horses

The Shetland pony - Welsh pony compared with the Shetland-Arabian and Hackney ponies-Mexican and Indian ponies.

The Breeds of Donkeys .

The mule and hinny.

Questions. 


\section{JuDGING HoRses}

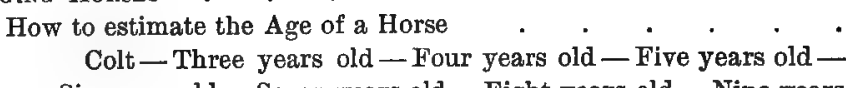

Six years old - Seven years old — Eight years old - Nine years old - Ten years old - Eleven years old - Aged horses.

Detecting Unsoundness . . . . . . . .

Blemish - Unsoundness - Impaired vision - Defective hearing - Poll-evil - Sweenied shoulders - Fistulæ - Splints Ring-bone - Side-bone - Scratches - Unsound hoofs - Thoroughpin - Spavin - Curb - Forging and overreaching.

The Horse Score-card . . . . . . .

Method of using the score-card - Rules of scoring - Scorecard for horses - Measurements of horses.

General Appearance in Light Horses $\quad$. . . . . . . $\quad 44$

The height - Eorm - Action - Quality - Temperament.

Detail Characters or Features of a Light Horse . . . .

Head - Neck - Chest - Shoulders - Arms - Elbows -

Forearms - Knees - Cannons - Fetlocks - Pasterns - Feet -

Ribs - Body - Loins - Croup - Thigh - Hocks.

Judging a Heavy Horse . . . . . . . . . 50

General appearance in heavy horses - Weight - Form Action - Market classes of horses.

Questions . . . . . . . . . . . .

\section{CHAPTER III}

Principles of Feeding . Food .

Use of food - Composition of food - Water - Ash - Protein - Carbohydrates - Fat.

Functions of Food Materials

Water - Ash - Protein - Carbohydrates - Fat.

Digestibility of Food .

Digestion - Size of digestive organs - Digestible nutrients Digestibility of food materials.

Maintenance Rations and Productive Rations .

Maintenance rations - Productive rations - Feeding-standards for farm animals. . 
Balanced Ration . . . . . . . . . .

Nutritive-ratio-Computing rations - Wolff-Lehman Method - Armsby's method.

Questions

\section{CHAPTER IV}

Feeding tpe Horse

Food requirements for work - Regularity in feeding - Order of supplying food - Watering the horse - Salt - Individual rations.

Feeding the Work Horse

Amount to feed - Method of feeding - Cost of a ration Feeding mules - Feeding the brood mare.

Feeding the Foal . . . . , . .

Food for the young foal - Feeding grain - Weaning the foal - Sample rations for the horse.

Questions

\section{CHAPTER V}

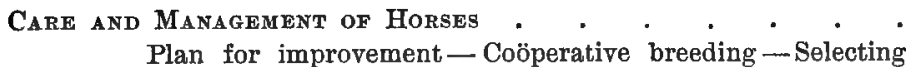
breeding stock - The breed and type - Uniformity - Soundness - Registration of farm animals.

Grooming and Care . . . . . . . . . .

Care of the horse's teeth - Clipping - Bedding the horse Blankets-Stable blanket-Outdoor blanket-Care of the feet-Growth of hoof - Shoeing - Treating sick horse's Feeding sick horses.

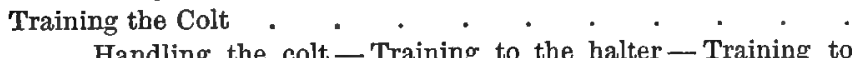
90

Handling the colt - Training to the halter - Training to drive with lines-Training to the uses of the bit - Importance of a good mouth - Bitting the colt - Harnessing the colt - Hitching double - Hitching single.

Harness and Harnessing .

The bridle - The bit - The check-rein - Fitting the collar - Breast harness - Fitting the back-strap and crupper - Fly nets - Caring for harness. 


\section{PART TWO-CATTLE}

\section{CHAPTER VI}

Breeds of Cattue

The dairy type - The beef type.

The Major Breeds of Dairy Cattle .

Jersey dairy cattle - Inspection of Jersey cattle - Description of Jersey cattle - Jersey milk and butter-fat records Holstein-Friesian dairy cattle - Description of Holstein-Friesian cattle - Holstein-Friesian milk and butter-fat records Guernsey dairy cattle-Description of Guernsey cattleGuernsey milk and butter-fat records - Ayrshire dairy cattle - Description of Ayrshire cattle - Ayrshire milk and butterfat records.

The Minor Breeds of Dairy Cattle . . . . . .

Dutch-Belted cattle - Brown Swiss cattle - French-Canadian cattle-The Kerry cattle.

The Major Breeds of Beef Cattle .

Shorthorn beef cattle - Shorthorn families - Description of Shorthorn cattle - Hereford beef cattle - Hereford compared with the Shorthorn - Aberdeen Angus beef cattle Aberdeen Angus families - Aberdeen Angus compared with Shorthorn - Galloway beef cattle - Galloway compared with the Shorthorn.

The Minor Breeds of Beef Cattle.

Polled Durham cattle-Devon cattle - Red Polled cattle

- Sussex cattle - West Highland cattle. Questions

\section{CHAPTER VII}

Judging Cattle

How to estimate the age of cattle-Examination of the horns.

Judging Dairy Cattle

Score-card for dairy cattle - Measurements of cattle.

General Characteristics in Dairy Cattle .. . . . . .

Form - Quality - Constitution - Temperament. 
Detail Characteristics of a Dairy Cow

Head — Neck — Horequarters - Body - Hindquarters -

Udder - Milk veins - Milk signs.

Judging Beef Cattle

Score-card for Beef Cattle.

General considerations of Beef Cattle

Form of beef cattle - Quality of beef cattle - Condition of the feeder-Uniformity among feeders.

Detail Characteristics of Beef Cattle

Head - Neck - Forequarters - Body - Hindquarters -

Fat steer-Market classes of beef cattle - Cuts of beef.

Questions

\section{CHAPTER VIII}

\section{Feeding Datry Cattue}

Food requirements for milk.

Effect of Food on the Composition of Milk . . . . .

Effect of food on total solids - Effect of food on the percentage of fat-Food and flavor of milk - Order of supplying food-Effect of food on quantity of milk - Watering the milking cow.

Feeding the Milking Cow

Summer feeding of dairy cattle - Soiling - Winter feeding of dairy cattle - Concentrated feeds-Dry forage - Succulent feeds - Silage - Roots and tubers.

The Calf

Feeding the calf-Danger of overfeeding calf-Calf on whole milk - Calf on skim-milk-Removing horns from young calves - Sample rations for the dairy cow.

Questions

\section{CHAPTER IX}

\section{Care and Management of Dairy Cattle}

Sanitary Milk

The cow-The stables - Milk-house - Milk utensils -

- Milking - Milking machines - Milk-reeords - Method of keeping records - Valne of milk-records.

Testing Milk for Butter-fat
Sampling the milk-Using the acid - Whirling the bottles

- Reading the percentage of fat-C.Testing associations General plan of organization-Records of performance and 
of breeding - The individual animal the unit of improvement

- Formation of the dairy herd.

The Dairy Barn

Light in abundance should enter the dairy barn - Ventilation essential to health - King's system of ventilation - Window ventilation - Floors are best made of cement - The silo The size of the silo-Filling the silo.

Diseases of Cattle

Tuberculosis - Methods of infection - Prevention of tuberculosis.

Questions

\section{CHAPTER $\mathrm{X}$}

\section{Feedivg Beef Cattle}

Essentials of Feeding Cattle

Age at which to feed cattle - Form for feeding cattleCondition of feeding cattle - Quality of feeding cattle - Uniformity in feeding cattle - Food requirements for beef - W intering stockers and feeders - Roughage increases feeding capacity.

Summer Feeding on Pasture .

Method of summer feeding - How to turn to grass - Feeding grain to cattle on pasture-The pastures.

Winter Feeding in Drylot

Feeding grain to cattle in dry-lot - Baby-beef - Feeding for baby-beef production - Sample rations for fattening cattle. Questions

\section{CHAPTER XI}

Care and Management of Befe Cattee

Plan of improvement-Coöperative grading-up-Raise heifer calves from best cows - Farms for fattening cattle. Equipment for Summer Feeding

Pasture - Feed-bunk - Self-feeder — Shades - Water Salt.

Equipment for Winter Feeding

Shelter for winter feeding - The feed-pot-Platform for feed-bunks - Dry-forage-rack — Water-tanks. Questions 


\section{PAR'T THREE - SHEEP}

\section{CHAPTER XII}

\section{Breeds of Sheep}

The fine-wool type - The mutton type.

American Merino fine-wool sheep - Description of American Merino fine-wool sheep-The American Merino fleeces -Delaine Merino fine-wool sheep-Delaine Merino compared with American Merino - Rambouillet fine-wool sheep - Rambouillet compared with the American Merino.

The Mutton Breeds of Sheep .

Southdown mutton sheep - Description of the Southdown sheep - Shropshire mutton sheep-Shropshire compared with the Southdown - Hampshire mutton sheep - Hampshire compared with Southdown - Oxford Down mutton sheep - Oxford Down compared with Southdown - Suffolk Down mutton sheep - Suffolk Down compared with Southdown - Dorset-Horned mutton sheep - Dorset-Horned compared with Southdown-Cheviot breed-Cheviot compared with the Southdown.

Long-wool Breeds of Mutton Sheep

Leicester long-wool sheep - Description of Leicester sheep -Cotswold long-wooled sheep - Cotswold compared with the Leicester - Lincoln long-wooled sheep-Lincoln compared with Leicesters - Black-faced Highland sheep. Goats

Angora goat - Milk goat.

Questions

\section{CHAPTER XIII}

Jodging Sheep

Catching sheep-Holding sheep-How to estimate the age of sheep - Score-card for sheep.

General Appearance of Sheep

Form - Condition and weight-Quality - Constitutional vigor - Uniformity.

Detail Characters of Sheep

$$
\text { Head - Neck - Shoulders - Chest-Body - Rump-Leg }
$$


of mutton - Legs - Examination of the fleece - Market classes of sheep - Cuts of mutton.

Questions

\section{CHAPTER XIV}

Feeding Sheep

Sheep are delicate - Food requirements for sheep.

231

Feeding the Flock .

The flock in summer-Pasture for sheep-Turning to pasture - Change in pasture - Providing shade - The use of sown pastures - The flock in winter - The winter ration Exercise - Care of the feet-Bedding.

Fattening Sheep

Growing winter lambs - The winter quarters for winterlamb production - Feeding the lambs - Growing spring lambs - Feeding lambs in the fall-Getting the lambs on full feed - Fattening lambs in winter-Feeding in the semi-arid West-Feeding in the corn-belt-Feeding in the East Sample rations for fattening sheep.

Questions

CHAPTER XV

Care and Management of She

Plàn of improvement-Coöperative breeding - Choosing breeding stock - Type - Uniformity .

Dipping Sheep

Importance of dipping - The dipping vat-How dips are used-Frequency of dipping.

Shearing Sheep

When to shear - Hand shearing - Machinery shearing Tying the wool - Docking the lambs.

Practical Sheep Barns

Ventilation - Drainage - The interior arrangement - The feed-racks - The quantity of bedding - The sheep lot. Questions

\section{PART FOUR - SWINE}

\section{CHAPTER XVI}

Breeds of Swine

Lard type - Bacon type. 
Pure Lard Breeds of Swine

Poland China lard-hog - Description of Poland China hog - Berkshire lard-hog-Berkshire compared with Poland China - Duroc-Jersey lard-hog - Duroc-Jersey compared with Poland China - Chester White lard-hog — Chester White compared with Poland China - Hampshire lard-hog - Hampshire compared with Poland China - Essex lard-hog-Essex compared with Poland China - Small Yorkshire lard-hogSuffolk lard-hog.

Intermediate breeds of swine

Cheshire hog - Description of the Cheshire - Victoria hog - Victoria compared with Cheshire - Middle Yorkshire hog. Pure Bacon Breeds of Swine . . . . . . . .

Large Yorkshire bacon-hog-Description of the Large Yorkshire - Tamworth bacon-hog - Tamworth compared with Large Yorkshire.

Questions

\section{CHAPTER XVII}

JUDGING Swine

Score-card for swine.

General appearance of Lard-hogs .

Form - Weight and condition - Quality - Constitution Uniformity.

Detail Characters of the Lard-hog

Head - Jowls - Neck - Shoulders - Back and loin — Sides

- Rump-Hams - Legs.

Judging Bacon-hogs

Condition - Form - - Sides - Market classes of swine - Cuts of pork.

Questions

\section{CHAPTER XVIII}

The Feeding of Swine

Food requirements for swine.

Preparing Food for Swine

Grinding feed - Soaking the feed-Cooking the feed Feeding the pigs - Weaning the pigs. 
Feeding the Breeding Herd . .
Feeding the herd in summer - Pasture for swine - Roots for swine - Pumpkins and squashes-Feeding the herd in winter.

Fattening Swine

Feeding the lard-hog - Feeding the lard-hog in summer Feeding the lard-hog in winter-Feeding the bacon-hog Summer feeding on pasture-Winter feeding in dry-lotSample rations for swine.

Questions

\section{CHAPTER XIX}

Care and Management of Swine

Plan of improvement - Coöperative breeding - Selecting breeding stock - The type - Uniformity - Dipping swine. Shelter for Swine .

The large hog-house - The individual hog-house - The hog lot - Hog-wallows - Diseases of swine - Hog cholera Prevention of cholera - Quarantine lot. Questions

\section{PART FIVE-POULTRY}

\section{CHAPTER XX}

Breeds of Poultry.

The egg type-Tlie meat type - The general purpose type - Ornamental type.

The Egg Type of Fowls .

Characteristics of egg breeds.

The Meat Type of Fowls

Characteristics of meat breeds.

General Purpose Breeds of Fowls .

Characteristics of general purpose breeds.

The Ornamental Breeds of Fowls .

Characteristics of ornamental breeds.

Turkeys, Ducks, Geese, and Guinea-Fowls 
How to estimate the age of poultry - Young fowls - Old fowls.

Methods of Judging Poultry .

Comparative judging - Score-card judging - Score-card for poultry.

Detail Characters of Fowls

Symmetry - Weight - Condition - Head - Comb - Wattles and ear-lobes - Neck - Back - Breast - Body and Fluff Wings - Tail - Legs and toes.

Questions

321

324

\section{CHAPTER XXII}

\section{Feeding Poultry}

Essentials of Feeding Poultry

Grit and mineral matter-Meat scraps-Green foodPreparation of grain - Nutritive ratio.

Feeding Young Chickens

Frequency of feeding - Amount to feed - Sorting uneven flocks - Exercise.

Feeding for Egg Production.

Feed a variety - Amount to feed - Condition of fowls -

Mineral matter.

Feeding for Meat Production

Feeding the fowls - Kind of food - Broilers - Roasters -

Sample rations for poultry.

Questions

\section{CHAPTER XXIII}

Care and Management of Poultry

$337-348$

Improvement of fowls - Incubation - Natural incubation - Artificial incubation - Brooders.

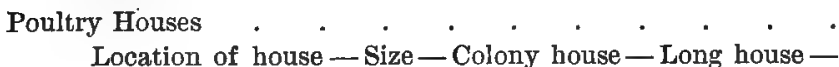

Scratching-shed - Windows - Floors - Interior fixtures -

Labor-saving appliances - Yards, parks, and ranges.

Questions 


\section{APPENDIX}

Dhass

- Part I. Laboratory Exercises

1. Habits of domestic animals - 2. Age of farm animals -3. Measuring horses - 4. Scoring the horse - 5. Weighing the horse -6 . Soundness -7 . Harness and harnessing -8. Splicing a rope-9. Rope halter - 10. Plan of horse barn - 11. Mixing feed-12. Hays - 13. Nutritive ratio14. Forming a ration - Choosing foods for a ration15. Forming a ration for a horse-16. Measuring grain -17 . Measuring hay - 18. Measuring silage - 19. Scoring the dairy cow -20 . Measuring dairy cows -21 . Forming ration for a dairy cow-22. Cost of milk-23. Removing horns - 24. Plans for a cow barn-25. Rough analysis of milk - 26. Qualitative determination of milk ash -27. Test for per cent of fat by the Babcock method. - 28. Babcock test for skimmed milk-29. Babcock test for cream30. Babcock test for whole milk using different amounts of acid. - 31. Effect of dirt in the keeping qualities of milk 32. Study of the keeping qualities of milk - 33. Pasteurization of milk - 34. Study of milk bacteria - 35. Preparation of a starter culture for butter making - 36. Study of starter made in last exercise - 37. Cottage cheese making 38. Weight of dressed carcass by measurement - 39. Cuts of meat-40. Wool -41. Forming a ration for sheep42. Plan of sheep barn - 43. Age, sex, and vitality of fowls -44. Egg and meat types - 45. Making material for killing chicken lice - 46. Killing chicken lice--47. Poultry houses -48. Coop for hen with chicks - 49. Feed-Hoppers for poultry - 50. Structure of the egg - 51. Preserving eggs.

Part II. Agriculturat Library . . . . . .

882

Part III. Adpresses of Agricultural Colleges and Experiment Stations and of the United States Department of Agriculture

Part IV. Average Weights of Feeding Stuffs. . . . Part V. Energy Values of Feeding Stuffs . . . . 386-387

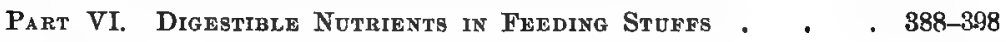
INDEX 


\section{LIST OF ILLUSTRATIONS}

Jersey cow of excellent type

Frontispiece

Points of the horse

PAGF:

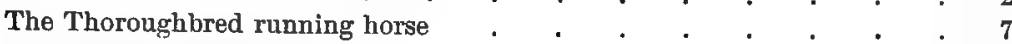

The Arabian horse.$\quad$. $\quad . \quad$. . . . . . . . . 9

The American Saddle horse . . . . . . . . . . 10

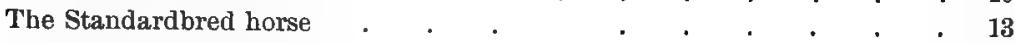

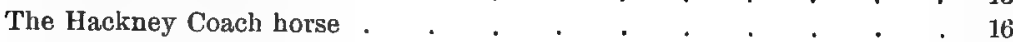

The French Coach horse . . . . . . . . . . . 17

The German Coach horse . . . $\quad$. . . . . $\quad$. 19

The Percheron draft horse . . . . . . . . . 22

The Clydesdale draft horse . . . . . . . . . . . 24

The Shire draft horse . . . . . . . . . . 26

The Belgian draft horse . . . . . . . . . . 27

The Suffolk draft horse . . . . . . . . . 28

Shetland ponies . . . . . . . . . . . . . 30

Catalonian Jack . . $\quad$. . . . . . . . . 32

Lower front teeth of the horse at three years of age . . . . . . $\quad 36$

Lower front teeth of the horse at four years of age . . . . . . . 36

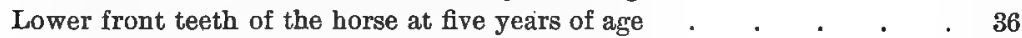

Lower front teeth of the horse at six years of age . . . . . 36

Lower front teeth of the horse at seven years of age . . . . . $\quad 36$

Lower front teeth of the horse at eight years of age . . . . . $\quad$. 36

Lower front teeth of the horse at nine years of age . . . . . . 36

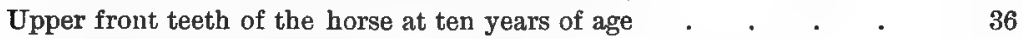

Upper front teeth of the horse at eleven years of age . $\quad . \quad$. $\quad . \quad$. 37

Upper front teeth of the horse at twenty-one years of age . $\quad . \quad$. $\quad$. 37

Side view of horse's teeth at five years of age . . . . . . . 37

Side view of horse's teeth at twenty-one years of age . . . . . . . 38

Light horse of good form . . . . . . . . . . 45

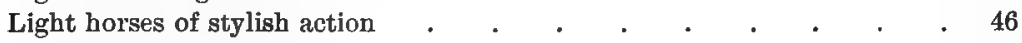

Draft horse of good form . . . . . . . . . . 50

Percheron stallion . . . . . . . . . . . . . 55

Clydesdale mare . $\quad . \quad$. $\quad . \quad$. $\quad . \quad$. $\quad . \quad$. 57 
Shire mare - . . . . . . . . . . . . 61

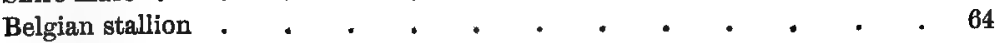

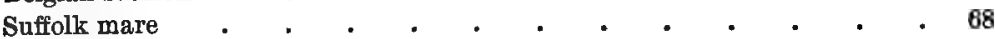

A well-fed draft team . . . . . . . . . . . . . 74

Hackney Coach mare and foal three weeks old . . . . . . . 77

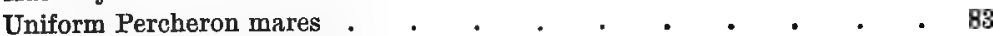

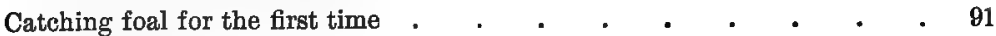

Teaching foal to lead . . . . . . . . . . . . . . . 92

Bitting harness . . . . . . . . . . . . . 94

Acquainting the horse with the training cart . . . . . . . . . 96

Types of collars . . . . . . . . . . . . . . . . 100

Points of the dairy cow $. \quad . \quad . \quad . \quad . \quad . \quad . \quad . \quad . \quad . \quad 104$

Points of the beef cow $\quad . \quad$. . . . . . . . . . . . . 106

The Jersey cow "Tormentor's Lass" . . . . . . . . . 109

The Holstein-Friesian cow "Colantha 4th's Johanna" . . . . . 112

The Guernsey cow "Dolly Dimple" . . . . . . . . . 114

The Ayrshire cow . . . . . . . . . . . 116

The Dutch-Belted cow . . . . . . . . . . . 118

The Brown Swiss cow . . . . . . . . . . . 118

The Shorthorn bull "Avondale" . . . . . . . . . . . 121

The Hereford cow . . . . . . . . . . . . 123

The Aberdeen Angus steer "Shamrock 2d" . . . . . . . . 125

Galloway heifers . . . . . . . . . . . . . 126

Devon herd . . . . . . . . . . . . . . . 127

Red Polled herd . . . . . . . . . . . . . 128

Cow's teeth arranged according to age . . . . . . . . 130

Dairy cow of good type . . . . . . . . . . . . . . 134

Beef steer of good type $\quad$. . . . . . . . . . . 140

Diagrams of cuts of beef $\quad$. $\quad . \quad$. . . . . . . . 142

Holstein-Friesian cow . . . . . . . . . . . . . 146

Jersey cow . . . . . , . . . . . . . . . 151

Apparatus for cooling milk . $\quad$. . . . . . . . . 159

Apparatus for testing milk for percentage of butter-fat . . . . 163

Dairy barn and silos . . . . . . . . . . . 166

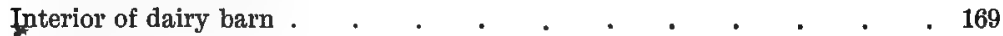

Fattening steers on pasture . . . . . . . . . . . . . . . 188

Points of the sheep . . . . . . . . . . . . . . . . . . . 196

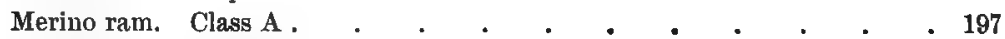

Merino ram. Class B . . . . . . . . . . . 198

Merino ram. Class C . . . . . . . . . . . 198 
The Delaine Merino ram "Beacon" .

The Rambouillet .

The Southdown

The Shropshire

The Hampshire

The Oxford

The Suffolk .

The Dorset-Horned

The Cheviot

The Leicester

The Cotswold

The Lincoln

The Black-faced Highland

Sheep's teeth arranged according to age

Mutton sheep of good type .

Judging sheep. Fullness of shoulders

Width of chest

Fullness of back at shoulder tops

Fullness of back at loins

Width of rump

Condition of leg of mutton

The finest of the fleece

The coarsest of the fleece

Diagrams of cuts of lamb and mutton .

Flock of Shropshire sheep

Flock of Southdown lambs .

Shearing sheep by machinery

Shearing the back

Sheep and wool when finished

Interior view of sheep barn .

Points of the pig .

The Poland China

The Berkshire

The Duroc-Jersey

The Chester White

The Hampshire

The Small Yorkshire

The Cheshire 
The Large Yorkshire

The Tarnworth

Lard hog of good type

Diagrams of the cuts of pork

A thick, fat porker

A well-finished bacon hog $\cdot$

A pen of well-bred Chester White swine The individual hog-house

Points of the fowl

The White Leghorn male

The White Leghorn female

The Light Brahma male

The Light Brahma female

The Barred Plymouth Rock male

The Barred Plymouth Rock female

The Hamburg

The turkey .

The Pekin duck

A flock of geese

Judging poultry

Young chicks feeding in litter of straw

Feeding the flock. Colony houses

A breeding flock of White Leghorn

The long poultry house

Poultry house with scratehing shed

Interior fixtures of the poultry house

Outdoor feed hopper

Parts of harness

Side.splice, first stage .

Side splice, second stage

Side splice, third stage

Side splice, fourth stage

Side splice, fifth stage .

Side splice completed .

Rope halter. Forming the eye

Rope halter. Loose guard, loop type .

Rope halter. Standard guard, loop type

Rope halter. Spliced halter

Whipping the end of a rope

273

277

282

290

291

297

300

306

300

309

311

312

315

315

316

317

319

320

324

329

331

338

342

343

344

346

351

352

352

353

353

353

353

354

355

355

356

Section of an egg 


\section{PART ONE - HORSES}

WITH A GENERAL CHAPTER ON FEEDING OF ANIMALS 


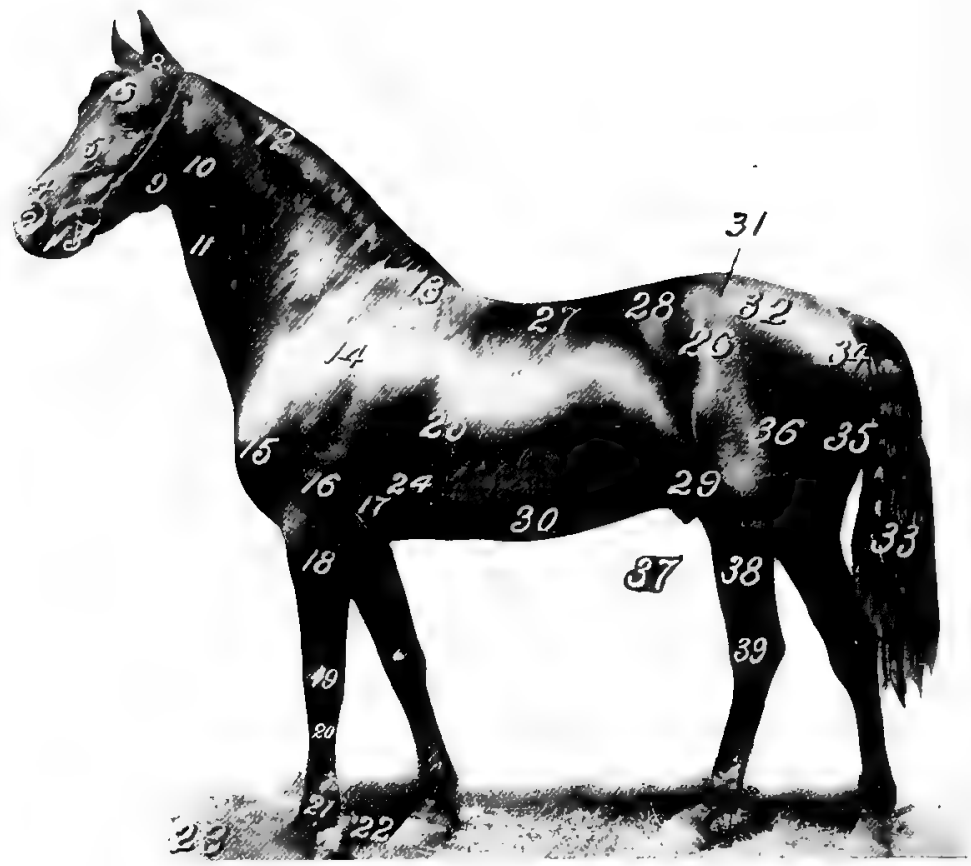

Fig. 1. - Points of the horse.

1. Mouth.

2. Nostril.

3. Chin.

4. Nose.

5. Face.

6. Forehead.

7. Eye.

8. Ear.

9. Lower jaw.

10. Throatlatch.

11. Windpipe.

12. Crest.

13. Withers.
14. Shoulder.

15. Breast.

16. Arm.

17. Elbow.

18. Forearm.

19. Knee.

20. Cannon.

21. Fetlock.

22. Pastern.

23. Fort.

24. Fore flank.

25. Heart girth,

26. Coupling.
27. Back.

28. Loin.

29. Rear flank.

30. Belly.

31. Hip.

32. Croup.

33. Tril.

34. Buttock,

35. Quarters.

36. Thigh.

37. Stifle

38. Lower thigh.

39. Hock. 


\title{
ANIMAL HUSBANDRY
}

\author{
CHAPTER I \\ THE BREEDS OF HORSES
}

There are two distinct types of horses, - light and heavy. The light is useful for driving and light, fast work. This group is further divided into running, trotting, pacing, saddling, coaching, and similar types. Horses belonging to the light type are usually designated light horses, while those belonging to the heavy are called draft horses. As the form or conformation best adapted for one type is different from that of the other, we cannot find both united in the same animal. It is a physical impossibility to have maximum speed and maximum draft in the same engine, and it is no less the case among horses.

1. Light type. - In conformation, horses belonging to the light type vary considerably, depending on the purpose for which they are adapted. For example, the saddle horse differs in many respects from the running horse, and the trotter or pacer has many characteristics unlike either. However, since all horses belonging to the light type are intended for light and rather fast work, they possess many points in common.

In general conformation, the light type of horse is rather tall, the limbs long, and the distance from the chest to the ground is more than one-half the height of the horse from the withers to the ground. The distance from the withers to the knee and from the hips to the hock is great. The animals are somewhat narrow but rather deep in front. In general form the light type resembles the greyhound. 
2. Heavy type. - In general conformation, the heavy type of horse is massive, blocky, low set, the limbs short, and the distance from the chest to the ground one-half the beight of the animal from the withers to the ground. In general form, this type resembles the bull dog. Weight is important. In order to pull heavy loads the draft horse must possess plenty of weight. A draft horse in fair condition at maturity weighs from fifteen hundred to twenty-four hundred pounds, according to class.

There are several breeds belonging to each of these types. We have various light breeds developed to perform light, fast work; coach breeds for stylish action and coach work; and draft breeds to perform light, medium, and heavy draft work. In addition, there are several breeds of ponies, produced, in this country at least, largely to meet the needs of children and for saddle purposes.

\section{THE LIGHT BREEDS OF HORSES}

The several breeds of light horses owe their development to their environment. Much of the early improvement is due to horses from Arabia, a country especially noted for the quality of her horses. The rather dry, barren soil makes it necessary for the horses to graze over large areas to secure sufficient food. A natural selection, therefore, is continually at work, and only the horses of quality and endurance survive. It is stated, also, that the food, though scant, stimulates the development of dense, firm bone. Horses from Arabia have been introduced into many countries to improve the light breeds.

3. The Thoroughbred horse. - This is the running race horse of England. In connection with the Arabian horse the Thoroughbred has been the fountain head at one time or another of all that stands for quality among the light breeds of horses. This breed is very popular among English sportsmen.

4. History of the Thoroughbred horse. - There have been running horses in England from the beginning of the thirteenth 
century. Improvement has been made from time to time by the importation of superior animals to be mated with the foundation stock of the country, the origin of which is unknown. The Romans introduced horses of light build, and running horses were brought from Germany. Spanish horses were also used in the improvement. Then followed Arabian horses. Charles II, of England,

The Name, Native Home, Approximate Height, Weight, Uses, and Common Color of Each of the Breeds of Light Horses

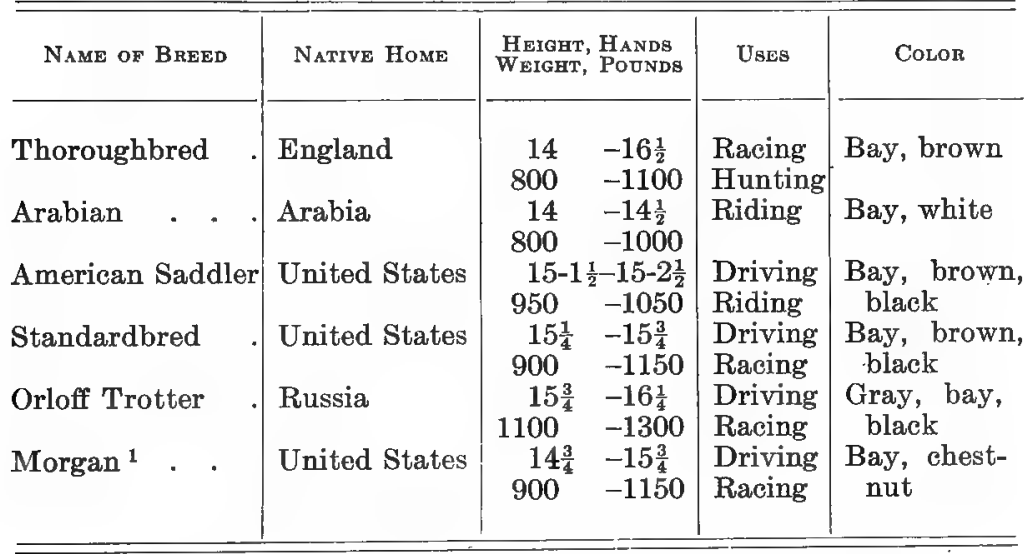

1 Sometimes considered merely a family of the Standardbred.

introduced the Royal Mares from Arabia and other Oriental countries. The end of the seventeenth and beginning of the eighteenth century witnessed the arrival of the most famous of these Oriental horses. In 1689, Byerly Turk was introduced by Captain Byerly; in 1706, Darley Arabian was imported from Aleppo, Syria, by a Mr. Darley; and in 1728, Godolphin Barb was imported by Lord Godolphin. From these notable horses sprang the three most famous Thoroughbred sires as follows: Herod, descending from Byerly Turk; Eclipse, descending from Darley 
Arabian; and Matchem, descending from Godolphin Barb. The Thoroughbred has been bred without stain of alien blood for considerably more than a century, and subjected to the most rigorous system of selection for strength and staying power by the test of performance on the turf.

5. Description of the Thoroughbred horse. - The head is fine and lean and of moderate size; the eyes prominent and intelligent; and the ears of medium size and carried in a lively manner. The neck is long and fine; the shoulders slope obliquely back; the chest tends to be narrow yet deep; the body is cylindrical with the depth at withers rather less than half the height, and with the underline from elbow to stifle longer than the top line from withers to hips. The croup is long and level, with the tail attached medium high and carried gracefully. The hindquarters are a distinctive feature of the breed, being long, strongly muscled, and exhibitingt great driving power. The legs above the knees and hocks are long and distinctly muscled. The knee and hock joints are of medium size, clearly defined, and strongly supported. The cannons are short, deep, and clean cut, with tendons well detached. The pasterns are rather sloping, being carried at an angle of about 45 degrees. The feet are of medium size, wide, and high at the heel. The action is a very important feature and should be straight, free, and easy (Fig. 2).

6. Famous Thoroughbred races. - With this breed races are run under the saddle. The rider or "jockey" must be of light weight and skilful. Running events are looked upon with favor in England, where there are many famous race courses. The socalled "classics" of the English turf are the St. Leger, established in 1776; the Epsom Oaks, first run in 1779; the Epsom Derby, established in 1780; the Two Thousand Guineas, first run in 1809 ; and the One Thousand Guineas, established in 1814. Over each of these tracks many famous contests have been held and at the present time they are considered the center of English social and sporting functions. 


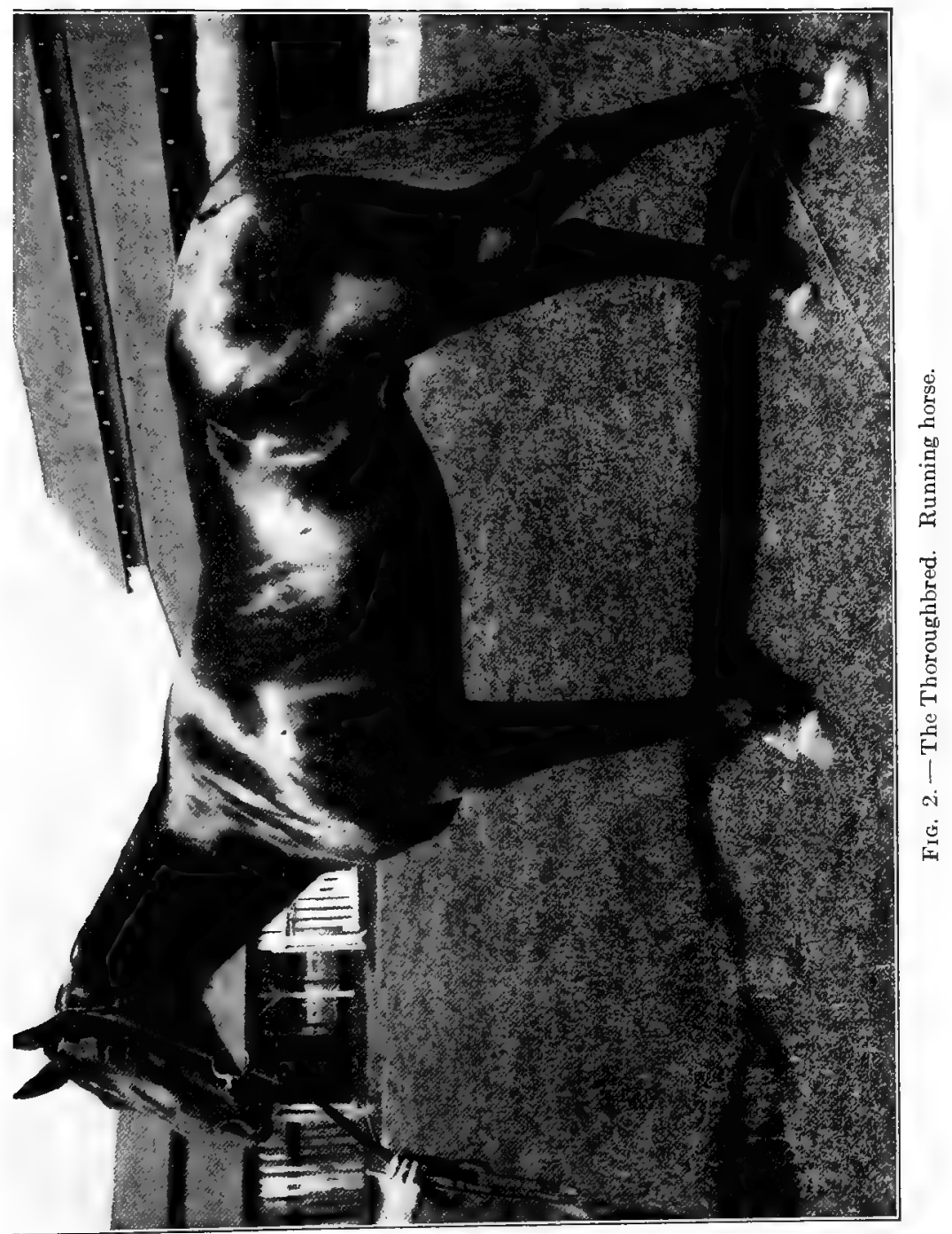


In England all of the major racing events are for comparatively long distances, and as a rule over a straight course. As a result of these long races the English Thoroughbred shows great endurance at high speed.

7. English track records. - The following table shows the length of the course and the comparative track record for each of the major English Classics:-

Comparative Track Records in England

\begin{tabular}{|c|c|c|c|}
\hline Name of Track & Length of Track & YEAR & RECORD \\
\hline St. Leger & 1 mile, 6 furlongs and 132 yards & 1910 & 3.04 \\
\hline Epsom Oaks & $1 \frac{1}{2}$ miles and 29 yards & 1905 & 2.38 \\
\hline Epsom Derby & $1 \frac{1}{2}$ miles and 29 yards & 1910 & $2.35 \frac{x}{5}$ \\
\hline
\end{tabular}

8. American track records. - In America, running races are conducted over the ordinary race course, and as a rule for much shorter distances than in England. All things considered, racing is not held in so high favor here as in England. There are, however, a number of annual events held in the United States, perhaps a greater number than in England, though they are not so well patronized.

The following table shows the comparative track records for a few of the more noted tracks at various distances:-

Comparative Track Records in America

\begin{tabular}{|c|c|c|c|c|c|c|}
\hline \multirow{3}{*}{ Name of Track } & \multicolumn{6}{|c|}{ Distance } \\
\hline & \multicolumn{2}{|c|}{$\frac{1}{2}$ Mile } & \multicolumn{2}{|c|}{1 Mile } & \multicolumn{2}{|c|}{$1 \frac{1}{2}$ Mile } \\
\hline & Year & Record & Year & Record & Year & Record \\
\hline Saratoga, N.Y. & 1874 & $0.47 \frac{3}{4}$ & 1910 & $1.37 \frac{2}{5}$ & 1902 & $2.31 \frac{4}{5}$ \\
\hline Sheepshead Bay, N.Y. & 1895 & 0.48 & 1906 & $1.37 \frac{3}{5}$ & 1908 & $2.30 \frac{3}{5}$ \\
\hline Gravesend, N.Y. & 1890 & $0.48 \frac{1}{2}$ & 1907 & $1.38 \frac{2}{5}$ & 1907 & 2.31 \\
\hline Morris Park, N.Y. & 1889 & 0.46 & 1904 & $1.38 \frac{2}{5}$ & 1901 & $2.34 \frac{1}{5}$ \\
\hline Belmont Park, N.Y. & & & 1905 & $1.37 \frac{2}{5}$ & 1908 & $2.32 \frac{1}{5}$ \\
\hline Harlem Park, Ill. & 1900 & $0.47 \frac{1}{5}$ & 1903 & $1.37 \frac{2}{5}$ & 1897 & $2.32 \frac{3}{4}$ \\
\hline Santa Anita, Cal. & 1909 & $0.46 \frac{1}{5}$ & 1908 & $1.37 \frac{1}{5}$ & 1908 & $2.31 \frac{1}{5}$ \\
\hline
\end{tabular}


9. The Arabian horse. - Because of the clannish nature of the Arabian tribes, little is known of the early history of their horses. Certain it is, however, that they developed a strain of horses second to none in beauty and stylish action as well as in stamina and endurance. The best Arabian horses are found in the desert

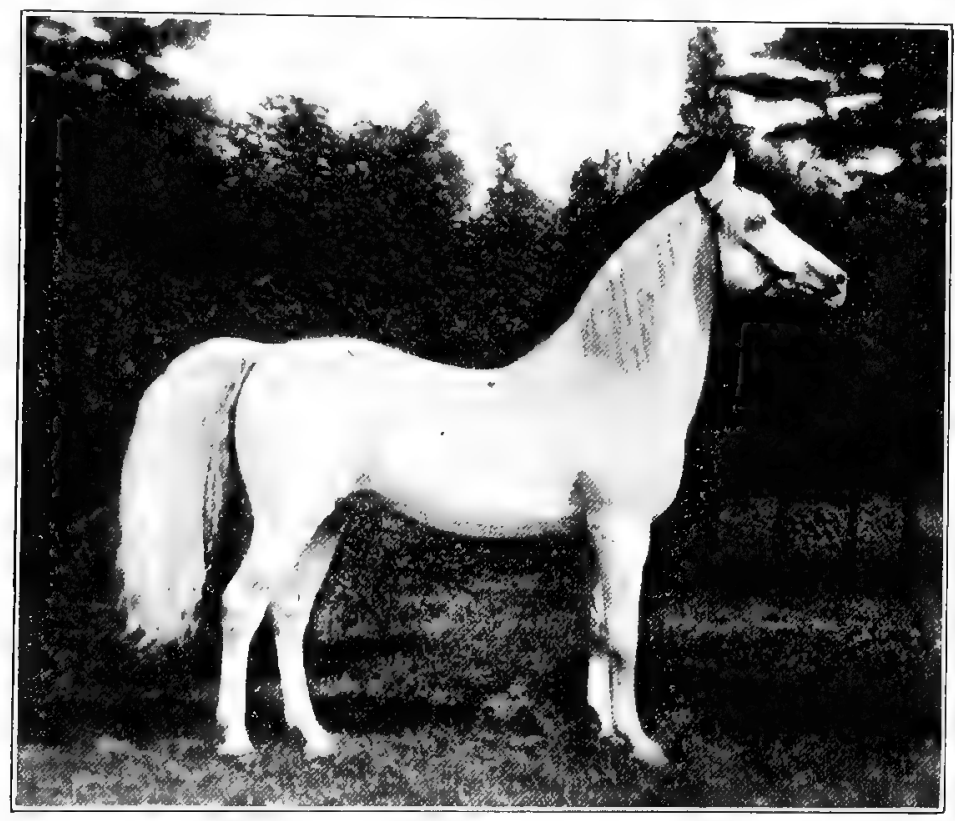

FIG. 3. - The Arabian horse.

region among the migratory Bedouin tribes, of which the two most powerful groups are the Shammar race in the north and Anezah in the south. The latter race have the best horses. There are a number of noted families of Arabian horses of which the most famous are the Keheilet Ajuz and descendants; the Maneghi with three sub-families; the Hadban, with five sub-families; the Jelfon, with its sub-families; and Homdani, with two sub-families. 
10. The Arabian compared with the Thoroughbred. - In general conformation, the Arabian is more symmetrical and more stylish than the Thoroughbred, which is somewhat angular, with joints more or less prominent. The body of the Arabian horse is shorter, with the ribs more curved and longer, particularly the rear ones, thus giving a straighter underline. The legs are not

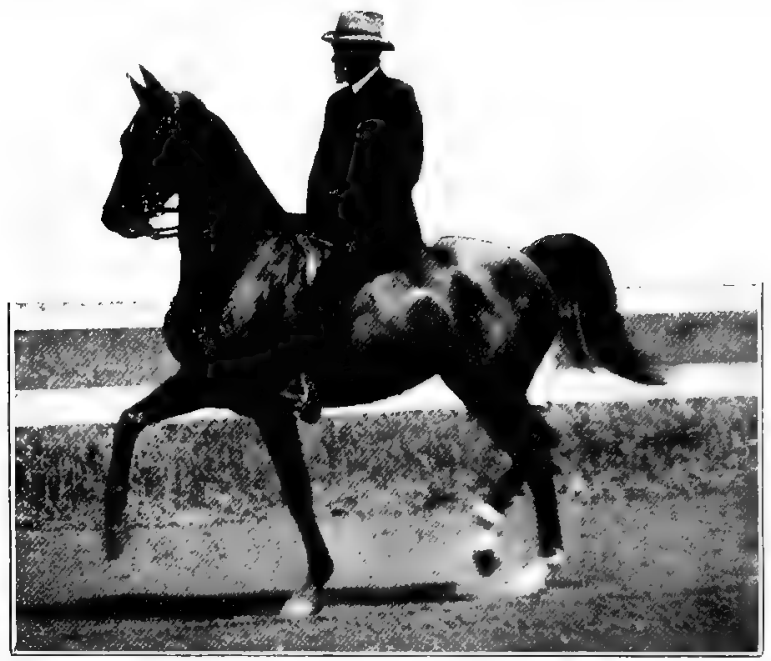

FIG. 4. - The American Saddle horse.

so long as in the Thoroughbred horse. While the Arabian horse is more stylish in the carriage of the head, neck, and tail, and while he possesses great stamina and endurance, he is not nearly the equal of the Thoroughbred for speed (Fig. 3).

11. The American Saddle horse. - This breed is the outgrowth of necessity. In early days, before the establishment of improved roads, traffic was by trails through the forests and the only means of travel was on horse-back. Thus the use of the saddle horse hocamo very common, particularly in the southern states. Virginia, Kenturky, Tennesser, and Missouri contributed largely 
to the development of the American Saddle horse. In fact, so much of the breeding has been accomplished in Kentucky that this breed is often spoken of as the Kentucky Saddle Horse. Thoroughbred blood was used extensively in the improvement of the breed. By far the most important animal in the foundation of the breed was. Denmark, from whom practically all of the noted saddlers of to-daiy: are descended.

12. The American Saddler compared with the Thoroughbred. The Saddler shows more style in the carriage of the head and arch of the neck and tail as well as in the general symmetry of form. The height and weight exceed that of the Thoroughbred. The shoulders and pasterns are sloping and long, the pasterns in particular being long, strong, and springy, thus favoring an easy gait.

The gaits of the Saddler are especially distinctive. Saddlers are divided into two classes according to the gaits they can perform : the walk-trot-canter horse, the most usual of saddle horses ; and the gaited saddle horse, capable of performing the walk, trot, canter, rack, and one or more of the three slow gaits, the running walk, or fox trot, or slow pace (Fig. 4).

13. The Standardbred horse. - This breed includes both trotters and pacers, often erroneously considered as two breeds. They have a common history and are distinguished only by their gait. This is sometimes interchangeable, and the same horse may pace on one occasion and trot on another. This breed represents the road type.

14. History of the Standardbred horse. - This breed is of American origin, although traceable to animals imported from England, where for many years horses have been both trotted and run under the saddle. While the breed is of recent origin, yet Norfolk and Yorkshire, England, have been noted for their trotting horses for more than a century. The English Thoroughbred, however, furnished the major part of the improved blood entering into the foundation of the American Standardbred horse. The early ancestry can be traced in an unbroken line to Darley Arabian, Byerly Turk, and Godolphin Barb. Perhaps the most important 
foundation animal was Messenger, a Thoroughbred imported from England in 1788, and the second most noted Bellfounder, also imported from England, in the year 1822.

15. Hambletonian 10. - This horse was a great-grandson of Messenger. It is safe to say that no horse of any breed or period in this or any other country has excited an interest so universal or has represented such a vast sum of money in his offspring and descendants as that of Hambletonian 10, sometimes referred to as Rysdyks Hambletonian. He was born May 15, 1849, and died March 27, 1876. It is said that during his career he sired 1333 colts, earning a service fee of $\$ 207,790$ for his owner.

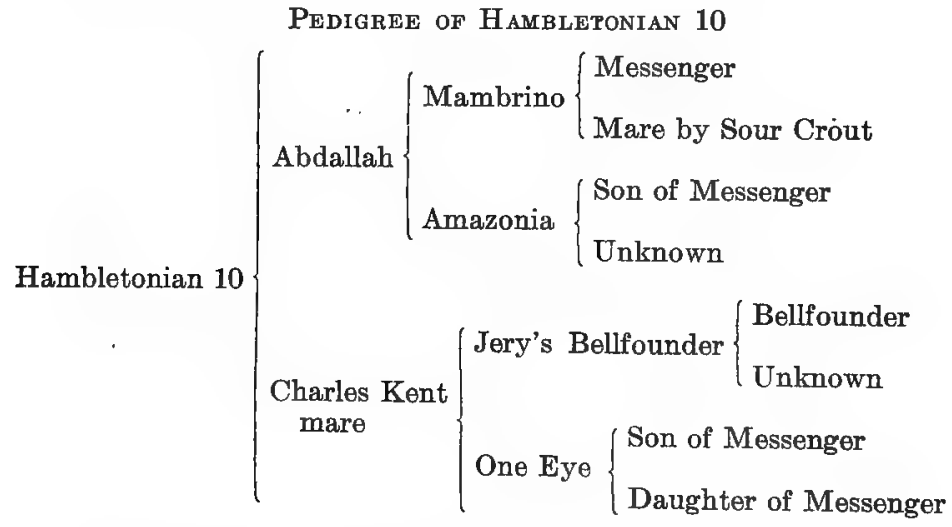

There are several notable families of Standardbred horses, of which the Hambletonian descending from Hambletonian 10 is perhaps the most famous. Other families are the Mambrinos, descending from Mambrino Chief; the Morgans, from Justin Morgan; the Clays, from Henry Clay; and the Hal family, descending from Tom Hal.

16. The Standardbred compared with the Thoroughbred. - In conformation the trotter and pacer tends to be angular, the muscles and joints showing prominence, with the ribs more or less noticeable, 
similar to the Thoroughbred. The trotter is the larger and the ribs are somewhat longer, particularly the rear ones, giving a straighter underline than in the Thoroughbred. Powerful trotting or pacing action is essential. It must be true, varying neither to the right nor left. Long reaching knee and hock action with the

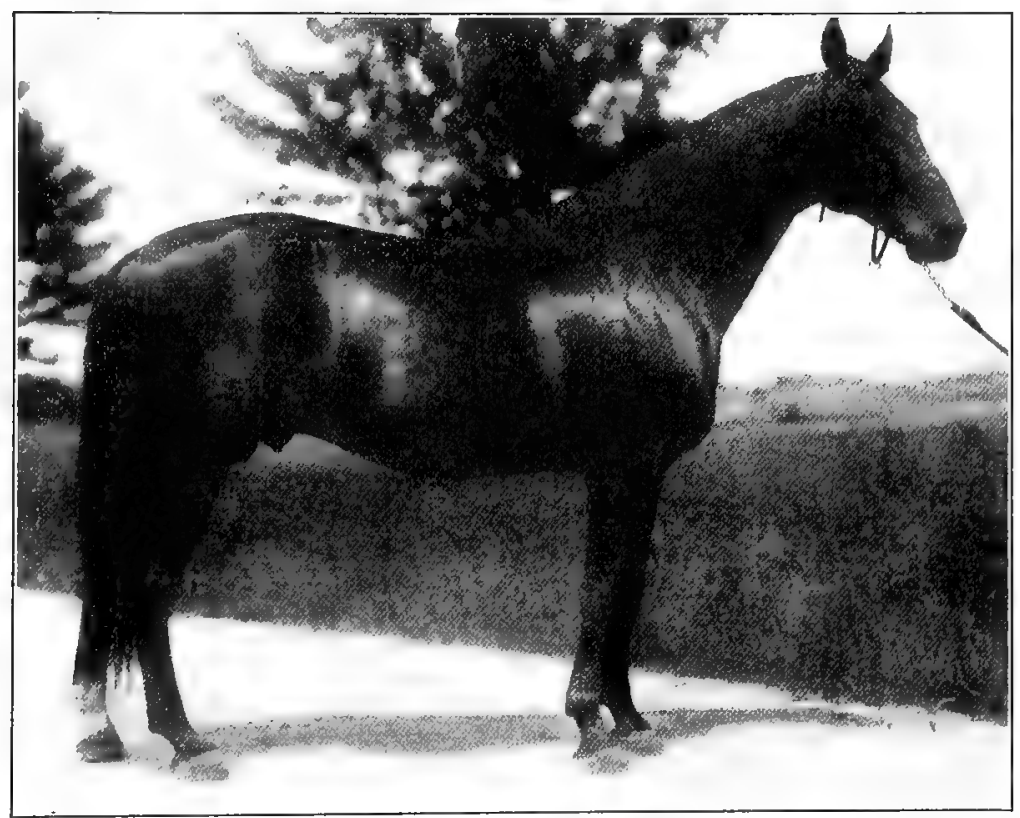

FIG. 5. - The Standardbred. Trotting and pacing horse.

feet picked up smartly is most essential. This is America's principal race-horse and speed at the trot is the major requirement (Fig. 5).

17. Trotting and pacing records. - There are many standard trotting and paring events, and while the horses at the top of such events are constantly changing, yet the fastest records seem worthy of special mention. 
The following table contains the world's records for the more important events:-

Trotting Records

\begin{tabular}{|c|c|c|c|c|c|c|}
\hline Even & & & NAME OF HORse & Puace & DATE & RECORD \\
\hline $\begin{array}{l}\text { Half mile } \\
\text { One mile } \\
\text { Two miles } \\
\text { Five miles }\end{array}$ & . & $\begin{array}{l}\cdot \\
\cdot \\
\cdot\end{array}$ & $\begin{array}{l}\text { Major Delmar } \\
\text { Uhlan } \\
\text { The Harvester } \\
\text { Zambora }\end{array}$ & $\begin{array}{l}\text { Memphis, Tenn. } \\
\text { Memphis, Tenn. } \\
\text { Lexington, Ky. }\end{array}$ & $\begin{array}{l}1904 \\
1912 \\
1910 \\
1902\end{array}$ & $\begin{array}{r}0.59 \frac{1}{2} \\
1.58 \\
4.15 \frac{1}{4} \\
12.24\end{array}$ \\
\hline
\end{tabular}

Pacing Records

\begin{tabular}{|c|c|c|c|c|c|c|}
\hline \multicolumn{3}{|c|}{ Event } & \multirow{2}{*}{ NAME OF HoRSE } & Place & Date & RECORD \\
\hline Half mile & & . & & Memphis, Tenn. & 1903 & 0.56 \\
\hline One mile & & • & Dan Patch & Memphis, Tenn. & 1905 & $1.55 \frac{1}{4}$ \\
\hline Two miles & . & . & Dan Patch & Macon, Ga. & 1903 & 4.17 \\
\hline Five miles & . & . . & Lady St. Clair & San Francisco & 1874 & $12.54 \frac{3}{4}$ \\
\hline
\end{tabular}

THE COACH BREEDS OF HORSES

The several breeds of coach horses are useful for stylish action and heavy carriage or coach work. They owe their origin and improvement, in part at least, to the light breeds, particularly the Thoroughbred and Arabian. These two breeds did much to decrease the size and improve the action as well as to increase the endurance of the coach breeds.

18. The Hackney coach horse. - This breed of horses was developed in Norfolk and Yorkshire, England, and was formerly spoken of as the Norfolk Trotter. The active development of the Hackney began in the eighteenth century by the importation of Arabian, Barb, and Turkish horses, which were crossed on the mares of Norfolk. Thoroughbreds were also used in the early 
The Name, Native Home, Approximate Height, Weight, Uses, and Common Color of Each of the Breeds of Coach Horses

\begin{tabular}{|c|c|c|c|c|}
\hline NAME of Bresd & $\begin{array}{l}\text { Native } \\
\text { Home }\end{array}$ & \begin{tabular}{|l} 
Height, \\
WeIGHT, Pounds \\
Peund
\end{tabular} & Uses & CoLOR \\
\hline Hackney . . & England & $\begin{array}{c}15 \frac{1}{2}-15 \frac{3}{4} \\
1000-1200 \\
15-16\end{array}$ & Park driving & Chestnut \\
\hline French Coach . & France & $\begin{array}{c}1200-1350 \\
16-16 \frac{1}{2}\end{array}$ & Coach driving & $\begin{array}{l}\text { Bay, brown } \\
\text { chestnut }\end{array}$ \\
\hline German Coach & Germany & $1350-1450$ & $\begin{array}{l}\text { Heavy coach } \\
\text { driving; } \\
\text { general } \\
\text { utility }\end{array}$ & $\begin{array}{l}\text { Black, brown } \\
\text { Chestnut }\end{array}$ \\
\hline Cleveland Bay & England & $\begin{aligned} 16 & -16 \frac{3}{4} \\
1200 & -1550\end{aligned}$ & $\begin{array}{l}\text { General util- } \\
\text { ity }\end{array}$ & Bay \\
\hline
\end{tabular}

improvement. Perhaps the most noted of the early animals was a horse known under a variety of names, as Schales, Shales, Shields, and the Original Shales. This horse is said to be a grandson of the Thoroughbred Eclipse. The Fireaways, the Bellfounders, and the Phenomenons are direct descendants of the Original Shales as well as the ancestors of our present-day Hackneys.

19. Description of the Hackney. - There is much variation in type, although this breed is regarded as blockier of form than any of the other Coach breeds. The Hackney is described as a powerfully built, short-legged, big, broad horse, with an intelligent head, neat neck, strong, level back, powerful loins, and as perfect a shoulder as can be produced (Fig. 6).

Formerly the Hackney was valued for its long and strong action at the trot, but at the present time its chief merit resides in the high and often flashy action of the knees and hocks. It is said that the noted Hackney stallion, Confidence, transmitted this quality to his offspring. It is stylish, attractive action, not speed, 


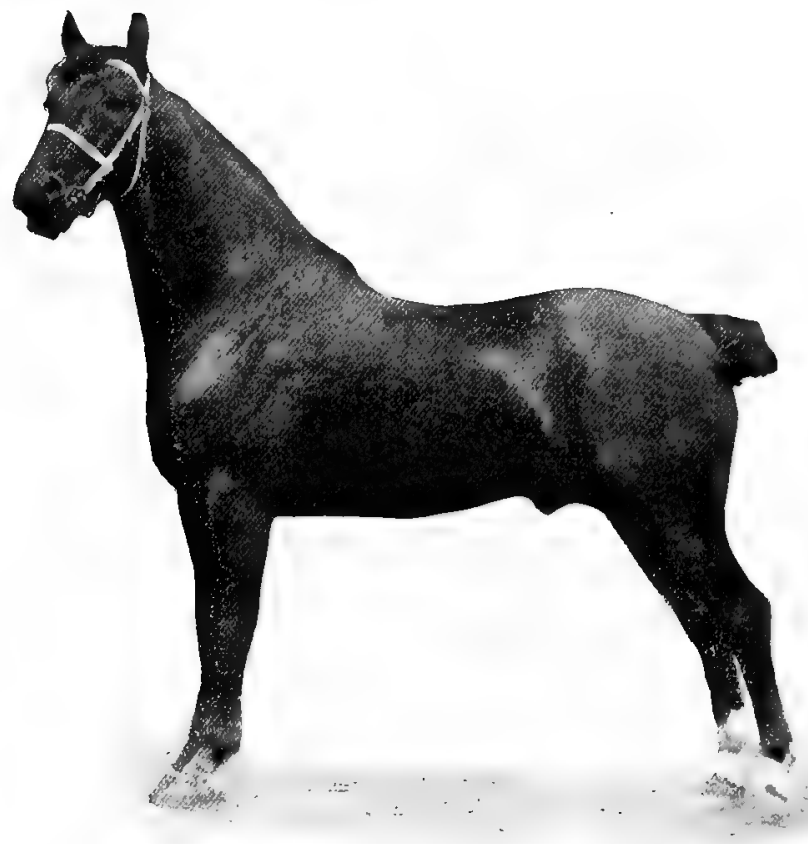

Fic. 6. - The Hackney Coach horse.

that is important at the present time, and this breed is in demand for fashionable equipment.

20. The French coach horse. - The name French Coach is of American origin, there being no breed of that name in France. The term Demi-Sang, meaning half-blood, is the name in use to designate the Coach horse in France. This name was form r'y applied to the offspring of English Thoroughbred and Norman draft horses. For more than two centuries the French government has given material aid to horse breeding, and the French Coach horse owes its present perfection to such support. 
21. Classes ố horses in France. - There are three classes of breeding horses in France. First, those owned by the government. In 1910 there were of these 3445, of which 2214 were coach, 664 draft, and 567 Thoroughbred. Second, those subsidized

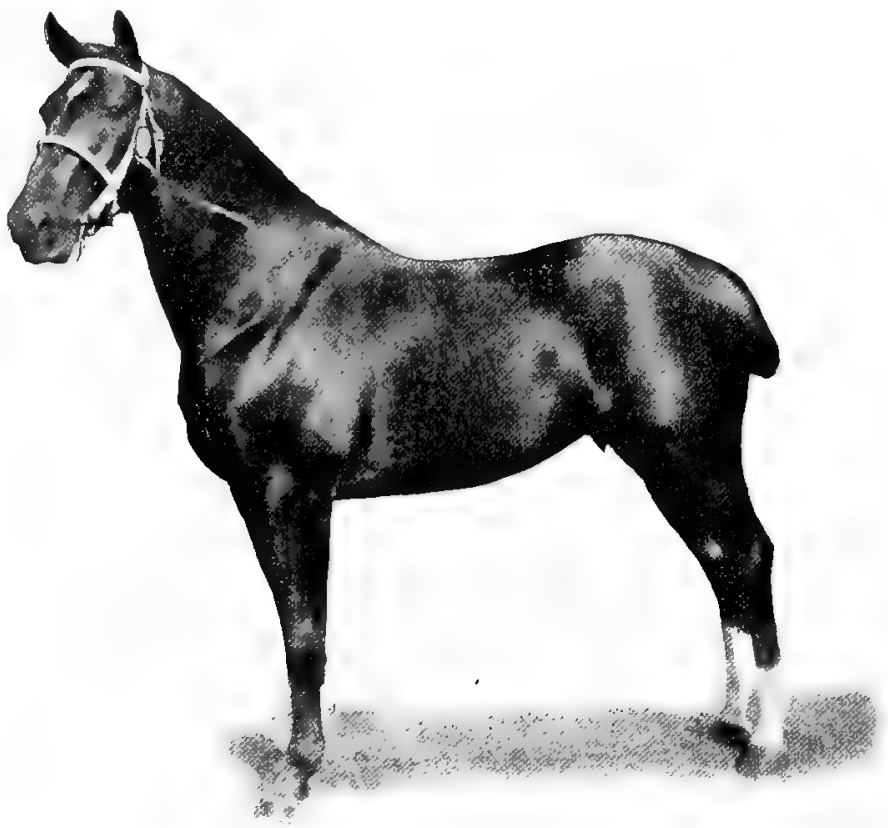

FIG. 7. - The French Coach horse.

by the government. The owners of such approved animals are allowed from 300 to 5000 francs ( $\$ 60$ to $\$ 1000$ ) bonus annually from the Minister of Agriculture. In 1910 there were 1709 approved and subsidized horses in France. Third, those that have been authorized by government officials. In 1910 there were 191 animals of this class. All other horses are prevented from standing for public service by a law passed in $\mathbf{1 8 8 5}$. 
22. French coach compared with the Hackney. - In general conformation the French Coach is not so smooth or symmetrical as the Hackney. The French Coach is larger than the Hackney, possessing very good length of body, with a long, somewhat arching neck and a long, wide, level croup. The French horse possesses the larger bone and the more powerful muscling. The action, particularly at the trot, is longer and more powerful, rather than high and flashy as in the Hackney (Fig. 7).

23. The German coach horse. - This breed was developed in northwestern Germany, particularly in the fertile lowlands drained by the Elbe, Weser, and Ems rivers. The states that contributed to the development of this breed are Hanover, Oldenburg, Schleswig-Holstein, and East Friesland. The German Coach horse owes its origin to horses introduced from the Orient. As early as 1552 Count Johanna imported horses from Turkey to Oldenburg and took an active interest in improving the horse stock. Many of the German States took an active interest in developing horses somewhat similar to France. Thus we have several types of German horse varying in size and conformation, most of them taking their names from the state in which they were developed. The more important of these types are: the East Prussian or Trakehnen horse, the Hanoverian borse, the Holstein horse, the Oldenburg horse, and the East Friesland horse.

24. German coach compared with Hackney. - The German horses are exceedingly variable in size and weight, and all types lack the smooth outline and symmetrical form of the Hackney. The East Prussian or Trakehnen type is the lightest and, with the Holstein and Hanoverian types, is useful for light carriage and saddle purposes. The Oldenburg and East Friesland types are the largest and are used for heavy coach work and as farm or general-purpose horses, but are seldom used under the saddle. The action at the walk and trot is longer and not so high and stylish as in the Hackney (Fig. 8). 


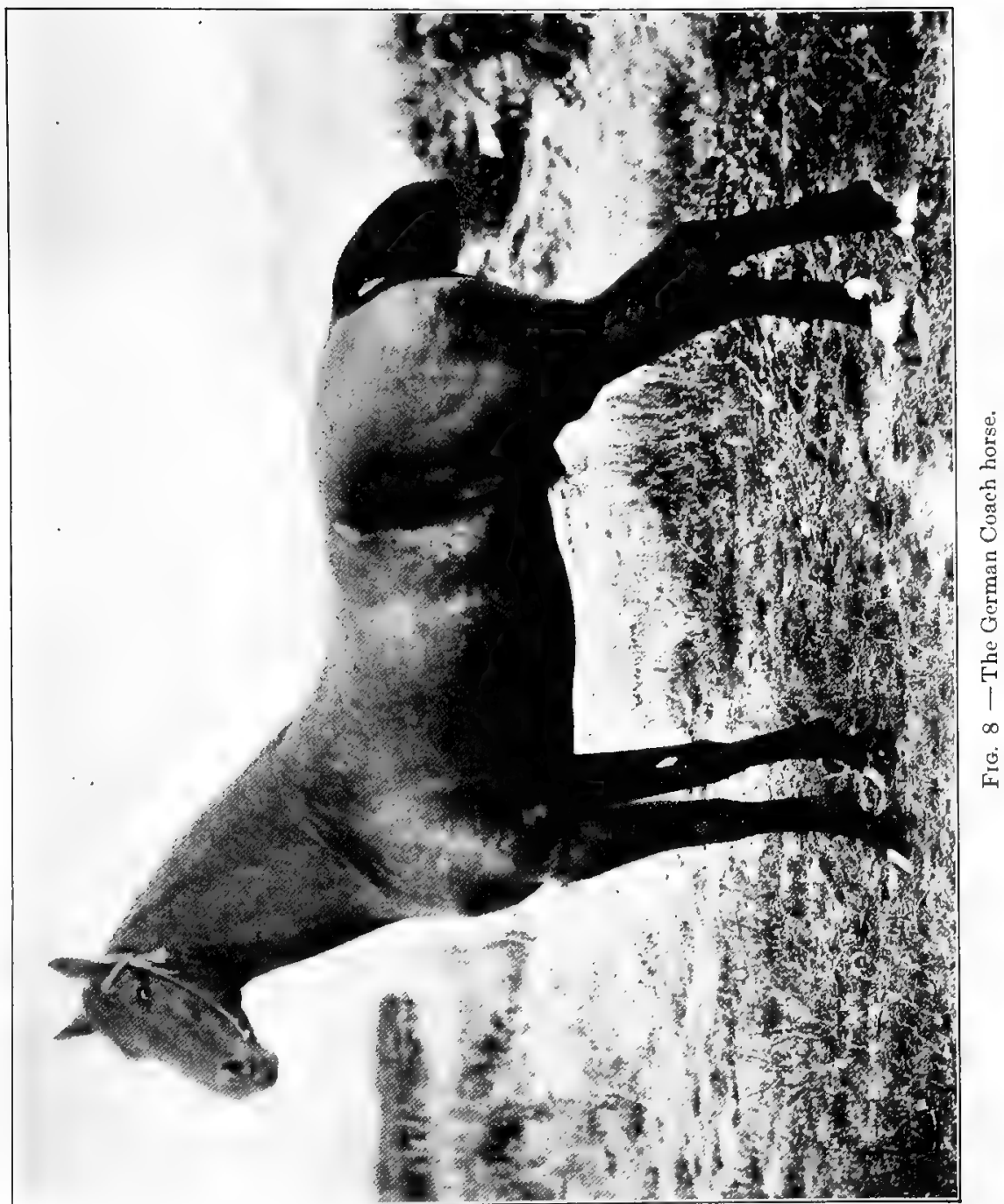


25. The Cleveland Bay coach horse. - This breed was formerly known as the Old Coaching or Chapman horse. It is stated that the origin of the breed traces to a cross between the Yorkshire cart mares and an Oriental horse of note, belonging to one of the three great families descended from Dark Horse, Barley Harvest, and Farmer's Glory. The Cleveland Bay is the oldest type of large-sized carriage horse and has existed probably without much variation in the North and East Ridings of Yorkshire for more than two centuries. The breed sustained a serious blow when the development of railways reduced the demand for stage-coach horses, and when it became a common practice to breed carriage horses by mating Thoroughbreds with small mares, but it was saved from extinction by being employed for farm work.

26. Cleveland Bay compared with the Hackney. - The former is more upstanding and larger than the latter, possessing good sloping shoulders, a back of good length, powerful loins, and long quarters. The Cleveland Bay lacks the attractiveness in the carriage of the head, neck, and tail, and the action is not so stylish or flashy as in the Hackney, although the movement is strong and powerful.

\section{THE DRAFT BREEDS OF HORSES}

The horse is very.susceptible to climatic conditions. A temperate climate and fertile grassy plains produce horses distinguished for size and strength, while highlands and mountain ranges, with bleak, cold climate and. scanty subsistence, dwarf the frame, and produce a hardy, diminutive animal. There is no exception to this in nature although man may do much by supplying warm quarters and abundant food, and by selection to counteract the influence of climate. Thus the fertile plains of Germany and France, with their agreeable climate and abundant forage, have produced the ponderous draft horse which still distinguishes the region, and has been the source from which all of the countries have drawn the foundation for their draft breeds. These very 
large horses lack quality and activity which are essential to efficiency in draft horses. To improve the quality and action light horses have been used in the founding of each of the draft breeds.

The Name, Native Home, Approximate Height, Weight, Uses, and Common Color of Each of the Breeds of Draft Horses

\begin{tabular}{|c|c|c|c|c|}
\hline NAME OF BREED & N ATIVE HOME & $\mid \begin{array}{l}\text { HEIGHT, HANDS } \\
\text { WEIGHT, POUNDS }\end{array}$ & UAES & Color \\
\hline Percheron . . & France & $\begin{array}{c}15 \frac{1}{2}-17 \\
1800-2300 \\
15 \frac{1}{2}-17\end{array}$ & Heavy hauling & Black, gray \\
\hline French Draft. & France & $\begin{array}{c}1800-2300 \\
16-16 \frac{1}{2}\end{array}$ & Heavy hauling & Black, gray \\
\hline Clydesdale & Seotland & $\begin{array}{cc}1800 & -2300 \\
16 & -17\end{array}$ & Heavy hauling & Light bay \\
\hline Shire . . & England & $\begin{array}{cc}1800 & -2300 \\
16 & -17\end{array}$ & Heavy hauling & Light bay \\
\hline Belgian & Belgium & $1600-2300$ & Heavy hauling & $\begin{array}{l}\text { Bay, black, } \\
\text { brown }\end{array}$ \\
\hline Suffolk & England & $1600-2000$ & Heavy hauling & Chestnut, bay \\
\hline
\end{tabular}

27. The Percheron draft horse. - This breed was developed in France, particularly in the region of La Perche, although all Normandy in northwestern France is famous for Percherons. The real origin is obscure, although Oriental horses played an important part in the formation of this breed. Large numbers of Arab, Barb, and Turkish horses were introduced into France at the time of the Saracen invasion in the early part of the eighth century. As the Saracens were defeated and their army captured, practically all of these horses remained in France and no doubt did much to improve the quality and action of the native stock. For more than two centuries the French government has given material aid to the improvement of draft horses similar to the French Coach horse.

About 1820 two Oriental stallions, Godolphin and Gallipoli, 
were purchased for the government horse-breeding farm at Le Pin and were used on French mares. These horses were gray and no doubt had considerable influence in developing the gray color among the horses of La Perche. The general effect of this Eastern

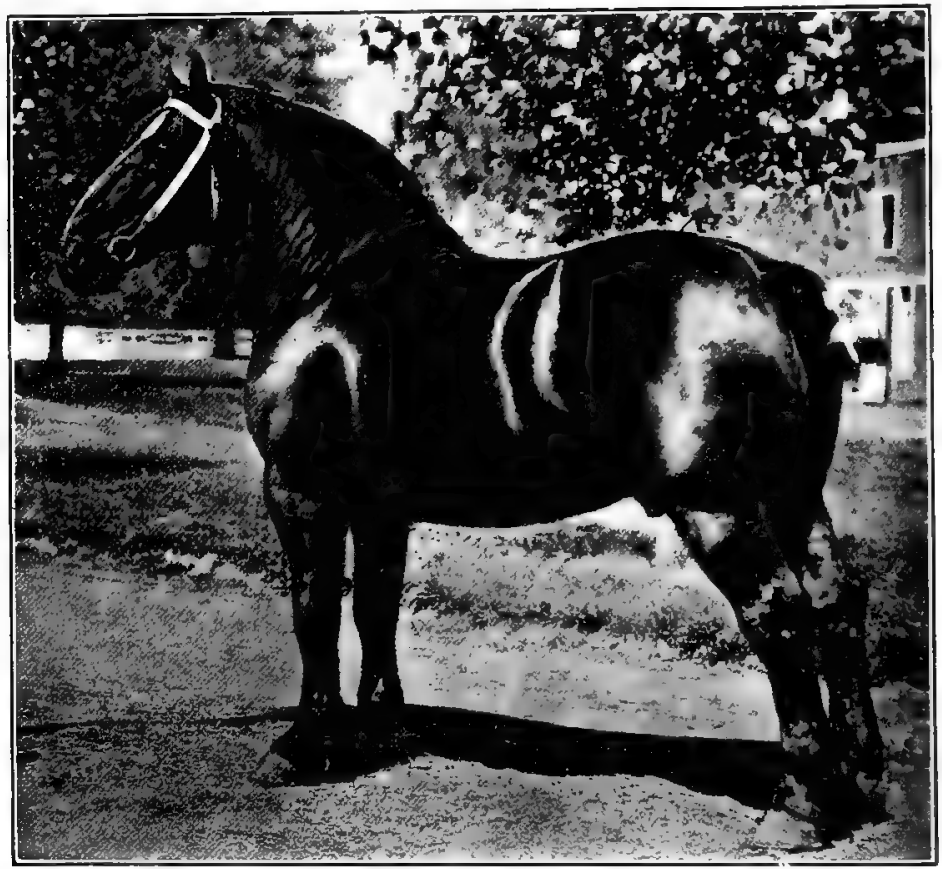

FIG. 9. - The Percheron draft horse.

blood on the French horse has been to improve the quality, action, and style. Because of the general excellence, the Percheron is the most important breed of draft horses in America.

28. Description of the Percheron. - The more approved type demands all the best features of a model draft horse. The general form is massive and low-set. Weight is a most important con- 
sideration of a true draft horse, and in this respect the Percheron is second to none. The head is rather large and not so clean-cut as in the light breeds. The nose or face is straight, with nostrils of ample size. The neck is short, strong, and powerfully muscled. The shoulders are more upright than in the lighter breeds. The chest is broad and deep, indicating a large capacity in the vital organs. The body is comparatively short on top, long below, broad along the back, with the ribs strongly arched and of great depth. The loins are short, broad, and thickly muscled. The croup is broad and wide, but with a tendency to steepness which is very objectionable and affects both the beauty and the power of the horse. The legs above the knees and hocks are heavy and powerfully muscled, while the joints are fairly large and not so clearly defined as among lighter horses. The cannons are short and strong. The pasterns are more upright and not so clearly defined as in the light breeds. The feet are large. The action is true and strong and is perhaps second to none, although the adherents of the Clydesdale breed claim superiority for their breed (Fig. 9).

29. The French draft horse. - The history and description of this breed is practically the same as that of the Percheron. In fact, all Percherons are French Draft horses. In America, it has been the custom to refer to draft horses introduced from France as French Draft horses, which formerly caused much confusion, as there are several clearly recognized breeds of draft horses in France, such as the Percherons, already considered, the Boulonnais, the Bretons, the Ardennais, the Nivernais, and the Picardys. Each of these breeds, as it developed, became similar to the Percherons. It is extremely doubtful whether any draft horses come to this country from France that cannot be properly listed as belonging to one of these breeds (Fig. 9).

30. The Clydesdale draft horse. - The Upper Ward of Lanark, in the valley of the Clyde River, has long been renowned for powerful farm horses, the superior size and strength being due, in part 
at least, to the capacity of the soil to support large-framed animals. After the union of the Scotch and English crowns in the early part of the seventeenth century, strong trade relationships sprang up between the two countries. The Scotch cattle dealers driving

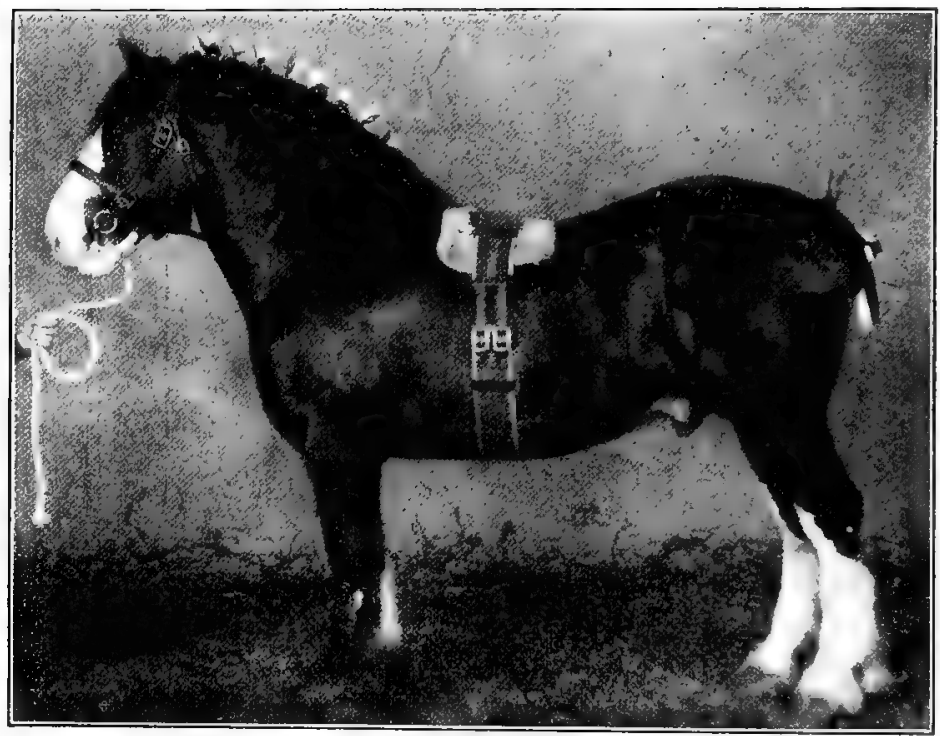

FIG. 10. - The Clydesdale draft horse.

herds into England returned with English horses which were mated with the native stock, thereby improving the quality and increasing the size. English blood continued to be introduced into Scotland until comparatively recent times. Perhaps the most famous of the English importations was a horse named Lintock. During recent ycars, however, the Clydesdale has been maintained as a pure breed. Among the most noted horses of the breed are Baron's Pride and his son Baron of Buchlyvie, the latter selling for $\$ 47,500$, the highest price paid for a draft horse. 
31. Clydesdale compared with the Percheron. - While the two breeds are of approximately the same size, the former possesses certain distinctive features, on which loyal Scotchmen lay great emphasis. The most important of these features are the color markings, the hairy legs, and the action. The coloring is usually bay or brown and the characteristic markings are a white blaze on the face and one or more white feet. From the back of the legs below the knees and hocks grows an abundance of long hair called the feather. The Clydesdale breeders have always given special attention to the action, with the result that it is not surpassed by any other draft breed. In general, the Scotch horse is more upstanding than the French horse, the legs are longer, and the body longer and lighter, particularly in the region of the flanks. The face or nose is often slightly Roman (Fig. 10).

32. The Shire draft horse. - During its past history, this breed has been known in England as the Great Horse, War Horse, Cart Horse, Old English Black Horse, Giant Lincolnshire, Strong Horse, and Shire. The breed was developed in the lowlands of England, particularly ,in Lincolnshire and Cambridgeshire. In early times, heavy, active horses were in great demand for war purposes, and this led to large importations of the heavy Black Horse of Normandy and the Flanders. One of the early improvers of the breed was Robert Bakewell, who introduced horses from Holland. The history of the Shire shows a slow but persistent development of an improved type through a long period of time.

33. Shire compared with the Percheron. - In general appearance, the Shire resembles the Clydesdale, particularly in the color markings and the feather of the legs. In conformation, however, the Shire more closely resembles the Percheron, the form being massive and low-set, the back broad, the ribs well sprung and of good length, particularly the rear ones, thus giving a deep body. The Shire is perhaps more powerfully built than the Percheron, but lacks the action of both the Scotch and the French horses. This is due, in part at least, to the rather straight shoulders, the 
short and powerfully muscled legs, and to the rather short and straight pasterns (Fig. 11).

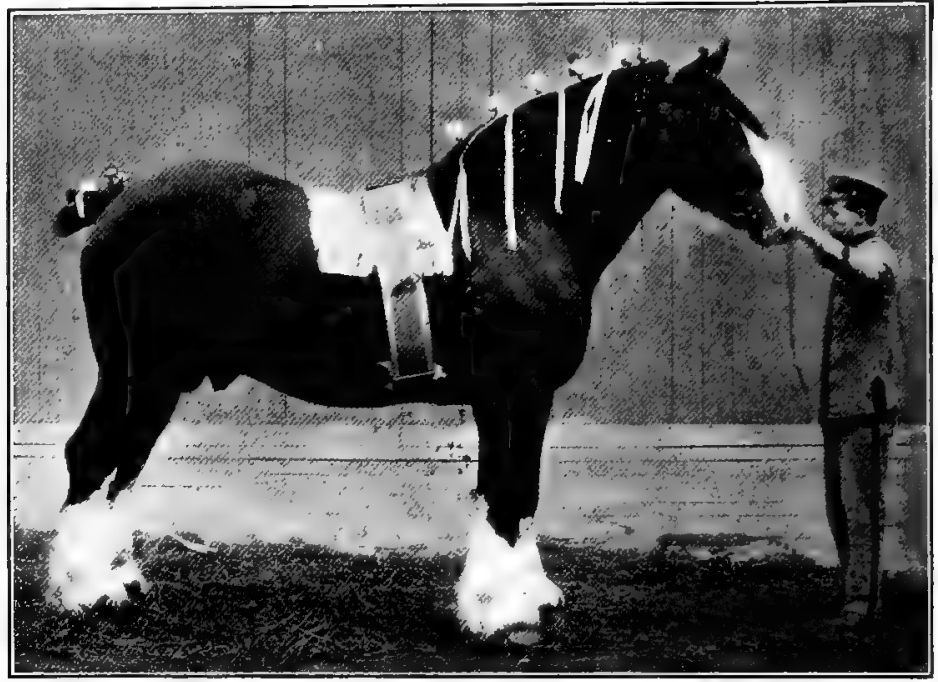

FIG. 11. - The Shire draft horse.

34. The Belgian draft horse. - For many centuries Belgium has been noted for the size and quality of her horses. The very early literature states that the people of Belgium were very good judges of horses and that they were willing to pay high prices for a superior class of horses. Unlike most other draft breeds that have been developed, this breed has been almost entirely the product of its environment. In the development of the breed, no particular animals appear to have been prominent nor has any breeder of outstanding merit appeared. The breed owes its improvement to the efforts of many small breeders working with a few animals each, rather than a few breeders working with many horses each as is usually the case. Modern improvement, however, is of comparatively recent date and is due to the efforts of the govern. 
ment, which awards a maintenance bounty to horses of approve standing.

35. Belgian compared with the Percheron. - In general con formation the Belgian is of the most compact form, having a maxi

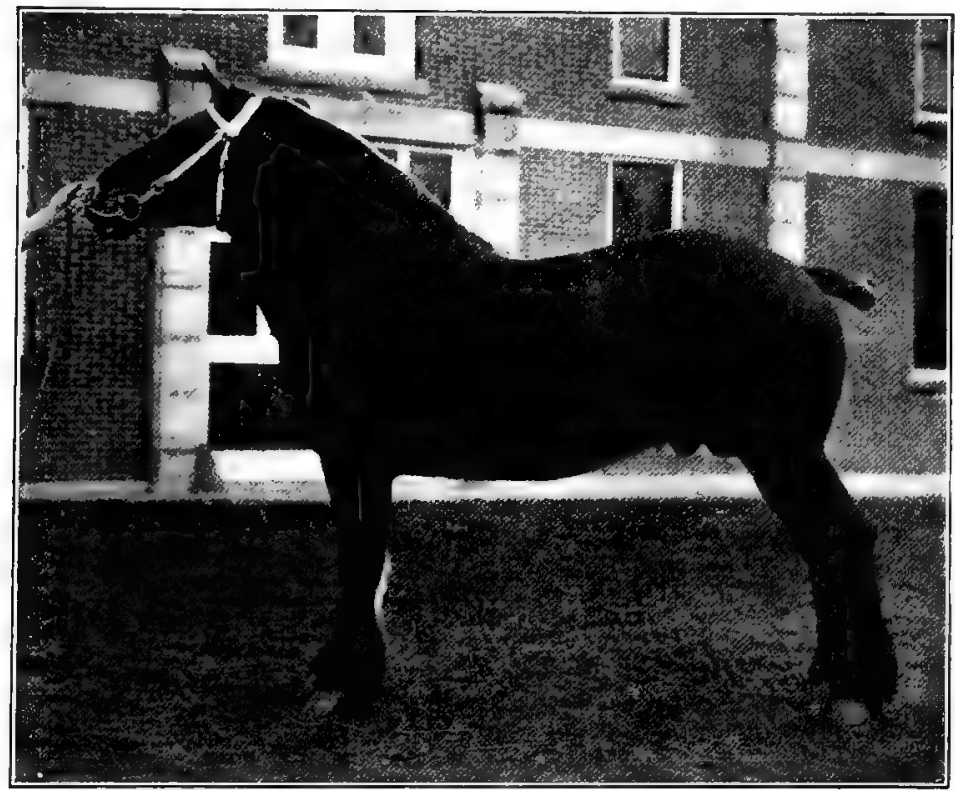

FIG. 12. - The Belgian draft horse.

mum of weight for its size. The Belgian is even more cornpac1 than the Percheron. The body is very full in the breast anc unusually broad and deep of back, no breed, in proportion to it: size, showing so much body girth. The rump is often rather shor and steep, with the tail set low, which is objectionable. The fact or nose is straight. The lower legs are free from the long hain characteristic of the Clydesdale and Shire (Fig. 12).

36. The Suffolk draft horse. - Previous to the latter half of 
the eighteenth century the history of this breed is obscure. Mr. Crisp of Ufford, Sussex, was one of the early improvers of the breed. The Crisp Horse, born in 1768, is recognized as the progenitor. Most of the present-day Suffolks descend from this horse. The history from the time of the Crisp Horse has been clearly and

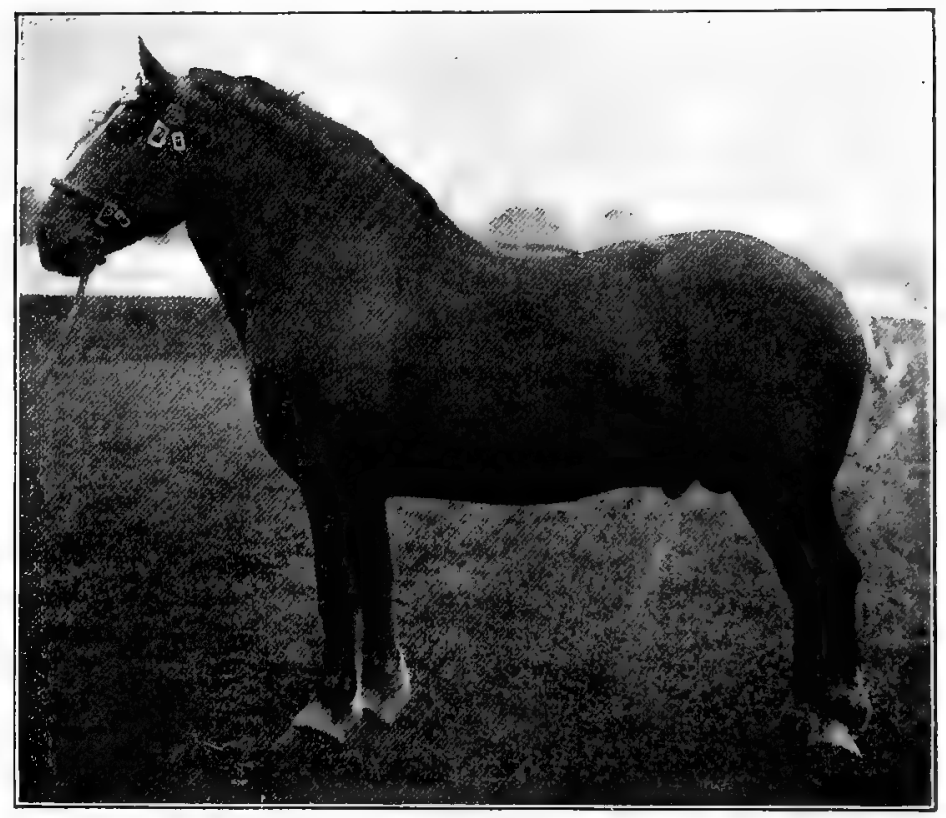

IIG 13. - The Suffolk draft horse.

fully traced, and stands accepted by breeders generally. Formerly there were several tribes of Suffolks, the more important being the Blake tribe, the Wright tribe, the Shadingfield tribe, and the Martin Boxer tribe. This breed is the least known of the draft breeds in America.

37. Suffolk compared with the Percheron. - The former is somewhat smaller than the latter, although the body of the English 
horse is characterized by greater depth and more circumference, considering the size, than is the case with the French horse. The ribs of the Suffolk have an unusual spring and depth, thus giving the body a very round, full form. The rump is full and well carried out, the tendency to steepness being slight. The characteristic color of the Suffolk is chestnut (Fig. 13).

\section{THE PONY BREEDS OF HORSES}

As has been suggested, the various breeds of ponies owe their small size, in a large measure, to adverse climatic conditions and scanty subsistence, although the size of the modern breeds is controlled by man. The pony breeds vary greatly in both size and conformation, according to the environment and the purpose for which they are selected.

The Name, Native Home, Approximate Height, Weight, Useg and Common Color of the Breeds of Ponies

\begin{tabular}{|c|c|c|c|c|c|}
\hline Name of $\mathrm{B}$ & BREED & NaTIVE Home & $\begin{array}{c}\text { Height, INCHES } \\
\text { Werght, Pounds }\end{array}$ & UsES & Color \\
\hline Shetland & . & $\begin{array}{l}\text { Shetland } \\
\text { Islands }\end{array}$ & $\begin{array}{cc}34 & -44 \\
250 & -400 \\
48 & 56\end{array}$ & Riding, driving & $\begin{array}{l}\text { Black, brown, } \\
\text { piebald }\end{array}$ \\
\hline Welsh & . & Wales & $\begin{array}{c}400-600 \\
48-56\end{array}$ & Driving, riding & Brown, gray \\
\hline Exmoor & . & $\begin{array}{l}\text { Devon- } \\
\text { shire }\end{array}$ & $\begin{array}{c}500-800 \\
\text { Under } 56\end{array}$ & Driving, riding & Bay, gray \\
\hline Arabian & - & Arabia & $600-800$ & Driving, riding & Bay, white \\
\hline Hackney & - & England & $\begin{array}{c}\text { Under } 56 \\
600-800\end{array}$ & Driving, riding & Chestnut \\
\hline Mexican. ${ }^{1}$ & & $\begin{array}{l}\text { Mexico } \\
\text { Western }\end{array}$ & $\begin{array}{c}\text { Under } 56 \\
600-850\end{array}$ & Riding & Duns, mixed \\
\hline Indian 1 & - & $\begin{array}{l}\text { United } \\
\text { States }\end{array}$ & $\begin{array}{c}\text { Under } 56 \\
600-850\end{array}$ & Riding & $\begin{array}{l}\text { Duns, bays } \\
\text { mixed }\end{array}$ \\
\hline
\end{tabular}

1 Not recognized as a breed. 
38. The Shetland pony. - This, the smallest of all ponies, is in many respects the most important. In England and other countries, this breed has been used extensively in the coal mines, while in America it is practically restricted to the use of children, for which it has no equal. The native home of this breed, the Shetland Islands, is situated to the north of Scotland, from which it is separated by about two hundred miles of very rough and dangerous sea. The climate is cold and the forage scant.

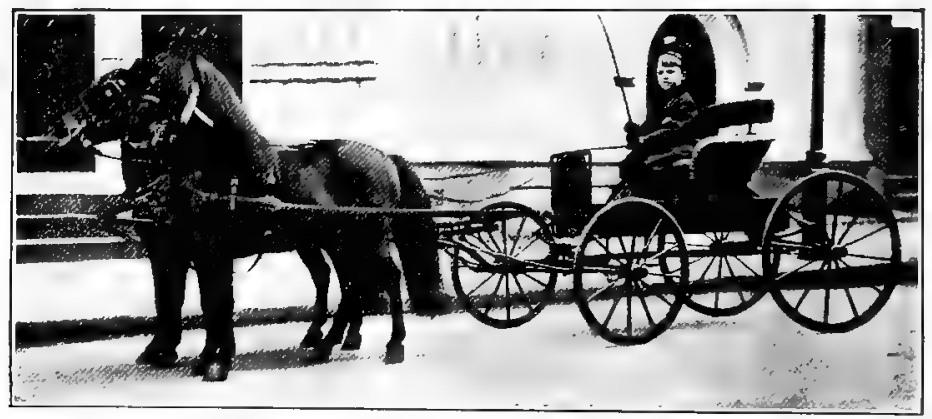

FIG. 14. - Shetland ponies.

In general form the Shetland pony resembles a diminutive draft horse. The best specimens are compact in build, having small head and ears, short muscular neck, full chest, deep body, broad back, heavy muscular quarters, and short legs. The temper is very mild and the disposition cannot be improved upon (Fig. 14).

39. Welsh pony compared with the Shetland. - The former is the larger and more upstanding. The general conformation of the Welsh pony resembles that of the light type, in fact, Thoroughbred and Arabian horses have been used in the improvement of the breed. The Welsh pony, because of its more active temperament, is not so desirable for children's uses as the Shetland.

40. Arabian and Hackney ponies. - The history and description of these ponies are similar to those of the Arab and Hackney 
horse already considered, with the single exception of the height, which is 56 inches or under.

41. Mexican and Indian ponies. - These are descendants of horses brought to America by the early Spanish settlers. They have remarkable endurance and are capable of the severest work under the saddle. They have a very remarkable spirit which is frequently far from amiable, although this varies with the climatic conditions and the treatment. In the south these ponies are called Mustangs, in the central and western states they are called Bronchos, and in the north they are often spoken of as Cayuse. They increase in wildness from south to north, the Mustangs being the tamest and the Cayuse the wildest.

\section{THE BREEDS OF DONKEYS}

The several breeds of donkeys or jacks vary in form and size, although the differences are not so marked as in horses. These variations are brought about by the same conditions as bring about variations in horses.

The Name, Native Home, Approximate Height, Uses and Common Color of THE BREeds of JACKS

\begin{tabular}{|c|c|c|c|c|c|c|c|}
\hline NAME OF 1 & $\mathrm{Brr}$ & EED & & Native Home & $\begin{array}{l}\text { HEIGHT, } \\
\text { HaNDS }\end{array}$ & Uses & Color \\
\hline Andalusian & & . & . & $\begin{array}{l}\text { Andalusia, } \\
\text { Spain }\end{array}$ & $14 \frac{1}{2}-15 \frac{1}{2}$ & Siring mules & Gray \\
\hline Maltese & . & . & & $\begin{array}{l}\text { Malta, } \\
\text { Islands }\end{array}$ & $14-14 \frac{1}{2}$ & Siring mules & Brown, black \\
\hline Catalonian & & . & & $\begin{array}{l}\text { Catalonia, } \\
\text { Spain }\end{array}$ & $14 \frac{1}{2}-15 \frac{1}{2}$ & Siring mules & Black brown \\
\hline Majorca & . & . & • & $\begin{array}{l}\text { Majorca } \\
\text { Islands }\end{array}$ & $15-16$ & Siring mules & Black \\
\hline Italian . & . & & & Italy & $13-14$ & Siring mules & Blue, black \\
\hline Poitou . & - & . & . & France & $14 \frac{1}{2}-15$ & Siring mules & Black \\
\hline
\end{tabular}


42. The mule and hinny. - The mule is an important draft animal in America. It is not a true breed, as ordinarily considered, but is a hybrid, having for its sire a donkey, commonly termed a jack, and a mare for a dam. The reciprocal cross is known as a hinny. The female donkey is called a jennet. The mule partakes of many of the characters of the jack. For example, the

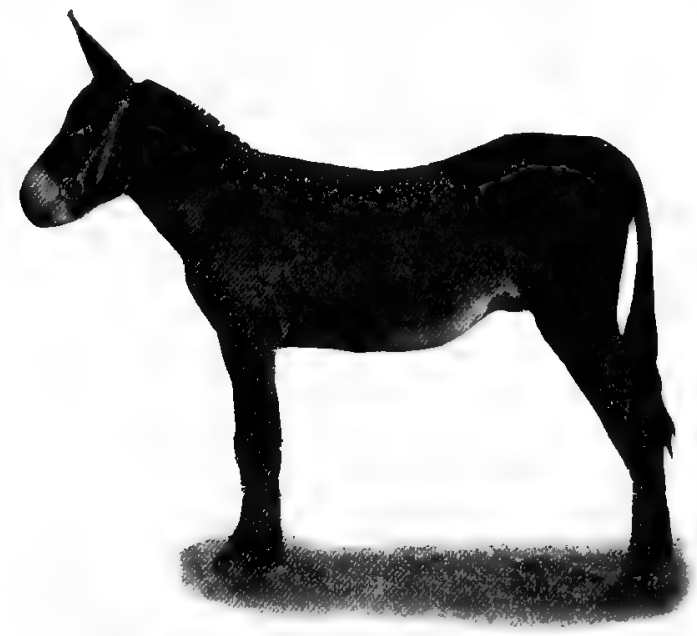

Fiv. 15. - Catalonian Juck.

long ears, slender body, tufted mane, sparely haired tail, slender foot, and the braying voice.

\section{QUESTIONS}

1. What is the relative importance of horses, cattle, sheep, swine, and poultry in your county?

2. How many pure-bred horses are there in your county? Give the name of each and the breed to which it belongs. Give the pedigree for at least four generations. 
3. Compare the price of pure-bred draft, coach, and driving horses. Which is the highest priced and why?

4. Which breed of horses is the most popular in your county? Who are the principal breeders?

5. What is the nature of the soil in your region? Which are the most important farm crops, fruits, and vegetables grown? What type of horse is best suited to the cultivation of each and why?

6. Why have the French breeders been so successful in breeding draft horses? Why is it that England leads in the breeding of Thoroughbreds, while America holds first place in raising trotters and pacers?

7. Are there enough horses produced in your county to fill the demand ? If not, how many are shipped into the county? What do they cost?

8. Are there any mules bred in your county? Which is the more profitable, breeding horses or mules? Why is it that large contracting firms prefer mules?

9. Give the name of a few horse owners who exhibit horses at your state, county, or town fair. Give the names of a few prize-winning horses.

10. What is the track record of your state, county, or town fair racetrack. Give the name of the horse that made the record. 


\section{CHAPTER II}

\section{JUDGING HORSES}

BEFORE attempting to judge a horse, we should learn the method of determining age and of locating unsoundness. These are important factors in determining the animal's present and prospective value. Familiarity with the signs that indicate age and unsoundness is, therefore, often extremely useful. While a knowledge of such signs is not difficult to secure, skill in their application depends much on practice.

\section{HOW TO ESTIMATE THE AGE OF A HORSE}

The order of the appearance of the teeth and their method of wearing are considered the most important and accurate means of estimating the age of domestic animals, and are the means employed by all horsemen. These are, however, not absolutely accurate, and much depends on the condition as well as on the individuality of the animal. The teeth of animals that have bones of somewhat open structure are likely to indicate that the animals are older than they really are; while the teeth of those whose bones are of fine close texture may indicate them to be younger than they are.

43. Colt. - Before the end of the first year the colt is provided with a set of temporary or milk teeth, the first or middle pair appearing at about two weeks of age; the second or intermediate pair at two to four weeks of age; and the third or lateral pair appearing at about five months of age. The difference in size of the jaw bone between the foal and the grown horse makes a 
change from milk to permanent teeth necessary. The permanent replace the temporary teeth at two and one-half or three years of age up to five years.

44. Three years old. - At about two years and nine months of age the permanent pair of center nippers replaces the temporary ones, and by the time the animal is three years of age they are ur: and ready for use. They will have deep cups and are much larger than the temporary teeth. If the colt be a male, small tusks will appear at about this time (Fig. 16).

45. Four years old. - At about three years and nine months, the intermediate pair of permanent nippers appears and is up and ready for use at four years of age. The center pair shows much wear and the cups are about one-third gone. The tusks, if any, have enlarged, but are still sharp on their points and flattish on the inside (Fig. 17).

46. Five years old. - At about four years and nine months, the permanent corner nippers make their appearance and are up and ready for use at five years of age. At five years of age the horse has a full mouth of permanent teeth; the center nippers show two years' wear and have changed slightly in shape, having become rounder on the inside, the cups being two-thirds gone; the intermediate nippers show one year's wear, the cup being onethird gone. Five years is the age preferred on the market, and occasionally horsemen extract the temporary nippers, and so hasten the appearance of the permanent teeth (Fig. 18).

47. Six years old. - The cups in the center pair in the lower jaw have disappeared, or nearly so; they have become much smaller in the intermediates and show one year's wear in the corner nippers (Fig. 19).

48. Seven years old. - At seven, the cups are gone from the intermediate pair in the lower jaw, and have become quite shallow in the corner nippers. There is a notch in the upper corner nipper where it overlaps the lower one. Marked changes in shape have taken place in the nippers; they are becoming thicker from inside 


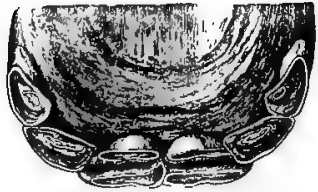

FIG. 16.- Lower front teeth at three years of age. Two center permanent teeth up.

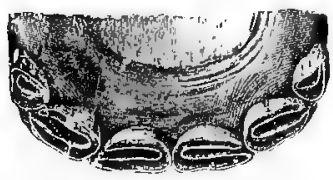

Fig 17.- Lower front teeth at four years of age. Four center permanent teeth up.

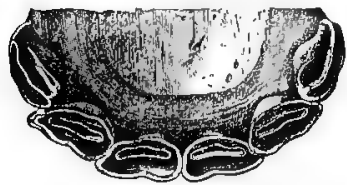

FIG. 18.- Lower front teeth at five years of age. All permanent teeth up.

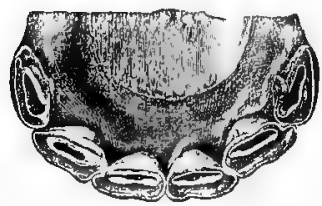

FIG. 19. - Lower front teeth at six years of age. Cups out in center puir.

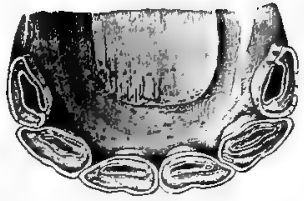

FIG. 20. - Lower front teeth at seven years of age. Cups out of intermediate pair.

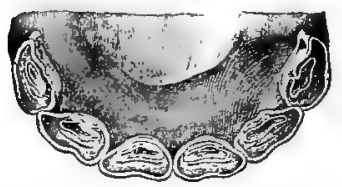

Fig. 21. - Lower front teeth at eight years of age. Cups all out.

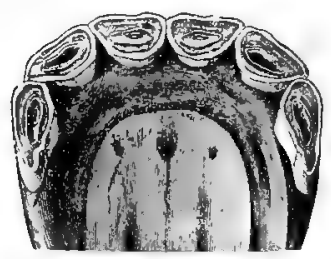

FIG. 22.- Upper front teeth at nine years of age. Cups out of center pair.

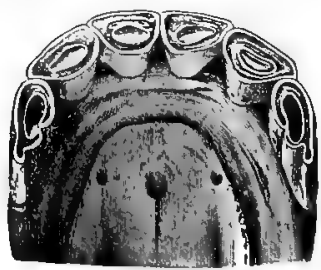

FIG. 23.-Upper front teeth at ten years of age. Cups out of intermediate pair. 
out, rounder on the inside, and meet at a sharper angle than when they first made their appearance (Fig. 20).

49. Eight years old. - At eight years, the cups are gone from all the nippers of the lower jaw. They are present in all of the upper jaw (Fig. 21).

50. Nine years old. - The cups in the center pair of nippers of the upper jaw have disappeared, but are still present in the intermediate and corner nippers. The cups are not likely to disappear at as regular intervals in the upper jaw as they did in the lower. Therefore it is not always possible to tell the age of the horse so accurately (Fig. 22).

51. Ten years old. - At ten years of age, the cups have disappeared from the upper intermediates, but are still retained in the corner nippers, though shallow. The teeth are more triangular in shape, and those of the upper and lower jaw meet at a sharper angle as the age increases (Fig. 23).

52. Eleven years old. - At eleven years, the cups are gone from all the nippers of the upper jaw. However, because of the fact that some horses have denser bones than others, it is

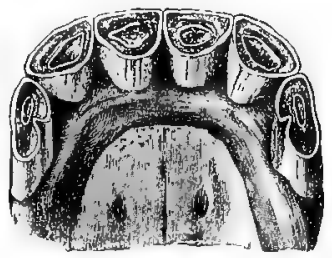

lig. 24.-- Upper front teeth at eleven years of age. Cups all out.

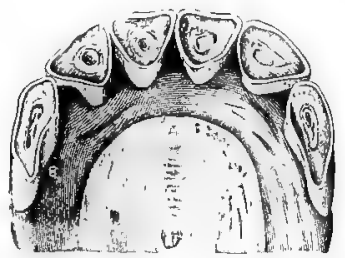

Fig. 25. - Upper front teeth at twenty-one years of age. Note the triangular forn.

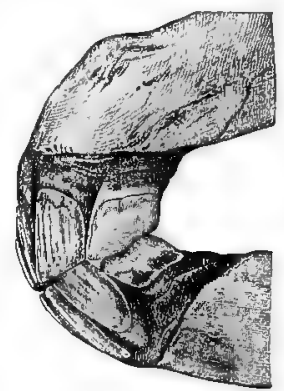

FIG. 26. - Side view at five years of age. not uncommon to find shallow cups in the upper corner teeth as late as the twelfth or the fifteenth year (Fig. 24).

53. Aged horses. - After the horse has passed the twelfth year, 


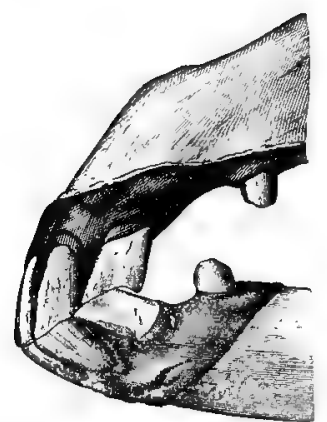

FIa. 27. - Side view at twenty-one years of age. Note the sharp angle at which the teeth meet.

a year or two matters little. Muck depends on the individuality of the animal, as some animals are worth more at fifteen than others attwelve One's judgment of the value of. a horse at these ages should be formec on general appearances and activi. ties rather than on age.

In old horses, the nipper teetr have become nearly triangular showing long wear and meeting $\mathrm{a}^{1}$ an acute angle. The tusks are large blunt, and round (Figs. 25, 27).

\section{DETECTING UNSOUNDNESS}

A satisfactory definition of soundness or unsoundness is no easily given. The term "unsound" as used by horse-dealer in this country is often loosely applied. It may mean anythin! from a bad habit to a defect that renders the animal absolutel: worthless. The best usage warrants dividing these imperfection into two classes, - blemishes and unsoundnesses.

54. Blemish. - This may be defined as something that de preciates the value of a horse without interfering with his useful ness, such as wire cuts, car bruises, and the like, which mar th appearance of a horse but do not limit his functions.

55. Unsoundness. - This may be defined as an imperfectio: of so serious a nature as to interfere with the usefulness of a horse such as ring-bones, side-bones, splints, curbs, and the like.

56. Impaired vision. -- A horse by its action will usually betra imperfect eyesight. Blind horses have a peculiar high steppin gait or are inclined to shy readily and often without cause. Th ears are exceedingly active, as if trying to aid the eyes. Blinc ness may be discovered by moving the hand gently in front of th 
eyes or by closing the eye with the hand and excluding the light for a moment; the pupil should dilate to its utmost capacity; when the hand is removed and the light strikes the eye, the pupil should rapidly contract to its normal size. This shows that the eye is sensitive to light.

57. Defective hearing. - When the horse's ears are rigid, it indicates that the hearing is defective. The animal is unresponsive when spoken to, and the eyes are active. Defective hearing is more common than supposed.

58. Poll-evil. - This is a disease located at the top of the head and is indicated by the parts being exceedingly tender. Its causes are many, and it is very serious.

59. Sweenied shoulders. - This is a wasting away of the muscle on the outside of the shoulder blade. This can be readily detected, as the shoulder appears flat and the blade bare of muscle.

60. Fistulæ. - Exceeding tenderness at the withers may indicate that the horse has fistulæ, though at the time there may be no external signs.

61. Splints. - Bony bunches on the inside of the cannon are called splints. These must not be confused with the two small bones associated with the cannon. Splints located on the back part of the leg near the tendon or close to the knee joint are considered most objectionable, as they are likely to interfere with the action and cause the animal lameness. When located on the side they are less likely to cause lameness and are not so objectionable.

62. Ring-bones. - Bony bunches on the fetlock and pastern are called ring-bone. There are two forms, called high and low, depending on the location.

63. Side-bone. - Just at the top of the hoof, on either side, the cartilages should be examined to see that they are not ossified, forming side-bones. These are common on the front feet only.

64. Scratches. - These are located on the back of the pastern, and can be easily detected; they often cause the horse a great deal of pain and annoyance. 
65. Unsound hoofs. - The hoofs should be closely examined for quarter cracks, thrush, corns, and laminitis.

66. Thoroughpin. - This occurs between the tendon and the upper point of the hock. It consists of a soft swelling and may be easily detected, as it can be pushed from side to side.

67. Spavin. - There are three kinds of spavin - bone, bog, and occult. Bone-spavin is the most common, and consists of a bony growth on the inside and front of the hind leg just below the hock. Bog-spavin occurs in the natural depression on the inner and front part of the hock and consists of a soft swelling, formed by the oil, which accumulates from the joint.

68. Curb. - This occurs on the back of the cannon just below the hock. It may be easily detected by looking at the leg from the side, as it is a variation from a straight line that should run from the point of the hock to the fetlock joint.

69. Forging and overreaching. - A horse is said to forge when the shoes of the hind feet strike those of the fore feet, making a characteristic sound. Overreaching is the striking of the fore and hind feet in such a way as to injure the horse.

\section{THE HORSE SCORE-CARD}

The score-card gives, in systematic order, a detailed description of the parts of an ideally perfect animal. It emphasizes the relative importance of the various parts, and teaches the method of seeing the parts in a logical and orderly way that none may escape observation. The score-card deals with one animal, comparing it with an ideal of what the animal should be. It is primarily an aid to the study and teaching of stock-judging. After having learned the method of examination, - the art of seeing the parts instead of the animal as a whole, - and after securing an idea of the relative importance of the parts, we are ready to discard the card and take up comparative judging.

70. Method of using the score-card. - Both types of horses are placed on the same card in this book, although the description and 
the numerical value differ in nearly every case. This has been done to facilitate teaching, as it indicates rather vividly the difference in the two types. The card is divided into several main divisions, each of which is assigned a numerical value, and these are again divided into a number of parts, each of which is described. At the right of each description is given a figure which shows the percentage value attached to each particular part.

71. In scoring, first note that part critically, and if the animal is as nearly perfect as possible, leave blank the column headed "Students," which means that there is no cut, and that the part is worth all the card allows. If the part is imperfect, make a cut taking away from the numerical value assigned the part, the percentage which indicates how much it would have to be improved to be perfect. Make the cut on the percentage basis, that is, if scoring say the weight of a draft horse which is deficient 10 per cent, take 10 per cent of the numerical value given the character, which is .8 . Place the .8 in the column headed "Students." Continue until all parts have been noted in the order given and the deficiencies recorded. Add the deficiencies and subtract from 100 , which gives the score of the animal. When the work has been finished, each student should correct his card to correspond with that of the instructor, who will give his reasons for each cut made and discuss the merits and demerits of the animal in detail.

72. Rules of scoring. - It is not considered advisable to make a cut of less than 5 per cent on the percentage basis. Seldom will a part deserve a cut of more than 50 per cent, as an important part deserving a greater cut than this is so seriously at fault that it may disqualify the animal. The scorer must use his judgment in deciding the proportionate score to allow between these limits. It takes a very good animal to score 80 , and an exceedingly choice one to score 90 and above.

Score-card for horses. - Each breed of horses has its own scale of points varying in detail and numerical value, but they are similar to the following:- 


\section{STUDENT'S SCORE-CARD}

\section{HoRsES}

Scale of Points

A. General Appearance : Draft 35 : Driving 43 :

Age - Estimated ........ yrs; actual ......yrs.

Height - Estimated..... . hands; actual... .hands

Weight - Estimated..... . ibs; actual......lbs.

Form, for draft, low, massive, symmetrical ; for driving, high, lithe, indicative of extreme activity

Quality, bone, flat; tendons, clean; skin and hair fine

Color, according to breed

Action, step, smooth, quick, long ; trot, rapid, straight, regular

Attitude, members vertical .

Temperament, lively, pleasant

\section{B. Head and Neck : Draft 5 : Driving 5 :}

Head, lean; length, two-fifths height of withers; width, of forehead, more than one-third length of head; depth of head, one-half its length. For driving, smaller, carried higher and more horizontal

Muzzle, fine; nostrils, large; lips, thin; teeth sound .

Eyes, full, bright, and intelligent

Ears, short, clean, fine, directed forward, wide apart .

Neck, pyramidal, muscled; throat, clean, fine; windpipe large. Depth of insertion at shoulder equals length of underline, 2 to 4 inches shorter than head. For draft, neck shorter, thicker, more horizontal

\section{Forequarters : Draft 20 : Driving 19 :}

Shoulders, long, extending into back; point of shoulder to point of withers, equals length of head. For draft, shorter and more upright

Arms, relatively short, 12 to 13 inches. For draft, more horizontal

Forearms, vertical, long, 14 to 15 inches: wide. For draft, shorter, more heavily muscled . . . . . .

Knees, clean cut, wide, deep, for driving, 2 inches, for draft, 3 inches, strongly supported .

Cannons, vertical, short, 9 to 10 inches, lean, wide; tendons well detached. For driving, longer

Fetlocks, wide, thick, olean, free from puffiness

Pointa Deficrent

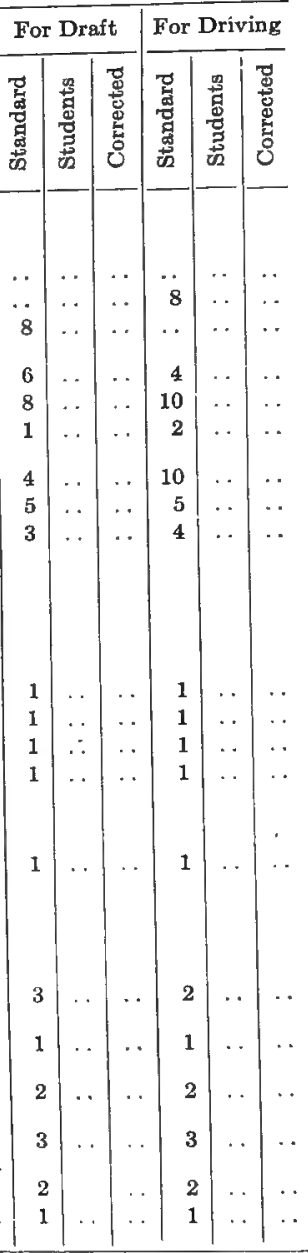




\section{S'TUDENT'S SCORE-CARD - Continued}

\section{Horses}

Scale of Points

Pasterns, angle 45 degrees, fetlock to ground, 7 to 8 inches. For driving, long, sloping ; for draft, short, more upright

Feet, round, even size; horn dark colored, dense ; sole, concave; bars, strong; frog, large, elastic; heel, vertical, one-half length of toe

\section{Body : Draft 10 : Driving 8 :}

Chest in general, high, long. For draft, wide, half height of horse ; for driving, higher

Withers, clearly defined for driving

Breast, for driving, high, projecting. For draft, broad and muscular

Ribs, long, round curvature, wide apart

Back, straight, short, muscular; shoulders, to haunch equals length of head. For driving, longer .

Loin, wide, short, thick, strongly joined to hips

Underline, long; for draft, flank low. .

E. Hindquarters : Draft 30 : Driving 25 :

Hips, level, wide in proportion to other parts, for clraft, smooth ; for driving more prominent

Croup, wide, long, muscular, 2 to 4 inches shorter than head. For driving, horizontal ; for draft, shorter, more oblique.

Tail, set and carried high, long, full, fine .

Thighs, for driving, long, 15 to 16 inches, upright; stifle, deviated outward. For draft, shorter, more horizontal, muscular

Buttocks, heavily muscled, well descended

Gaskins, for driving, long, 14 to 15 inches, upright; for draft, shorter, more horizontal, heavily muscled

Hocks, clean cut, large, straight, deep, for driving 3 inches, for draft 4 inches. For draft wider.

Cannons, 11 to 12 inches long, otherwise as above . . .

Fetlocks as above.

Pasterns as above; angle 60 degrees

Feet, compared with above, more oval, more concave; heels, higher, more separated; walls, more vertical .

PoINTs Defictent

\begin{tabular}{|c|c|c|c|c|c|}
\hline \multicolumn{3}{|c|}{ For Draft } & \multicolumn{3}{|c|}{ For Driving } \\
\hline 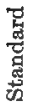 & 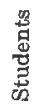 & 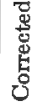 & 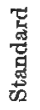 & 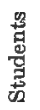 & $\begin{array}{l}\text { 总 } \\
\text { 总 } \\
\text { 岁 } \\
\text { 今 }\end{array}$ \\
\hline 2 & . & $\ldots$ & 2 & . & $\cdots$ \\
\hline 6 & . & . . & 6 & $\ldots$ & . \\
\hline 3 & .. & $\ldots$ & 2 & $\ldots$ & $\ldots$ \\
\hline 0 & . & . & 1 & . & .. \\
\hline 1 & $\ldots$ & $\ldots$ & 1 & $\ldots$ & $\cdots$ \\
\hline 2 & .. & . & 1 & . & $\ldots$ \\
\hline 2 & $\ldots$ & $\ldots$ & 1 & .. & $\ldots$ \\
\hline 1 & . & $\ldots$ & 1 & $\ldots$ & $\ldots$ \\
\hline 1 & . & . & 1 & $\cdots$ & . \\
\hline 1 & $\cdots$ & . & 1 & . & $\cdots$ \\
\hline 4 & . & .. & 3 & .. & \\
\hline 1 & $\cdots$ & . & 1 & . & . \\
\hline 3 & $\cdots$ & $\ldots$ & 3 & $\ldots$ & $\cdots$ \\
\hline 2 & $\cdots$ & . & 1 & . & $\cdots$ \\
\hline 3 & . & . & 2 & . & $\cdots$ \\
\hline 6 & $\ldots$ & $\ldots$ & 4 & . . & $\ldots$ \\
\hline 2 & . & . & 2 & . & . \\
\hline 1 & . & . & 1 & . & .. \\
\hline 2 & $\ldots$ & $\cdots$ & 2 & $\cdots$ & $\cdots$ \\
\hline 5 & $\cdots$ & $\cdots$ & 5 & . & .. \\
\hline & $\cdots$ & . & . & $\cdots$ & " \\
\hline
\end{tabular}


73. Measurements of horses. - Since the light type differs in conformation from the heavy type, a few exact measurements are recorded to fix in mind the more important differences. The heavy horses measured were from transfer stables and the light horses from the Columbus, Ohio, Driving Park:-

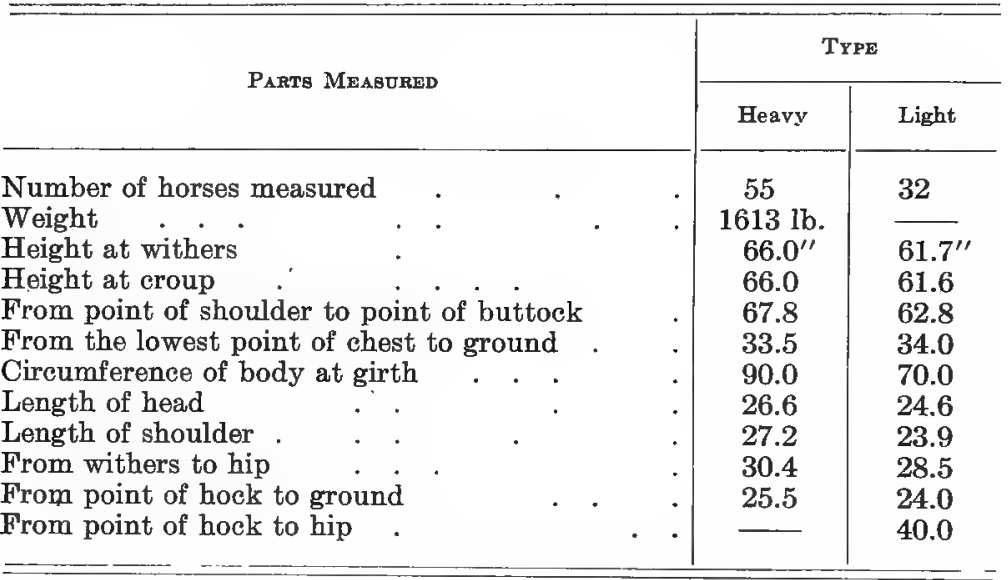

\section{GENERAL APPEARANCE IN LIGHT HORSES}

The height, form, action, quality, color, and temperament are very important characters among light horses; and add to or detract from their desirability.

74. The height. - The unit for measuring the height of a horse is a hand, which is equal to four inches. Where the accurate height is desired, a measuring staff, marked off in hands and inches, is used. Where absolute accuracy is not desired, and where the measuring staff is not available, the height must be estimated. This can be facilitated by chinning the horse, first finding out how high it is from the ground to the point of your chin when you stand erect. The measurement of the height is taken at the withers. 
75. Form. - One of the first characters to attract attentic among light horses is the general form. This varies according $t$ the object sought, that of the coacher being full and plump, whi that of the trotter or runner will be lean and angular. The pos tion and direction of the limbs should receive special consideration

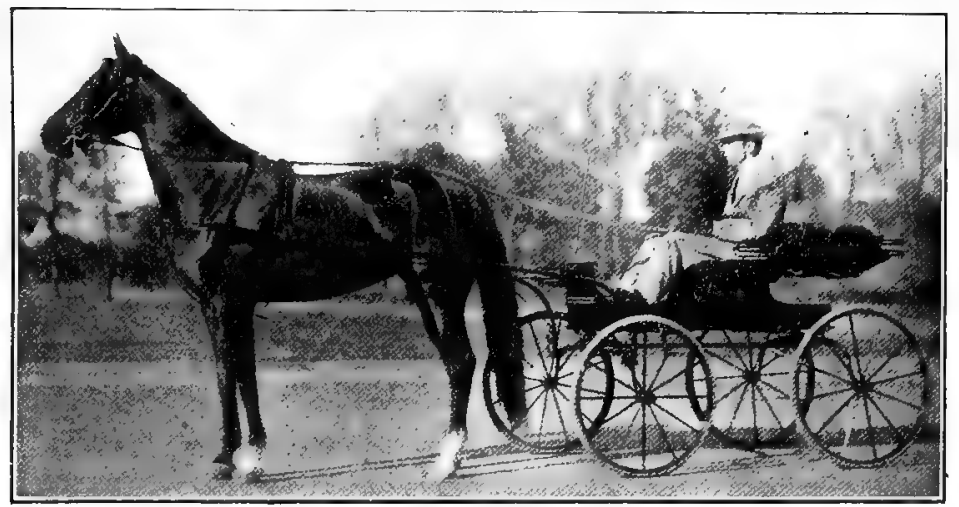

FIG. 28. - Light horse of good form.

They should be viewed from in front, from behind, and from eithe side. The fore leg when viewed from the side should be so forme that a plumb line dropped from the elbow joint would pass throug the middle of the knee, the cannon, and the fetlock, and fall a shor distance behind the heel; when viewed from in front, the lin lowered from the point of the shoulder would divide equally th knee, the cannon, and the foot, leaving between the two feet a interval equal to the width of the hoof. The hind leg when viewer from behind should be so formed that a plumb line lowered fror the point of the buttock will pass through the middle of the hock cannon, pastern, and foot, leaving between the two feet an in terval almost equal to the width of the hock. This line shoul. also just touch the back of the hock and the pastern join (Fig. 28). 
76. Action. - In the market for light horses there is no single feature held in higher estimation than that of good action. Desirable action varies according to the objects ought, but to sell well a light horse must possess as much as may be displayed and used to advantage. Excellence at a walk is a very desirable quality in all types of horses. The feet of the active walkers leave the ground with a quick snap, and move straight away, swerving

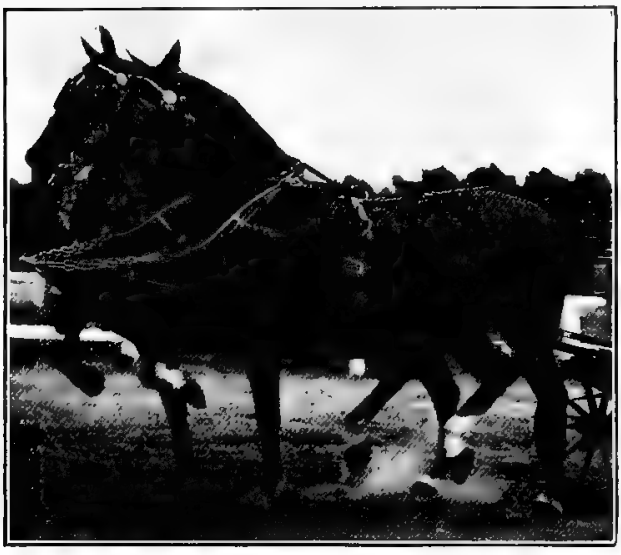

FiG. 29. - Light horses with stylish action. neither to the right nor to the left, nor should the folding of the knees or the flexing of the hocks result in an outward pitching or spreading. In addition to being snappy, regular, and straight, it should be fast.

Action at the trot will vary according to the class. In the roadster a strong, long-reaching kneeand-hock action, with the feet picked up quickly, is most essential. The stride should be long and not too high. In the coacher, a rather high, bold knee-and-hock action is most sought. In all classes the movement should be straight and regular (Fig. 29).

77. Quality. - This is a term rather loosely applied and has reference to the bones, skin, and hair. Evidences of desirable quality are clean-cut features, soft skin, silky hair, and clean dense bone. In those horses possessing quality the lines of the face are clearly defined, the veins in the skin show clearly, and there is a complete absence of coarseness. Freedom from coarseness in the joints and tendons emphasizes soundness and guarantees 
durability. Another evidence of quality is seen in those animals whose muscles stand out clearly defined and distinct.

Coarse hair is associated with coarse thick skin, which indicates an abundance of connective tissue, which in turn is associated with soft, spongy bones that cannot endure strain or hard usage.

78. Temperament. - This is reflected in the action and manners. It should be lively and pleasant. When possible, the purchaser should know something of the ancestors of the horse under consideration, as a horse may inherit characteristics which cannot be discovered until he has been used some time, and peculiarities of temper are among these characters.

\section{DETAIL CHARACTERS OR FEATURES OF A LIGHT HORSE}

79. Head. - Among light horses the head should be lean, with broad forehead tapering towards the nostrils, and the features of the face should be distinct. The nostrils should be large, open, and of pink color. The eye should be large, full, clear, and bright, indicative of a kind, generous disposition and good health. The jaw-bones should be strong and wide, providing ample room for a large wind-pipe. The ears should be active, refined, neither large nor small, carried close and erect and turning slightly in at the tips. Lop ears indicate laziness. A smooth neat attachment of head to neck is highly essential.

80. Neck. - A nicely arched and well-muscled neck of good length, carrying the head gracefully, is a highly desirable feature of the light horse. Much of the style and symmetry of the coach horse is observed in the make-up and carriage of the head and neck. The neck and body should blend smoothly at the attachment.

81. Chest. - Among light horses the chest should obtain its capacity more from depth than width. A deep chest permits a freer play of the shoulders, and indicates staying power.

82. Shoulders. - To give elasticity to the movement and to permit of quick and clean action, the shoulder should be long and 
sloping well into the back, thus strengthening the back and extending the length of the underline. The high action of the coach horse and the long-reaching clean action of the roadster depend much on a long oblique shoulder.

83. Arms. - Among light horses the arm should be short and comparatively upright, giving the animat an upstanding appearance.

84. Elbows. - The elbow should work snugly alongside the animal; if too closely "tied in," as it is termed, the toes are usually thrown out; if turned out, the toes are likely to be thrown in.

85. Fore-arms. - These should be long, wide, and well muscled. The muscles should be well developed and stand out distinctly just below the junction of the leg and body and taper gracefully downward.

86. Knees. - The knees should be wide, deep, and straight. They should be much broader in front than the remainder of the leg, either above or below. The bone forming the projection at the back of the knee should be prominent, since this gives a better attachment for the muscles and tendons, which pass over it, thereby giving the leg a deeper appearance and increasing the efficiency.

87. Cannons. - Cannon-bones should be short, wide, clean, and the tendons well detached. The back tendons should be parallel to the cannon-bones, and there should be no shrinking below the knees, as this indicates weakness. The cannon should be free from bony growths and puffiness.

88. Fetlocks. - They should be clean, free from fullness due to wind-galls, and should be wide, giving favorable attachments to the tendons.

89. Pasterns. - The pasterns should be sloping and strong. When the horse is standing, they should form an angle of 45 degrees with the floor and 135 degrees with the cannons. The upright pasterns cannot resist concussion, and bone diseases, such as ring-bones, side-bones, and the like, are the result. Again, it 
lessens the usefulness of the light horse, especially the saddler, as the step is short and stilted and very disagreeable to the rider.

90. Feet. - They should be round, dense, fine in texture, of good size, and perfectly sound. They should be of equal size and shape and in line with the pastern. The hoof should have an oily coat of natural wax, and should not appear flat, brittle, shelly, or contracted. The heel should be rather vertical and abcut one-half length of toe. The sole should be concave; the bars strong, and the frog large, elastic, and bear the mark of natural usage as a buffer. The dark-colored feet seem to be in favor.

91. Ribs. - These should be well sprung from the spine, of good length, and well inclined to the rear. The well-sprung rib gives lung capacity, the deep rib gives digestive capacity, and the ribs well inclined to the rear add much to the strength of the back.

92. Body. - The back should be short, strong, and well muscled. The body should have a short back with a long underline which not only adds strength to the back, but gives the legs free play and insures freedom of movements. The long back, the roach back, and the sway back are all very objectionable.

93. Loins. - These should be wide, short, thick, and strongly joined. This combination results when the ribs are directed well backward. If the distance from the last rib to the hip is great, the horse is likely to be weak in the coupling and irregular in his action.

94. Croup. - This should be long, muscular, and fairly straight. The croup of light horses should be more horizontal than in heavy horses. This in connection with its length allows greater play of the main muscles, which is favorable to the production of speed. While examining the croup, the hips should also be observed, to see that they are of equal prominence and squarely placed.

95. Thigh. - This should be muscular, long, and deep. It should be so situated as to extend the muscles as far down towards the hock as possible, without giving the leg too straight an appearance. Horses show much variation in the muscling of the 
quarters; some are full and heavily muscled, some decidedly lacking and called " cat hammed," while others are fairly full in this region, with deep, hard muscles.

96. Hocks. - The hocks should be wide, properly set, and clean. They should also be free from gumminess, fleshiness, and puffs of all kinds, and the bone firm without the least indication of unsoundness. The bone forming the point of the hock should be prominent, 'since this gives a better attachment for the muscles and tendons which pass over it, thereby giving the hind leg a deeper appearance and increasing its efficiency.

\section{JUDGING A HEAVY HORSE}

In choosing a heavy horse, it must be borne in mind that the fatter the animal the more difficult it is to detect many of the defects which would stand out clearly were the animal not padded with a thick coat of fat.

97. General appearance in heavy horses. - The same general method should be followed in examining a heavy horse as a light

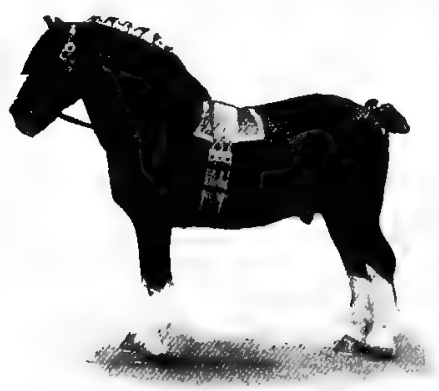

FiG. 30. - Draft horse of good form. one, with the difference, that we place more stress on weight.

98. Weight. - Among draft horses, weight is a very important consideration; in fact, a horse must weigh at least 1500 pounds to be classed as a draft animal. Draft horses are divided into three classes according to their weight: light draft, 1500 to 1600 pounds; medium draft, 1600 to 1800 pounds; and heavy draft, 1800 pounds and up. This weight must be due to strong bone, heavily muscled, as well as to large proportions, and not the result of excessive fatness. 
99. Form. - In form, the draft horse should be massive, compact, blocky, and low set. Power and not speed is the requirement, and in order to attain this the animal must be close to the ground, strong, and heavy. In animals of speed we find long bones, long muscles, and slightly angular joints; in animals of strength we find heavy bones, heavy muscles, and a comparative freedom from angularity about the joints (Fig. 30).

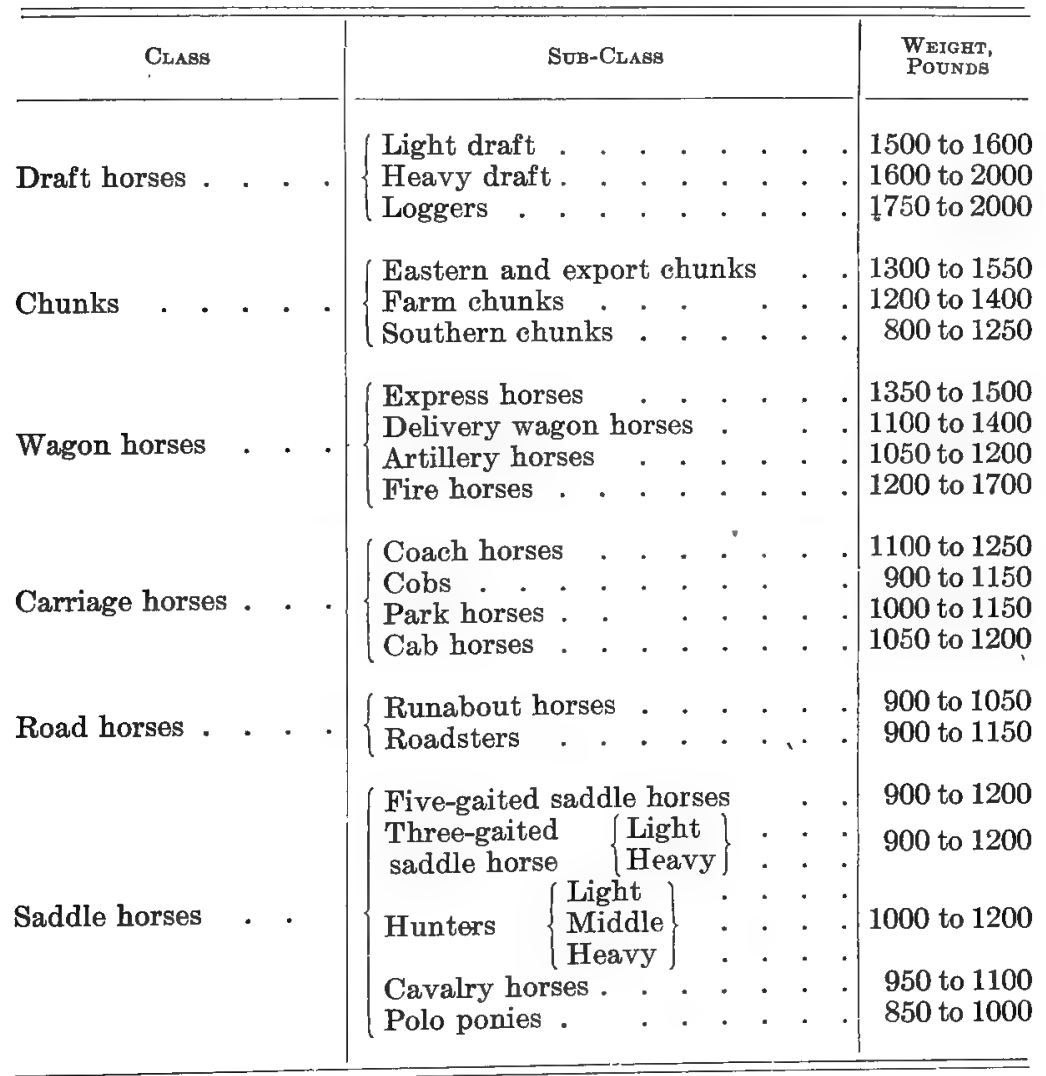


100. Action. - While action in the heavy horse is not considered as desirable as in the lighter types, yet it should receive much attention. The walk deserves special notice since it is the principal gait of the draft horse.

101. Market classes of horses. - On the market, horses are classified largely according to their uses. While there is much variation among different horse markets, the preceding table will give an idea of the nature and extent of the various market classes and sub-classes. Each sub-class is further divided into several grades as choice, common, inferior and the like. (See table, p. 51.)

\section{QUESTIONS}

1. Why is it so essential to cultivate the power of observation in judging? How does the association of ideas strengthen the memory?

2. Which is the more symmetrical, a young horse or an old one? Which has the more pliable skin, and why? Why do the joints on aged horses become prominent?

3. How can you tell the sex of a mature horse by examining the mouth? Why do the cups disappear from the lower teeth before they do in the upper teeth?

4. What does it indicate if a horse rests one front foot by projecting it forward? By flexing it and resting on the toe? What do the following irregularities indicate:- broken teeth; discharge from nostrils; rigid ears; tender withers; white hairs on front of knees; and small white spots over the body?

5. What are the principal uses of the score-card? Why is it never used in practical horse-judging?

6. Why is the hand used in measuring the height of horses? Which is the taller, the draft or driving horse? Which has the longer legs?

7. Is the horse as tall from the ground to the withers as his body is long from the shoulder to the buttock? How many head lengths in a horse's height?

8. Why should the distance from the withers to the knees and from the hips to the hocks be great in the trotting horse? Why comparatively short in the draft horse? 
9. Why should the shoulders and pasterns be long and sloping in the trotting horse and comparatively short and straight in the draft horse?

10. Why are rather light, long muscles, working parallel to the bones, desired for the fast horse; and heavy, short muscles, working at right angles to the bones, desired in horses for draft? 


\section{CHAPTER III}

\section{PRINCIPLES OF FEEDING}

THE economic feeding of farm animals involves a knowledge of the principles underlying the practice. The better knowledge one has of the food, its source, use, composition, and digestibility, the more familiar one is with the function of the various food materials, and the balancing of rations, the more intelligently can one choose the foods that constitute the ration.

\section{FOOD}

Food may be defined as any material that an animal can take into its digestive organs and from which it can absorb matter for the nourishment of its own body. Plants and their products and by-products constitute the food of farm animals, although some farm animals are in part carnivorous, feeding on other animals or parts of animals. The plant during growth absorbs heat from the sun, which is held in latent form in the plant compounds. When these compounds are taken into the animal body and broken apart by digestion, some of this stored heat or energy is transferred to the animal body.

102. Use of food. - The matter and energy the animal collects from the food are put to three distinct uses : first, to support life ; second, to reproduce life; and third, reserve supply stored up in some form. The animal must maintain its existence, and for this both energy and matter are required. A large part of the energy of the food goes to the maintenance of the body temperature. The body temperature of farm animals is considerably above that 
of the surrounding atmosphere, and its maintenance requires much heat, as the body is continually giving off heat. The body tissues become worn out and must be constantly renewed by the matter and energy from the food. In the case of young animals, there is a constant formation of new tissue. This requires more matter than energy. Again, the muscular function of vital processes requires much energy, which must be supplied by the food. Of the total amount of food that an animal will ordinarily consume, a very large proportion goes to support life and a small amount to production.

103. Composition of food.-The value of a food depends, among other things, on its composition. There is a tendency to ignore the fact that a food should be considered with reference to its composition. It is assumed that a pound

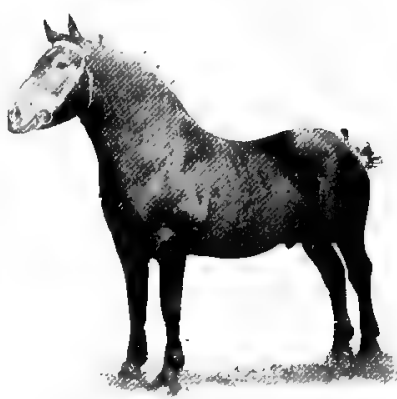

FIG. 31. - Percheron stallion. of timothy hay, for example, is equivalent to a pound of clover hay, when as a matter of fact their composition is such as to make them widely different, so that one will not take the place of the other. The number of compounds found in the food is very large, and many of them are very complex in their nature. For convenience in comparing foods, these compounds are grouped into classes. These classes are few in number, easy to comprehend, and serve the purpose well from a practical point of view. We recognize five distinct groups, one of which is divided into two sub-groups. They are as follows: -

1. Water

2. Ash (mineral compounds)

3. Protein (nitrogenous compounds)

4. Carbohydrates $\left\{\begin{array}{l}\text { Crude fiber } \\ \text { Nitrogen-free extract }\end{array}\right.$

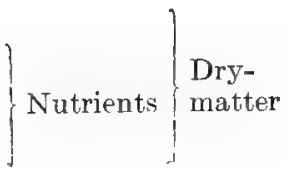


It is customary to group together all the substances of a food except the water, and to speak of them collectively as dry-matter, and not with respect to their total weight. Ash is also eliminated, and the remaining three constituents are called nutrients.

104. Water. - Water is present in all foods, even the driest. It varies widely in different foods, running as low as 8 or 10 per cent in the case of grains or concentrates, such as corn, oats, or cotton-seed meal, and dried brewers' grains, to 85 or 90 per cent in the more watery foods, as silage, roots, tubers, and the like. Even dry hay varies considerably in this respect, alfalfa containing as low as 9 per cent and some clovers as high as 20 per cent. Water not being a nutrient, its presence or absence is an important factor in determining the usefulness and therefore the value of food.

105. Ash. - Ash or mineral matter is present in all plant food, although it forms but a small part, shelled corn containing only 1.5 per cent, and alfalfa, one of the highest, containing only 8 per cent. The leaves and the region of the germ in grain contain the most ash. The animal secures the ash from the food directly by transfer. Most plants contain sufficient ash to meet the needs of the animal, corn and certain prepared foods being the only exceptions. In young animals, because of the rapid growth of bone that is taking place, in milk cows and egg-production hens and the like, it is of special importance to have sufficient mineral matter supplied by the food.

106. Protein. - Of the three nutrients - protein, carbohydrates, and fats - the protein is considered to be the most important. This is perhaps due to two factors: first, protein is absolutely essential to the animal body, and second, the percentage of protein is relatively small in most plants. Like the other nutrients, the protein group contains carbon, hydrogen, and oxygen, and in addition it also contains nitrogen, which is the characteristic element of the entire group. It is on the element nitrogen that the importance of this group depends. Protein 
- enters largely into the composition of the bones, muscle, lean meat, white of egg, and the curd of milk. Animals can procure this protein only from the protein of food.

The amount of digestible protein in various foods varies within rather wide limits, corn containing only 8 per cent, while cottonseed meal runs as high as 32 per cent, but the larger number of food materials contain rather small amounts of protein. There are comparatively few foods that are relatively rich in protein. The value of the food depends very largely on the protein that it contains. Protein is not, however, as digestible as some of the other nutrients.

107. Carbohydrates. - There are two sub-groups of carbohydrates - nitrogen-free extract and crude fiber. The carbohydrate group contains carbon, hydrogen, and oxygen, but no nitrogen. The nitrogen-free extract is composed largely of starches and sugars, and constitutes the larger part of the dry-matter of most plants. Starch alone forms as much as 75 per cent of the dry-matter of corn, wheat, potatoes, and some other foods. It is easily digested, more so than any of the other three constituents, and therefore foods rich in nitrogen-free extract are ordinarily classed as most readily digestible. Fiber or crude fiber constitutes the tough woody part of plants. The stems of all plants contain more fiber than does the leafy part. Variation in the digestibility of foods depends

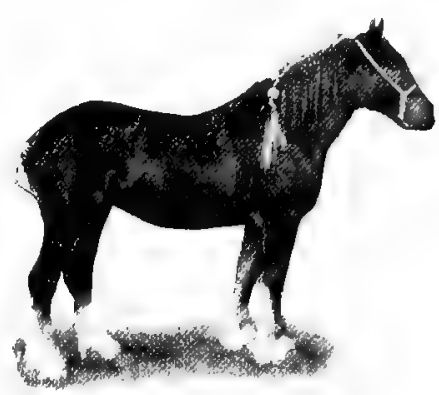

Fig. 32. - Clydesdale Mare. largely on the amount of crude fiber, which is mostly insoluble and hence largely indigestible. Crude fiber is the least valuable of the four nutrients, because of its indigestibility. Young plants contain less crude fiber than plants that have matured and formed seeds, and hence are more digestible. 
108. Fat. - Plants also contain fat or oil. It occurs in largest quantities in the seed, and varies widely, running less than 2 per cent in rye to 30 and 35 per cent in flaxseed.' Fats like carbohydrates contain carbon, hydrogen, and oxygen, but no nitrogen. The oil content of food is determined by extracting the fat by ether; hence in tables giving composition of food, the fat is often designated as ether extract. A given weight of fat will develop $2 \frac{1}{4}$ times as much heat energy as an equal weight of carbohydrates. If we multiply fat, therefore, by $2 \frac{1}{4}$, it reduces it to the starch or carbohydrate equivalent. Fats are not so readily digested as nitrogen-free extract.

\section{FUNCTIONS OF FOOD MATERIALS}

A knowledge of the function of the various food materials will enable one to choose and balance a ration more economically, and to adapt it to the needs of the animal.

109. Water. - The water of the food takes the place to a certain extent of the water that an animal would otherwise drink. In the case of food containing a large amount of water, the total consumption of water by the animal will be greater than otherwise. Watery foods will not, however, satisfy the animal in this respect, as it will still drink water. In many cases the large consumption of water is of advantage to the animal; this is particularly true of the dairy cow, which, in addition to the water needed for her own body, secretes large amounts in the milk. Animals require much water, particularly the younger ones, whose bodies are more than 50 per cent water.

110. Ash. - The ash or mineral matter is chiefly used in the formation of bone, but also to some extent in the tissues, blood, digestive fluids, and the like. Young animals fail to develop if given no mineral matter, and mature animals become weak and inactive if deprived of common salt. Hogs, if closely confined, and fed on corn alone, are likely to be 
weak-boned because of the lack of mineral matter in the food. If to the corn ration some food rich in mineral matter, such as alfalfa, or even wood ashes, is added, no difficulty is experienced. Hens always require more lime than is found in the food. This is strikingly illustrated when we compare the composition of eggs and corn, for example, the former containing 12.2 per cent ash, the latter only 1.5 per cent. The ash in the food of the milk cow also deserves special consideration on account of phosphoric acid, lime, and potash so abundantly found in the milk which she secretes.

111. Protein. - So far as known, the proteids of the food are the only source of the proteids of the body. In other words, the muscles, the connective tissues, the blood, the skin, the hair, the horn, the hoofs, and the larger part of the tissues of the secretive and excretive organs, owe their formation to the protein of the food. Since these are the tissues that largely determine the vigor and quality of the animal, and since they are formed rapidly in the early stages of growth, a normal and continuous development demands an abundant supply of protein food. In addition to this, protein is a source of fat and can serve as fuel, or as a source of energy.

112. Carbohydrates. - Carbohydrates are used to maintain heat and to produce fat. Formerly it was thought that carbohydrates were used for the former purpose only, but it is now well established that the animal fats may have their source in the carbohydrates. Again, experiments with milk cows show clearly that milk-fat may also be derived from carbohydrates. Because carbohydrates can be used as heat-producers and as fat-formers, and because of their ease of digestion and cheapness of production, this group of nutrients is very important.

113. Fat. - Fat, like carbohydrates, serves as a source of heat and of animal fat. The differences are that the supply of carbohydrates is much larger, and the heat value of a similar weight of fats much greater, - as we have already seen 
$2 \frac{1}{4}$ times as great. There seems to be experimental evidence showing that vegetable fat becomes deposited in the animal without change, whereas fat formed from carbohydrates involves complex transformation.

\section{DIGESTIBILITY OF FOOD}

The value of food depends on the digestibility of the various materials of which it is composed, and not alone on its composition as shown by a chemist. In order to get a clear conception of digestion, it will be necessary to review briefly the process through which the food materials must pass on their way from the food to the flesh or energy of the animal body.

114. Digestion. - The process of digestion is largely a process of solution, aided to a certain extent by chemical changes that take place through the influence of various ferments with which the food comes in contact as it passes through the digestive tract. The digestive organs form a canal through the body, and the food in its passage through this tract or canal is acted upon by various fluids. Each fluid has a special work to do in the process of digestion. The food is taken into the mouth, where it is reduced to fine particles in order that the digestive juices may better do their work and in order to put it into condition to be swallowed. During this mastication, a digestive fluid, called saliva, is poured upon the food, moistening it and changing a part of the starch to sugar. After leaving the mouth the food passes down the esophagus into the stomach, where the digestive fluid, called gastric juice, is poured upon it, changing part of the protein. When the food leaves the stomach, it enters the small intestines, where it comes in contact with two digestive fluids - the bile from the liver, and the pancreatic juice from the pancreas. The bile prepares the partly digested food for the action of the pancreatic juice and changes the fats. The pancreatic juice has a more complex function. It contains at least three distinct ferments, 


\section{Principles of Feeding}

one changing the proteids, another the starch, and the third the fats. As the material passes along the intestines it comes in contact with a juice secreted by the walls of the intestines which acts upon the starch, but there is little action on the proteids and fats. From the time the food enters the stomach, during its entire course along the digestive tract, in some way not wholly understood, the digested food has been absorbed and received into vessels, through which it is distributed to the various parts of the body. A part of the food materials, however, in passing through the digestive tract, escapes digestion. The amount of food digested depends on the kind of food, the amount fed, the class of animal, and the condition of the animal's health.

115. Size of digestive organs. The length and capacity of the digestive organs of the various farm animals differ widely. Among ru-

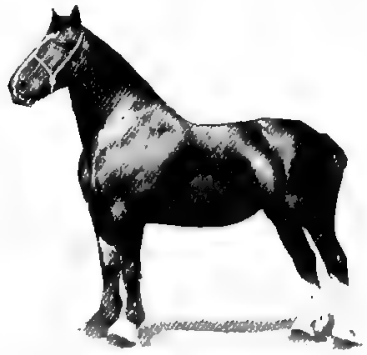

Fic. 33. - Shire mare. minating animals, - those capable of re-chewing the previously swallowed food, the cow, sheep, and goat, - the stomach is a very complicated organ. It has four divisions or sacks called paunch, honeycomb, many-plies, and rennet. The paunch is very large and may be considered as a reservoir for the storage of bulky foods. Because of this provision, ruminating animals can be fed on foods containing much more bulk than can the pig or horse. The food during its retention in the paunch becomes thoroughly softened and undergoes some fermentation, then it is re-chewed, - called chewing the cud, - and swallowed. The stomach of the horse and pig is a single sack and has not nearly so great capacity.

The varying length of intestines and capacity of stomach in farm animals is illustrated in the following table:- 
Length of Intestines and Capacity of Stomach of Farm Animals

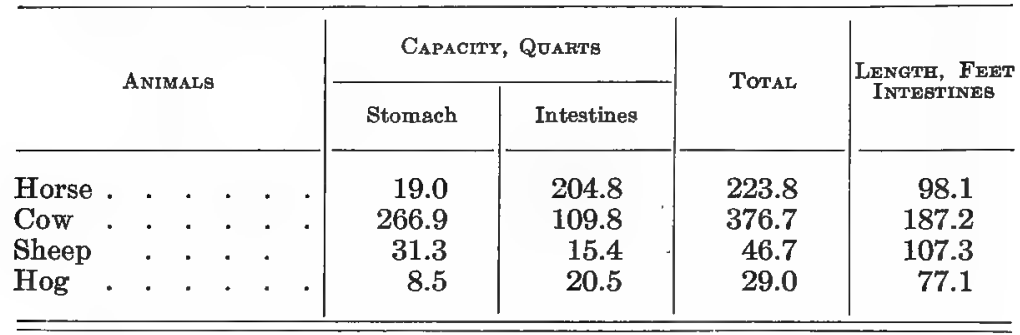

116. Digestible nutrients. - Digestible nutrients are those parts of food materials that are digested and appropriated to the animal's use. Our knowledge of the amount of the food materials that are digested is based on experimental data, and while not absolutely accurate, is sufficiently so for practical purposes. The method of determining the digestible nutrients is as follows: the animal is fed for a sufficient length of time on a certain food or combination of foods, so that the digestive organs contain only the food under test. Then for a certain length of time the animal is fed a carefully weighed allowance of some food, the composition of which has been previously determined by a chemist. Provision is then made for collecting all excreta. By making an analysis of this waste matter, the undigested protein, carbohydrates, and fat are found. This, deducted from the total in the food, gives the digested part. The amount of each constituent digested divided by the total in the food gives the percentage digestible. This is called the "coefficient of digestibility." Having the composition of the food as determined by the chemist, and the digestible coefficient as determined with the animal, it is an easy matter to calculate the amount of digestible nutrients in the various foodstuffs. It is with the digestible nutrients, and not the total food materials, that the feeder is concerned in choosing a ration. A great deal of work has been done at the various experiment stations 
to determine the digestibility of food-stuffs. For ready reference Table 6, showing the amount of digestible nutrients in a large number of foods, is published in the Appendix.

117. Digestibility of food materials. - Among the various food materials the carbohydrates as a rule are the most digestible, running as high as 95 per cent in case of corn, while the crude fiber is the least digestible, and between these lie fat and protein. In general the fat is more digestible than the protein. As a rule, the digestible coefficient falls when large amounts of foods are used. If we crowd the consumption of food, the animal does not digest it as thoroughly as it would if fed smaller amounts. On the other hand, we cannot secure á greater digestibility by limiting the consumption. Animals under a starving ration do not digest any more than when fed a normal amount. The grains are more highly digestible than the coarse fodders; for example, in corn the protein is 76 per cent digestible, the crude fiber 58 , the nitrogen-free extract 93 , and the fat 86 per cent digestible, while in timothy hay the protein is 56 per cent, the crude fiber 58 , the nitrogen-free extract 63 , and the fat 57 per cent digestible.

\section{MAINTENANCE RATIONS AND PRODUCTIVE RATIONS}

A ration may be defined as the quantity of food that is consumed by an animal weighing one thousand pounds in twentyfour hours. In forming rations, it is necessary to take into account the purpose for which the animal is used. For convenience of study, rations are divided into two general classes, - rations for maintenance and rations for production.

118. Maintenance rations. - A maintenance ration is one that supplies the needs of a resting animal without producing any kind of labor and with no loss or gain of body substance. We have already seen that a certain amount of the food consumed by the animal goes to support life, maintain body temperature, repair waste tissue, and to provide muscular activity of vital processes. 
Since the demands on the body for maintenance are largely for the production of muscular energy and heat, nine-tenths or more of the maintenance ration may consist of carbohydrates.

119. Productive rations. - Productive rations may be looked upon as made up of two parts: that which is needed to maintain the animal, and that which may be applied to production after

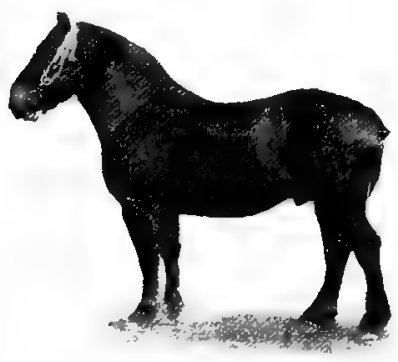

Fig. 34.-Belgian stallion. the bodily needs have been supplied. It is the food consumed and digested in excess of the amount required for maintenance that enables the animal to produce. The question, then, is as to the quantity of food the animal will consume and make sufficient returns for in production. While it is true in a sense that the amount of production is in proportion to the amount of food assimilated in excess of that required for maintenance, it is only within rather narrow limits that this relation holds strictly true. The individuality of the animal plays an important part. All farm animals will eat and digest more food than is required for maintenance, but the amount of product that comes from this excess of food is variable, and in many cases this makes the difference between a profitable and an unprofitable animal.

120. Feeding-standards for farm animals. - A feeding-standard is a rule to which all rations should conform for a given purpose. The Germans have done much work in establishing such standards, which have long been in general use as guides in computing rations for farm animals. More recently, Kühn, Kellner, Armsby, and others, working with the energy value of food, have suggested feeding-standards based upon the amount of energy required to yield a given product. 


\section{BALANCED RATION}

A balanced ration is one that contains the food nutrients in the proper proportion to meet the needs of the animal for a given purpose. Skill in balancing a ration depends much on one's knowledge of the composition and digestibility of the more common foods.

121. Nutritive-ratio. - The nutritive-ratio is the proportion between the digestible protein in a given food and the digestible carbohydrates and fats. It is ascertained in the following manner: multiply the digestible fat by $2 \frac{1}{4}$, add the product to the digestible carbohydrates, and divide their sum by the digestible protein.

The method of calculating the nutritive-ratio of corn, the digestible nutrients of which are protein 7.8 , carbohydrates 66.8 , and fat 4.3 , is as follows :-

FAT

4.3

9.67

76.47

Nutritive-ratio $1: 9.8$.

$\begin{array}{cccc} & \text { Heat Equivalent } & & \\ \times & 2 \frac{1}{4} & & \\ & \text { Carbohydratei } & & \\ +\quad 66.8 & = & \\ +\quad \text { Protein } & & \\ & 7.8 & = & \\ \div \quad & & & \end{array}$

This gives a nutritive-ratio of $1: 9.8$ for corn, and it means that for each pound of digestible protein in the corn there are 9.8 pounds of digestible carbohydrate and fat equivalent. A nutritive-ratio may be distinguished as "narrow" or "wide." A narrow ration is one in which the proportion of protein is quite large, say $1: 4.5$, whereas a wide ration is one where the carbohydrates are large, say $1: 8$ or $1: 10$. These terms do not represent exact values, but are used in a general way.

122. Computing rations. - There are two methods of computing rations in common practice : first, according to the digestible nu- 
trients in the food, usually known as the Wolff-Lehman method, and second, according to the energy value of the food, commonly known as the energy or Armsby method. ${ }^{1}$

123. Wolff-Lehman method. - To illustrate the method of calculating a ration for a given purpose, we will assume the case of a horse weighing approximately 1000 pounds and at moderate work. From the discussion on food requirements for the horse, p. 71, we learn that the standard ration is as follows:-

\begin{tabular}{c|c|c|c|c}
\hline \hline Dry-MatTer & Protein & Carbohydrateg & Fat & Ratio \\
\hline 24.0 & 2.0 & 11.0 & 0.6 & $1: 6.2$ \\
\hline
\end{tabular}

Let us choose from Table 6 of the Appendix such foods as will supply the conditions. For a trial ration, we will take fourteen pounds of timothy hay, ten pounds of oats, and two pounds of bran. The digestible nutrients in these are calculated as follows :-

Calculation of Dry-Matter and Digestible Nutrients in Trial Ration for a Horse at Medium Work

\begin{tabular}{|c|c|c|c|c|c|}
\hline \multicolumn{3}{|c|}{ Tiмothy $\mathbf{H A Y}_{\text {aY }}$} & \multicolumn{3}{|c|}{ Ground Oats } \\
\hline $\begin{array}{l}\text { In } 100 \\
\text { Pounds }\end{array}$ & & $\begin{array}{l}\text { In } 14 \\
\text { Pounds }\end{array}$ & $\begin{array}{l}\text { In } 100 \\
\text { Pounds }\end{array}$ & & $\begin{array}{l}\text { In } 10 \\
\text { Pounds }\end{array}$ \\
\hline $86.8 \div 100 \times 14$ & $=$ & 12.152 & $88.0 \div 100 \times 10$ & $=$ & 8.80 \\
\hline $2.8 \div 100 \times 14$ & $=$ & 0.392 & $10.1 \div 100 \times 10$ & $=$ & 1.01 \\
\hline $42.4 \div 100 \times 14$ & $=$ & 5.936 & $52.5 \div 100 \times 10$ & $=$ & 5.25 \\
\hline $1.3 \div 100 \times 14$ & $=$ & 0.182 & $3.7 \div 100 \times 10$ & $=$ & 0.37 \\
\hline
\end{tabular}

In like manner, calculate the digestible nutrients in two pounds of bran and arrange the result in tabular form as follows:

1 Farmers' Bulletin, No. 346, United States Department of Agriculture. 
First Trial Ration for 1000-Pound Horse at Moderate Work

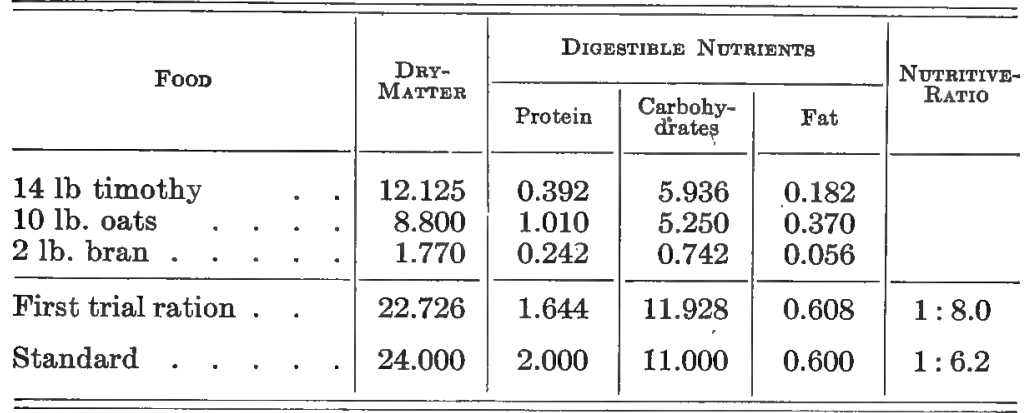

This trial ration falls considerably below the standard in drymatter and is too wide. We must therefore add a food rich in protein. We will try one pound of linseed meal, old-process :-

Second Trial Ration for 1000-Pound Horse at Moderate Wort

\begin{tabular}{|c|c|c|c|c|c|c|}
\hline \multirow{2}{*}{\multicolumn{2}{|c|}{ Foon }} & \multirow{2}{*}{$\underset{\text { MATTER }}{\text { DRY- }}$} & \multicolumn{3}{|c|}{ Digestible NUTRIenta } & \multirow{2}{*}{$\begin{array}{l}\text { NuTritive- } \\
\text { RaTiq }\end{array}$} \\
\hline & & & Protein & $\begin{array}{c}\text { Carbohy- } \\
\text { drates }\end{array}$ & Fat & \\
\hline $\begin{array}{l}\text { Ration as above } \\
1 \mathrm{lb} \text {. linseed }\end{array}$ & $\cdot \cdot$ & $\begin{array}{r}22.726 \\
0.902\end{array}$ & $\begin{array}{l}1.644 \\
0.302\end{array}$ & $\begin{array}{r}11.928 \\
0.320\end{array}$ & $\begin{array}{l}0.608 \\
0.069\end{array}$ & \\
\hline Second trial ration & .. & 23.628 & 1.946 & 12.248 & 0.677 & $1: 7.0$ \\
\hline Standard & . . & 24.000 & 2.000 & 11.000 & 0.600 & $1: 6.2$ \\
\hline
\end{tabular}

The second trial ration is still slightly too low in dry-matter and protein, and somewhat too wide in the ratio. From these trial rations we learn the method of calculating ratios.

124. Armsby's method. - In this method it is necessary to know the digestible protein and the energy value for each food. The energy va'ue is expressed in therms which is the quantity of heat required to raise the temperature of 1000 kilograms $(2,204.6$ 


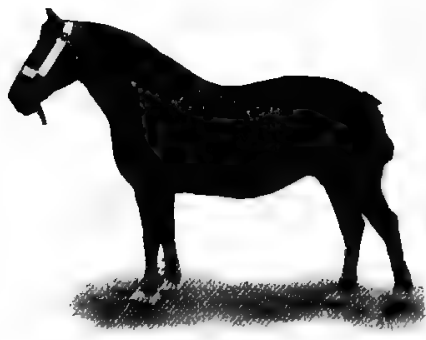

Fig. 35. Niıff ...k m..pe. pounds) of water one degree $\mathrm{C}$. To illustrate the method of calculating a ration according to the energy value of the food, we will use the same materials as in the Wolff-Lehman illustration. From the discussion of energy requirenents for the horse, p. 71, we learn that the requirement for a 1000 -pound horse at medium work is as follows:-
KIND OF WORK

Medium work
Direstible Protejn, Pounds

1.4
Energy Value, Therms

12.40

By choosing the same trial ration as in the Wolff-Lehman illustration and using Table 5 of the Appendix for the dry-matter, digestible protein and energy value, we get the following:

First Trial Ration for a 1000-pound Horse at Medium Work

\begin{tabular}{|c|c|c|c|}
\hline FOOD & DRY-MATTER $_{\text {RT }}$ & Digegtible Protein, Pounds & EnergyValue, Therms \\
\hline $\begin{array}{l}14 \mathrm{lbs} \text {. timothy } \\
10 \mathrm{lbs} \text {. oats } \\
2 \mathrm{lbs} \text {. bran }\end{array}$ & $\begin{array}{r}12.152 \\
8.900 \\
1.762\end{array}$ & $\begin{array}{l}0.287 \\
0.836 \\
0.204\end{array}$ & $\begin{array}{l}4.698 \\
6.627 \\
0.964\end{array}$ \\
\hline $\begin{array}{l}\text { First trial ration } \\
\text { Requirement }\end{array}$ & 22.814 & $\begin{array}{l}1.327 \\
1.4\end{array}$ & $\begin{array}{l}12.289 \\
12.40\end{array}$ \\
\hline
\end{tabular}

This trial ration falls considerably below the requirement. Now, by adding one pound old-process linseed meal we get the following :- 
Second Trial Ration for a 1000-Pound Horse at Medium Work

\begin{tabular}{|c|c|c|c|}
\hline Food & Dry-Matter & Drgebtibla Protein, Pounds & $\begin{array}{l}\text { ENERGY VALUE, } \\
\text { THERMA }\end{array}$ \\
\hline $\begin{array}{l}\text { Ration as above } \\
1 \mathrm{lb} \text {. linseed. }\end{array}$ & $\begin{array}{r}22.814 \\
0.908\end{array}$ & $\begin{array}{l}1.327 \\
0.275\end{array}$ & $\begin{array}{r}12.289 \\
0.789\end{array}$ \\
\hline Requirement & 23.722 & $\begin{array}{l}1.602 \\
1.4\end{array}$ & $\begin{array}{l}13.078 \\
12.40\end{array}$ \\
\hline
\end{tabular}

This ration is slightly too low in dry-matter and too high in digestible protein and energy value, but it serves to illustrate the method of calculating a ration by the energy method. It also serves to indicate the difference between the two methods, as according to the Wolff-Lehman standard the protein is practically correct, whereas according to the Armsby standard the protein is slightly too high.

\section{QUESTIONS}

1. How do plants obtain their nutrients? In what respects do corn and wheat differ from clover and alfalfa? How does clover and alfalfa enrich the soil?

2. Name the more important elements entering into the composition of food. Which come from the air and which from the soil?

3. Name the elements entering into the composition of protein. Why is protein so essential to animal life?

4. Why is the animal that masticates its food rapidly subject to digestive disorders? Which should masticate its food more thoroughly, the horse or the cow? Of the five classes of farm animals which can consume the larger quantities of forage and why?

5. How long does it require each class of farm animals to digest grain, dry forage, and succulent food?

6. What amount of the total food consumed goes to maintenance? What amount to production? Does this vary with the season of the year?

7. In computing rations which is the more advantageous, the WolffLehman or the Armsby standard? Which the more scientific? Which 
the more practical? Which will meet average farm conditions best and why?

8. Which will encourage maximum food consumption, feeding a narrow or a wide ration?

9. What are some of the principal advantages and disadvantages in balancing rations on the average farm?

10. Name the common feeds used in your vicinity. Divide them into three groups as follows: first, low protein group, containing less than 10 per cent; second, medium protein group, containing 10 to 20 per cent; and third, high protein group, containing more than 20 per cent. (See Table 6 of the Appendix.) 


\section{CHAPTER IV}

\section{FEEDING THE HORSE}

IN the feeding of horses it is important to have a standard or guide to aid in making up the ration. The guides are especially useful to beginners.

125. Food requirements for work. Many experiments have been made to determine the exact relation between the amount of muscular work performed and the amount of nutrients required per day. And as a result of such work the following standards have been suggested:-

Wolff-Lehman Standard showing the Amount of Food riguired per 1000-Pounds Live Weight for Horses at Light, Medium, and Heavy Work

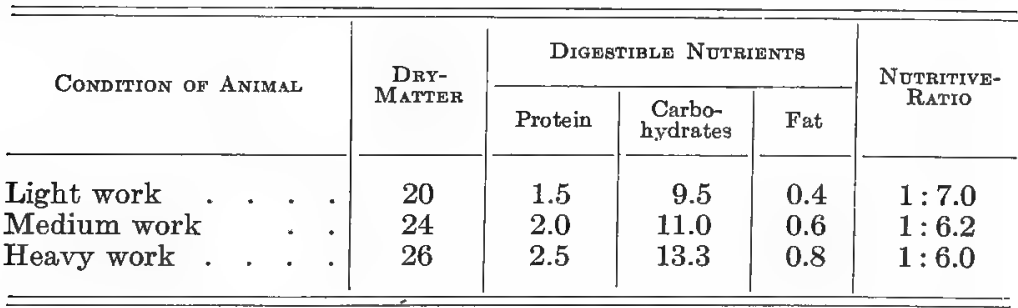

Armsby's Standards showing the Digestible Protein and Energy required for a 1000-Podnd Horse at Light, Medium, and Heavy WORK

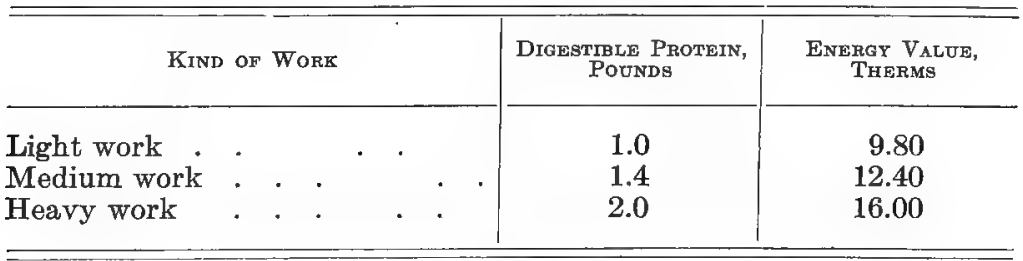


These standards were arranged to meet the need of the average horse under normal conditions. They are to serve as guides, to be modified to meet conditions, and not as laws, fixed and absolute.

126. Regularity in feeding. - The importance of regularity in everything that pertains to the management of the horse cannot easily be overestimated. This applies particularly to feeding. Whatever feeding-stuffs are employed in the ration, the horse should be fed regularly and uniformly at all times. The horse anticipates the feeding hour, and becomes nervous if it is delayed. He neighs and coaxes for his food with great regularity. The horse's digestive system and his vital activities become accustomed to a certain order, which should be followed. To change the order for even a single meal produces more or less digestive disturbance.

127. Order of supplying food. - Because of the small size of the horse's stomach, the order of supplying grain, hay, and water assumes much importance. Investigators have shown that the stomach of the horse must fill and empty itself two or three times for each meal given. During the fore part of the meal the material is pushed into the intestines almost as soon as it enters the stomach by the food which follows, while toward the end of the meal, passage is slow and the digestion in the stomach more perfect. This being true, it would seem that the more nutritious foods should be fed toward the end of the meal, especially since some of the important nutrients are largely digested in the stomach and at the entrance of the small intestines.

128. Watering the horse. - Many persons feed the horse before watering, while others water before feeding. There are objections to either method. For best results the horse should be watered both before and after feeding. When thus watered he will not drink to excess.

129. Salt. - This should be kept before the horse at all times. While little is known from investigations on this subject, it is evident from the extreme fondness of the horse for salt that it 
should be regularly supplied him. It is best not to place too much before him at a time as some horses will eat it to excess.

130. Individual rations. - The successful horseman will study each individual and modify the ration according to the varied needs; one horse should have a little more than the regular allowance, and the next possibly a little less, because some horses are more difficult to keep in condition than others doing the same work and living under similar conditions.

In handling horses we should remember that they are very sensitive animals and that we cannot be too quiet in our treatment of them. Striking them or shouting commands at them is an inconsiderate practice; it causes the animals to lose confidence in the master, renders them less teachable, and destroys nervous energy.

\section{FEEDING THE WORK HORSE}

The work horse has a very hearty appetita, a vigorous digestion, and responds, more readily than any other animal, to intelligent care. He should be fed liberally and frequently, the quantity given being regulated by the size of the animal as well as the amount and kind of work he is required to do.

131. Amount to feed. - In general, the horse should be supplied with something over two pounds of provender daily for each hundred pounds of weight. Of this about two-thirds, the exact quantity depending on the severity of the labor performed, should be grain in some form. If the work is exceedingly heavy, the grain in the ration should be increased and the hay diminished; whereas, if the work is light, the grain should be diminished and the hay increased. The morning meal should be comparatively light, consisting mostly of grain. It should not possess much bulk.

In many of the larger stables the mid-day meal is omitted. But most horsemen think that some grain should be given at noon, which seems reasonable from our knowledge of the horse's stomach. In any case, the mid-day ration should not be large. 
The heavy feéding should come at night, after the day's work is over, and when the animal has ample time to masticate and digest his food. A very good practice is as follows:-

132. Method of feeding. - For the morning meal, feed onefourth of the horse's ration at least one hour before going to work. It should be in condition to be easily and rapidly consumed, so as

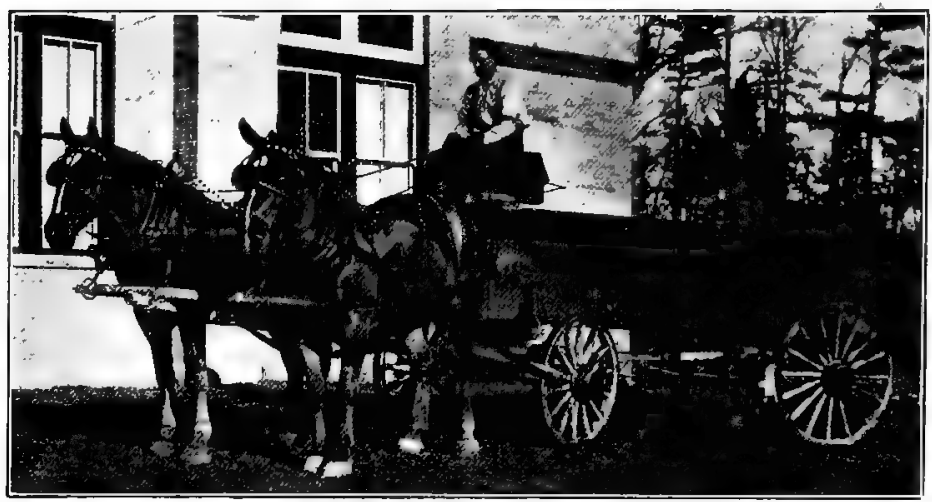

Fig. 36. - A well-fed draft team. Weight 3500 pounds.

to be well out of the way when the animal is led from the stable. After being watered, he is ready for the morning's task. If the work is exhausting and exacting, he should be fed after five hours of labor. When he comes to the stable at mid-day, he should have a drink of fresh, cool water, but he should not drink too rapidly or gorge himself if very warm. At this time give him another quarter of his daily allowance. No greater service can be rendered the horse at this time than to remove the harness so that he can eat his meal in quiet and comfort and gain a few minutes of muchneeded rest. If possible, he should have one hour to consume his meal. He should be watered again before going to work. He is now ready for the second half of his day's labor. When the horse comes to the stable in the evening, tired and warm, he should, first 
of all, be allowed a fresh, cool drink, care being taken as before that he does not drink too rapidly. He is now ready for the remainder of his day's allowance. Unharness at once, and when the sweat has dried, give him a thorough brushing. If for some reason the horse is forced to stand idle in the stable for a few days, the ration should be decreased. Otherwise he will become stocky and his legs becomé swollen and stiff.

During cold weather a more carbonaceous ration may be used. When more food goes to furnish heat for the body, it is reasonable that a horse needs a large proportion of heat-making food. Equal parts of corn and oats by weight would be more satisfactory and ordinarily much cheaper than a larger proportion of oats (Fig. 36).

133. Cost of ration. - In providing a ration, whether for summer or for winter use, due consideration should be given to the cost. Roughage is ordinarily much cheaper than grain, but a horse at work is unable economically to dispose of a large proportion of bulky food. If considerable time and energy must be expended in masticating rough feed, the usefulness of the horse for work is lessened thereby. The more concentrated the food, within proper limits, the less percentage of energy will be needed to make it available. The proportion of grain to roughage depends on the amount and kind of work to be performed. A horse at hard work should never be expected to consume more roughage than grain by weight.

134. Feeding mules. - Mules should be fed similärly to horses. A mule is less likely to overfeed and gorge himself than a horse, and will make use of coarse foods that the horse will not eat unless forced to do so by necessity. Mules are often preferred by large business concerns, not that they consume less food for a given amount of work than horses, but that their feeding can be trusted to less skillful hands without seriously endangering the mule's health. If an extra large mess is given the mule, he eats what he wishes and leaves the rest; not so with the tired horse, which will eat all the grain that is given him up to the point of seriously 
endangering his health. For best results the ration of the mule should be comprised of easily digested and nutritious feeds, which should be varied from time to time, as no animal loves a variety better than the mule. The ration should be suitable to the kind of work. In all essential features the mule is very similar to the horse, and what we suggested for horses applies with equal force to mules.

135. Feeding the brood mare. - Mares in foal should be fed much as suggested for work horses with perhaps the addition of more protein foods, as bran and oil meal. The ration should be such as will supply the demands for energy and in addition allow abundant nourishment for the development of the foal both before and for a time after birth. A very good ration for the pregnant mare is as follows: four parts ground oats, four parts wheat bran, or its equivalent, and one part linseed meal, with bright clover or alfalfa hay for roughage.

FEEDING THE FOAL

It is essential that the new-born foal get the first milk from the dam. This fore-milk looks thick and yellow. It is a natural purgative for the removal of the material that has accumulated in the foal's digestive traet during the last few days of its development. Its prompt removal is essential to the life of the colt.

136. Food for the young foal. - It often happens that the milk of the mare is insufficient to promote healthy, vigorous growth in the foal, and occasionally it becomes necessary to raise a foal entirely independent of the dam. In such cases the best addition or substitute for the milk of the mare is that of the cow. The milk of the mare has more sugar and less fat than the milk of the cow. One should get milk from as fresh a cow as possible, and the poorer in fat the better, as mare's milk will average only about 1.2 per cent fat, while the milk of most cows runs above 3 per cent. Gruels, made by boiling beans or peas and removing the skins 
by pressing the pulp through a sieve, or oil meal and shorts made into a jelly by boiling, are excellent for the motherless colt.

137. Feeding grain. - As soon as the foal is old enough, it should be encouraged to nibble at grain, preferably ground oats. It will begin to munch in the grain and hay at three or four weeks

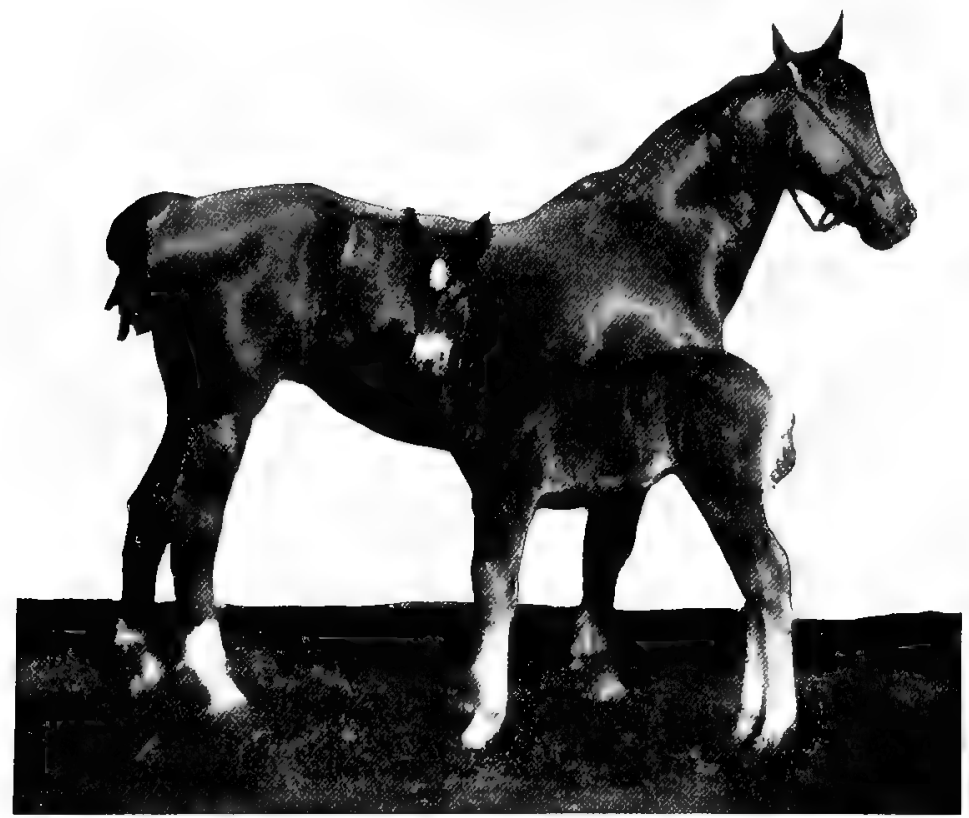

Frg. 37, - Hackney Coach mare and foal three wecks old.

of age, and should be encouraged to eat. It will eat only a very little at first. If it is necessary that the foal have milk after it is two months old, skimmed milk should be substituted for fresh cow's milk. Never feed a colt sour milk. Never feed milk from unclean vessels. Should there be any trouble from constipation, it will be well to add about one-half pint of oil meal per day to the ration. Oil meal can be fed with profit to growing colts, as it 
furnishes a large proportion of muscle-forming and bone-forming food.

138. Weaning the foal. - This is more a question of preparation than of the absolute removal of the foal from the dam; and the simplicity of the weaning process depends on the thoroughness of the preparation. If the foal has been accustomed to grain as suggested, if it has been permitted to take increasingly more as it grew, then the process will not be difficult, for as the ration increases in amount of grain, it will decrease in the amount of milk consumed. When the time arrives for complete separation, there will be very little if any set back or disturbance to either foal or dam.

Foals are usually weaned at four to six months of age, depending on conditions. If the mare was bred soon after foaling and conceived, it is best to wean the foal early, so that the mare will have time to recuperate and nourish the fetus. If for any reason mare and foal are not doing well, it is perhaps best to wean comparatively early. If, on the other hand, the mare has a full flow of milk and her services are not needed, there is no reason for weaning the foal under six months of age. When dam and foal are separated it is better for both that the separation be complete. Care should also be taken to see that the new quarters, where the weanlings are confined, are so constructed and arranged that they cannot injure themselves while fretting over the separation.

139. Sample rations for the horse. - The following rations are collected from various sources and furnish a guide in determining the kind and amount of feed that should be allowed the horse under various conditions :- 


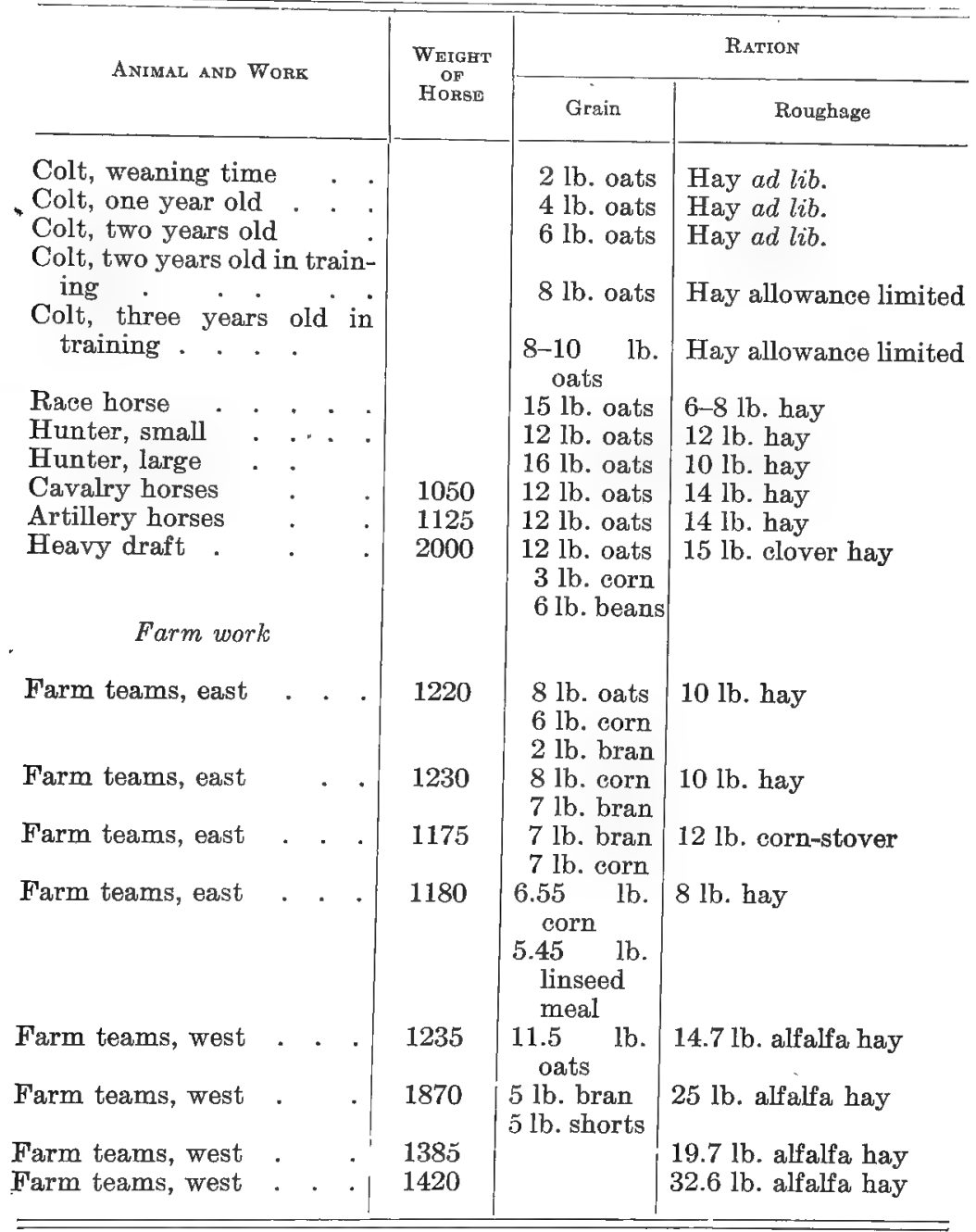




\section{QUESTIONS}

1. Why is it now not thought essential' to feed the horse so much protein as formerly? Does a hard-working horse use up its muscles? Explain.

2. How do the Wolff-Lehman and Armsby standards compare in respect to protein, carbohydrates, and nutritive ratio? Which meets the condition of your animals?

3. Should the horse be watered at the public watering trough? Which demands more frequent watering, the horse or the cow?

4. Name the foods that are commonly fed horses in your vicinity. Find out exactly what some persons are feeding and calculate the dry-matter, nutritive-ratio, and energy value. Compare with the standards. How may it be improved?

5. In what season of the year may we feed a comparatively wide ration, and why?

6. Compare the feeding of the draft horse, driving horse, and idle horse. Which is most difficult to keep in good condition? Why is exercise essential to the horse?

7. Why should the work horse be fed sparingly in the morning and at noon? Why do some drivers neglect the noon meal?

8. Why should the brood mare be worked continuously with but a week or ten days' rest just after foaling? Why is moderate work preferred to permitting several 'mares the run of a pasture?

9. Should the colt be confined to a stall while its mother is out at work? Explain. Why do so many young colts die under three weeks of age?

10. Why have the Arabian people been so successful in producing horses of superior quality? 


\section{CHAPTER V}

\section{CARE AND MANAGEMENT OF HORSES}

WhILE we have no available data in the United States on the number of horses and mules consumed, or used up, in a year, yet a very conservative estimate would be approximately two million, this to include export animals as well as those consumed at home. These horses must be replaced as consumed, or there will be a horse famine. There are approximately ten million mares in the United States, of which we will assume one-half, or five million, are of breeding age. If we are to raise the two million colts, both horse and mule, it means that at least one-half, of this number must be bred each year.

140. Plan of improvement. - A clearly defined plan of procedure should be thought out before the farmer makes the attempt to breed horses. To do this a good knowledge of horses and horsebreeding should be secured. Breeding establishments and horseproducing farms should be visited. One should familiarize himself with the methods of successful horse-breeders, should note the conditions that lead to success and those that cause failure. The horse-producer should study his conditions. Some conditions will be favorable to the production of one class, some to another. It should be kept clearly in mind, whatever the type or class chosen, whether it is light or heavy, or for speed or draft, that none but superior horses will sell at remunerative prices. There will always be an overproduction of common horses, which will be the first to be affected by oversupply and other business depressions, and the last to be revived. The market should be studied also. In some sections the demand will be for a certain class and in other sections another class will be in most demand. 
141. Coöperative breeding. - From observations made in localities where horses are bred in a commercial way, it would seem advisable to breed on the coöperative plan. It is apparent that the formation of horse-breeding associations in townships and counties would do much to advance the progress of the industry. Such associations should be formed of breeders who possess the same class or breed of mares. It would be the work of such an association to protect the interests of its members, provide suitable stallions each year for use on the mares owned by the members, advertise stock, attract buyers, hold sales, make exhibits at the county, district, and state fairs, hold meetings for discussion of horse-breeding matters, and educate the farmers of the locality to better methods of breeding, feeding, and developing marketable horses.

142. Selecting breeding stock. - In the selection of breeding stock, we must keep in mind the principle of heredity that "like produces like." This applies to the brood mare as well as to the stallion. Bad qualities in the mare are as likely to appear in the colt as are bad qualities possessed by the stallion. The influence of the mare in the transmission of qualities to the foal is often underestimated, and frequently ignored entirely by horse-breeders. This icannot be other than a serious mistake, and the farmer who keeps worthless mares for breeding simply because he cannot sell them, will not be able to compete with his neighbor who keeps only the best brood mares, even though they both patronize the same stallion.

It is a serious but common error in breeding horses to suppose that the bad points in one animal can be fully offset or overcome by the good points in the mate. The statement that the stallion controls the outward characters and the mare the internal characters has led many breeders to think that the offspring would resemble the paternal prrent irrespective of the mother. Such is not the case. The foundation of successful horse-breeding is to mate two animals each of which is as nearly perfect as possible. 
143. The breed and type. - Choose the breed which best suits the conditions, the markets, and the tastes of the breeders. There is no best breed or type for all conditions. Light horses naturally belong on land devoted to grass, to dairy industry, and to marketgardening, where but little plowing and other heavy horse work is required, and the necessity of reaching the market, the station, or the creamery requires quick-moving horses.

On farms devoted to fruit-growing and the like, where the horse work is somewhat heavier than on the dairy farm, the coach horse

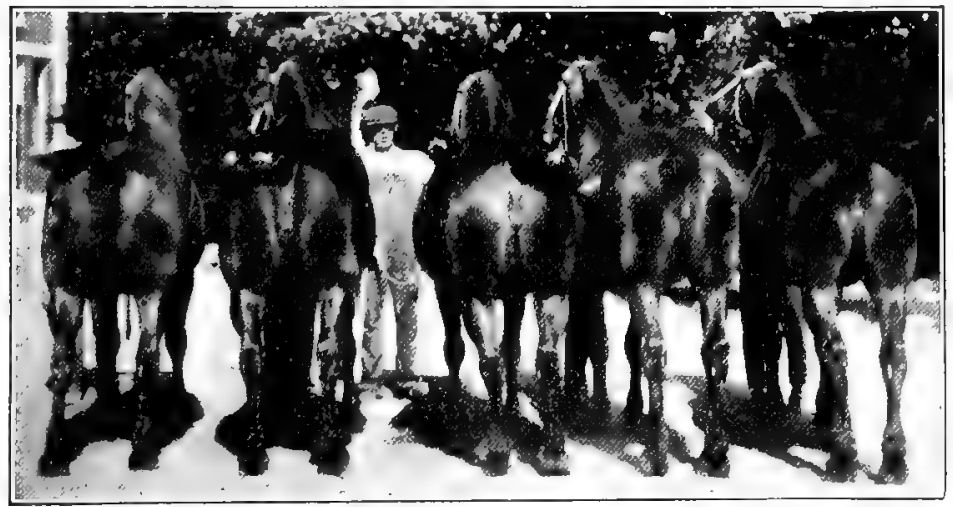

FIG. 38. - Uniform Percheron mares.

may be used. Coach horses are well adapted to fruit farms with one exception, - they are rather too tall to be used to best advantage in tilling under trees in the orchards.

On grain farms, where there is much plowing and the work to be done is hard, heavy horses are needed. On general farms the draft horse finds his true place. Draft horses can be reared with less risk than the lighter and more active types, such as the roadster and the coachers. They do not require so much training, and can be put to light work younger. The draft horse is in great demand for city traffic. Again, the roadster and the coacher require much 
training before they can be marketed, if good values are to be secured. This training requires skill, time, and money, which should be taken into account. A well-bred and well-trained coach or driving team will bring a good price, but the skill, time, and money required to breed and train them is too great for the general farmer.

144. Uniformity. - Each community should produce horses uniform in type. As it is now, each district produces a number of types. For this reason, buyers in search of a particular type or breed of horse do not know where to find it, and buy, here and there throughout a wide territory and at a great outlay for traveling expenses, individual horses of the right type, until the lot has been gathered together. Such districts may sell large numbers of horses annually, but they are of nondescript type and character. These horses neither make a name for the district as a horse-breeding center nor attract buyers willing to pay appreciative prices. The individual farmer will do better to cast in his lot with the majority of his neighbors, and breed the same type as they are breeding, even though this type may not be the one that suits his fancy best or even the one that is best suited to the district.

145. Soundness. - It is of great importance that the stallion be free from all forms of unsoundness or disease that are hereditary, transmissible, or communicable to the offspring. It is equally important that the mares bred to him should be sound in the same way, for not until both mare and stallion used for breeding purposes are free from unsoundness can we hope to raise the excellence of our horses to the degree possible as the result of intelligent breeding and development.

146. Registration of farm animals. - Each of the important breeds of farm animals has a society which looks after its interests. This society publishes a book of record in which may be recorded the ancestors of each animal of the breed. This is spoken of as registration, and the record as the pedigree of the animal. When 
thus recorded the animal is called a pure-bred. These books of record are known by various names according to the class of animal registered. Thus among horses, it is called a studbook, among cattle and swine it is called a herdbook, and among sheep it is called a flockbook.

\section{GROOMING AND CARE}

Nothing contributes so much to the beauty and the luster of the coat as grooming. On arriving at the stable, the animal should be fed, unharnessed, given a thorough grooming, and blanketed. The legs should be given a thorough and rapid brushing. Time spent in cleaning and rubbing the horse in the evening after the day's work is done is worth much more than time thus spent in the morning.

147. Care of the horse's teeth. - Occasionally a horse does not feed well, due to irregularities of his teeth. If the first, or milk teeth, are not looked after, they are likely to remain, causing the second, or permanent teeth, to grow in crooked. The young horse's mouth should be closely watched and the persistent milk teeth removed with forceps. Again, it must be remembered that the upper jaw is somewhat wider than the lower, and as the teeth are not perfectly opposed, a sharp edge is left unworn on the inside of the lower molars and on the outside of the upper, which may cut the tongue or cheeks. This condition can readily be felt by the hand, and the sharp edges when found should be filed down by a guarded rasp; otherwise the tongue and cheeks become sore, the food irritates them, and the horse will not feed well.

148. Clipping. - This consists in cutting the hair over the entire surface of the horse's body. Several advantages are secured from clipping: it improves the appearance of the horse and makes his coat more easy to keep clean; a clipped horse is less liable to take cold than a long-coated one because the evaporation is more rapid and the animal does not get so warm; the natural process of shed- 
ding the hair is a draft on the vitality of the animal, the appetite is diminished, and the horse loses flesh. Clipping accomplishes in a very short time what nature requires much time to do.

When horses cannot be protected from the cold and wet, either in the stable or outside of it, they should not be clipped in the fall. Animals exposed to the weather grow a long coat for their own protection.

149. Bedding the horse. - A horse at hard work needs rest at night, and much more rest is possible when the animal is given a good liberal bed. The bedding should not be permitted to become foul, as this will not only lessen the comfort of the animal but promote disease as well. Of bedding materials, straw leads the list, but when high in price, it may be replaced by other materials, such as shavings from the planing mill, rejected parts of corn stalks, tan bark, leaves, and the like. Old straw is preferred to new, as it is dryer and more elastic. The more broken and bruised the straw, the less its bulk and elasticity and the greater the quantity that must be used.

150. Blankets. - In cold climates the use of blankets is indispensable. The horse will prove more efficient and will endure much longer if reasonably protected against sudden changes in temperature, the cold rains, and heavy winds.

151. Stable blanket. - The usefulness of a horse can be prolonged and his efficiency increased by proper blanketing and grooming. On arriving at the stable very warm and sweating, the horse should not be blanketed until he has ceased to steam, nor should he be left in a draft. If blanketed at once, little opportunity is given for him to dry off, the blanket will become damp, and the hair remain so all night. In case the blanket is not used until the animal has ceased to steam and is somewhat cooled; which will be in a quarter of an hour, the hair will be dry and smooth the following morning. Stable blankets may be dispensed with in the hot summer months if the flies are excluded by screens or by some other means. If blankets are used at this time, they should be of light 
material and kept clean. As soon as the nights begin to get cool, the blankets should be resumed, as an early use will arrest to a marked degree the growth of hair. This may obviate the necessity of clipping. In case the horse is clipped, he should be covered with an extra heavy blanket, or with two blankets, for a time.

152. Outdoor blanket. - The use of the outdoor blanket is as important as the use of the stable blanket. If the horse is allowed to stand out doors, either for a short or for a long time, he should be well blanketed. If one is going to stop but a short time, the temptation is strong not to blanket the animal. The horse cools off rapidly and may chill, so that it is best to blanket if only for a moment. In the spring when the weather is fair, one is likely to think that no ill will result from leaving the animal unblanketed. It is best at all times, on stopping the animal, to see that he is well protected.

153. Care of the feet. - Because of the great importance of the foot, it should be carefully cared for throughout the active career of the horse. Each evening, after the horse returns from work as well as in the morning before he is sent out, the sole of the foot should be examined and all foreign materials removed. For this purpose.a small hay hook with the point sharpened is excellent. It is very common to find foreign bodies, such as nails and stones, either driven into the wall or sole of the foot, or collected in the clefts along the frog, and it is very essential that they be removed if the hoof is to remain in healthy condition.

Occasionally the hoofs have a tendency to dry out, thus becoming hard and brittle. Such hoofs should be oiled with some good oil, such as linseed or olive oil, or with hoof ointment, of which there are many kinds on the market. This will soften the wall of the hoof and make it less likely to crack or break. It often happens that a piece is worn or broken from the side of the hoof, which throws the weight of the body in such a way as to bring a strain upon the joints of the leg, causing deformity and disease. such break occurs, the hoof should be leveled with a rasp. When 
horses are closely confined in the stable, the hoofs grow out long, and if not trimmed, will deform the limb and make traveling difficult.

154. Growth of hoof. - The rate of growth of the hoof is of much importance, for we are often interested to know how long it will take a crack, such as quarter-crack, side-crack, or toe-crack, a cleft, or a calk to disappear. On the average, the hoof grows one-third of an inch a month. Hind hoofs grow faster than fore hoofs and unshod ones faster than shod. While influenced to some extent by work or exercise, grooming, moisture, and food, the time required for the horn to grow from the coronet to the ground varies in proportion to the distance of the coronet to the ground. The toe, therefore, depending on its height, grows down in ten to thirteen months, the sides, six to eight, and the heel in three to five months.

155. Shoeing. - The horse's hoof wears off faster than it grows out, and it becomes sore. In order to prevent the hoof from wearing too rapidly the feet are shod. While there are many reasons for applying shoes, the most important are as follows: -

First, to prevent wearing away of the hoof in order that it may not get sore. Horses show need of shoeing first in the fore feet, and in some parts of the country only the fore feet are shod. For this purpose the light shoe is preferred. Second, to prevent slipping on ice or mud. For this purpose, when the work is hard, heavy shoes with large calks are best, but for easy work they may be lighter. Third, horses are shod to modify their action.

Of the many things to be considered in fitting a shoe perhaps the most important is to keep the foot perfectly level, thus preventing undue weight being thrown on one side, and other attendant injuries. The frog should be left in its natural size and shape to serve as a cushion for the foot. Make the foot normal. Then make the shoe fit the foot. In fitting a shoe, nothing will aid one as much as a careful examination of the wear of the old shoe. The shoe should be fitted cold or not so hot as to burn the sole when placed against it in fitting. In nailing the shoe to the foot, the 
nail holes should not be too near the edge of the sole, for in such case it is necessary to drive the nails too far up into the wall to make them hold. On the other hand, the nail holes should be well back, the nails small in size, and when driven, should be brought out well down on the hoof. If driven high, when the shoes are reset, or the animal reshod, the former nail holes are near the edge and serve to weaken the hoofs and interfere with driving the new nails. After driving the nails, they are to be clinched in a small groove fitted for that purpose. Smooth with rasp, but never rasp the outside of the hoof as it will remove the natural protective covering. This natural covering should not be removed, as the hoof will absorb water in the wet season and dry out much more rapidly in the dry season.

156. Treating sick horses. - Horses that are ailing should rcceive much care. In many cases good care is to be preferred to the use of medicine. In other cases rest is to be preferred to both. The aim is to hasten recovery from the ill effects of the ailment, and to be most successful one must understand the horse thoroughly and be able to supply his every need. He must be careful, painstaking, and patient. The first thing to be done is to look for the cause of the trouble, and if possible, to remove it. If the disease is contagious, the ailing animal should be put away from other animals equally susceptible to the disease. Whether the disease is contagious or not, the quarters should be comfortable. Note carefully the surroundings of the animal, the work it has been doing, the exercise, general care, food, water, and the source of infection if the disease is contagious.

157. Feeding sick horses. - The food should receive much attention. When the horse can eat, a small quantity of easily digestible and nutritious food should be given. The food should not contain much bulk and should be rather laxative, as sickness often brings constipation. It should be as attractive as possible, as the appetite is usually poor and sometimes lacking. When it can be prevented, medicine should not be put in the food or water, 
unless tasteless and odorless, as the horse is likely to refuse the food when it is important that he should have it. Natural foods, such as fresh grass, roots, bran mash, and milk, are to be preferred to prepared foods, though the use of patent stock foods may prove beneficial in certain minor ailments, when a tonic is valuable. The feed boxes should be kept clean, and if any food is left, it should be removed and not left until the next meal.

In certain ailments, it is necessary to protect the horse against the cold or from drafts. This can be done by the use of blankets. To protect the limbs, bandages may be applied. The bandage should be made from strips of woolen cloth about three inches wide and five to eight feet long. Make it into a neat roll, then apply by beginning at the lower or smaller part of the limb and wind upwards.

\section{TRAINING THE COLT}

The usefulness of the horse will depend much on his courage and fearlessness, and it is to promote these that the colt should become familiar with man at as early an age as possible. A colt should never be frightened. Too many persons thoughtlessly try to make the young colt show off by doing something to startle it, by running at it, throwing sticks, "shooing " it, and the like. This should never be done if a reliable animal is to be developed.

158. Handling the colt. - The foal should be taught very early the uses of the halter; first to lead, then to drive. But even before haltering the youngster may be taught to "stand over," to have his foot raised, to back, and the like. In handling the colt be careful about the ears, the back of the fore legs, and the flanks, as these are often very sensitive. Catch the colt by putting one hand under the neck and the other under the hams or around the buttocks (Fig. 39). Never catch a colt around the neck only - if this is done, the colt will go backwards and perhaps fall - but instead catch him around both ends, as described; then if he 
attempts to go forward, press back with the hand under his neck, and if he attempts to go backwards, press forward with the hand that is around the buttocks. Colts caught in this way will let

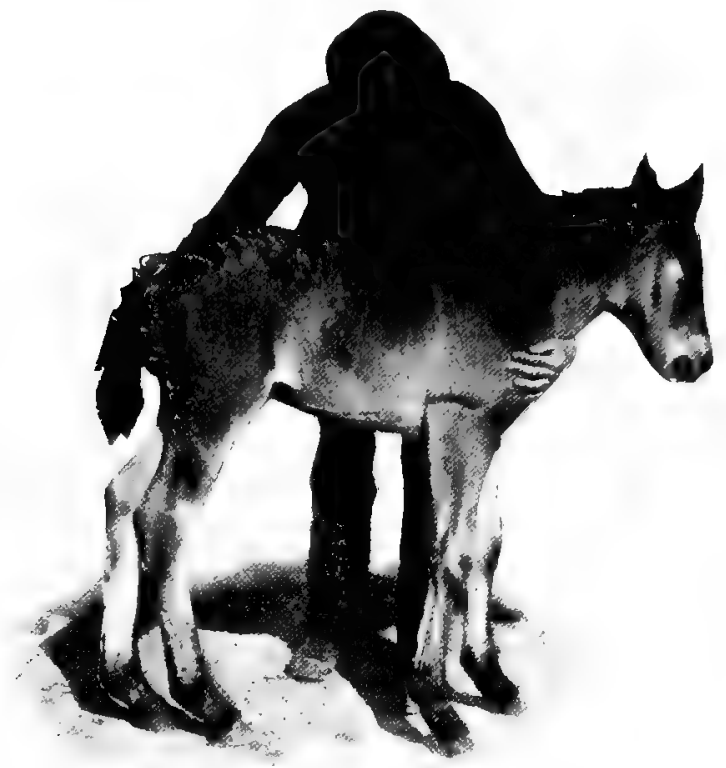

FIG. 39. - Catching foal the first time.

one walk up to them, whereas if they are caught around the neck, there may be difficulty in coming near them.

159. Training to the halter. - When ready to halter the foal, choose a strong, well-fitting halter and not a new one that smells of a lot of things that are new to the colt, but one that has recently been used. Care should be taken not to pull heavily on the noseband at any time. Occasionally deformed face lines and necks are caused in this way. It is not necessary to drag a colt by the halter in order to suggest to him that his business is to follow. As 
a matter of fact, the reverse effect is usual, and the harder a colt is pulled, the harder he holds back. If, on the contrary, he is coaxed along the accustomed route, as to the water trough and back, he will soon follow promptly. If he resents, however, other means must be tried. Secure a small rope, the size of a light clothes

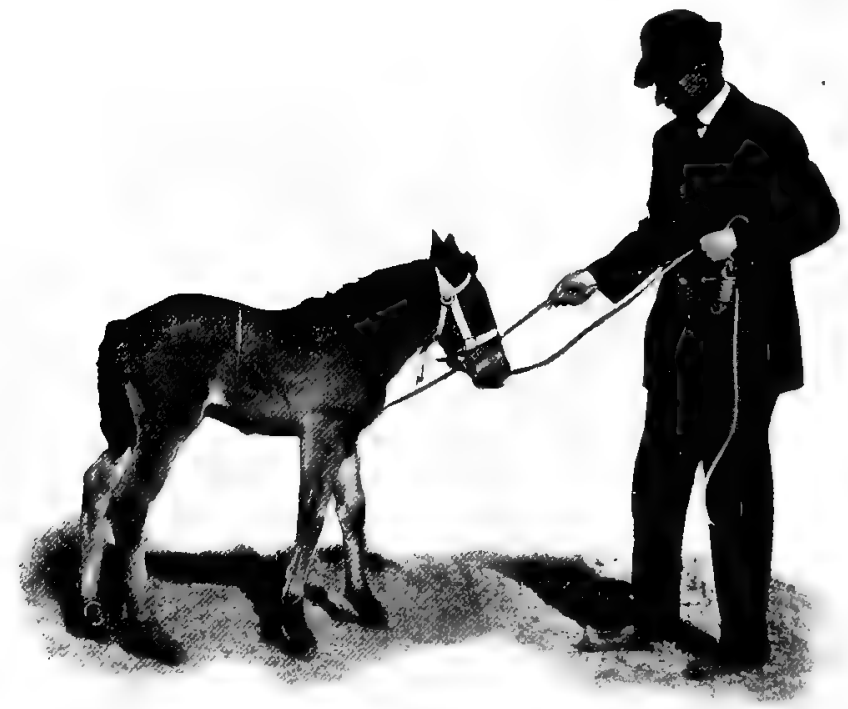

Fia. 40. - T eaching foal to lead.

line, about ten feet long, tie a noose or fasten a ring on one end, place this gently over the colt's back just in front of the hips with the noose or ring on the under side of the body, so that when the other end of the rope is run through the noose, the rope can be closely drawn around the flanks; pass the rope along under the body, then between the fore legs, then up through the ring in the halter. Hold the halter strap in one hand, the light rope in the other, pull gently in the halter strap, and as the colt begins to shake his head give the light rope a sharp pull and the colt will 
immediately step forward. Do not be in a hurry, but give the colt time to get used to the lesson. Soon he will follow wherever you lead (Fig. 40).

160. Training to drive with lines. - After the colt understands the uses of the halter and will lead, he may be taught to be driven with lines. To do this successfully a surcingle properly adjusted is required. The surcingle must be provided with loops or rings on each side, placed well below the center of the body, the lines passed through these and fastened to the rings on either side of the halter; never use a bit in the mouth of a very young colt. Now the lines will pass the hind quarters low down, and thus prevent the colt from turning with his head towards the trainer. It is very important to keep the reins low in turning to make the guiding process easy. After a little, as the colt becomes accustomed to being driven, he can be touched up with the lines, guided to the right or left, but he should be stopped often to assure him he is doing well.

161. Training to the uses of the bit. - It is best perhaps to train the horse to the uses of the bit when he is about two years of age. The manner in which the horse is educated to know and mind the bit will go far towards determining his usefulness. Inasmuch as the conveyance of the master's desire to the horse's mind for execution is through the hands, reins, bit, and mouth, no progress can be made and none should be attempted until this means of communication has been well established.

162. Importance of a good mouth. - No factor contributes so much to the pleasure, comfort, and safety of either rider or driver as a responsive mouth in a horse - one that always obeys promptly the slightest instruction from the master. A good mouth to a large extent is natural to the horse. Tender and bad mouths usually result from improper handling. Bad mouths are very aggravating and often the cause of many other imperfections tongue lolling, crossing the jaws, hobbling, irregular and unsteady gaits, and the like - many of which when well established are very difficult to overcome. 
163. Bitting the colt. - The young animal can usually be made familiar with the uses of the bit by the application of the bitting harness. This harness consists of an open bridle with a large smooth bit and check-rein, a surcingle and crupper, and two sidelines running from the bit to buckles on either side of the surcingle (Fig. 41). The adjustment of the bridle is important. The length

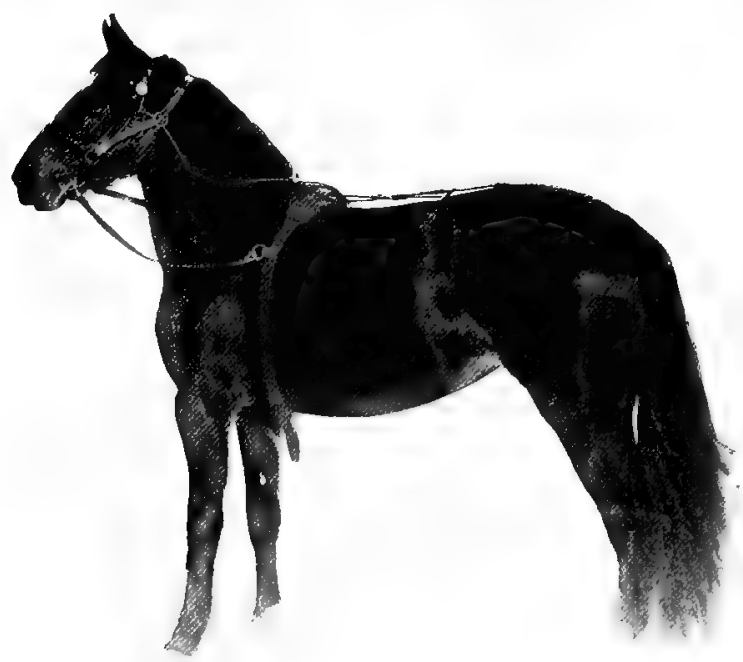

FIG. 41. - Bitting harness used to familiarize the horse with the bit.

of the head-stall must be so adjusted as to bring the bit in mild contact with the bars of the mouth. With the bitting harness properly adjusted, turn the colt into the familiar open paddock to get used to having the bit in his mouth. The check- and sidereins should be left slack at first. Gradually from day to day the reins should be shortened, care being taken that they are never made so short as to place the head in an uncomfortable position, or draw the bit so tightly as to make the corners of the mouth sore. The colt should be subjected to the use of this apparatus 
for a few hours each day for perhaps a week or less, depending on the individual. Real lines may now be substituted for the sidereins and the colt driven until he knows how to guide this way and that; to stop at the word "whoa," and to step forward at the command "get up." Train the colt to stand absolutely still when being harnessed, saddled, or when it is desired that he should stand. A horse that is continually stepping about while one is working with him is but half trained at best.

164. Harnessing the colt. - After the colt has become familiar with the bitting apparatus and has learned to obey simple commands he may be harnessed. Do not use new harness, smelling of things unfamiliar, but one that has been in constant use, preferably by a horse that the colt knows. After being driven with the bitting apparatus for a time and the colt is rather tired, put him in his stall, bring the collar to him, let him smell of it if he likes, then put it right on as if he were an old horse. Now get the harness, walk up to him, and lift it gently over his back. Do not stand off and throw the harness over his back, for the loose straps hitting his back and abdomen will be resented, and he may kick. Walk behind him, put the crupper strap on, then step to the side and fasten the bands.

The harness should be of good quality and in good repair; if a part breaks, there may be trouble and the colt ruined for all time. See to it that it fits perfectly. The colt's shoulders are likely to be tender and easily abraded, and we must see that the collar fits him well. A breast-collar is admissible when the load is light. The saddle and the crupper also need careful attention. Care should be taken to have them fit, neither too loose nor too tight, and then to keep them clean lest they abrade the back or tail and produce a vicious horse.

165. Hitching double. - With the harness properly adjusted, the colt is ready to be hitched to a vehicle. Get a well-trained, gentle, but active horse if the colt is active, for it is a mistake to hitch a quick, active colt with a slow, lazy horse. The vehicle 
to which they are attached should be provided with a good brake. The colt should be attached to the "off side" and the team be driven at first in a closed field till the colt learns what is wanted of him. When hitching the colt double for the first few times, it is well to keep a pair of single lines on the colt's bridle which can be handled by an assistant.

166. Hitching single. - When the colt is desired for single use, it is often advisable to train him to go single from the first.

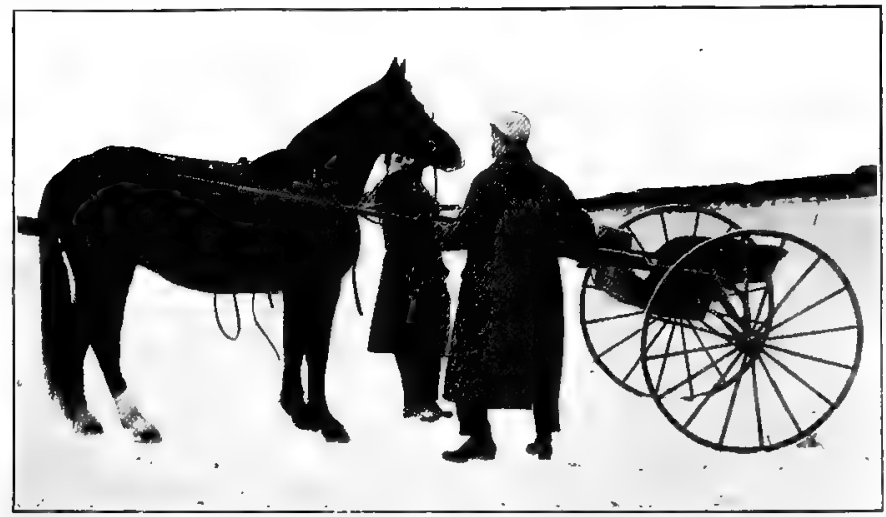

FIG. 42. - Acquainting the horse with the training-cart.

This may be done after he has become familiar with the bit, harness, and use of the lines. When training the colt to go single, a training-cart - one with long shafts, substantially constructed, and the seat so arranged that the driver can get off and on quickly - should be employed. The shafts should be twelve or fourteen feet long, with provision at the ends for the attachment of a strap across from point to point to prevent the colt in rearing from throwing his front leg over the end of the shaft. At first a kickstrap attached to each shaft and passed over the colt's rump should be used, at least till the colt is accustomed to the shafts. When the colt is first hitched, an assistant should hold him until 
the driver is ready, then he should be allowed to go. As soon as he has become familiar with the vehicle he should be compelled to stand still until he is wanted to start (Fig. 42).

\section{HARNESS AND HARNESSING}

In harnessing the horse, much care should be exercised in properly adjusting the various parts of the harness. Properly fitted harness adds much to the efficiency and comfort of the horse. This is well emphasized by the sore mouth, shoulders, neck, back, and tail produced by poorly fitted harness. The tension on these parts is rather great, and as they are very tender they are the places likely first to show abrasion. Sores thus produced give the horse much pain and are likely to become a cause of viciousness. Sore mouth thus often provokes a horse to run away; sore shoulders and neck often provoke balking; and sore tail often provokes kicking. Since the efficiency and comfort of the horse depend so largely on the adjustment of the bit, lines, collar, saddle, and crupper, it seems desirable to discuss each of these separately.

167. The bridle. - When one recalls the extreme tenderness of the mouth, the cruel manner in which it is often bitted, the irritation from the sores, he can understand why a horse may lag behind till the parts become numbed, then begin to pull, holding the head to one side, going with mouth open, lolling the tongue, slobbering, tossing the head, crossing the jaws, and in many other ways showing evidence of the discomfort he is suffering.

168. The bit. - Bits of many types have been devised to meet the various and peculiar habits of horses, most of which have been designed to punish the horse and irritate the sensitive parts. With the punishment of the whip at the rear and a harsh and severe bit at the front the horse is between two goads, and if he does not balk, rear, plunge, or run away, he is exceptional.

A good-sized straight bit covered with leather or rubber, if the mouth is tender, cannot be improved on in most cases. One 
must be careful to get a bit of the proper length for the horse's mouth. Many bits are too long and are pulled out of adjustment in the mouth, so that the pressure on either side is not equal. The bit must be of the correct length for the particular animal, and properly adjusted.

Some horses work better with the jointed or snaffle bit. It gives more room for the tongue, and the pressure is more evenly distributed on the jaws than with the straight bit. Severe bits, of which there are many in the market, and which are intended for punishment, should never be used unless it is absolutely necessary.

In the training and driving of high-acting horses, the curb-bit may be used. A horse properly bitted with this shows himself to better advantage than with any other kind of bit. The curbbit should be used only by those who are familiar with it, as it may become an instrument of torture in the hands of the inexperienced.

The choice of the proper bit for each horse can be determined only by trial, and if several changes are necessary, one should not be discouraged. However, when it has been determined which bit best serves the purpose, no further change should be made. After becoming used to a certain kind of bit a horse does not take kindly to a change. It makes him uncomfortable and may interfere with his action.

169. The check-rein. - The check-rein should be properly adjusted. In common practice there are two methods of checking the horse's head - by means of the side-rein and by the overcheck rein. The former is used more often on work horses, the latter on driving horses. The side-rein is used with and without check hooks at the throat-latch. This rein is not so effective as the over-check rein in compelling the animal to hold his head up, but it is much more comfortable to the horse and enables him to handle himself more efficiently. Horses checked with the siderein are not so likely to stumble as those with the over-check rein, 
and they will pull a much heavier load. This is because they have more liberty with the head, are able to see the ground immediately in front, and to lower the head and thus throw more power into the collar.

The over-check rein was devised for trotting horses, but has become so popular that it is used almost exclusively for driving horses. It holds the horse's head in such position that he is unable to see the ground immediately in front of him, and he is therefore very likely to stumble. It also holds the head in such a way that he cannot pull efficiently. This is particularly true in ascending a steep grade. Again, it holds the head and neck in such an unnatural position that the neck soon becomes numbed, and the horse is seen to toss his head from side to side and to take other characteristic attitudes in search of relief.

The horse should always be reined mildly. Without the rein he is likely to become careless in his habits, shambling in his gait, and to yield to the temptation to eat grass when standing. When the animal lowers his head and neck, the lines, collar, and breastharness slip down and he is likely to become tangled in the harness and may get into difficulty.

170. Fitting the collar. - The service of the horse is largely accomplished by the shoulders, and it is of the utmost importance that the collar fit the neck and shoulders perfectly. Poorly fitted collars cause the horse much pain, result in sore necks and shoulders, and are a common cause of viciousness and bad habits. Because of the extreme importance of having a well-fitting collar, many makes have been put on the market, such as the leather, the sweeny, the half sweeny, the pneumatic, the steel, and the humane, each asserting superiority over the others (Fig. 43). Each has its advantages and disadvantages.

Fitting the collar is a rather difficult task. It is so firm and stiff that usually it is impossible to buckle the harness tight enough to bring it to the shape of the animal's neck, and the shoulders are therefore adjusted to the collar rather than the collar to the 
shoulders, with sore shoulders as the result. To avoid this soreness, it is necessary that the stiff collar be adjusted to the shoulders of the horse for which it is intended.

Every horse should have his own collar. It should fit close to the neck along its entire width and should never be tight in some places and loose in others. The hame-straps should be properly adjusted at top and bottom to suit the shape of the horse's neck. Be sure at all times that the lower hame-strap is buckled as tightly as the thickness of the neck will permit. Occasionally the careless
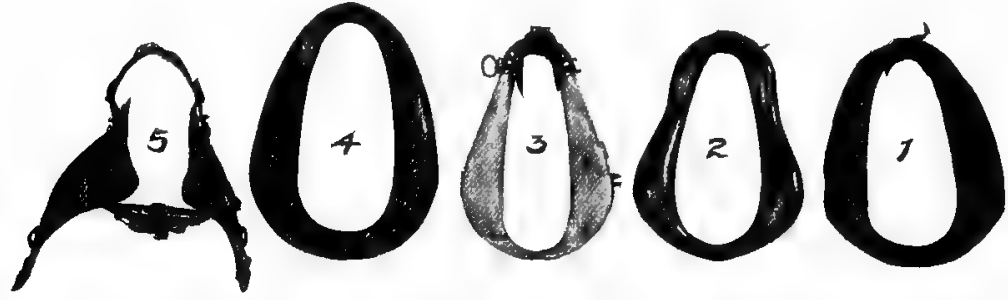

FIG. 43,- Types of collars: (1) leather; (2) half sweeney: (3) steel ; (4) pneumatic ;

(5) humane.

driver fails to buckle the hames tightly, and when the horse is backed, the hames slip off the collar.

171. Breast harness. - For light driving, breast harness is permissible and is to be preferred for such light rigs as runabouts and buggies. In the adjustment of breast harness, care should be taken that the neck strap is not so long as to let the breast harness drop and interfere with the action of the fore limbs. On the other hand, the neck strap should not be so short as to draw the breast harness up and choke the animal. The breast harness is intended for light work only, and if the load is heavy, the horse may choke. This is particularly true in ascending a steep grade.

172. Fitting the back-strap and crupper. - Perhaps next in importance to the bit and collar is the crupper. If the back- 
strap or the check-rein is too short and the crupper is drawn too tight against the tail, it is likely to cause soreness; since this is a very tender part, it may lessen the reliability of the horse. A horse with a sore tail is hard to manage. At any time he may get his tail over the line, become excited through fear that the abraded part will be injured, clamp his tail down on the line, and be difficult to control.

173. Fly-nets. - The use of fly-nets often brings much comfort to working animals. Such horses should be provided with throatlatch cloths when the bot-flies are present, as these pests are very annoying, and the animals in fighting them will often become excited, with a consequent lessening of their usefulness. Whether to use fly-nets or fly-blankets may depend on conditions. The use of the fly-blanket is not advised by many persons, but there are conditions in which it proves very desirable, particularly on horses whose color is such as to fade on being exposed to the direct rays of the sun. The fly-blanket, while very efficient in retaining the color and keeping out the flies, is not so presentable and is much warmer than the open net. Leather fly-nets are the most presentable and the most desired by horsemen. But fly-nets and fly-blankets are rather annoying to the teamster and are more or less expensive, for which reasons they are often discarded entirely.

174. Caring for harness. - The proper care of the harness should receive much consideration, as care will increase the length of its usefulness and lessen the liability of its injuring the animal. It is very important that the bearing parts be kept scrupulously clean at all times. This applies particularly to the parts in constant contact with the animal, as the collar, saddle, and crupper. It is not possible to prevent sore shoulders, sore back, and sore tail if these parts are permitted to become dirty, which they will, because of the sweat and dandruff. They must be carefully watched and frequently cleaned. 


\section{QUESTIONS}

1. How many horses are there in the world? What per cent of these are in the United States? How many mules are there and what per cent are in the United States? How many horses are in your state? In your county? Name the ten leading horse-breeding states. The leading mule-breeding states. Name the ten leading horse markets. The leading mule markets.

2. Why is the demand for draft horses increasing while the demand for driving horses is decreasing?

3. What is meant by heredity, transmission, and inheritance? What is the cause of variation? What is the basis of improvement in horse breeding? What is meant by selection? What is the unit of selection? What is the value of a pedigree and individual merit in selection? What is meant by Mendel's Law?

4. Why should the horse be groomed in the evening after the day's work is done rather than in the morning before going to work, as is the custom?

5. Why should the work horse with along, thick coat of hair be clipped? Which has the finer coat, a clipped or an unclipped horse? How do the stable and the outdoor blankets affect the hair?

6. Why should the colt's hoof be rasped and leveled up frequently? Why should the young hoof not be pared with a knife? What is the function of the frog? Should a shoe be fitted to the hoof when hot?

7. Name the more common diseases of horses and give brief symptoms of each.

8. Why should the colt be trained when young? Can a horse reason? Has the colt a good memory? How are horses taught to obey commands? How many commands should the average horse be taught? What is the most common cause of viciousness among horses? How can vicious habits be overcome?

9. How many kinds of bridle-bits are you familiar with? When should a severe bit be used? How many kinds of collars are you familiar with? Which kinds give best results?

10. Give a method of familiarizing an untrained horse with pressure caused by the harness. What parts of the horse are most sensitive to such pressure? 
PART TWO-CATTLE 


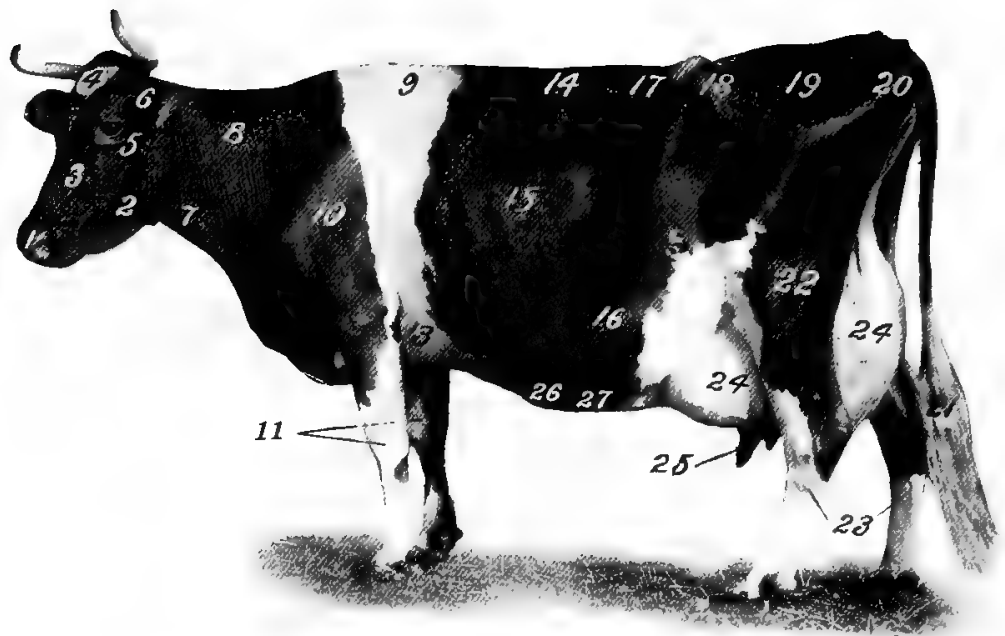

FIG. 44. - Points of the dairy cow.

1. Muzzle.

2. Jaw.

3. Face.

4. Forehead.

5. Eye.

6. Ear.

7. Throat.

8. Neck.

9. Withers.
10. Shoulder.

11. Fore legs.

13. Chest.

14. Back.

15. Ribs.

16. Barrel.

17. Loin.

18. Hips.

19. Rump.
20. Pin bones.

21. Tail.

22. Thigh.

23. Hind legs.

24. Udder.

25. Teats.

26. Milk wells.

27. Milk veins. 


\section{CHAPTER VI}

\section{BREEDS OF CATTLE}

There are two distinct types of cattle: first, the dairy type, adapted to the production of milk; and second, the beef type; employed for the production of beef. These types are controlled by the demands made on the body of the animal. For example, in milk production the udder is perhaps as important an organ as any, whereas in beef production it is needed only to sustain the young. Again, in the case of beef production it is very important that the animal take on flesh and that the body be plump and full, whereas in the production of milk this would be considered an objection, as the food should go to the production of milk and not to fat. These two types are of necessity widely different and one can no more have maximum milk production and maximum beef production in the same cow than he can have maximum speed and maximum force in the same horse.

175. The dairy type. - When we reflect upon the purpose for which dairy cows are kept, the type becomes apparent. They are useful for the milk they can secrete, and not for the flesh of their bodies; and as the food goes to produce milk and not fat, the body will be spare and not fleshy. The secretion of milk takes place in the udder and allied organs; therefore, the rear development will be large. Furthermore, we cannot have large, production without a large factory; thus a large secretion of milk calls for a large digestive tract, which adds to the rear development (Fig. 44).

In general appearance, the form of the dairy cow resembles that of a triple-wedge. Viewed from the side, she shows greater 


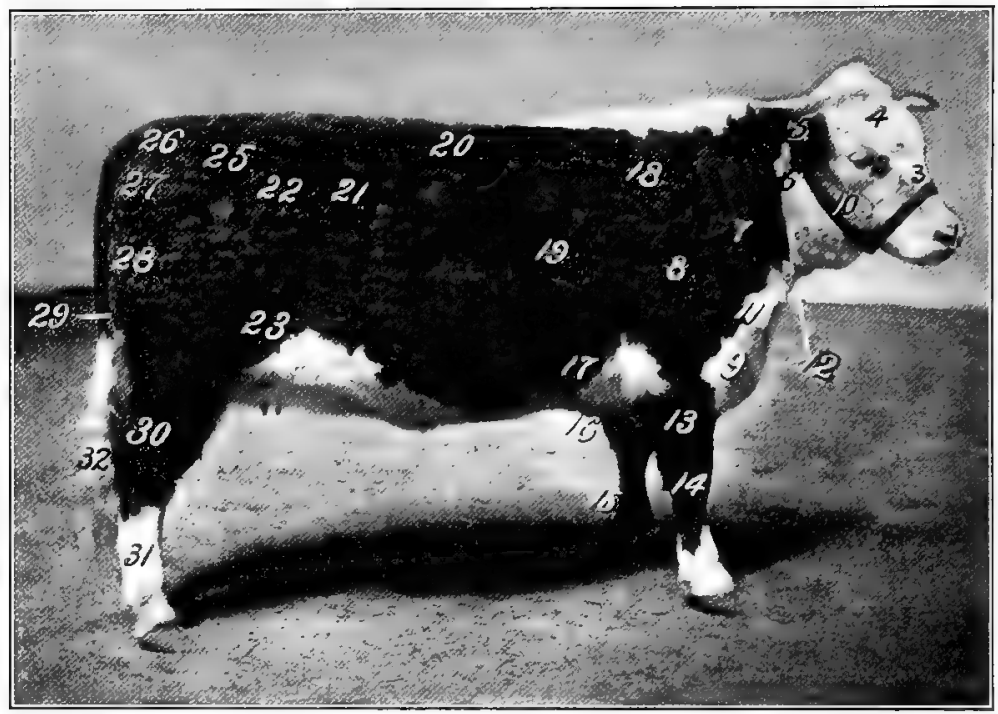

FIG, 45.-Points of the beef cow.

$\begin{array}{ll}\text { 1. Muzzle. } & \text { 12. Dewlap. } \\ \text { 2. Eve. } & \text { 13. Arm. } \\ \text { 3. Face. } & \text { 14. Shin. } \\ \text { 4. Forehead. } & \text { 15. Fore legs. } \\ \text { 5. Ear. } & \text { 16. Chest. } \\ \text { 6. Neck. } & \text { 17. Fore flank. } \\ \text { 7. Shoulder vein. } & \text { 18. Crops. } \\ \text { 8. Shoulder. } & \text { 19. Ribs. } \\ \text { 9. Brisket. } & \text { 20. Back. } \\ \text { 10. Jaw. } & \text { 21. Loin. } \\ \text { 11. Breast. } & \text { 22. Hip. }\end{array}$

23. Hind flnnk.

25. Rump.

26. Tail-head.

27. Pin bones.

28. Thigh.

29. Twist.

30. Hock.

31. Shank.

32. Tail, 
depth of body behind than in front. Viewed from the rear and top, she gradually widens from the chest to the hips. Viewed from the front and top, she gradually widens from the withers backward and downward to the abdomen. While this is the desired form and many superior cows possess it, yet exceptions occur, and many heavy milkers are not associated with this form. Fleshiness, however, is distinctly objectionable in the milking cow.

176. The beef type. - In the beef type, the food goes to the production of flesh; hence a tendency to fatten is desirable. The quality of the flesh in different parts of the body varies widely. In the meat-market, flesh forming certain parts of the body is worth many times that from other parts. We demand therefore in the beef type, not only an animal with a tendency to take on fat, but this tendency must be accelerated in the region of the valuable cuts of meat.

In general appearance, the form of the beef type resembles that of a brick set on edge. Viewed from the side, the top and bottom lines are parallel. There is no wedge shape; the animal is as deep in front as behind. Viewed from the rear and top, the withers and chest present an appearance almost as wide as the hip and rump. The animal is compact and broad of back from shoulders to hips. Cattle of the beef type are often referred to as "blocky," indicating compactness and squareness of form (Fig. 45).

There are several breeds belonging to each of these types, some of which are better suited to perform their function than others. The dairy breeds that are the more perfectly adapted to milk production are spoken of as the major dairy breeds, while those that are not so well suited to milk production are called the minor dairy breeds. In like manner, we have the major and minor beef breeds, the former signifying those breeds of beef cattle that are the better adapted to the production of beef. 


\section{THE MAJOR BREEDS OF DAIRY CATTLE}

The Name, Native Home, Condition of Horns, Approximate Weight, and Common Color of Each of the Major Dairy Breeds

\begin{tabular}{|c|c|c|c|c|}
\hline NAME OF BreED & Native Home & HORNB & $\begin{array}{l}\text { WHIGHT, } \\
\text { PoUNDS }\end{array}$ & CoLOR \\
\hline Jerseys & Jersey Islands & Horns & $800-1200$ & Fawnlike \\
\hline Holstein-Friesian & Holland & Horns & $1400-2000$ & Black and white \\
\hline Guernseys . . & Guernsey Islands & Horns & $1000-1500$ & Yellow fawn \\
\hline Ayrshires . . & Seotland & Horns & $1000-1400$ & Red, white \\
\hline
\end{tabular}

177. Jersey dairy cattle. - The Island of Jersey is one of a group known as the Channel Islands, situated in the English Channel, a few miles off the coast of France, but belonging to Great Britain. The principal islands of the group are Jersey, the largest, Guernsey, Alderney, and Sark. The climate is mild and balmy. The exact origin of the cattle on the Island of Jersey is uncertain. Because of the color, however, it has been assumed that they descended from stock on the neighboring section of France, particularly Normandy and Brittany. The fawn color has been attributed to the cattle of Normandy, while the blacker color has been credited to the Brittany cattle. At an early date, however, steps were taken to keep the breed pure by preventing outside cattle coming into the Island. In 1763, an act was passed, which has since been rigidly enforced, and supplemented by further acts, prohibiting the landing of cattle on the Island except for the purpose of slaughter. Even before the enactment of laws, the purity of the cattle was maintained by the persistency with which the people of the Island cling to their own breed. There are about 40,000 cattle on the Island.

In 1833 the Royal Jersey Agricultural and Horticultural Society was organized, with the purpose of improving the cattle. In 1834 the society originated a score-card for Jerseys; in 1836 it 
recommended that one superior breeding animal be kept in each parish; and in 1838 it enacted several rules which were useful in the development of the Jersey breed.

178. Inspection of Jersey cattle. - On the Island of Jersey the high standing of the breed is preserved by a system of inspec-

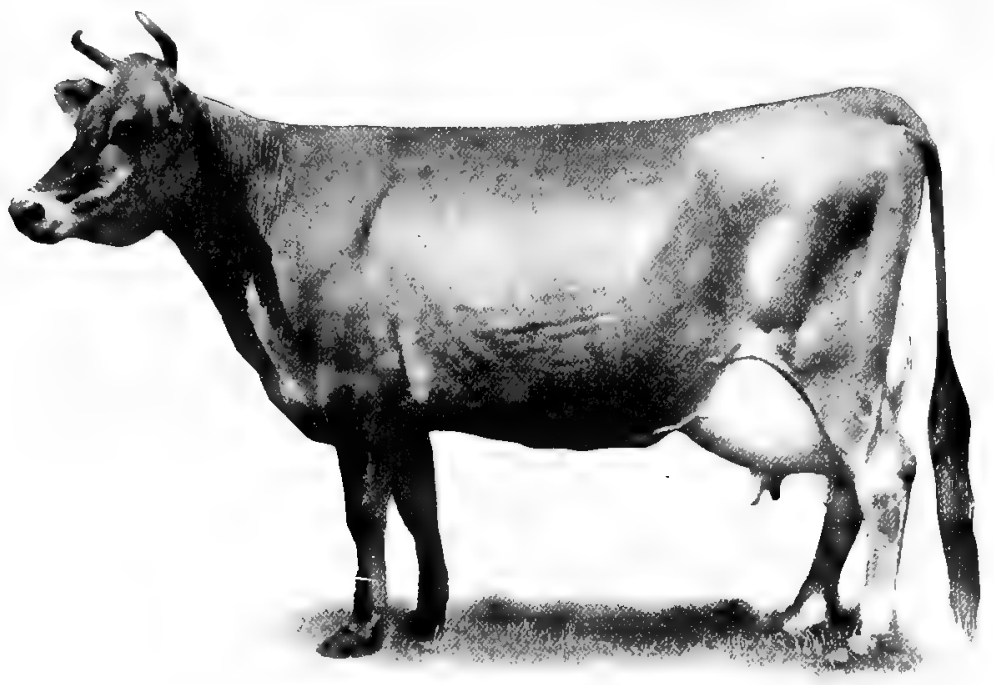

FIG, 46. - The Jersey cow "Tormentor's Lass." Dairy type.

tion which is made a conditional precedent to registration. The following are the necessary conditions to registration :-

(1) Every animal must be inspected by competent judges, and if it is considered fit, it obtains a qualification, namely, commended or highly commended.

(2) Every bull submitted for qualification must be accompanied by his dam, in order that the merits of the latter may be taken into consideration in awarding a commendation to the former.

(3) No heifer, although she may be descended from registered 
parents, can be entered in the herdbook until she has a calf, and if at the time of her examination, she is a poor milker, she receives no commendation.

179. Description of Jersey cattle. - This breed is one of the smallest of the dairy breeds. While the color is described as fawnlike, it is quite variable in its shade, being yellow, red, gray, brown or silver fawn. The general conformation of the Jersey is low and muscular. The head is small, short, lean and dish-faced. The horns are crumpled or incurved, small, waxy, and often blacktipped. The ears are small, delicate and yellow-colored within. The neck is fine and short. The body is well rounded, large and deep. The tail is fine and long. The skin secretions are usually yellow; and as seen in the ear, at the tip of the tail, and about the udder, indicate the richness of the milk. The udder is symmetrical, extending up well behind, and well forward, and while it is usually very mellow and milks out well, it is often criticised for its small size, as well as for small teats. The milk veins are highly developed, tortuous or winding in form, passing well forward and entering the abdomen through milk wells (Fig. 46).

10 Leading Yearly Records among Jersey Cows, April 1, 1913

\begin{tabular}{|c|c|c|c|c|c|c|}
\hline \multirow{2}{*}{ NAME or Cow } & \multicolumn{2}{|c|}{ MILK } & \multicolumn{2}{|c|}{ Butten-Fat } & \multicolumn{2}{|c|}{$85 \%$ BUTTER } \\
\hline & Lb. & $\mathrm{Oz}$. & Lb. & $\mathrm{Oz}$. & Lb. & $\mathrm{Oz}$. \\
\hline Jacoba Irene & 1.7253 & 3.2 & 952 & 15.4 & 1121 & 2.1 \\
\hline Sophie 19th of Hood Farm . & 15099 & 6.0 & 931 & 15.5 & 1096 & 6.9 \\
\hline Lass 38th of the Hood Farm & 15284 & 0.0 & 890 & 5.6 & 1047 & 7.5 \\
\hline Olga 4th's Pride . . & 16275 & 13.2 & 851 & 11.7 & 1002 & 0.6 \\
\hline Adelaide of Beechlands & 15572 & 1.6 & 849 & 9.9 & 999 & 8.9 \\
\hline Rosaire's Olga 4th's Pride. & 14104 & 13.6 & 836 & 15.8 & 984 & 11.0 \\
\hline Warder's Lady & 14820 & 11.0 & 819 & 15.0 & 964 & 10.0 \\
\hline Pearly Exile of St. Lambert & 12345 & 8.0 & 816 & 1.2 & 960 & 1.0 \\
\hline St. Mawes Poppy . . . . & 12934 & 4.8 & 800 & 13.5 & 942 & 2.7 \\
\hline Financial Countess & 13248 & 2.4 & 795 & 4.6 & 935 & 10.0 \\
\hline
\end{tabular}


180. Jersey milk and butter-fat records. - As a butter-fat producer, this breed is justly famous. Jersey milk holds first place for the production of superior butter, as well as for the percentage of butter-fat contained, although the flow or yield of milk is not so great as in some of the larger dairy breeds. As early as the seventies, records were kept of the milk and butter produced, and at the present time, the American Jersey Cattle Club is giving attention to the testing of cows for milk and butter-fat yield. These results are recorded in the Register of Merit.

181. Holstein-Friesian dairy cattle. - This breed of dairy cattle originated with the ancient Friesland people, who occupied the shores of the North Sea, between the river Ems and the Rhine. The Friesians were the oldest inhabitants of Holland, and were known as herdsmen, hunters, and fishermen. It is stated that for over a thousand years the cattle of Friesland have been famous for the production of milk, butter, and cheese. Early writings refer to the Dutch cattle as being large and great milk producers. They were popular and became widespread, entering Oldenberg and Holstein in Germany, Denmark, Belgium, France, Russia, and other countries. 'In North Hólland, at the present time, there are some 80,000 head of pure-bred cattle of this breed and in Friesland at least 125,000 .

The breed name, Holstein-Friesian, is of American origin, there being no breed of that name in Europe. Holstein is a small province in Germany between the Baltic and North Seas, about a hundred miles east of Friesland, which is in Holland. Formerly Friesland cattle were brought to America under the name Dutch Friesian, and cattle from Holstein under the name Holstein, being sold as different breeds and championed by different breeding associations, each breed having a separate herdbook. These two breeds, however, were essentially the same, having a similar origin, and are the same in all important characteristics. In order to promote the interests of the two breeds, the breeders and importers 
finally came together and united their interests, agreeing to call the breed, Holstein-Friesian.

182. Description of Holstein-Friesian cattle. - This breed is one of the largest of the dairy breeds. While the color is described as black and white, the proportion of black to white varies

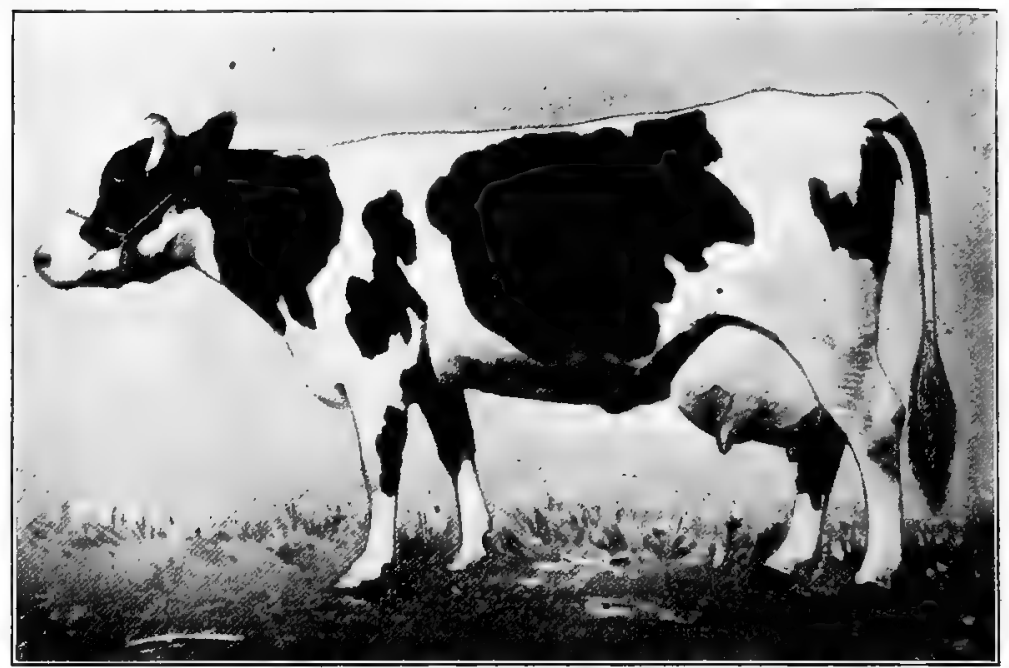

FIG. 47. - The Holstein-Friesian cow "Colantha 4th's Johanna." Dairy type.

greatly. In America at the present time considerable white with black patches is the popular color, although very excellent animals will be observed in which black predominates. In Holland, red and white is occasionally seen, while in America, red bars an animal from being recorded in the herdbook. The head is lean and tends to be somewhat long, with straight nose or face. The horns should be short, tapering gradually, and curved forward and inward. A white horn with a black tip is preferred. The neck is moderately long and slender in the female and large and arched in the male. The shoulders are prominent, with withers 
moderately thick. The body is large with long, well-sprung ribs of great length, thus giving constitution and digestive capacity. The hips are prominent with long rump and thin thighs. The udder is very large and well proportioned, extending up well behind and well forward, although, with increasing years, it often becomes somewhat pendant. The teats are of good size and the milk veins large, but not so tortuous as in the Jersey (Fig. 47).

183. Holstein-Friesian milk and butter-fat records. - As a milk producer this breed is justly famous. Following the lead of the Jersey breeders, the Holstein-Friesian breeders early began to keep data on the amount of milk and butter produced, and wonderful milk records have been reported. While the Jersey is especially noted for the richness of its milk, the Holstein-Friesian is equally as well noted for its large milk flow. These results are reported in the Advanced Register.

10 Leading Yearlit Records among Holstein-Friegian Cows, April 1, 1913

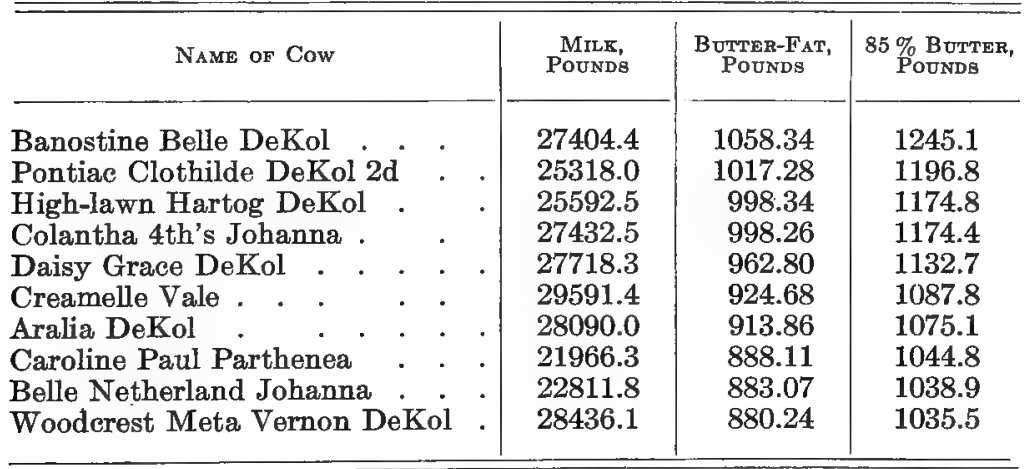

184. Guernsey dairy cattle. - This breed was developed on the Islands of Guernsey and Alderney, the climate being similar to that of Jersey Island. The Guernsey cattle are supposed to have the same French ancestry as the Jerseys. It is assumed 
that the red color and the size are derived from the use of cattle from Normandy and the darker colors from Brittany cattle, taken to the island in very early times. In the latter part of the eighteenth century, however, a law was passed forbidding the bringing

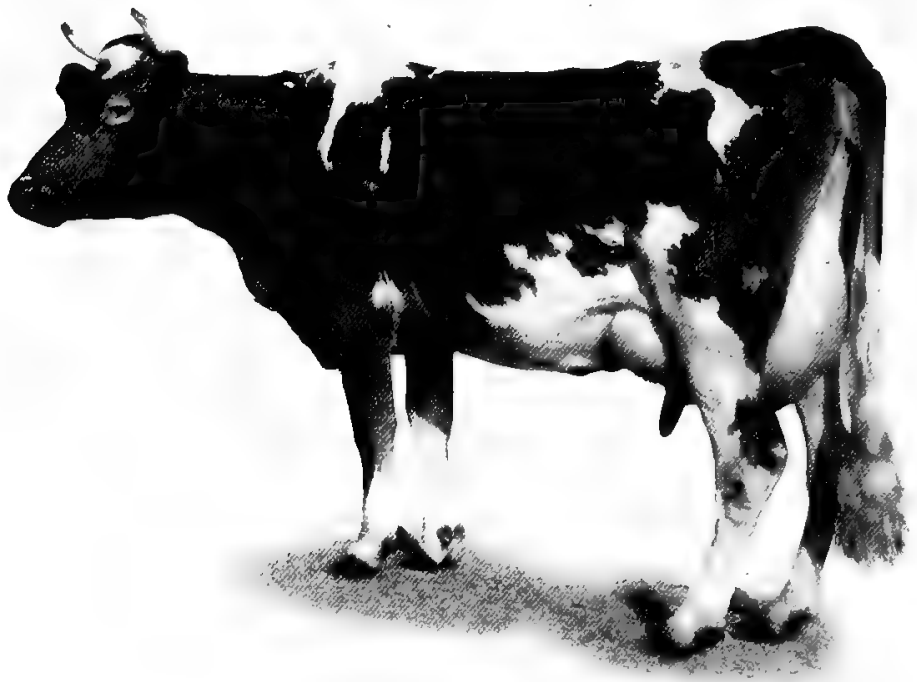

FIG. 48. - The Guernsey cow "Dolly Dimple." Dairy type.

of cattle to the islands except for immediate slaughter. The Royal Guernsey Agricultural and Horticultural Society is largely responsible for the improvement of the breed. Annual exhibitions are held, in which there is strong competition, as prizes are awarded according to merit. As compared with the Island of Jersey, Guernsey is rather small and maintains only about 5000 head of cattle.

185. Description of Guernsey cattle. - In size this breed ranks as medium. The color is either yellow, brown, or reddish fawn, with white markings or with white on the limbs and under 
part of the body. The head is of medium size, with muzzle of buff or flesh color. The horns are white or amber colored, though often colored a deep yellow. They are of medium length, curving gracefully around inward and slightly upward. The neck is short and fine; the shoulders inclined to be angular; the ribs well-sprung and long, giving good capacity; and the rump long and level. The udder is large, extending up well behind, and showing more fore-udder development and larger teats than does the Jersey. The milk veins are large, crooked and long, entering the abdomen through large wells. Guernsey breeders lay special emphasis on a rich, yellow secretion of the skin, especially as seen in the ear, tip of tail, and about the udder (Fig. 48).

186. Guernsey milk and butter-fat records. - The cows of this breed are noted for being retentive milkers, perhaps holding their flow better than any other breed, a good illustration of which is seen in the case of Spotswood Daisy Pearl, giving 24,675 pounds of milk and 1225.6 of fat in fifteen months.

10 Leading Yearly Records among Guernsey Cows, April 1, 1913

\begin{tabular}{|c|c|c|c|c|}
\hline NaME of Cow & & $\begin{array}{l}\text { MILK, } \\
\text { PodNDs }\end{array}$ & $\begin{array}{c}\text { BUTTER-FAT, } \\
\text { POUNDS }\end{array}$ & $\begin{array}{c}85 \% \text { BUTTER, } \\
\text { POUNDS }\end{array}$ \\
\hline $\begin{array}{l}\text { Spotswood Daisy Pearl . } \\
\text { Dairy Maid of Pinehurst } \\
\text { Dolly Dimple } \\
\text { Imp. Beauty of Park Farm . } \\
\text { Yeksa Sunbeam } . \\
\text { Murne Cowan } \\
\text { Dolly Bloom } \\
\text { Glenanaar of the Glen . } \\
\text { Imp. Princess of the Blicqs . } \\
\text { Langwater Hope }\end{array}$ & $\begin{array}{ll}\cdot & \cdot \\
\cdot & \\
\cdot & \cdot \\
\cdot & \cdot \\
\cdot & \\
\cdot & \cdot \\
\cdot & \end{array}$ & $\begin{array}{l}18608.2 \\
17285.3 \\
18458.8 \\
14686.8 \\
14920.8 \\
16729.3 \\
17297.5 \\
16813.1 \\
12608.8 \\
15078.8\end{array}$ & $\begin{array}{l}957.38 \\
910.67 \\
906.89 \\
898.82 \\
857.15 \\
845.41 \\
836.21 \\
780.66 \\
774.16 \\
773.59\end{array}$ & $\begin{array}{r}1126.3 \\
1071.4 \\
1066.9 \\
1057.4 \\
1008.4 \\
994.6 \\
983.7 \\
918.4 \\
910.8 \\
910.1\end{array}$ \\
\hline
\end{tabular}

187. Ayrshire dairy cattle. - This breed was developed in southwestern Scotland, particularly in the county of Ayr, from which the breed derives its name, although in its formative period, 
it was known as the Dunlop and the Cunningham breed. The origin of this breed is complex. About 1770, Teeswater cattle were introduced into Ayr. A little later John Dunlop, of Dunlop," imported cows of large size and of uncertain ancestry, but from which sprang a strain known as the Dunlop breed for more than a century. It is stated cattle of the Channel Islands crossed with

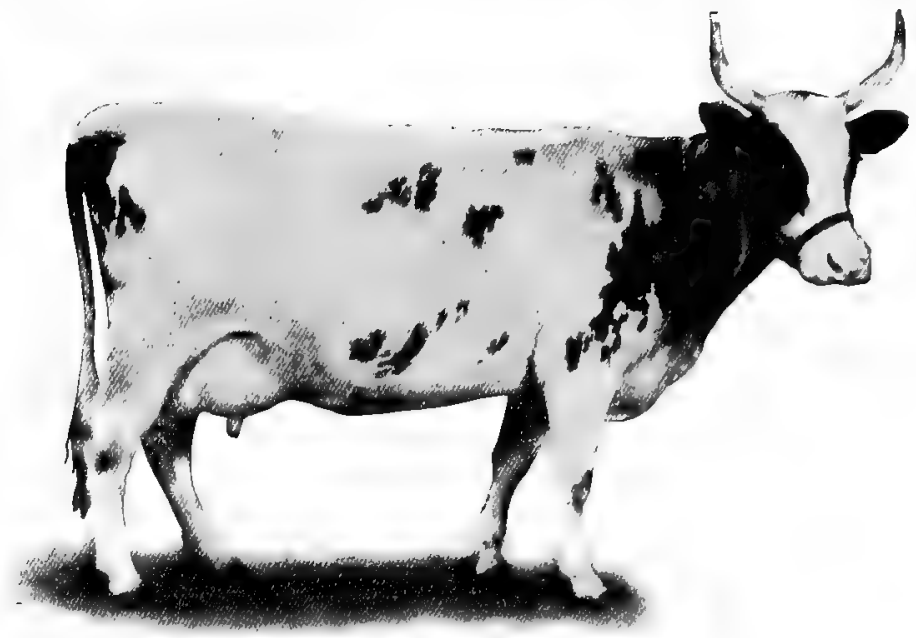

FIs. 49. - The Ayrshire cow. Dairy type.

Shorthorns were early used in Ayrshire. Early in the nineteenth century cattle from the Highlands, from Hereford and from Devon found their way to Ayrshire. The Highland and Agricultural Society of Scotland did much to improve the breed by awarding liberal premiums to cattle of merit. In 1853, the Ayrshire Agricultural Association adopted a score-card and began systematic efforts at improvement according to a scale of points.

188. Description of Ayrshire cattle. - This breed is of medium size and possesses more of a beefy tendency than some of the 
other dairy breeds. In general conformation, therefore, this breed is' a little smoother than the Jersey, Holstein-Friesian or Guernsey, yet it is not so smooth as to conceal the wedge shape of the body when viewed from behind. The color is variable, though red, white, and brown predominate. The common color in America is red and white patched, with a tendency toward a predominance of white. The head is of medium size, and the face straight. The horns are white with black tips and often rather long. They are curved outward and upward, and often, especially with cows, turn back at the tips. The back is straight from the base of the horns to the tail ; the ribs are long and well sprung; and the rump high, broad, long, and level. The thighs and hind quarters are often somewhat fleshy. The udder presents an unexcelled form, extending high behind and carried very well forward. The teats are of medium size and the veins large and long. The temperament is often of a nervous character (Fig. 49).

189. Ayrshire milk and butter-fat records. - This was the last of the four major dairy breeds to adopt a systematic method of testing cows and of recording performance, although very creditable records have been made.

10 Leading Yearly Records among Ayrshire Cows, April 1, 1913

\begin{tabular}{|c|c|c|c|}
\hline NAME of Cow & Milm, Pounds & $\begin{array}{l}\text { BUTTER-FAT, } \\
\text { POUNDS }\end{array}$ & $\mid \begin{array}{c}85 \text { \% B BTTter, } \\
\text { Pounds }\end{array}$ \\
\hline Lily of Willowmoor & 22106 & 888.70 & 1045.5 \\
\hline Netherhall Brownie 9th & 18110 & 820.91 & 965.7 \\
\hline Gerranton Dora $2 \mathrm{~d}$ & 21023 & 804.79 & 946.8 \\
\hline Jean Armour. & 20174 & 774.73 & 911.4 \\
\hline Rena Ross : : & 15072 & 643.71 & 757.3 \\
\hline The Abbess of Torr & 14582 & 640.72 & 753.8 \\
\hline Auchenbrain White Beauty $2 \mathrm{~d}$ & 14721 & 636.90 & 749.3 \\
\hline Hazel of Sand Hill & 11078 & 627.13 & 737.8 \\
\hline Auchenbrain Favorita Beauty 5th & 14158 & 611.87 & 719.8 \\
\hline Matie of Sand Hill . . & 13897 & 593.16 & 697.8 \\
\hline
\end{tabular}




\section{THE MINOR BREEDS OF DAIRY CATTLE}

The Name, Native Home, Condition of Horns, Approximate Weight, and Common Color of Each of the Minor Dairy Breeds

\begin{tabular}{|c|c|c|c|c|}
\hline NaMe OF BREED & Native Home & Horns & $\begin{array}{l}\text { WeIght, } \\
\text { Pounds }\end{array}$ & Color \\
\hline Dutch Belted. & Holland & Horns & $1100-1700$ & $\begin{array}{l}\text { Black, white } \\
\text { belt }\end{array}$ \\
\hline Brown Swiss . & Switzerland & Horns & $1200-1600$ & Brown \\
\hline French Canadian & Canada & Horns & $800-1000$ & Black \\
\hline Kerry . . . & Ireland & Horns & $600-900$ & Black, red \\
\hline
\end{tabular}

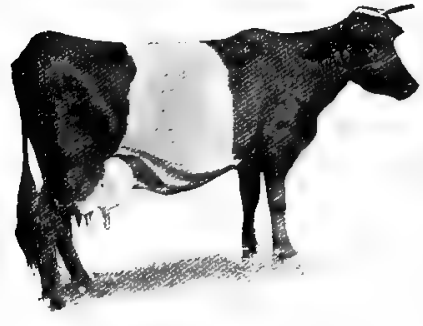

FIG. 50. - The Dutch Belted cow.

190. Dutch Belted cattle. - This breed is readily distinguished from other breeds of cattle by the characteristic color, which is more or less ornamental. They are only fair in milk and butter-fat production, and no better than the other dairy breeds for beef, hence they are not popular in America, where only a few are to be found (Fig. 50).

191. Brown Swiss cattle. - This breed is often classified as belonging to the dual-purpose type. This type comes between the beef and dairy type, combining in one animal the valuable qualities of dairy and meat types. Brown Swiss cattle are distinguished by their form and color. They rank only fair as milk and beef producers and are not especially popular in America (Fig. 51).

192. French Canadian cattle. -

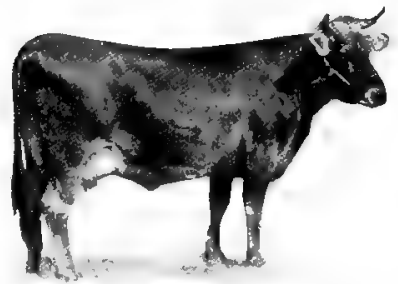

FIG. 51. - The Brown siwiss cow. In type this breed shows considerable resemblance to the Chan- 
nel Island cattle, especially the Jerseys. These cattle are noted for their hardihood and are, therefore, well adapted to the rigors of Canadian winters. French Canadian cattle give very good yields of milk, but have never become common in the United States where very few are to be found.

193. The Kerry cattle. - In Ireland, this breed is often known as the poor man's cow. There are two types of Kerry cattle the true Kerry and the Dexter-Kerry. The latter is the smaller, although 1000 pounds is seldom exceeded even by a true Kerry. Although the Kerry is a fair milk producer, it is not popular in America. Even in Ireland, where it is commonly bred, the Shorthorn is the leading breed.

\section{THE MAJOR BREEDS OF BEEF CATTLE}

The Name, Native Home, Condition of Horns, Approximate Weight, and Common Color of Each of the Major Begf Bregds

\begin{tabular}{|c|c|c|c|c|}
\hline Name of Breed & Native Home & Honns & $\begin{array}{l}\text { WeIGHT, } \\
\text { Pounds }\end{array}$ & Color \\
\hline Shorthorns & England & Horns & $1400-2000$ & Red, white, roan \\
\hline Hereford. & England & Horns & $1400-2000$ & Red and white \\
\hline Aberdeen Angus. & Scotland & Hornless & $1400-1800$ & Black \\
\hline Galloway . & Scotland & Hornless & $1200-1800$ & Black \\
\hline
\end{tabular}

194. Shorthorn beef cattle. - This breed originated in northeast England, and first became popular in' the counties of Durham, Northumberland, Lincoln, and York. The river Tees forms the dividing line between Durham in the north and York, the largest county in England, on the south. In the valley of the Tees the Shorthorn received its early development and improvement, from which it spread over the rest of Great Britain and the civilized world. Formerly the cattle of this valley were referred to as Teeswater cattle, and known as Holderness. While authorities differ somewhat as to the particular stock used in the develop- 
ment of the Shorthorn, all are agreed that the largest factor entering into their production was the native cattle of northeastern England, although about the middle of the eighteenth century bulls were introduced from Holland.

-Improvement of the Shorthorn began about 1750 although little progress was made prior to the time of Messrs. Charles and Robert Colling. These brothers began breeding about 1784, Charles at Ketton in Durham and Robert at Brampton, not far distant from Charles. One of their stock bulls was Hubback, and they bred the Durham Ox and The White Heifer That Traveled as well as Favorite and Comet. Charles Colling's herd was dispersed in 1810 and Robert's in 1818, and in 1820. At these dispersion sales, their animals were scattered broadcast throughout the land.

Thomas Bates of Kirklevington and Thomas Booth, first of Killerby and later of Warlaby, were famous English breeders at the beginning of the nineteenth century. Bates was a careful investigator, keeping accurate records of the food consumed to beef and milk produced. He laid much stress upon milk production. Booth laid special emphasis upon the beef type, and his cattle were noted for their easy-feeding and thick-fleshing tendencies.

Amos Cruickshank of Aberdeen, Scotland, was also a very famous breeder of Shorthorns. He established his herd about 1837 and gradually developed a type known as Scotch which is low-set, thick fleshed, and early maturing.

195. Shorthorn families. - There are a number of very important tribes of families of Shorthorns. Thomas Bates developed the Duchess, Oxford, Waterloo, Cambridge Rose, Wild Eyes, Foggathorpe, and other tribes. Thomas Booth developed the Anna, Isabella, Medora, Halnaby or White Strawberry, Bracelet, Moss Rose, Mantalini, Blossom or Fairholme, Cherry Blossom, and like strains. Amos Cruickshank established the Violet, Venus, Mimulus, Picotee, Broadhook, Lady, Nonpareil, Orange Blossom, Lancaster, Victoria, Secret, Lavender, Spicy, Lovely, and the other tribes. 
196. Description of Shorthorn cattle. - This is the largest of the beef breeds and adheres closely to the ideal beef type, although certain tribes, notably Bates bred, tend to milk production and are known as dual-purpose cattle. The head is short and broad, especially between the eyes. The horns are small and short, and preferably curved forward. The neck is short and

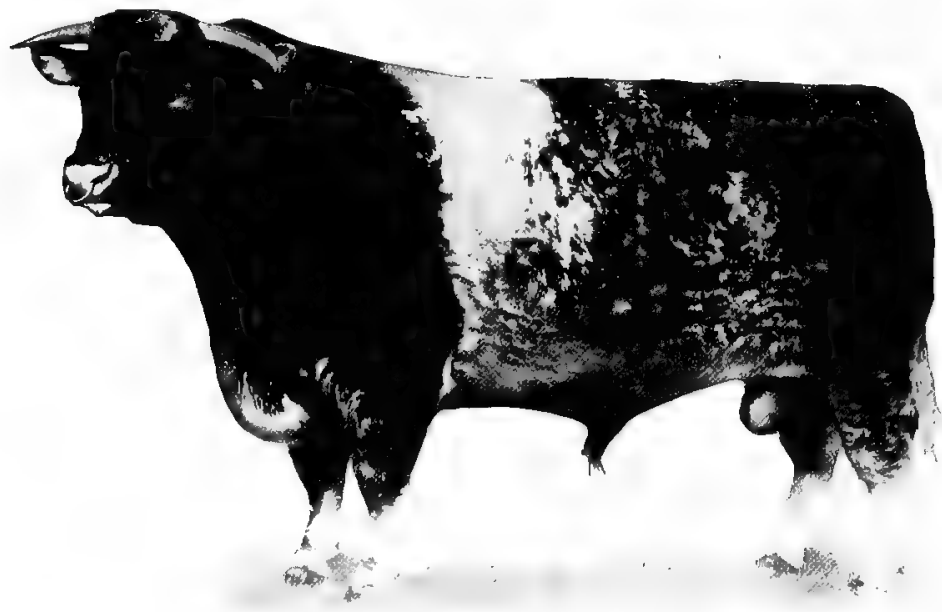

FIG. 52. - The Shorthorn bull "Avondale." Beef type.

thick. The back is broad and straight, the ribs so well sprung and long as to give a large girth and good digestive capacity, with loins strong and broad. The rump is long, level and broad, while the quarters and thighs are long, thick, and deep, the fleshing being carried well towards the hocks. The legs are short, possessing small, clean bone, and strong joints. The color is red, white, and roan, and the temperament exceedingly mild (Fig. 52).

197. Hereford beef cattle. - This breed originated in southwestern England, particularly in the county of Hereford. The very early origin is no doubt much the same as the other English 
breeds, the aboriginal cattle playing an important part. The Hereford is one of the oldest breeds of cattle in England.

Improvement in the Hereford began about the middle of the eighteenth century under the leadership of a son of Richard Tompkins, known as Benjamin the Elder, who was born in 1714 and died in 1789, at Wellington Court. He was a most successful breeder and possessed a noted herd of cattle, which passed to his son, also named Benjamin, and often called Benjamin the Younger, who in turn did much to improve the Hereford. The bulls Wellington and Silver Bull were two of his most famous animals. Through the efforts of the elder and younger Tompkins the Herefords gradually matured earlier, became more refined and better covered with flesh over the back.

The early Hereford was still further improved by William Galliers of Wigmore Grange, who was intimate with Benjamin Tompkins the Elder and who used much the same blood in the work of improvement; by John Pierce of Ryall, who was a close friend and disciple of Tompkins the Younger, from whom he obtained some of his best stock; by John Hewer; and by Thomas Jeffries of The Grove, Pembridge.

198. Hereford compared with the Shorthorn. - The former is approximately the equal of the latter in size. The color of the Hereford is a uniform characteristic, the face, breast, top of the neck, and legs from the knees and hocks down, and perhaps the belly, being white with the balance of the body red, which varies in shade. The head is short, broad, with the face often slightly dished, and crowned with whitish or yellowish horns, which spring forward and up in the cows, though down in the bulls, with a graceful curve. The neck is short.and smooth, although there is occasionally a very heavy throat; the shoulders are well laid and the chest broad but the dewlap is often overdeveloped. The back is straight, the ribs well-sprung and long, giving capacity. The rump, however, often lacks the levelness and fullness of the Shorthorn, while the thighs are even more deficient, being thin and pared off and lacking 
in thickness and depth. In temperament the Herefords are less docile than the Shorthorns. It is stated, however, that the Herefords excel the Shorthorns in three important characteristics, first, in ability to take on fat at an early age; second, as baby beef producers, and third, for grazing on the open range (Fig. 53).

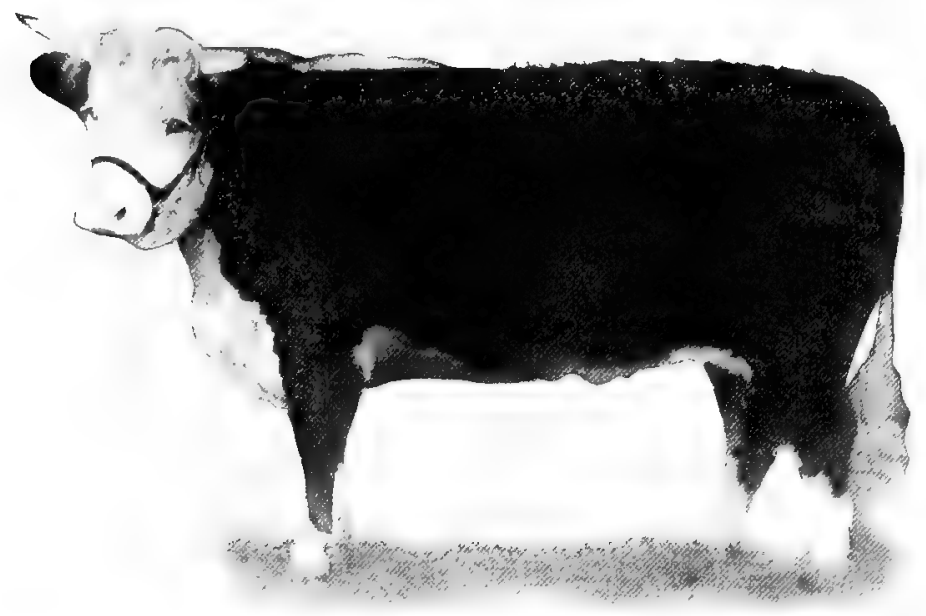

FIG. 53. - The Hereford cow. Beef type.

199. Aberdeen Angus beef cattle. - This breed was developed in northwestern Scotland, particularly in the counties of Aberdeen, Kincardine, and Forfar, which have a damp, cold climate. The early origin of the breed is speculative and attracts attention because of the polled or hornless character of the head. Hormess cattle, however, are not uncommon. They were known to exist among the wild white cattle of Great Britain, and within the past few years, hornless cattle have been developed among the wellestablished horned breeds, such as the Herefords, Jerseys, and Shorthorns, cattle with which the presence of horns seemed to be a fixed character. Formerly the Aberdeen Angus breed was known by 
many local names, the two common ones being " Buchan humlies" from the Buchan district, and the "Angus doddies" from the Angus district. The words "humle" and "dodded" are the Scotch terms for polled or hornless.

Improvement of the Aberdeen Angus began early in the nineteenth century under the leadership of Hugh Watson, of Keillor, Forfar. Watson was to the Aberdeen Angus what the Colling brothers were to the Shorthorns, and the Tompkins family to the Herefords. In his improvement, Watson emphasized family lines, and bred each family rather within itself. His most famous cow, Old Grannie, was one of the most noted cows of which we have record. She lived to be thirty-six years old, and gave birth to twenty-five calves, the last one in her twenty-ninth year.

The early Aberdeen Angus was still further perfected by William McCombie of Tillyfour, Aberdeen, who laid special stress upon individual merit in mating, as well as superior pedigree, and by Sir George Macpherson Grant of Ballindalloch, whose herd was regarded as the premier one of Scotland.

200. Aberdeen Angus families. - There are a number of important strains or families of Aberdeen Angus such as the Queens, descending from Queen Mother, the Ericas from Erica, the Blackbirds from Lady Ida, the Nosegays from Nosegay, the Heather Blooms from Heather Blossom, and the Prides descending from the Pride of Aberdeen.

201. Aberdeen Angus compared with Shorthorn. - The former is not so large as the latter. The striking difference between the two breeds is the absence of horns, and the black color of the Angus. Thë Aberdeen Angus head is short, forehead prominent and tapering at the poll. While the ribs are well-sprung, they are somewhat rounded, giving a cylindrical body, and thus lacking the broad back and loin of the Shorthorn. The rump often slopes considerably and the thighs are frequently rather thin, thus the Aberdeen Angus lacks the squareness and the depth in hindquarters of the Shorthorn. The claim is made that the quality of the Aberdeen Angus 
meat excels that of the Shorthorn. The Scotch breed is more active in temperament than the English (Fig. 54).

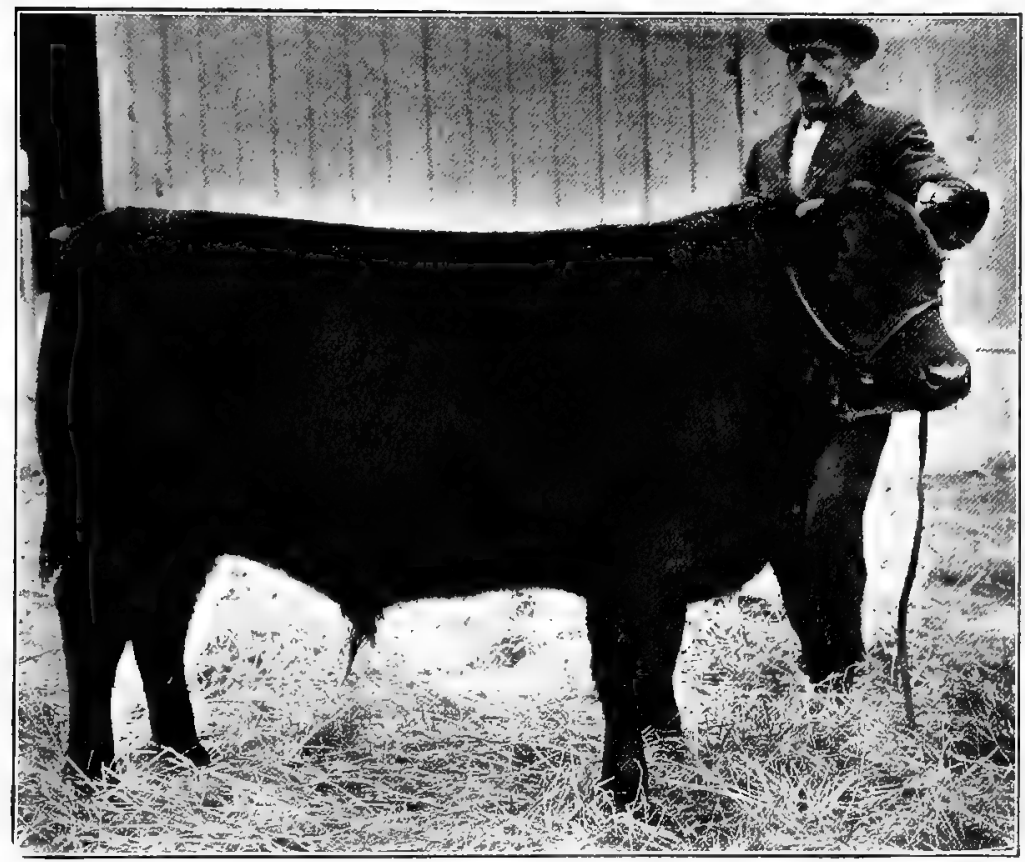

Fig. 54. - The Aberdeen Angus steer "Shamrock 2d." Beef type.

202. Galloway beef cattle. - This breed was developed in southwestern Scotland, particularly in the counties of Wigton and Kirkeudbright, and parts of Dumfries and Ayr, that formed the ancient kingdom of Galloway. The climate is rather damp and cold much of the time, which resulted in the development of a breed particularly noted for its ability to endure inclement weather. The Galloway is a very old breed, and the early origin is obscure, as in the case of the Aberdeen Angus. The early improvement of 
the Galloway was due largely to careful selection and to the united efforts of Scotch breeders generally. Among the more noted of the early improvers of the breed were Lord Selkirk, Murry of Broughton, Herring of Corrough-tree, Gordon of Greenlaw, Maxwell of Munches, Maitland of Kirkcudbright, Cathcart of Genoch, Stewart of Plygell, and many others. In 1851, the breed was

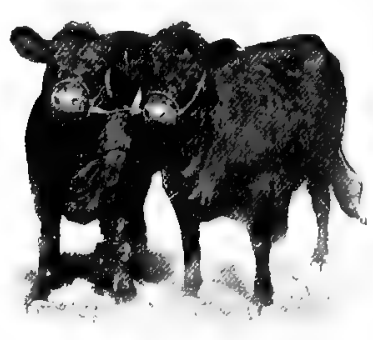

FIG. 55, - Galloway heifer's. Beef type. promoted by establishing the annual Galloway sale at Lockerbie, which was soon followed by another established at Castle Douglas.

203. Galloway compared with the Shorthorn. - The Galloway differs strikingly from the Shorthorn in its lack of horns, its black color, its long, shaggy coat of hair, and its comparatively small size. The Galloway head is of good type but less peaked at the poll than that of the Aberdeen Angus. While the back of the Galloway is straight from the poll to tail head, it is often deficient in spring of ribs as compared with the Shorthorn. The claim is made that the Galloway does not, as a rule, mature as early or fatten as rapidly as the Shorthorn, Hereford, or Aberdeen Angus, although Galloway cattle produce a very high-class grade of meat, fine in grain and flavor, with the lean and fat well interspread. The Galloway is of even a more active temperament than the Aberdeen Angus. The Galloway is ahead of the Shorthorn in hardihood and in the value of the hide, which, owing to the long coat of silky hair, is useful in the manufacture of robes, coats, and the like (Fig. 55).

\section{TIIE MINOR BREEDS OF BEEF CATTLE}

204. Polled Durham cattle. - Because of the similarity, this breed is often spoken of as hornless shorthorns, the development 


\section{Breeds of Cattle}

and characteristics of the two breeds being practically the same. There are two groups of Polled Durhams, the Single Standard and the Double Standard, the former being eligible to record in the the Polled Durham Herdbook only, and the latter may be recorded in both the American Shorthorn Herdbook and the Polled Durham Herdbook.

The Name, Native Home, Condition of Horns, Approximate Weight, and Comion Color of Each of the Minor Beef Brelids

\begin{tabular}{|c|c|c|c|c|}
\hline Name of Breed & Native Home & HoRns & $\begin{array}{l}\text { WEIGHT, } \\
\text { PoUnd }\end{array}$ & Color \\
\hline Polled Durham & England & Hornless & $1400 \cdot 2000$ & Red, white, roan \\
\hline Devon: & England & Horns & $1200-1800$ & Red \\
\hline Red Polled & England & Hornless & $1200-1800$ & Red \\
\hline Sussex . . & England & Horns & $1200-1800$ & Red \\
\hline West Highland & - Scotland & Horns & $900-1200$ & Red, black \\
\hline
\end{tabular}

205. Devon cattle. - This breed is often considered as a dualpurpose breed. It is distinguished by the bright red color, by its graceful, upturned, waxy-colored and black-tipped horns, and by

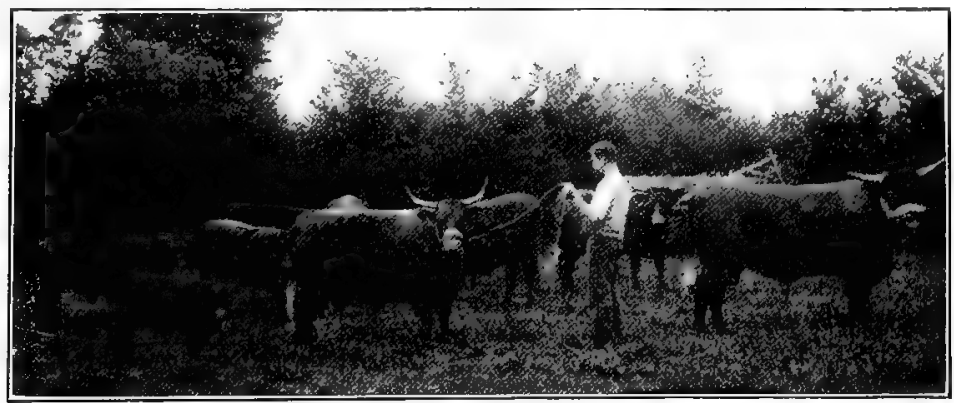

FIG. 56. - Devon herd.

its symmetrical general appearance. The Devon is often referred to as deerlike in character, owing to its natural refinement and general activity. Cattle of this breed rank high as oxen (Fig. 56). 
206. Red Polled cattle. - This breed is also considered as a dual-purpose breed, in which capacity it is often given first rank. It is readily distinguished by its color, its lack of horns, and by the general conformation, as it lacks in massiveness and presents some of the features of the dairy-type. The udder is of fair size with a tend.. ency to be pendent, and rather large teats are common (Fig 57).

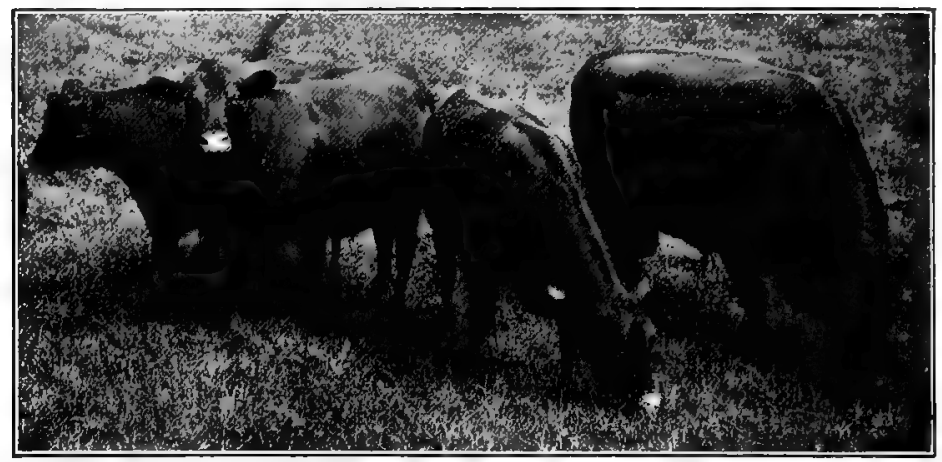

FIG. 57. - Red Polled herd.

207. Sussex cattle. - This breed resembles the Devon somewhat, although it presents more size and general beefiness, having a more massive body, deeper shoulders, a thicker neck, heavier horns, and appearing coarser generally.

208. West Highland cattle. - This breed is easily distinguished by its small size, shape of horns, shaggy coat of hair, and general appearance. It is hardy, rugged, and attractive, and is especially noted for the quality of its meat, which is unexcelled, although the breed is late maturing, slow fattening, and possessed of a very nervous disposition.

\section{QUESTIONS}

1. How many pure-bred dairy cattle are there in your vicinity? What breeds are the most common? Why are they preferred?

2. Are there any creameries or skimming stations in your county? 
If so, how much milk is received at each daily? Approximately how many cows supply this milk? What is the average yield per cow? How much do some of the better cows yield? What becomes of the butter or cream?

3 . Are there any cows tested for advanced registry in your county? What are some of the highest records? Give the name and pedigree of the cows making them.

4. Give the names of a few of the leading exhibitors of dairy cattle at your state, county, or town fair. Give the name of a few of the prizewinning animals.

5. How many pure-bred beef cattle are there in your vicinity? What breeds are the most popular? Why are they preferred?

6. Compare the four leading beef breeds in early maturity, temperament, grazing ability, and in the quality of meat.

7. Give the names of a few of the leading exhibitors of beef cattle at your state, county, or town fair. Give the name of a few of the prize winning animals.

8. Give the names of the grand champion steers at the International Live Stock Show, Chicago, for the past five years. By whom were they fitted and exhibited? 


\section{CHAPTER VII \\ JUDGING CATTLE}

Since the age of cattle is a very important factor in determining their value, we should learn the methods of estimating it before attempting to judge them.

209. How to estimate the age of cattle. - As with horses, the teeth furnish the best index to the age of cattle, although the

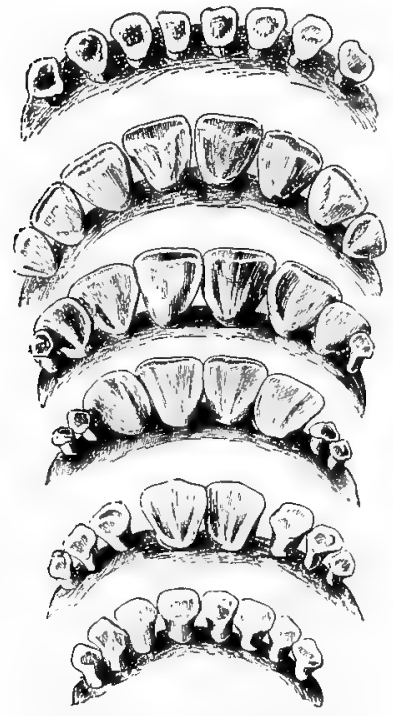

FIG. 58. - Cow's teeth arranged according to age. Lower row 12 months of age, second row 18 months, third row 27 mont hs, fourth row 36 months, fifth row 45 months and top row ten years of age. horns, when present, are used to some extent. While the order of the appearance of the permanent teeth and their method of wearing are considered the most accurate means of estimating age among cattle, they are not absolutely accurate nor are they as dependable as in the horse. Teeth in cattle vary in much the same manner as in the horse (p. 34).

The calf is often born with the central pair of milk teeth, and the remaining pairs appear within the first month after birth. The calf is provided with four pairs of incisor teeth. There are incisors in the lower jaw only, the upper being provided with a cartilaginous pad.

When the animal is approximately eighteen months of age, the middle pair of milk teeth is replaced by permanent ones, which are fully twice as broad as the milk teeth, hence easily 130 
recognized (Fig. 58). The intervals between the appearance of the succeeding pairs vary much according to the conditions, but can be stated as approximately nine months, perhaps more rather than less. In general the age of the animal at the time each pair is up and in full wear may be estimated as follows:-

First or middle pair of permanent teeth . . . . . . . . 18 months

Second or first intermediate pair of permanent teeth . . . 27 months

Third or second intermediate pair of permanent teeth . . . 36 months

Fourth or lateral pair of permanent teeth . . . . 45 months

If there is a variation from this table, the cow is likely to be older rather than younger than the teeth indicate according to the ages. In fact, some authors say the first pair of permanent teeth appear at two years of age; the second pair at three; the third pair at four; and the fourth pair at five years of age.

210. Examination of the horns. - The horns of cattle are often used in estimating the age. During the first two years the horns grow rapidly, and in this time they make approximately their entire growth. After two years of age, the growth is slow, and each year's addition is marked by a more or less distinct ring. The first ring does not make its appearance until the animal is approximately three years old. The age is estimated, therefore, by adding two to the number of rings present.

\section{JUDGING DAIRY CATTLE}

In the judging of a dairy cow, all points that have any relation to milk production and symmetry of form should be considered. In order that no part escape notice, some system must be followed in judging an animal, and this system can be acquired by the use of the score-card. The methods of using the card and rules of scoring are similar to those suggested in scoring the horse (p. 40).

211. Score-card for dairy cattle. - While each breed of dairy cattle has its own scale of points varying in detail, they are also similar to the following:- 


\section{STUDENT'S SCORE-CARD}

\section{Darry Cattle}

\section{Scale of Points}

\section{General Appearance, 13 per cent}

Form, wedge shape as viewed from front, side and top. Spare as indicated by prominent joints and clean bone and lack of muscular development along ribs and loins

Quality, free from "coarseness throughout; " skin soft, pliable; secretions abundant; hair fine . . . .

Temperament, inherent tendency to dairy performance

Head, 8 per cent

\section{Muzzle, broad}

$\mathrm{Jaw}$, strong, firmly joined

Face, medium length; clean

Forehead, broad between eyes, dishing

Eyes, large, full, mild, bright

Fiars, medium size, fine texture, secretions oily and abundant, yellow color

\section{Forequarters, 9 per cent}

Throat, clean are, smoothly joined to shoulders, free from dewlap

Withers, narrow, sharp

Shoulders, sloping, smooth; brisket light

Fore legs, straight, clean, well set under body

\section{Body, 23 per cent}

Crops, free from fleshiness

Chest, deep, roomy; floor broad

Back, straight, strong; vertebra open

Ribs, long, deep, sprung, wide apart .

Barrel, deep, long, capacious

Loin, broad, strong

\section{Hindquarters, 12 per cent}

Hips, prominent, wide apart

Rump, long, level, not sloping

Pin Bones, wide apart

Tail, neatly sot on, long, tapering

Thighs, spare, not fleshy .

Hind legs, well apart, giving ample room for udder

\section{Mammary Development, 35 per cent}

Udder, large, very flexible, attached high behind, carrying well forward; quarters even, not cut up .

Teats, wide apart, uniformly placed, convenient size Milk veins,-large, tortuous, extending well forward . Milk wells, large

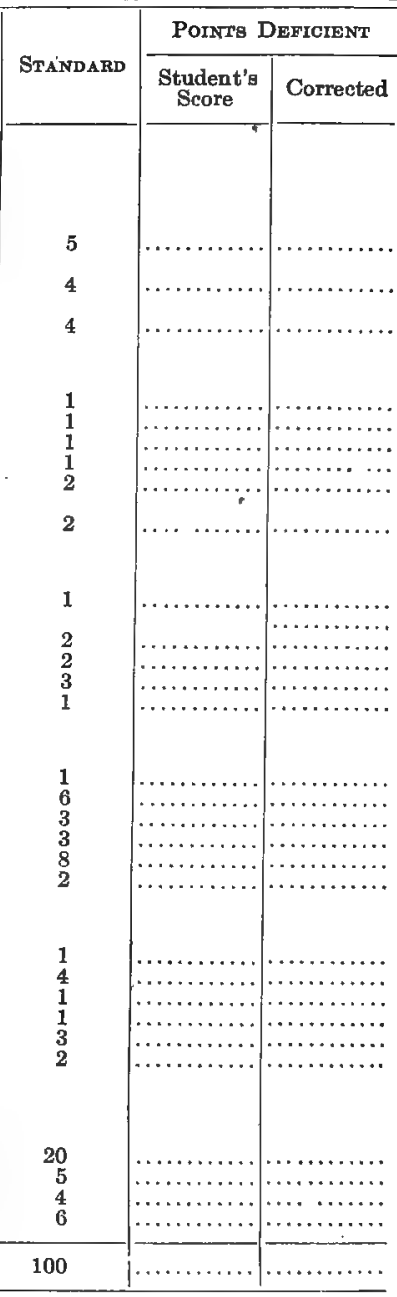


212. Measurements of cattle. - Since the dairy type differs in conformation from the beef type a few exact measurements are recorded to fix the more important differences in mind. Since the form of the thin steer differs from that of the fat steer a few measurements are recorded to illustrate this difference in conformation.

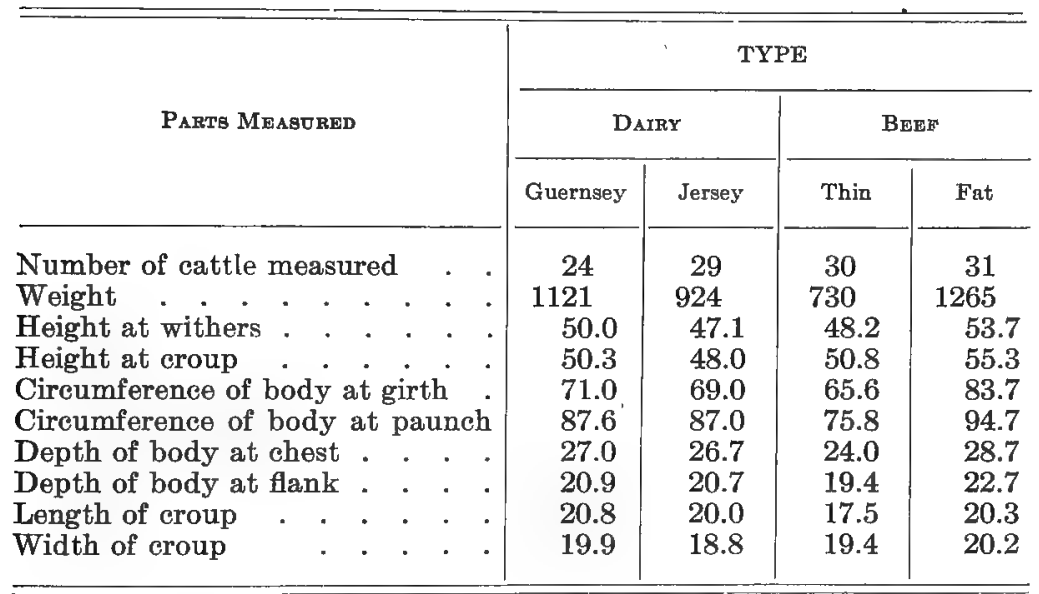

\section{GENERAL CHARACTERISTICS IN DAIRY COWS}

213. Form. - The general form should be considered from two points of view : first, with respect to angularity; second, freedom from beefiness.

The typical form of a dairy cow is that of a triple wedge. Viewed from either side she should show greater depth of body behind than in front. The shoulder should be lower than the hips, and the floor of the chest higher than the bottom of the udder. If a straight edge were laid along the back and allowed to project forward, and a second straight edge placed along the under line touching the bottom of the udder, the abdomen, and the floor of the chest, 
and allowed to project forward, it should meet the one from the back a short distance in front of the animal. Viewed from the rear and top the dairy cow should gradually widen from the chest to the hips. Straight edges placed along either side and projecting forward should meet a short distance in front of the animal.

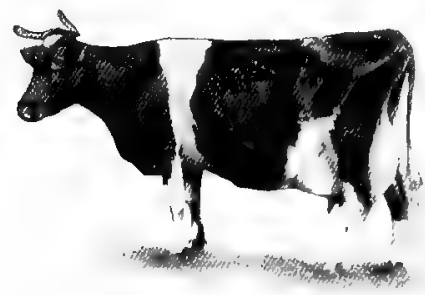

Fig. 59. - Dairy cow of good type. Viewed from the front and top she gradually widens from the withers backward and downward (Fig. 59).

The dairy cow should be spare. If she tends naturally to take on fat, she is worth just so much less as a milk cow. There should be an absence of fleshiness throughout, particularly in the region of the shoulders, the back, the rump, and about the tail-head, places likely first to show fat among animals possessing such atendency.

214. Quality. - The quality is a very important factor in the choice of a dairy cow. It is well determined by the condition of the skin, hair, and bone. The skin should be soft, mellow, oily to the touch, and comparatively thin. Care must be exercised in respect to the thinness of the skin, as a thin, papery skin is usually associated with weakness of constitution. The skin lining the ear, as well as that in the region of the udder, inside the thighs, and at the root of the tail, should be of a golden color, and the secretions abundant. The hair should be soft, silky, and comparatively short. Black hairs will usually be harsher than white hairs, even on the same animal. While many good milking cows are loose in form, possessing an open conformation, yet the bone should be dense and of fine texture. Dairy cows possessed of a tight, heavy skin, coarse, harsh hair, and of a heavy, rough, coarse bone are deficient in quality.

215. Constitution. - Because of the peculiar conditions under which most dairy cows are kept, the constitutional vigor deserves 
much attention. Vigor is estimated by the expression, by the condition of the hair and hide, and by the chest capacity. The expression of the eyes, ears, and head should be mild and lively, and the animal should be on the alert. The chest capacity should be large, particularly across the floor. A good way to note the width of the floor of the chest is to place the hand along the chest between the front legs, as the width between the front legs should be great. Narrowness between the front legs is objectionable for the reason that it indicates lack of constitution.

216. Temperament. - The dairy cow should have a good temperament. Among cattle there are two divisions of temperament: the nervous and lymphatic. In a cow of the former temperament, the nervous organization is strong and well developed, while a cow of lymphatic temperament is sluggish in disposition and inclined to fatten. For the dairy we desire a cow of nervous temperament, one that is sensitive and active, possessing greatest vitality, and that is capable of giving all organs the greatest producing powers.

\section{DETAIL CHARACTERISTICS OF A DAIRY COW}

217. Head. - A dairy cow should have a long, lean, and feminine head. There should be freedom from coarseness and heaviness. The face should be prolonged, lean, and the features distinct. The poll should be prominent and the forehead broad. The eyes should be mild, bright, and full. The nostrils should be large, permitting of the free passage of air. The ear should be of medium size, fine quality, and of an orange color inside. The horn should be rather small and free from coarseness, especially at the base.

218. Neck. - This should be rather long, slim, and fine, carrying the head gracefully. There should be freedom from fullness and heaviness. The windpipe should be rather prominent, especially up near the throat. While the neck should have a neat attachment at the head and shoulders, it should not blend so smoothly as in beef cattle, because of the lack of flesh. 
219. Forequarters. - The shoulders should be prominent, free from beefiness, and rather angular. The withers should be lean, thin, and refined. Both withers and shoulders should be free from meatiness and heaviness. The legs should be straight and short with fine shanks.

220. Body. - The producing powers of the dairy cow depend largely on the depth and volume of the barrel. The chest should be deep, with a large heart girth, and broad, particularly as noted between the fore legs. The ribs should be long and sufficiently arched to provide a capacious body. The abdomen should be large and deep, indicative of capacity, and should be well supported. The back should be lean, backbone rather prominent and strong. In many good dairy cows there is much distance between the spinal processes, and the cow is said to be "open jointed." The loin should be broad, although the space between the last rib and hip may be rather open.

221. Hindquarters. - As a whole, the hindquarters in a dairy cow should be wide, long, and deep. There should be freedom from fullness and meatiness, particularly at the tail-head. In many very good cows there is a slight rise from the hips to the attachment of the tail. The hip bones should be rather sharp, prominent, and wide apart, thus giving ample room for the generative organs. They should not be lower than the spine. The rump should be long and wide, with the thurls and pin-bones high and wide apart. From the points of the hips to the tail-head there should be a marked hollow, due to the absence of flesh. The thigh should be outcurved and thin, as this provides room for the udder. A thick thigh and a full twist are decidedly objectionable in a dairy cow. The legs should be comparatively short.

222. Udder. - Too much stress cannot be placed on the importance of thoroughly examining the udder when choosing a dairy cow. It should be considered from two points of view: the size and form, and the quality.

The udder should be large. In form it should be moderately 
thick, attached high and full behind, extending well down, though not pendulent, and extending far in front. The quarters should be comparatively even, with the teats of convenient size and well placed. 'The length of the udder is important since it gives a long line of absorption. It should be approximately thirty inches from the attachment at the back to where it joins the belly.

More important than the size and form of the udder is its quality. Perhaps the best way to determine this is to see the udder milked out. When empty, the udder should almost lose its form. It should appear to consist of folds of soft, pliable, and loose skin. Those of experience can determine by the touch whether the udder is large because fleshy or large because filled with milk.

While there are many defects of the udder, the most common are small front quarters, with the teats much higher, or close to the hind ones; fleshy udders which reduce but little with milking and yield a small flow; udders entirely deficient in size and often with very unequal quarters. One must be on the alert for small teats, so deficient in size as to be very inconvenient when milking.

223. Milk-veins. - These should be large, tortuous, and branching, as well as long, thus extending well forward and passing into the body through large holes called " milk wells." These veins are considered important as they indicate the amount of blood that passes through the udder. The veins usually lack development in heifers with their first calves.

224. Milk signs. - In the cow as in the bull there are several so-called milk signs that are relied upon more or less in the choice - of a dairy animal. The more important of such signs are an "open" organization, a large "escutcheon," large "thigh ovals," and a long tail.

JUDGING BEEF CATTLE

225. Score-card for beef cattle. - Each breed of beef cattle has its own scale of points, but they are similar to the following :- 


\section{STUDENT'S SCORE-CARD}

\section{Beef Catthe}

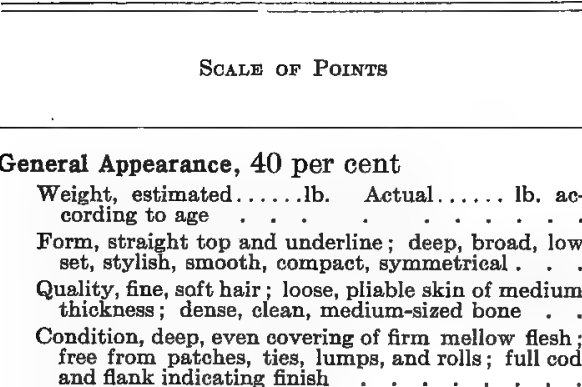

\section{Head and Neck, 7 per cent}

Muzzle, broad ; mouth Iarge; nostrils large and open

Eyes, large, clear, placid

Face, short; jaw strong .

Forehead, broad, full .

Ears, medium size ; fine texture.

Neok, short, thick, blending smoothly with shoulder; throat olean with light dewlap.

\section{Forequarters, 9 per cent}

Shoulder vein, full .

Shoulders, smoothly covered, compact, snug, neat .

Brisket, trim, neat; breast full

Legs, wide apart, straight, short ; arm full ; shank fine

\section{Body, 30 per cent}

Chest, full, deep, wide ; girth large; crops full

Ribs, long, arched, thickly and smoothly fleshed .

Back, broad, straight, thickly and smoothly fleshed.

Loin, thick, broad .

Flank full, even with underline

\section{Hindquarters, 14 per cent}

Hips, smooth

Rump, long, wide, level; tail-head smooth; pinbones wide apart, not prominent

Thighs, deep, full

Twist, deep, plump

Legs, wide apart, straight, short; shanks fine, smooth

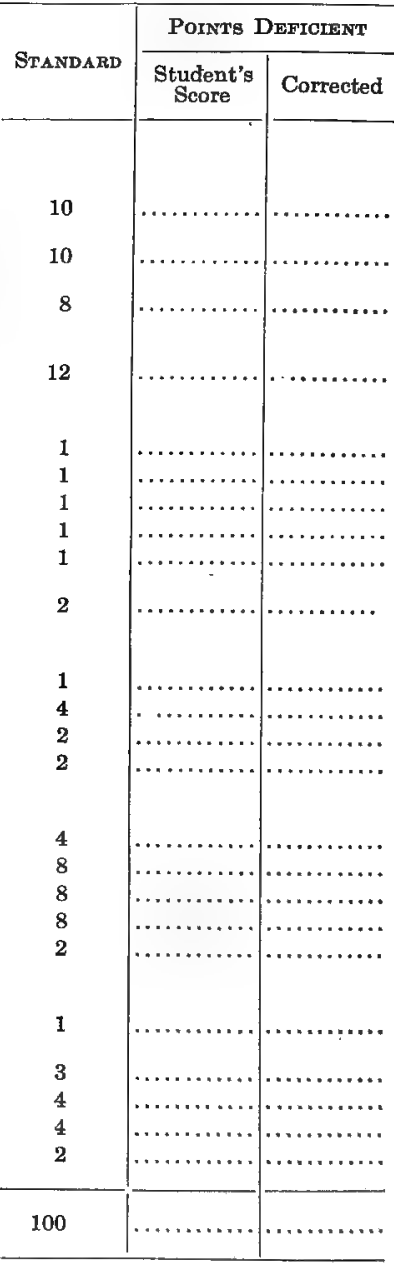




\section{GENERAL CHARACTERISTICS OF BEEF CATTLE}

226. Form of beef cattle. - In form the beefer in general should resemble a brick set on edge. It should fill out a parallelogram. The top and bottom lines should be parallel. The shoulders and chest should be almost as wide as the hips and rump. Feeders should be "blocky," indicating compactness and squareness of form. Those with long bodies are termed "rangy," while those with long legs showing too little depth and fullness of body are termed "leggy," both of which characteristics are objectionable in a feeder. Steers standing high from the ground, light in the flanks, and shallow in the heart girth rarely make good feeders.

227. Quality of beef cattle. - Quality is determined in the same way as in dairy cattle, that is, by a soft, mellow hide, silky hair, and a fine bone. The condition of the skin is thought to be an important indication as to the probable feeding qualities of a steer. If the skin is mellow and elastic to the touch, it indicates good " handling." Animals possessed of such skins usually fatten rapidly, whereas those with heavy, stiff skins often fatten slowly.

The food influences the handling to a marked degree. When the animal is liberally fed, especially on oily, laxative foods, the skin is soft and elastic and the hair usually silky and fine. On the other hand, if the animal is scantily fed, or with improper foods the skin often becomes tightly attached to the body, and it feels dry and paper-like. Cattle possessed of tough, coarse hair ; tight, harsh skin; rough, heavy bones with coarse joints, prominent hips, and rough, open shoulders are objectionable as feeders.

228. Condition of the feeder. - In inspecting a lot of cattle with a view to choosing feeders, it is important to note their condition in respect to thrift and fleshiness. The indications of thrift are a good coat of silky hair; soft, pliable skin ; a clean and mild eye; and an absence of discharge from the nostrils. Thriftiness is of much importance if steers are to make economical and profitable beef-producing animals. 
229. Uniformity among feeders. - Cattle chosen for feeding purposes should be of uniform age, color, type, breeding, condition, and quality. While such uniformity will not add to their ability to take on flesh or to make economical gains, it will add materially to their general appearance when on the market. Such a lot of fat steers will command a much higher price than a similar lot of mixed colors, or of mixed types, or of mixed breeding, or even of mixed ages.

\section{DETAIL CHARACTERISTICS OF BEEF CATTLE}

230. Head. - This is usually considered a good index in the choice of a feeder. It should be broad and short, as such accompanies a low-set, thick, and wide body; whereas a long, slim face is usually associated with a long, slim body. The face and cheeks should be full and deep with a broad, strong lower jaw. The nostrils should be large, indicating that there is abundant lung capacity.

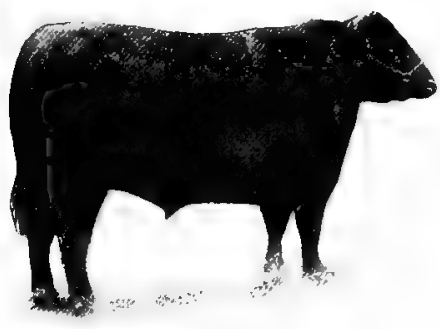

Fig. 60. - Beef steer of good type.

The eyes should be large, prominent, and mild, indicating a quiet temperament. The beefer should be quiet, as a restless, nervous animal usually proves unsatisfactory. The forehead should be somewhat prominent and covered with a mass of wavy hair. The ear should be of medium size, pointed, and covered inside and out with fine silky hair, and should be neatly attached to the head. If horns are present, they should be of fine texture and free from coarseness.

231. Neck. - This should be short and thick, tapering gradually from the shoulders to the head. It should be neatly attached to the hearl and smoothly blended with the shoulder.

232. Forequarters. - The shoulders should be well laid in, 
smoothly covered with flesh, compact, and blending neatly with the body. The crops or withers should be full, thick, and broad. Both shoulders and crops should be covered uniformly with flesh. Rough, angular shoulders, unevenly covered with flesh, are among the most common defects of feeding cattle.

233. Body. - The chest should be wide, deep, and full, with light development of brisket, yet sufficient to fill out the squareness of the body. Narrow-chested animals are, as a rule, poor feeders. The ribs should be well sprung and long, giving an abundance of room for the vital organs, such as lungs and heart, and to provide large digestive capacity. The back should be broad and straight from the shoulder to the tail-head, and covered with thick, even flesh. The loin should be wide. and joining the body to the hindquarters, with little or no departure from a straight line.

234. Hindquarters. - As a whole, the hindquarters in the feeder should be wide, long, and deep. The hips should be wide and in proportion with the other parts, but not prominent. The rump should be long from the hips to the tail-head, with pin-bones and thurls rather high and wide, but not prominent. The rump should be level and free from hollowness. The thighs should be full and fleshed well down to the hock, with twist full.

235. Fat steer.- In judging fat steers, one must keep in mind the demands of the butcher. He desires a steer to dress with a relatively small percentage of offal; with a relatively large percentage of meat in the region of the valuable cuts; and an animal that is in the proper condition to slaughter, that is, neither over nor under fed. Fullness at the base of the tongue and just in front of the point of the shoulder, a full twist, a full, thick flank that stands out and rolls as the animal walks, fullness at the tailhead and along the rump, indicate that degree of fatness essential to the highest quality of beef.

236. Market classes of beef cattle. - On the market, beef cattle are divided into classes according to age, condition, and 
quality. While this classification varies on the different markets, the following will give an idea of the nature of the classification:-

Beef cattle. - This class includes exports, shipping, and dressed beef steers of prime, choice, good, medium, and common grades.

Butcher stock. - This class includes the better grades of heifers, cows, and bulls, and common and inferior steers. Butcher stock is made up largely of cows and heifers. There are 12 grades.

Cutters and canners. - This class includes thin cows and bulls, and inferior steers and heifers. In fact, anything of a low, inferior grade may be classed as cutters and canners.
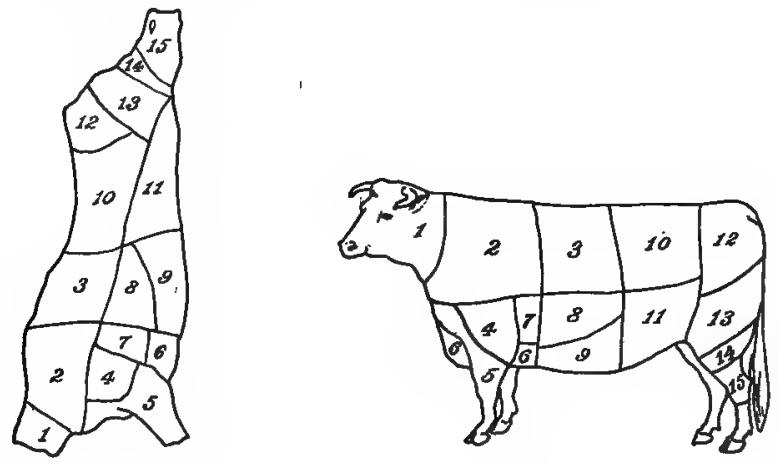

Fig. 61. - Diagrams of cuts of beef.
1. Neck.
2. Chuck.
3. Ribs.
4. Shoulder clod.
5. Fore shank.

6. Brisket.

7. Cross ribs.

8. Plate.

9. Navel.

10. Loin.

11. F'ank.

12. Rump.

13. Round.

14. Second cut round.

15. Hind shank.

Texas and western range cattle. - In reality this is a sub-class of beef cattle; it includes all grades of Texas cattle and branded cattle from the western ranges. Such grades are very similar to the standard grades of beef cattle.

Milkers and springers. - Cows classed as milkers and springers are sold in the market as butcher stock or as cutters and canners. Stockers and feeders. - This class includes calves, yearlings, two- 
year-olds, and older cattle. It may include steers, heifers, or bulls.

Veal calves. - This class includes all grades of veal calves.

237. Cuts of beef. - The methods of cutting beef into parts, and the terms used to designate the different "cuts" as these parts are commonly called, vary in different localities. However, the preceding diagrams will serve to show the parts of the animal from which the cuts are taken. These may serve to aid in dealing with the meat market (Fig. 61).

\section{QUESTIONS}

1. How are farm animals classified in the entry list at fairs and shows?

2. How does a cow's mouth differ from that of a horse?

3. Why should a dairy cow be of triple-wedge shape and spare? Is a dairy cow highest at the withers or at the croup, and why? Why should the tail be long?

4. Contrast the four major dairy breeds in respect to the shape and size of the udder, teats, and milk veins.

5. Why is an open or loose organization of advantage to the dairy cow? What are the external indications of such an organization? Why is a mild temperament desired in the dairy cow?

6. Why should the beef animal be of parallelogramic form and fleshy? Why should the steer be thick-fleshed over the back, loin, and rump?

7. Contrast the four major beef breeds in form. Which is the most desirable, and why?

8. Why should a drove of fat steers be uniform in age, weight, type, condition, and quality when shipped to market?

9. Why is the heavy developed brisket looked upon with less favor than formerly, particularly in Hereford cattle?

10. In judging feeding cattle, what disposition should be made of the condition of flesh? Assuming that other characters are equal, should thin cattle be given the preference, and why? 


\section{CHAPTER VIII}

\section{FEEDING DAIRY CATTLE}

TuE feeding of the dairy cow differs essentially from the feeding of the horse. This is due, in part, to the increased digestive capacity and to the nature of the resulting product. The object is to feed the cow so as to secure the maximum milk production.

Wolff-Lehman Standard showing the Amount of Food required Per 1000 Potnds Live Weight for the Growing and the Matdre Cow yielding Varying Quantities of Milk

\begin{tabular}{|c|c|c|c|c|c|c|}
\hline \multirow{2}{*}{\multicolumn{2}{|c|}{ Condition of Animal }} & \multirow{2}{*}{$\underset{\text { MATTER }}{\text { DRY- }}$} & \multicolumn{3}{|c|}{ Digestible Nuttrimato } & \multirow{2}{*}{$\begin{array}{l}\text { NTTRitive- } \\
\text { Ratio }\end{array}$} \\
\hline & & & Protein & $\begin{array}{l}\text { Carbo- } \\
\text { hydrates }\end{array}$ & Fat & \\
\hline \multicolumn{2}{|c|}{ Growing Cattle, Dairy Breed } & & & & & \\
\hline Age, Mo. & Weight & & & & & \\
\hline $2-3$ & 150 & 23 & 4.0 & 13.0 & 2.0 & $1: 4.5$ \\
\hline $3-6$ & 300 & 24 & 3.0 & 12.8 & 1.0 & $1: 5.1$ \\
\hline $6-12$ & 500 & 27 & 2.0 & 12.5 & 0.5 & $1: 6.8$ \\
\hline $12-18$ & 700 & 26 & 1.8 & 12.5 & 0.4 & $1: 7.5$ \\
\hline $18-24$ & 900 & 26 & 1.5 & 12.0 & 0.3 & $1: 8.5$ \\
\hline \multicolumn{2}{|c|}{$\begin{array}{c}\text { Milking Cows, when yielding } \\
\text { Daily }\end{array}$} & & & & & \\
\hline \multirow{4}{*}{\multicolumn{2}{|c|}{$\begin{array}{l}11.0 \mathrm{lb} \text {. of milk } \\
16.6 \mathrm{lb} \text {. of milk } \\
22.0 \mathrm{lb} \text {. of milk } \\
27.5 \mathrm{lb} \text {. of milk }\end{array}$}} & 25 & 1.6 & 10.0 & 0.3 & $1: 6.7$ \\
\hline & & 27 & 2.0 & 11.0 & 0.4 & $1: 6.0$ \\
\hline & & 29 & 2.5 & 13.0 & 0.5 & $1: 5.7$ \\
\hline & & 32 & 3.3 & 13.0 & 0.8 & $1: 4.5$ \\
\hline
\end{tabular}


238. Food requirements for milk. - The quantity of food required by a milking cow depends on many factors, the chief of which are the kind of food, the quantity of milk yielded, the quality of the milk, as well as the individuality, the weight, and the age of the animal.

Armsby's Standard showing the Digestible Protein and Energy REQUIRED FOR A 1000-Potnd CoW YIELdING VARYING QUANTITIES OF Average Milk

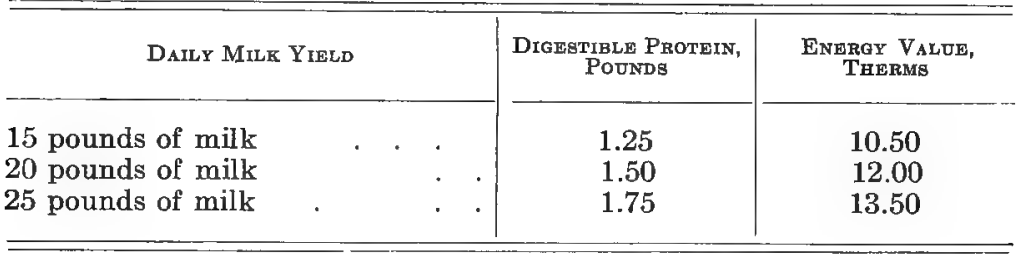

Haecker's Standard showing Food of Maintenance per 100 Pounds Live Weight and Nutrients required for the Production of 1 Pound of Milk testiña a given per cent of Butter-Fat ${ }^{1}$

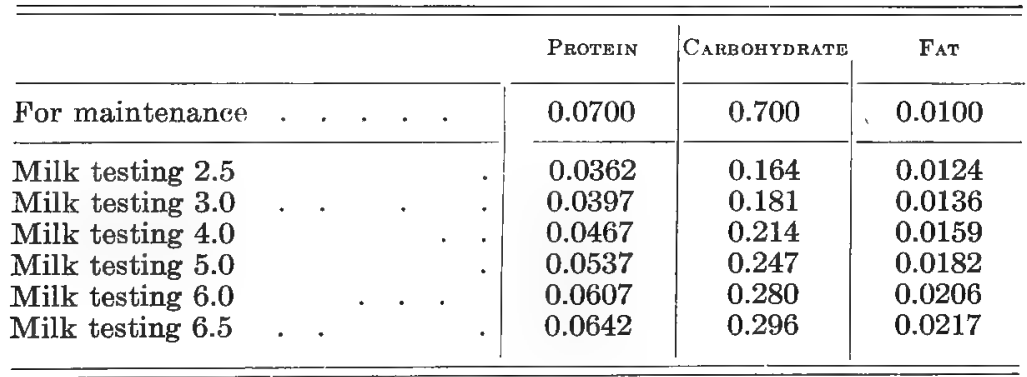

${ }^{1}$ Minnesota Agricultural Experiment Station Bulletin No. 79.

EFFECT OF FOOD ON THE COMPOSITION OF THE MILK

It is asserted that the food may affect the milk in many ways, the two most important being its composition and its flavor. 
There are three ways in which the composition might be affected: first, by changing the proportion of water and total solid matter; second, by changing the proportion of fat, sugar, and proteids; and third, by changing the constituents or consistency of the fat.

239. Effect of food on total solids. - In the great majority of cases the conclusion of experiments is that no consistent relation seems to exist between the quantity or character of the food and the composition of the milk. In a few cases a temporary change

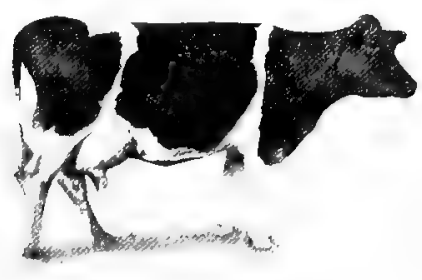

FIG. 62. - Holstein-Friesian cow. occurred in the milk immediately after changing the food, but in most cases the milk soon returned to its normal composition. While in a very small number of experiments the milk appeared to undergo slight permanent change, yet one is forced to the conclusion that the quality of the milk cannot be changed at will by the feed. The treatment of the cattle has a greater influence upon the character of the milk than does the food consumed.

240. Effect of food on the percentage of fat. - The idea prevails that it is possible to feed fat into milk. After a painstaking perusal of the expcrimental work, one is forced to conclude that it is not possible materially and permanently to increase or diminish the percentage of fat by changes in the amount and character of the food, providing, of course, that the animals receive sufficient nutrition in all cases. A cow that has been insufficiently fed and has never had a chance to develop, may be fed such an abundance of rich milk-producing food as slightly and permanently to increase the percentage of fat in her milk; but beyond this we probably cannot go.

241. Food and flavor of milk. - It is definitely known that certain foods, especially if fed in large quantities, impart bad odors to the milk. Chief among the foods producing such deleterious effects 
are cabbage, turnips, onions, silage, wild leeks, and the like. It is held that such odors may be imparted to the milk in two ways: first, by transference through the animal, and second, by absorption from the air of the stable.

242. Order of supplying food. - Because of the supposed ill effect of some foods in giving odors to the milk, the order of supplying certain of these foods assumes much importance. In the case of cabbage, turnips, and the like, it is perhaps best that they be fed after milking. Hay, which is likely to contain more or less dust, is best fed after milking also, and in either of these cases grain would necessarily be fed first. Perhaps the ideal way is to feed the grain and succulent food together, sprinkling the grain over the succulent food, and then when these are both cleaned up, to feed the hay. A good order for the day's work is as follows: in the morning, milk first, then feed grain, then silage, clean stable, water, feed hay, groom the animals, then, on pleasant days, turn them out for an hour or so. In the afternoon, water, clean stables, feed grain, milk, feed silage, arrange bedding, and lastly feed some long hay. Sufficient attention is not usually given to the day's program, in the dairy business.

243. Effect of food on quantity of milk. - Occasionally the statement that we cannot increase the percentage of fat in milk by feeding is taken to mean that we cannot increase the total fat yield. This, of course, is not true. We can very materially increase the total yield of fat by increasing the total flow of milk by liberal feeding. This is demonstrated on every hand. On the farms where no succulent food is fed during the winter, and very little grain, it is well known that the cows will give a much larger flow when turned to pasture in the spring. On the average the percentage of fat will remain the same.

244. Watering the milking cow. - The milch cow requires a liberal supply of water. She not only has the demands of her body. to meet, but must supply water for the milk as well. When we recall that cows have yielded over one hundred and thirty-four 
pounds of milk in a single day, we can see the urgent need of a large supply of water. It has been fairly well proved that cattle provided with water constantly give a slightly larger yield than those watered twice daily, though the difference is not marked. This observation has led to the placing of small troughs or vessels in the stable immediately in front of the animals.

There are two factors that must not be lost sight of in watering the milking cow: regularity and temperature of water in winter. Whatever method of watering is employed, the animal should be watered regularly and uniformly. When we recall the large amount of water necessary to meet the needs of the high-producing cow, it becomes apparent that she should not be compelled to drink icecold water. It requires much food to heat this water to the body temperature, and the animal.will not drink as much as it needs. To take the chill off drinking water in winter is now an accepted practice with progressive dairymen.

\section{FEEDING THE MILKING COW}

Feeding dairy cattle naturally divides itself into two parts: the summer period when the cows are at pasture, and the winter period when they are stabled and fed their entire ration.

245. Summer feeding of dairy cattle. - Pasture is one of the essentials of successful dairy farming. The favorable influence of early spring pasture on the secretion of milk is well known. The flow is materially increased, as is the total yield of fat, though the percentage of fat is perhaps not materially altered.

As a rule, in the early part of the pasture season, the cows will obtain sufficient food from the pastures alone, but later in the season it will often be necessary to supplement the pasture. This may be done by soiling, - cutting the forage and feeding it to the cattle green, - with silage, or with grain.

Experiments seem to indicate that the feeding of grain to cows on pasture is profitable, especially when there is scarcity of pas- 
turage, although they will consume but little while the pasture is abundant and nutritious. It would seem wise, however, in case the animals eat it, to provide a few pounds of wheat bran, or bran and oats mixed, particularly in the case of heavy milkers, as this will insure maximum production.

246. Soiling. - This consists of cutting green crops and feeding them fresh. Successful and economical soiling means furnishing to the milking cow a supply of green forage during the growing

Example of Rotation of Solling Crops, showing Kind of Forage, Seed to Acre, Time of Seeding, Approximate Areas, and Time of Cutting for a Herd of 10 Cows, allowing 60 Pounds of Forage a Cow Daily or 600 Pounds a Day in Alu.

ILIIINOIS - FRASER'S SOILING SYSTEM AS BASIS

5 Months - May 15 to October 15-10 Cows-60 Pounds pisr Cow Darly

\begin{tabular}{|c|c|c|c|c|c|}
\hline \multicolumn{2}{|c|}{ Kind of Crop } & Seed per Acre & $\begin{array}{l}\text { Time of } \\
\text { Seeding }\end{array}$ & Area & Time of Cutting \\
\hline \multirow{3}{*}{\multicolumn{2}{|c|}{$\begin{array}{l}\text { Rye . } \\
\text { Alfalfa or wheat } \\
\text { Red clover . . . }\end{array}$}} & $2 \mathrm{bu}$. & Fall & 1 acre & May 15-May 31 \\
\hline & & $2 \mathrm{bu}$. & Fall & $\frac{1}{2}$ acre & June 1-June 10 \\
\hline & & $20 \mathrm{lb}$. & Spring & $\frac{1}{2}$ acr $\theta$ & June 11 -June 20 \\
\hline Mixed & $\begin{array}{l}\text { Timothy } \\
\text { Red top }\end{array}$ & $10 \mathrm{lb}$. & Spring & 1 acre & June 21-July 1 \\
\hline Mixed & Oats & $\begin{array}{l}2 \mathrm{bu} . \\
1 \mathrm{bu} .\end{array}$ & Spring & $\frac{1}{2}$ acre & July 1-July 5 \\
\hline Mixed & $\begin{array}{lll}\text { Oats } & \cdot & . \\
\text { Peas } & \cdot & \cdot\end{array}$ & $\begin{array}{l}1 \frac{1}{2} \text { bu. } \\
1 \frac{1}{2} \text { bu. Can- } \\
\text { ada peas }\end{array}$ & Spring & $\frac{1}{2}$ acre & July 6-July 10 \\
\hline $\begin{array}{l}\text { Corn, e } \\
\quad \text { ting : }\end{array}$ & $\begin{array}{l}\text { arly ; 2d cut- } \\
\text { lfalfa }\end{array}$ & $10-20 \mathrm{lb}$. & Spring & $\frac{1}{2}$ acre & July $11-J u l y ~ 31$ \\
\hline $\begin{array}{l}\text { Corn, } \\
\text { cuttir } \\
\text { grass }\end{array}$ & $\begin{array}{l}\text { medium; } 2 \mathrm{~d} \\
\mathrm{ag} \text {, clover and } \\
\text { as }\end{array}$ & $10-20 \mathrm{lb}$. & Spring & $\frac{1}{2}$ acre & Aug. 1-Aug. 31 \\
\hline $\begin{array}{l}\text { Corn, } 1 \\
\text { ting a }\end{array}$ & $\begin{array}{l}\text { ate; } 3 d \text { cut- } \\
\text { lfalfa }\end{array}$ & 10-20 lb. & $\begin{array}{l}\text { Late } \\
\text { spring }\end{array}$ & $\frac{1}{3}$ acre & Sept 1-Sept. 30 \\
\hline Rape & . . . & $10 \mathrm{lb}$. & June & $\frac{1}{2}$ acre & Oct. 1-Oct. 15 \\
\hline
\end{tabular}


season. It means that crops and areas must be so arranged that one green crop will succeed another diring the entire season. There are many advantages of soiling, such as increased food production from a given area, providing three times that of pasturage; less waste, as the cattle are not constantly tramping and lying on the forage; greater variety of food, as the succession of crops provides many changes; increased milk and butter production when prices are high, as in the fall; less discomfort of animals, as they are fed in the cool stables; and less fencing required. One great objection is the increased labor; such as preparing the soil for the crops, seeding every few days, cutting the crop of green material and hauling to stables, - the food being green and heavy, - and the extra labor of carrying for the cattle in the stable.

247. Winter feeding of dairy cattle. - Winter feeding is the most expensive, and the profit to be derived will depend, in a large part, upon the economy of the winter ration. This does not mean that the cow should be fed sparingly; on the other hand, the good dairy cow should be fed abundantly with a variety of nutritious feeds. A good dairy cow should make economical use of seven to ten pounds of grain per day, and fifteen to twenty pounds of dry forage, or better still, thirty to forty pounds of succulent food," and five to ten pounds of dry forage or hay, the exact amounts to be varied to meet conditions.

248. Concentrated feeds. - The more common grains fed to dairy cattle are the cereals - corn, oats, wheat, barley, and rye - and the mill refuse, of which there is an almost endless variety upon the market. The amount of grain that can be fed with profit to a dairy cow will depend on the price of the food, the yield of the cow, and the price obtained for her products. Some have suggested the feeding of as many pounds of grain per day as the cow produces pounds of butter-fat per week. In determining the amount and kind of grain, it is necessary to take into account the forage that is to go with it. For example, in many dairies 
it is found that bran may be replaced ton for ton by carefully cured alfalfa hay, or by five tons of pea-vine silage when not too succulent.

249. Dry forage. - The more common dry forage crops fed to dairy cattle are clover, alfalfa, or mixed hays and corn stalks. Occasionally pure timothy hay is fed, though this is not to be recommended, particularly if cut late. Straws of the various small grains are also used, but they are even more worthless as a dairy cow feed than is timothy hay. Hay cut early is more valuable ton for ton, though the yield obtained per acre will not be so great. The exact amount of dry forage that should be fed cannot be stated, as it will depend on the amount of grain and whether or

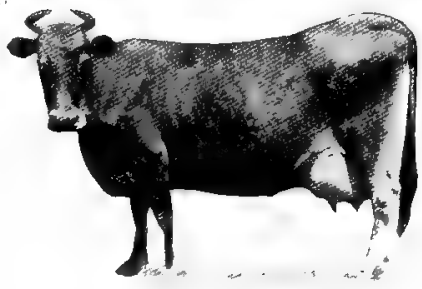

FIG. 63. - Jersey cow. not silage is being used. Let the rule be to feed all the hay the animal will eat with relish.

250. Succulent feeds. - Some kind of succulent food should be fed the dairy cow during her entire lactation period. The common succulent foods used in feeding dairy cattle are silage, roots, or tubers. Silage is preferable, but if the herd is not large enough to warrant the construction of a silo, roots make a good substitute. The amount of succulence it is profitable to feed will depend much on the attendant conditions. Thirty to forty pounds serve most conditions.

251. Silage. - Green food preserved in the silo is coming to be a very common succulence for the dairy cow. While there are many green plants, such as alfalfa, clover, cowpea vines, and the like, preserved in this way, corn is the most important silage crop. No other plant will furnish nearly so much silage per acre as corn. All silage contains a very high percentage of water, and for this reason is bulky. As a succulent food for milking cows, 
good corn silage is hard to improve on. It is very palatable, readily digestible, and to stimulate the flow of milk it is second only to grass.

252. Roots and tubers. - When the construction of a silo is not convenient, one can procure a good succulent food by raising roots and tubers. While there are may roots and tubers, such as potatoes, beets, flat turnips, ruta-bagas, and the like, that may be grown, mangels are the most important root-crop as a succulent food for cattle. These roots all possess a very high percentage of water, even more than silage. As a succulent food for the milking cow they are excellent, being palatable, almost entirely digestible, and stimulating the flow of milk.

\section{THE CALF}

253. Feeding the calf. - It is especially important for the calf that it get the first or colostrum milk of the dam. This milk is rich in mineral matter and ash, is a powerful laxative, and is effective in removing the fecal matter from the alimentary canal and in addition it serves as a tonic. The calf should be allowed to suck the dam a few times; some recommend until the milk is fit for human consumption, usually about the eighth or ninth milking, while others recommend separating them on the second day, provided the calf is strong and the cow's udder in good shape, as the cow is more easily reconciled to the separation, and the calf can then be more easily taught to drink than if it has sucked the cow for some time.

254. Danger of overfeeding calf. - When feeding by hand, there is much danger of overfeeding and gorging the calf's stomach, thereby causing digestive disorder, scours, and death. When permitted to run with the cow, the calf sucks many times daily, - ten to twenty, - taking only a little milk at a time. When removed from the dam and left from eight to twelve hours, it gets exceedingly hungry, and when offered milk in large quantities, 
will gorge itself and bring digestive disorders that may prove fatal.

255. Calf on whole milk. - For the first few weeks, the calf should be given the milk from its own dam, since changing to another cow is likely to throw the digestive system out of balance, and result in digestive disorders such as scours, colic, and the like. The milk should be fed from a clean pail, directly after milking, while still at the body temperature. The amount of milk fed should be carefully regulated. A good plan with the average calf is to give four pounds (two quarts) of whole milk three times daily.

256. Calf on skim-milk. - Whole milk, being rather expensive, should not be fed longer than is necessary. The change from whole milk to skim-milk should begin when the calf is four weeks of age. This change should be made gradually, so that the calf may adjust itself to the new feed without trouble. Increase the skimmilk one pound each day and decrease the whole milk by the same amount.

When two or three weeks old, the calf should be taught to eat a little grain. This is best accomplished by placing a handful in the pail immediately after the calf has finished drinking the milk. It is not a good practice to put the grain in the milk, as the calf will swallow it with the milk and not learn to masticate it properly. After the calf has learned to eat the grain, a box should be provided in which to feed the grain. The grain should be fresh and clean. At six weeks of age, the calf should be eating one pound daily of the following mixture: 3 parts corn meal, 3 parts ground oats, 3 parts wheat bran, and 1 part linseed meal.

257. Removing horns from young calves. - When dairy cattle are desired without horns, the removal is very easily accomplished while the calf is very young. As soon as the horn can be located by examining the head with the hand, clip the hair away from the budding horn. Wrap a stick of caustic potash in paper to protect the hand, dip the end of the stick in water, and rub this upon the tip of the horn until the skin or scurf begins to loosen up 
and gets red, taking care all the time that none of the potash comes in contact with the skin surrounding the horn. In a few days the place will scale over. One application is sufficient.

258. Sample rations for the dairy cow. - The following rations are collected from various sources, and furnish a guide in determining the kind and amount of feed that should be allowed a dairy cow. They apply to a 1000-pound dairy cow yielding 22 pounds of average milk:-

\begin{tabular}{|c|c|c|c|}
\hline \multirow{2}{*}{ No. } & \multicolumn{2}{|c|}{ RATION } & \multirow{2}{*}{ RATIO } \\
\hline & Grain & Forage & \\
\hline 1 & $\begin{array}{l}3 \mathrm{lb} . \text { corn meal } \\
3 \mathrm{lb} \text { oats } \\
2 \mathrm{lb} \text {. linseed meal } \\
\end{array}$ & $20 \mathrm{lb}$. hay & $1: 6.7$ \\
\hline 2 & $\begin{array}{l}3 \mathrm{lb} \text {. oats } \\
3 \mathrm{lb} \text {. wheat bran } \\
2 \mathrm{lb} \text {. gluten feed }\end{array}$ & $\begin{array}{l}50 \mathrm{lb} \text {. roots } \\
\text { corn stalks ad lib. }\end{array}$ & $1: 6.9$ \\
\hline 3 & $\begin{array}{l}3 \text { lb. middlings } \\
3 \text { lb. dry brewers' grains } \\
2 \text { lb. linseed meal } \\
\end{array}$ & $\begin{array}{l}40 \text { lb. corn silage } \\
\text { corn stalks ad lib. }\end{array}$ & $1: 7.3$ \\
\hline 4 & $\begin{array}{l}2 \text { lb. oats } \\
4 \text { lb. wheat bran } \\
2 \text { lb. gluten meal } \\
\end{array}$ & $\begin{array}{l}40 \text { lb. corn silage } \\
\text { hay ad lib }\end{array}$ & $1: 6.8$ \\
\hline 5 & $\begin{array}{l}3 \mathrm{lb} . \text { oats } \\
2 \mathrm{lb} \text {. wheat bran } \\
1 \mathrm{lb} \text {. linseed meal } \\
1 \mathrm{lb} \text {. cotton-seed meal }\end{array}$ & $\begin{array}{l}50 \text { lb. corn silage } \\
\text { hay ad lib. }\end{array}$ & $1: 6.6$ \\
\hline 6 & $\begin{array}{l}2 \text { lb. oats } \\
2 \mathrm{lb} \text {. wheat bran } \\
2 \mathrm{lb} \text {. corn } \\
\end{array}$ & $\begin{array}{l}30 \text { lb. corn silage } \\
\text { clover hay.ad lib. }\end{array}$ & $1: 7.4$ \\
\hline 7 & $\begin{array}{l}4 \mathrm{lb} \text {. wheat bran } \\
2 \mathrm{lb} \text {. corn meal } \\
\end{array}$ & $\begin{array}{l}30 \text { lb. alfalfa silage } \\
\text { clover hay ad lib. }\end{array}$ & $1: 5.0$ \\
\hline 8 & $\begin{array}{l}4 \mathrm{lb} \text {. oats } \\
2 \mathrm{lb} \text {. corn meal } \\
\end{array}$ & $20 \mathrm{lb}$. alfalfa hay & $1: 4.4$ \\
\hline 9 & $\begin{array}{l}4 \mathrm{lb} . \text { wheat bran } \\
2 \mathrm{lb} \text {. cotton-seed meal }\end{array}$ & $\begin{array}{l}30 \text { lb. corn silage } \\
\text { cotton-seed hulls ad lib. }\end{array}$ & $1: 7.8$ \\
\hline 10 & 6 lb. wheat bran & $\begin{array}{l}40 \text { lb. corn silage } \\
\text { cowpea hay ad lib. }\end{array}$ & $1: 5.9$ \\
\hline
\end{tabular}




\section{Grain Mixture for Calf Ration}

3 parts corn meal

3 parts ground oats

3 parts wheat bran

1 part linseed meal

\begin{tabular}{|c|c|c|c|}
\hline AGE, Mo. & Grain MixtuRe LB. & SUMmer & WINTER \\
\hline $\begin{array}{r}6 \\
12 \\
18\end{array}$ & $\begin{array}{l}2 \\
4 \\
6\end{array}$ & $\begin{array}{l}\text { pasture } \\
\text { pasture } \\
\text { pasture }\end{array}$ & $\begin{array}{l}\text { clover hay } \\
\text { clover hay } \\
\text { clover hay }\end{array}$ \\
\hline
\end{tabular}

\section{QUESTIONS}

1. Which standard calls for the most protein, Wolff-Lehman, Armsby, or Haecker? Which calls for the most carbohydrates? Which standard is the most accurate for the cow yielding milk containing a high percentage of fat?

2. Does the food fed affect the percentage of fat? The percentage of total solids? The color of the fat? The churning properties of the milk? Or, the total yield of milk?

3. Name six foods that affect the flavor of milk. When should such foods be fed? Why should hay not be fed immediately before milking?

4. How much protein would there be in the milk of a cow yielding 30 pounds per day? What factors would influence this? What other needs would the cow have for protein? Where must this protein come from?

5. Why does the heavy yielding milk cow need large amounts of water? In how many ways may this be supplied? What food calls for a heavy consumption of water?

6. Why is succulent food so essential to the high yielding milk cow? In how many ways may this succulence be supplied? Which is the more digestible? Which promotes milk yield more efficiently?

7. How many acres of soiling crops would be required for a herd of twenty cows in your vicinity? Arrange a soiling system that will fill your conditions. Since the soiling system is so efficient, why is it not in more general use with dairy farmers?

8. Why are cows on test for advanced registry records fed and milked 
four times daily? Would better results be obtained from feeding and milking six times per day? Why?

9. Why is a fresh cow's milk unfit for human consumption? How does this first milk differ from average milk? Why is it so essential for the calf? Why are Jersey calves thought to be more difficult to raise than Shorthorn calves? Why are milk substitutes of questionable value in calf breeding?

10. Name the foods that are commonly fed dairy cattle in your vicinity. Find out exactly what some persons are feeding and calculate the dry-matter, nutritive ratio, and energy value. Compare with the three standards. How can such a ration be improved? 


\section{CHAPTER IX}

\section{CARE AND MANAGEMENT OF DAIRY CATTLE}

THE production of clean milk calls for exacting care of the dairy cow. This is so important in milk production that milk is classified according to the care given the herd.

\section{SANITARY MILK}

By sanitary milk is meant a clean, wholesome product produced under sanitary conditions. The principal factors to be considered in its production are the cow, the stable, the milk house, the milking, and the cooling and storing of the milk.

259. The cow. - In the production of clean milk extra care must be given the cows. They must be curried daily to remove the loose hair and dirt. The udder and rear parts of the cow should be clipped, thus removing the long dirt-catching hair and rendering the parts much more easily cleaned. The udder should be wiped with a damp cloth just before milking. Care should be taken to feed clean, nutritious foods and such as will not contribute an undesirable flavor to the milk. The drinking water for the cows should be clean, fresh, and the tanks protected from possible contamination.

260. The stables. - If one is to produce sanitary milk, the stable must be kept clean. This applies to dust, cobwebs, and the like, as well as to the manure and litter. Much light and good ventilation are essential. The floors should be of cement. The gutters and litter should be cleaned out twice daily, and the material hauled to the field, or placed in a protected water-tight pit outside the barnyard, of sufficient distance to prevent odors 
from reaching the stable. The covered shed, if one is used, and stable-yard must be clean and well drained.

The cows should be bedded liberally, particularly if the floor is of cement. The bedding should not be permitted to become foul, as this not only lessens the comfort of the cattle, but makes it more difficult to keep them clean, and it promotes disease. Old straw makes the best bedding material, but, when high in price, it may be replaced by many other materials, such as shavings from the planing mill, - which make a clean and sweet bedding, by tan-bark, by leaves, and the like.

261. Milk-house. - Preferably the milk-house should be separate from the barn and located at a safe distance from all sources of contamination, yet convenient to the cows. It should be divided into two rooms, one for heating water and cleaning the utensils, and the other for weighing, sampling, cooling, and storing the milk. The milk-house should be well lighted and well ventilated, the floors should be constructed of cement, and the walls and ceiling made tight and smooth in order that they may be easily cleaned. The windows and doors should be screened to exclude the flies.

262. Milk utensils. - The milk-cooler, the pails, cans, strainers, and the like, should be first soaked in warm water, then washed in boiling water containing some cleaning material, rinsed in clean, hot water, and then sterilized with steam. After this thorough cleaning, they should be inverted in the pure air, preferably in the sunlight.

263. Milking. - The milker should be cleanly in his habits, and should milk with dry hands. A small-topped milk pail should be used to exclude the dirt as far as possible. As soon as each cow is milked, the milk should be taken directly to the milk-house and there weighed, a record made of the weight, a sample taken to test for the fat, then it should be strained, and immediately run over a cooler, reducing its temperature as low as possible (Fig. 64). The milk should then be kept at as low a temperature as possible. 


\section{Care and Management of Dairy Caltle}

A good plan is to set the cans in a vat containing ice, and cover the vat with a lid. If this is not convenient, set the cans in running well or spring water. During transportation, cover the cans

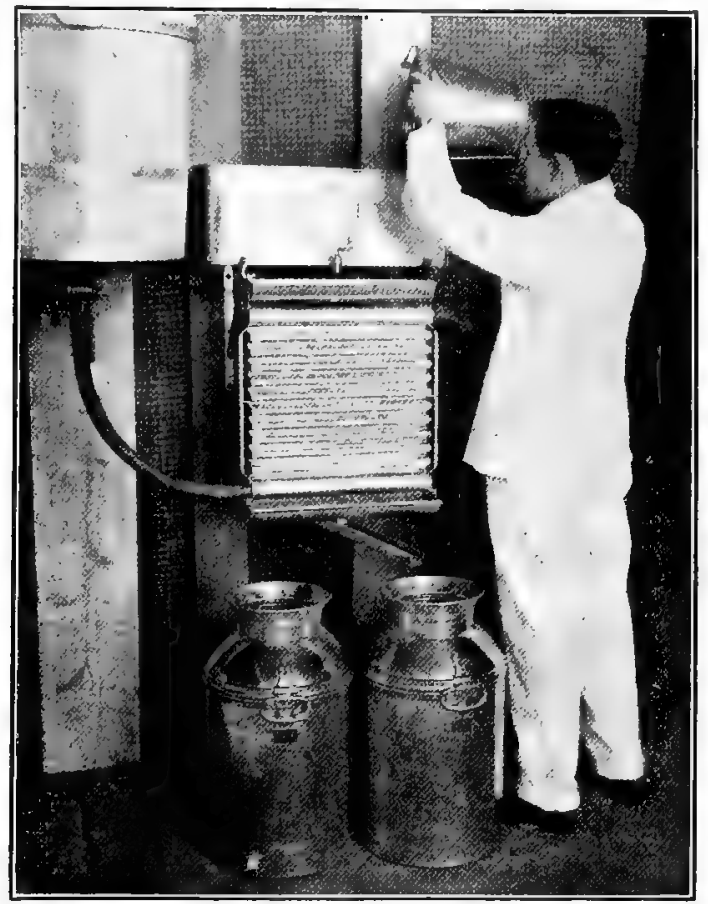

Frg. 64. - Cooling milk. Milk cooled immediately after drawing will keep sweet much longer than otherwise.

with a blanket. In summer the blanket should be wet, in winter dry.

264. Milking machines. - Perhaps the most important factor retarding the development of dairying is the difficulty of securing milkers who can be depended on to do their work satisfactorily. In general the size of the dairy is restricted to the number of cows 
that the owner can attend to at such times as his help fails him. If the question of milking the cows, without being so dependent on hired help, could be satisfactorily solved, the number of animals kept on many dairy farms would increase up to the limit of the acreage to feed the animals.

There are now machines on the market that will milk cows. There are, however, many questions relative to their use that cannot be answered with much positiveness; chief of which are the efficiency with which they milk, the effect on the cow, the effect on the milk, and their economy.

It is well known that one milker may secure more milk than others from the same cow, and that after a cow has become accustomed to a milker, a change results in a decrease in the production. It may be expected, therefore, that the immediate effect of changing from hand to machine milking will be attended by the same results. The figures available go to show that, taking the year through, the average cow yields approximately as much milk to the machine method as to the hand method of milking, particularly if she is stripped by hand after the machine milking.

265. Milk-records. - Record of performance among dairy cattle constitutes the only method of determining their value. Without such records, we would not be able to choöse the very high- or the very low-producing, or the profitable from the unprofitable animals. At present, many dairy herds possess cattle producing at a loss - not yielding sufficient milk to pay for the food consumed - yet in the absence of accurate records the fact goes unobserved and the owner does not know the profitable from the unprofitable animals. No person is able to go into a herd of ten cows and pick out all the best by examination. Records are absolutely necessary to determine profit and loss.

266. Method of keeping records. - Records are more easily kept than is generally supposed. The time and cost of keeping a record of the amount of milk and butter-fat yielded by each cow 
is quite insignificant, especially when compared with the value of such records. The materials needed are a pair of scales, a hand Babcock tester with outfit, and a blank milk-sheet.

Once each month the milk from each cow should be tested for the percentage of butter-fat. To do this, one should take a sample of the milk for two successive days. The sample need not be large, but the quantity should be in proportion to the flow. Onehalf pint saved from the two days' milking is sufficient. This should be placed in a jar and covered to prevent evaporation. In warm weather it is necessary to put some sort of preservative into the milk, otherwise it will sour, and in that case cannot be tested. For each cow there should be a jar with her name pasted upon it, thus avoiding any possibility of getting the samples mixed. By placing the percentage of fat thus obtained on the recordsheet, one has a complete record of each animal each month. By multiplying the total milk by the per cent of fat, one gets the total amount of fat. This completes the record for the month.

267. Value of milk-records. - The highest degree of success cannot be attained unless we know the production of each individual cow. In addition, such records serve a much larger usefulness because they enable us to mate the animals more judiciously. Not only are the low-producers unprofitable in themselves, but in the absence of a record of their production, they are propagated, and their offspring in turn prove unprofitable.

\section{TESTING MILK FOR BUTTER-FAT}

The materials needed in testing milk for butter-fat are a centrifugal tester, test-bottles, a 17.6 c.c. (cubic centimeter) pipette to measure the milk, a 17.5 c.c. acid measure, and sulfuric acid, all of which can be purchased for about five dollars from any dairy supply company (Fig. 65). They may be ordered of a hardware dealer. Sulfuric acid is sold at any drug store. 
268. Sampling the milk. - The milk to be tested should be thoroughly mixed just before sampling. To do this, pour back and forth between two vessels several times. With the pipette, measure out 17.6 c.c. of milk, and place in the test-bottle. To do this, suck the milk up above the 17.6 c.c. mark. Quickly place the index finger over the upper end of the pipette, then by releasing the pressure allow the milk to run down to the 17.6 c.c. mark. Place the point of the pipette into the test-bottle neck, holding both pipette and bottle at an angle, then remove the finger to allow the milk to flow into the bottle. To be sure that every drop is out of the pipette blow through it into the test-bottle. The sampling should be done in duplicate to make sure of the results.

269. Using the acid. - Much care should be exercised not to spill the sulfuric acid on the hands, clothing, or floor. Should any be accidentally spilled, pour on plenty of water, than add a little lime or baking soda. Always keep water and lime at hand for this purpose.

After all the samples of milk to be tested have been measured, the acid should be added. To do this, fill the acid measure to the 17.5 c.c. mark, and gradually pour into the test-bottle, holding the bottle in a slanting position. By turning the bottle the acid will carry down all particles of milk left in the long neck. Hold the bottle by the neck and give it a circular motion for a few moments, thus mixing the milk and acid until no milk or clear acid is visible. The contents of the bottle should be dark colored and hot. Do not allow the bottle to stand too long before mixing or the test will not be clear.

270. Whirling the bottles. - The bottles and machine should be hot; and if it is not a steam machine, use boiling water to warm it. Place the bottles in the machine so that each will have another directly opposite to keep the machine in balance. Whirl five minutes. Then stop, and with the pipette or a cup with small spout, add hot water to each bottle until the contents 
Care and Management of Dairy Cattle

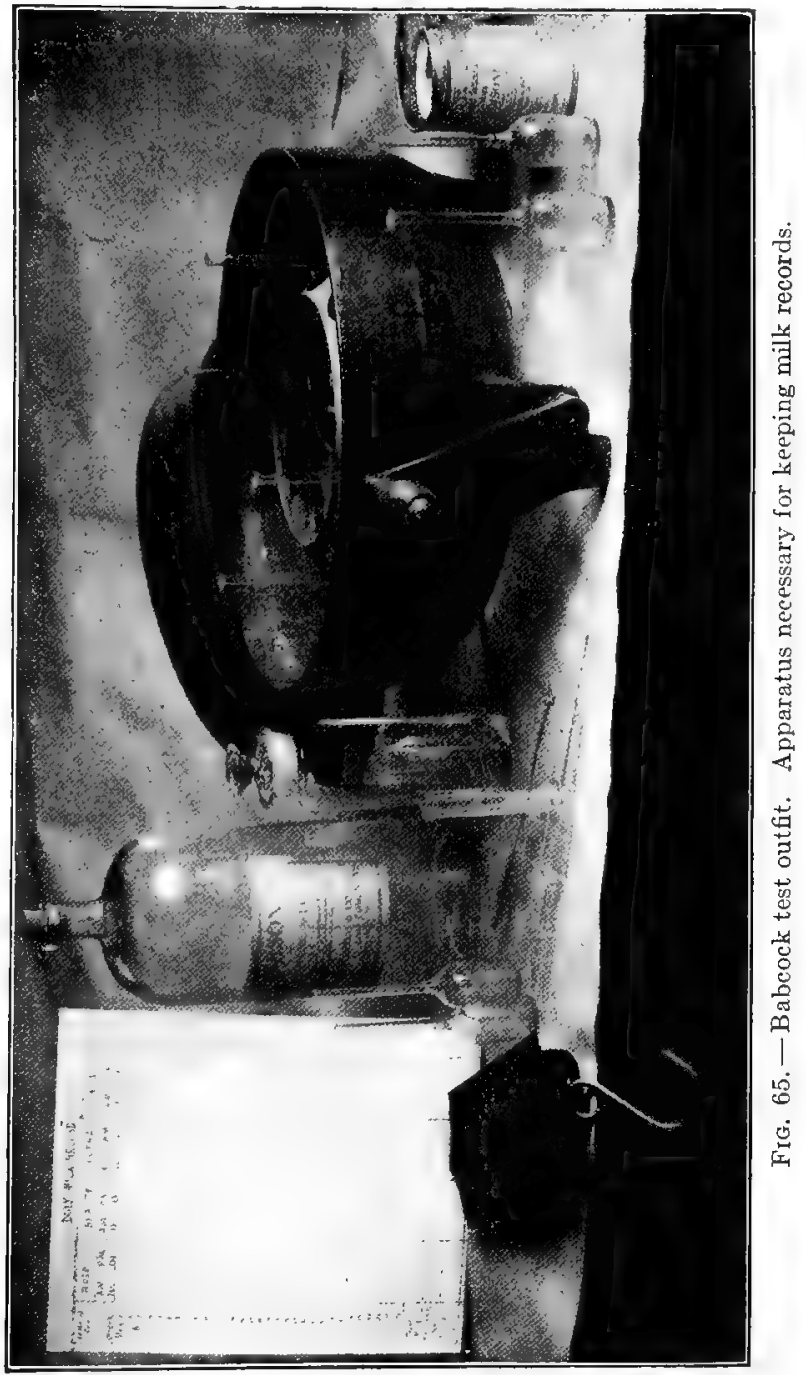


come up to the bottom of the neck. Whirl two minutes. Add hot water sufficient to bring the top of the fat nearly to the top of the graduation on the neck of the bottle. Whirl one minute. The fat should form a clear column free from black or white patches in the neck of the bottle.

271. Reading the percentage of fat. - Keep the fat warm. Hold the bottle by the upper end of the neck, letting it hang in a perpendicular position on a level with the eye. Read the mark at the top and bottom of the column of fat. The difference between these is the percentage of fat in the milk. For example, if the top reading is 8.2 and the bottom 5.0, then the milk tests 3.2 per cent.

Much care should be exercised in cleaning the test-bottles as they should be perfectly free from dirt when used.

272. Testing associations. - In those sections of the country in which dairying is extensively practiced, the forming of testing associations will prove very advantageous. Cow-testing associations are organizations of farmers having for their object the determination of the production of the individual cow in the herd.

273. General plan of organization. - A number of dairymen, twenty to twenty-five, having a total of 300 to 600 cows, effect an organization, elect officers, adopt a constitution and by-laws, and give the officers power to employ a man to do the testing. This tester visits each of the herds once a month, weighs the milk of each cow for a period of twenty-four hours, takes the samples of the same and tests for percentage of fat. In some cases the tester weighs the feed of each cow and figures the cost of the ration. The tester makes a complete record for each cow in the herd, of the amount of milk, the percentage of fat and total fat, and the food consumed, leaves a copy of this record with the dairyman, and proceeds to the next herd, to return again in about one month. In addition he gives all the helpful suggestions possible, such as the successful practices of the other members of the association. The entire cost to the dairyman is approximately one dollar 
per cow in addition to boarding and providing passage for the tester.

274. Records of performance and of breeding. - In order to mate dairy cattle judiciously, it is absolutely essential that we know not only something of the performance of the animals thus. mated, but the records of production of their ancestors as well. Such records enable us to mate the best with the best, and in so doing improve the strain with which we are working.

275. The individual animal the unit of improvement. - In the improvement of dairy cattle by breeding, the individual must be considered as the unit. This applies to sire and dam alike. The longer the line of high-producing ancestry, the more certain are we that the offspring in turn will be a high-producer. The importance of this individual record of performance, backed by ancestors with similar records, cannot be overestimated. Having satisfied one's self as to the individual excellency of both sire and dam, one must even then be prepared to accept some low-producers, for such is the law of chance, which accompanies all breeding operations. One may, however, rest assured that on the average the offspring of individuals thus carefully selected will be equal to their parents, and that he will be rewarded by obtaining a few that will exceed the records of their parents.

276. Formation of the dairy herd. - Perhaps one of the mostdiscussed questions in the formation of a dairy herd is whether to begin with pure-bred or grade cows. Opinions differ widely as to which is the more profitable. Pure-bred animals are much sought for breeding purposes; their offspring are therefore more valuable and command a higher price than do the offspring of grades. Therefore, if the value of the calves is taken into consideration, a pure-bred herd is a more profitable one, other things being equal, than a grade herd. On the other hand, by the grading-up process, that is, by continually selecting and breeding the cows that are the best producers to a pure-bred bull, it is entirely possible and by no means difficult to establish a herd of grade 
cows that will equal in the production of milk any herd of purebred animals. If, therefore, milk-production alone is sought, a grade herd may produce as largely as a pure-bred.

The enterprising and progressive owner will hardly be content with grades only. In the beginning his bull will be pure-bred; presently he will want a pure-bred cow to match, then one or two more. Thus he will be steadily and properly working towards a pure-bred herd, and gaining in knowledge and experience at the same time. This will be found a much better plan, especially with the beginner or those unaccustomed to handling registered stock, than to purchase a pure-bred herd in the beginning.

\section{THE DAIRY BARN}

The dairy cow is perhaps the most difficult of farm animals to stable properly. The purpose for which she is kept, that of supplying milk; the use to which the milk is put, that of human

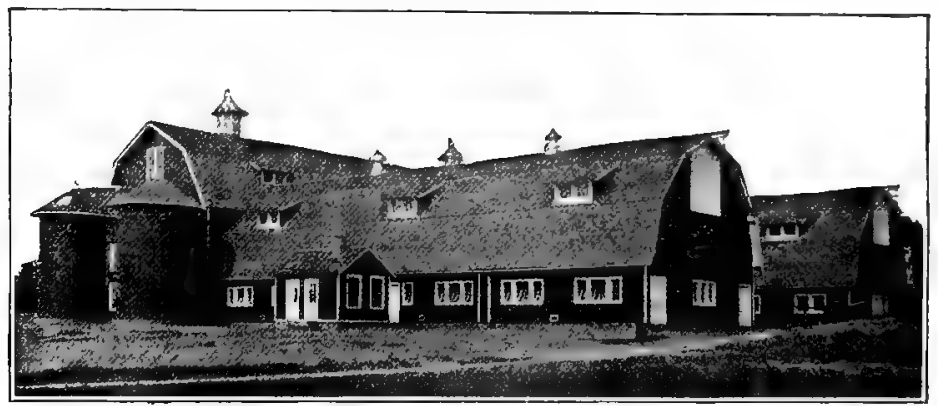

FIG. 66. - Dairy barn and silos.

food; the raw condition in which it is used; the place from which it is drawn, being exposed to greatest filth; the manner in which it is drawn, by hand and often by unclean milkmen; and the condition of her manure, as well as the fact that if maximum production is to be obtained, she must be fairly warmly 
housed, yet provided with an abundance of light and much fresh air; - all serve to complicate the problem of providing suitable quarters for the dairy cow.

There are certain fundamentals that should be provided in every building in which the dairy cow is stabled. Chief among these are light, ventilation, sufficient room, smooth and light walls and ceilings, a good floor, a comfortable and convenient stanchion and properly constructed mangers.

277. Light in abundance should enter the dairy barn. - Sunlight is nature's disinfectant. With sufficient light and proper ventilation, germ diseases are not likely to occur. It is said that direct sunlight will kill the growing tuberculosis germ in a very few minutes. Hence, cattle kept in well-lighted and well-ventilated quarters are not so likely to contract this much dreaded disease. Again, light shows dirt and makes it easy to keep the barn clean. Dark stables are likely to be dusty or dirty and damp, thus providing conditions for germ growth. In addition to health, cleanliness, and the like, a barn in which the sun shines freely is a cheerful place in which to work.

278. Ventilation essential to health. - The importance of pure air in a cow stable cannot be overestimated. It is essential to the well-being of the herd; without it, disease will surely work destruction. While there are many methods of ventilating a dairy barn, the King system in some of its modified forms is admitted to be the most efficient. If in addition the windows are arranged as suggested, p. 168, ample ventilation can be procured.

279. King's system of ventilation. - While there are many methods of arranging this system, it consists essentially of two parts: the inlets and the outlets, in the form of flues. This system will not work if the walls of the barn are full of cracks, or if the floor is made of loose boards. The floor, walls, ceilings, and windows must be so constructed as to prevent any large quantity of air from leaving or entering. 
The inlets may be so constructed as to meet two conditions: first, they must admit the fresh air near the ceiling, where the barn air is warm, in order that the fresh air may mingle with the warmest air of the stable and raise the temperature before descending to the floor. In the second place, they must not permit the warm air to pass out instead of the cold fresh air to come in. This is accomplished by constructing the inlet flue so that it begins near the ground on the outside and ends near the ceiling on the inside. All that is necessary is to have the outer end of the flue several feet lower than the inner end. They should be placed on all four sides of the stable to take advantage of the wind.

The outlets must be so constructed as to meet three conditions. First, the ventilators should reach nearly to the stable floor in order to remove the air from that point. This is desirable because the refuse gases from the animals being heavier than the other air of the stable remain near the floor. The colder air is at the floor, and it is desirable to remove this, particularly in the winter, in order that the warmer air at the ceiling may move downward. In the second place, these ventilators should be provided with an opening near the ceiling for the removal of the warm air when the stable becomes too warm, particularly if the animals are to be kept in the stable most of the time. This opening must be provided with a door or slide to be closed or opened at will. In the third place, it is important that these ventilators be so constructed as to afford as little inconvenience as possible, particularly when they extend through the hay loft, where they are sometimes in the way of the hay fork. The ventilating flue should be as large as convenient. The essentials of a good ventilating flue are similar to those of a good chimney.

280. Window ventilation. - If it is not possible to install the King system in one of its many forms, the windows can be so arranged as to form a fair system of ventilating the cow stable. To do this, hinge them at the bottom, allowing the top to open 
inward. Place a board edgewise along each side of the window, so that the air will not enter at the bottom and blow directly on the animals when the window is open. By leaving several of the windows open an inch or two at the top, fair ventilation will be

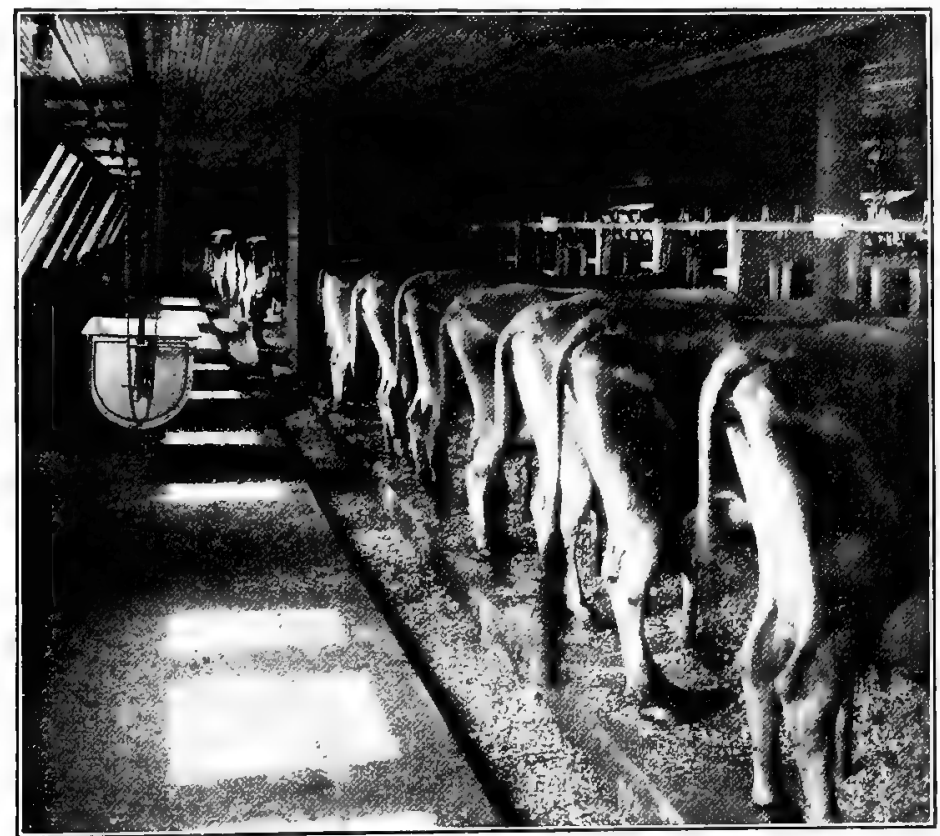

FIG. 67. - Interior view of dairy barn, showing litter-carrier, cement floor, gutter, and arrangement of windows.

provided without serious drafts. When this plan is employed, it is best to open the windows on the side of the harn away from the wind, and to regulate the size of the opening according to the severity of the weather.

281. Floors are best made of cement. - While many objections have been raised to the use of cement, such as its cost, its being 
cold and damp, injuring the cattle and the like, it is nevertheless the most desirable material from which to construct floors for the cow stable. The gutters and mangers should likewise be laid in cement. Cement has two very great advantages over all other materials: it is easily kept clean, and if properly put down, is durable. If desired, plank may be laid over the cement where the cows stand. Cement may be made dry and fairly warm by placing a layer of some non-conducting material, such as building paper, an inch or so beneath the surface.

282. The silo. - The silo has passed the experimental stage, and the economy as well as the practicability of preserving fodder in it has been fully demonstrated. Silage is a valuable food, and is relished by all classes of farm animals, but it is more particularly adapted to ruminating animals like cattle.

The fundamental principle in the preservation of green forage placed in a silo, is the exclusion of air. To prevent the air from reaching the silage, the silo must be constructed with airtight walls. These walls must be rigid enough to prevent springing out of shape by the pressure of the silage, for in this case air will enter next to the wall. The pressure is greatest from the second to the sixth day after filling. The silage at this time begins to heat and settle, and if the walls are not sufficiently rigid to prevent any bulging, a considerable loss of silage is likely to result. The walls should be perpendicular, and the diameter the same from the bottom to the top.

283. The size of the silo. - On being exposed to the air, silage spoils rapidly, and to avoid this it must be fed off at the rate of one and one-half to two inches daily in the winter, and three inches in the summer. A good plan is to construct the silo so that the horizontal feeding area for each cow will be approximately six square feet daily. If we feed six square feet off the top and two. inches down, this means one cubic foot to the cow. The approximate weight of a cubic foot of silage is forty pounds, though this varies much between the top and the bottom. 
Approximate Capacity in Tons of Round Silos of Different Diameters and Depths and the Area required to fill them as Well as The Amodnt that SHodld be Fed daILY

\begin{tabular}{|c|c|c|c|c|}
\hline $\begin{array}{l}\text { INSIDE : } \\
\text { DIAMETER } \\
\text { FEET - }\end{array}$ & 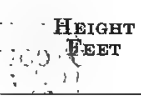 & $\begin{array}{l}\text { CAPACITY } \\
\text { TONS }\end{array}$ & $\begin{array}{l}\text { ACREAGE TO FILL } \\
10 \text { TONS TO ACRE }\end{array}$ & $\begin{array}{c}\text { PoUNDS THAT } \\
\text { SHOULLD BE FED } \\
\text { DAILY }\end{array}$ \\
\hline 10 & 28 & 42 & 4.2 & 525 \\
\hline 10 & 36 & 61 & 6.1 & 525 \\
\hline 12 & 30 & 67 & 6.7 & 755 \\
\hline 12 & 38 & 94 & 9.4 & 755 \\
\hline 14 & 30 & 91 & 9.1 & 1030 \\
\hline 14 & 38 & 128 & 12.8 & 1030 \\
\hline 16 & 30 & 119 & 11.9 & 1340 \\
\hline 16 & 42 & 193 & 19.3 & 1340 \\
\hline 18 & 36 & 196 & 19.6 & 1700 \\
\hline 18 & 46 & 282 & 28.2 & 1700 \\
\hline 20 & 36 & 243 & 24.3 & 2100 \\
\hline 20 & 50 & 382 & 38.2 & 2100 \\
\hline 22 & 36 & 292 & 29.2 & 2300 \\
\hline 22 & 50 & 469 & 46.9 & 2300 \\
\hline
\end{tabular}

284. Filling the silo. - Occasionally the construction of a silo is criticised, whereas the fault may be found in the method of filling. It is essential to the preserving of silage that it be well packed, keeping it level and thoroughly tramped. This very important task is often intrusted to a lad who spends his time in standing in the breeze of the blower, with the result that the silage comes out of the silo somewhat molded the following winter.

\section{DISEASES OF CATTLE}

Cattle are very subject to certain diseases which render their usage for domestic purposes questionable. Milk from diseased cows, or meat from diseased carcasses, may endanger the lives of those who consume it. The sick cow should receive much care, as 
in many cases good care is to be preferred to the use of medicine, p. 89.

285. Tuberculosis. - Perhaps no disease to which cattle are subject is more discussed than tuberculosis. This is due in large measure to the use of cattle to provide food for the human race. There are perhaps few diseases so common among cattle as tuberculosis, particularly among those animals that are kept closely confined.

Tuberculosis is a communicable germ disease, and is, therefore, preventable. The disease is caused by a small germ or bacterium known as Bacillus tuberculosis. This germ is, of course, invisible to the naked eye.

286. Methods of infection. - As tuberculosis is a communicable germ disease, the methods of infection should receive much attention. This can be made clear by considering from two points of view: first, how the germs escape from diseased animals; and second, how sound animals become infected. All diseased animals possess the germ. This germ escapes when the tissues it has destroyed are being discharged from the body. Thus, if the lungs are affected, the animal on coughing dislodges the germs, which may be forced directly out of the body or lodged in the mouth, when they leave the body with the saliva. In the cases in which the germs are found in the saliva they are left in the watering troughs, on the bottom of the mangers, on the grass, on other animals when licked by diseased ones, and in fact spread wherever the diseased animal goes.

When the germs have escaped into the watering troughs, mangers, on the grass, and the like, they are readily taken up by healthy cattle. In case the germs escape in the milk, whatever feeds upon it is liable to infection. The length of time that will pass after infection and before the disease visibly appears varies widely, even to months or years. The length of time the animal may possess the disease varies equally as much. With some it may prove fatal in a few months; others may carry it for years. 
287. Prevention of tuberculosis. - Since tuberculosis is a communicable germ disease, it is therefore preventable. If a herd is known to be healthy, never bring a new animal into the herd until it has been tested, and if there is the slightest suspicion that it is tubercular, it should be excluded.

\section{QUESTIONS}

1. How many dairy cattle are there in the United States? How many in your state? In your county? How does your state rank with other states in the production of milk and butter? How does your county rank with other counties of the state? Name the ten leading dairy states. Which state possesses the largest number of cattle to the square mile? To the farm?

2. Why are records of performance essential in herd improvement? In breeding, which is the more important, a record of performance or a pedigree? Are there any cow testing associations in your state? In your county? Have they resulted in improvement?

3. In grading up a herd, when should the surplus calves be disposed of ? Which calves should be retained?

4. How young should a heifer freshen? What is the average age of a milk cow? What percentage of the herd must be replaced each year in order to keep the number uniform?

5. At what period of life does a cow give her maximum yield of milk? Does an old cow give milk with a higher percentage of fat than a young one?

6. In testing milk with a centrifuge tester, why is it that the fat rises to the top? Why will milk keep sweet longer at a low temperature than at a high? Why does milk sour? Why does pasteurization of milk increase its keeping qualities? How do bacteria get into milk?

7. How is sanitary milk produced? Are there any sanitary farms in your county? How much do they get for their product?

8. Are there any milking machines in use in your county? How long does it take the machine to milk four cows yielding an average of six quarts each? Does it milk the animals clean? How long would it take a good hand milker to milk a cow yielding six quarts? Wherein lies the 
advantage of the machine? Which milk contains the most fat, that drawn first or last?

9. Why is it essential that the floor and walls be tight when the King ventilating system is used? Why should the dairy barn be warm, well lighted and well ventilated?

10. Why should the silo be air tight? Which is the more desirable, a high, narrow silo or a low, wide one? Why? Why should silage be well packed? 


\section{CHAPTER X}

\section{FEEDING BEEF CATTLE}

Fefding beef cattle differs considerably from feeding dairy cattle. The production of milk is largely an independent industry because of the fact that successful dairymen have time for little if anything else; whereas beef production is not a special industry and does not require all of the farmer's time, and on the average is conducted successfully only in connection with grain farming. Successful beef producers regard beef-raising as a convenient way of marketing grain, as well as a means of conserving soil fertility, and also a profitable means of utilizing coarse forage which otherwise would be largely wasted.

\section{ESSENTIALS OF FEEDING CATTLE}

In considering cattle with a view of estimating their profit as beef producers, there are a number of essentials to be taken into account. Chief among these are the age, form, condition, quality, uniformity, and the price.

288. Age at which to feed cattle. - To secure some idea of the age at which gains can be made most cheaply, let us examine the composition of the body of an old and a young steer :-

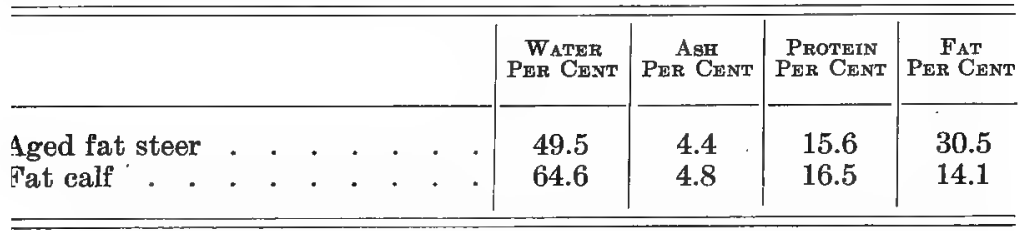


This would seem to indicate that the aged steer in fattening required considerably more solid food, particularly those foods rich in fat, whereas the calf requires less fat, and less dry-matter to the pound of gain. As water is cheaper than fat we would expect the calf to make the cheaper gains, and such is the case. Not only does the age influence the cheapness of the gains, but it affects the rate of gain as well. The younger animal having the advantage.

289. Form for feeding cattle. - The form of the steers should be such as to meet two conditions: those demanded by the cattle feeder, and those demanded by the butcher. The cattle feeder wishes an animal that will make rapid and economical gains in the feed lot, while the butcher wishes one that will dress a relatively high percentage of edible meat, particularly of the high-priced cuts, such as prime of rib, porterhouse, sirloin, rump, and round, which are taken from the back, loin, rump, and quarters. In general the form that best fills these conditions will be low set, deep, broad, and compact, rather than high up, gaunt, narrow, loosely made.

Cattle possessing such a form are likely to prove rapid and economic producers while in the feed lot, thus making a profit for the feeder, and when slaughtered to dress a relatively high percentage of edible meat, particularly of the high-priced cuts. Such an animal should dress out 55 to 60 per cent or better with approximately one-half of the edible meat in the region of the.valuable cuts, and this will sell for about 75 per cent of the value of the entire carcass, leaving the other half from the region of low-priced meat to bring the other 25 per cent of the valuation.

290. Condition of feeding cattle. - In considering steers to feed, their condition should be carefully scrutinized from two points of view : their thrift, and the amount of flesh they possess. Feeding cattle should be thrifty but not coarse. On the other hand, too much refinement is likely to prove disappointing, as it often 
means delicacy or lack of thrift, and no animal lacking in thrift should find its way into the feed lot.

To make rapid and economic feeders the cattle should not possess much flesh at the beginning of the feeding period. The thinner the steer at the beginning of the feeding process, the more rapid and economical gains it will make, provided there is no lack of thrift. If we examine the bodies of the thin and fat steer, it may give us an insight as to why the animal gains in flesh more rapidly and on less feed when in a thin condition:-

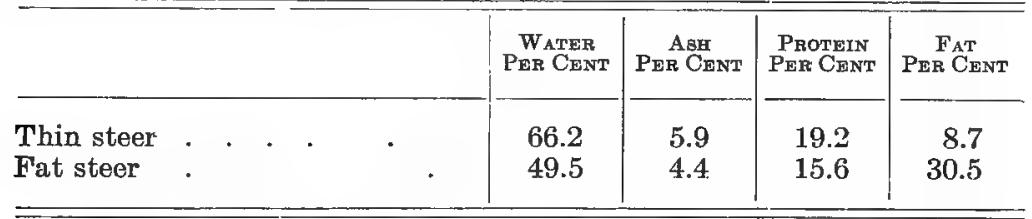

The body of the thin steer contains a relatively high amount of water and low fat, whereas the fat steer's body contains a relatively small amount of water and high fat content. This may have a bearing on the fact that a thin steer gains more rapidly and on less feed than a fat one, and also on the fact that as the full feeding proceeds the gains are made less rapidly and require more feed.

291. Quality of feeding cattle. - Quality should be considered from two points of view : general quality, and handling quality. By general quality is meant that general refinement of external form found in the neat head, fine horn, dense bone, smooth outline, and compact body. This quality is affected by nothing so much as breeding. General quality and good breeding are closely associated, well-bred animals being likely to possess quality, whereas it is often wanting in the common-bred steers. The importance of general quality in feeding cattle cannot be over estimated, as steers possessing it will give higher profit to both the cattle feeder and the butcher, not because such animals will necessarily make more meat from a given amount of food, but 
because they will dress out better and bring a higher price on the market.

Good handling quality indicates that the steer is a good feeder. By good handling quality is meant a fine, silky hair and a loose, mellow skin. These are associated with thrift and the ability to take on flesh rapidly and economically, whereas a heavy, stiff hide is considered to indicate slower fattening.

292. Uniformity in feeding cattle. - Feeding cattle should be uniform in age, weight, color, type or form, condition, breeding, and quality. Since young steers gain more rapidly than aged ones, and aged steers fatten more rapidly than young ones, it is not likely that a lot of steers of mixed ages would all be ready to market at the same time. If some of the animals are fat, while others are only half fat, they will not command as high a price on the market as though they were uniform in flesh. Not only must they be uniform in flesh, but they must be approximately uniform in weight, if the highest price is to be obtained. Butchers and packers desire cattle uniform in weight, so that the cuts of meat will run uniform, as their trade demands. While uniformity of color does not add to the animal's capacity to take on flesh economically or to his ability to dress out well, yet the butchers desire such similarity and are willing to pay for it. The cattle should be uniform in type or form. If they vary in type, the weight of the cuts of meat will likewise vary, and to this the butcher objects. The butcher also demands animals equal in condition and quality, to meet the demands of his trade calls.

293. Food requirements for beef. - The quantity of food required to fatten a beef animal depends on many factors, chief of which are the kind of food, the age, weight, and condition as well as the individuality of the animal.

No definite quantities can be given that will apply to all animals, to all conditions, and to all foods. The standards furnish us a guide to be modified by the judgment and experience of the feeder:- 
Wolff-Lehman Standard, showing the Amount of Food required Per 1000 Pounds Live Werght for both the Growing and Fattening Beef Animal

\begin{tabular}{|c|c|c|c|c|c|c|c|}
\hline \multicolumn{3}{|c|}{ Condition of ANIMAL } & \multirow{2}{*}{$\underset{\text { MatTer }}{\text { Dry- }}$} & \multicolumn{3}{|c|}{ Dragstive Nutriente } & \multirow{2}{*}{$\begin{array}{l}\text { NutrRitrve- } \\
\text { Ratio }\end{array}$} \\
\hline \multicolumn{3}{|c|}{$\begin{array}{c}\text { Growing Cnttle } \\
\text { Beef Breeds }\end{array}$} & & Protein & $\begin{array}{l}\text { Carbo- } \\
\text { hydrates }\end{array}$ & Fat & \\
\hline $\begin{array}{l}\text { Age, Mo. } \\
2-3\end{array}$ & $\begin{array}{l}\text { Weight } \\
160\end{array}$ & & 23 & 4.2 & 13.0 & 2.0 & $1: 4.2$ \\
\hline $3-6$ & 330 & & 24 & 3.5 & 12.8 & 1.5 & $1: 4.7$ \\
\hline $6-12$ & 550 & & 25 & 2.5 & 13.2 & 0.7 & $1: 6.0$ \\
\hline $12-18$ & 750 & & 24 & 2.0 & 12.5 & 0.5 & $1: 6.8$ \\
\hline $18-24$ & 950 & & 24 & 1.8 & 12.0 & 0.4 & $1: 7.2$ \\
\hline $\begin{array}{r}\text { Fatter } \\
\text { First perio }\end{array}$ & Fattening Crttle & & 30 & 2.5 & 15.0 & 0.5 & $1 \cdot 65$ \\
\hline Second pe & 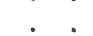 & & 30 & 3.0 & 14.5 & 0.7 & $1: 5.4$ \\
\hline Third peri & . . & & 26 & 2.7 & 15.0 & 0.7 & $1: 6.2$ \\
\hline
\end{tabular}

Armsby's Standard, showing the Digestible Proteln and Energy ReQUired per 1000 Pounds Live Weight for a Growing Steter of Vartous Ages and Weigets

\begin{tabular}{c|c|c|c}
\hline Age, Months & Weight, Pounds & $\begin{array}{c}\text { Digestidit Protein, } \\
\text { Pound }\end{array}$ & $\begin{array}{c}\text { ENergy Valut, } \\
\text { Theris }\end{array}$ \\
\hline 6 & 425 & 3.0 & 14.3 \\
12 & 650 & 2.5 & 10.7 \\
18 & 850 & 2.0 & 8.8 \\
24 & 1000 & 1.7 & 8.0 \\
30 & 1100 & 1.5 & 7.3 \\
\hline
\end{tabular}

294. Wintering stockers and feeders. - Large numbers of feeding cattle are purchased in fall and early winter for the special purpose of economically disposing of such roughage as corn stalks, straw stack, second-class clover hay, clover chaff after the seed has been removed, and the like. Wintering cattle with a view to fattening the following summer on pasture is a very convenient way of converting such feeds into cash. 
While different systems of feeding might undoubtedly be recommended.for cattle of various ages and quality, there are at least three conditions that should be kept clearly in mind: first, cattle wintered on roughage alone, provided they retain their thrift, will make more economical beef producers the following summer on pașture than when they receive grain along with the roughage; second, cattle wintered on a too liberal grain ration may fail to make a profit the following summer on pasture; and third, other things being equal, cattle wintered on a ration containing a liberal supply of protein, particularly if this protein is contained in the roughage, as clover, alfalfa, or cowpea hay, will make greater and more economical gains during both winter and summer than if this nitrogenous roughage is wanting.

295. Roughage increases feeding capacity. - It is conceded by experienced cattle feeders that roughing steers preparatory to putting them on full feed requires much skill. The feeding of an abundance of roughage encourages the enlargement and development of the digestive organs, thus increasing the capacity for handling more concentrated feeds later on. This, of course, gives the thin animal a large paunch, which must certainly be reduced before the animal is ready for market. A large-paunched steer is not wanted on any fat-cattle market. Therefore, in the early part of the feeding process, the enlarging of the paunch should be encouraged in order to increase the capacity, while the latter part of the feeding period should be devoted to reducing this paunch and smoothing up the steer.

\section{SUMMER FEEDING ON PASTURE}

Fattening cattle in the summer on pasture is usually more profitable than winter fattening. By such feeding the labor is reduced to a minimum, there is no handling of bulky foods, no bedding to provide, no lots to clean of manure, and no outlay for an extensive plant; such as sheds, lots, and the like. 
296. Methods of summer feeding. - There are two methods of fattening beef cattle on pasture: pasturing alone with no grain, which is called "grass fattening"; and feeding grain, often all they will eat, in connection with the pasturage. Which of these methods should be employed will depend on conditions. When land is cheap and there is an abundance of pasture, one may secure fairly good returns from pasturing without grain. On the other hand, if the pasture is limited, the land high in price, and one has the grain, no doubt it will be more profitable to feed grain in connection with the pasture. While cheaper gains can usually be made from pasturing alone, the cattle cannot, as a rule, be made very fat, and hence will not command a high price on the market, a drawback which offsets the advantage of cheap gains. There are, however, many experienced cattle feeders who rely on grass fattening, particularly on the edge of the corn-belt. Cattle feeders in the corn-belt will, as a rule, secure greater returns from a liberal grain feed in connection with the pasture.

297. How to turn to grass. - As cattle are very subject to bloating if turned to succulent grass, especially if it is wet with dew or rain, much care should be exercised. This is particularly true when they are turned to clover or alfalfa. If it is convenient, one should turn the cattle out for an hour or so in the afternoon and then take them up for the day, turning them out the following day at noon and leaving a few hours longer, then taking them up again, when on the third day they may be allowed to remain.

298. Feeding grain to cattle on pasture. - The amount and kind of grain that should be fed to fattening cattle on pasture will depend much on the previous treatment, age, condition, and quality of the cattle, as well as the time of marketing them. Young stock, that are to be made thick fat, will need grain continually throughout the summer. Older cattle, that are not intended for market until fall, may well have their grain withheld until the pasture begins to get short, say along in July. Many cattle feeders prefer to "warm the cattle up " in the feed lot before going 
to grass, and then to finish them on pasture, disposing of them by the middle of July, before the hottest of the weather, and just about the time the pasture begins to fail. Under this system it would be necessary to feed grain liberally from the beginning of the pasture season.

There is difference of opinion as to the kind of grain that should be fed cattle of the various ages on pasture. In some cases perhaps corn alone cannot be improved on, particularly if there is

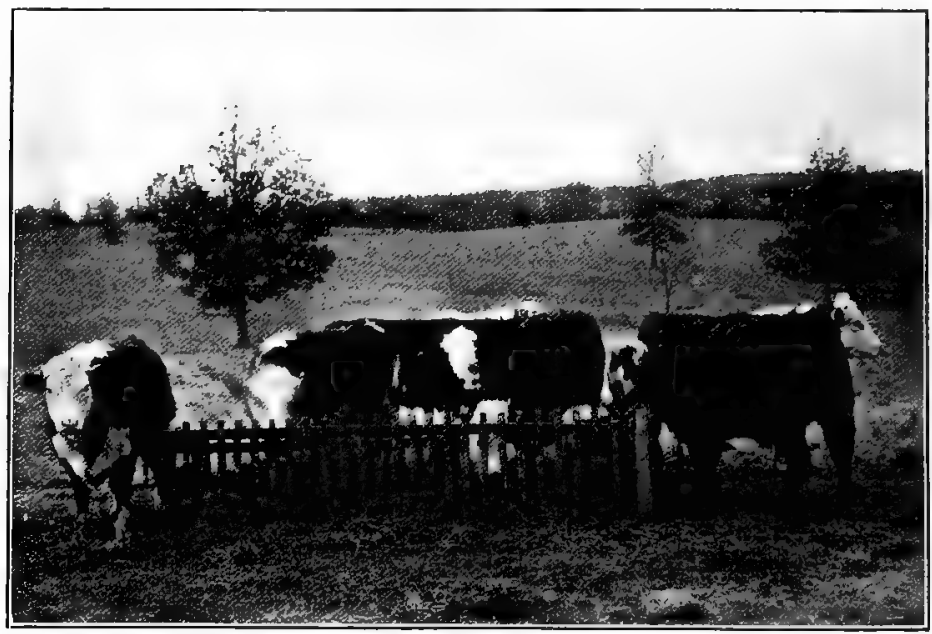

FIG. 68. - Fattening steers on pasture. Feeding clover hay to supplement the pasture.

leguminous grass, as clover or alfalfa, in the pasture. With young stock, however, it is advisable to supplement corn with a food rich in protein, as linseed or cotton-seed meal.

299. The pastures. - There are two general plans for providing pasture land: permanent pastures; and pastures in rotation with other crops. No definite suggestions can be given as to the choice between these further than to say that all depends on the location. 
If those farms or parts of farms that are unsuited for growing grains can be laid to permanent pasture, it will, on the average, be profitable to do so. Each of these systems has certain advantages. For example, permanent pasture simplifies the fencing, provides the water supply, the shade, and the feed racks or bunks, while pastures in rotation give a much better opportunity to distribute the manure to all parts of the farm. Permanent pastures, even if seriously affected by drouth, are not likely to be a failure, while pastures in rotation occasionally do fail. Properly managed permanent pastures will increase in value with age.

The pasture crop is perhaps the most neglected of crops. With proper management it can be improved. First, secure a good stand; second, keep down the weeds; third, drain pasture land well ; fourth, top-dress permanent pastures with manure when convenient ; and fifth, do not turn to pasture too early in the spring, as this hinders the growth of the young plants before they get a start.

\section{WINTER FEEDING IN DRY-LOT}

While feeding steers in the summer time on pasture may be the most profitable for those cattle feeders possessing the pasture, there are many farms, especially in the corn-belt, lacking in pasture and yet possessing an abundance of grain and dry forage that the farmer desires to convert into beef. On such farms winter feeding in the dry-lot is the common practice. This system of feeding beef cattle is not without its advantages. For example, the feeding is done at a time of year when there is little other work, and if the cattle are measurably protected from the wind and rain, they suffer less from the weather than from the heat and troublesome flies of summer. When the steers are purchased in the fall and fattened during the winter, the cattle feeder has his money tied up a much shorter period, resulting in correspondingly quicker returns. Such a system affords a very convenient method of converting the previous crop, grain and dry forage, into ready cash 
to finance the farm the coming season, as the steers are marketed and out of the way before farm work begins in the spring.

300. Feeding grain to cattle in the dry-lot. - The amount and kind of grain that should be fed to fattening cattle in the dry-lot will depend much on the age, condition, and quality of the cattle as well as upon the kind of dry forage. Young stock will need a heavy grain ration from start to finish if they are to be made fat, whereas older cattle may be fed grain rather sparingly at first, gradually increasing to a full grain feed sixty days before marketing.

The amount of grain that can be fed economically to fattening cattle depends much on the kind of dry forage. On the average, animals receiving a leguminous forage, such as clover, alfalfa, or cowpea hay, will make economical use of a larger grain ration than when other forage, such as timothy, red-top, corn stalks, and the like, is fed. In fact, fattening farm animals will make more economical use of a larger grain ration if the grain also contains a high percentage of protein. The length of the fattening period will also have much to do with the amount of grain that should be fed. If it is intended to market the steers in 100 days or less, they will have to be full-fed grain from the beginning if they are to be made reasonably fat, whereas if the feeding period is to last 150 days or more, the cattle may be fed grain rather sparingly at first.

The kind of grain to feed fattening cattle likewise depends largely on the cattle and the kind of dry roughage. When rather young steers are being fattened, it is the common opinion that a more nitrogenous ration should be used; whereas in the case of older and more mature cattle the grain ration often contains less protein. The kind of roughage determines, in part, the kind of grain that should be fed. When the cattle are being fed a dry roughage containing much protein, as clover, alfalfa, or cowpea hay, the grain may contain a correspondingly less amount of protein. On the other hand, when the dry forage lacks the protein, the de- 
ficiency should be made up by feeding a grain rich in protein, as cotton-seed or linseed meal. In addition, the length of the fattening period will have an influence on the kind of grain to feed. If the period is short, it will be necessary to feed very fattening foods, such as corn and cotton-seed meal, from the beginning; whereas if the cattle are to be fed 150 days or more, they may be given foods containing less fat during the early stages of the feeding period.

301. Baby-beef. - By baby-beef is meant fat cattle between one and two years of age and weighing from 800 to 1100 pounds. First of all, the cattle must be young. They must be well bred and of fine quality, as such cattle can be finished for the market at a much younger age than the plainer kinds. The cattle to be used in the production of baby-beef should not be permitted to lose their calf fat.

302. Feeding for baby-beef production. - If young animals are to be made fat, they must be fed liberally on fat-producing feeds, particularly grain. Heavier grain feeding is required in the production of baby-beef than of older beef. Calves and yearlings have a tendency to grow rather than to fatten, and to overcome this they must be fed a heavy ration of grain, a fact not to be lost sight of in figuring the cost. In the beginning the calf should be fed considerable quantities of dry forage, such as clover, alfalfa, or cowpea hay, as such foods have a tendency to increase the digestive capacity of the calf, thereby enabling it to handle large quantities of grain later on. If heifer calves instead of steers are fed, they will finish more quickly and hence should be marketed earlier. The younger the prime heifers are at the time of the marketing, the less discrimination in price the butcher will make between them and steers.

303. Sample rations for fattening cattle. - The following rations furnish a guide in determining the kind and quantity of feed that should be allowed fattening cattle. They apply to 1000 pounds live weight:- 


\begin{tabular}{|c|c|c|c|c|}
\hline \multirow{2}{*}{$\begin{array}{c}\text { AGE AND } \\
\text { WEIGHT OF } \\
\text { CATTLE }\end{array}$} & \multicolumn{2}{|l|}{ RATION } & \multicolumn{2}{|c|}{$\begin{array}{c}\text { FoOD PER } \\
\text { POUND GAIN }\end{array}$} \\
\hline & Grain & Dry Forage & Grain & $\underset{\text { Forage }}{\text { Dry }}$ \\
\hline $\begin{array}{c}\text { Calves } \\
457 \mathrm{lb} .\end{array}$ & $\begin{array}{l}22 \mathrm{lb} \text {. shelled corn } \\
3 \mathrm{lb} \text {. cotton-seed meal }\end{array}$ & $12 \mathrm{lb}$. clover hay & 5.9 & 2.9 \\
\hline $\begin{array}{l}\text { Calves } \\
534 \mathrm{lb} .\end{array}$ & $\begin{array}{l}18 \mathrm{lb} \text {. shelled corn } \\
2.5 \mathrm{lb} \text {. cotton-seed meal }\end{array}$ & $\begin{array}{l}5 \mathrm{lb} \text {. clover hay } \\
18 \mathrm{lb} \text {. corn silage }\end{array}$ & 5.8 & $\begin{array}{l}1.4^{1} \\
5.3^{2}\end{array}$ \\
\hline $\begin{array}{l}\text { Yearlings } \\
854 \mathrm{lb} \text {. }\end{array}$ & $\begin{array}{l}19 \mathrm{lb} \text {. shelled corn } \\
2.5 \mathrm{lb} \text {. cotton-seed meal }\end{array}$ & $\begin{array}{l}4.5 \mathrm{lb} \text {. clover hay } \\
18 \mathrm{lb} \text {. corn silage }\end{array}$ & 7.9 & $\begin{array}{l}1.7^{1} \\
6.8^{2}\end{array}$ \\
\hline $\begin{array}{l}\text { Yearlings } \\
808 \mathrm{lb} \text {. }\end{array}$ & $19 \mathrm{lb}$. shelled corn & 11 lb. alfalfa hay & 7.7 & 4.7 \\
\hline $\begin{array}{c}\text { Two years } \\
1010 \mathrm{lb} .\end{array}$ & $\begin{array}{l}16 \mathrm{lb} \text {. shelled corn } \\
3 \mathrm{lb} . \text { cotton-seed meal }\end{array}$ & $\begin{array}{l}4 \mathrm{lb} \text {. clover hay } \\
15 \mathrm{lb} \text {. corn silage }\end{array}$ & 7.6 & $\begin{array}{l}1.5^{1} \\
5.8^{2}\end{array}$ \\
\hline $\begin{array}{c}\text { Two years } \\
979 \mathrm{lb} .\end{array}$ & 10 lb. snapped corn & $\begin{array}{l}12 \mathrm{lb} \text {. prairie hay } \\
10 \mathrm{lb} \text {. alfalfa hay }\end{array}$ & 4.7 & 10.5 \\
\hline $\begin{array}{c}\text { Two years } \\
893 \mathrm{lb} \text {. }\end{array}$ & $20 \mathrm{lb}$. ear corn & 10 lb. clover hay & 9.5 & 4.0 \\
\hline $\begin{array}{c}\text { Two years } \\
1017 \mathrm{lb} .\end{array}$ & $\overline{18} \mathrm{lb}$. shelled corn & 7 lb. timothy hay & 9.3 & 3.4 \\
\hline
\end{tabular}

${ }^{1}$ Clover hay.

2 Corn silage.

Sample Rations for wintering Cattle with no Attempt to fatten TWEM

\begin{tabular}{|c|c|c|c|}
\hline \multirow{2}{*}{$\mathrm{W}_{\text {CIIGHT of }}$} & \multicolumn{2}{|c|}{ Ration for Each Steer } & \multirow{2}{*}{$\begin{array}{c}\text { GAIN } \\
\text { PER } D_{A Y} \\
\text { LB. }\end{array}$} \\
\hline & Grain & Dry Forage & \\
\hline $736 \mathrm{lb}$. & none & $16 \mathrm{lb}$. timothy hay & 0.4 \\
\hline $707 \mathrm{lb}$. & none & 20 lb. whole cornstalks & 0.2 \\
\hline $743 \mathrm{lb}$. & none & 44 lb. corn silage & 1.0 \\
\hline $788 \mathrm{lb}$. & none & 20 lb. cowpea hay & 0.5 \\
\hline $767 \mathrm{lb}$. & 4 lb. shelled corn & $\begin{array}{l}9 \mathrm{lb} \text {. cornstalks } \\
9 \mathrm{lb} \text {. clover hay }\end{array}$ & 0.9 \\
\hline $783 \mathrm{lb}$. & 4 lb. shelled corn. & 19 lb. cowpea hay & 1.5 \\
\hline \multirow[t]{2}{*}{1} & $6 \mathrm{lb}$. shelled corn & 17 lb. timothy hay & 1.4 \\
\hline & 6 lb. shelled corn & 19 lb. clover hay & 1.9 \\
\hline
\end{tabular}

${ }^{1}$ Weight approximately as above. 


\section{QUESTIONS}

1. How do the Wolff-Lehman and Armsby standards compare in respect to the protein required for the growing animal? Why this difference? Which of these requirements meets your conditions?

2. Which requires the more protein, beef production or milk production? How much protein would there be in the flesh of a steer gaining two pounds per day? Compare with the dairy cow yielding thirty pounds of milk.

3. Why does a young steer gain more economically than an old one? A thin one more than a fat one? One of good form more than one of poor form? And one of good quality more than one of poor quality?

4. How should the following lots of cattle be wintered, if intended for fattening the following summer: calves, fancy yearlings, fancy heifers, inferior steers, and common cows?

5. Assuming that it is desired to market the first of October, how should the above lots be fed, if they have the range of a good blue grass pasture?

6. Is there as much permanent pasture land in your county as formerly? Why? What grasses constitute the pasture? How many animals will ten acres support? How can this be increased?

7. Why is baby-beef popular with the butchers? Under what conditions is baby-beef the most profitable for the farmer? Why do farmers who buy their cattle prefer to feed older ones?

8. Are the beef cattle of your vicinity raised in the county or are they shipped into it for fattening? Where do they come from?

9. Why should considerable time be taken to put range cattle on full feed? Why do these cattle often refuse grain, especially at first?

10. Approximately how many carloads of fat cattle are shipped from your county annually? Where do they go? 


\section{CHAPTER XI}

\section{CARE AND MANAGEMENT OF BEEF CATTLE}

To be successful in the production of beef cattle, we must have due regard for regularity in all matters pertaining to the care and management of the cattle. This applies particularly to feeding and watering. Cattle anticipate the hour of feeding and become nervous if it is long delayed; they bellow, coax, and become much excited, all of which must be avoided if beef is to be produced economically.

304. Plan of improvement. - Before deciding upon a plan of breeding beef cattle, one should visit farms where beef cattle are successfully bred, noting conditions and comparing them with his own. Such improvement as he may be able to bring about must be upon the common native cattle of the community. To dispose of the native cattle and purchase well-bred uniform cattle would be very expensive and in most cases very unprofitable. The task is then to adopt some plan of breeding that will result in an improvement of the native stock. In most cases this can be most profitably accomplished by the grading-up process; that is, by the use of pure-bred bulls on the native common females.

305. Coöperative grading-up. - A very successful plan to improve the beef-producing qualities of the cattle of a locality is by the coöperative grading-up method. The formation of beefbreeding associations throughout a given locality would do much to advance the progress of the industry, p. 164.

306. Raise heifer calves from best cows. - Because of the excellency of the heifer calves from the good cows, the cattle feeder is tempted to fatten them for beef. This should not be done. 
They should be reserved for breeding purposes. Many cattle breeders are actually reducing the quality of their beef-producing herd by fattening the best calves and reserving the poorer ones for breeding because they will not make good feeders.

307. Farms for fattening cattle. - While cattle feeding may be conducted on any farm, there are two general types of farms on which it is likely to prove more profitable. First, grain farms that grow large quantities of dry forage incidental to the grain, which would be otherwise wasted; second, pasture farms, where for some reason grain cannot be successfully grown and where the land is suitable for pasture.

\section{EQUIPMENT FOR SUMMER FEEDING}

In considering the profits likely to result from steer feeding, among the first items to be taken into account is the equipment. While the equipment for beef-production is not nearly as extensive as for milk-production, there are, nevertheless, a few necessities to be provided. Since the equipment for summer feeding on pasture differs from"that of winter feeding in the dry-lot, each will be considered separately.

308. Pasture. - The importance of properly managed pastures cannot be overestimated. The general management, such as the importance of a good stand of grass; of keeping down the weeds; of providing suitable drainage; of top dressing with barnyard manure when convenient; and of not turning to pasture too early in the spring, is very important.

309. Feed-bunk. - While any kind of durable box or trough, slightly elevated, may be used in feeding grain, a feed-bunk will prove the most efficient. These feed-bunks are three feet wide, fifteen feet long, inside dimension, and two and one-half feet high. One bunk of the dimensions given will be sufficient to accommodate fifteen to twenty cattle, depending on their size. Any kind of lumber may be used, but oak is most durable and will make 
a stronger bunk. Such a bunk can be moved from place to place.

310. Self-feeder. - This is a feed box or bin holding a large amount of grain and so arranged that part of the grain is accessible to the cattle at all times. The great advantage stated for selffeeders is that they save labor. They have been used with varying success, some cattle feeders using them continuously, others using them one or two years and then abandoning them. In some localities the self-feeder is common, in others it is not known.

311. Shades. - When there are trees in the pastures, the matter of shade need receive no attention, but in the absence of natural shade, some provision should be made for it especially during the hot, dry weather when the flies are troublesome. Droves of fattening cattle occasionally become so excited, due to the excessive heat and flies, that they bunch up or stampede and sometimes injure one another.

312. Water. - Fattening cattle must be supplied with an abundance of fresh water at all times. Many pastures throughout the country are not thus supplied. As a rule beef cannot be produced economically on such farms. The hotter and dryer the weather, the more water the cattle need, and this is just the time when there is likely to be a shortage. In the absence of runaing water, perhaps the most efficient source is a good well, equipped with a wind pump. When the water is pumped by hand and the drove of cattle large, the water supply is likely to be deficient. It is also important that the water be fresh and clean. Hot, stale, and muddy water, laden with mosquito larvæ and other impurities, is not fit for cattle to drink. Something better than mudholes should be supplied.

313. Salt. - This should either be kept before the feeding cattle at all times or supplied them regularly twice each week. A very good plan is to cut a common salt barrel in two at the middle and place one-half where the cattle can have free access to it. This should be under a shed, as rain dissolves the salt. 


\section{EQUIPMENT FOR WINTER FEEDING}

The equipment for feeding cattle in the winter deserves special attention; not that it is difficult or expensive but that the proper kind of equipment is often neglected and much money expended for items that are not only unnecessary but positively objectionable. The most particular item is that of efficient shelter. Other items are the feed-lot and its location, the racks from which to feed dry forage, and the like.

314. Shelter for winter feeding. - While it is essential to provide warm winter quarters for the dairy cow, because she is thin in flesh and because of the nature of her product, such warm quarters are not necessary for the fattening steer. The fattening steer possesses a coat of fat or flesh which serves to protect him from the cold, and when on full feed the heat generated in the body by masticating, digesting, and assimilating the food is sufficient to maintain the body temperature. No doubt the needs of the fattening animal are such as to make a reasonable amount of cold air beneficial rather than detrimental. But it is very desirable that the fattening steer be kept dry and provided with a comfortable dry bed. Dry quarters are far more important than warm quarters. A structure which protects the animals from the rain and snow and provides them with a dry comfortable bed is sufficient.

315. The feed-lot. - Relatively too little attention is given the feed-lot. In choosing the location of the lot, consideration should be given to drainage and the natural protection. A south slope is the most desirable, as the water will drain off quickly after a rain, and the full benefit of the sun's rays will be received. A muddy lot is one of the greatest objections to winter feeding. Over much of the grain belt the soil is rather impervious to water, which is held at the surface. The cattle in walking mix the water with the soil, which is often clay, thus making a most disagreeable mud.

The only known corrective for such lots is to pave them, at 
least in part, particularly where the animals must lie and where the feed-bunks and racks are placed. For this purpose various materials are used, chiefly cobblestones, bricks, cement, and plank. Before laying the pavement a grade should be established slightly higher than the surrounding surface, to eliminate the surface water. The grade should have a slope of at least one inch to six feet.

316. Platform for feed-bunks. - On soils that are porous and from which the water drains off rapidly, the mud gives little inconvenience except about the feed-bunks, dry-forage-racks, and watertank. About these and extending back six feet, may be placed a few loads of coarse gravel or, better still, a pavement similar to that described above, or a plank platform. Whatever the material used in construction, it should be so arranged that the farmer may drive alongside the bunk or rack with a load of feed.

317. Dry-forage-rack. - It is not advisable to have the feedbunks and the dry-forage-racks combined, since the litter from the dry forage falling upon the grain renders it distasteful to cattle, particularly when on a full grain ration. Neither is it advisable to construct such racks under the shed except where the climate is very disagreeable, though they should be placed to the south of the shed or barn to protect them measurably from the winds and driving storms. The form and shape of the dry-forage-racks will depend on the condition in which dry forage is fed, cornstalks calling for one form, hay for another, and chopped hay or shredded fodder for still another. As these racks are likely to be permanent, they should be constructed to meet the particular conditions under which they are to be used.

318. Water-tanks. - When the water-tanks are not too large, a very good way to prevent freezing, except in very severe weather, is to encase the tank in a box or frame and fill this frame with litter from the horse stable. The frame should be so constructed as to permit the use of a layer of this manure at least one foot thick all around the tank. 


\section{QUESTIONS}

1. How many beef cattle are there in the United States? How many in your state? In your county? How does your state rank with other states in the production of beef? How does your county rank with other counties of the state? Name the ten leading beef-producing states. Which state possesses the largest number to the square mile? To the farm?

2. Why has the quality of beef-producing animals deteriorated during the past decade, especially throughout the principal agricultural states? If this condition continues where are we to get our beef supply?

3. In selecting breeding stock to improve the quality of our beef, what are the essential factors to be considered? Why is coöperative breeding of advantage?

4. Why is summer feeding on pasture likely to be more profitable than winter feeding in the dry lot?

5. Why is a warm barn objectionable as winter quarters for fattening steers? Why do fat cattle differ from dairy cattle in this respect?

6. When a farmer buys cattle and fattens them, how much above the purchase price per hundred pounds must he obtain to make a profit? What is this difference called? What factors influence it?

7. When is a fat steer ready for the market? What changes take place in his flesh if he is held too long after being finished?

8. Which is the best season of the year to market steers in your vicinity? How much does the local buyer deduct for "drift," when he purchases the cattle at the farm?

9. Name the ten largest beef cattle markets in the United States. How many cattle are handled at each annually?

10. Name the more common diseases of cattle. Give symptoms of each. Why is tuberculosis so common among cattle? How can it be stamped out?

11. How much does your local butcher pay for the cattle he slaughters? How much will the animals lose in dressing? How much does the butcher charge for the beef? Approximately what are his profits on a steer that weighs 1000 pounds alive? What are some of the other products upon which the butcher realizes besides the beef? 
12. Approximately what percentage of the live steer is edible? What percentage of the dressed carcass is edible?

13. Compare the economic food-production of beef and dairy cattle. Find out the exact amount of food consumed, and the exact amount of milk produced by a good cow for one year. Calculate the amount of milk produced for each 100 pounds of food consumed. From some beeffeeding experiment, calculate the number of pounds gained by the animal for each 100 pounds of food consumed. Which produces human food more economically, the dairy cow or the beef animal?

14. On the basis of food consumed, at what price per pound must beef retail in order to be as remunerative as milk retailing at five cents per quart? Has this a bearing upon the increasing popularity of the dairy cow and the decreasing popularity of the beef animal?

15. Wherein has the beef animal the advantage of the dairy cow? In what particular sections of the country is beef production likely to remain a profitable industry? Explain. 
PART THREE - SHEEP 


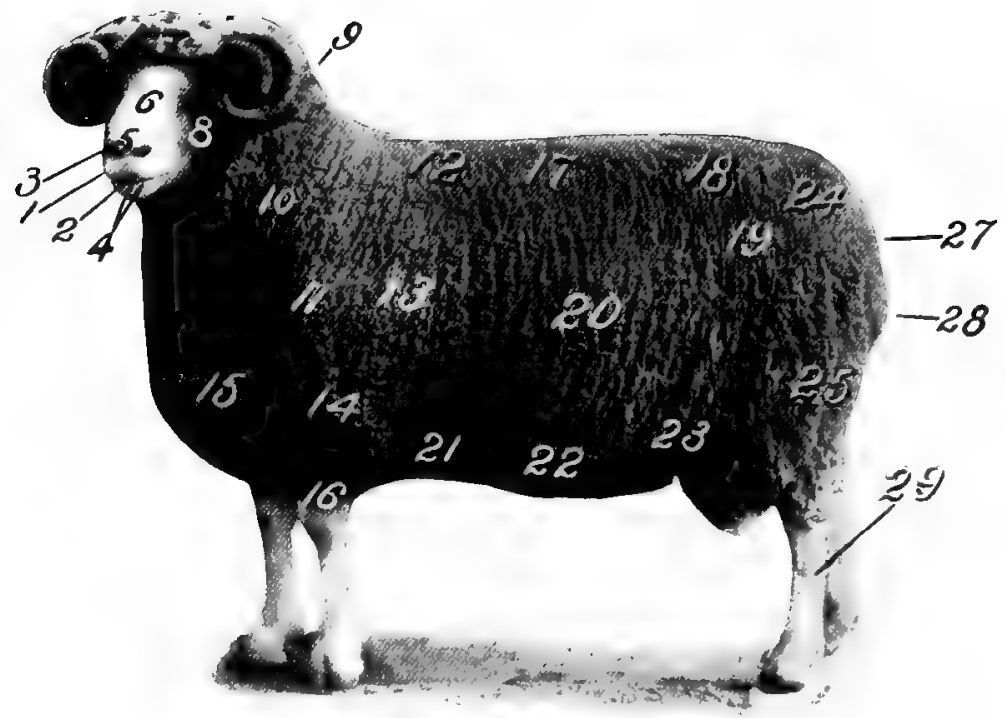

FIG. 69.- Points of the sheep.
1. Muzzle.
2. Mouth.
3. Nostril.
4. Lips.
5. Nose.
6. Fare,
7. Forehead.
8. Eyre.
9. Ear.
10. Neck.
11. Shoulder vein.
12. Shoulder top.
13. Shoulder.
14. Arm.
15. Brisket,
16. Fore leg.
17. Back.
18. Loin.
19. Hip.
20. Ribs.

21. Fore flank.

22. Belly.

23. Hind flank,

24. Rump.

25. Leg of mutton.

27. Dock.

28. Twist.

29. Hind leg. 


\section{CHAPTER XII}

\section{BREEDS OF SHEEP}

THERE are two distinct types of sheep: the wool type, adapted for the production of wool, and the mutton type, adapted for . the production of meat. These types are controlled to a considerable extent by the demands made upon the body of the animal. Thus in the case of wool production as much skin surface as possible is desired, and the skin is thrown into folds. On the other hand,

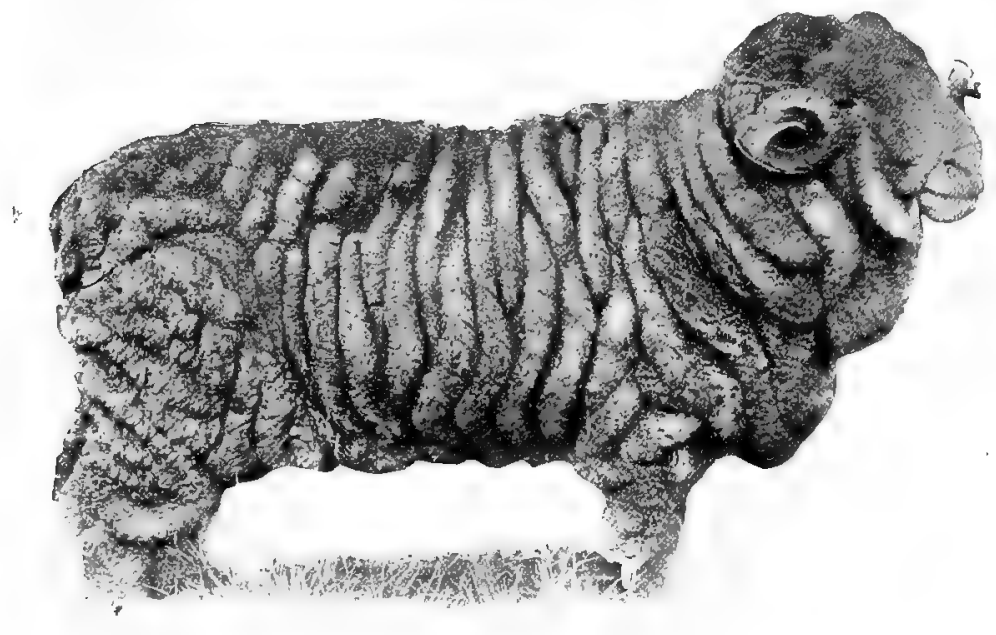

FIG. 70,-Merino ram. Class A.

in the mutton type the carcass is the product, and a plump, full body is desired. The energy of the food should go to the production of mutton and not of wool. These two types, therefore, are of 
necessity widely different, and one can no more expect maximum wool production and maximum mutton production in the same sheep than he can have greatest milk flow and greatest yield of beef in the same cow.

319. The fine-wool type. - This type may be compared to that of the dairy cow. The body is spare, lacking in fullness, in breadth

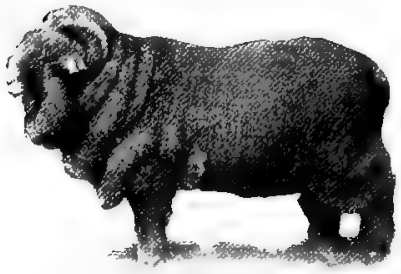

F1G. 71.- Merino ranı. Class B. of back, and in general thickness throughout. The wool is rather short, very thick over the entire body, and exceedingly fine.

There are three classes of finewool sheep, grouped according to the folds or wrinkles on the neck and body. By common consent these forms are distinguished by letter as follows: Class A.-Merino, representing those with heavy folds at the neck and over the body and hindquarters, and possessing an abundance of yolk or grease (Fig. 70). Class B.- Merino, representing those with fewer and smaller folds on neck and body, and carrying less yolk in the wool (Fig. 71). Class C. - Merino, representing those with comparatively smooth bodies, possessing less yolk than Class B, though the wool is, as a rule, somewhat longer (Fig. 72). Of the three classes $A$ is perhaps the heaviest shearer, a case being reported of an animal shearing 36 per cent of his gross weight.

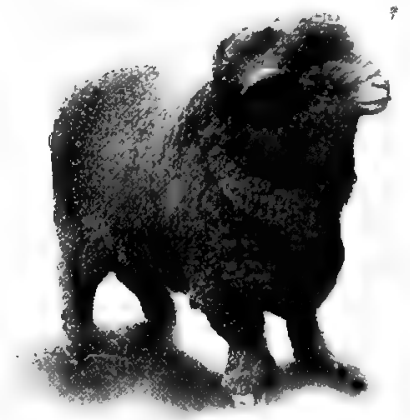

Fig. 72. - Merino ram. Class C.

320. The mutton type. - In form, this type resembles beef cattle. The animals are low-set, compact, and blocky in appearance. This type is uniformly covered with a smooth, deep layer of high-class 
mutton, without wads of fat or patchiness on sides or rump. The fleece covering is exceedingly variable in length and fineness.

Sometimes sheep are classified according to the quality and length of the wool, in which case we have the fine-wool type, noted for the fineness of the fleece, the coarse-wool type, so called because of the coarse fiber of wool, and the long-wool type, noted for the length of the fleece. The coarse-wool and the long-wool correspond with the mutton type (Fig. 75).

\section{THE FINE-WOOL BREEDS OF SHEEP}

The Name, Native Home, Color of Points, Approximate length of Wool, Weight of Fleece, and the Average Weight of Sheep for Each of the Fine-Wool Breeds

\begin{tabular}{|c|c|c|c|c|c|}
\hline $\begin{array}{l}\text { NAME OF } \\
\text { BREED }\end{array}$ & $\begin{array}{l}\text { Native } \\
\text { Home }\end{array}$ & $\begin{array}{l}\text { Color of } \\
\text { PoInTs }\end{array}$ & $\begin{array}{l}\text { LENATH OF } \\
\text { WOOL, IN. }\end{array}$ & $\begin{array}{c}\text { WeIGHT OF } \\
\text { FLEECE, LBS. }\end{array}$ & $\begin{array}{l}\text { WEIGHT OF } \\
\text { SHEEP, LBG }\end{array}$ \\
\hline $\begin{array}{r}\text { American } \\
\text { Merino }\end{array}$ & $\begin{array}{l}\text { United } \\
\text { States }\end{array}$ & White & $2-2 \frac{3}{4}$ & $12-25$ & $100-150$ \\
\hline $\begin{array}{l}\text { Delaine } \\
\text { Merino }\end{array}$ & $\begin{array}{l}\text { United } \\
\text { States }\end{array}$ & White & $3-5$ & $10-20$ & $100-150$ \\
\hline $\begin{array}{l}\text { Rambouil- } \\
\text { let }\end{array}$ & France & White & $3-4$ & $10-15$ & $150-185$ \\
\hline
\end{tabular}

321. American Merino fine-wool sheep. - Because this breed of sheep has been so vastly improved in America, its native home is given as the United States, although it is of Spanish Merino origin. The word "Merino" means "from over the sea." In Spain, there formerly existed two great groups of sheep, one known as Estantes, or stationary, a rather coarse-wooled type; the other known as Transhumantes, or migratory, a fine-wooled type, which was driven up into the mountains to graze during the summer and returned in the fall to their original home. The American Merino descended largely from the latter type, although collected from 
a number of provinces, the more important being Paular, Aguirre, Negrette, Guadalupe, Escurial, and Infantado.

During the eighteenth century the Spanish Merino was widely distributed, being introduced to Sweden in 1723, to Saxony in 1765, to Germany in 1768 , to France in 1768, to England in 1787, to the United States in 1793, and to Australia in 1797.

In America, improvement began with the importations of Seth Adams, in 1801, then of Massachusetts, but later of Ohio; with the importations of Colonel David Humphreys of Connecticut in 1802 ; with the importations of Robert Livingston of New York in the same year; and with the importations of William Jarvis of Vermont, who began in 1809 and at different times introduced a total of about 4000 Spanish Merinos, which were well distributed throughout the eastern states. These men did much to improve the Merino, particularly the character and quality of the fleece, and to their flocks trace most of the best fine-wool sheep of to-day.

322. Description of American Merino sheep. - In size, this breed ranks medium, with a form typical of fine-wool sheep. The head is small, with nose and ears white, and with the rams carrying heavy, spirally twisted horns, while the ewes are hornless. The neck is thin and of medium length, shoulders sloping, chest narrow but deep, withers thin, back rather narrow, rump often steep, thighs thin, and legs small and fine. The skin is an important factor and should be bright pink in color. It is often folded about the nose, neck, breast, shoulders, lower sides, rump, and thighs (Figs. 70, 71).

323. The American Merino fleece. - This is the finest wool produced. The more folds on the body and the more crimped the fiber, the finer the staple. The fleece covers the entire body except the nose, lower third of head, and the ears. It contains much oil or yolk, which, if scoured off, may shrink the wool 65 per cent in weight. Because of this excess of oil, the wool collects dust, giving the outside of the fleece a dirty black color. 
The Comparative Diameter of the Wools of Different Breeds of SHew

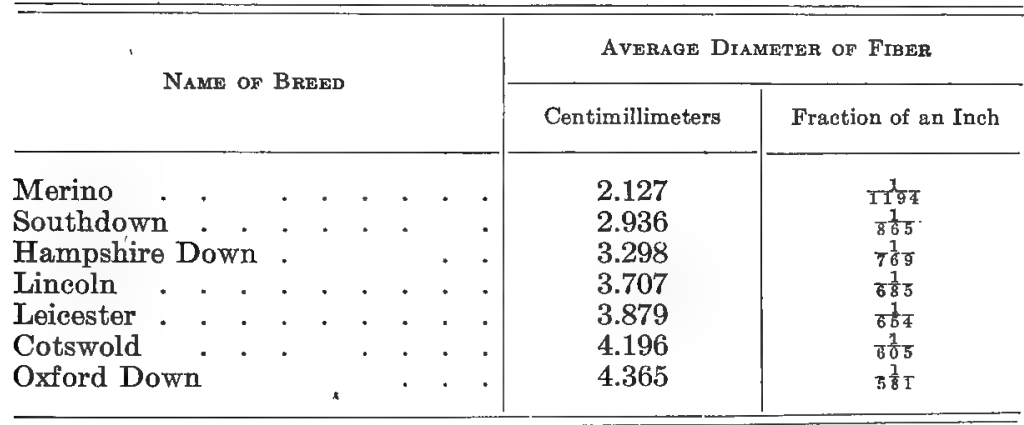

324. Delaine Merino fine-wool sheep. - The word "Delaine" is of French origin and signifies "from wool." Delaine wool can be combed and spun with the fibers of full length, making a fabric of great strength and durability. It is used in making fine, untwilled, worsted dress goods. The Delaine type has been developed from importations of Spanish Merinos, somewhat similar to the American Merino. There are several families of Delaines, of which the following are most important:-

The Dickinson Delaine. - This family was originated and developed by William R. Dickinson of Steubenville, Ohio, who bred from about 1809 to 1830 . James McDowell became possessed of some of the Dickinson flock and established the McDowell strain of Dickinsons.

The National Delaine. - This family was originated by Alexander Reed of Washington County, Pennsylvania, who began breeding about 1821, although the sheep he used in establishing the family was imported from Spain by R. W. Mead in 1820 . Animals from the Reed flock became widely distributed among breeders in Pennsylvania and West Virginia, who developed the family, perhaps more than Reed.

The Black Top Spanish Delaine. - This family of Merinos was 
established by William Berry of Washington County, Pennsylvania, who began the work about 1821, although the sheep employed in the breeding operations descended from the Colonel Humphrey importation of 1802. Mr. Berry endeavored to produce a large,

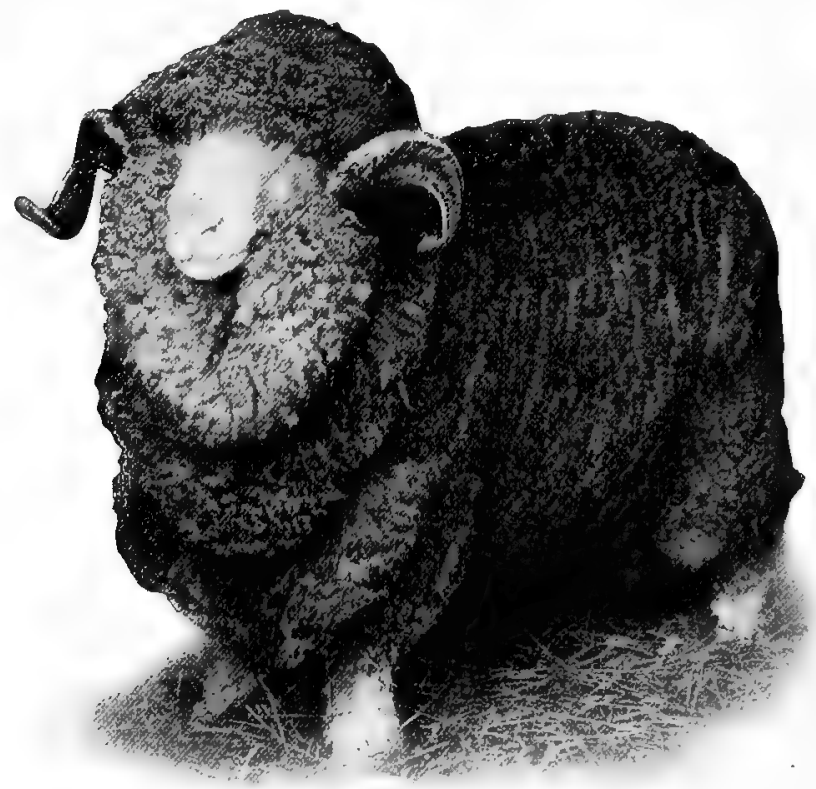

FIG. 73. - The Delaine Merino ram "Beacon." Fine-wool type.

heavy-shearing, fine-wool sheep, selecting those of darkest outer covering, which he termed Black Tops.

325. Delaine Merino compared with the American Merino. In a very general way these two types are similar, with the Delaines possessing fewer folds of the skin, although the several families of Dalaines vary widely in size and conformation. Thus in the Dickinson Delaine, which is one of the largest, the standard weight for mature rams is 200 pounds, and that for ewes, 150 pounds, 


\section{Breeds of Sheep}

while in the National Delaine, which is perhaps one of the smallest, the standard weight for a mature ram is $\mathbf{1 5 0}$ pounds, and for the ewe, 100 pounds. Likewise, there is considerable variation in the conformation, the mutton qualities of some of the families having been especially looked after by the breeders until they possess somewhat the form of the mutton type (Fig. 73).

326. Rambouillet fine-wool sheep. - This breed of sheep was developed in France, although of Spanish Merino ancestry. It takes its name from the Royal farm at the village of Rambouillet,

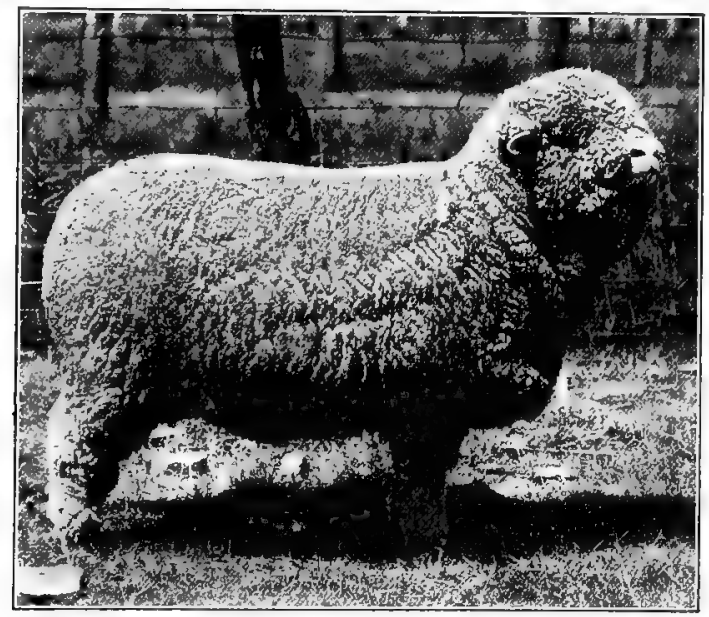

FIG. 74. - The Rambouillet. Fine-wool type.

near Paris. The first importation of sheep to this Royal farm was in 1786, when M. Gilbert was sent to Spain and selected a flock of 366 animals representing several different families. In 1801, Gilbert made a second importation, securing 237 sheep, which he says was not the equal of the first importation. Improvement was secured principally by selection, the object being to produce a large carcasi, of good mutton form, covered with a good fleece. The French government officials kept careful 
records of their breeding operations at Rambouillet for upwards of a hundred years. Much progress was made in point of size, but the fleece did not increase in the same ratio.

327. Rambouillet compared with the American Merino. - The former does not differ from the latter except in size and possibly in a smoother body. Individuals of the former, both male and female, may go as much as a hundred pounds heavier than the latter. The Rambouillet is often criticised for possessing a tendency to coarseness of bone and length of leg. The large body, usually smooth and free from folds, except occasionally a few wrinkles on the neck, is completely covered with a fine, white fleece, which, however, lacks the yolk or oil of the American Merino (Fig. 74).

\section{THE MUTTON BREEDS OF SHEEP}

The Name, Native Home, Color of Points, Approxmate Length of Wool, Weight of Fleece, and the Average Weight of Sheep for Each of the Mutton Breeds

\begin{tabular}{|c|c|c|c|c|c|}
\hline $\begin{array}{c}\text { NAME OF } \\
\text { BREED }\end{array}$ & $\begin{array}{l}\text { Native } \\
\text { Home }\end{array}$ & $\begin{array}{c}\text { Color of } \\
\text { PoINTS }\end{array}$ & $\begin{array}{l}\text { LENGTH OF } \\
\text { WOOL, IN. }\end{array}$ & $\begin{array}{l}\text { WEIGHT OF } \\
\text { WOOL, LBS. }\end{array}$ & $\begin{array}{l}\text { WEIGHT OF } \\
\text { SEEEP, LES. }\end{array}$ \\
\hline Southdown & England & Gray & $2-3$ & $4-8$ & $125-175$ \\
\hline Shropshire & England & Dark brown & $3-4$ & $8-12$ & $155-225$ \\
\hline Hampshire & England & Dark brown & $3-4$ & $5-8$ & $180-250$ \\
\hline Suffolk Down & Wngland & Black & $3-5$ & $5-8$ & $180-240$ \\
\hline Oxford Down & England & Brown & $4-6$ & $6-10$ & $200-325$ \\
\hline Dorset & England & White & $3-4$ & $6-9$ & $150-225$ \\
\hline Cheviot & $\begin{array}{l}\text { Scotland } \\
\text { England }\end{array}$ & White & $5-8$ & $6-10$ & $150-225$ \\
\hline
\end{tabular}

328. Southdown mutton sheep. - This breed was developed in southeast England, particularly in the county of Sussex. Extending east and west through this region is a range of low chalky hills known as the South Downs from which the breed derives its name. The native sheep were small and ill-shaped, with light 
forequarters, long, drooping back, lacking spring of rib, and with the wool short, coarse, and thin.

Improvement began about 1775 under the leadership of John Ellman, of Glynde, who doubtless received his inspiration from

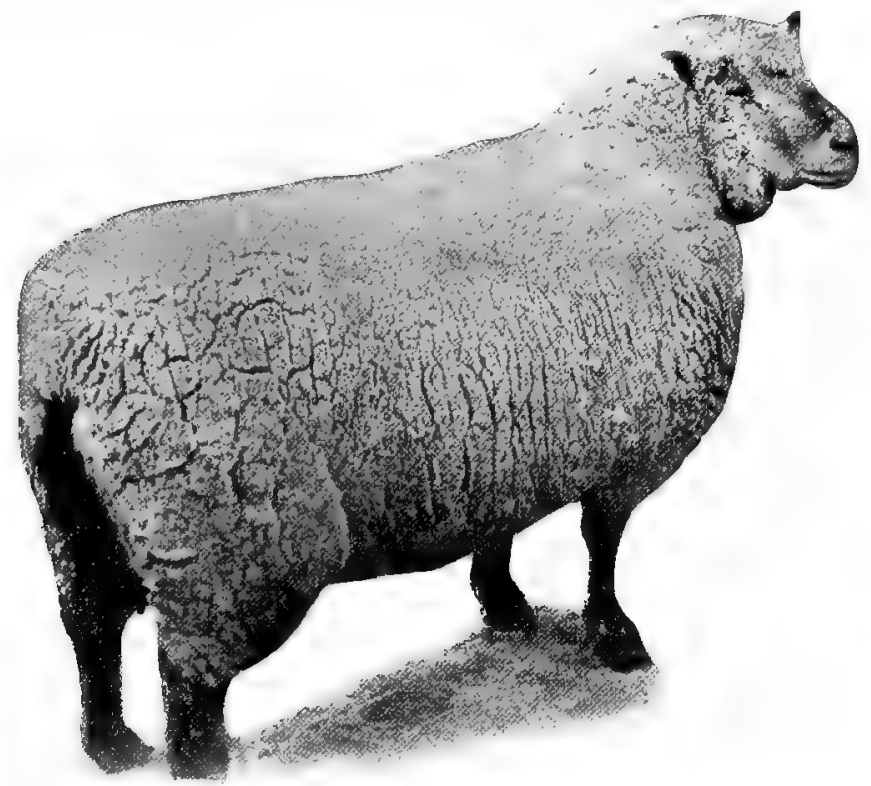

FIG. 75. - The Southdown. Mutton type.

the success of Bakewell with the Leicester. Ellman was impressed with the necessity of improving the native sheep to secure a better mutton form and an ease of fattening. He procured the best sheep that he could find and succeeded in creating a superior mutton type. He possessed a very large flock numbering about 1400 head. Jonas Webb of Barbaham, Cambridge, England, was another noted Southdown breeder. He began breeding about 1821 with a selection of sheep from the Ellman flock. Webb purchased the 
best sheep he could buy, regardless of price. He built on Ellman's foundation and produced the best known type of mutton sheep, improving the general symmetry, increasing the size, promoting the early fattening tendency, and improving the quality of the flesh.

The Southdown was the first of the Down or mutton breeds to be improved, and has been used in the development of the other mutton breeds, more particularly the Shropshire, Hampshire, and Oxford. It early became the favorite breed of the English royalty and aristocracy, and remains so to the present time.

329. Description of the Southdown sheep. - In size this breed is inferior to the other mutton breeds. Notwithstanding this, the form is so meritorious that the animals are very heavy for their size. The head is of medium size and hornless, with the forehead and cheeks well covered with wool. The neck is short and thick; the shoulders are broad and full; the back is broad and straight, with ribs well arched and long, giving capacity ; the rump is broad, square, and full; and the hindquarters long, with the twist extremely deep and full. The skin should be a bright pink in color. The entire body should be covered with a compact fleece of moderate length, which should be white in color and which should carry some oil or yolk (Fig. 75).

330. Shropshire mutton sheep. - This breed was developed in the counties of Shropshire and Stafford, Fingland. The origin of the breed is obscure. The name, as applied to sheep, is mentioned in English literature as far back as the fourteenth century, there being at that time a grade of wool designated as Shropshire. The improvement, however, is of comparatively recent date, for Plymley, writing on the agriculture of Shropshire in 1803, describes the native sheep as possessing horns and black faces, and clipping a fleece of about two pounds.

The Shropshire owes much of its present improvement to Samuel Meire, of Berrington and Harley. He sought to reduce the general coarseness, to remove the horns, to improve the levelness of the back, to increase the spring of ribs, and to improve the mut- 
ton qualities generally. He secured Southdown rams of John Ellman and used them in his flock. Leicester blood was also introduced for the purpose of improving the feeding qualities. Both the Southdown and the Leicester improved the general symmetry of the Shropshire sheep.

331. Shropshire compared with the Southdown. - The former is the larger and ranks among the heaviest of the mutton breeds.

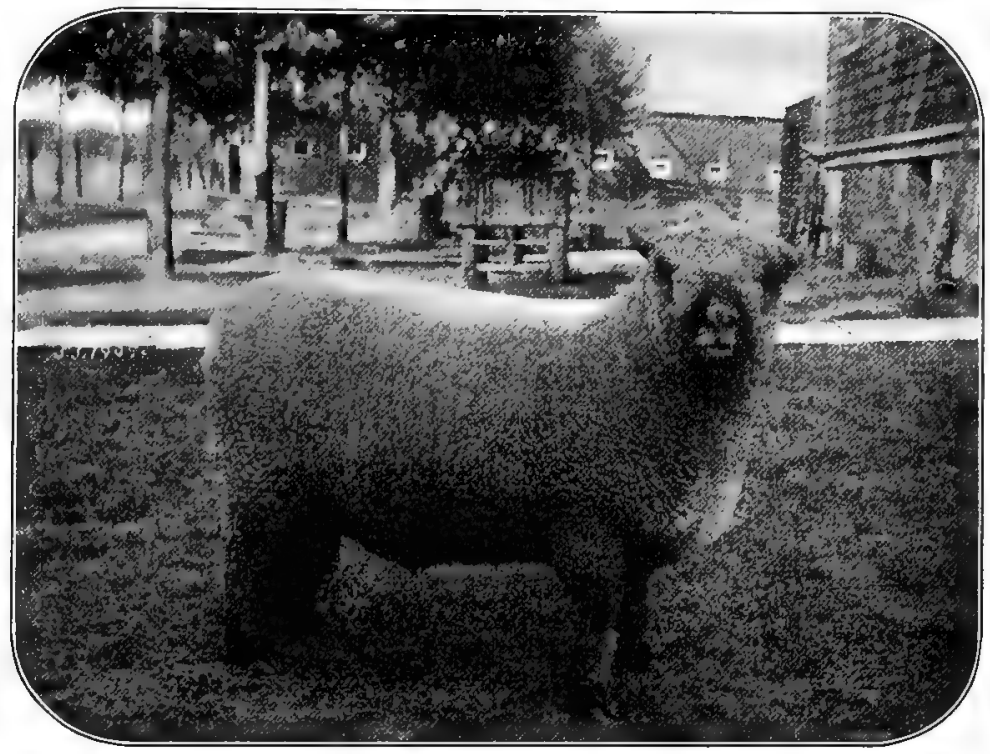

FIG. 76. - The Shropshire. Mutton type.

The more approved type of Shropshire calls for all the best features in the mutton sheep. The head is hornless, and in the best specimens is covered with a cap of wool almost to the nostrils. In form it is not so good in the thigh and twist as the Southdown. In general outline the Shropshire is taller and more rangy than the Southdown. The length of wool as well as the quantity exceeds 
that of the Southdown, and it is said that the Shropshire excels in fecundity, early maturity, and quick-fattening qualities (Fig. 76).

332. Hampshire mutton sheep. - This breed was developed in central England, particularly in the county of Hampshire. The early origin is more or less obscure, but traces back to at least two

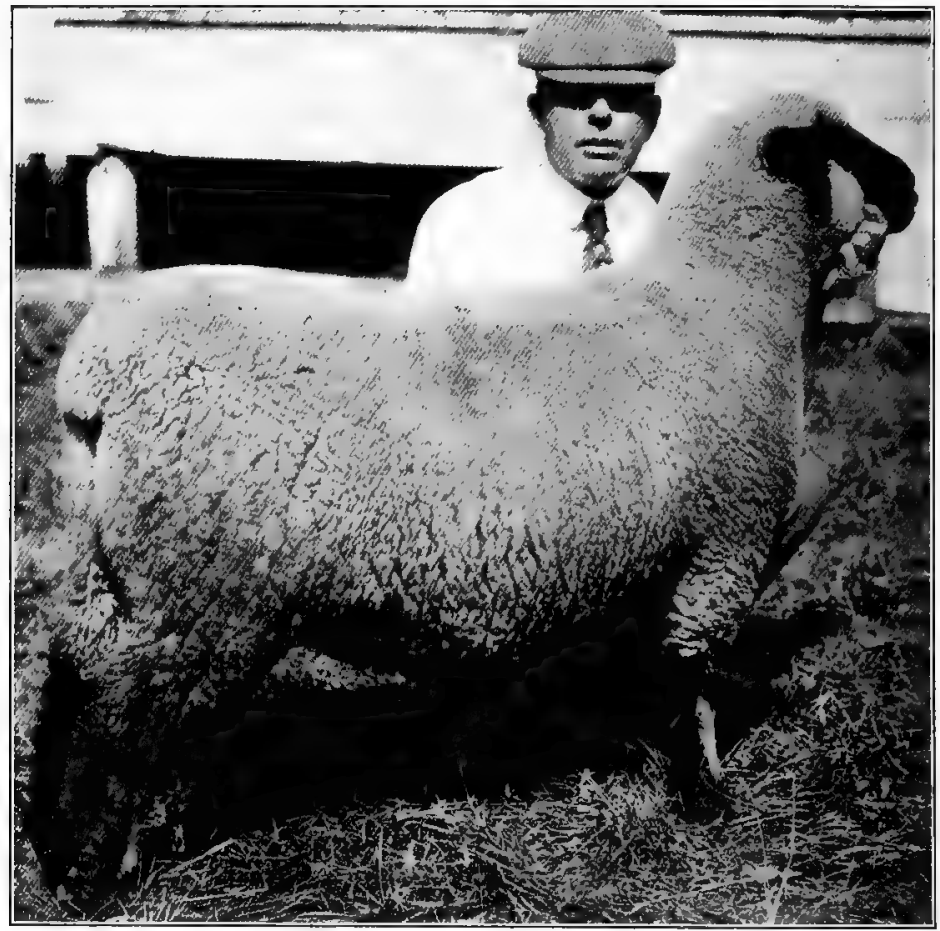

Fig. 77. - The Hampshire. Mutton type.

sources. Formerly there existed in Wiltshire, and to some extent in Hampshire and other near-by counties, a large, slow-maturing, narrow-backed, horned type of sheep known as Wiltshire-horned. 
In Berkshire there was another large, strong-boned, and horned type known as the Berkshire-knot sheep. These two types were interbred and crossed with the Southdowns, which resulted in a type known as the West Down, the ancestor of the present-day Hampshire.

Marked improvement of the Hampshire breed began about 1834 under the leadership of William Humphrey of Oak Ash, Newbury. He procured a choice flock of West Downs and began his work by selection, but later conceived the idea that crossing would be of advantage. Consequently he obtained three Southdown rams from Jonas Webb, and crossed on his ewes with success.

333. Hampshire compared with Southdown. - The former is the larger and coarser throughout, with the fleece somewhat resembling that of the latter, although it is coarser and less dense. The face of the Hampshire is inclined to be long, and the nose somewhat Roman in the rams. The ears are large and drooping, and the face and legs almost black. As compared with the Shropshire, it is longer in body, and longer of leg; which, in connection with its coarse features, gives it a very much larger general appearance (Fig. 77).

334. Oxford Down mutton sheep. - This breed was developed in England, principally in the county of Oxford. The origin of the Oxford Down breed of sheep is comparatively recent. 'About 1829, John T. Twynham conceived the idea of developing a new breed of sheep combining the desirable qualities of the long-wooled breeds and of the Down breeds. He began breeding by mating compact Costwold rams with Hampshire ewes. A little latér, perhaps about 1833, Samuel Druce and William Gillet began a similar line of breeding, and introduced Southdown blood to some extent, although the Hampshire was the chief source of Down blood. Up to 1857 the breed was known as Down-Cotswold, but in that year the name "Oxfordshire Down" was adapted. Later it was changed to Oxford Down, and is now commonly spoken of as Oxford. 
335. Oxford Down compared with Southdown. - The former is larger and coarser, with a longer fleece and darker points. The Oxford is the largest of the Down breeds, standing very much higher than the Southdown, and is more rangy. As would be expected, from the Cotswold ancestry, the Oxford has a longer

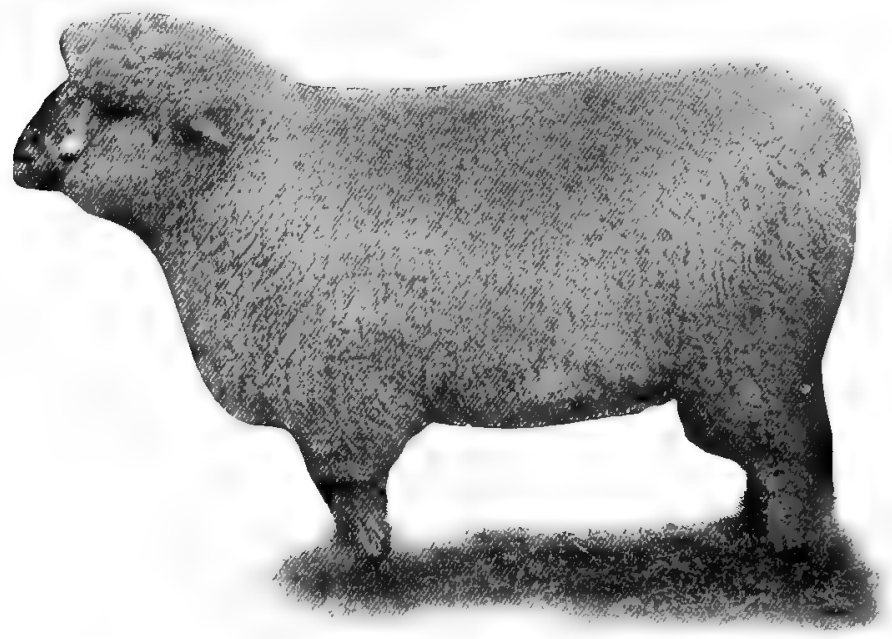

FIG. 78. - The Oxford. Mutton type.

and coarser fleece than any other breeds of the mutton group; while from the Hampshire line, it inherits a tendency to dark or bluish skin, as well as black spots and hairs in the fleece. The modern Oxford, however, is being rapidly improved, and these objectionable features overcome (Fig. 78).

336. Suffolk Down mutton sheep. - This hreed was developed in southeastern England in the counties of Suffolk, Norfolk, Essex, and Kent. The Suffolk is the result of a cross between the old Norfolk breed and the Southdown. This old Norfolk breed resembled the Blackfaced Highland to some extent, having the 
same colored points, large bone, long, spiral horns, long body, flat ribs, and rather nurrow loins. Later Hampshire blood was used with marked success. The Southdown cross removed the horns from the old Norfolk breed, gave a better carcass, and increased the early-maturing and easy-fattening qualities, while

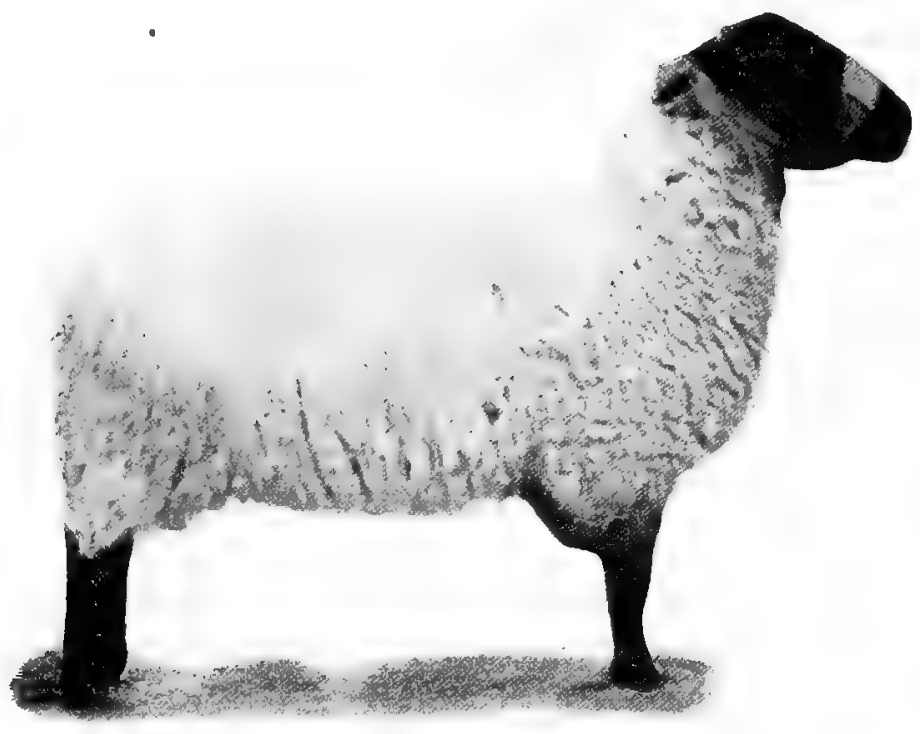

Frg. 79. - The Suffolk. Mutton typc,

the Hampshire cross gave size and weight. The modern Suffolk is a conspicuous example of the remarkable success in crossbreeding.

337. Suffolk Down compared with Southdown. - The former is larger and more rangy with black face and long, clean, black legs. No doubt, because of its ancestry, it slightly resembles the Southdown in character and wool, but is about one-third larger in body and much longer in the leg. The ears are black, rather large, and 
tend to droop. There is considerable resemblance between the Suffolk and the Hampshire, but, as a rule, the breeds can be distinguished by the bareness of the Suffolk head, which is free from wool (Fig. 79).

338. Dorset-Horn mutton sheep. - This breed originated in central and southern England, notably in the counties of Dorset,

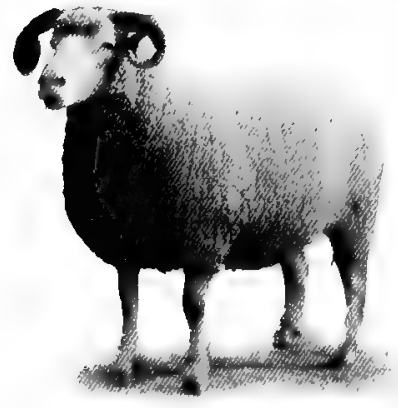

Fig. 80.--The Dorset-Horn. Mutton type. Somerset, and Wiltshlre. In England the breed is often spoken of as Somerset. This is one of the oldest distinct breeds of sheep, no other breeds or race having mingled with it. The original stock was small, light in the shoulders, with white face and legs, but a flesh-colored nose. Both males and females have horns. The stock of Somerset was somewhat larger, coarser, and longer wooled than that of Dorset County. The general improvement of the breed as a whole was brought about by selection on the part of several breeders in western Dorsetshire. Perhaps the most noted of the early breeders was Richard Seymour of Bradpole, Dorset County.

339. Dorset-Horn compared with Southdown. - The former is larger, longer bodied, and longer of leg than the latter. While the fleece of the Dorset somewhat resembles that of the Southdown, the general features present a strong contrast. Among Dorsets both sexes have horns, those of the male being curved backward and around spirally; those of the female curved outward, downward, and forward. The face and legs are pure white. In length, quality, and quantity of fleece, the Dorset ranks intermediate between the Southdown and the Shropshire (Fig. 80).

The Dorset-Horn hreed is famous for its prolificacy, breeding 


\section{Breeds of Sheep}

twice annually, and for its ability to produce lambs earlier in the season than any other breed.

340. Cheviot breed. - This breed was developed in the border country between England and Scotland, taking its name from the hills bounding the two countries. The origin of the breed is obscure, as sheep have been bred for a very long time among these hills on the Scottish border. The monks of the middle ages had

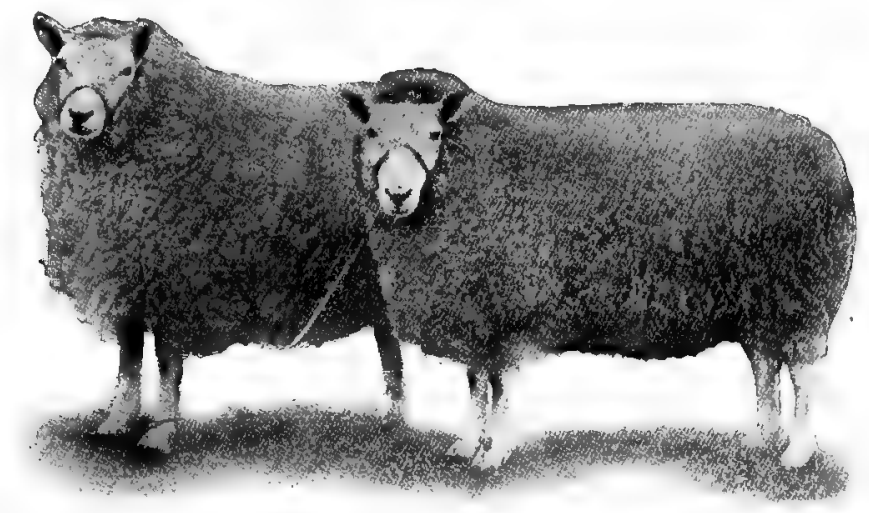

Fig. 81.-The Cheviot. Mutton type.

the breed about the pasture lands of the old monasteries. We are indebted to these sheep-farming churchmen for the first improvement. The breed owes its present condition to selection and better care on the part of breeders generally.

341. Cheviot compared with Southdown. - These two breeds present a strong contrast. The face and legs of the Cheviot are white and free from wool, although the body is closely covered with long, soft wool, which is pure white. The breed is very hardy and active; in fact, the temperament is characteristic of Scottish animals generally (Fig. 81). 


\section{LONG-WOOL BREEDS OF MUTTON SHEEP}

The Name, Native Home, Color of Ponsts, Approximate Length of Wool, Weight of Fleece, and Average Weight of Sheep for Each of the Long-Wooled Mútion Breeds

\begin{tabular}{|c|c|c|c|c|c|}
\hline$\underset{\text { BAMEED }}{\text { NaME }}$ & Native Home & $\begin{array}{l}\text { CoLOR OF } \\
\text { POINTE }\end{array}$ & $\begin{array}{l}\text { LENGTH OF } \\
\text { WOOL, IN. }\end{array}$ & $\begin{array}{l}\text { WEIGHT OF } \\
\text { WOOL, LBS. }\end{array}$ & $\begin{array}{l}\text { WEIGHT OF } \\
\text { SHEEP, LBE. }\end{array}$ \\
\hline Leicester. & England & White & $6-10$ & $6-10$ & $180-240$ \\
\hline Cotswold . & England & $\begin{array}{l}\text { White, } \\
\text { spotted }\end{array}$ & $8-14$ & $8-12$ & $200-265$ \\
\hline Lincoln & England & $\begin{array}{l}\text { White, } \\
\text { mottled }\end{array}$ & $10-18$ & $10-14$ & $275-350$ \\
\hline $\begin{array}{l}\text { Blackfaced } \\
\text { Highland }\end{array}$ & Scotland & Black & $8-14$ & $4-7$ & \\
\hline
\end{tabular}

342. Leicester long-wooled sheep. - This breed was developed in Leicester County, England. The origin of the breed is obscure. Formerly there existed in Leicester a Iong-wooled, large, coarse, narrow-backed, and slow-feeding type, and it was from this type that the modern Leicester was developed. The first improvement was accomplished by Robert Bakewell, who began his sheep breeding efforts about 1755 . His object was to produce a breed that would fatten quickly and mature early. Before this, size and bodyweight had been the aim of breeders generally. Bakewell attracted wide attention, and his flock became very famous. He let his rams instead of selling them, and some excellent prices were obtained. Thus, in 1787 , he let three rams for $\$ 6000$. The Leicester as improved by Bakewell retains to-day many of the original features.

343. Description of Leicester sheep. - This breed is fairly large, with long body, very wide back, and a tendency to be long of leg. The face and legs are free from wool and covered with a soft, white hair. While the face is only medium in length, the nose is often Roman in form. For a large sheep, the body is plump and 


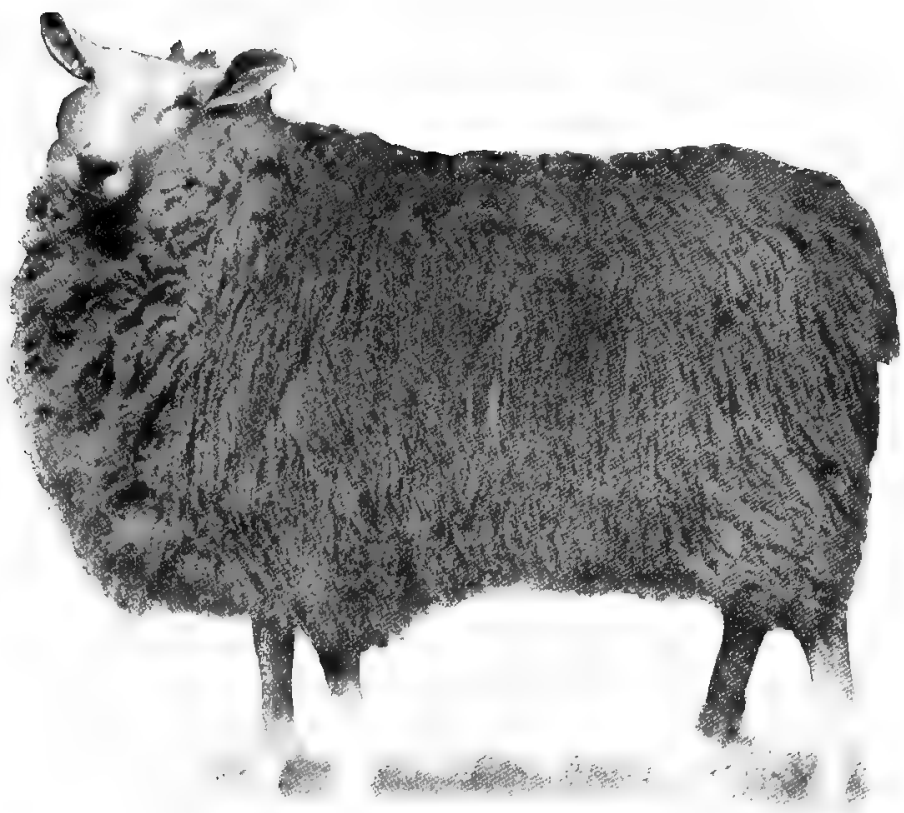

FiG. 82.-The Lcicester. Mutton type.

full. The fleece is excellent for a coarse wool, and usually lies over the body in fine spiral locks. Usually no wool extends in front of the ears (Fig. 82).

344. Cotswold long-wooled sheep. - This breed was developed in Gloucester County, England. The name of the breed is derived from attendant conditions. Formerly, sheep were kept in shelters known as "Cots," and were pastured on the treeless hills known as "Wolds," from which the term Cotswold is derived. The origin is obscure, but much of the improvement was secured by using Leicester rams on Cotswold ewes. The use of Leicester blood reduced the size, improved the symmetry, and increased the early-maturing qualities. 
345. Cotswold compared with the Leicester. - Because of the intermingling of the blood of these breeds, they resemble each

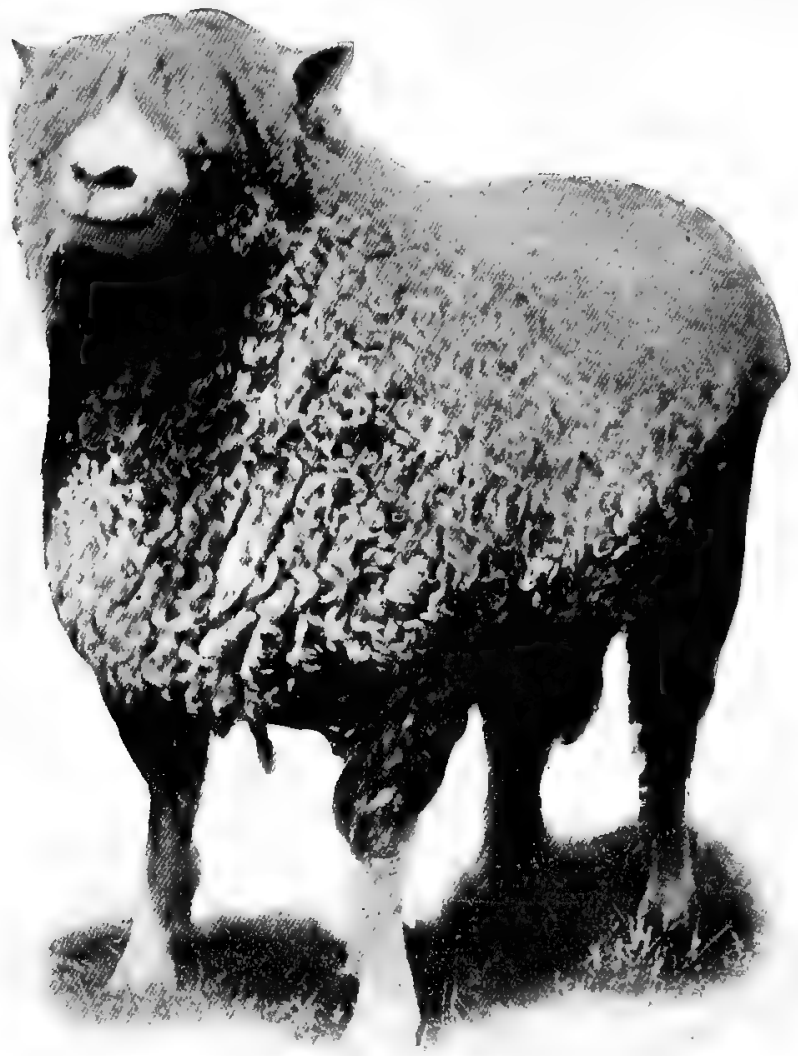

Fig. 83.- The Cotswold. Mutton type.

other somewhat, although the Cotswold is the larger and possesses the longer wool. The head of the Cotswold is a distinguishing feature, being usually white, but sometimes slightly mixed or 
spotted with gray or brown, and with curls or locks hanging over the forehead, often extending to the nostrils. As a rule, the back is fully as broad as the Leicester's, but often lacks the depth, especially behind (Fig. 83).

346. Lincoln long-wooled sheep. - This breed was developed in Lincoln County, on the east coast of England. The native

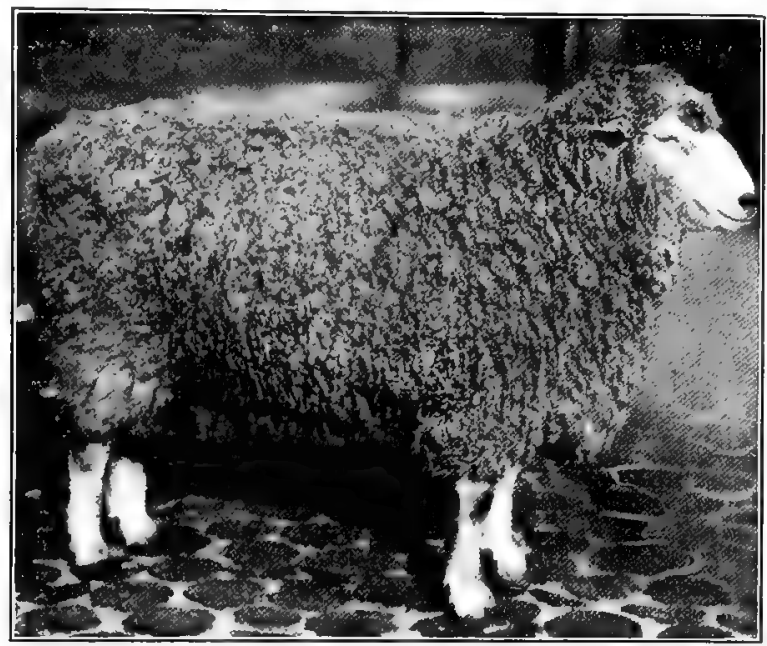

FIG. 84. - The Lincoln. Mutton type.

sheep of Lincolnshire were remarkable for their size and for length of wool, but they were of a coarse type and late-maturing. This old-fashioned type was much improved by the use of Leicester rams such as Bakewell had produced. This Leicester blood reduced the coarseness, improved the symmetry, and increased the early-maturing qualities. Much jealousy sprang up between the Lincoln and Leicester breeders, with the result that neither spared time nor money to promote their respective breeds.

347. Lincoln compared with Leicesters. - The Lincoln is the largest and longest-fleeced breed of sheep in Britain. For length 
of fiber and strength of staple no other breed can rival it. The Lincoln possesses a broader and deeper body than the Leicester, and the legs do not appear so long. The Lincoln can be distinguished from the Cotswold by the absence of long locks hanging from the forehead, although there may be a short foretop (Fig. 84).

348. Blackfaced Highland sheep. - This breed developed in the Highlands of Scotland, notably in the counties of Perth and

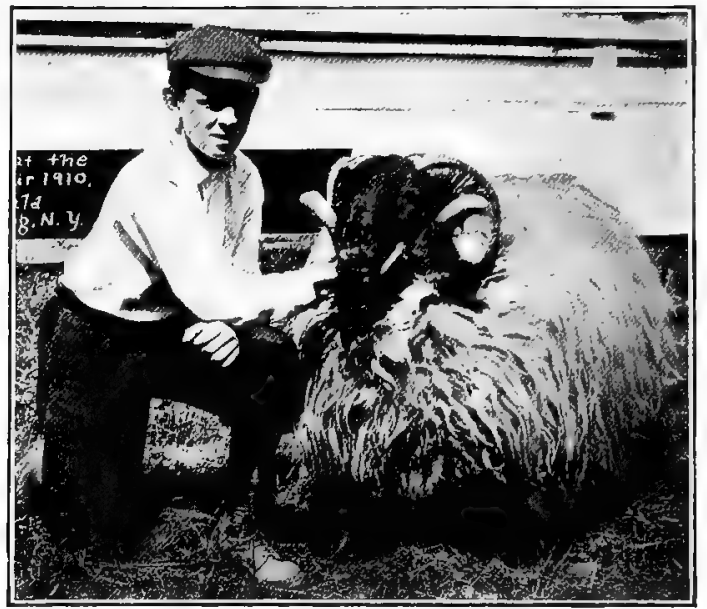

Frg. 85. - The Blackfaced Highland.

Dumbarton. It may justly claim to be one of the oldest in Britain, and as such, its early history is little known. The fact that the breed was extremely hardy and could endure the higher lands even better than the Cheviot, gave it foothold which it retains to the present time.

Both sexes have horns. Those of the male are rather large, taking one or two spiral curves, while those of the female are small, thin, and curved, but not spiral. The body is that of a typical mutton sheep. The fleece is long and coarse, often full 
of kemp, and lacks density over the entire body. Ac the name indicates, the face and legs are black (Fig. 85).

\section{GOATS}

The goat is closely allied to the sheep. As with other classes of live stock, the goat has developed along two types according to the demands made upon it. Thus we have one type grown for its fleece, and a second propagated for the milk it can produce. Perhaps the Angora is the best representative of the type grown for its fleece.

349. Angora goat. - This herd developed in Angora, Asia Minor. The origin is obscure, some writers venturing to say that

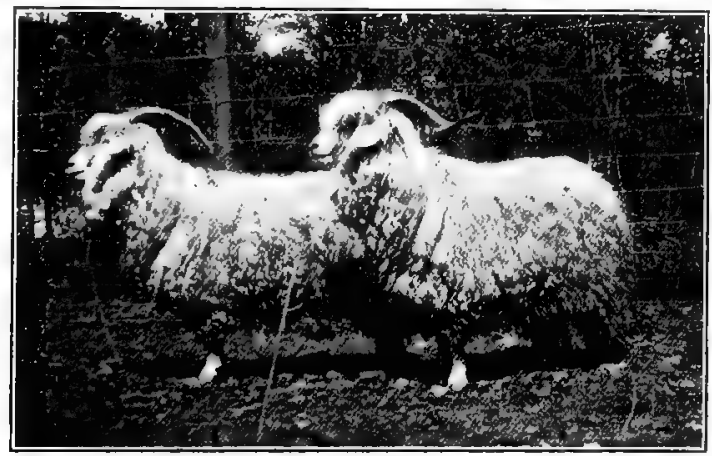

FIG. 86. - The Angora goat.

the breed originated 2400 years ago in the district of Angora. The Angora goat owes its present development to selection and better care on the part of Angora fanciers generally. The fleece of the animals should be pure white, and grow to the length of about ten inches during the year. It should hang in ringlets or wavy curls, the wave extending throughout the entire length of the hair (Fig. 86). 
In addition to his value for the fleece, the Angora is held in high esteem as a renovator of brush land. The goat is a natural browser and not a grazing animal. In brush land, therefore, he is in his element, taking the tender twigs and thus destroying the brush very effectively.

The fleece of the Angora, which is commercially known as mohair, differs from wool in having no exterior scale and, therefore, does not possess the felting quality. Mohair is used extensively in the manufacture of plush, such as is used in upholstering. Besides plush, which is the principal item, it may be used in the manufacture of coats and coat-linings, table covers, mittens, and gloves and the like.

350. Milk goat. - Because of its antiquity we are in doubt as to the origin of the milk goat. Whatever may have been its

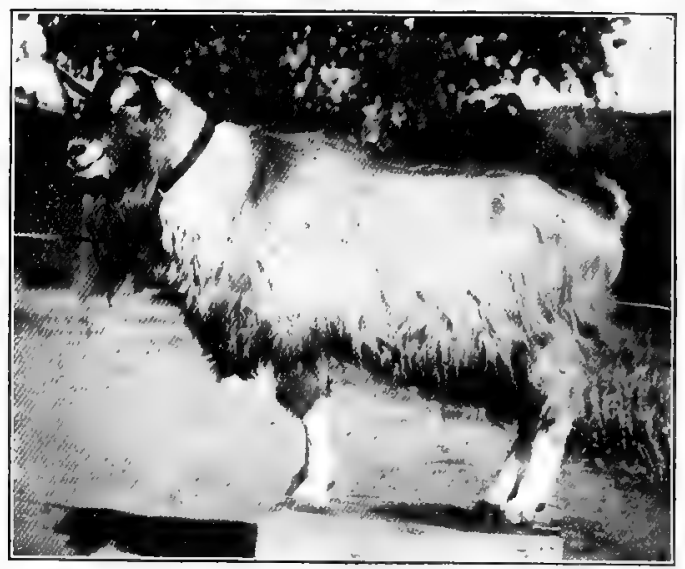

FIG. 87. - The milk goat.

origin, however, it has exerted a strong influence on the economic welfare of the people among whom it has been found. The milk goat owes its present development to its economic worth as a 
milk-producing animal among the poorer people of various foreign countries.

The milk of the goat is chalk-white in color and contains about $4 \frac{1}{2}$ per cent of fat. An average yield of a quart a day is not uncommon. When goats are kept under proper conditions, and with due regard for cleanliness, the milk is wholesome and no unpleasant flavor is noticeable (Fig. 87).

There are many breeds of milk goats, of which the Maltese, Toggenburg, Saanen, Appenzell, Schwarzthal, and the Nubian are the most notable.

\section{QUESTIONS}

1. How many pure-bred sheep are there in your vicinity? What breeds are the most common? Why are they preferred?

2. Give the names of a few of the leading sheep exhibitors at your state, county, or town fair. What are some of the prices obtained for their prizewinning stock?

3. Why has England been so successful in developing mutton sheep, while America holds first place among the fine-wool sheep? Why has the fine-wool sheep become so popular in France?

4. Which breeds of sheep shear the heaviest fleece? Why? Why is Class A - sheep with heavy folds - not so popular as formerly?

5. Why has the milk goat never become popular in America? Why are they extensively used in many foreign countries? Considering the body weight, how does the milk goat compare with the dairy cow in yield of milk and butter fat? 


\section{CHAPTER XIII}

\section{JUDGING SHEEP}

THE wool-covering of the body of the sheep makes an examination of the form rather difficult. The wool is often so trimmed as to deceive. An expert trimmer, possessing much skill with the shears, can give a rather inferior sheep the appearance of a plump full form; thus animals with sway backs, narrow, flat ribs, narrow, peaked rumps, are often so trimmed as to conceal such defects. Therefore, do not depend on the eye alone, but fortify it with the touch, carefully noting each character. During this examination, keep the fingers and thumb together and the hand flat. Never stick the fingers into the wool. When it is desired to examine the wool, open up the wool with the hand flat (Fig. 96).

351. Catching sheep. - There are two proper ways to catch sheep : first, by the hind leg above the gambrel joint; second, by placing the hand underneath the jaw and around the neck. Do not catch a sheep by its wool, as this not only pulls and injures the wool, but leaves a black mark or bruise on the body which interferes very much with the sale of the carcass of mutton. If the shepherd's crook is used in catching the sheep, the aim should be to catch above the gambrel joint, as there is danger of injuring the leg if caught below this joint.

352. Holding sheep. - To hold a sheep, stand on the left side and place the left hand under the animal's jaw, keeping the right hand free to place behind the sheep in case it attempts to move backward. Do not attempt to keep the sheep from moving backward by pulling on the head or the wool, as either of these methods will be quickly resisted, and will result in injury to the 
wool and carcass. Gently place the right arm around back of the thighs, and the sheep will stop the backward movement at once. Likewise do not attempt to keep the animal from going forward by pulling on the wool, but place the left hand gently under the jaw.

353. How to estimate the age of sheep. - The order of the appearance of the permanent teeth furnishes the best index to the age, especially from one to four years of age (Fig. 88). The age at which the permanent teeth make their appearance is approximately as follows:-

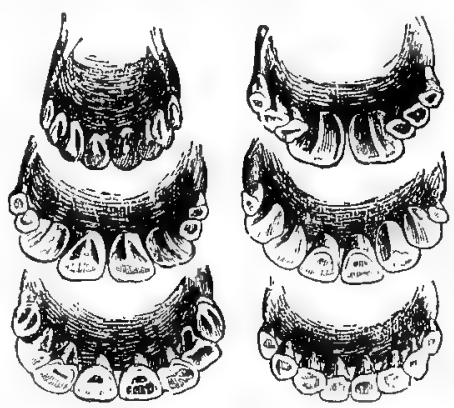

Fri. 88. - Sheep's teeth arranged according to age.

12 months. 15 months.

26 months. 37 months. 48 months. 8 years.

First or middle pair of permanent teeth

15 months Second or first intermediate pair of permanent teeth . . . 26 months Third or second intermediate pair of permanent teeth . . . 37 months Fourth or lateral pair of permanent teeth

48 months

354. Score-card for sheep. - Each breed of sheep has its own scale of points, varying in detail, but similar to the following in general characteristics. (See p. 224.)

\section{GENERAL APPEARANCE OF SHEEP}

355. Form. - This will vary according to the object sought. In the fine-wool sheep, the form may differ materially from that desired for mutton. Class $A$, fine-wool, should have very heavy folds over the entire body. Great depth of body is often more sought than width, and the animals are often quite angular in appearance. The form sought is that which indicates great vitality, and gives much surface for the production of wool. Finewool sheep are therefore often high-standing; deep of chest, 


\section{STUDENT'S SCORE-CARD}

\section{Mutton Sheep}

Scale of Points

Age

General Appearance, 38 per cent

Weight, score according to age, * ' t ive ish

Quality, clean bone; silky hair; fine, pink skin ; light in offal, yielding high percentage of meat

Condition, deep, even covering of firm flesh, especially in regions of valuable cuts. Points indicating ripeness are, thick dock, back thickly covered with flesh, thick neck, full purse, full flank, plump breast

Head and Neck, 7 per cent

Muzzle, fine, mouth large; lips thin; nostrils large and open

Eyes, large, clear, placid

Face, short; features clean-cut

Forehead, broad, full

Ears, fine, alert

Neck, thick, short, free from foilds

\section{Forequarters, 7 per cent}

Shoulders, covered with flesh, compact on top; snug

Brisket, neat, proportionate; breast wide .

Legs, straight, short, wide apart, strong ; forearm full ; shank smooth, fine

Body, 20 per cent

Chest, wide, deep, full

Ribs, well sprung, long, close

Back, broad, straight, long, thickly fleshed

Loin, thick, broad, long

\section{Hindquarters, 16 per cent}

Hips, far apart, level, smooth

Rump, long, level, wide to tail-head.

Thighs, full, deep, wide

Twist, plump, deep

Legs, straight, short, strong; shank fine, smooth

Wool, 12 per cent

Quantity, long dense, even

Quality, fine, pure; crimp close, regular, even

Condition, bright, sound, clean, soft, light. .

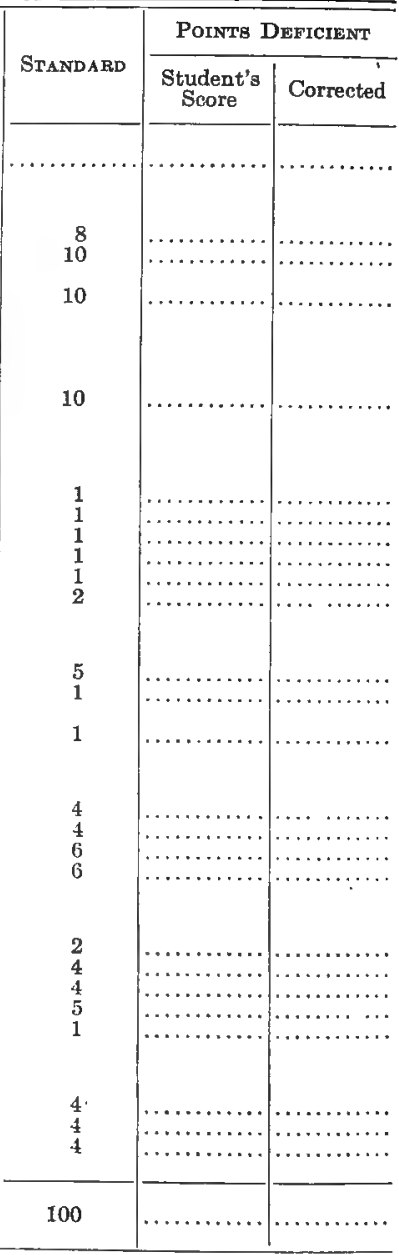


though narrow; Iong of body, though well supported; light in the hindquarters, with skin fold varying according to the class.

On the other hand, the form of the mutton sheep should be comparable to that of the beef animal. They should be low and condensed in organization. The top and bottom lines should be parallel, the shoulders and chest almost as wide as the hips and rump. The body should be short and thick, as long bodies lacking in depth and fullness are objectionable to the sheep feeder and to the butcher. The region of valuable cuts of mutton are the same as those of beef, that is, along the back, loin, rump, and thigh; hence these regions

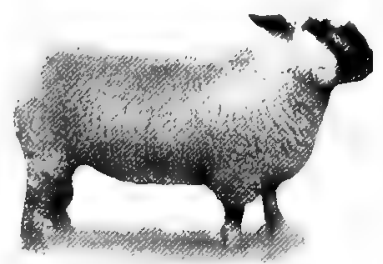
should be exceedingly strong and well developed. (See Fig. 89.)

356. Condition and weight. - Since the weight depends much on the condition of the sheep, they will be considered together. As weight is a breed characteristic, no definite figures can be suggested, but the animals chosen should be fairly large for the particular breed to which they belong. Among wool sheep, the condition should be such as to indicate thrift and health; excessive fleshiness is not essential. In general, the condition must be determined by the touch, as the wool often deceives the eye. Among mutton sheep a fair amount of flesh is desirable, even in the breeding stock, as the tendency to fatten quickly is a very important consideration in this type.

357. Quality. - Sheep possessing much quality are desired for both mutton and wool production. With sheep, as with other farm animals, quality is determined by the bone, skin, and hair. The bone should be dense, clean, and of fine texture. The skin should be soft, pink in color, and comparatively thin. Care must be exercised in respect to the thinness of the skin, as a thin paper skin is often associated with weakness of constitution. The hair on the 
ears, face, and legs should be soft and silky. Sheep possessing a tight, heavy, pale skin, coarse, harsh hair about the face and on the legs, and heavy, rough, coarse bone are deficient in quality.

358. Constitutional vigor. - This deserves much attention, for in its absence the wool will be of poor quality and the mutton sheep an unprofitable animal. Vigor is estimated by the general expression, by the condition of the skin, and by the chest capacity. The expression of the eyes, ears, and head should be mild and lively, and the sheep should be on the alert. The skin should be deep pink and not pale. The chest capacity should be large. A good way to estimate the chest capacity among sheep is to note the distance between the front legs along the floor of the chest. If the distance between the legs is small, it denotes a narrow chest. A narrow chest is always objectionable, as it may indicate lack of constitutional vigor.

359. Uniformity. - The importance of uniformity in a flock of sheep, chosen either for wool or mutton, cannot be overestimated. They should be uniform in type, size, and breeding. While such uniformity may not add to the production of wool or to the ability to take on flesh, it materially improves their general appearance, and increases their market value. Either the butcher or the sheep breeder will pay more for a uniform flock than for one in which such regularity is wanting.

\section{DETAIL CHARACTERS OF SHEEP}

360. Head. - This part should be short, with strong jaws and large nostrils. The mouth should be examined to note the age and condition of the teeth. Sheep with missing teeth are undesirable either for mutton or wool. The eyes should be mild, bright, and prominent; the forehead broad and full. The ears should be refined, short, and active. Coarse, leathery ears are objectionable, as they indicate poor quality. The horns, if present, should be strong, rather angular at the base, and have a spiral shape turning backward and around, sometimes making two complete turns. 


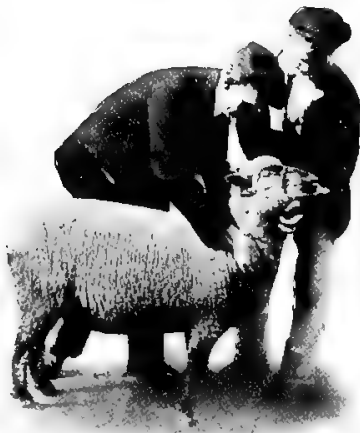

Frg, 90. - Judging sheep. Fullness of shoulders.

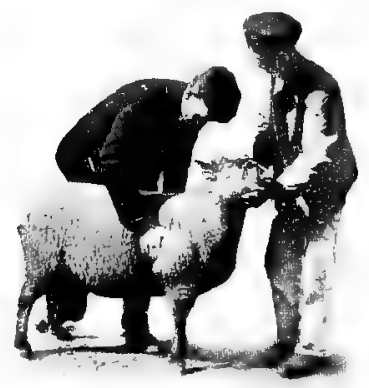

FIG. 91. - Width of chest.

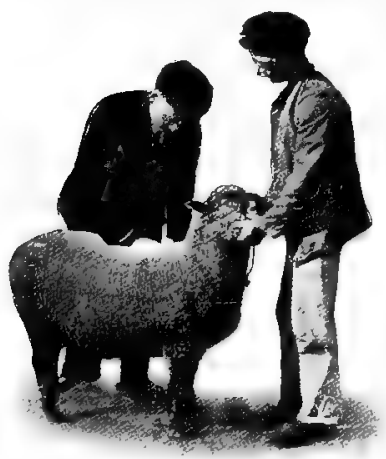

FIg. 92. - Fullness of back at shouider tops.

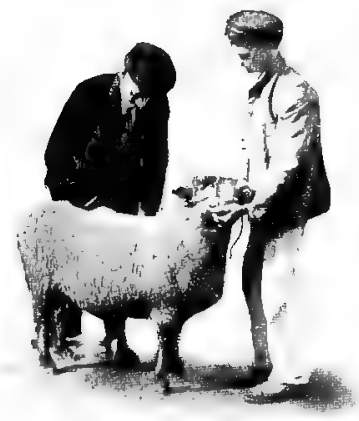

Fig. 93. - Fullness of back at loin.

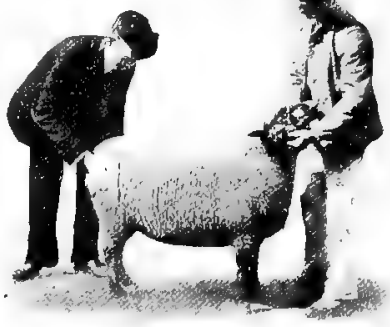

FIG. 94. - Width of rump.

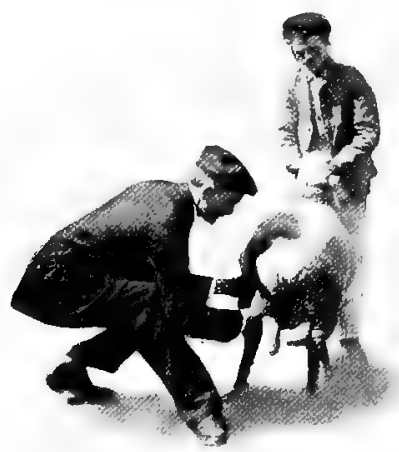
Fra. 95.-Condition of leg of mutton. 
361. Neck. - With the flat hand, note the length and fullness of the neck. Among mutton sheep the neck should be full, short, and neatly attached to the head and shoulders. In fine-wool sheep it may possess some length, deep folds, and lack the fullness, though it should be neatly attached at both head and shoulders.

362. Shoulders. - Among mutton sheep the shoulder should be full, neat, and closely rounded along the sides and over the top. Sharp, angular shoulders are very objectionable. They should be smoothly curved with flesh (Fig. 90).

363. Chest. - With the flat hand, note the capacity of the chest as follows: kneeling on the left side of the animal, place the left hand on the floor of the chest, between and just back of the fore legs, at the same time placing the right hand on the back just to the rear of the shoulder-tops. In this position one can note lack of depth as well as the narrowness of the chest at both top and bottom. Next note the heart girth and width of chest by placing one hand on either side at the same time (Fig. 91).

364. Body. - With the hands in the same position, one either side of the animal, note the width of the body. Next place the flat hand on the back at the shoulder-tops, and note the width and straightness of the back from the shoulder-tops to the tail-head, by pressing down gently as the hand is drawn to the rear. In so doing, one must observe that the sheep does not move his back as the hand is passing over, making the back appear swayed when in reality it is not (Figs. 92, 93).

365. Rump. - This should be long, wide, and level. These characteristics can be ascertained only by the touch. The fleshiness should be carried well down to the hock, and the twist should be plump and full (Fig. 94).

366. Leg of mutton. - This includes the rump also, and is the most valuable cut of mutton; therefore, the thigh should be heavily meated. This can be determined only by the touch, and to do this one places the left hand around the leg at the flank, and the right around the rear at the thigh (Fig. 95). 
367. Legs. - These should be carefully observed. Sheep's legs are at best far from straight. As a rule, the fore legs of finewool sheep are too close together, the knees almost touching. This is objectionable, for, as we have already observed, fore legs placed close together indicate a narrow ehest, which in turn signifies lack of constitutional vigor. Fine-wool sheep also have very crooked hocks, which is equally as objectionable. Often the legs below the hocks are carried too much under the borly, the shanks being too slanting. The toes are often neglected and let grow out too long, which throws the legs still farther out of their proper position.

368. Examining the fleece. In the examination of the wool the chief factors to consider are 'the quantity, the quality, and the condition. In considering the quantity the entire body must be examined. To note the quantity

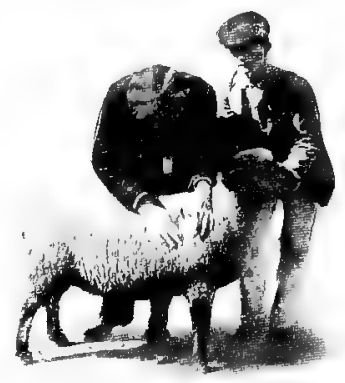

Fig. 96. - The finest of the fleece. along the abdomen and arm pits, the sheep should be turned up and placed on its rump. With the sheep in this position, the wool along the abdomen and arm pits can be carefully noted. These

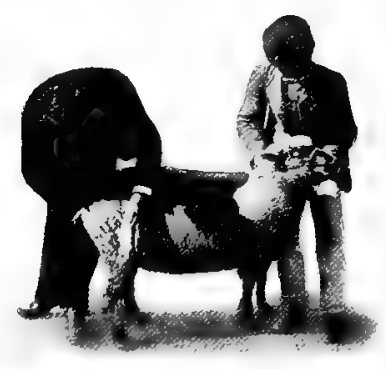

FIG. 97. - The conrsest of the fleece. places shoubd be densely covered, though such is seldom the case among many of the mutton breeds. In considering the quality, the best method is to open the fleece along the side just back of the shoulder and in the region of the thigh. With the hands placed in a flat position, open the wool just back of the shoulder (Fig. 96). It is in this region that the finest and 
soundest wool of the fleece is found. With the hands in like position, open the wool along the thigh (Fig. 97). In this region the poorest and coarsest wool of the entire fleece is to be found.

369. Market classes of sheep. - On the market, sheep are divided into classes according to age, condition, and quality. Classes vary in the different markets, but the following table will give an idea of the nature of the classification. Each subclass is divided into a number of grades, as prime, common, and inferior :-

Clasgs

Sub-Clabs

\begin{tabular}{cl}
\multicolumn{1}{c}{$\begin{array}{c}\text { Clasg } \\
\text { (Native and western sheep) }\end{array}$} & $\left\{\begin{array}{l}\text { Lambs } \\
\text { Yearlings } \\
\text { Wethers } \\
\text { Ewes }\end{array}\right.$ \\
Feeder sheep & (Western sheep) \\
Breeding sheep & $\left\{\begin{array}{l}\text { Bucks and stags } \\
\text { Lambs } \\
\text { Yearlings } \\
\text { Wethers } \\
\text { Ewes }\end{array}\right.$ \\
& $\left\{\begin{array}{l}\text { Ewes } \\
\text { Bucks }\end{array}\right.$
\end{tabular}

370. Cuts of mutton. - The diagrams which follow very clearly indicate the parts of the animal from which the cuts of mutton are taken, a knowledge of which is useful in dealing with the meat market (Fig. 98).

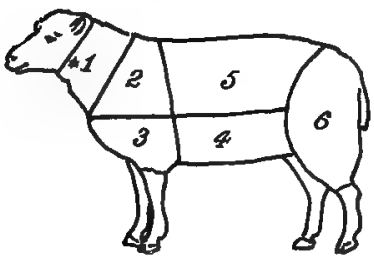

1. Neck.

2. Chuck.

3. Shoulders.

4. Flank.

5. Loin.

6. Leg.

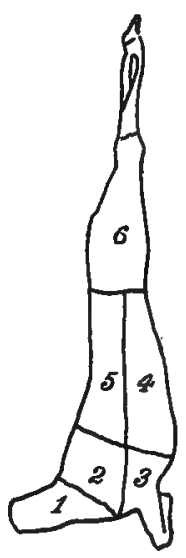

FrG. 98. - Diagrams of cuts of lamb and mutton. 


\section{QUESTIONS}

1. Why are sheep the most difficult of farm animals to judge? What precautions should be taken that we be not deceived? How should a sheep be held?

2. Contrast the three fine-wool breeds of sheep, and give distinguishing characteristics. Contrast the form of the mutton and wool type. Why is constitutional vigor so essential in fine-wool sheep? In mutton sheep?

3. Why is a careful examination of the skin of first importance in judging sheep? What knowledge can be gained from an examination of the mouth?

4. Why is the finest of the fleece produced just back of the shoulder, and the coarsest on the thigh? Where are bare places most likely to be found? Which breeds are the most subject to this defect?

5. Name the uses of wool. Of mohair. In the manufacture of woolens, how are the wools classified? Describe each class and give the particular uses. Can the quality of the wooi be influenced by the feed ?

6. How can unsound wool be detected? Name the more important causes of unsound wool. Why do the woolen manufacturers discriminate against unsound wool ?

7. Name the most valuable cuts of mutton and locate the region on the sheep's body from which they come. Compare with the most valuable cuts of beef.

8. Approximately what percentage of the total weight of the carcass is located in the region of valuable cuts? What percentage of the total price will these sell for on the market? 


\section{CHAPTER XIV}

\section{FEEDING SHEEP}

SHEEP are among the most difficult of farm animals to feed. Thorough familiarity with their habits is essential to success. Sheep are naturally very timid in their disposition, very dainty feeders, and are easily frightened out of their appetite. " A sudden noise or disturbance of any kind will often greatly frighten them, and sometimes create a stampede or panic in the entire flock.

371. Sheep are delicate. - Sheep are the most susceptible of farm animals to the ravages of parasites, both internal and external. These parasites in some one or more of their many forms are responsible for the larger number of failures in this country. No part of our land is free from them all. In certain localities one form will be the more destructive, in other localities another form is to be dreaded. For example, in the corn-belt, the stomach worm (Strongylus contortus) is by far the most serious, while in the far West, scab is the more troublesome. As a rule, little attention is given these parasites; the flock becomes infested, many of the sheep become ill and die, and the others fail to thrive, and sometimes the owner does not know what causes the trouble.

While sheep can withstand the cold without suffering much inconvenience, they cannot endure the rain or snow that saturates their wool, nor dark, damp, and poorly ventilated quarters. Such conditions lead to colds, running at the nose, catarrh, intlammation, diarrhœa, and all kinds of sheep diseases. From this it follows that if sheep are to prove profitable, they must 
be kept quiet, fed nutritious food, and provided with proper quarters.

372. Food requirements of sheep. - The quantity of food required by sheep depends on many factors, chief of which are the kind of food, and the age, weight, condition, and individuality of the animal, as well as the chief product sought, whether wool or mutton :-

Wolff-Lehman Standards Showing the Amount of Food required per 1000 Pounds Live Weight for Both Wool and Mutton, as well as Growing, Mature, and Fattening Sheep

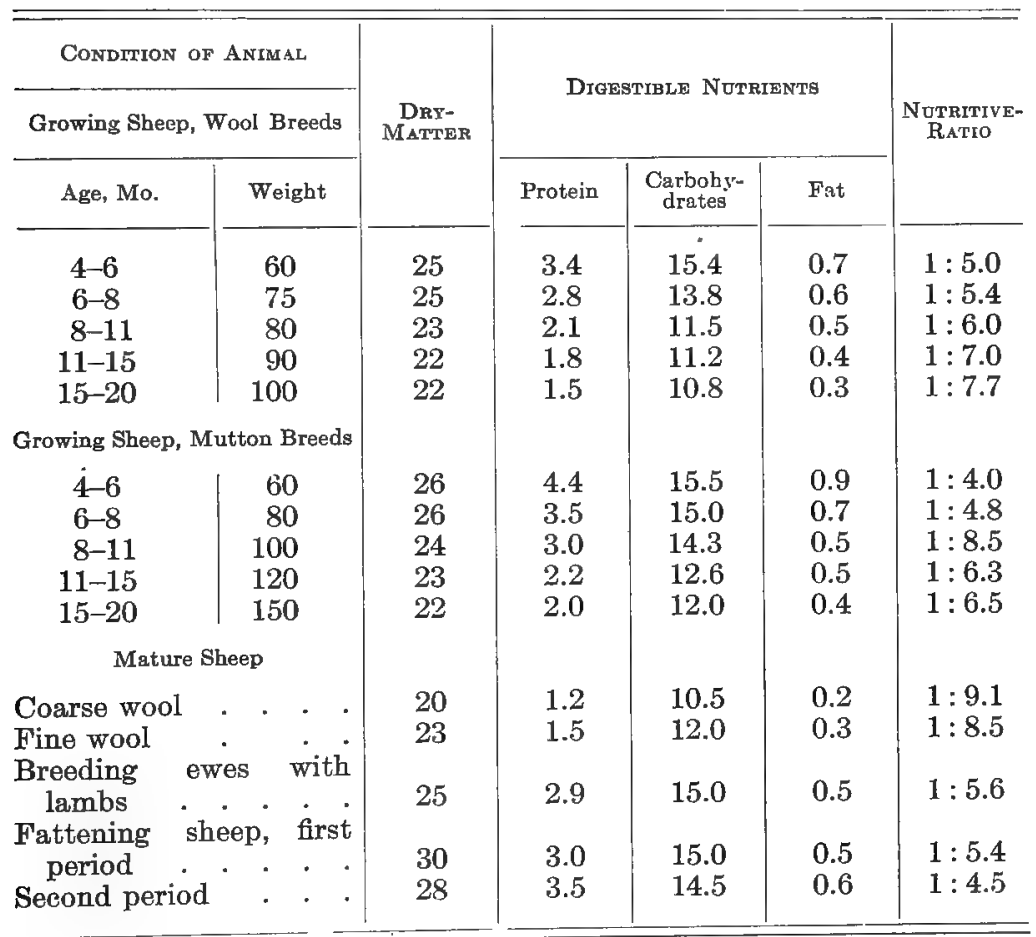


Armsby's Standards showing the Digestible Protein and Energt required Per 1000 Pounds Live Weight for a Sheep of Variodg Ages and Weights

\begin{tabular}{c|c|c|c}
\hline Age, Mo. & Weight, Pounds & $\begin{array}{c}\text { Digegtigle Proten, } \\
\text { Pounds }\end{array}$ & $\begin{array}{c}\text { Energy Valde, } \\
\text { Therms }\end{array}$ \\
\hline 6 & 70 & 4.2 & 18.5 \\
9 & 90 & 2.7 & 15.5 \\
12 & 110 & 2.1 & 12.7 \\
15 & 130 & 1.8 & 11.5 \\
18 & 145 & 1.5 & 11.0 \\
\hline
\end{tabular}

FEEDING THE FLOCK

373. The flock in summer. - Unlike stock cattle, the flock of sheep must receive careful attention in summer as well as in winter, particularly in those regions infested with stomach worms, - the sheep's greatest enemy. These worms have done more to discourage the propagation of sheep than all other causes combined, especially on the fertile farm lands in the central states. These pests seldom trouble sheep in cool regions, or in cold weather. Lambs are especially susceptible to attack, the older suffering much less and being more easily managed in summer.

374. Pasture for sheep. - Pastures for sheep need similar care to that suggested for cattle pastures. The stand of grass, the drainage of the soil, and keeping down of weeds deserve much attention. It is even more important that they be kept free from weeds, particularly burrs of various kinds, as these are especially injurious to the wool, p. 182.

Sheep thrive on pasture as nowhere else. They are particularly adapted to grazing short forage, and prefer it, as it is tender and juicy. In fact, sheep often keep parts of the pasture grazed so closely as to injure the plants, while the grass in other parts of the same field is left to grow up and seed. This can be pre- 
vented in part by mowing the entire pasture twice each year. The sheep will then pasture on the tender second growth.

375. Turning to pasture. - Care should be exercised in turning sheep to pasture, otherwise some of the flock may be troubled with bloat. The extent of the trouble depends much on the condition as well as the kind of grass, young succulent grass being more troublesome than older and riper grass, and alfalfa or clover more than blue grass or orchard grass. In regions of much dew, alfalfa is likely to he the most troublesome of all. After alfalfa

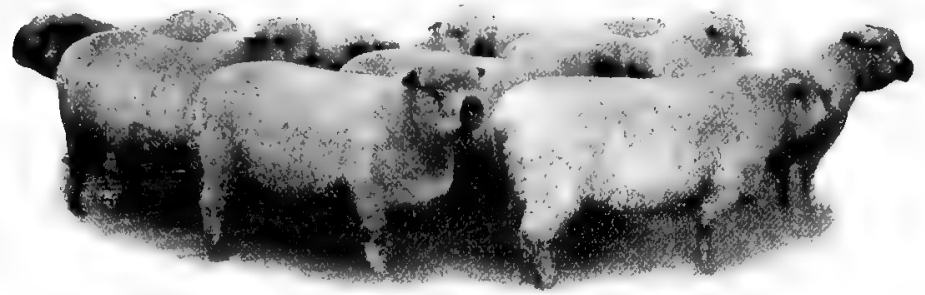

FIG, 99. - Flock of shrojshire ewes.

becomes woody there is not so much danger from bloating. Mixed grasses are also less dangerous. There are many methods suggested for turning sheep to pasture, but the one suggested on page 181 is as good as any.

376. Change in pasture. - When convenient, an occasional change of sheep from one pasture to another will prove advantageous. On farms heavily stocked with sheep, there are two reasons for this: first, the change gives a chance for the fresh grass to grow, thereby preventing the sheep from cropping parts of the pasture too closely; and, second, it lessens the danger from parasitic germs by allowing the larvæ to die before finding lodgment in the sheep's body. More satisfactory results would be obtained by dividing large pastures into several small ones, and pasturing 
them in turn from the time warm weather sets in until the cool weather of the fall.

377. Providing shade. - Sheep on pasture should be given protection from the sun. They are fond of shade and will seek it. The shade tree is not sufficient for sheep, artificial shade being much preferred. The objection to the shade tree as a resting place for sheep is the danger of parasite infection.

When the pasture is near the shed or barn, no better shade can be provided than to give the sheep the freedom of these quarters, which should then be slightly darkened by hanging blankets or gunny sacks over the windows. A blanket may be so hung over the door that the sheep in passing into the shed will brush the flies off their backs. If small sheds are provided in the field, they should be placed on runners in order that they may be moved from place to place as the sheep are changed from one field to another. This plan scatters the manure more thoroughly, and does away with much of the evil caused by parasites. These shades need be only a roof, and may be made of pine boards, as it is not essential that they be rain-proof. They need not be high. Such a roof sixteen feet square will provide shade for a flock of forty sheep.

378. The use of sown pastures. - The best way to care for the flock in summer, in order to avoid parasite infection, particularly with a flock of lambs, is to sow special pasture crops for the flock. In this way the owner may have various green forage crops coming on regularly at different times, and thus avoid having the sheep graze on the same area for any considerable time. It avoids practically all danger from the many parasites that attack sheep during the summer season. There are many plants that may be used as green feeds for summer pasture, chief of which are rye, oats, alfalfa, clover, rape, kale, cabbage, turnips, and pumpkins. The seeds from the pumpkin are among the best vermifuges known, for which reason the pumpkin ranks high as a succulent food for sheep. 
379. The flock in winter. - In winter the flock is entirely dependent on the care of the owner, and it must receive more careful attention than during the summer. This is the season of catarrhs, running at the nose, inflammation, diarrhœa, and the like. When convenient, the change from the fields to the yards should be made gradually. The flock should be yarded at night as soon as the pastures become crisp from night frosts, as frosty forage is likely to lead to digestive disorders. Hay should be provided in the lot, so that the sheep will not go to pasture hungry in the forenoon. If on permanent pasture, or where there is much old grass, such yarding is not so necessary, as the sheep will feed on the dead grass in preference to the frosty succulent grass.

380. The winter ration. - The feeds that should enter into the winter ration will depend on the kind available. If convenient, succulence of some kind should be provided. On farms where there are silos, nothing is better than corn silage. In the absence of silage, roots will serve, some sheep owners even preferring roots to silage. The roots suggested for late fall use, such as mangels and rutabagas, will serve admirably. Some grain as wheat bran, oats, linseed meal, and the like should be fed, particularly to the ewes that are to lamb in the spring. Clover, alfalfa, and mixed hays constitute the best dry forage.

381. Exercise. - In order to keep the sheep healthy and thrifty they should take exercise daily. This often becomes a serious problem in the cold climates when the ground is covered with deep snow much of the winter season. It may be advisable to remove the snow from parts of the lot, and feed them some dry forage in some spot not too near the winter quarters.

382. Care of the feet. - During the winter season, when the sheep are rather closely confined, it is important to watch the feet and see that the toes do not grow out too long, as they very often do at this season of the year. Long toes should be trimmed. The aim in trimming should be to keep the feet natural, so that 
the sheep stands squarely upon them. Lack of trimming is sometimes responsible for diseases of the feet.

383. Bedding. - This should be used liberally, otherwise the floors will become damp and foul smelling. Sheep lying on damp, filthy beds are subject to the same ills as those exposed to draughts. Fresh bedding is of greatest importance during the lambing season, as damp, filthy quarters are particularly hurtful to lambs and will soon prove fatal to them. At this time, fresh bedding should be put down daily. This not only increases the healthfulness of the sheep-fold, but increases the quantity of valuable manure as well.

\section{FATTENING SHEEP}

Feeding sheep to fatten them differs considerably from feeding the flock in general or feeding for the production of wool; it is somewhat similar to feeding cattle for the production of beef.

384. Growing winter lambs. - In recent years a considerable demand has developed for winter lambs, particularly in the eastern cities. Because of the forced methods of feeding adopted in pushing the lambs forward so as quickly to prepare them for market, they are spoken of as "hot house" lambs, a term which has misled many as to the conditions under which the animals are raised. Winter lambs command a very high price on the market, particularly from Christmas to Easter. The difficulty in the production of winter lambs is to get the ewes to lamb in the late fall and early winter.

Perhaps the best plan is to choose grade Merino ewes and mate with a vigorous pure-bred Horn-Dorset ram in the early spring, say in May on being turned to pasture. This should result in the lambs being dropped in October, November, and December. It is not considered a good plan, however, to have the lambs dropped before the ewes go into winter quarters, as the lambs are exposed to danger from stomach worms.

385. The winter quarters for winter-lamb production. - The 
term " hot-house" lambs has led many to think that extra warm quarters must be provided, some thinking that artificial heat must be used, others that the roof or side of the sheep barn should be of glass construction, resembling a green-house. Not only is such extra equipment unnecessary, but if the quarters are too warm, neither the ewes or lambs will thrive. On the other hand, winter lambs cannot be grown if the ewes are exposed to the rain, snow, or storm. The winter quarters must be well lighted, well ventilated, and free from draughts. There should be sufficient window space to make the quarters light and comfortable. Artificial heat is entirely unnecessary.

386. Feeding the lambs. - The ewes should be fed milk-producing foods, such as wheat bran, silage, and clover hay, in order that the milk flow be large, but in addition to the dam's milk the lambs should be taught to eat grain as soon as they will take to it. Some lambs will begin to nibble grain when only ten däys or two weeks old, and they should be encouraged to do so. A lamb creep should be provided. This "creep" consists of a little pen with openings so small that the lambs may pass in and out at will, but through which the sheep cannot pass. The grain boxes within the creep should be flat-bottomed, and placed rather low. The first feed put into the trough may be wheat bran, to which has been added a little brown sugar. At first it may be necessary to aid the lambs by placing some of this mixture on their lips. The troughs must be cleaned daily and the food kept fresh. After the lambs have learned to eat grain, the following mixtures should be used : 40 parts of cracked corn, 50 parts of wheat bran, and 10 parts of oil meal, coarse ground. This may be varied by adding oats, barley, or gluten feed, as circumstances demand. Lambs thus cared for should grow rapidly and fatten at the same time, so that by the time they are ten to twelve weeks of age, they will weigh from 50 to 60 pounds, when they should be slaughtered.

387. Growing spring lambs. - Because of the difficulty in getting ewes to conceive sufficiently early for the growing of winter 
lambs, and the disadvantages of dressing and marketing, many sheep owners prefer to grow spring lambs. There is much profit in selling lambs afoot in May and June. Usually the highest prices are obtained in June, as at this time the supply of winterfed western lambs is exhausted, and the summer-fed lambs are not yet on the market in any considerable number.

The foundation stock and the management should be much the same as that suggested in growing winter lambs. The ewes should be mated in August, September, and October, as the lambs should be dropped in late January, Feburary, and March, not later than

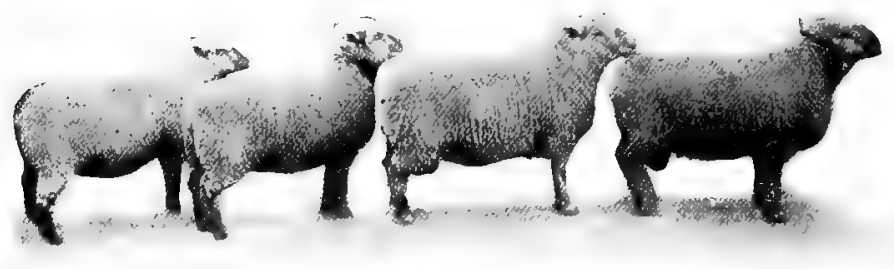

FIG. 100. - Flock of Southdown lambs.

March. The lambs should be provided with creeps and fed grain in the same manner as advised for winter lambs; for if they are to be marketed in a thick fat condition at the age of four or five months, they must be forced from the beginning. It is rather difficult to fatten lambs for the spring market if they once lose their baby fat.

Lambs dropped in February and thus cared for should make a weight of approximately eighty pounds by the middle of June. As this is the weight demanded of this class of mutton, it should be the aim of the sheep owner to supply it. When there are several lambs, or when one is located convenient to market, it may be advisable to make two drafts, selling the larger and fatter ones say the first of June, and the remainder of the lamb flock the latter part of the month. 
388. Feeding lambs in the fall. - Lambs may be fattened at almost any season, but ordinarily the fattening period extends from September until the following May. Fall feeding is extensively practiced both by the farmer who raises his own lambs, and by the sheep feeder who buys his lambs either locally or from the western range, and fattens them in seventy to one hundred days. Fall feeding is practical on pasture, either permanent or sown, when supplemented by feeding grain.

389. Getting the lambs on full feed. - Much care must be exercised in getting a flock of lambs on full feed, particularly if they are from the range and not familiar with grain. Furthermore, many of the plants used in fall pastures for fattening lambs are likely to produce bloating, and for this reason much care must be exercised in turning the flock to pasture, particularly if the grass is composed of alfalfa, clover, or rape plants. These are most excellent crops for fattening lambs in the fall, but due care must be exercised in turning on the sheep. The grain should be fed sparingly at first and gradually increased from day to day until the full amount is being fed. Most satisfactory results can be obtained by feeding the grain twice daily. Care must be exercised never to feed more than the lambs will consume; or if there is any grain remaining, it should be removed before a new supply is placed in the troughs.

Lambs thus cared for should make rapid and economical gains. Under such feeding, 60-pound lambs should attain a weight of 85 pounds in 75 days, and be sufficiently fat for the market. Thus, lambs put on feed September 1 would be ready for the market November 15. When the flocks are sufficiently large and the sheep feeder is located conveniently near to market, it will, as a rule, pay to make two drafts, selling the fattest at the end of about 75 days, and the remainder of the flock in 90 to 100 days. This keeps the two flocks more even, and avoids holding those already fat for the slower maturing ones to fatten, and avoids selling a few thin in flesh after the majority have fattened. 
390. Fattening lambs in winter. - By far the greater number of lambs are fattened during the winter season. The methods employed differ fundamentally in different localities. In the West, little or no attention is paid to shelter; in the corn-belt, much attention is given to the shelter, at least to protect the lambs from the rain, snow, and storm, and to provide them dry footing and exercise ; in the East, where lamb-feeding is rapidly developing, shelter is considered essential.

391. Feeding in the semi-arid West. - Large flocks of lambs are shipped from the ranges to points where alfalfa hay is available. Here the sheep are confined in corrals which are divided into lots containing approximately 500 head. No shelter is provided other than that furnished by the fence, or the alfalfa hay, which is often stacked near by. Rain and snow storms are rather infrequent, and it is felt that the loss occasioned by the lack of protection is less expensive than shelter. These corrals provide accommodations for many thousands of sheep. To save labor in feeding, the lots are arranged in rows, with feeding lanes between. In these lanes the hay is stacked and fed out each morning and evening. Sometimes the fence has a space between the first and second boards large enough for the sheep to introduce its head, and the rack is arranged on the stack side of the fence. In each lot are placed rows of grain troughs sufficient to accommodate the entire flock. These lots are provided with water, often pumped by windmills, though sometimes by hand or with an engine. Salt is kept before the animals at all times. In this way, one man can care for 2000 or more head of sheep.

392. Feeding in the corn-belt. - In the corn-belt the practice is entirely different; few sheep are fed by great numbers of farmers. Here feed, both grain and hay, is very abundant, but the climate is the objectionable element. Sheep need dry coats and dry footing. The dripping skies of the corn-belt make this impossible, without providing shelter from the rain and snow. 
Much care should be exercised in getting the lambs on full feed. The lambs may be fed hay liberally, but the grain must be fed sparingly, beginning with one-fourth pound to the head daily, and gradually increasing the ration to one pound by the time the sheep have been on feed three weeks, and continuing until they are getting all they will consume. The lambs should not be fed more grain than they will clean up at each feeding. As the grain is increased, less hay will be required. Lambs thus cared for should make a gain of 25 to 30 pounds in 100 days, when they should be fat and ready for the market. If desired, two droves of lambs may be fed each winter, purchasing the first drove in November, and fattening by the last of January; immediately purchasing a second, and fattening by the first of May.

393. Feeding in the East. - During the recent high price of mutton, many lambs have been fed in the eastern part of the United States, and the methods are peculiar to the East.

The feeding pens are usually rectangular in shape, with hayracks and grain-troughs the entire length of either side. These grain-troughs are protected with vertical slats, so arranged that there is just room for one lamb to feed in each opening, and there are just as many of these openings as lambs, and not one more. When the lambs are feeding, they are packed solid along either side of the pen. The space allowed each pen is approximately twice the room on which a sheep stands while feeding. Water and salt are supplied in this pen, and the lambs do not leave it from the time they are put in until they are finished and ready for the market. The lambs are put on full feed in about three weeks and forced until fat.

394. Sample rations for fattening sheep. - The following rations are collected from various sources, to furnish a guide in determining the kind and amount of feed that should be allowed fattening lambs. In all cases the rations are calculated for 100 head:- 


\begin{tabular}{|c|c|c|c|c|}
\hline \multirow{2}{*}{$\begin{array}{l}\text { WEIGRT } \\
\text { OF } \\
\text { LAMBS }\end{array}$} & \multicolumn{2}{|c|}{ RATION } & \multicolumn{2}{|c|}{$\begin{array}{l}\text { Food PER } \\
\text { PoUND GAIN }\end{array}$} \\
\hline & Grain & Dry Forage & Grain & $\begin{array}{c}\text { Dry } \\
\text { Forage }\end{array}$ \\
\hline $56 \mathrm{lb}$. & $\begin{array}{l}49 \mathrm{lb} . \text { bran } \\
37 \mathrm{lb} \text {. linseed meal } \\
37 \mathrm{lb} \text {. cotton-seed } \\
\text { meal }\end{array}$ & $\begin{array}{l}147 \mathrm{lb} \text {. hay } \\
143 \mathrm{lb} \text {. roots }\end{array}$ & 4.5 & $\begin{array}{l}5.4 \\
5.3^{1}\end{array}$ \\
\hline $110 \mathrm{lb}$. & $\begin{array}{l}140 \mathrm{lb} \text {. soy beans } \\
10 \mathrm{lb} \text {. bran }\end{array}$ & $180 \mathrm{lb}$. elover hay & 3.5 & 4.7 \\
\hline 109 lb. & $\begin{array}{l}135 \mathrm{lb} \text {. corn } \\
10 \mathrm{lb} \text {. bran }\end{array}$ & $180 \mathrm{lb}$. clover hay & 3.2 & 4.2 \\
\hline $80 \mathrm{llb}$. & $\begin{array}{l}81 \mathrm{lb} \text {. shelled corn } \\
81 \mathrm{lb} \text {. bran }\end{array}$ & 107 lb. clover hay & 6.4 & 4.2 \\
\hline $83 \mathrm{lb}$. & $164 \mathrm{lb}$. oats & $\begin{array}{l}140 \mathrm{lb} \text {. clover hay } \\
100 \mathrm{lb} \text {. roots }\end{array}$ & 5.2 & $\begin{array}{l}4.5 \\
3.1^{1} \\
\end{array}$ \\
\hline $83 \mathrm{lb}$ & $\begin{array}{l}132 \mathrm{lb} \text {. corn } \\
33 \mathrm{lb} \text {. oil meal }\end{array}$ & 110 lb. clover hay & 4.8 & 3.2 \\
\hline $89 \mathrm{lb}$. & $\begin{array}{l}94 \mathrm{lb} \text {. shelled corn } \\
94 \mathrm{lb} \text {. oats }\end{array}$ & 95 lb. hay & 4.9 & 2.5 \\
\hline $62 \mathrm{lb}$. & $\begin{array}{l}97 \text { lb. cotton-seed } \\
\text { meal }\end{array}$ & $\begin{array}{l}97 \mathrm{lb} . \text { cotton-seed } \\
\text { hulls }\end{array}$ & 3.4 & 3.4 \\
\hline $89 \mathrm{lb}$. & 67 lb. corn & $290 \mathrm{lb}$. alfalfa hay & 2.2 & 10.0 \\
\hline $80 \mathrm{lb}$. & $80 \mathrm{lb}$. corn & Pasture & 1.7 & \\
\hline $81 \mathrm{lb.}$ & $78 \mathrm{lb}$. oats & Pasture & 1.9 & \\
\hline
\end{tabular}

1 Roots.

\section{QUESTIONS}

1. How do the Wolff-Lehman and Armsby standards compare in respect to the protein requirement for the growing sheep? In the Wolff-Lehman standards, why is there such a difference between the wool and mutton breeds?

2. Why do sheep require so much attention? Why are they so easily frightened? How can we restore confidence? Why is it of advantage to have a few goats in a flock of sheep?

3. How can we reduce the ravages of internal parasites to a minimum? 
Name a good vermifuge and succulent food. Why should extra care be used in turning sheep to pasture? What kind of pastures require greatest caution? Why is the shade tree objectionable in a sheep pasture?

4. Why do "hot-house" lambs command so high a price on the market? What class of trade do these lambs fill? Why do not more farmers produce them? During what season of the year are hot-house lambs in greatest demand?

5. Are the sheep fattened in your vicinity raised in the county? How long does it take to fatten an average mutton sheep? What are the indications of a fat sheep? How many fat sheep are shipped from your county annually? Where do they go?

6. Arrange a soiling system for sheep that will fill your conditions. How many acres would be required for a flock of one hundred sheep?

7. Give the advantages and disadvantages of pumplins as a succulent food for sheep.

8. Of the four sub-classes of mutton sheep, which will make the most economical gains? Explain.

9. At what age should we begin to feed the young lambs grain? For each one hundred pounds of food consumed, at what age will sheep make the greatest gain? Explain.

10. Give the advantages and disadvantages of Indian corn as a grain for sheep; of oats; of bran; of clover hay; of alfalfa hay and of timothy hay. 


\section{CHAPTER XV \\ CARE AND MANAGEMENT OF SHEEP}

SHEEP may be successfully grown on any general farm or where there is an opportunity for changes in grazing. When the farm has the equipment and is located convenient to a railroad leading to one of our larger cities, winter-lamb production may be most profitable, whereas if the farm lacks equipment, and has much cheap grazing land, some other form of sheep production would doubtless yield the greater profit. Each farmer must make a careful study of his conditions, such as location, facilities for shipping, demands of his market, condition of the soil, and the like, then lay his plans accordingly.

395. Plan of improvement. - A clearly defined plan should be outlined before the farmer makes an attempt at breeding sheep. The intending sheep breeder should make a careful study of successful sheep farms, noting the conditions wherein his differs, and the modifications that must be adopted. The farmer who rushes into sheep breeding blindly, because the price of wool or mutton seems to warrant it, is likely to pay dearly for his experience.

396. Coöperative breeding. - The value of united effort cannot be overestimated in breeding sheep. This does not mean that the farmers should be partners from a financial point of view, but all should help to advance the interests of each other's flock. Free conversation on all matters relating to the flock will prove of common advantage; the owners will improve in sheep knowledge, and the flocks improve in excellency. There are many things that a few sheep breeders would be able to do that one alone would hardly undertake. Not least among these is the purchasing of 
a pure-bred ram of high grade. The influence of such a ram left in the flocks of several breeders would stimulate interest and result in improvement.

397. Choosing breeding stock. - In choosing the foundation flock, the farmer must have in mind the demand that he means to supply, wool or mutton, and, if mutton, whether he means to raise hot-house lambs or older mutton. He should bear in mind that in general "like produces like" and that "blood will tell." This applies to the ewes as well as to the ram.

398. Type. - The type depends on the individual preference of the breeders. The advisability of selecting wool or mutton sheep will depend on the conditions. Mutton is preëminently adapted to the corn-belt, although a great many wool sheep are found there. Where hot-house and early spring lambs are to be produced, Merino and Horn-Dorset blood must predominate. Where the grazing land is much broken, some breed other than the pure mutton is likely to give best results. For such lands, a good grazing breed is demanded. Whatever breed is chosen, there should be no further change, for it is indiscriminate and zigzag crossing that has produced our present common stock.

399. Uniformity. - In choosing the foundation flock of breeding ewes, no single factor is of greater importance than uniformity. The ewes should be uniform in type, weight, quality, and breeding. Such a flock will cost slightly more than one not uniform in these characters, but will prove much more profitable. Uniformity is a market requirement, and when it is wanting in the breeding ewes, it will also be lacking in the crop of lambs. When one is producing wool, an even, uniform clipping is to be desired. Furthermore, if the breeder wishes to sell his surplus ewes for breeding purposes, they will command a much higher price if uniform in all features, both because of their intrinsic worth, and because of their improved general appearance. This is well illustrated by the Champin Shropshire flock (Fig. 99). 


\section{DIPPING SHEEP}

Dipping the sheep is an essential part of sheep growing. No farmer should attempt to raise sheep without planning to dip them, not only upon their arrival at the farm, but twice annually thereafter. The process is very simple as well as inexpensive.

400. Importance of dipping. - There are two essential reasons why all sheep should be dipped: first, to free them of ticks; and second, to free them of scab germs. It is impossible for lambs infected with ticks or other parasites to thrive. A good dip cleanses the skin, increases the quantity, and improves the quality of the wool. Thus all sheep, whether foundation stock or lambs intended for fattening, should be dipped immediately upon their arrival on the farm.

Sheep ticks can be entirely overcome by dipping. Sheep ticks inhabit no other farm animals, and once eradicated, there is no possible chance of their reappearing, unless brought to the flock on infested sheep, or carried in some manner, as in the clothing of shearers, from an infested flock.

Sheep scab can likewise be prevented by dipping. This scab is caused by a minute parasite, too small to be seen by the naked eye, which irritates the skin, causing a watery exudate. This exudate forms a crust beneath which the scab mite burrows, greatly irritating the animal, causing loss of flesh, intense itching, loss of wool, and the death of the sheep. The mite is transferred from one sheep to another, and soon the entire flock is affected.

Unless well disinfected, sheep are apt to become infected with the scab mite in the stock-yards, railroad stock-pens, or in stockcars. As they multiply very rapidly, a few parasites gathered up in this way will soon run through an entire flock. When once the sheep become affected and scabs formed, the disease is hard to eradicate. If it is taken in time, prevention is very easy.

401. The dipping vat. - The nature of the dipping vat or tank will be determined largely by the size of the flock. For a small 
flock such as is kept on the average farm, a simple trough of wood, metal, or concrete, 16 inches wide at the top and 6 inches at the bottom, 4 feet deep, and 8 to 12 feet long, will prove ample. The vat must be narrow so the sheep cannot turn around; must be deep so they can be plunged clear under and no spot escape the dip; and the longer the vat, the quicker the dipping can be performed, as each animal should remain in the dip at least one minute. The end of the vat at which the sheep enter should be perpendicular, so that they may be made to jump into the dip and thus be completely submerged. At the other end, there should be a gradual incline up which the sheep can walk.

402. How dips are used. - The dip must be hot. The best temperature is that which a man can endure with the bare arm. If the dip is too hot, it will scald; if too cold, it will be less effective. The water may be heated in a large kettle and kept hot by throwing red-hot irons or heated stones into the tank.

The best dip to use is some one of the coal-tar preparations, as Zenoleum, Naptholeum, Daytholeum, Milk Oil, and the like. These are fairly cheap, very effective, cleansing to the skin, healing to diseased eyes and mouth, pleasant to use, and sure death to all forms of parasite life. The direction given on the cans in which the coal-tar comes is to use at a strength of one part of dip to 100 parts water. While this is strong enough to kill ticks, it is not sufficient to remove scab germs. When the sheep have first arrived or when dipping for scab, use one part dip to forty parts water.

403. Frequency of dipping. - All sheep arriving at the farm should be dipped before they infect the lots. In addition to this the entire flock should be dipped at least once a year, better twice annually. One dipping should take place soon after shearing, as less dip,will be required. It should not, however, follow too closely after shearing. A pleasant day should be selected, and the sheep should be well protected until dry. It will take them several hours to dry out. At this time it should not take more than one quart 
of the mixture to a sheep, whereas if the sheep is not shorn, it will take approximately one gallon. The second dipping should be in the fall, some fair day just before the sheep are placed in their winter quarters. This second dipping will pay because of its invigorating influence, even though the sheep are free from ticks.

\section{SHEARING SHEEP}

Formerly it was the custom to wash the sheep before shearing, and shear later in the season than at present. This was in the days of the spinning wheel and hand loom. The practice of washing the wool was continued somewhat later, for it was thought that it prepared the wool for the manufacture. This it did not do, but it did render the wool lighter by removing the natural oil, and hence was a distinct disadvantage to the farmer.

404. When to shear. - The time for shearing will depend somewhat on the conditions. If winter lambs are sought, the shearing should be done in March or before, whereas, if there is no hurry about the lambs, and the sheep are not well protected, the wool may be left on until warm weather. With the coming of warm weather, the wool must be removed or the sheep will not thrive. When at all practicable, early shearing is to be recommended, as the sheep will do much better. The amount of wool taken off will be greater if the sheep are shorn regularly in March or April than if they are shorn in June.

405. Hand shearing. - Hand shearing requires much skill and considerable practice. A good man will shear from 40 to 100 sheep in a day, using common hand shears. While each shearer has his own method, it is some modification of the following: the sheep is placed on its rump, with its back to the shearer, supported by the left arm, with the shears in the right hand. The wool is then removed from the brisket and neck down to the shoulders. The fleece is then opened down the abdomen and first clipped on the left side as far around as the back bone, and then on the right side 
in a similar manner, all the time exercising much care in keeping the fleece together. Care must be exercised not to cut too deep at one strike, or the sheep will not be smooth. The points of the shears must be kept close to the hide, otherwise a second stroke will be necessary, which injures the wool and takes much time.

For the beginner to shear a sheep by hand is really a very difficult task, and if the sheep be a fine-wool, the task is still greater.

406. Machinery shearing. - Shearing sheep with a machine is a much more easy task than shearing by hand, and the beginner can do better work with it. On the market there are both hand and power machines, but on the average farm the hand machine is, of course, the one to use. To operate the machine requires two men or a man and boy, - one to turn the machine, the other to shear the sheep. If available, the beginner should take a coarsewooled sheep, as the fine-wools are more difficult to shear. With a rather coarse-wooled sheep, one can follow the directions that come with the machine, and shear the sheep, even though he has never seen the operation (Figs. 101, 102, 103).

407. Tying the wool. - The fleece is rolled with the belly and loose ends inside, the cut ends out. All very dirty pieces should be removed and never tied up in the wool. Special wool twine should be used to tie the fleece, as binder twine greatly injures the wool, for small bits of the fiber often get into the fleece, and, not taking the dyes, must be picked out by hand.

Later, the wool is packed in large sacks for shipment. In filling the large bags care should be exercised to see that the wool is well packed and the corners all well filled.- After being packed full the bags are sewed at the top. If stored, the wool should be put in a dry place where there is no danger of mice cutting the bags and building nests of the wool.

408. Docking the lambs. - Unless the lambs are to be sent to market under three months of age, they should have the tail removed. The tail is of no use to the sheep and is likely to become 


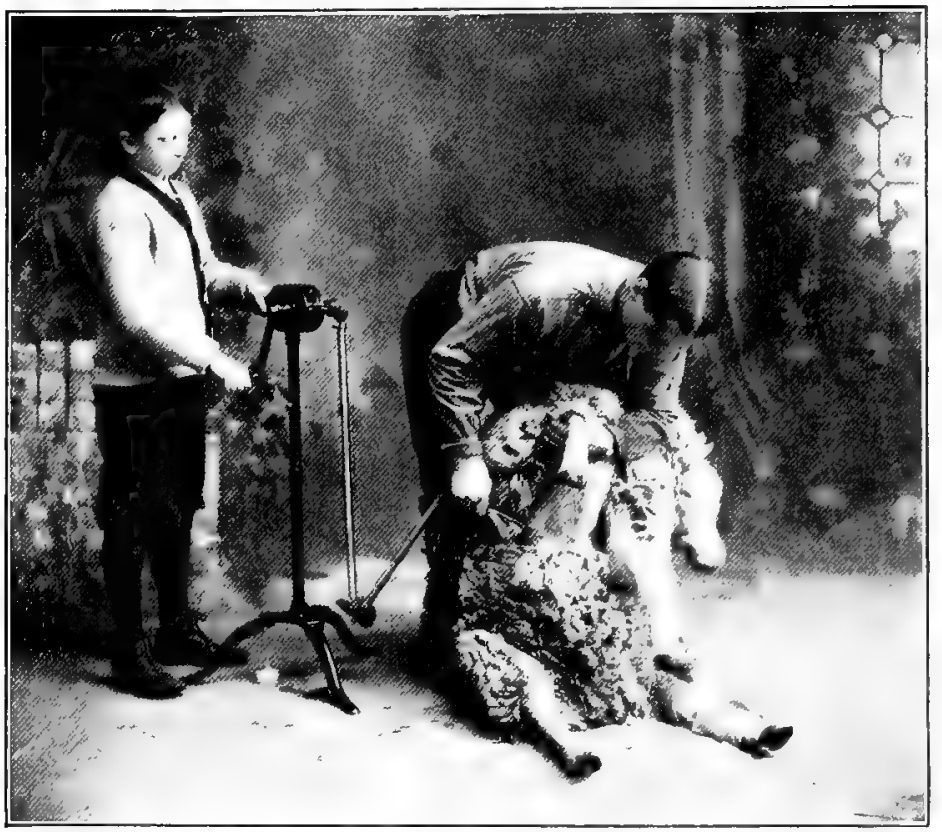

FIG. 101. - Shearing sheep by machinery. Shcaring the abdomen.

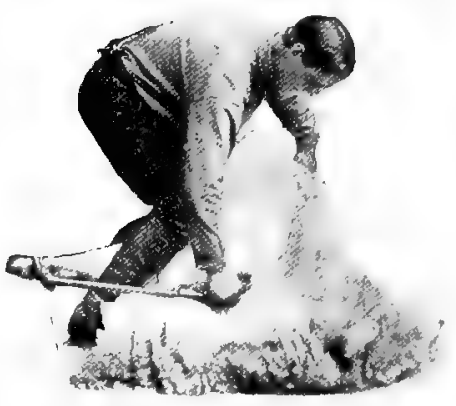

Fra, 102. - Sluearing the back.

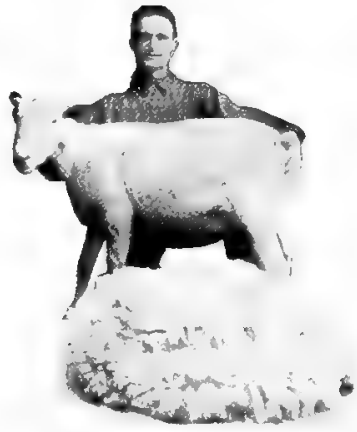

FIG. 103.- Sheep and wool when finished. 
foul. Docked lambs thrive better than undocked, and they present a fuller and squarer appearance. The lambs should be docked at ten days to two weeks of age, or even younger if strong. This may be done by severing the tail with a sharp knife, cutting from the under side, by the use of a mallet and sharp chisel; or, better still, by the use of docking pincers.

\section{PRACTICAL SHEEP BARNS}

Proper shelter for the flock adds greatly to its comfort and thrift. It need not, however, be either elaborate or costly. In the sheep barn there are several factors that must be provided for, but extra warmth not being one of the factors, the rest is comparatively simple and inexpensive. Chief among the factors for which provision must be made are ventilation without draughts, sunshine, drainage, convenience for feeding, arrangements for separating the ewes at lambing time, storage for grain and hay, and, if possible, a root cellar.

409. Ventilation. - The ventilation of the sheep barn should receive careful consideration. This must be so arranged that there are no draughts, as such will result in colds, running at the nose, catarrh, and like troubles. Many experienced sheep owners prefer to ventilate the sheep quarters by placing doors across one side of the barn.

An abundance of sunshine is essential to the well being of the breeding flock in winter. Sunshine is nature's greatest disinfectant, and keeps the quarters light and cheery. If the row of doors arranged for ventilation is on the south side of the quarters, as it should be, it will admit sufficient sunshine on days when the doors can be kept open. It is often necessary to close them on account of the severity of the weather, just after shearing, or just after dipping, and in such cases extra windows are very convenient. These may preferably be placed along the south side between the doors, as then they will serve their maximum efficiency. 
410. Drainage. - In selecting a site for the sheep-barn, due consideration should be given to drainage. Sheep cannot survive damp and muddy footing. Wet floors and muddy lots are to be avoided. If possible, select ground from which there is a little slope in all directions, facing the barn to the south and arranging the lots on the south slope. It would be of much advantage to have the place protected on the north and west by a grove or bluff.

411. The interior arrangement. - In arranging the sheep

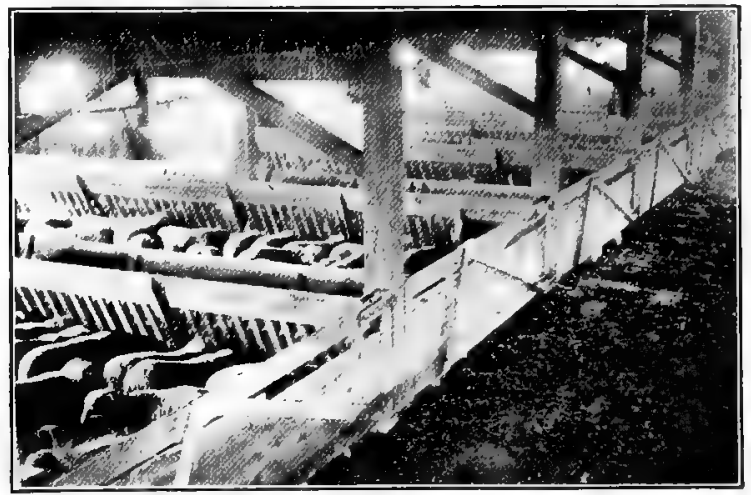

Fig. 104. - Interior view of sheep barn.

quarters, convenience of feeding must be kept in mind. This factor is often complicated by the desirability of having provision for separating the ewes at lambing time. As a rule, it is more difficult to feed the sheep in two lots than in one. This difficulty can often be overcome, in large part at least, by using the feed-rack as a partition for the two pens. Such an arrangement also saves the material otherwise necessary for the partition. To facilitate labor in feeding, ample provision should be made for storage of all feed, hay, and straw in the loft, grain in a bin on the ground floor, and if possible, a cellar for the storage of roots. Where convenient, water should be placed in the barn (Fig. 104). 
The size of the sheep barn will depend entirely on the number of sheep in the flock. 'Experienced sheep owners do not agree as to the amount of space required, some stating that ten square feet is sufficient, others that they desire eighteen square feet for each animal. In practice, twelve square feet of floor space will be ample for each breeding ewe.

412. The feed-racks. - Movable feed-racks are to be preferred. They should be comparatively long and narrow. The racks may be used in different places if desired. In many modern sheep barns, the combination hay-rack and grain-trough is used, although it is better to have the two arranged separately. When it comes to forced feeding, as in fattening lambs, the combination rack has the objection that more or less dirt filters down into the grain-troughs, and the sheep with their dainty appetites do not feed as well as when the grain-troughs and the hay-rack are separated.

413. Quantity of bedding. - Bedding should be used very liberally in both the sheep barn and at least a part of the lot. A fresh supply should be put down every few days.

414. The sheep lot. - If possible, the sheep should at all times, except in the very severest of winter weather, have free access to a small lot. If this is dry, and a part well bedded, the sheep will spend much of their time outside and will be much benefited thereby. The lot should not be muddy. Where sheep are allowed to tramp in the mud, trouble from foot-scald is likely to result; particularly is this true if there is much sheep manure mixed in the mud. Foot-scald is usually known as foot-rot. This disease is hard to eradicate.

A straw stack in the sheep lot has many advantages. It keeps the sheep out of the wind, provides them a clean place to lie, and they will eat of the straw to some extent. It has the disadvantage, however, that the chaff gets in the wool, and for this reason is objected to by many good sheep owners. Yet ewes and lambs delight in lying alongside such a stack, and they will be found there more often than in the barn, except in very severe weather. 


\section{QUESTIONS}

1. How many sheep are there in the United States? How many in your state? In your county? How does your staterank with other states in the production of sheep? How does your county rank with other counties in the state? Name the ten leading sheep states. Which states possess the largest number to the square mile? To the farm?

2. In selecting breeding stock to improve the quality of the sheep, what are some of the essential factors to be considered? Why is uniformity of first importance in the mutton flock?

3. Name the more common external parasites that trouble sheep. How may they be prevented?

4. Why are sheep no longer washed before shearing? Which is more efficient, hand or machine shearing? How many sheep can a man shear by hand in a day? How many with the machine? What influences the number of sheep one can shear in a day? Why should the fleeces be of uniform weight?

5. Which type of sheep, wool or mutton, requires the warmer quarters? Why? How much barn space should be allowed for each sheep? Why is it essential that sheep be provided with facilities for exercise?

6. Name the ten largest sheep markets in the United States. How many sheep are handled at each annually? 


\section{PART FOUR-SWINE}




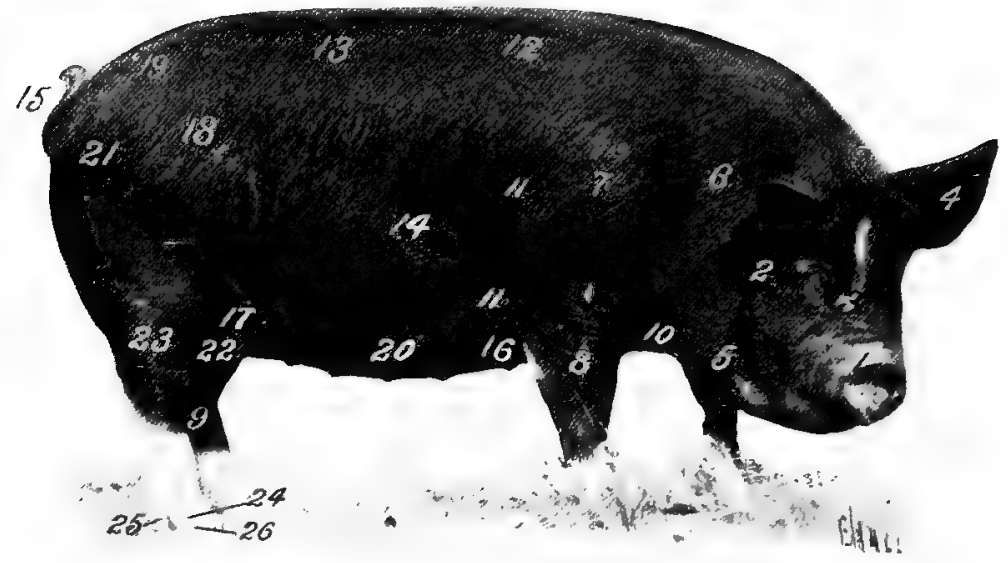

FIG. 105. - Points of the pig.

$\begin{array}{ll}\text { 1. Snout. } & \text { 10. Breast. } \\ \text { 2. Eye. } & \text { 11. Chest line. } \\ \text { 3. Facc. } & \text { 12. Bark. } \\ \text { 4. Ear. } & \text { 13. Loin. } \\ \text { 5. Jowl. } & \text { 14. Side. } \\ \text { 6. Neck. } & \text { 15. Tail. } \\ \text { 7. Shoulder. } & \text { 16. Fore flank. } \\ \text { 8. Fore leg. } & \text { 17. Hind flank. } \\ \text { 9. Hind leg. } & \text { 18. Hip. }\end{array}$

19. Rump.

20. Belly.

21. Ham.

22. Stifle.

23. Hock.

24. Pastern.

25. Dewclaw.

26. Foot.

18. Hip. 


\section{CHAPTER XVI}

\section{BREEDS OF SWINE}

There are two distinct types of swine: the lard type, noted for the production of thick fat; and the bacon type, known for the production of bacon.

415. Lard type. - Swine of this type far outnumber those of the bacon type in America. As a type, the lard-hog has reached its highest development in the corn-belt of the United States. This is often called the American type of hog, and is not looked upon with favor by people of other countries because of its extreme fat development.

The lard-hog should be coinpact, with the body very wide and deep. The shoulders should be full although not coarse, with the hindquarters or hams carried out straight to the tail-head, and well fleshed down to the hock. Since the valuable cuts lie along the back, rump, and quarters, the general conformation of the lardhog should be similar to that of the fat steer. The flesh covering should be thick and evenly distributed throughout the body, particularly over the shoulders and quarters. The size and weight are determined largely by the market conditions. Formerly very heavy hogs were in demand, but at the present time pigs weighing from 225 to 250 pounds will command the highest price, all other conditions being equal (Fig. 106).

416. Bacon type. - The true bacon type of hog is little grown in the United States. Denmark, Great Britain, and Canada furnish most of this class of pork. In recent years the American breeders, particularly those east of the corn-belt, have given this class of swine some active consideration, but its production is not likely to make much headway in America. We prefer the rapid-fattening, 
heavily fleshed, and early-maturing lard type. In contrasting the general appearance of the bacon type with the lard type, we note that the body of the former lacks the width of the latter, the shoulders and hams are lighter and longer, the body is somewhat longer, and the animal stands on somewhat longer legs. The weight of the bacon hog is not so great as of the lard type, American - markets preferring 155 to 195 pounds and the Danish markets 160 to 220 pounds (Fig. 114).

There are several breeds belonging to each of these types. There are also a number of breeds that rank intermediate between the typical lard and the typical bacon types. We will, therefore, consider the breeds of swine under three general classes; the pure lard breeds, the intermediate breeds, and the pure bacon breeds.

\section{PURE LARD BREEDS OF SWINE}

The Name, Native Home, Relative Size, Position of the Ear, and Color of efach of the Breeds of Pure Lard Swine

\begin{tabular}{|c|c|c|c|c|}
\hline Name of Breed & Native Home & SIzE & $\underset{\text { POSIII }_{\text {PAR }}}{\text { OF }}$ & CoLOR \\
\hline Poland China . & United States & Medium & Drooping & Black \\
\hline Berkshire . & England & Medium & Erect & Black \\
\hline Duroc Jersey . & United States & Medium & Drooping & Red \\
\hline Chester White & United States & Large & Drooping & White \\
\hline Hampshire & America & Medium & Erect & Black, belt \\
\hline Essex . & England & Small & Erect & Black \\
\hline Small Yorkshire & England & Small & Erect & White \\
\hline Suffolk & England & Small & Erect & White \\
\hline
\end{tabular}

417. Poland China lard-hog. - This breed was developed in southern Ohio, particularly in the counties of Warren and Butler along the Miami river valley. The origin is not clearly understood, but it is known that several foreign breeds entered into the 
early improvement. The chief strains used were the Russian, Byfield, Big China, Irish Gragier, and the Berkshire. Besides the Warren County hog, previous to 1816 , two strains were known in the Miami valley, the Russian and the Byfield. When these were imported is not known.

The Russian hog is described as possessing superior length and height, with rather large but fine bone, and quiet temperament. The color was white, and the hair long and coarse.

The Byfield hog was of two types, one rather large, with long, flat ribs and lopped ears ; the other, more refined, with ears pointing forward. Both types were white in color.

The Big China hog was introduced into Butler County in 1816. John Wallace, a trustee of the Shakers' Society of Union Village, shipped one boar and three sows from Philadelphia. The members of the Shakers' Society did much toward developing the Poland China.

The Berkshire hog was introduced to the Miami valley in 1835 . Munson Beach of Lebanon shipped some hogs of this breed from New York State. The Berkshire improved the symmetry and increased the early-maturing quality. It also gave the black color to the Warren County hog.

The Irish Gragier hog was imported to Warren County from Ireland, in the fall of 1839, by William Neff. The Neff stock is described as possessing considerable size, a long body with superior back, very fine hams, and white color. It is stated that no foreign blood has been used in the development of the Poland China since 1845. The modern Poland China hog owes its excellence to selection, judicious mating, and better care on the part of breeders generally.

418. Description of Poland China hog. - The color is black, with six white points - white in the face, on the feet, and tip of the tail. The head is of medium length, and the face straight. The cheeks are full; the ears drooping; the body broad and deep, but with a curved back and low rump; superior hams, and short legs. 
The Poland China meat has been subject to criticism because of the rather large amount of external fat, although the American

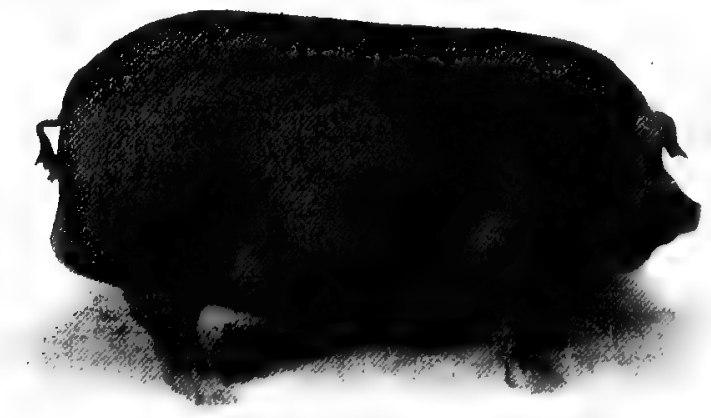

FIG. 106. - The Poland China. Lard type.

trade does not object to this, and the price is the same as for other breeds (Fig. 106).

419. Berkshire lard-hog. - This breed was developed in England, notably in the counties of Berkshire and Wilts. Little is known of the origin, although Berkshire has long been known as a swine-raising county. The old Berkshire was very much coarser than the present type, and possessed lopped ears. The color was a sandy or reddish brown, spotted with black. Even in its unimproved state, the Berkshire hog had a reputation for producing a good quality of meat.

The early improvement of the Berkshire was due to the use of Chinese, Siamese, and Neapolitan blood. These crosses served to lessen the size and to improve the coarseness of the old Berkshire, so as to render it more suited to the demand which has arisen for small and delicate pork. The more prominent of the early breeders were Richard Astley and Lord Barrington. Later William Hewer of Sevenhampton, Wiltshire, was a leading breeder. The breed owes its present improvement to selection and carc on the part of Berkshire breeders generally, American as well as English. 
420. Berkshire compared with Poland China. - These two breeds are somewhat similar in general characteristics though differing widely in details. In color they are much the same, being black with six white points. The head of the Berkshire is short and the face gracefully dished; the ears are carried erect or pointed straight forward; the body lacks the breadth and clepth of the Poland China, but the back is level and fairly straight, with long, level rump. The entire back outline shows much less arch than is characteristic of the Poland China (Fig. 107).

The general quality of the Berkshire is held in high esteem, as is also the quality of the meat. When properly fed, the meat has

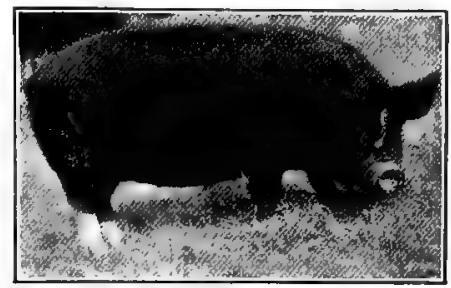

FIG. 107. - The Berkshire. Lard type.

a fine grain and a desirable blending of fat and lean, spoken of as marbling. For this reason the breed stands high in public favor.

421. Duroc-Jersey lard-hog. - This breed developed in the Unitect States, and, as is the case with so many of our domestic breeds, little is definitely known of the early origin. Red or sandy colored pigs have existed in this country for a great many years. It is stated that slave traders imported red hogs from western Africa. These were known as the Guinea breed. As early as 1837, Henry Clay imported red hogs from Spain, commonly known as Spanish red hogs. In 1852, Daniel Webster introduced red hogs from Portugal to Massachusetts. The old Berkshire, which was frequently marked with red, may be responsible for some of the red pigs found in America.

Whatever the origin, it is certain that a large breed of red hogs attained considerable prominence in New Jersey, which was subsequently known as Jersey-Red. This breed possessed Iarge lop ears; a rather long, deep body; with coarse bone and bristly 
hair. It was valued because of its size, strong constitution, and rapid growth.

At the same time the Jersey-Red was being developed, a similar breed was being formed in Saratoga County, New York. This breed subsequently became known as the Duroc. This strain owes its origin to Isaac Fink, who procured a red boar and used it on his common sows with great success, so that his herd became very popular. The Durocs were finer in bone and carcass than the Jersey-Reds.

The present Duroc-Jersey breed is the result of the amalgamation of the blood of these two strains. This union was due largely to

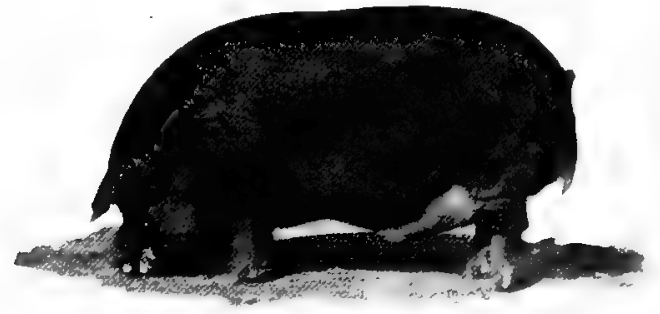

FIG. 108. - The Duroc-Jersey. Lard type.

the efforts of Colonel F. D. Curtis of Saratoga County, New York. He was a very influential breeder and did much to promote the amalgamation.

422. Duroc-Jersey compared with Poland China. - In many respects these two breeds are similar, although there is striking contrast in color, the Duroc-Jersey being always red, and the Poland China black. The head of the Duroc-Jersey is of medium length, and the face straight or slightly dished, the ears are of medium size and droop forward, and the body is broad and deep, with the back less arched than in the Poland China. Under similar conditions, the general quality and the quality of the meat compares favorably. When corn fed, both are too fat for foreign trade (Fig. 108). 
423. Chester White lard-hog. - There are three strains of Chester Whites, each with a somewhat different origin.

(1) The original Chester White. - This strain first became prominent in Chester County, Pennsylvania, where white hogs have existed for many years. They were, perhaps, introduced by the earliest settlers. Captain James Jeffries, who in 1818 imported a pair of white pigs from England, is commonly spoken of as the founder of the strain. Later, Harvy Atwood introduced Chinese

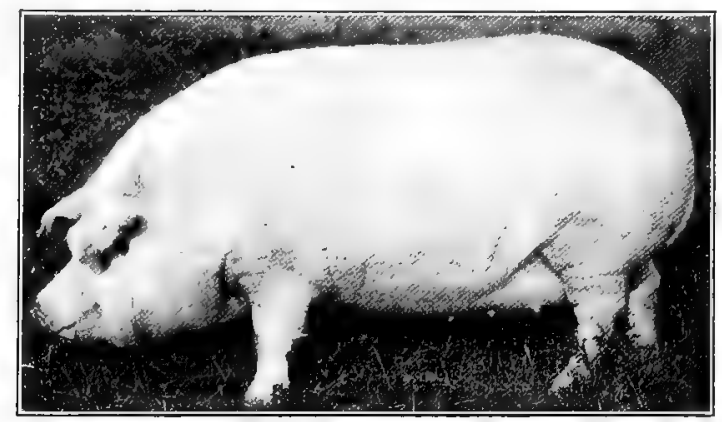

FIG. 109. - The Chester White. Lard type.

stock from England to Delaware County. The stock from the Jeffries and Atwood herds were blended together, along with the common swine, which resulted in the original Chester White strain.

(2) Todd's Improved Chester White. - This strain was developed in Connecticut and Ohio. The Todd Brothers of Connecticut purchased a black and white boar imported from England in 1827, and known as Norfolk Thin Rind. This boar was mated with a white sow of undoubted Irish Gragier blood. In 1830, the Todd Brothers moved to Ohio, taking with them these two hogs, which served as foundation stock. S. H. Todd, a son of one of the Todd Brothers, was allied with the improvement of this strain for over forty years. 
(3) The Ohio Improved Chester White. - This strain developed near Salem, Ohio. It owes its origin to L. B. Silver, who in 1865 began breeding Chester Whites with a view of producing a superior type.

424. Chester White compared with Poland China. - The former is larger than the latter and can always be distinguished by the color. The head of the Chester White is of medium length, and the face straight; the ears are large and drooping; the body lacks the width and depth of the Poland China, but the back is straighter. Common with all white swine, the skin is subject to sunscald and scurfiness, especially when exposed to a hot sun and dry weather. In quality of meat the Chester White ranks intermediate between the Poland China and the Berkshire (Fig. 109).

425. Hampshire lard-hog. - This breed, formerly known as Thin Rind, was developed in America. The name was changed to Hampshire by order of the American Thin Rind Association, in 1904. The American history of this breed traces back through

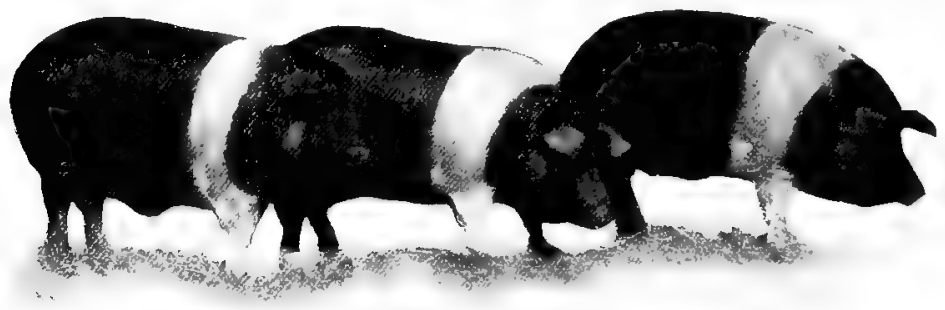

FIG. 110. - The Hampshire. Lard type.

Canada and Massachusetts to Hampshire and Essex, England. About 1820 to 1825, MacKay imported Thin Rinds from Hampshire, England, to Boston, Massachusetts. Later, these hogs found their way to Kentucky. Some of these animals were taken to the central states, where the breed has been greatly improved by careful selection. 
426. Hampshire compared with Poland China. - These breeds can readily be distinguished by the characteristic color markings of the Hampshire, which is black with a white belt around the body at the girth. The head of the Hampshire is of good length, with the face straight; the ears, though erect, incline slightly forward and the body lacks the breadth, depth, and length of the Poland China. This is due in part at least to the fact that the Hampshire was formerly classed as a bacon-hog. During recent years, its success in the pure lard classes warrants classifying it as a pure lard-hog. The statement is made that the quality of the meat is not surpassed by any other of the pure lard breeds (Fig. 110).

427. Essex lard-hog. - This breed was developed in Essex County, England, where there formerly existed a rather small, roach-backed, flat-ribbed, slow-maturing hog of a nervous disposition. Improvement was begun by Lord Western, who, in 1830, imported a pair of black Neapolitans from Italy to Essex County, England. This Neapolitan cross gave most satisfactory results. Berkshire and Black Suffolk blood was also used. Later, Fisher Hobbes, a tenant of Lord Western, became interested in the breed and did much to improve the Essex. In England, the Essex is often spoken of as Small Black or Black Suffolk.

428. Essex compared with Poland China. - The former is much smaller than the latter, and possesses certain very distinguishing features. The color is entirely black. The head is short, the face slightly dished, while the ears are small, fine, and carried erect. The Essex is a short, thick, deep, chunky type of pig, with short, fine-boned legs. The meat is fine and of good flavor, but possesses a tendency to excessive fatness.

429. Small Yorkshire lard-hog. - This breed was developed in England, where it is known as Small White; the name Small Yorkshire being of American origin. The breed is thought to be of Chinese origin, though different at present from the early Chinese type. As early as 1818, Robert Collings and Charles Mason, both Shorthorn breeders, interested themselves in the improvement of 
the Small White, then known as the Chinese. Many types or strains of the Small Whites have been developed in England, but at present they are all classed as one breed. In general symmetry

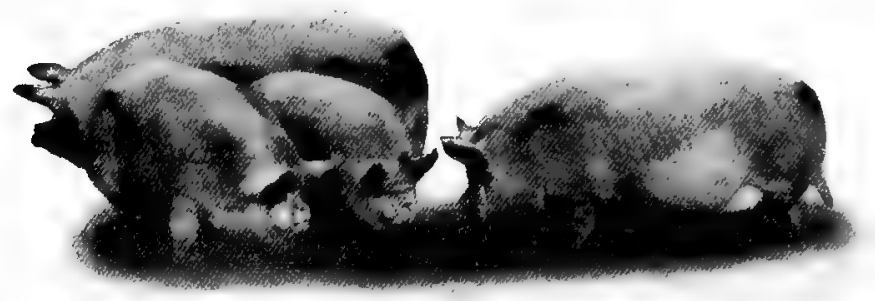

FIG. 111. - The Small Yorkshire.

this breed is almost perfect, but carries too much fat and is rather small (Fig. 111).

430. Suffolk lard-hog. - There are two distinct breeds of this name, one in America, the other in England. The American breed is white, the English breed black in color. In England, Essex, Small Black, and Black Suffolk are synonymous terms for the same breed. The American Suffolk is no doubt of the same origin as the Small Yorkshire or Small White of England.

\section{INTERMEDIATE BREEDS OF SWINE}

The Name, Native Home, Relative Size, Position of Ear, and Color of Each of the Breeds Intermediate between Pure Lard and Pure Bacon

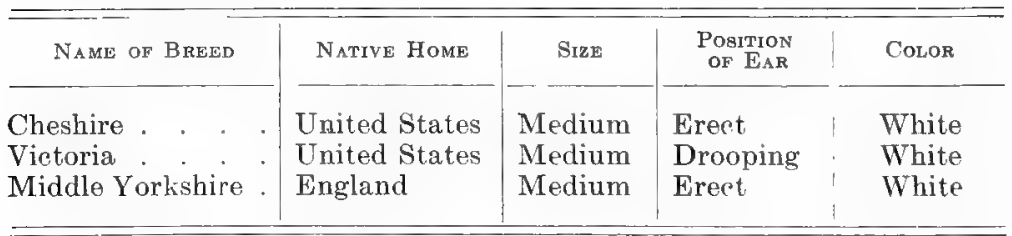


431. Cheshire hog. - This breed developed in New York State. The origin is obscure. About 1855, two Yorkshire hogs of the middle class were imported from England to Jefferson County, New York. These were crossed on sows from Cheshire, England. Later, White Suffolk blood was mingled with this cross. A. C. Clark of Belleville did much to promote the interests of the breed. In 1870 he won the Packers' Prize of $\$ 500$ for the best pen of pigs exhibited at a fair at St. Louis, Missouri. This breed is bred to-day primarily in New York State.

432. Description of the Cheshire.- In general conformation this breed ranks intermediate between the pure lard type and the

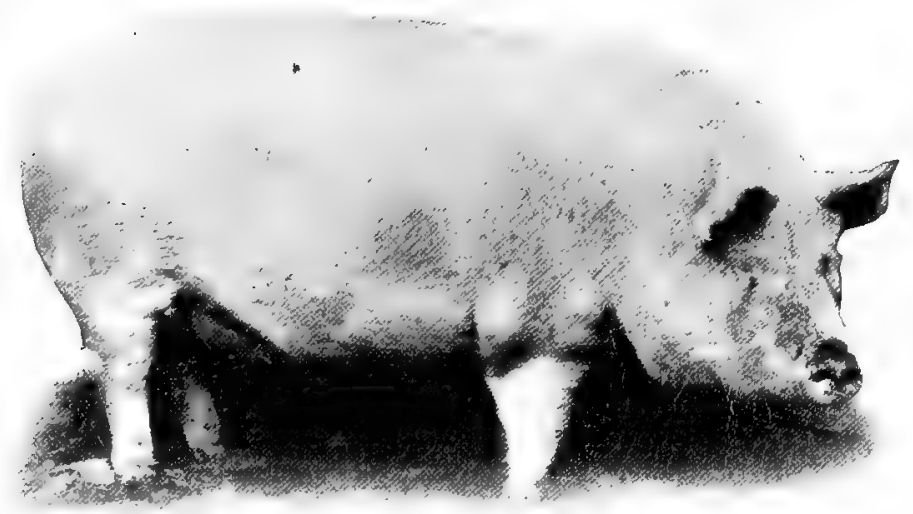

FIg. 112. - The Cheshirc.

bacon type. It lacks the massiveness of the former, and the length and depth of the latter. The color is white. The head is of medium length, and the face slightly dished, the ears are small, fine, and stand erect, the body is of medium width, depth, length, and slightly arched, and the shoulders and hams are well developed. The general quality and the quality of the meat is unexcelled. The lean and fat are well interspread, giving the meat a marbled appear- 
ance. When properly fed, the Cheshire produces excellent bacon (Fig. 112).

433. Victoria hog. - There are two strains of Victorias, each with a different origin.

(1) The Davis or Indiana Victoria. - This strain was originated about 1870, in Lake County, Indiana, by G. F. Davis, who combined the blood of the Poland China, Berkshire, Chester White, and Suffolk. These breeds were crossed, and then careful selection practiced to secure a definite type. The descendants of this strain secured the ascendancy, and represent the Victoria breed at the present day.

(2) The Curtis or New York Victoria. - This strain was originated about 1850, in Saratoga County, New York, by F. D. Curtis, who first combined the blood of the Irish Gragier and the Byfield, and then crossed their descendants with the Yorkshire. Careful selection was exercised until a type was established.

434. Victoria compared with Cheshire. - In general conformation, the former resembles the pure' lard type to a greater extent than the latter, being thicker set, broader, and deeper, standing on shorter legs. Both breeds are white. The Victoria has a rather short head and a medium dished face, ears small and carried erect, shoulders and hams thick and full, and length and depth of side meat, which ranks second to that of the Cheshire in quality.

435. Middle Yorkshire hog. - This breed was developed in England where it is termed Middle White. It was originated from a cross between the Large White and the Small White breeds. The Middle White resembles in many essentials and even in size, the Large White. Its head is shorter and heavier, face more dished, and ears erect. It does not make such rapid growth when young, although it fattens as quickly after the age of six months. The Middle White also has a tendency to lay on a larger proportion of fat to lean flesh, thus improving the meat. 
PURE BACON BREEDS OF SWINE

Name, Native Home, Relative Size, Position of Ear, and Color of Each of the Pure Bacon Breeds of Swine

\begin{tabular}{l|l|l|l|l}
\hline Name of Breed & Native Home & Size & Position of Ear & Color \\
\hline $\begin{array}{l}\text { Large Yorkshire } \\
\text { Tamworth . }\end{array}$ & $\begin{array}{l}\text { England } \\
\text { England }\end{array}$ & $\begin{array}{l}\text { Large } \\
\text { Large }\end{array}$ & $\begin{array}{l}\text { Erect } \\
\text { Erect }\end{array}$ & $\begin{array}{l}\text { White } \\
\text { Red }\end{array}$ \\
\hline
\end{tabular}

436. Large Yorkshire bacon-hog. - This breed was developed in Yorkshire county, England, where it is known as Large White. The early origin is obscure, but the breed undoubtedly descended from a race of large, coarse-boned, leggy, white hogs that was common in Yorkshire and adjacent counties over a century ago.

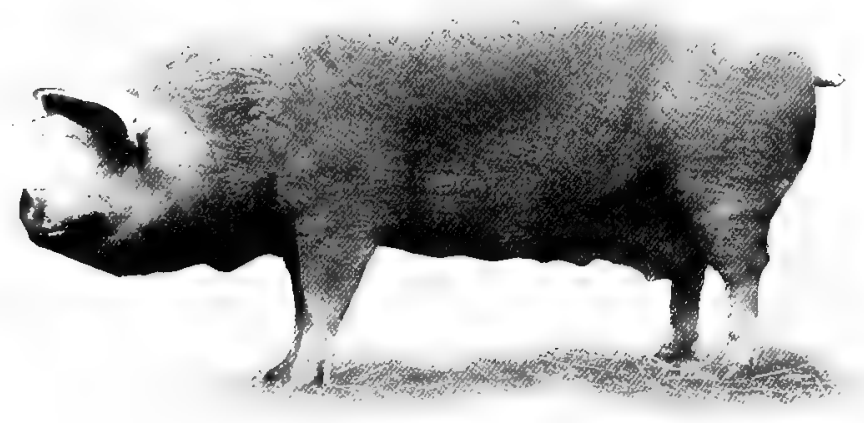

Fig. 113. - The Large Yorkshire. Bacon type.

Marked improvement began about the middle of the nineteenth century, by using the White Leicesters on old Yorkshires. These Leicesters are described as large, with small heads, erect ears, fine 
hair, and light bone. This cross was still further improved by breeding the largest and best young sows to Small Yorkshire boars that possessed great fattening capacity. Joseph Tuley of Keighley was the foremost of these early improvers. His herd of Large Whites was very popular, and his animals commanded a high price. It is not too much to say that the Small White, with its fine bone and easily fattening tendencies, produced a very marked improvement in the old Yorkshire, which has been still further improved and brought up to its present high standard of excellence by judicious selection in the hands of skillful breeders.

437. Description of the Large Yorkshire. - This is one of the largest breeds of swine. The conformation is typical of baconhogs in general ; that is, upstanding, comparatively narrow, deep and long, with light shoulders and hams. The color is white. The head is of medium length and the face dished, the ears of medium size and carried erect, although with age they are inclined to droop, and the body is long and deep, but lacks breadth.

In the production of bacon, the Large Yorkshire ranks second to none. In Denmark, England, Ireland, and Canada, where bacon is an important industry, the Large Yorkshire and its crosses is the most common blood used (Fig. 113).

438. Tamworth bacon-hog. - This breed was developed in central England, notably in Stafford and near-by counties. The origin is uncertain. As first known, it was a long-legged, narrowbacked, and late-maturing type. Whether improvement was brought about solely by selection, or whether cross-breeding was resorted to, is not known. The improvement followed the conversion of England into cultivated lands, as the farmers needed a less active type of swine. The statements that crosses were made with White and Neapolitan strains meet with disfavor. F. C. Fidgeon, who had known the breed for over sixty years, is inclined to the opinion that the Tamworth owes its present excellence solely to selection and better care.

439. Tamworth compared with Large Yorkshire. - These two 
breeds are about equal in size and somewhat similar in general conformation, though differing widely in detail characters. The Tamworth is red. The head is notably long, and the snout tends to be narrow with straight or slightly dished face, the ears are comparatively large and should be carried erect, though, with age, they often droop; the body is similar to that of the Large Yorkshire,

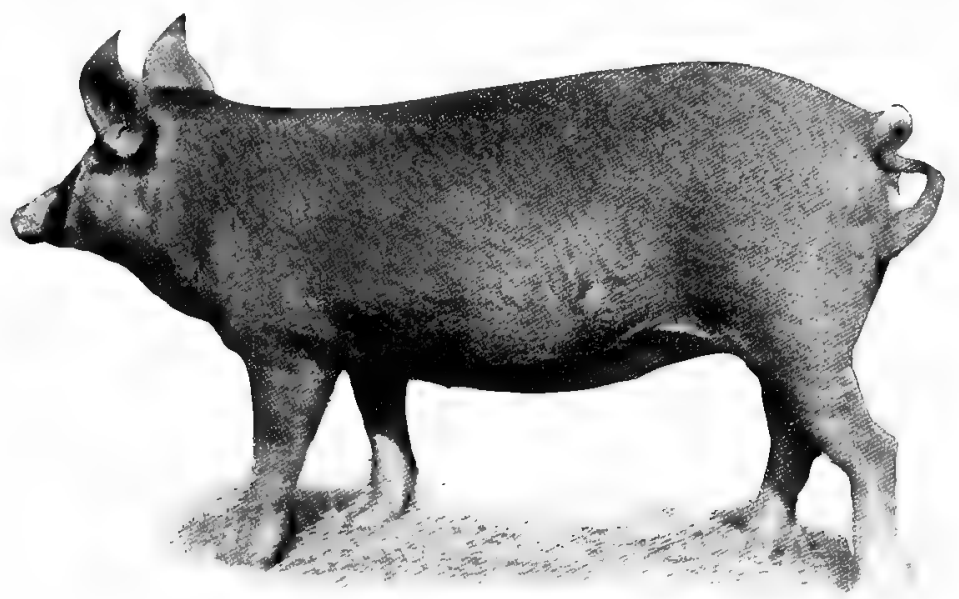

FIG. 114. - Tho Tamworth. Bacon type.

being long, deep, and narrow, and the shoulders and hams are light and long. The bacon ranks high, but is second to that of the Large Yorkshire (Fig. 114).

\section{QUESTIONS}

1. How many pure-bred swine are there in your vicinity? What breeds are the most common? Why?

2. Give the name of a few of the leading swine exhibitors at your state, county, and town fair. What are some of the prices obtained for the prizewinning stock? 
3. Why has America, particularly the corn-belt, been so successful in developing breeds of lard-hogs? Why has England been so successful in developing bacon breeds? What type is most common in Canada? Why?

4. Contrast the eight breeds of lard-hogs in respect to early maturity prolificacy, quality of meat, and general quality.

5. Is there a relationship between the size of a hog and the rate of maturity or the quality of the meat?

6. Contrast the pure lard, intermediate, and pure bacon breeds in respect to fertility. Explain the variation.

7. Why is the fancy character - white belt about the body - of the Hampshire likely to prove a detriment to the breed?

8. Has color among swine any relation to sectional adaptability? Explain.

9. Classify the breeds of swine according to size. Name the principal disadvantages of the very small and very large breeds.

10. Name the breeds of swine formed by crossing two or more varieties. Name the advantages and disadvantages of this method of breed formation. 


\section{CHAPTER XVII}

\section{JUDGING SWINE}

IN judging swine, as in judging all other classes of meat animals, the butcher's preference must be the leading guide. This preference is determined largely by the demands of the market. The condition of the animal, its weight, quality, and uniformity are among the most important points.

440. Score-card for swine. - Each breed of swine has its own scale of points, varying in detail and numerical value, but similar to the following in general characteristics. (See p. 276.)

\section{GENERAL APPEARANCE OF LARD-HOGS}

441. Form. - The general form of the lard-hog is of primary importance. It should be compact, with the body deep, broad, smooth, and symmetrical. The length should be medium, as too long a back is likely to result in weakness just back of the shoulders. The hog should have the larger part of its weight in the region of the most valuable cuts; that is, along the back, loin, and hams. While the forequarters, neck, and head are parts of lesser value, they must show much development in order to insure constitutional vigor and vitality, which is largely controlled by chest capacity. The chest, therefore, should be broad, deep, and carried well forward. This development gives the hog a parallelogram development similar to that desired for beef cattle (Fig. 115).

442. Weight and condition. - The weight will depend largely on the condition, and as these determine the market value they will be considered together. Formerly, heavy hogs, those weigh- 


\section{STUDENT'S SCORE-CARD}

\section{LARD-HOGS}

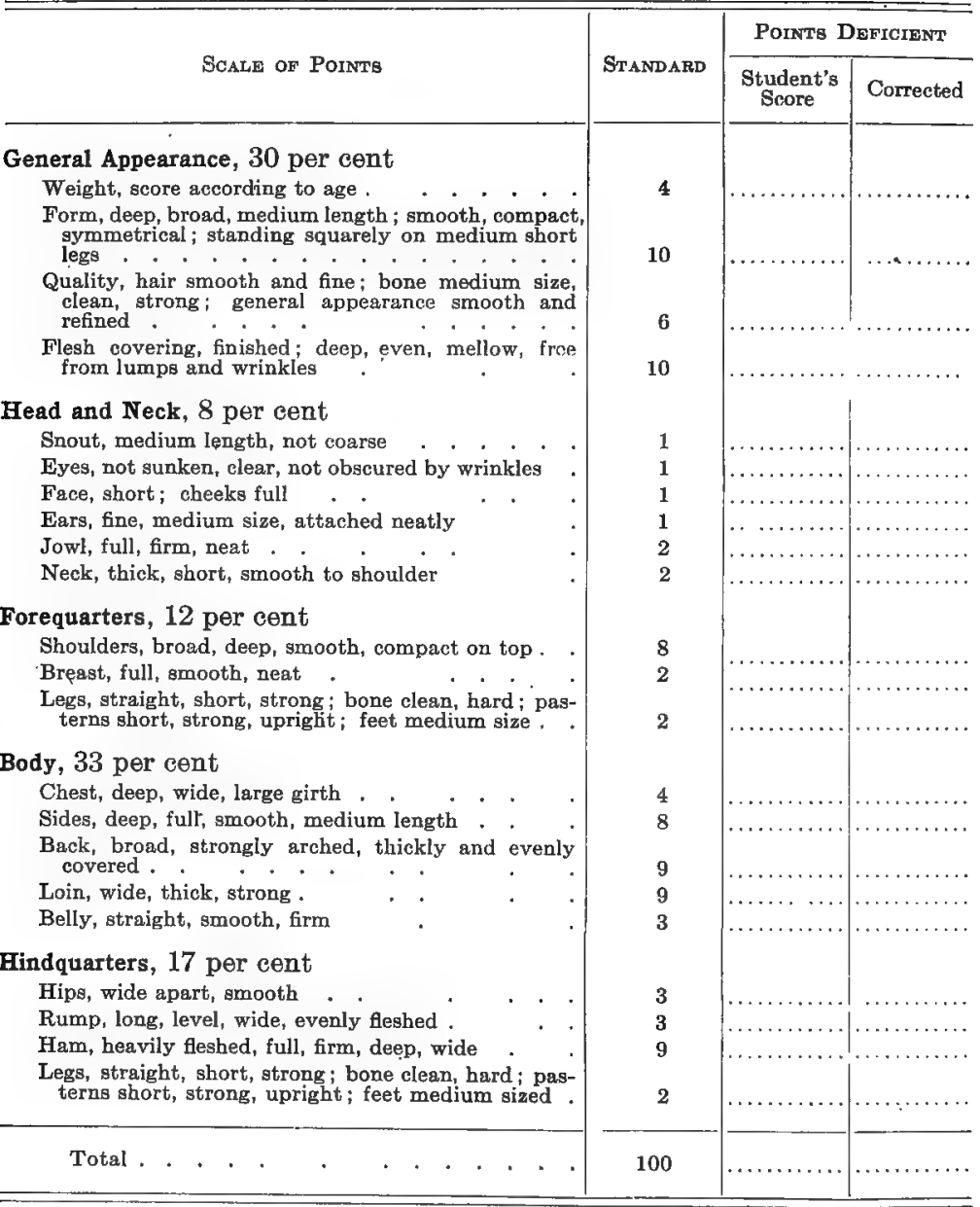


ing from 400 to 500 pounds, commanded the highest price, but at the present time the market demands a much lighter hog. While market demands are exceedingly variable, in general the most desirable weight is from 180 to 275 pounds, though heavier hogs sometimes command a premium on the market.

443. Quality. - The indications of quality are fine hair, freedom from bristles, and a comparatively light, dense, and clean bone. Fineness of the parts in general is an evidence of quality. This is often overdrawn, as too much fineness leads to delicacy, which sometimes results in the hogs being too small, facial features too fine or small, and the bone fine to the point of weakness. On the other hand, hogs with coarse bone, coarse hair, and coarse hide are

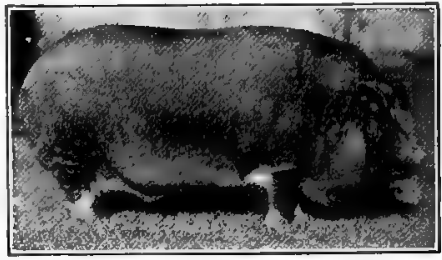

FIG. 115. - Lard-hog of good type. likely to be poor feeders, and the butcher objects to them because of the large percentage of offal which they dress. In addition to being rather fine and free from bristles, the hair should lie close to the body and the skin be free from wrinkles and undue roughness caused by scurf.

444. Constitution. - The indications of a good constitution and much vigor are a deep, broad, and well-advanced chest, thus giving capacious chest capacity and good heart girth. The chest should be deep from the top of the shoulder to the brisket, which should be placed low down; it should be wide, as indicated by much width between the front legs, and the brisket should be well advanced between the front legs. The flank, both front and rear, should be full and well let down, as this also indicates good constitution.

445. Uniformity. - One of the most important general considerations in choosing a herd of swine, either for breeding or feeding, is the uniformity. While this adds nothing to their ability to make economic gains, it does add materially to their selling value. 
The butcher will very often pass by a mixed drove of hogs, even though they are of good quality and in good flesh, refusing to place a bid on them merely because he lacks the facilities for handling such mixed lots. Separate them into uniform droves, and he is attracted to them at once, and will pay an extra premium for the same animals he refuseid to bid on before.

\section{DETAIL CHARACTERS OF THE LARD-HOG}

446. Head. - No facial character among any class of farm animals is more variable than the hog's snout. In some breeds, notably the Tamworths and Hampshires, the snout is very long and straight from the ears to the tip of the nose; in other breeds, as the Yorkshires, it is long and dished; while in others it is short and straight, as in the Poland China ; and in still others it is short and very much dished, as in the Berkshires. The eyes should be wide apart, clear, and prominent. Folds of fat about the eyes, while rather common, are very objectionable. The ears should be of medium size for the breed and fine in texture. The way the ear is carried depends on the breed. Whatever the carriage, ears should be neatly attached to the head. Large and coarse ears are usually associated with heavy, coarse bone, and are, therefore objectionable on any breed.

447. Jowls. - The jowls should be firm, smooth, of medium size, and not pendulous. Jowls that are flabby, owing to the excessive amount of fat, are very objectionable. They should be firm, indicating an intermixture of lean meat. The size of the jowls is rather a breed characteristic, being rather large in the Poland China and Berkshire, and rather small in the Tamworth and Hampshire. The medium-sized jowls for the breed are to be preferred. They should be free from heavy folds, not pendulous and loose.

448. Neck. - The neck should be of medium length and possess sufficient width and depth to swell smoothly into the shoulder and 
pass back without any noticeable depression. A neck too thick and too heavy is objectionable because it indicates general coarseness and increases the relative percentage of cheap meat.

449. Shoulders. - Shoulders should be long, full, and level on top. While long shoulders are not necessarily correlated with a deep chest or constitutional vigor, they give the hog a more symmetrical appearance. They should be full, especially at the lower end, which is often a weak point, and just forward of the shoulders in the region known as the shoulder-vein. The shoulder should not be too heavy, as it is a comparatively cheap cut, nor should the skin be too thick and heavy, as this indicates reversion to ancestral types, because these parts were abnormally developed in the wild hog as a protection in fighting.

450. Back and loin. - These should be of moderate length, straight, broad, and evenly fleshed throughout. They should be very carefully considered, as the back and loin furnish some of the most valuable cuts. Here pork chop and pork roasts are secured. The back should be strong, and this can best be obtained by moderate length, as too long a back is likely to be weak, particularly just back of the shoulders. It should be straight, or, better still, slightly arched, gradually rising from the neck to the center of the back, and from there sloping very gradually to the tail. There should be no depression or sway in the back from the shoulder to the tail. The back should be broad, and this breadth should be evenly maintained from the shoulder to the tail. The flesh covering should be even and firm, giving a smooth carcass when slaughtered.

451. Sides. - The sides should be as long as possible and yet maintain sufficient strength of back. They should be deep and thick. The ribs should be well arched and continue low down, giving feeding capacity. The underline should run straight from front flank to rear flank, giving the side an even width throughout its entire length. Sides should be firm and smooth, and free from wrinkles and flabbiness. The sides should be even with the hams 
and shoulders, and carry the fullness well down, giving the animal a symmetrical and well-balanced appearance.

452. Rump. - This should be long, wide, and fairly level. It should be long so as to increase the length of the ham. The width should be carried back proportionately with the back, as a peaked rump is very objectionable. Narrow, peaked rumps mean thin hams, which do not sell well in the market. As a rule, hogs droop considerably from the hips to the tail ; nevertheless the nearer the rump approaches the level, the better the cuts of meat will be. The rump should be evenly and smoothly fleshed from hips to tail.

453. Hams. - The hams should 'be wide, deep, and plump. Viewing the pig from behind, the hams should be wide from between the legs to the outside; viewing from the side, they should be deep, that is, long from the tail downward and fleshed well down to the hock. Such a conformation will give a long, wide, and plump ham when slaughtered. Often the hams lack fleshing above the hocks, the region being bare and thin, which results in a poor ham when slaughtered. The flesh should be firm, indicating that there is not too much fat, as very fat hams are not desired on the market. Extra fat hams sell at low prices.

454. Legs. - The legs should be short, straight, strong, tapering, and well placed. Knees that are considerably bent, or "bucked knees," and hocks that are very much cramped, are common defects among swine. Crooked knees, those which come too close together, and hocks too close, are all too common. Another very serious objection, particularly among fat-hogs, is the tendency of their pasterns to break down, leaving the animal to walk on the dew-claws. Although common, and often among the very best bred hogs, this is very serious and always to be guarded against. Sometimes the underline slants upward from the front to the hind flank, due to the hind legs being longer than the fore legs. This should not be. 


\section{JUDGING BACON-HOGS}

455. Condition. - The flesh is not so thick as on the lard type of hog, rarely exceeding one and one-half inches, but it must be firm, smooth, and even over all parts. It should be firm, as this indicates the presence of lean meat; it should be smooth and free from wrinkles and seams, as smoothness indicates even fleshing and good quality; and the flesh covering should be even over all parts of the body in order that the cuts of bacon may be uniform.

456. Form. - The form should be long, level, and deep. It should be long in order to give length to the side cuts; it should be level and free from sway back; and it should be deep in order to increase the percentage of side meat. The shoulders and hams should be light and the animal of uniform width from the shoulders to the hams. Width is not sought, but both length and depth are of prime importance. The form should appear trim and neat, and the animal be free from all coarseness in hair, hide, and bone.

457. Sides. - Among bacon-hogs, the sides are of prime importance, as the choicest bacon comes from this region. It is, therefore, essential to have as much as possible of the desired weight in this region. The sides should be long, smooth, and level. From shoulder to ham should be as long as possible without increasing weakness, thus giving long side cuts; they should be smooth and free from wrinkles and seams; and they should be level from shoulders to hips. A swaying back or a too pendulous belly are very objectionable.

458. Market classes of swine. - On the market, swine are divided into classes according to weight and condition. While these classes are exceeding variable between the different markets, yet the following table will give an idea of the nature of the classification. Each sub-class is divided into a number of grades. 
Prime Heavy Hogs, 350-500 lb.

Butcher Hogs, 180-350 lb. $\left\{\begin{array}{l}\text { Heavy Butchers, 280-350 lb. } \\ \text { Medium Butchers, 220-280 lb. } \\ \text { Light Butchers, 180-220 lb. }\end{array}\right.$

Packing Hogs, 200-500 lb. $\left\{\begin{array}{l}\text { Heavy Packing, 300-500 lb. } \\ \text { Medium Packing, 250-500 lb. } \\ \text { Mixed Packing, 200-280 lb. }\end{array}\right.$

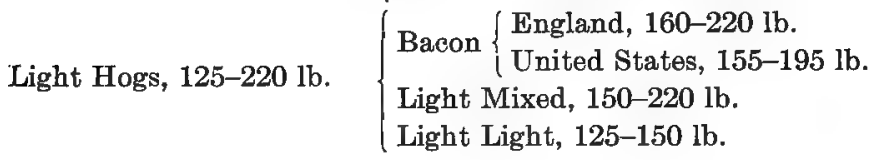

459. Cuts of pork. - The diagrams which follow show very clearly the parts of the animal from which the cuts are taken (Fig. 116).

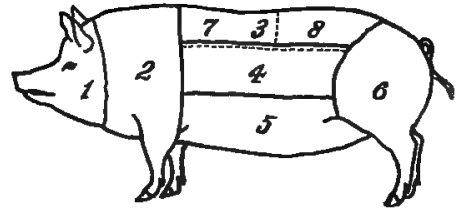

1. Head.

2. Shoulder.

3. Back.

4. Middle cut.
5. Belly.

6. Ham.

7. Ribs.

8. Loin.

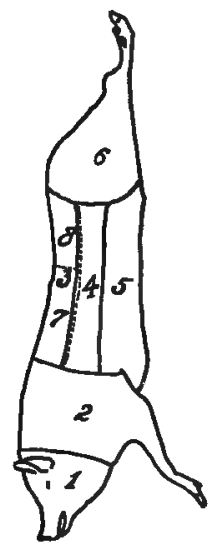

FIg. 116. - Diagrams of cuts of pork.

\section{QUESTIONS}

1. In judging, how do we estimate the age of swine since an examination of the mouth is practically impossible? How do we estimate quality in swine? 
2. Why are wrinkles so objectionable in swine? Where do they occur most frequently? Why is too much refinement objectionable among swine? Why is coarseness about the shoulder so objectionable in swine?

3. When judging swine in the show ring, how are they held? Is this difficult, particularly in a class of old males?

4. Classify the various breeds of swine according to color. Why is white objectionable in the south? Why is a reddish tint objectionable on a Poland China?

5. Why are fancy color markings objectionable, especially such as in the Hampshire breed of swine?

6. Name the breeds of swine that are likely to possess poor feet. Why are some breeds more susceptible to poor feet than others?

7. Classify the breeds of swine into two classes, according to the position of the ear, one in which the ears are carried erect and the other in which they are lopped. Has this characteristic any relation to general quality among swine?

8. Of the three sub-classes of butcher hogs, which will make the most economical gains? Explain.

9. Which is American bacon not popular in England? Why is Candian bacon preferred? 


\section{CHAPTER XVIII}

\section{THE FEEDING OF SWINE}

No farm animal equals the hog in turning food quickly into marketable meat; and none has yielded more profit to the average American farmer. In health, no farm animal is more easily cared for than the hog; it requires little shelter and will eat any article of food placed at its disposal. From this it would seem that the hog is the most economical meat-producing animal. This is true during health. The effort should be, then, so to feed and manage the herd as to keep it in good thrift at all times.

Wolff-Lehman Standard, showing the Amount of Food required per 1000 Pounds Live Weight for Both Growing and Fattening SwINE

\begin{tabular}{|c|c|c|c|c|c|c|}
\hline \multicolumn{2}{|c|}{ Condition of ANimal } & \multirow{3}{*}{$\underset{\text { MATTER }}{\text { DRY- }}$} & \multirow{2}{*}{\multicolumn{3}{|c|}{ Digestibla Nutrinats }} & \\
\hline \multicolumn{2}{|c|}{ Growing Swine, Breeding } & & & & & $\begin{array}{l}\text { NuTRITIVE- } \\
\text { RATIO }\end{array}$ \\
\hline Age, Mo. & Weight & & Protein & $\begin{array}{l}\text { Carbo- } \\
\text { hydrates }\end{array}$ & Fat & \\
\hline $2-3$ & 50 & 44 & 7.6 & 28.0 & 1.0 & 4.0 \\
\hline $3-5$ & 100 & 35 & 5.0 & 23.1 & 0.8 & 5.0 \\
\hline $5-6$ & 120 & 32 & 3.7 & 21.3 & 0.4 & 6.0 \\
\hline $6-8$ & 200 & 28 & 2.8 & 18.7 & 0.3 & 7.0 \\
\hline $8-12$ & 250 & 25 & 2.1 & 15.3 & 0.2 & 7.5 \\
\hline \multicolumn{7}{|c|}{ Growing Swine, Fattening } \\
\hline $2-3$ & 50 & 44 & 7.6 & 28.0 & 1.0 & 4.0 \\
\hline $3-5$ & 100 & 35 & 5.0 & 23.1 & 0.8 & 5.0 \\
\hline $5-6$ & 150 & 33 & 4.3 & 22.3 & 0.6 & 5.5 \\
\hline $6-8$ & 200 & 30 & 3.6 & 20.5 & 0.4 & 6.0 \\
\hline $8-12$ & 300 & 26 & 3.0 & 18.3 & 0.3 & 6.4 \\
\hline
\end{tabular}


460. Food requirements for swine. - The food required for a given gain among swine varies with the kind of food and the age and weight of animals. Foods vary largely in the energy they contain. The older and the larger the animal the more food required for a given gain.

\section{PREPARING FOOD FOR SWINE}

Foods for swine are often prepared by grinding, soaking, or cooking. There have been many experiments to determine the efficiency of each of these methods. These tests give more or less contradictory results, and it is difficult to determine from a perusal of the literature to what extent the food is rendered more efficient by such preparation. There can be little doubt, however, but that each of these methods increases the efficiency of certain foods under given conditions.

461. Grinding feed. - The advisability of grinding feed for swine depends much on the kind of food and to some extent on the age of the animals. Most of the experiments have been with the grinding of corn, and the results have been varying. With smaller and harder seeds and grains, such as peas, beans, millet, and the like, there is a much better showing in favor of grinding. The Canadian Central Experimental Farm conducted experiments which show a saving of 17 per cent in favor of grinding these smaller and harder seeds. The same may be true of corn when the grain is very hard and dry.

462. Soaking the feed. - It is a rather common practice to soak whole grains and to wet meals before feeding. Soaking is a less expensive process and in many instances may be as good as grinding. One rather strong objection to feeding soaked grains, especially when the animals are used to eating the grains whole, is that they are likely to swallow the grains entire without mastication. Soaking or wetting is, however, a very cheap method of preparing hard grains for swine, by rendering them more palatable and adding succulence. 
463. Cooking the feed. - As a general practice, cooking food for swine is no longer regarded as profitable. In fact, cooking certain foods renders some of the nutrients less digestible. Cooking feeds for swine, however, has many advantages, chief of which are that it softens small and hard seeds; increases the succulence and to some extent the palatability of certain dry grains, such as peas and beans; reduces the water content of certain other feeds, such as roots and tubers, which contain more water than swine can economically use; and renders foods more uniformly mixed. Furthermore, cooked foods do not sour so readily, and the hard grains or particles of feed become thoroughly softened. It is considered best to put a variety of foods into the cooker.

464. Feeding the pigs. - At about three weeks of age, the pigs are likely to begin to nibble at their mother's food, to bite at the grass, and perhaps try to root. This indicates that they are acquiring an appetite, and they should be encouraged to take food other than that supplied by the mother. Place a small trough in one corner of the lot or pen, and arrange a fence across the corner, so the sows cannot have access to it, but the young pigs can. Into this trough a little sweet milk may be poured three times daily. Do not provide more than the pigs will drink at once, and never leave the milk to sour in the trough, as digestive disorders and death are sure to follow. In'a few days, replace the milk with a small amount of bran and shorts, scalded and made into a gruel.

465. Weaning the pigs. - With pigs fed as suggested above, the weaning process is easy and simple. As the pigs learn to rely more on the extra food, the mother's milk-producing food should be cut down so that she will not be in the height of her flow when the pigs are taken away. The age to wean pigs varies, but, as a general rule, it is safer to say the best age for weaning is between seven and ten weeks. 


\section{FEEDING THE BREEDING HERD}

Feeding the breeding herd differs essentially from fattening. In feeding the herd the object is to keep the animals in a healthy and thrifty condition. Flesh formation is to be encouraged and fattening discouraged. If the breeding herd is permitted to become too fat, the animals fail to breed regularly, the litters are small, and the dangers from disease are increased. Feeding the breeding herd naturally divides itself into two parts, summer and winter feeding.

466. Feeding the herd in summer. - It is the common practice to confine the breeding herd in too crowded quarters. This close confinement and a too exclusive grain feeding account for much of the shy breeding among many of the more prominent breeds. Another serious mistake is the too liber use of corn. While no food equals corn for fattening swine, it is not a good grain for the breeding animals, and its too exclusive use is a common cause of barrenness or of small litters.

Ample room should be provided. Nothing is better than pasturing or soiling. Soiling is likely to involve too much labor on the average American farm, but in such cases there is usually an abundance of pasture. When on pasture the breeding herd need receive no grain until a short time before farrowing, when grain should be fed sparingly. The well-fed sow will be more quiet at farrowing time and be less likely to injure her pigs than will the lean gaunt one lacking in milk. When grain is fed, the kind will depend somewhat on the kind of pasture; but as a general rule nothing is better than wheat bran or middlings, as it is rich in protein and mineral matter, two elements much needed by the developing pigs. Furthermore, bran stimulates the flow of milk, waich is very essential for the sow with a large litter.

4i7. Pasture for swine. - Swine may be turned to any pasture land that is available, - permanent or sown pasture. When proper $y$ ringed, they are no more injurious to pastures than any 
other farm animal. Since the common pasture plants are not available before warm weather, it is often of advantage to provide an earlier forage. Rye sown somewhat early in the fall makes an excellent substitute for pasture grass, early the following spring. Among the permanent pasture grasses, blue grass comes on very early and provides much succulence throughout the season. Clover, alfalfa, and cowpeas are unexcelled as swine pasture in the regions where they thrive. For a quick growing crop, rape is probably to be accorded first place.

468. Roots for swine. - Roots are valuable as a food for swine during the late fall and winter months. They are mainly desired because of their stored succulence and to serve as a substitute for pasture. In the United States, roots have not been so commonly used as in Canada or the Old Country, though of late years they have increased in favor, and their usefulness, especially in the corn-belt, is being recognized. Sugar-beets, mangels, ruta-bagas, turnips, and carrots are grown as food for swine. Of these, many prefer mangels largely because of their high yield per acre, although they will not give as good results as sugar-beets.

469. Pumpkins and squashes. - These are much relished by swine in the late fall and early winter. In addition to their succulence the seed is very rich in protein; thus they make a very good supplement for corn. Pumpkin seeds are a natural vermifuge. When many pumpkins are fed, the animals should be watched closely to see that they do not get an overfeed of seed and digestive disorders follow.

470. Feeding the herd in winter. - More care mùst be given the feeding of the herd in winter than in summer; although if roots or other succulent food has been provided, the matter will be less difficult than if the farmer is obliged to rely entirely on dry feeds. The cheapness and the great abundance of corn really adds to tie difficulty of wintering the herd. The great temptation all through the corn-belt is to feed a too exclusive corn ration. This dificulty is increased by the fact that no food equals corn in the fottening 
of swine; and the majority of swine feeders let the herd run with the fattening swine, with the result that the breeding herd gets so fat that its breeding powers are materially lessened, the sows often become barren, and those that do breed farrow small litters of pigs lacking thrift and vigor.

To avoid such difficulties, the breeding herd must be separated from the fattening swine and fed a growing ration rather than a fattening ration. The object should be to keep the herd thrifty, but not fat. This can best be done by feeding such grains as wheat bran, middlings, and the like; also roots, pumpkins, and skim-milk for succulence. Alfalfa, clover, or cowpea hay in small quantities may be fed with profit. Hay should be fed from a rack and not thrown upon the ground, as the animals will tramp it under their feet. When the hay is clean and sweet, and slightly, salty, the swine will eat it and be much benefited thereby.

When the grain is fed in the form of meal, better results will be secured by mixing with water, or better still skim-milk, and fed as a mash. If skim-milk is used, much care should be taken not to feed the animals too much, as they will take on flesh rapidly and may become too fat. A very good mixture is made by using one part meal to five parts of water or skim-milk.

\section{FATTENING SWINE}

In fattening, the sole object is the economic production of pork. As a rule, the animals are forced to the limit of their ability as feeders, fattened and marketed under one year of age. In this respect pork production is somewhat similar to beef production. The same general factors apply in both cases.

471. Feeding the lard-hog. - If light hogs are to be the product, the fattening process will begin much earlier in the life of the animal than if heavy hogs are to be produced. Feeding for fattening naturally divides itself into two parts, winter and summer feeding. 
472. Feeding the lard-hog in summer. - As a rule, swine should be fed in comparatively small droves. It is very important that the drove be made up of individuals of the same age as well as the same size. If a few of the individuals are larger and stronger, they will crowd the smaller and weaker ones back and get more than their allotment of the food.

Whatever food-stuffs are used, the swine should be put on full feed slowly. Fattening swine make better returns for the food

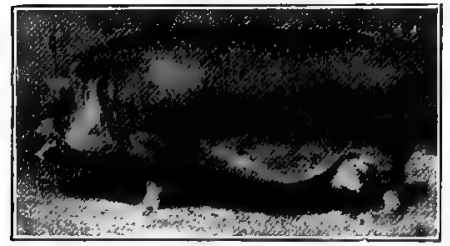

FIG. 117, - A thick, fat porker. consumed when their appetites are kept keen; they wait eagerly for their food and relish it much better than when overfed. If convenient, they should be fed both mash and dry grain. Nothing makes a better food for swine than meal and skim-milk.

Swine will make much better returns for the food consumed if they have access to green forage. Where fattening hogs are turned to pasture, it must be so arranged that they need not graze over too large an area. If at all convenient, it will be more profitable to cut the green forage and feed to the hogs. In this way a smaller area will support a large number of hogs, and the swine need not rustle to get the much needed succulence.

It is very important that fattening swine be provided with shade and an abundance of cool, fresh water. The sebaceous glands of the hog are very rudimentary, and the animal cannot perspire and therefore must keep cool by radiation. This is one reason why hogs desire mud wallows, and for best results these must be provided, particularly for thick, fat animals, which suffer greatly with the heat during the warm summer months. To avoid the extreme heat of summer many swine feeders plan to have the animals fat by the first of July, when they are sold.

473. Feeding the lard-hog in winter. - When roots or other 
succulence is available for winter use, much better results can be obtained than if dry feed alone must be depended on. Sugarbeets, roots, turnips, potatoes, artichokes, and pumpkins are often used. No succulence exceeds skim-milk for winter feeding. In the absence of any other succulent food, mashes should be made, as suggested for summer feeding. For best results, mash or succulent food, grain, and a small amount of dry forage should bə fed. Sweet, clean clover or alfalfa hay should constitute the dry forage. It should be fed from a rack.

Care should be exereised in providing dry quarters and lots as free from mud as possible. The warmth of the quarters best suited for fattening swine may depend somewhat on the feeds used. When corn, in one of its many forms, as ear corn, shelled corn, corn meal, and the like, constitutes the major part of the ration, the quarters need not be so warm as when an abundance of more succulent food is fed, such as skim-milk.

474. Feeding the bacon-hog. - In the production of bacon, the foods must differ from those used in feeding the fat-hog. In some cases the same food-stuffs may be used in part, but the mixture must be varied. Corn, the mainstay in the production of the fat-hog, cannot be used with success in larger proportions than onethird of the grain ration. A larger proportion is likely to produce an undesirable quality of bacon. The foods very largely used are shorts,

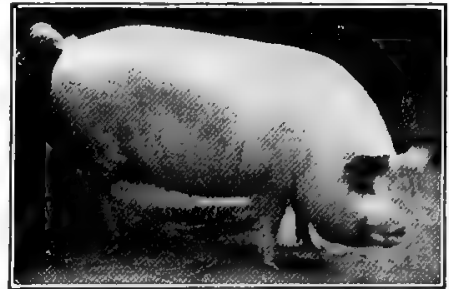

FIG. 118. - A well-finished baconhog. oats, peas, barley, and skim-milk. Barley is perhaps the food most used, especially in Canada, where bacon production finds much favor. It is often fed ground or soaked. Usually it is fed in connection with small amounts of other food, as peas, oil meal, finely ground oats, tankage, and the like. Peas are used to a considerable extent in the production of bacon in 
Canada. "Canada pea-fed bacon" has good market reputation. Among some large bacon feeders, however, peas are not held in high estimation, the statement being made that they give dry, rather hard, and flavorless bacon. Oats are often objectionable because of their hulls, which contain little nutrition and much crude fiber; yet when the price is low, they are extensively used. Crushing the oats is considered the best method of preparation.

Skim-milk is held in high esteem by the bacon feeder ; therefore localities devoted to dairying other than market milk are admirably adapted for the production of bacon. It may be fed in the same proportion as to the fat-hog, - that is, three to five parts milk to one of meal.

475. Summer feeding on pasture. - Clover, alfalfa, cowpeas, or rape are excellent pastures for bacon production. Less protein-rich grain or less skim-milk is required when the swine have access to such ranges. No cheaper or more economical gains can be obtained than from a light grain ration when the animals have these pastures.

476. Winter feeding in dry-lot. - Bacon production during the winter season is approximately 25 per cent more costly than feeding on pasture. For best results, some succulent food should be supplied. This may be furnished by growing roots, such as sugar-beets, mangels, turnips, and the like, and storing them for winter use. When the animals are confined to a dry-lot, more portein-rich food is required, which calls for larger amounts of oil meal, shorts, tankage, or skim-milk, most of which must be purchased. This balancing is very essential in the production of bacon, as quality is what commands the extra price. The lean and fat must be well interspersed, and this can be secured only by properly balancing the ration.

477. Sample rations for swine. - To give sample rations for horses, cattle, and sheep is a comparatively simple matter, but such is not the case with swine. The composition and amount of the ration are influenced by the age and weight of the animal. 
For 100 pounds live weight, the younger the animal the more food required, and in addition it should contain more protein than for the older animal. To gain an idea of the efficiency of various grain mixtures, the following data are taken from Bulletin 65 of the Missouri Experiment Station:-

Feed and Gains in Weight, 90 Days

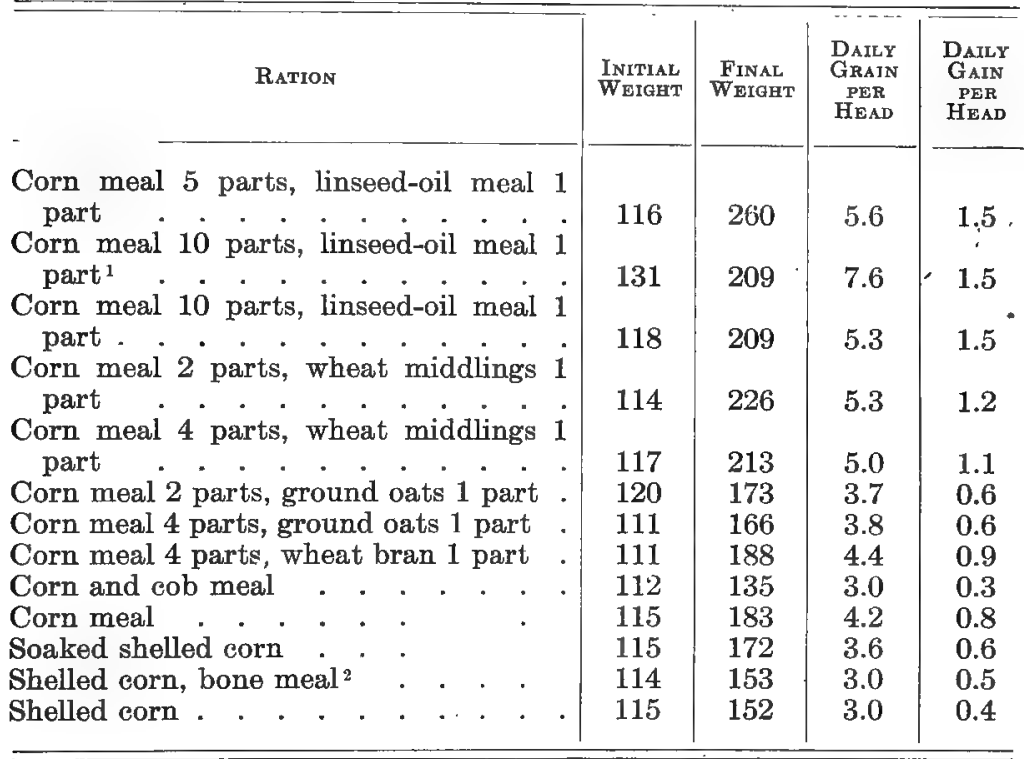

1 Sixty days.

${ }^{2} 6.2$ pounds bone meal per head in ninety days.

\section{QUESTIONS}

1. Which is the more economical meat producer, beef cattle, mutton sheep, or 'swine? Why? When slaughtered, which dresses the highest per cent of edible meat? Explain.

2. Why is it more profitable to prepare food for swine than for any other class of farm animals? What are the common methods of preparation? Which is the more economical? Why'? 
3. Why is it often difficult to give swine their food, particularly when the food is placed in a trough?

4. Wherein does feeding the breeding herd differ from feeding the fattening herd? Explain.

5. At what age is a young pig likely to eat more than is good for him? How can this be prevented? What is the objection to exclusive corn feeding?

6. How can swine be prevented from rooting? What pasture grasses are they most likely to destroy? How many hogs can be pastured on one acre of land? What factors influence this number?

7. How many carloads of fat swine are shipped from your vicinity each year? Where do they go to? Approximately what is the average weight?

8. Why do fat swine often refuse to stay in their shed even in the severest of weather? Why do fattening swine need an abundance of fresh air? Has this an effect upon the amount of food required to fatten swine? Does the quarters affect the rate of gain? 


\section{CHAPTER XIX}

\section{CARE AND MANAGEMENT}

Aside from the various points on care and management discussed in the chapter on feeding, special attention is now given to improved sanitation and equipment. Many of the common diseases that often prove fatal to swine are due entirely or in a large measure to carelessness or indifference in management. It is well known to swine breeders that few hogs are free from lice. These vermin are blood suckers, and in a very short time they produce a weakened condition of the animal, thereby rendering it far more susceptible to other diseases; even cholera is more virulent and more deadly when the herd is infested with lice.

Since swine are reared and finished in one place, if success is to be attained, the feeder must be a breeder as well. Many good swine feeders often fail to exercise proper judgment in breeding. Breeding swine is as much a business as feeding swine, and should be conducted with that understanding. When the price of hogs is high, the tendency is to rush into swine raising, forgetting the advantages of good quality, with the result that in a few months the hog market is glutted with animals of inferior quality which, of course, command only a low price.

478. Plan of improvement. - Before formulating a plan for breeding swine, we will have to decide upon the kind of hog we are going to breed. Some will wish to breed market hogs only, others breeding hogs only, while still others may wish to produce both market and breeding hogs. When market hogs only are to be produced, grades may prove as profitable as pure-bred animals, especially if much care is taken in the production of the grades, and a pure-bred 
boar is used. On the other hand, if breeding hogs are to be produced, pure-bred animals only can be grown with profit. This calls for much knowledge of the principles of breeding, such as selection, mating, and the like. Another question that will modify the plan is the amount of capital available for the establishment of the business. When the capital is small and the experience wanting, the grade herd is to be preferred. The beginner may well start with not more than two or three sows, in pig when purchased, as he can acquire much valuable experience with even so small a number, while his risk will not be great The second year he may add to the number of sows, secure a suitable and pure-bred boar, and each succeeding year carefully increase the number of sows bred. In this way, one. should soon find himself in possession of a large herd, and of sufficient knowledge to put it to profitable use.

479. Coöperative breeding. - Pure-bred boars are likely to be costly, and to be profitable they should be kept in constant use. Since the average farmer does not possess sows enough to get the maximum use of the boar, it is often a good plan for a number of farmers to coöperate in the purchase of a boar. Such coöperation not only reduces the cost of service, but aids in increasing the uniformity of the animals in a locality. Furthermore, when a number of farmers coöperate in the purchase of a hog, a much better animal can be secured than if each purchases on his own account.

480. Selecting breeding stock. - Many practical questions enter into the selection of swine for breeding purposes. As a general rule, the animals chosen should be rather large for the breed to which they belong. In the past few years there has been a tendency to reduce the size of market hogs, and this has extended to the brood sows, with the result that many of the sows now used for breeding are decidedly too small for the farrowing and raising of two large and strong litters of pigs each year. Probably the greatest fault of improved swine breeding is the striving for too great refinement. If large litters of strong pigs are to result, the 


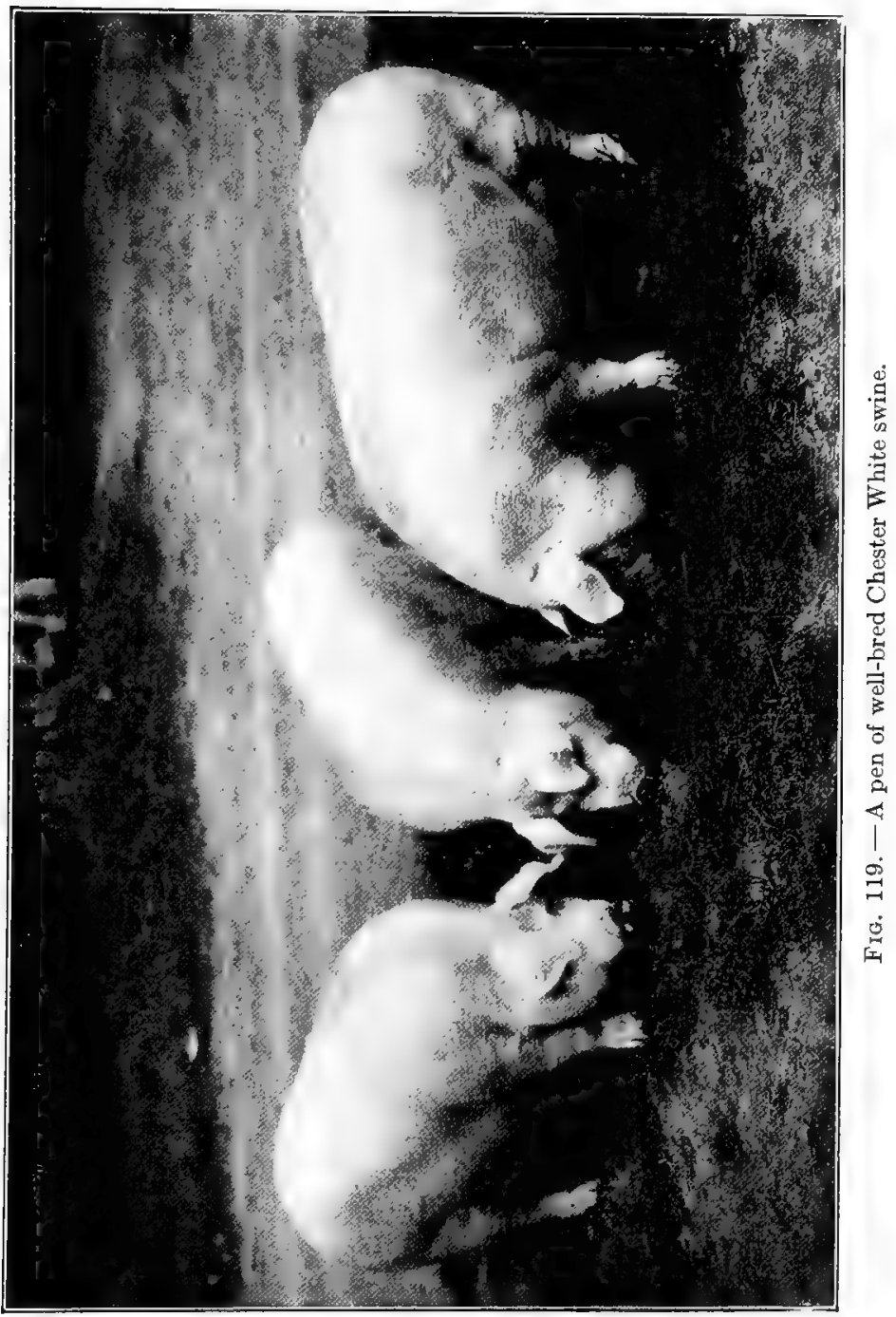


sows must possess much size and length and a good constitution, as shown in sufficient width and depth of the chest region.

481. The type. - A consideration of prime importance in the selection of a breed or type is the likes and the dislikes of the breeder. One is much more likely to succeed with the animals he likes and to fail with other animals of equal merit that he dislikes. Other than this there is little to choose, as each breed has its weak and its strong points. In some sections, however, certain breeds will remain the most popular because of their adaptability to the climate. Thus in certain parts of the United States, especially the West and South, white hogs are not looked on with favor because they are more liable to be sun-scalded, to have scurvy, and often mangy skins. Again, in the corn-belt, bacon types doubtless will never be most popular because the available food is not such as to produce bacon.

482. Uniformity. - In selecting animals for the breeding herd, it is very important that they be similar in age, size, color, condition, and quality. The importance of this similarity among market swine cannot be overestimated. To get animals that will remain uniform, it is essential to know something of the herd from which they come. A herd noted for its uniformity is likely to produce animals that are uniform. In addition to the uniformity, the herd should be prolific. The sows should farrow and raise two litters of six or more pigs each year. Prolificacy is hereditary. A prolific herd is likely to produce prolific animals.

483. Dipping swine. - To free the hogs from lice or other vermin, all newly acquired hogs should be dipped immediately upon arriving at the farm in much the same way as suggested for sheep, p. 248. The hogs should not be permitted to infect the quarters or lots before dipping. The same dipping-vat as that suggested for sheep may be used, as well as the same coal-tar preparation, although the solutions may be used somewhat weaker for swine. All stock hogs should be dipped at least twice each year, or whenever they become infested with lice. 
Good results are reported from the use of a self-dipping device. This device consists of a shallow vat about ten inches deep and eight to ten feet square. It is built of two-inch plank and placed near by or convenient to the well or large water-tank. The vat is filled about three-fourths full of water and one quart of dip added. The dip is renewed about once in two weeks and the water supplied as needed. During the muddy season, the tank should be cleaned and a fresh start made. The liquid may be removed in a few minutes with a scoop shovel. The hogs wallow in this at will, and they do not seem to mind the dip; when the water is fresh they often drink small quantities of the liquid. This keeps the hogs free from lice and skin diseases and helps to keep down worms, cholera, and other swine plagues.

\section{SHELTER FOR SWINE}

Some one has fittingly said, "The hog does not need a palace or an upholstered cage, nor does he prosper in a dungeon." Occasionally much money is uselessly expended in the construction of a large and expensive building which is in use only a part of the year; more often, however, swine are housed in a hole in the straw stack or in a shed constructed from fence rails or poles and covered with straw or fodder. Such places are dungeons. There is no ventilation, they are dark and damp in wet weather, and soon become filthy dens of infection.

As with the barn for other farm animals, the hog barn should be well ventilated, well lighted, well drained, and dry, serviceable, and sanitary. Any structure that answers these conditions will prove fairly satisfactory. Convenience and adaptability should be considered in constructing the hog-house. In general, hoghouses are of two types: large houses, or those accommodating a considerable number of hogs; and small individual houses or cots.

484. The large hog-house. - There are almost as many types of large hog-houses as there are swine breeders or feeders who 
have built them, each having its advantages and disadvantages. When properly constructed, the large hog-house is serviceable, sanitary, and convenient; but, if properly constructed, they are expensive, especially since they are only used a part of the year. It is difficult to locate them accessibly to the pastures, particularly in case sown pastures are used, which are likely to be on various parts of the farm. Furthermore, when many sows are housed in close proximity to each other, if one is disturbed or molested in any way, all the others are likely to become fretful; and when feeding is begun in one part of the house the other animals become uneasy and often injure their litters.

485. The individual hog-house. - Of late years the small individual hog-house has become very common. These small

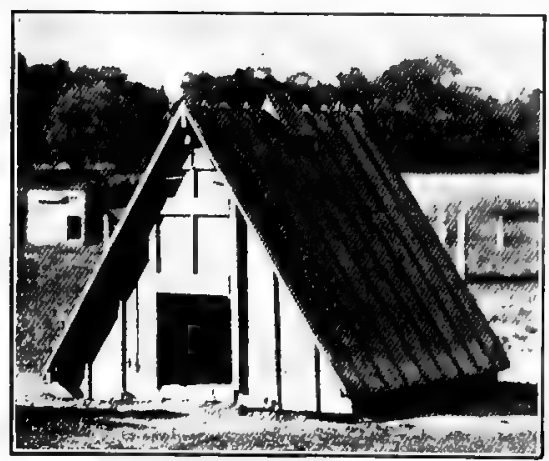

FIG. 120. - The individual hog-house. houses are constructed on runners so they can be moved from one field or lot to another. They are well adapted to accommodate a sow and her litter, and a few of these "cots," as they are often called, set side by side afford excellent shelter for a drove of hogs. The Wisconsin Agricultural Experiment Station has issued a bulletin devoted chiefly to the construction of these small houses, and from which we quote: "The portable hog-house is easily and economically constructed; it can be easily moved and located wherever desired; it is useful to the general farmer and to the breeder of pure-bred stock; and of all systems of housing swine it is the most natural and sanitary. Only the simplest workmanship is necessary to build the portable house, and much old lumber can be worked into it" (Fig. 120). 
486. The hog lot. - The lot in which hogs are quartered should be such as can be kept clean. A filthy and carelessly kept lot encourages disease by providing lodgment for the germs; and constant cleanliness is the most effective means of preventing germ dissemination. Where disease germs have once been established, an absolutely thorough disinfection is essential to eradicate them. To facilitate cleanliness and disinfection, at least a part of the lot should be paved with brick, stone, or concrete. On this pavement the cots may be placed during the winter season, and on it the feeding may be done.

487. Hog-wallows. - Some very successful breeders heartily favor hog-wallows, while others equally as successful are much opposed to their use. Those who are outspoken in opposition to the wallow have perhaps been influenced from infections due to a filthy wallow, or from infections at the time of an outbreak of cholera. There can be no doubt that filthy wallows are often a source of danger, nor can there be any doubt that once a cholera hog wallows in the water, however clean, all other hogs wallowing in or drinking this contaminated water are likely to contract the dreaded disease.

On the other hand, with the healthy herd there can be no objections to a clean mud wallow, and there are many advantages to be derived from it. During the heat of summer the hog cools mainly by radiation, and a cool mud bath is very soothing; it cleans the scurf from the skin and enables the hog to find protection from the flies. This wallow or mud bath should be so arranged that fresh water may be added as needed, and, to insure absolute freedom from all germ life, a quart of coal-tar dip may be poured into the wallow occasionally (p. 299).

488. Diseases of swine. - While swine are not ordinarily considered as being subject to so great a variety of diseases as horses, cattle, or sheep, they are very often attacked by ailments far more serious than afflict any other class of farm animals. Chief of these diseases are cholera, swine plague, and tuberculosis. 
Throughout the corn-belt of the United States, the loss caused by these diseases among swine is not equaled by any other class of diseases to which farm animals are subject. They are all contagious or infectious, and therefore with proper sanitary methods they can be prevented, although when the animal once becomes afflicted, there is no cure. It is the ravage caused by these diseases that makes pork production such a hazardous business. Sometimes the swine breeder or feeder will have a drove of swine ready for the market, when they will contract one of these diseases and the entire herd be taken in a few weeks.

489. Hog cholera. - Hog cholera is an infectious disease of swine. It exists in all sections of the United States, but is particularly prevalent in the corn-belt. In that section, it is the most dreaded disease to which swine are subject. Not so many animals are condemned at the large packing houses because of this disease as are condemned because of tuberculosis, but this is due to the nature of the disease. With cholera, the hogs die or recover quickly, while with tuberculosis they may linger for months. Cholera varies in its virulence; sometimes comparatively few hogs that have it will die, while at other times nearly every animal in the entire herd will succumb to the disease. When the disease once appears, it spreads very rapidly, not only among the animals of a herd, but across the country from one farm to another.

490. Prevention of cholera. - Up to the present time, there has not been discovered any means by which hog cholera can be cured, the only safeguard being prevention. All that is necessary to prevent the disease is to keep the germs of the disease away from the herd. In the vast majority of cases the germ is transported mechanically, in the bodies of sick hogs and on the feet of men or animals, including birds. It follows, therefore, that the chances of an outbreak of hog cholera will be greatly lessened, if not completely avoided, if the herd is protected from these sources of infection. To do this the herd should be placed on a part of the farm that will be least accessible to men or animals from other farms. 
491. Quarantine lot. - On every farm where hogs are kept in considerable numbers, a small quarantine lot should be provided. This lot should be located at some distance from the other lots, it should be tightly fenced, and at least a part of it should be paved. When a new animal arrives, it may be dipped and then placed in this quarantine pen for at least seven weeks. Cholera or any other diseases will be apparent before this. If all is well, the newcomer may then be turned with the herd. Such a pen could be used by any of the animals of the herd that may become sick, as all ailing hogs should be segregated at once until the nature of the disease is determined. Such a lot set apart for this purpose may prevent outbreaks of very serious diseases.

\section{QUESTIONS}

1. How many swine are there in the United States? How many in your state? In your county? How does your state rank with other states in the production of swine? How does your county rank with other counties in the state? Name the ten leading swine states. Which state possesses the largest number to the square mile? To the farm?

2. Name the essentials to be considered in herd improvement. Wherein does pork production differ from beef production? Why do farmers not purchase feeding swine the same as feeding cattle?

3. Why should all newly purchased swine be dipped before being brought to the farm? What are the advantages of a self-dipping vat?

4. Why is a wallow almost essential for swine in hot weather? Wherein does the swine's skin differ from that of other farm animals?

5. Why should each farm where swine are kept be provided with a quarantined lot? Where should this lot be located?

6. Name the more common swine diseases. Why is cholera so prevalent among swine? How is the disease distributed? How can it be prevented?

7. Name the ten leading swine markets in the United States. How many swine are handled at each annually?

8. Why do fat hogs not require so warm housing as sheep? In building a hog-house, how much floor space should be allowed for each 
200-pound hog? Why is a board floor slightly raised above the ground objectionable for hogs? Name some of the advantages of cement as a flooring material in the hog-house.

9. Give a system of marking pigs when young so that they can be identified later when it is desired to have them recorded in a herdbook. At what age are swine usually recorded? How does this compare with horses, cattle, and sheep?

10. Give advantages of coöperative swine breeding. In which classes of farm animals - horses, cattle, sheep, and swine - is coöperative breeding likely to prove most satisfactory? Explain the advantages and disadvantages of each. Why are not coöperative societies more common in the open country?

11. How are lice removed from swine? Describe the use of the rubbing post.

12. Can the New England States compete with the corn-belt states in producing the pork consumed in New England ? Explain.

13. Can a man sell his own hogs in the stock yards? Is it to his advantage to do so? Explain.

14. How much shrinkage in a carload of hogs must a shipper make allowance for? Compare with beef cattle and sheep. 


\section{PART FIVE-POULTRY}




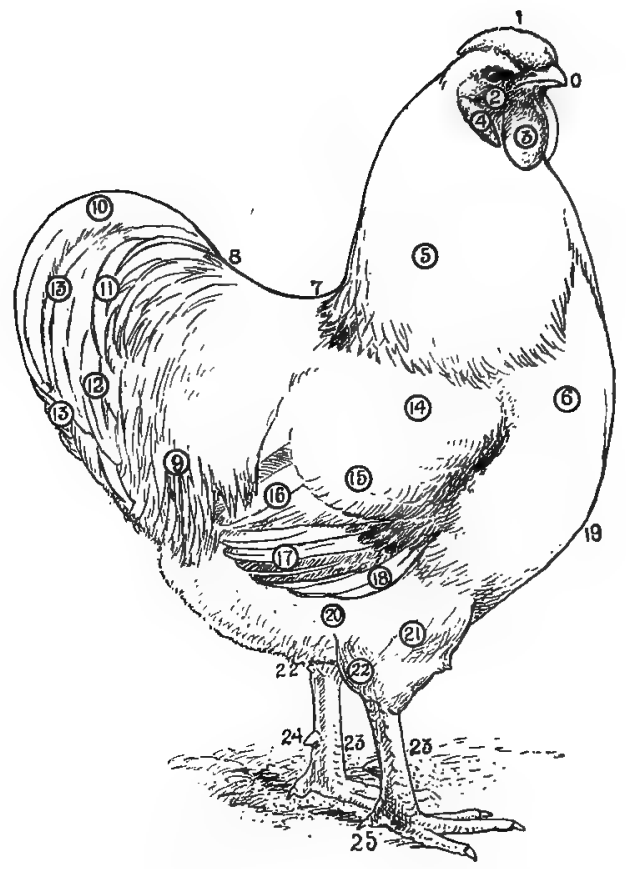

Fig. 121. - Parts of the fowl.

0. Beak.

1. Comb.

2. Face.

3. Wattles,

4. Ear lobe.

5. Hackle.

6. Breast.

7. Back.

8. Saddle.

9. Saddle feathers.

10. Sickles.

11. Lesser sickles.

12. Tail coverts.
13. Main tail feathers.

14. Wing bow.

15. Wing coverts, forming wing-bar.

16. Secondaries, wing bay.

17. Primaries, or flight feathers.

18. Flight coverts.

19. Point of breast-bone.

20. Fluff.

21. Thigh.

22. Knee joint.

23. Shank.

24. Spur.

25. Toes, or claws. 


\section{CHAPTER XX}

\section{BREEDS OF POULTRY}

Fow hs have been developed along utility lines similar to other classes of farm animals, although they are variously classed in the Standard of Perfection. ${ }^{1}$ These various classes, however, can be divided into types according to their usefulness as follows: the egg type, noted for the production of eggs; the meat type, known for the quality and quantity of its meat; the general purpose type, so called because of its ability to produce both eggs and meat; and the ornamental breeds, noted more for style and beauty than for general utility.

492. The egg type. - In general appearance this type is neat and trim, which gives it an air of activity. It is rather upstanding, the legs being comparatively long and the body spare, though long and deep. In this respect the egg type is similar to the dairy type in cattle (Figs. 122, 123).

493. The meat type. - In general appearance this type is much more compactly built and is heavier than the egg type. The meat type lacks activity. The neck is short, the body deep and full, and the legs short, giving a blocky form, similar to the beef type in cattle (Figs. 124, 125).

494. The general purpose type. - In general appearance, the breeds of this type rank intermediate between the egg type and the meat type, lacking the trim features and the activity of the former, but as a rule, much more neat and clean cut than the latter. The body is of good size and plump and full (Figs. 126, 127).

1 Standard of Perfection by the American Poultry Association. 
495. Ornamental breeds. - These consist of a large number of breeds varying in shape, size, color, and general utility, and propagated principally for their attractiveness (Fig. 128).

\section{THE EGG TYPE OF FOWLS}

The more noted breeds of the egg type belong to the Mediterranean Class, as grouped in the Standard of Perfection, to which should be added the Hamburg and Red Cap breeds.

The Name, Native Home, Number of Varieties, and Weight of Both Mature Male and Female for Each of the Breeds of Fowls belonging to the EgG Trpe

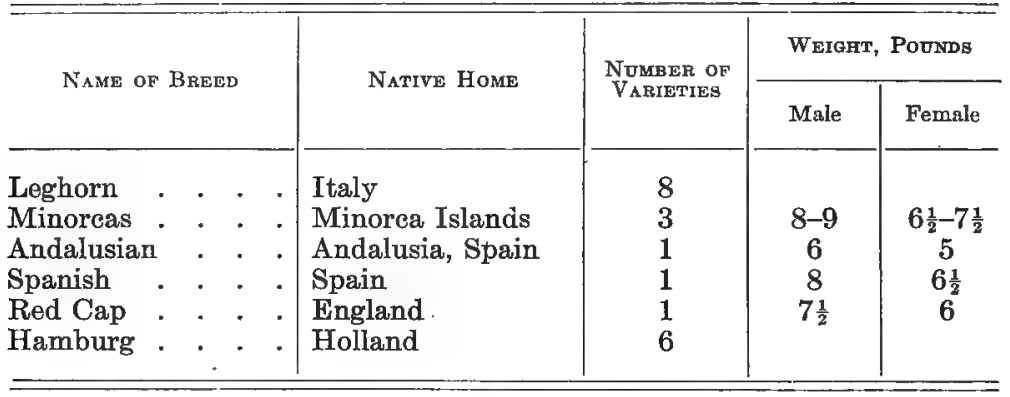

496. Characteristics of egg breeds. - In a general way each of the breeds of fowls belonging to the egg type possesses the following characteristics (Figs. 122, 123).

Size. - While there is much variation in size among the eggproducing breeds, yet they are classified as small or medium, although the heaviest of the mature fowls may weigh more than some of the lighter individuals of the larger breeds. Here is a case somewhat similar to milk production among cattle. The specific purpose for which these fowls are propagated being egg production, we do not care to sacrifice this product for increased meat production. 
Disposition. - Each of the egg-producing breeds is characterized by a rather nervous, active disposition. They are alert, and easily frightened, and when disturbed fly with the ease of wild birds. The flying habit is easily established, but difficult to overcome. Since excitement interferes with the egg-producing function, fowls of this type should be carefully handled. A little thoughtfulness and gentleness on the part of the attendant will entirely overcome this natural nervousness.

Maturing qualities. - The breeds of this type are among the earliest maturing fowls. They develop feathers, combs, and wattles very early in life, so that they assume the

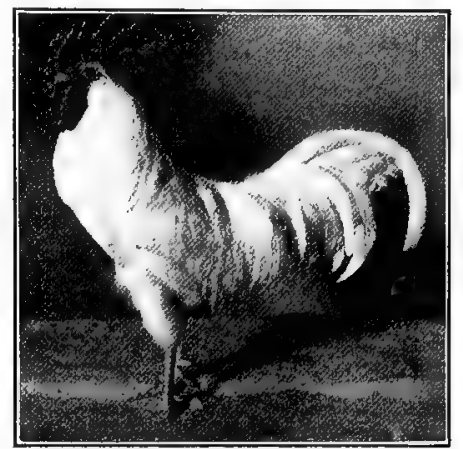

FIG. 122. - The White Leghorn male. Egg type. appearance of small adults. The feathering period is a very delicate one in the young fowl's life, because of the extra heavy demands made upon the system. The young fowl, therefore, that feathers rapidly, can be relied upon to have much constitutional vigor.

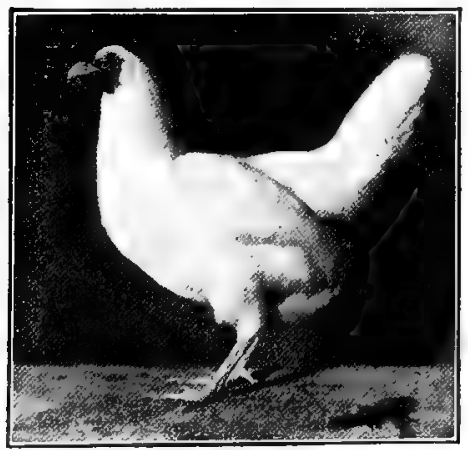

FIG. 123. - The White Leghorn female. Egg type.

Laying qualities. - As would be expected, the breeds of the egg type are second to none in egg production; although good individuals of other types may be superior in this respect to poor individuals of the egg type.

Meat-production qualities. - Because of the comparatively small bodies, the breeds of the egg type rank inferior in meat production, at least so far as quantity is concerned, although if the fowls are properly fed, the quality may be the equal of any. 
Brooding qualities. - Most of the egg-producing breeds are spoken of as " non-sitters," by which is meant a natural disposition not to incubate. With these fowls the tendency toward egg production has become so great that the hen has comparatively little desire to brood and exercise her maternal instincts. The brooding is usually done artificially (p. 339).

Foraging qualities. - The egg-producing breeds are among the most active and industrious fowls. They seem to be constantly in search of food: Because of their activity and light bodies, they may obtain a considerable portion of their own living, if provided with sufficient range. Not only will these breeds obtain much of their own food if given a large range, but they will thrive better and produce a greater number of eggs.

Sensitiveness to exposure. - All of the more noted egg breeds have large combs and watties, as well as long, naked shanks, which make them sensitive to cold. If exposed, these parts are liable to be frosted. This calls for more comfortable quarters in cold latitudes.

\section{THE MEAT TYPE OF FOWLS}

The breeds of this type belong to the Asiatic class as grouped in the Standard of Perfection.

The Name, Native Home, Number of Varieties, and Weight of Both Mature Male and Female for each of the Breeds of Fowls belonging to the Meat Type

\begin{tabular}{|c|c|c|c|c|c|}
\hline \multirow{2}{*}{\multicolumn{2}{|c|}{ NAME of BREED }} & \multirow{2}{*}{ Native Homp } & \multirow{2}{*}{$\begin{array}{l}\text { Nomber of } \\
\text { Varieties }\end{array}$} & \multicolumn{2}{|c|}{ Weight, Pounds } \\
\hline & & & & Male & Female \\
\hline $\begin{array}{l}\text { Brahma } \\
\text { Cochin . } \\
\text { Langshan }\end{array}$ & $\begin{array}{ll}\cdot & \cdot \\
\cdot & \cdot \\
\cdot & \cdot\end{array}$ & $\begin{array}{l}\text { Asia } \\
\text { China } \\
\text { China }\end{array}$ & $\begin{array}{l}2 \\
4 \\
2\end{array}$ & $\begin{array}{c}11-12 \\
11 \\
9 \frac{1}{2}\end{array}$ & $\begin{array}{c}8 \frac{1}{2}-9 \frac{1}{2} \\
9 \frac{1}{2} \\
7 \frac{1}{2}\end{array}$ \\
\hline
\end{tabular}


497. Characteristics of meat breeds. - In general, each of the meat breeds possesses the following characteristics (Figs. 124, 125).

Size. - The fowls of the meat-producing type are the largest of any in size, possessing broad, deep, full bodies, and standing on

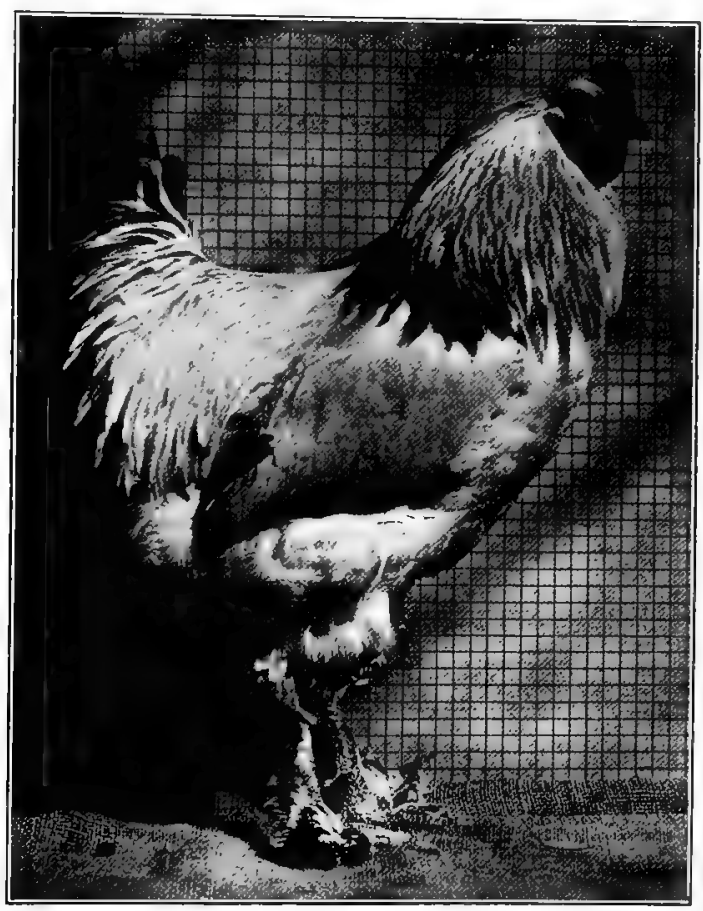

Fig. 124. - The Light Brahma male. Meat type.

short, thick legs. In this type the case is similar to beef production among cattle, hence a heavy, meaty carcass is desired.

Disposition. - The meat breeds are slow and more or less sluggish, possessing a phlegmatic temperament. Under gentle treatment they become very tame, and do not show a dislike to 
handling, as do the more nervous breeds of the egg type. They are easily confined and difficult to frighten.

Maturing qualities. - As a rule, large animals mature less rapidly than small ones. Thus the heavy, meat-producing breeds require

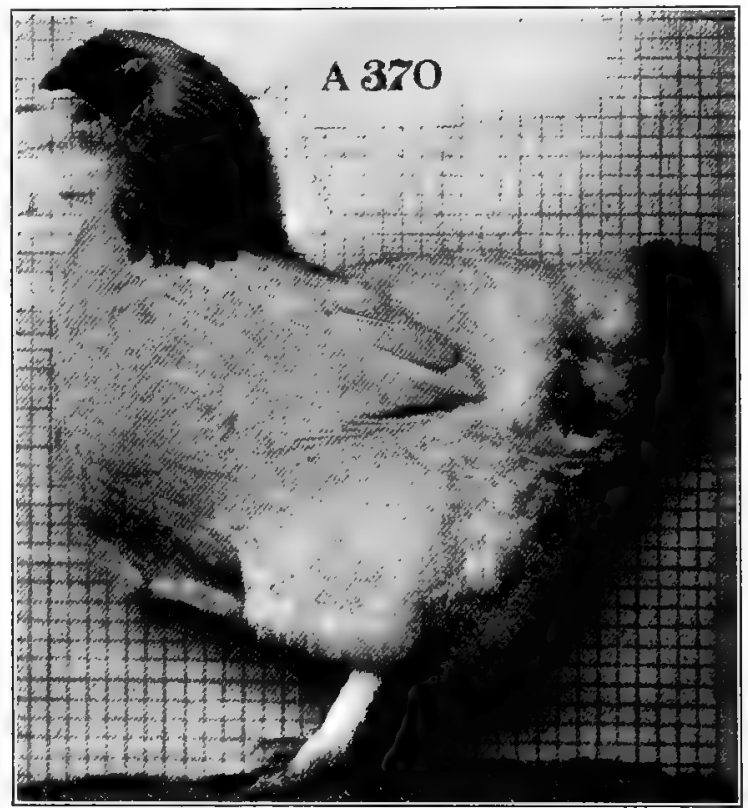

Fig. 125. - The Light Brahma female. Mrat type.

a much longer period to reach maturity than the egg breeds. Since the developing period is the critical one, the chicks are required to endure the strain for a considerable length of time. On this account they are considered somewhat more delicate than many of the lighter breeds.

Laying qualities. - In this respect the meat-producing breeds are quite inferior, although, if properly cared for, some breeds are 
considered good layers, particularly while young. In this respect they are not to be compared with the egg breeds.

Meat-producing qualities. - This, of course, is the special field of the meat breeds. Here they reach their maximum usefulness, at least so far as quantity is concerned, although possibly some other breeds may excel them in quality, particularly when properly fed.

Brooding qualities. - The meat breeds being of phlegmatic temperament have the brooding habit strongly developed, perhaps to a greater extent than that of any other class.

Foraging qualities. - These heavy breeds are not well calculated to seek their own living, even though provided with a wide range. Because of their slow, and in many cases, awkward movements, they work at a great disadvantage in foraging for insects and the like. Probably because of this they have little desire to roam far from home, unless compelled to do so in search of food.

Sensitiveness to exposure. - Since the meat breeds lack the extreme development in combs and wattles of the egg breeds, and since their shanks are covered with feathers to the toes, they can endure a much lower temperature without suffering from cold. For best results in fattening, however, they should be provided with comfortable, well-ventilated quarters.

\section{GENERAL PURPOSE BREEDS OF FOWLS}

The more noted breeds of the general purpose type belong to the American class as grouped in the Standard of Perfection, to which should be added the Orpington, Dorking, Houdan, and possibly others, depending on the object sought. This type ranks intermediate between the egg and meat types, and lacks definite bounds, so that there are a few breeds that might be placed in any one of the types, according to the fancy of the poultryman. 
The Name, Native Home, Number of Varieties, and Weight of Both Mature Male and Female for Fach of the Bregds of Fowls belonging to the General Purpose Type

\begin{tabular}{|c|c|c|c|c|}
\hline \multirow{2}{*}{ Name of Breed } & \multirow{2}{*}{ Native Home } & \multirow{2}{*}{$\begin{array}{c}\text { NUMBER of } \\
\text { VARIETIES }\end{array}$} & \multicolumn{2}{|c|}{ Weyght, Potnds } \\
\hline & & & Male & Female \\
\hline Plymouth Rock & United States & 6 & $9 \frac{1}{2}$ & $7 \frac{1}{2}$ \\
\hline Wyandotte & United States & 8 & $8 \frac{1}{2}$ & $6 \frac{1}{2}$ \\
\hline Java . & United States & 2 & $9 \frac{1}{2}$ & $7 \frac{1}{2}$ \\
\hline Dominique & United States & 1 & 8 & 6 \\
\hline Rhode Island Red & United States & 2 & $8 \frac{1}{2}$ & $6 \frac{1}{2}$ \\
\hline Orpington & England & 3 & 10 & 8 \\
\hline Dorking . & England & 3 & $7 \frac{1}{2}-9$ & $6-7$ \\
\hline Houdan . & France & 1 & 7 & 6 \\
\hline
\end{tabular}

498. Characteristics of general purpose breeds. - In a general way the breeds of this type possess the following characteristics in common (Figs. 126, 127) :

Size. - The fowls of the general purpose type are usually of medium size, although the larger may weigh more than the lighter of the meat breeds. As a rule, these fowls have blocky, compact bodies and comparatively short legs, although not so massive as the meat breeds.

Disposition. - The breeds of this type are fairly gentle. They are not easily frightened, and hence are easily confined if given sufficient range. Of course, if improperly treated, they may become wild, and take to their wings, which, after a time, they will use with the ease of the lighter breeds.

Maturing qualities. - The breeds of the general purpose type closely resemble the egg breeds in respect to maturity. They are hardy, grow quickly, and rapidly pass through the critical stages of early life. This is important, as they do not require the close attiention of the more delicate breeds.

Laying qualities. - While not equal to the egg-producing 
breeds in this respect, yet with proper care, they closely rival the egg breeds. Here much depends on the skill and object of the poultryman.

Meat-producing qualities. - As in the laying qualities, much depends on the object sought. While the general purpose breeds

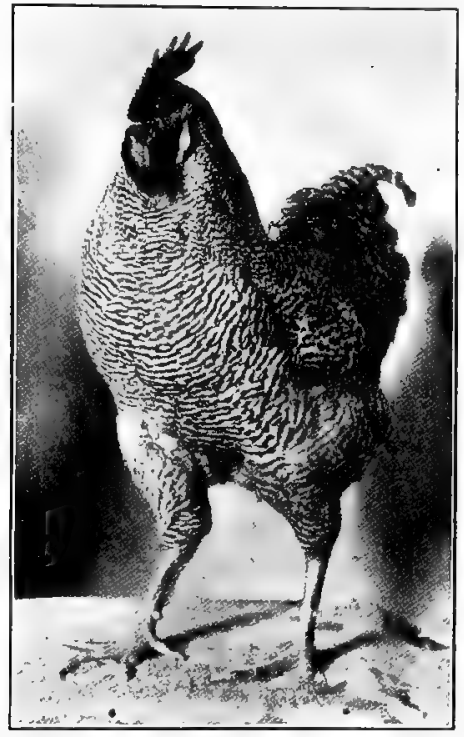

FIG, 126. - The Barred Plymouth Rock male. General purpose type.

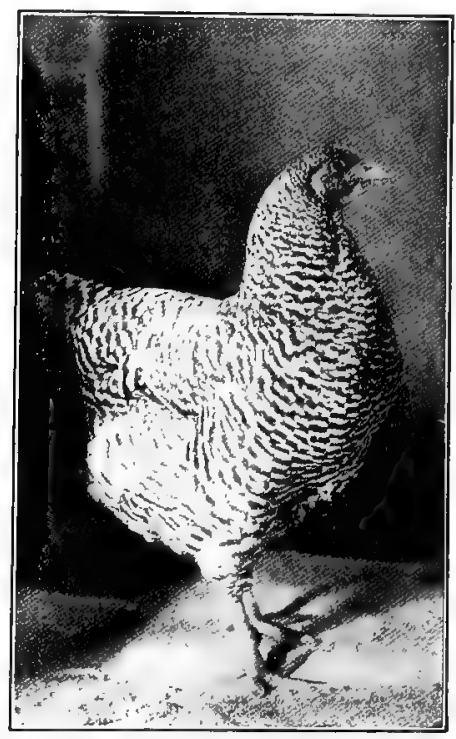

FIG. 127. - The Barred Plymouth Rock female. General purpose type.

rank inferior to the meat breeds in weight, yet with proper treatment they closely rival the meat breeds in other respects, such as ease of fattening, quality of meat, and the like.

Brooding qualities. - While not as persistent sitters as the meat breeds, the general purpose fowls make excellent mothers. In fact, they are probably among the best brooders, as they are more careful than the larger and more clumsy breeds, breaking fewer 
eggs. Further, they have an abundance of fluffy feathers which enables them to do their brooding well.

Foraging qualities. - The fowls of this type are among the most economical foragers, considering their size. If opportunity is afforded, they will roam a considerable range in search of insects and green food. In this way they often obtain their entire food supply.

Sensitiveness to exposure. - The medium-sized combs and wattles, the compact body, and the thick coat of rather fluffy feathers enable this type to endure a much lower temperature than that of the egg breeds, although they do not equal the meat breeds in this respect.

\section{ORNAMENTAL BREEDS OF FOWLS}

The more noted breeds of ornamental fowls belong to the Polish, Game and Game Bantam, Oriental Game and Bantam, Ornamen-

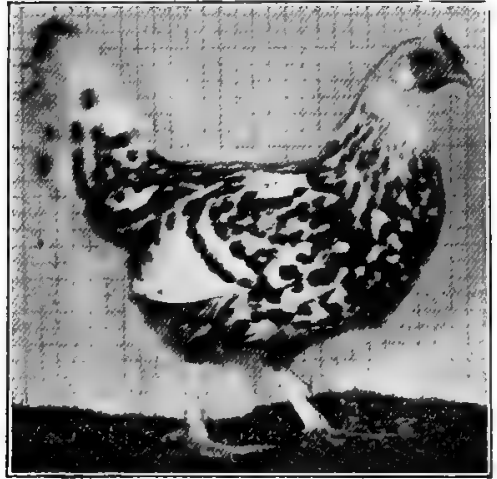

FIG. 128. - The Hamburg. A semi-ornamental breed. tal Bantam, and Miscellaneous Classes, which includes the Silkies, Sultans, and Frizzles, as grouped in the Standard of Perfection. There are many varieties belonging to some of these classes.

499. Characteristics of ornamental breeds. - There is great variation in size, shape, and color among these ornamental breeds. Undoubtedly some of the breeds will lay a number of eggs, under favorable circumstances, and, in addition, may produce. meat that is excellent for food; yet they are all inferior to the more specialized breeds. As a rule, the ornamental breeds are propagated for their beauty or attractiveness and for their novelty (Fig. 128). 
TURKEXS, DUCKS, GEESE, AND GUINEA-FOWLS

Many persons think that the term poultry comprises only chickens, whereas it really includes all kinds of domesticated fowls, the more useful being turkeys, ducks, geese, and guineas, in addition to chickens.

500. Turkeys. - Of all of our breeds of domestic animals the turkey is the only one that is a native of America. Undoubtedly

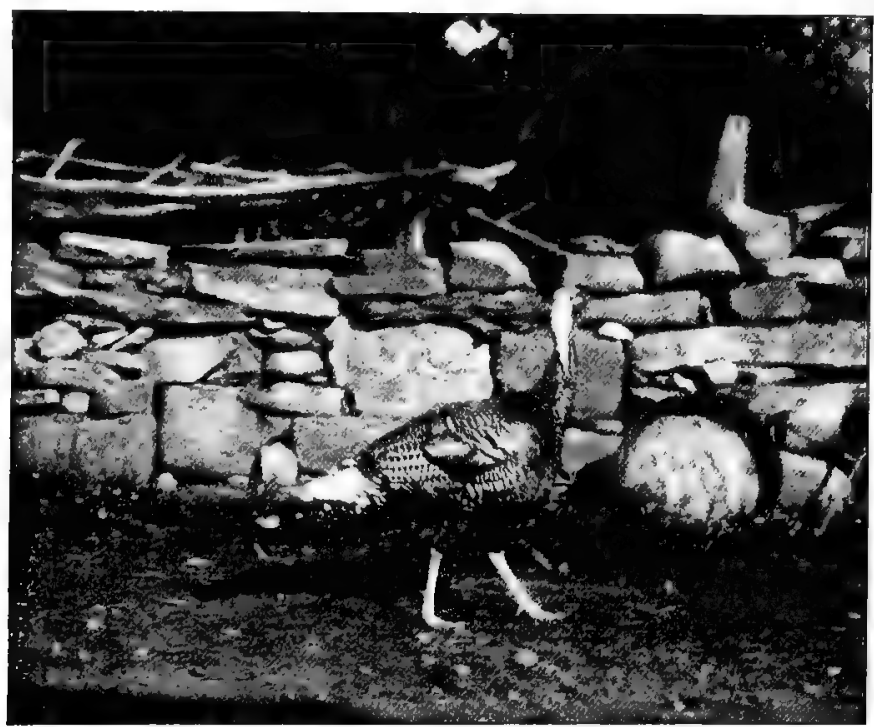

FIG. 129. - The turkey. A rover by nature.

our present domestic turkey descended from what is known as the American wild turkey, which existed in a wild state over the greater part of North America, from the Carolinas well up into Canada, although there are two other species in existence, one found in Mexico, the other in Honduras, Central America. While the records show that turkeys were grown in England as early as 
1541 and that they were reasonably plentiful in 1573 throughout the agricultural districts of England, yet these turkeys were of undoubted American origin. The wild turkey still abounds in the forest and mountainous regions of some of the Atlantic states, Mexico, and Central America. Like other wild game, however, it is rapidly disappearing, but owing to its shy nature, it is not likely to become extinct for many years.

The wild turkey is easily tamed, especially if the eggs are taken and incubated under a hen. Possibly, because of the ease with which the tame, or domesticated ones, were crossed with the wild ones, a number of varieties have sprung into existence. The Standard of Perfection recognizes six varieties, the bronze, Narragansett, buff, slate, white, and black.

In size the turkey ranks as the largest of fowls, the standard weight for adult males ranging from twenty-six pounds in the white to thirty-six pounds in the bronze, and the female from sixteen in the white to twenty pounds in the bronze. In general conformation, the turkey is rather up-standing, but with a broad, deep, full, and rather long body. Because of their size turkeys are useful for their meat, and considerable attention is given to raising them for market (Fig. 129).

The turkey has a rather nervous disposition, and by nature possesses a roving habit. For best results, therefore, free range must be provided. They become nervous and restless when confined to limited quarters. Under such conditions, they will not grow as large nor prosper so well as they will if given freedom. The turkey hen will lay from thirty to forty eggs in a season. The young fowls, when properly fed, furnish meat that is unexcelled as food.

501. Ducks. - These are web-footed, short-legged water-fowls raised chiefly for their meat, there being but a limited market for the eggs, except for hatching. The Standard of Perfection recognizes ten breeds and twelve varieties varying considerably in siz, shape, and color. Among the common breeds, the adult 
male weighs from seven to ten pounds and the female from six to eight pounds. These fowls have certain advantages over chickens that make them favorites with some persons. Ducks have a phlegmatic temperament, are difficult to frighten, and are easily confined. They are comparatively free from certain diseases that often trouble chickens. It is important to remember that the duck lacks the distinct crop or craw of the hen, and that the food passes more directly into the digestive organs. The food, therefore, does not undergo so complete a softening as that consumed by the hen. For this reason it is of the ut-

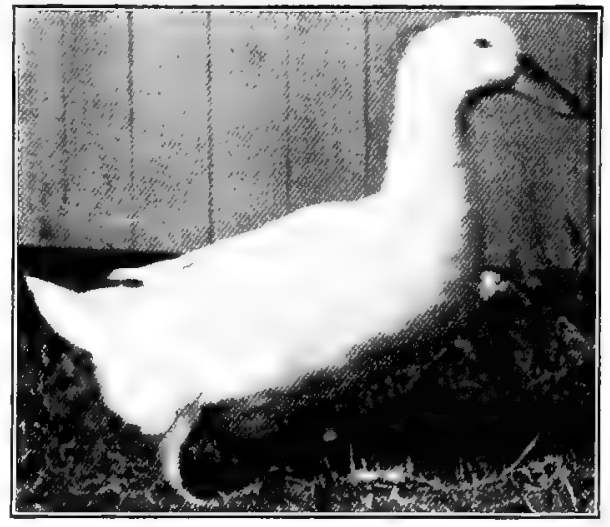

F1G. 130. - The Pelin duck. most importance that the food be consumed in a soft condition. In nature, ducks gather a large proportion of their food from streams, ponds, and marshy places (Fig. 130).

502. Geese. - These are also web-footed, short-legged, thickbodied water-fowls raised for their meat and feathers, and to some extent for ornamental purposes. The Standard of Perfection recognizes six breeds and seven varieties, varying considerably in size, shape, and color. These fowls are much larger than ducks, adult males weighing from twelve to twenty pounds and females from ten to eighteen pounds. In this respect, they rank second to the turkey. Geese are not raised so extensively as ducks. Possibly this is due to the fact that to thrive they should have free range and access to water, such as ponds, streams, and the like (Fig. 131).

503. Guinea-fowls. - These are rather deep, plump, round- 
bodied fowls that are occasionally met with on farms, although they cannot be classed as an economic bird. They are of a semi-

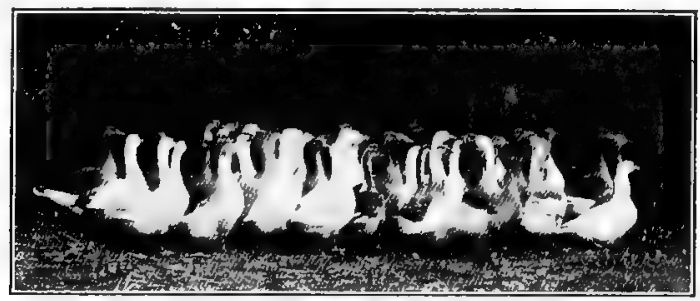

Fig. 131. - A flock of geese.

wild nature, refusing to make their nests other than in hiding. Often they refuse to brood under any conditions. There are at least four varieties of guinea-fowls.

\section{QUESTIONS}

1. Are there any breeds of pure-bred poultry in your vicinity? What breeds are the most common?

2. Give the names of a few of the leading poultry exhibitors at your state, county, or town fair. What are some of the prices obtained for prize-winning stock?

3. Why have the Mediterranean countries been so successful in developing egg breeds? Asia in developing meat breeds? And America in developing general purpose breeds?

4. Name four products that America contributed to agriculture. Why have not more of our wild animals been domesticated?

5. Why are ducks and geese provided with a web-foot? Why do they requirc a different kind of food from either the chicken or the turkey? 


\section{CHAPTER XXI}

\section{JUDGING POULTRY}

JUDGING poultry differs from that of other farm animals in that the various classes of fowls have definite standards. These standards are followed by poultrymen generally, and before one can judge intelligently, he must become familiar with the various standards as set forth in the Standard of Perfection published by the American Poultry Association.

504. How to estimate the age of poultry. - The age of fowls cannot be judged with exactness. About the best we can do is to distinguish between young fowls, say those under one year of age, and older ones, say those one year old and upward.

505. Young fowls. - The young fowl has a clean, smooth shank ; soft, short, and straight toe-nails; and the young male has a small, soft spur. The face is smooth and the eyes round and full. The skin is elastic and the flesh firm.

506. Old fowls. - In older fowls, the shanks show roughness, dead scales, and less color; the toe-nails are hard and rough, and the old male has a long, hard, bone-like spur, which is often curved. The face is wrinkled and puffy, while the eyes are not so round and full as in the younger fowls. The skin is usually loose and the flesh flabby.

\section{METHODS OF JUDGING POULTRY}

There are two distinct methods of judging fowls in common practice, the score-card and the comparative method. Poultry is the only class of farm animals where the score-card is used in placing awards. Both the comparative and the score-card method 
depend on an accurate knowledge and a correct interpretation of the Standard. In fact, to be a good poultry judge, the following qualifications are essential : first, one must have an accurate knowledge of the correct shape of the various parts of a typical fowl of the breed; also of the various cuts that the Standard prescribes for defects, so that he can instantly place a valuation on them. Second, he must have exact information concerning the colors and shades demanded by the Standard for each section of each variety, so that without bringing fowls together for comparison, he may give to each section a proper cut for its defect in color. Further, he must possess an intimate knowledge of the combinations of color that make up the strong points of parti-colored specimens.

507. Comparative judging. - This is the older method and has some advantages over the score-card. In the first place, it is always employed at the summer and fall shows where fowls are exhibited before they recover from their annual molt. It is also used where chicks are immature in size, form, and feather. In either of these cases the score-card, accurately applied, would show such low scores that poultrymen could not be induced to exhibit their fowls. In the second place, it is possible to select a more uniform lot of prize-winning fowls, particularly where the number of entries is large. When the score-card is employed in judging large classes, awards are often made to fowls very dissimilar in style and type.

In comparative judging the entries should be so arranged that all of the fowls of a class shall be adjacent to each other. First, pass along in front of the cages and note the poor exhibits, giving special attention to each. Then work over the best fowls until sure of the relative rank of each. In addition to a knowledge of the standard, this method calls for careful observation and much patience.

508. Score-card judging. - In this method each fowl is carefully scored according to the scale of points for the class. The awards are made on the basis of this score. This method is per- 
haps the more convenient as the judge handles each fowl but once, recording each character as he notes it. He is then done with that fowl. On the other hand, when judging a close class by the comparative method, the judge may be obliged to handle each fowl many times to arrive at a decision. For convenience, the exhibits should be arranged as in comparative judging. This is better than to have the judge seated at a central point and the fowls brought to him.

509. Score-card for poultry. - Each class of fowls has its own scale of points varying in numerical value, but similar in general characters. The following scale of points is for the general purpose type or the American class :-

\section{STUDENT'S SCORE-CARD}

\section{Fow Ls}

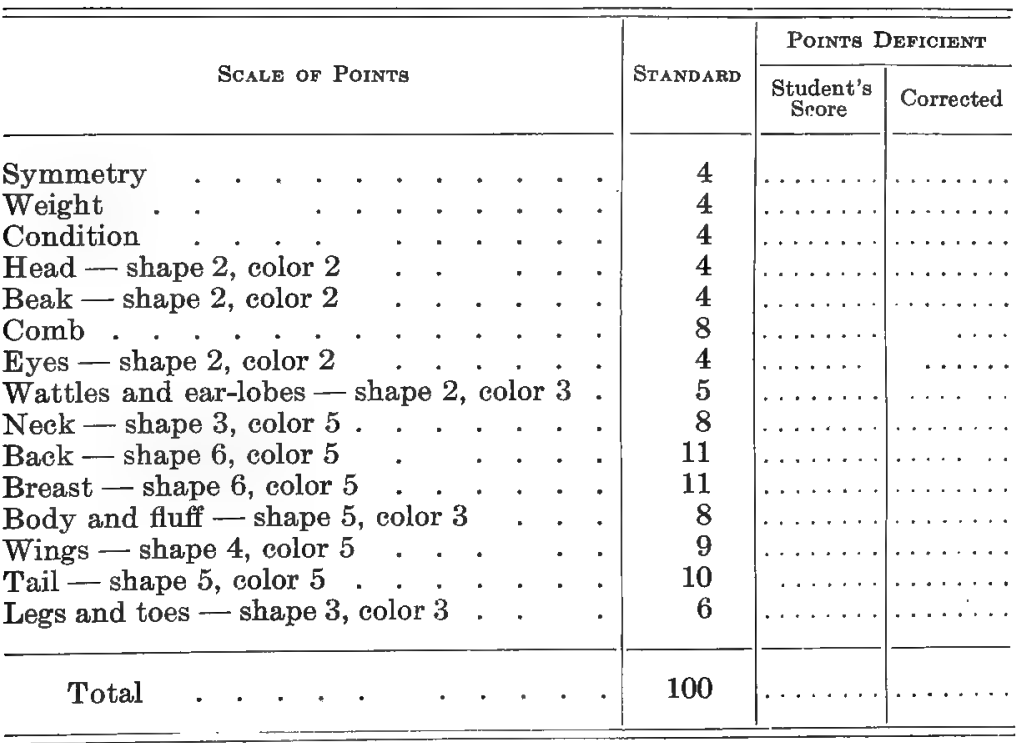




\section{DETAIL CHARACTERS OF FOWLS}

In judging poultry a detailed examination of the characters is of first importance. This is due to the minute shades of difference

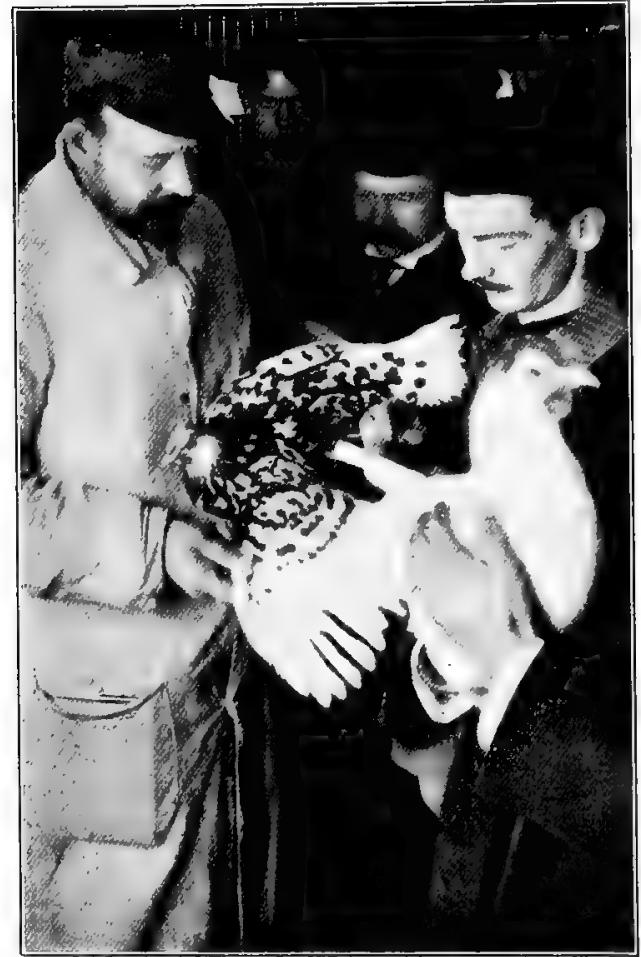

FIG. 132. - Judging poultry. between varieties and breeds. Such an inspection calls for a thorough knowledge of the Standard for each class under consideration. That no characters be overlooked, they should be considered in order (Fig. 132).

510. Symmetry. This should be noted before the fowl is touched. Symmetry refers to the harmonious union of the characters and to the gencral style and finish. It considers the fowl as a whole. The general make-up should be typical of the variety and the breed.

511. Weight. Where Standard weights are required, they should be taken and recorded before the judge handles the fowl. Cut according to the Standard rules. American varieties are criticised for over-weight as well as under-weight. Nonweight varieties should be cut for under-size. 
512. Condition. - This is the place to criticise for lack of care. Fowls that lack thrift, that are unclean with soiled plumage, that have their combs and wattles frost-bitten, and the like, should be severely scored, so as to protect the painstaking and careful poultrymen.

513. Head. - Close attention should be given the length and curvature of the skull and beak. The shape and condition of the eye are of special importance. Shape and color are considered separately.

514. Comb. - Note the shape and regularity of the comb, giving attention to color. Cut according to the Standard for the various varieties and breeds.

515. Wattles and ear-lobes. - The shape and color are so important that the score-card' considers them separately, giving a numerical value to each. The wattles should be of equal length, free from wrinkles and fine in texture. The ear-lobes should be small to medium for the variety, fine in texture, free from wrinkles, and equal in length.

516. Neck. - The neck varies in length according to the breed and class. It should taper gracefully from head to body, with neat attachment. Shape and color are considered separately.

517. Back. - The back differs in shape according to the breed and class. In the meat breeds, it is broad and comparatively short, while in the egg breeds it is of medium length and comparatively narrow. Shape and color are considered separately.

518. Breast. - The shape of the breast varies more, according to the condition in respect to fatness, than does any other character. It also varies according to the breed and class. In the meat type it is broad, deep, well-rounded, and full, while in the egg type it is prominent and lacks the breadth of the meat type. Shape and size are considered separately.

519. Body and fluff. - In respect to shape, the body varies in much the same way as the back and breast. In judging females, care must be exercised to notice whether they are pro- 
ducing eggs. The abdominal section covered by the fluff is likely to be abnormally developed while the egg-producing organs are active. Shape and color are considered separately.

520. Wings. - The wings should be of medium size for the breed under consideration. They should be well folded and carried close to the body. Note unnaturally shaped wings, also broken or missing feathers. Here again, shape and color are considered separately.

521. Tail. - This is one of the beauty points that requires careful attention. The position and carriage of the tail varies according to the breed and class. In some breeds it is carried upward and well forward, almost over the head, while in others it is carried rather low and almost straight backward. Note irregular carriage, also broken and missing feathers. 'Shape and color are considered separately.

522. Legs and toes. - As in the other characters, the legs and toes vary in length, shape, and position, according to the breed and class. Thus in the egg type the legs are comparatively long and slender, while in the meat type they are rather short and thick set. In the meat type the thighs, hocks, and shanks are considered separately. In most of the breeds, the plumage extends only to the hocks, whereas in a few others, it extends to the toes. Shape and color are separately considered, and, in scoring, a numerical value is given each.

\section{QUESTIONS}

1. Why is the score-card often used in practical poultry judging? Why is it not used in judging other classes of farm animals?

2. In the score-card for fowls, why is shape and color given a separate numerical valuation?

3. How does the Standard of Perfection promote uniformity? Would it be of advantage to have similar standards for each class of farm animals?

4. How does the coat of fowls differ from that of other farm animals? What advantage over other animals does this give fowls? How do Silkies differ from other fowls?

5. Why should symmetry be noted before the fowls are handled? Why is it of advantage to have the judge pass upon fowls in their cages rather than to have them brought to him seated at a central point? 


\section{CHAPTER XXII}

\section{FEEDING POULTRY}

THE general principles of feeding apply to fowls as well as to other farm animals. The poultry ration, therefore, should be properly balanced, and should contain sufficient nutrients to meet the needs of the fowl. It should provide a good variety and possess sufficient bulk to enable the digestive secretions to act on it quickly, although it should not contain too large an amount of indigestible fiber. Further, it should consist of food which the fowls like.

\section{ESSENTIALS OF FEEDING POULTRY}

There are a few points in which poultry feeding differs essentially from that of other farm animals. These are due in part to the manner in which the fowl prepares its food for digestion, and to the extra heavy demands made upon the system, especially in the production of eggs.

523. Grit and mineral matter. - Grit forms an essential part of a poultry ration. It has a double function, namely, to aid in grinding or crushing the food in the crop or gizzard, and to furnish the lime and mineral matter used in egg production. Most of the grits on the market contain little or no lime. Cracked oyster shells or mortar are the chief source of lime. They also meet the need of grinding material, although some grit should be fed in addition.

524. Meat scraps. - For best results, meat in some form is an essential part of every poultry ration. This is true of growing stock as well as of mature animals, whether being fed for egg or meat production. Meat is usually supplied in the form of beef 
scrap, principally because of its high-protein content and easy keeping qualities, although skim-milk is probably the most desirable of all meat foods. Green cut bone is very desirable for variety, although it must be fed in small quantities, preferably along with other meat food. Meat should form from ten to fifteen per cent of the daily ration.

525. Green food. - For best results green food in some form should be fed daily. Its chief value lies in its succulence, as it assists in digestion and promotes health. In summer the most desirable green food is clover pasture, while mangels, if fed in limited quantities, are perhaps best for winter use.

526. Preparation of grain. - The grain ration should consist of one-half to two-thirds whole grain and one-third to one-half ground feed. While fowls seem to prefer whole or cracked grains to ground feed, yet the great demands made upon the system necessitate supplying the food in the most readily available form, especially during heavy egg production. Fowls do not seem capable of grinding the whole grain rapidly enough to satisfy their needs, except during the season when they are least productive.

527. Nutritive ratio. - As with other farm animals, the nutritive ratio varies with the age and the product sought. Thus the growing chick requires a ration with a ratio of approximately $1: 4.0$, the egg-producing hen $1: 4.8$, while the fattening fowl requires a ration with a ratio of $1: 7.5 .^{1}$

\section{FEEDING YOUNG CHICKENS}

For a time after hatching, the young chick derives nourishment from the yolk of the egg, which is inclosed within its abdomen, just before it breaks from the shell. It is believed that too early feeding hinders the proper absorption of this yolk. Chicks begin to show signs of hunger twenty-four to forty-eight hours after hatching, at which time they should receive their first meal. This

1 From data furnished by Cornell University Poultry Department. 
first food must be of such character that it may be readily digested, such as stale bread dipped in milk. Ground or finely cracked grain soaked in milk may be fed to advantage. From the beginning, chicks should be encouraged to eat dry, cracked grain in addition to the moist feed. This food should contain fine grit, charcoal, and granulated bone.

528. Frequency of feeding. - For the first few days, the chicks are usually fed five times a day. They should be required to clean up their food, although they should be given all they will eat. The number of meals is later reduced to four and hen to three times daily. If kept in mall yards, the chicks should be fed more oftcn and given a smaller quantity at a feeding than if given a free range.

529. Amount to feed. - The morning meal should consist of grain, which should be fed under such conditions that the chicks will be obliged to hunt for it, as, for example, on a light litter of straw. The amount fed should be controlled by the appetites of the chicks. If, perchance, they should be overfed, no more food should be given until they are eager for it, and the subsequent feeding should be just sufficient to satisfy the

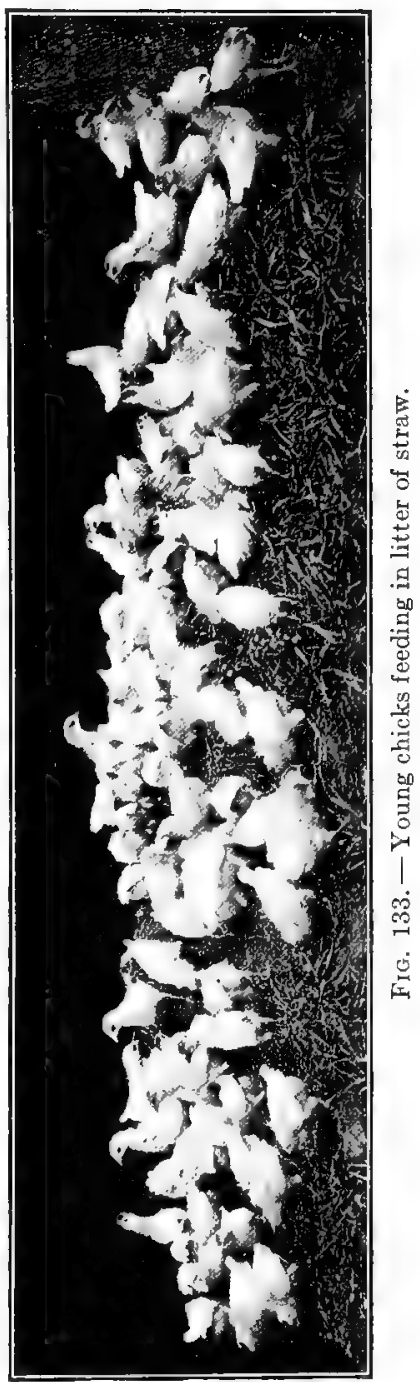


appetite. Green food should be given twice a day. At night the chicks should have all the food they will eat.

530. Sorting uneven flocks. - Chicks of different size should not be fed together, as the strong ones will take advantage of the weak ones. Hence, if the flock is uneven, the smaller chicks should be separated from the larger ones. Fresh, clean water should be constantly before the fowls, and it should be furnished in vessels that will not allow the down of the chick to become wet.

531. Exercise. - In developing young fowls, exercise is of the utmost importance, and when possible free range should be provided. Unless provision is made for sufficient exercise the young fowls will not make satisfactory growth and development. Young chicks, however, should not be permitted to run in moist land, but should be ranged on a dry southern slope.

\section{FEEDING FOR EGG PRODUCTION}

-In the feeding of fowls for increased egg production, a valuable lesson may be learned from the natural habits of the animals. As a rule, fowls lay most abundantly in the spring, particularly when left to shift for themselves. If given free range at this season of the year, they obtain green food in the tender shoots of grass and other young plants. They also obtain meat food in the form of insects, worms, and the like. Such natural food, in connection with some grain, forms a good ration for the egg-producing hen. In feeding for increased egg production, therefore, it should be the object to prolong spring-like conditions throughout the year.

532. Feed a variety. - "The fowls should eat about one-half as much mash (ground feed) by weight as whole grain. Regulate the proportion of grain and ground feed by giving a light feeding of grain in the morning and about all they will consume in the afternoon. In the case of heavy-laying fowls, restrict both night and morning feeding to induce heavy eating of dry mash, especially in the case of hens. This ration should be supplemented with beets, 


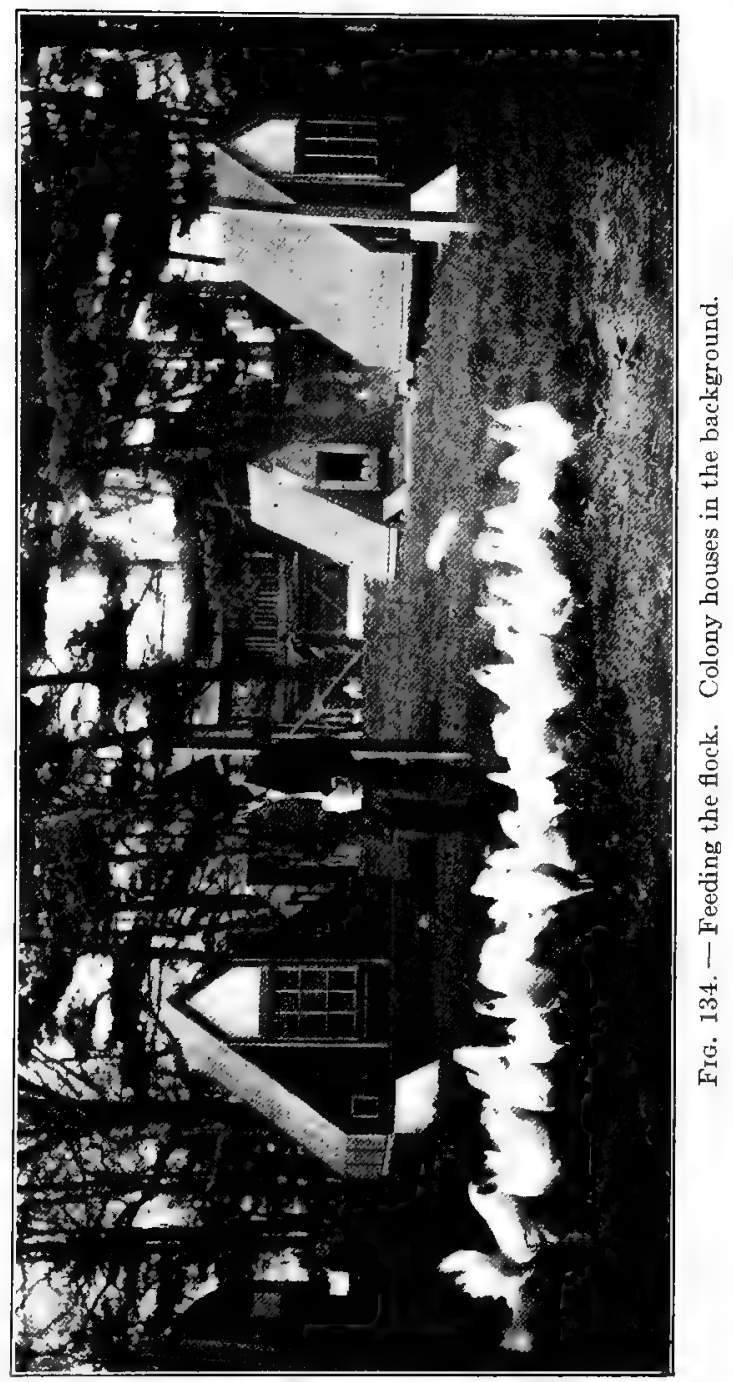


cabbage, sprouted oats, green clover, or other succulent feed, unless running on a grass-covered range. Grit, cracked oyster shells, bone, and charcoal should be accessible at all times. Green food should not be fed in frozen condition. All food and litter should be strictly sweet, clean, and free from mustiness, mold, or decay. Serious losses frequently occur from disease, due to the fowls taking into their bodies, through the intestinal tract or lungs, the spores of the fungus-causing molds.

533. Amount to feed. - "Another important point to emphasize in feeding is that there should be food available up to the limit, of a hen's capacity to eat, so that the high-productive hen shall not suffer from lack of something to eat. The method of dry feeding in a hopper makes it possible for the hen to take food when she likes. Formerly, in wet mash feeding, the amount hens could eat depended upon the good or bad judgment of the person who fed. For the person who will watch his hens and feed each day just what whole grain they need to keep the appetite right and the hens happy and busy, the dry feed-hopper for ground grain not only insures against underfeeding but also saves time.

534. Condition of fowls. - "The proper physical condition of the hen is an important point that needs to be taken into consideration. We must give a hen all she will eat of the right kinds of food, so that she may have surplus energy in the form of fat. The experience of years proves this to be true. More people overfeed than underfeed their hens. The hen must be fed, not only a ration having the correct nutritive ratio, but must be fed the right quantity, so that she will carry some surplus fat in her body. The ovum (yolk of the egg) is sixty-four per cent fat and is practically the only fat that is within the egg. Apparently a hen cannot function properly unless she has surplus fat in her body to put into the ova.

535. Mineral matter. - "We would emphasize the fact that we must feed lime in the form of oyster shells and also in the form of bone meal, granulated bone, or green cut bone, so that the fowls 
will have an available supply of mineral nutrients which are essential in egg production." 1

\section{FEEDING FOR MEAT PRODUCTION}

Fowls should be fattened for at least ten days to three weeks before they are put upon the market. This improves the quality of the meat by giving the right proportion of fat and lean, which makes it much more tender and juicy when cooked. There are two methods of fattening poultry in common practice, the pen method and the crate method. In the former method the fowls are fed in small yards or pens in flocks of from twenty-five to fifty each, while in the latter method the fowls are confined to crates. These are approximately six feet long, sixteen inches high, eighteen inches to two feet wide, and are usually divided into three equal-sized compartments, each holding from four to six fowls as the case may be.

536. Feeding the fowls. - Before the fowls begin to fatten they should be thoroughly dusted with insect powder to free them from vermin. This should be repeated at least twice during the fattening period. The fowls should be graded according to size to prevent fighting. During the first few days of feeding, care must be taken not to overfeed, as fowls somtimes overeat, and lose their appetite, especially at the beginning of the fattening process. The aim should be to give very little the first day and gradually increase, until by the end of the first week they should be receiving all they will eat three times a day. When moist food is given, feed just what the fowls will clean up, and remove what is rejected at the end of fifteen minutes. This is essential to keep the feeding utensils sweet and clean.

537. Kind of food. - There are many good fattening rations, but for best results, animal food, such as beef scraps or skim-milk is needed, even though the ration be balanced properly with grain. As a rule, beef scraps and meat meal are expensive for the farmer, but skim-milk gives equally good results and should be easily obtained on any farm. Some persons prefer to have all grains finely

1 Bulletin 37. New York State Department of Agriculture. 
ground and mixed with sour milk; while others prefer to feed some whole grain in addition.

538. Broilers. - These are young chicks usually marketed at six to twelve weeks of age. They derive their name from the fact that they are usually cut in half and broiled. Broilers are dressed in three sizes: squab broiler, weighing from three-fourths to one pound; small broiler, weighing from one to one and one-half pounds; and large broilers, weighing from one and one-half to two pounds. The small broiler is most in demand.

Broiler raising is regarded as a specialty and a business requiring the greatest skill for success. For this reason there are few exclusive broiler farms in America. Broilers command a very high price in the early spring months, and even as late as June, but when we consider the cost of rearing early winter chicks, and the great risk and losses connected with it, the prices are not so attractive as at the first glance.

539. Roasters. - This is a young fowl approximately full grown and weighing from eight to twelve pounds. The most profitable age to fatten them is from three to four months, as they grow and put on flesh at the same time. Roasters should be fattened as early in the season as possible, as the prices are low in the late summer and fall, when most farmers rush their stock to market.

540. Sample rations for poultry. - The following rations have been collected from various sources, and furnish a guide in determining the kind and amount of food that should be given poultry under various conditions :-

Ration for Young Chicks - First to Fourth Day

BY WEIGHT

Rolled oats . . . . . 8 parts

Bread crumbs . . . 8 parts

Sifted beef scrap . . . 2 parts

Bone meal

1 part

Moisten with sour skim-milk and feed five times a day.
BY WEIGHT

Wheat (finely cracked) - 3 parts Corn (finely cracked) . 2 parts Pinhead oat meal . . 1 part This dry mixture should be left before the chicks in a shallow. tray, along with the moist mash. 


\section{Ration for Young Chicks - Subsequent Feeding}

\section{Br WeIGHT}

Wheat bran . . . . 3 parts

Corn meal . . . . 3 parts

Wheat middlings . . . . 3 parts

Sifted beef scrap. $\quad 3$ parts

Bone meal . . . . . 1 part

Moisten with skim-milk and feed two or three times a day.
The dry cracked grain mixture suggested above should be given at least twice a day, scattered in light litter as soon as the chicks are able to find it, along with the moist mash.

\section{Ration for EgG Production}

WINTER

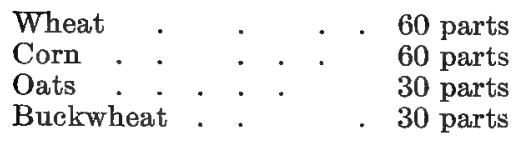

SuMMer

Wheat .

Corn

Oats

This whole grain mixture is fed morning and afternoon in a straw litter.

By WeIGHT

\section{(1)}

Corn meal • • • 60 parts Wheat middlings . . . 60 parts Wheat bran . . 30 parts Alfalfa meal . . . 10 parts Oil meal . . . . . 10 parts

Beef scrap . . . 50 parts Salt . . . . . . 1 part

This ground feed is fed dry in a hopper kept open during the afternoon only. Fed along with the whole grain mixture.

\section{Two Rations for Meat Production}

BY WEIGHT

Corn meal . . . . . 50 parts

Ground oats (hulls removed)

Animal meal

10 parts

10 parts

Moistened with sour skim-milk and fed three times a day.

Barley meal

By WrIGHT

Grit, charcoal, and fine cracked bone should be fed in separate hoppers with each of the above rations.

\section{QUESTIONS}

1. Why is the feeding of poultry essentially different from that of other farm animals? How do fowls masticate their food? How do chickens and turkeys differ from ducks and geese in this respect? 
2. Which type of young chicks are the most difficult to feed? Why? Why does the chick not require food for some time after hatching?

3. Compare the product yielded by an egg-laying hen with that of a dairy cow. Considering body weight, which excels, the hen or the cow? How does the product of an egg-laying hen differ from that of the dairy cow?

4. What are the functions of the mineral matter in the food of an egglaying hen? Of the protein? Of the fat?

5. Wherein does feeding poultry for meat production differ from feeding other meat-producing animals? What class of trade takes most of the broilers on the market? Compare the price of fat fowls, broilers, and roasters on the pound basis. Why this difference? 


\section{CHAPTER XXIII}

\section{CARE AND MANAGEMENT OF POULTRY}

ThE hen is probably even more susceptible to climatic changes, to fright, to unfavorable changes in diet and the like, than is the dairy cow. If the hen is functioning properly, laying an egg every day or every other day continuously, and if something should go wrong in her environmental conditions, such as excessive heat or cold, or if she should become frightened or suffer from any cause whatsoever, or if her food supply should be insufficient to meet her needs, she does not simply stop laying and wait for such conditions to disappear, but under such unfavorable conditions the ova may be reabsorbed into the body. Thus the hen that would have gone on laying, while eggs command a good price, not only stops laying, but draws back into her body and uses for maintenance the stored-up nutrients in the ova, which otherwise might have become valuable eggs. We must realize that if we are to secure high performance in hens, it must be as a result of the application of the same skill in feeding and breeding, as in the case of the wonderful performance of great dairy cows or trotting horses. ${ }^{1}$

541. Improvement of fowls. - In selecting eggs for hatching use only those from healthy stock. Weak parents produce weak eggs. Weak eggs develop into weak chicks. There must be health, vigor, and vitality at the start. There is great difference in the natural vitality of the different flocks of fowls of the same breed and variety, due to difference in the individuals. Thus a few of the thriftiest and best-laying hens should be placed by themselves in order that their eggs alone may be used for hatching.

${ }^{1}$ Bulletin 37. New York State Department of Agriculture. 
In selecting such fowls, probably the best time to make the choice is at the molting period, as thrifty fowls molt much more rapidly than those having weak constitutions. In making this selection, deep, long-bodied, wedge-shaped fowls are preferred for egg production. Two-year-old hens should be used, as they are more mature than yearlings and lay more perfectly developed eggs. With the breeding flock, thus selected, allow one male for each fifteen to twenty-five hens. For best results the malểs should be changed two or three times a week (Fig. 135).

In selecting eggs for hatching, choose only those that are typical of the variety, perfect in shape, normal in size, uniform in color,

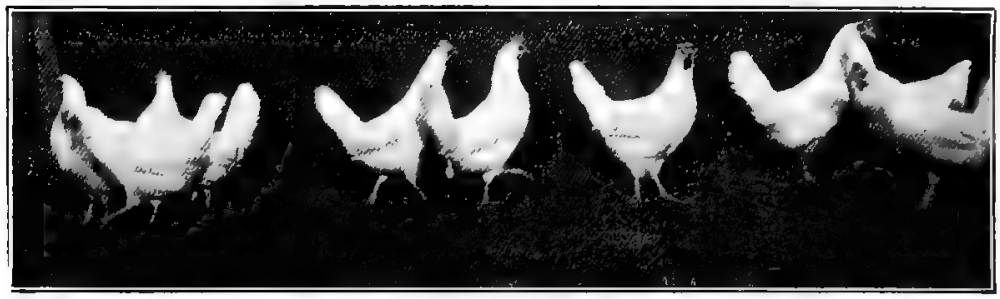

FIG. 135. - A breeding flock of White Leghorns.

and firm of shell. Any departure from this condition indicates faulty nutrition or secretion in the development of the egg, which would naturally result in weakness of the chick.

542. Incubation. - There are two methods of hatching eggs in common use, natural incubation and artificial incubation. The former method is used in small flocks and by farmers generally, while the latter is used in large flocks and on farms where poultry raising is a specialty.

543. Natural incubation. - In most respects the hen is superior to the artificial incubator. There is much difference between the breeds as well as among individuals of the same breed in respect to their usefulness for incubation purposes. All things considered, the general purpose breeds provide the best sitting hens. The 
meat breeds are persistent sitters, but clumsy, and the egg breeds too small, usually light, and untrustworthy. In selection of the individuals for brooding, choose hens that are least excitable when approached. A nervous hen is likely to break some of the eggs in the nest or to step on the little chicks when first hatched.

Successful incubation depends, not only on the hen's ability to hatch fertile eggs, but also on the nesting place and the environment. The hen that steals her nest and sits undisturbed usually brings off a good brood of chicks. In setting a hen, therefore, the object should be to make the conditions as nearly natural as possible. The brooding nest should be placed where laying hens cannot have access to it. A dust bath, fresh water, and the proper kind of food should be convenient.

The hen should be set on "china eggs" until she becomes accustomed to her new surroundings. Before she is placed on the nest, however, she should be thoroughly dusted with lice powder. When the hen becomes familiar with her nest, which will usually be about the second night, the real eggs may be placed under her. It requires approximately twenty-one days for the eggs to incubate.

Before the chicks are hatched, provision should be made for the hen and her brood. When the chicks are twenty-four to thirty-six hours old, they may be removed from the nest and placed in the coops provided for them.

544. Artificial incubation. - There are several types of machines that hatch eggs successfully. These incubators may be divided into two classes: those operated by hot air and those using hot water. The former system is used the more extensively in heating incubators ranging in capacity from sixty to six hundred eggs, while the latter is used more for heating large machines, say those holding one thousand eggs or more. The most successful methods of supplying heat to the egg chamber are diffusion and radiation.

The large incubator, one holding two hundred to six hundred eggs, is usually much more economical and efficient than is the 
one-hundred-egg machine. The expense for oil and labor in the operation of a large machine is comparatively much less than for a small one, and the results obtained from the former are surprisingly better, as the temperature, moisture, and other vital factors are more easily controlled.

545. Brooders. - When chicks are hatched artificially a brooder must be provided to take care of the little ones as they leave the incubator. There are many types of brooders and they may be divided into two classes, on the same principle as-incubators, according to the method of heating. A good brooder should be constructed of first-class material, put together in such a way as to supply a high temperature, pure air, and most important of all, opportunity for the chicks to select their own temperature.

The first need of a young chick is heat. It must be able to find a temperature of not less than 100 degrees Farenheit at all times, but to remain in such a high temperature would prove fatal. Every brooder, therefore, should provide an opportunity for the chicks to choose the temperature most agreeable to them. This will vary from 90 to 100 degrees. This temperature should be maintained during the first three or four weeks. It is better to err in having the heat higher than necessary, provided the chicks have an opportunity to get away from it, than it is to have too little heat. In the latter case, there is no remedy except huddling, which always results in weakness and great mortality.

\section{POULTRY HOUSES}

The poultry house should be comfortable, convenient, well ventilated, and sanitary, as well as of economical construction. In order to fulfill these requirements, the house must be constructed to meet the conditions of the climate. Failure in poultry keeping is often directly traceable to the conditions under which fowls are housed. Many of the most troublesome diseases are due primarily to poor location and improperly constructed houses. 
546. Location of house. - The poultry house should be located in a spot dry and well drained. If the ground is not naturally dry, it should be made so by underdrainage. Damp ground will produce a damp, cold, unhealthy house. Low places should also be avoided as they may be several degrees colder than higher places only a few rods distant. If possible, the poultry house should be placed on ground that slopes to the south. If this cannot be done, face the house toward the south so as to get the sun's rays throughout the day to keep the house bright and cheerful inside. This is especially desirable during the winter, when the poultry house is most needed.

547. Size. - As a rule the size of a poultry house will be governed by the number of fowls in the flock. In estimating size, four to five square feet of floor space per hen is generally thought to be sufficient. For a given floor space, the nearer square a house is the less it will cost for material and labor. While there are many types of poultry houses in common use, in a general way they can be grouped into two classes, the colony house and the long house.

548. Colony house. - This consists of a small house or cot adapted to a small flock or colony. In the case of large flocks, the fowls are divided into many colonies. Colony houses are of two types, the portable and the non-portable. The former has many advantages over the latter, especially for growing stock. The usual method of construction is to place the small house on runners and then have a team draw it from place to place as wished. This type of house makes possible the utilization of grain after harvest, which would otherwise be wasted, as the houses may be moved to the fields. This provides free range, and as the fowls are kept on clean ground, they get more insects than would be possible around the farm buildings (Fig. 134).

549. Long house. - This type of poultry house has the advantage of being comparatively less expensive to build. It requires less labor to care for the-fowls; as the attendant can go 


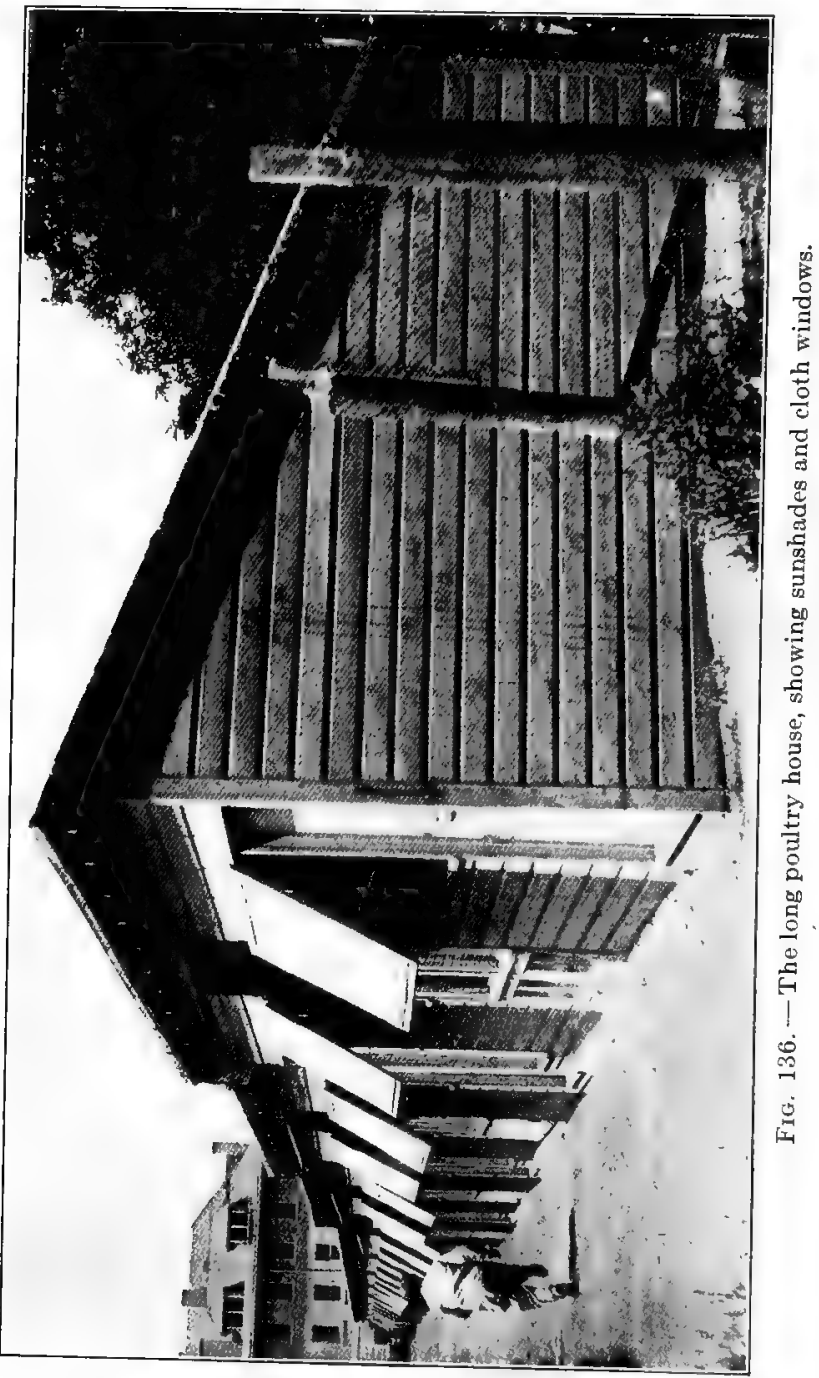


through the long house much more quickly than he can go from one detached house to another, as he must where several colony houses are used. On the other hand, the long house makes it necessary to keep the land more densely stocked and there is much less natural food such as insects, green grass, and the like. Large numbers of fowls kept close together increase the tendency to disease. The grounds and buildings need more careful attention to keep them sanitary, and unless the long house is provided

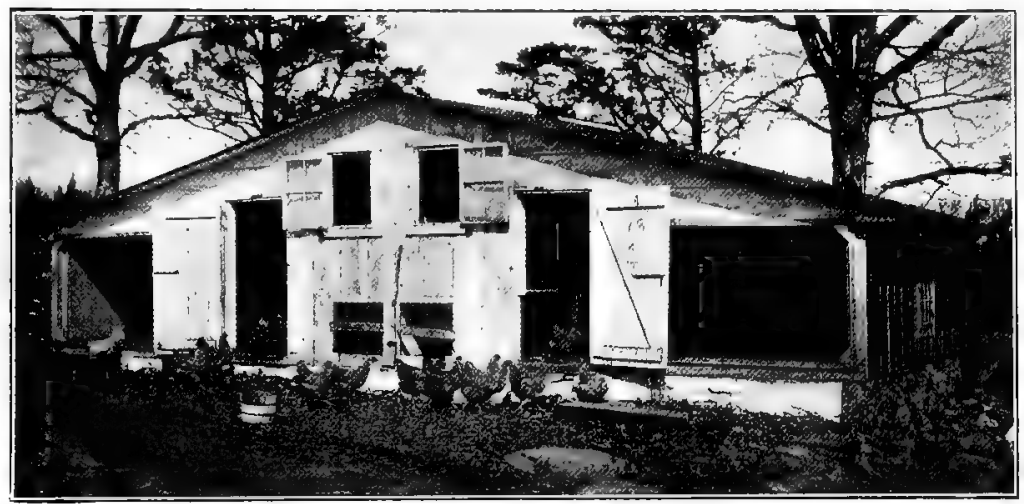

FIG. 137. - Poultry house with scratching-shed.

with partitions, the fowls are likely to do more or less crowding (Fig. 136).

550. Scratching-shed. - This shed was devised to permit the fowls to enjoy fresh air and exercise the year around. The open scratching-shed consists $\alpha^{\prime}$ an ordinary shed walled in on three sides but open to the south. It is attached to the main poultry house so that the fowls can pass to the shed at will.

Exercise is necessary to insure health. Fowls like freedom. The scratching-shed provides for both. Being in the cooler air during the daytime, seems to make the fowls less sensitive to the cold at night. Fowls are generally found to be more healthy and 
to lay more eggs in a year when they have lived in the fresh air of a scratching-shed (Fig. 137).

551. Windows. - These are a very essential part of the poultry house. They should be arranged high and low rather than wide,

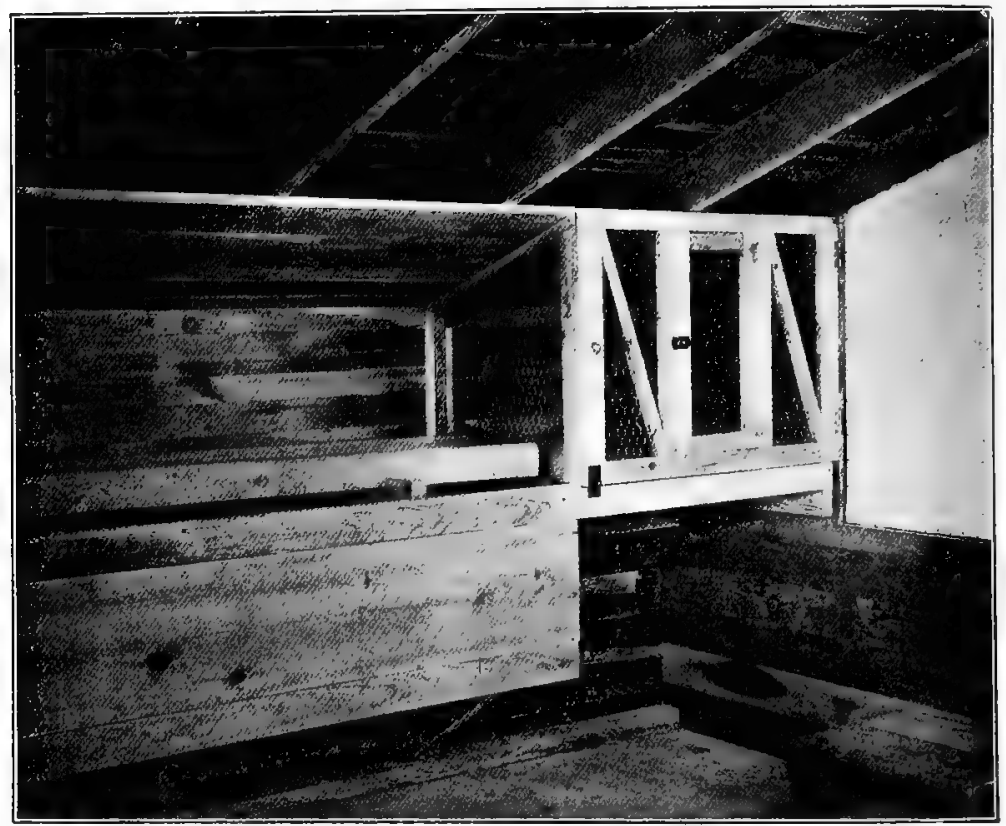

FIG. 138. - Interior fixtures, showing perches, droppings-platform and brooding coop.

so as to permit the sun to sweep the entire floor space, as it passes from east to west, drying the floor, killing disease germs, warming the building, and giving good cheer. In addition to glass, cloth windows should also be provided so as to facilitate ventilation. Provide one square foot of glass and one of curtain surface for each sixteen square feet of floor space. 
552. Floors. - The floor of the poultry house should be so constructed as to insure dryness, warmth, ease of cleaning, and durability, at reasonable cost. A properly constructed cement floor accomplishes all the requirements better than any other, although sand or dirt is much cheaper and sometimes advisable. Hens like a dirt floor if it is dry and kept clean. The dirt floor should be well above the outside surface so that the water drains away, leaving the floor dry and comfortable for the fowls.

553. Interior fixtures. - Every poultry house should be provided with perches, droppings-platform, nests, brooding coop, dust bath, water pan, grit- and feed-hoppers, and a grain supply can. The feed- and grit-hoppers should be rat proof, self-feeding, and non-wasting. All interior fixture should be simple; convenient, and portable, so as to be readily removable for cleaning and disinfecting (Fig. 138).

554. Labor-saving appliances. - Success in raising poultry depends largely on the attention given to details. Since the needs of fowls call for such painstaking effort, the efficiency of the attendant will depend largely on the use of labor-saving devices.

The economy in labor of feeding fowls in the long house is greatly increased by the use of an overhead car system, passing from one end of the house to the other. Where the feed room is not in connection with the house, the track can be extended over the intervening space, and the heavy work of carrying feed or other necessities lessened.

Where many fowls are kept in the flock, capacious feed-hoppers should be provided. These should be constructed for both indoor and outdoor use. These have the advantage of holding a large supply of the whole and ground grains, meat scrap, shell, and grit; sufficient to supply the fowls with food for several days.

In catching fowls much time is saved and fright and injury are avoided by the use of a catching-hook. This is made by attaching a No. 10 steel wire to the end of a broom handle, and then by bending a hook in the other end of the wire of sufficient size to 
catch the fowl about the shank. This hook should have a rather wide aperture so as to permit the shank to be easily caught, but the lower part of the hook should be sufficiently restricted to prevent the shank from being easily withdrawn. The successful poultryman will be constantly in search of appliances that will reduce his labor to a minimum (Fig. 139).

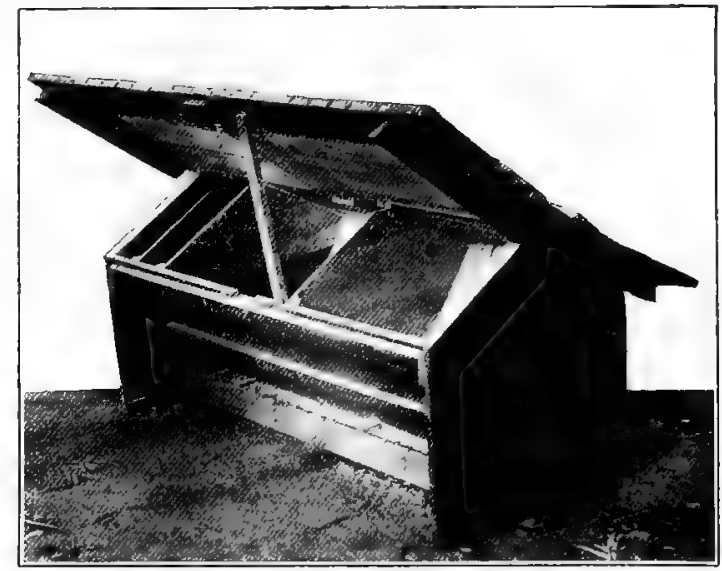

FrG. 139. - Outdoor feed hopper. A place for each kind of food.

555. Yards, parks, and ranges. - Among poultry, as well as other farm animals, exercise is essential to thrift and constitutional vigor. On farms where fowls are given free range, this is abundantly provided for and need receive little or no attention. On the other hand, where it is necessary to restrict the range of the fowls, the matter of exercise becomes a serious question, particularly among young fowls and among the egg-producing breeds.

While there is an utter lack of agreement among poultrymen as to the proper amount of park-space to provide, yet it would seem that sixteen square rods would provide ample yardage for a flock of fifty hens. While such a yard could be more cheaply 
fenced if square, yet it could be more economically cultivated if oblong, say two rods wide and eight rods long. Whatever may be the form or size of the park, it should be remembered that the first requisite is cleanliness. This can be facilitated by frequent cultivation. Perhaps the ideal condition is to have one part of the park in permanent grass, and another part under cultivation. Where convenient, plum and apple orchards provide excellent yard facilities for poultry. This has one particular advantage in that it offers an abundance of shade which in warm latitudes is essential.

\section{QUESTIONS}

1. How many domestic fowls are there in the United States? How many in your state? In your county? How does your state rank with other states in the production of poultry? How does your county rank with other counties in the state? Name the ten leading poultry states. Which possesses the largest number to the square mile? To the farm?

2. In selecting breeding fowls to improve the quality of the stock, what are the essential factors to be considered?

3. Which type of fowls provides the best sitting hens? Why? Why are artificial incubators and brooders inferior to hens in hatching and brooding chickens? Why are the incubators and brooders used?

4. Which type of poultry house is the most desirable on the average farm? Why?

5. Why should fowls that are closely confined be provided with a scratching-shed? Why is free range beneficial to poultry? Which types require the largest area? Which types are the most difficult to confine? Why? Are turkeys, ducks, and geese difficult to confine?

6. What diseases of poultry are most common in the region? What is the principal cause of such ailments? What is done to control them? 7. In nature, how many eggs does the hen lay in a season? In your region, how many eggs do the best hens lay in a season? The poor hens? What is the highest egg yield on record? Why is there such variation in the egg laying capacity of hens?

8. How are eggs sometimes tested by egg dealers? How long will eggs remain fresh in summer? In winter? How long will eggs keep in 
cold storage? In water-glass? Are such eggs as good as fresh ones? How are fresh eggs distinguished from those thus preserved?

9. What price do eggs bring in your locality? How many eggs would have to be sold to pay for the food given the fowls in a year? Compare with the food consumed and the milk yield of the dairy cow? Which is the more profitable?

10. What price per pound live weight does fat poultry bring in your vicinity? How much must each fowl gain per pound of food consumed to pay for the fattening? First, compare with egg production. Which is the more profitable, egg production or meat production? Second, compare with the beef animal. For the food consumed, which is the more profitable, beef production or the production of fat poultry? Name advantages fat poultry production has over beef production. Third, compare with mutton production. For food consumed, which is the more profitable, fattening sheep or fattening poultry? Name advantages poultry have over sheep. Fourth, compare with fattening swine. For food consumed, which is the more profitable, fattening swine or poultry? And fifth, compare the fattening of chickens, turkeys, ducks, and geese. Which is the most profitable? Discuss advantages and disadvantages of each class of poultry. 


\section{APPENDIX}

\section{PART I}

\section{LABORATORY EXERCISES 1}

\section{Habits of Domestic Animals}

Object. To learn the habits of animals.

Materials. Horse, cow, or sheep; watch.

Directions. Observe the horse as he starts to walk. With which foot does he begin, right, left, front, or hind foot? Compare with cow or sheep. While walking does the horse place his hind foot in front, behind, or in the track made by the front foot? When at the trot? When at the gallop? Compare with cow or sheep.

How are the legs placed when a horse lies down? How does the horse get up, front or hind quarters first? Compare with cow or sheep.

Take the watch in hand and count the number of respirations per minute, first of the horse, then of the cow or sheep. How do they compare?

Examine the mouth of a horse, and note the number of front teeth in both upper and lower jaws. Does the mare differ from the horse? Compare with the front teeth of a cow or sheep. Notice if they bite off the grass in the same manner. Have the teeth any influence on the manner of eating? Which animal eats grass off closer to the ground, and why? Which eats towards the wind, and which in the same direction the wind is blowing? Has the arrangement of the teeth and method of cropping the grass anything to do with this?

${ }^{1}$ Made up from New York State Syllabus with additions. 


\section{Age of Farm Animals}

Object. To tell the age of animals by the teeth. Material. A horse, cow, or sheep.

Directions. The age of the horse is estimated by the order in which the milk teeth are replaced by the permanent ones, and subsequent changes that take place in them (see pp. 34, 130, 223).

\section{Measuring Horses}

Object. To determine the proportion of the horse.

Materials. Two horses. Measure prepared as follows: a piece of board 18 inches long and 2 inches wide is nailed at right angles to a similar piece 4 feet long. Mark off the long piece in 1 inch lengths, beginning at the inside. Strap an ordinary carpenter's square so that it moves freely on the stick.

Directions. Take the measurements suggested on page 44 of two or more horses, if possible of different types.

\section{SCORING THE Horse}

Object. To compare light and heavy types of horses.

Materials. A heavy draft horse, a driving horse; a score card.

Directions. Carefully go over the animals, both heavy and light, and compare each point mentioned on the card. Compare the light horse with a greyhound and the heavy one with a bull dog. There are so many points to be considered in judging any animal that one who has not had any experience will omit some if he does not have a list of them, page 42 .

\section{Weighing the Horse}

Object. To determine the relative weight on front and hind limbs of the horse.

Materials. A horse; stationary scales.

Directions. Weigh the horse. Stand the horse with his front feet on the scales, his hind feet on the ground, weigh his fore- 
quarters. Stand with hind feet on the scales and the front on ground, weigh his hindquarters. What percentage of total weight are each of these? If possible, stand the animal so that his hind feet will be lower, and weigh the forequarters in this position. Lower the front feet and weigh the hindquarters. Does this change the percentage? Has this any bearing on an animal traveling uphill?

\section{SoundNESS}

Object. To learn to tell an unsound horse.

Materials. An unsound horse.

Directions. Carefully examine the animal and locate as many undesirable points as possible (see p. 38).

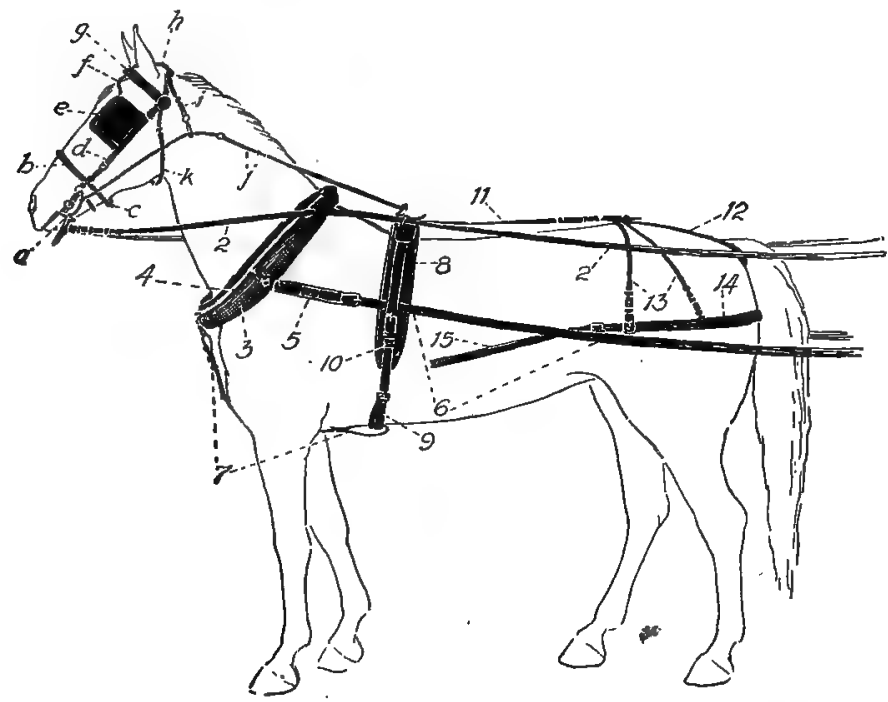

FIg. 140. - Parts of harness : 1 , bridle having the following pieces : $u$, bit; $b$, nose band; $c$, chin band; $d$, cheek straps; $e$, blinds; $f$, winker braces; $g$, brow band; $h$, crown band; $i$, gag swivel; $j$, side check; $k$, throat lateh; 2 , lines; 3 , collar; 4 , hames; 5 , hame tugs; 6 , traces 7 , martingale; 8 , saddle; 9 , girth; 10 , shaft tug; 11 , back strap ; 12 , crupper ; 13, hip strap; 14, breeching; 15 , holdback strap. 


\section{Harness and Harnessing}

Object. To learn the various parts of harness.

Materials. A set of harness.

Directions. Unbuckle and take the harness all apart. Note how each part is attached and where it comes from. Put together and see if you can get each part back in its proper place (Fig. 140).

\section{Splicing a Rope}

Object. To splice a rope.

Materials. A piece of five-eighths inch rope, and a marline spike which can be made from a block of hardwood.

Directions. "Untwist the strands of the rope end six to fifteen inches or more, depending on the size of the rope. Select as No. 1 the strand that is on the top of the rope and in the middle between

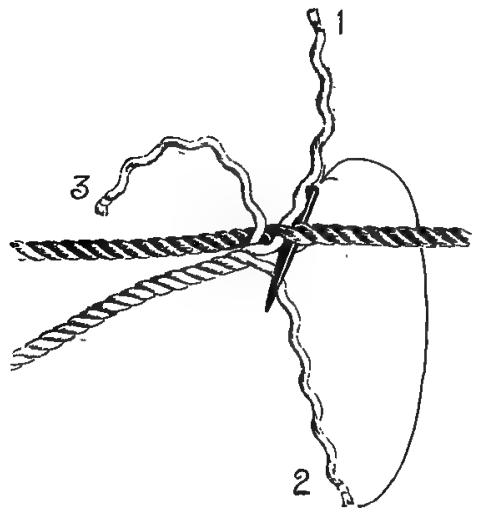

FIG. 141. - Side splicęrirst stage.

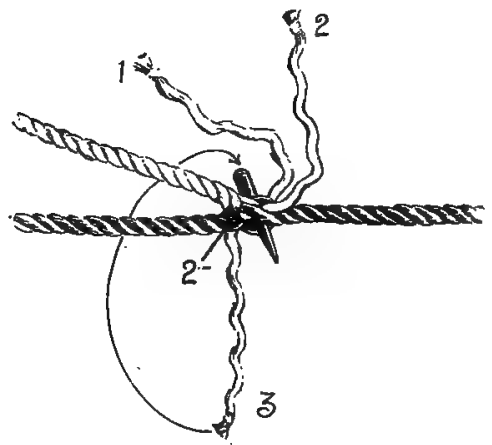

FIG. 142. - Side splice, second stage.

the other two strands. Raise a strand on the top of the solid rope and pass No. 1 under it diagonally to the right, as in Fig. 141. Pull it up securely. Turn the two ropes over to the position shown in Fig. 142. Raise the next strand on this side of the one first 
- raised and tuck No. 2 under it away from the body as in Fig. 142. When the marline spike is inserted for this tuck, it comes out where

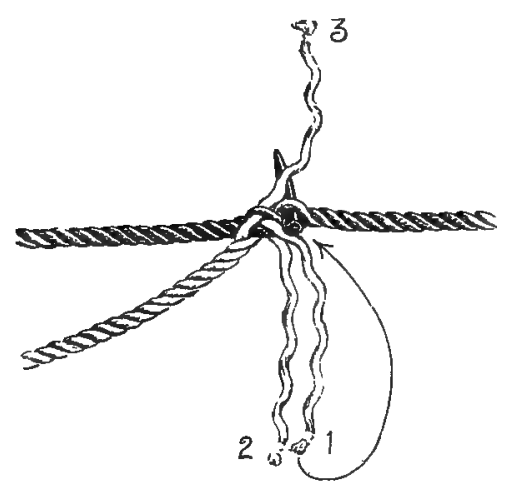

FIG. 143. - Side splice, third stage.

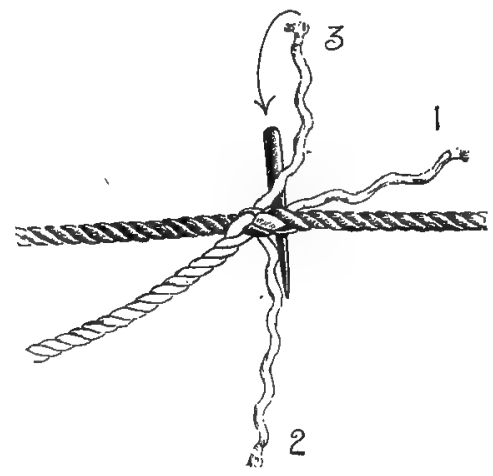

FIG. 144. - Side splice, fourth stage.

strand No. 1 went in, as shown in Fig. 141. Turn the ropes back to their original position (Fig. 143).

"Strand No. 3 is now to be tucked. This strand is inserted at the place where No. 1 comes through, as shown in Fig. 143 ; it comes out where No. 2 starts in, as indicated in Fig. 142, where the spike
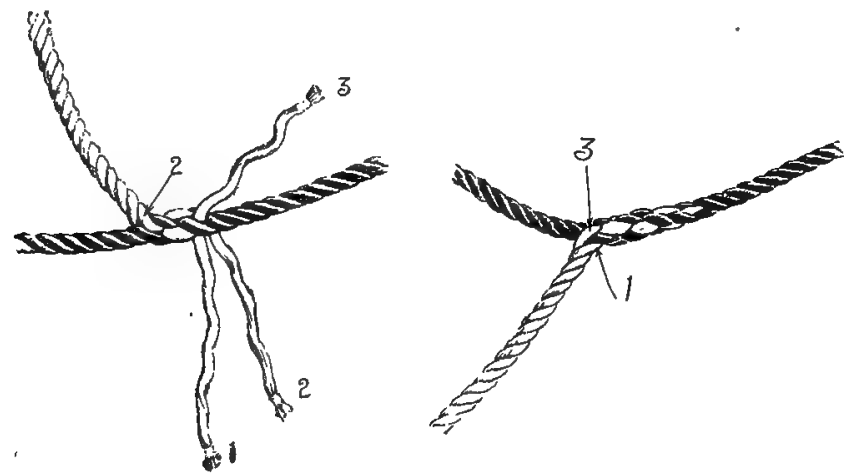

FIG. 145. - Side splice, fifth stage. FIG. 146. — Side splice completed. 
is shown inserted for tucking No. 3. Pull the splice up firmly and then proceed to splice the ends into the solid rope, as shown in Figs. 144 to 146 . Pound the splice and roll it under the foot." 1

\section{Rope Halter}

Object. To learn to make a rope halter.

Materials. A rope of the size and length called for in the table, p. 356, and a marline spike.

Directions. Measure from one end to $A$ (Fig. 147, 1) the distance given in the table, and with a lead pencil mark the point. From $A$ measure back toward the end the required distance to $B$ and mark the rope. Bend the rope at $A$ to form a bight, and lay it on the knees with the bend toward the right and the short rope away . from the body (see Fig. 147, 1). Raise the top strand of the rope at $B$ and pass the long end through under it away from the body, using the whole rope, as indicated by the arrow in Fig. 147, 1, and pull the rope through until $A$ is at the end of the loop as shown in
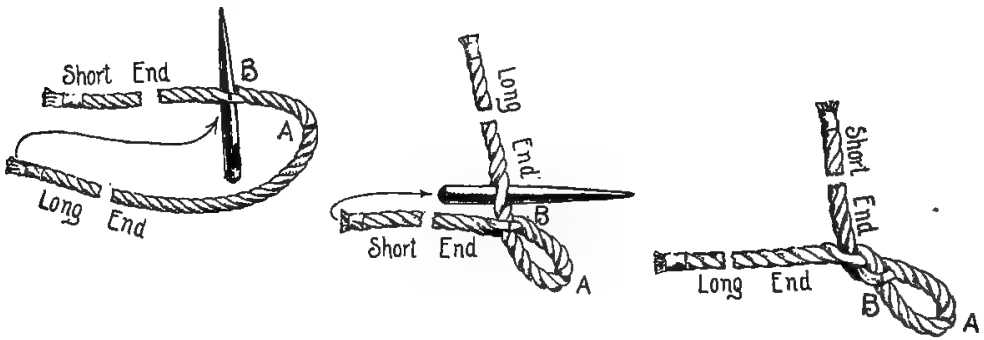

FIG. 147. - Rope halter. Forming the eye.

Fig. 147,2. Raise a strand on the top of the long end and pass the short end through under it from left to right, as indicated by the arrow in Fig. 147, 2, and pull up tightly as shown in Fig. 147, 3. From $B$ measure along the short end the distance given in the table to $C$, and from $B$ measure along the long end to $D$ (Fig. 148, 1).

${ }^{1}$ Cornelf Reading-Course Leaflet, Jan. 15, 1912. - H. W. RILEY. 

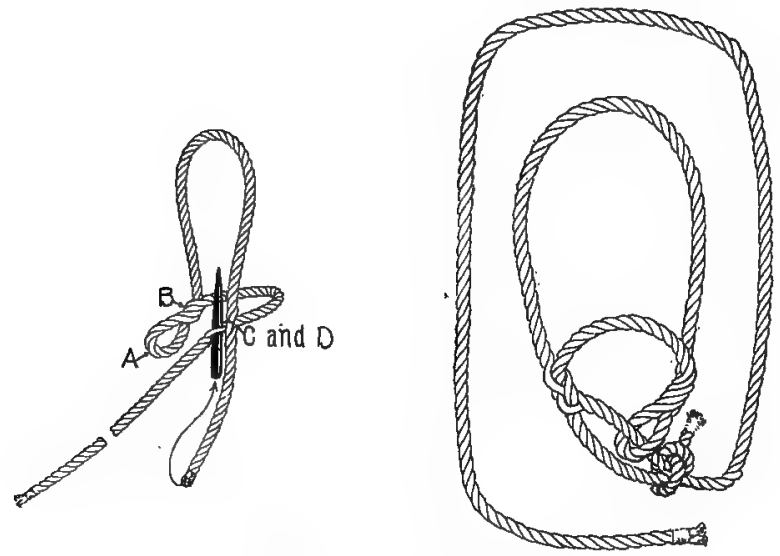

FIG. 148. - Rope halter. Loose guard loop type.

If the halter is to be of the guard loop type, as shown in Figs. 148,2 , and 149 , proceed as follows : form the halter over the knee, with the eye to the left, the short end over the knee for the head piece, the long end in front for the nose piece. At the mark $C$ on the short end raise the outside strand and pass the long end through from front to back up to the mark $D$, as in Fig. 148, 1. Just back of this crossing raise the outside strand of the long end and pass the short end through from below, as indicated by the arrow in Fig. 148, 1, and pull up tightly as in Fig. 147, 3.

Pass the long end through the eye and knot the short end, as in Fig. 148, 2, if the halter is to be of the loose guard loop type. If a standard guard loop halter is desired, whip the short end to the long one, as in Fig. 149.

To make a spliced halter, untwist the

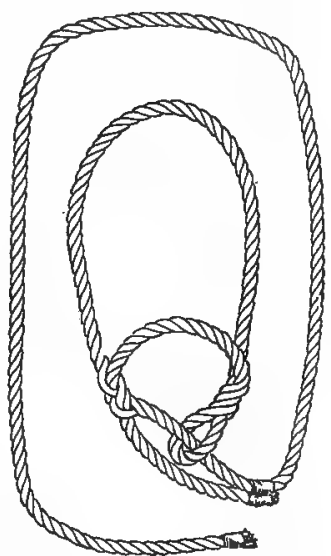

FIG. 149. - Rope halter. Standard guard loop type. 
strands of the short end down to the mark $C$. Form the halter over the knee, as described above, and as shown in Fig. 150, 1. Raise
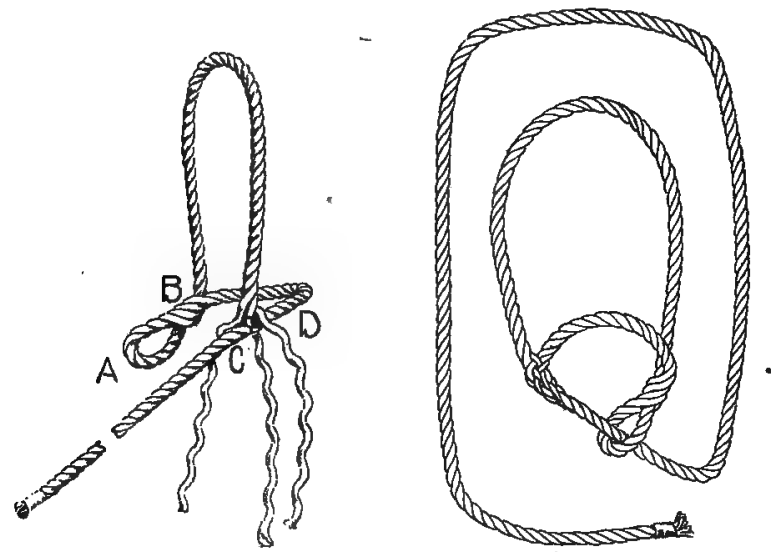

FIG. 150. - Rope halter. Spliced halter.

the outside strand of the long end at $D$, and pass downward under it the middle outside strand of the short end, pulling it down until

Approximate Dimensions for Rope Halters

\begin{tabular}{|c|c|c|c|c|c|c|c|c|c|c|}
\hline \multirow[b]{3}{*}{ TO BE USED FOR } & \multicolumn{4}{|c|}{ ROPE TO BE U\&ED } & \multicolumn{5}{|c|}{ Meastremente in Inches } & \multirow{3}{*}{$\begin{array}{l}\text { LENGTH } \\
\text { REMAIN- } \\
\text { ING } \\
\text { FOR } \\
\text { TIE } \\
\text { ROPE } \\
\text { (FEET) }\end{array}$} \\
\hline & \multirow[b]{2}{*}{$\begin{array}{l}\text { Di- } \\
\text { am- } \\
\text { eter } \\
\text { (In- } \\
\text { ches) }\end{array}$} & \multirow[b]{2}{*}{ Kind } & \multicolumn{2}{|c|}{ Total length for } & \multicolumn{2}{|c|}{ End to $A$} & \multirow[b]{2}{*}{$\begin{array}{c}\text { A } \\
\text { to } \\
B\end{array}$} & \multirow[b]{2}{*}{$\begin{array}{l}\text { B } \\
\text { to } \\
\text { C }\end{array}$} & \multirow[b]{2}{*}{$\begin{array}{l}\text { B } \\
\text { to } \\
\text { D }\end{array}$} & \\
\hline & & & $\begin{array}{l}\text { Stand- } \\
\text { ard } \\
\text { guard } \\
\text { or } \\
\text { spliced } \\
\text { type }\end{array}$ & $\begin{array}{c}\text { Loose } \\
\text { guard } \\
\text { type }\end{array}$ & $\begin{array}{l}\text { Stand- } \\
\text { ard } \\
\text { guard } \\
\text { or } \\
\text { spliced } \\
\text { type }\end{array}$ & $\begin{array}{c}\text { Loose } \\
\text { guard } \\
\text { type }\end{array}$ & & & & \\
\hline Sheep and small & & & Ft. Ins. & Ft. Ins. & & & & & & \\
\hline calves & $\frac{1}{1}$ & Cotton & 73 & 710 & 26 & 32 & $1 \frac{1}{2}$ & 18 & 11 & 4 \\
\hline Small cows . & $\frac{5}{8}$ & Manila & 112 & 120 & 46 & 56 & 3 & 34 & 12 & 6 \\
\hline $\begin{array}{l}\text { Average cows . } \\
\text { Horses, large }\end{array}$ & $\frac{5}{8}$ & Manila & 116 & 124 & 48 & 58 & 3 & 36 & 14 & 6 \\
\hline cows and bulls & $\frac{3}{4}$ & Manila & 120 & 130 & 53 & 64 & $3 \frac{1}{2}$ & 39 & 15 & 6 \\
\hline
\end{tabular}


mark $C$ is at the crossing, as shown in Fig. 150, 1. The strands should now be arranged exactly as shown in Fig. 141. Complete the splice as directed for the side splice and then pass the long end
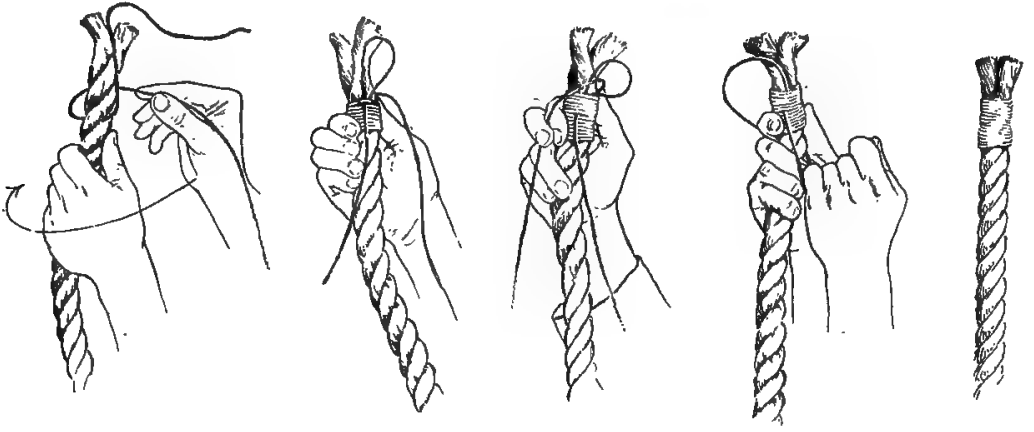

Fig. 151. - Whipping the end of a rope.

through the eye, as in Fig. 150,2. Finish the end by whipping (Fig. 151). ${ }^{1}$

\section{Plan of Horse Barn}

Object. To learn the general arrangement and space required in a horse barn.

Materiols. Drawing material.

Directions. Show ground plan, outside dimensions of barn, also dimensions and arrangement of stalls, feed room, harness room, and the like. Figure the cubic space for each animal.

\section{Mixing Feed}

Object. To study the physical condition of mixed feeds.

Materials. About 10 pounds of each of the following grains: corn, wheat, oats, wheat middlings, corn meal, wheat bran, oil meal, alfalfa meal, and meat scrap; magnifying glass; sçales; pails; shovel.

${ }^{1}$ Cornell Reading-Course Leaflet, Jan. 15, 1912.-H. W. Rruey. 
Directions. Weigh out the feeds in the formulas given below, mix them thoroughly, and observe carefully the following points: (1) bulk; (2) coarseness; (3) fiber content; (4) if ground feed, mix with water and note crumbliness or stickiness, and (5) palatability.

What does a quart of each food weigh?

A report of these observations on each sample should be made at the end of the practicum.

\section{SAMPLeS}

(1) $5 \mathrm{lb}$. cracked corn $5 \mathrm{lb}$. wheat

2 lb. oats

$\overline{12}$

(3) $1 \mathrm{lb}$. wheat middlings

$1 \mathrm{lb}$. corn meal

$4 \mathrm{lb}$. wheat bran

$1 \mathrm{lb}$. oil meal

$4 \mathrm{lb}$. alfalfa meal

1 lb. meat scrap

12

(5) $4 \mathrm{lb}$. wheat middlings

2 lb. corn meal

$1 \mathrm{lb}$. wheat bran
(2) 3 lb. cracked corn

3 lb. wheat

$6 \mathrm{lb}$. oats

$\overline{12}$

(4) $2 \mathrm{lb}$. corn meal

$2 \mathrm{lb}$. wheat bran

$2 \mathrm{lb}$. oil meal

2 lb. alfalfa meal

2 lb. meat scrap

$2 \mathrm{lb}$. wheat middlings

$\overline{12}$

$3 \mathrm{lb}$. oil meal

$1 \mathrm{lb}$. alfalfa meal

1 lb. meat scrap

12. HAYS

Object. To become familiar with the various hays used in feeding.

Materials. Few stalks of timothy, clover, alfalfa, and meadow hay, and a stalk of corn.

Directions. Examine each separately and closely. Note the leaves of each, the way the stalks branch, the stiffness of the stalk, and the like. Which leaves are the more easily broken or crushed, the timothy or the clover? Has this anything to do with the dust in the hay? May this not affect its quality? 


\section{Nutritive Ratio}

Object. To learn to balance rations.

Materials. None.

Directions. By "nutritive ratio" is meant the ratio which exists between the amount of digestible protein in a given feeding stuff, and the amount of digestible carbohydrates and ether extract it contains. It is computed as follows : the amount of digestible fat or ether extract is multiplied by $2 \frac{1}{4}$; the product added to the digestible carbohydrates, and the sum divided by the digestible protein. Calculate the nutritive ratio of the following foods : corn, oats, timothy, page 65 . See Table 6, page 388, for composition.

Calculate the ratio of the following ration :-

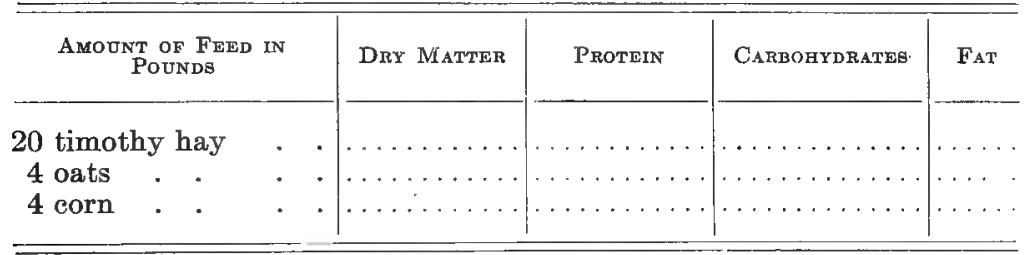

\section{Forming a Ration}

Object. To learn to form a ration from given feeds. Materials. None.

Directions. Form a ration, using any of the foods given below. It should contain 24 pounds of dry matter with a nutritive ratio of 1.6. Approximately one-third of the dry matter should be grain, page 66 .

\section{Choosing foods for a ration}

A food is purchased for the digestible material in it. The water and the indigestible material are like the "filler" in a fertilizer. Add the digestible protein, the digestible carbohydrates, and the 
digestible fat multiplied by $2 \frac{1}{4}$ in a food and the result will be a measure of the digestible material in that food. This sum is called the total nutriment of the food.

Divide the price per ton, which may be obtained from the local feed dealer, by the pounds of total nutriment in one ton. The result is the cost of one pound of total nutriment. The pounds of total nutriment in one ton of the common foods are found in column two of the table below. Put the price per ton of the foods available in column three and compute the cost of one pound of total nutriment in each. Choose for the ration, from the foods desirable from other standpoints, those foods which yield total nutriment the cheapest.

Common Foods Grotped according to the Protein Content

\begin{tabular}{|c|c|c|c|}
\hline Food & $\begin{array}{c}\text { Total } \\
\text { NUTRIMENT IN } \\
1 \text { TON. LABS. }\end{array}$ & Price per ton & $\begin{array}{l}\text { Cost of } 1 \text { LB. } \\
\text { OF TOTAL } \\
\text { NUTRIMENT }\end{array}$ \\
\hline \multicolumn{4}{|l|}{ Low Protein Group } \\
\hline Corn . . . . . . . . . . . . . . & 1686 & $\ldots \ldots \ldots$ & $\ldots \ldots \ldots$ \\
\hline Oats $\ldots \ldots \ldots \ldots \ldots$ & 1390 & $\ldots \ldots \ldots$ & $\ldots \ldots \ldots$ \\
\hline Wheat $\ldots \ldots \ldots \ldots \ldots \ldots$ & 1594 & $\ldots \ldots \ldots$ & $\ldots \ldots \ldots$ \\
\hline Rye ..................... & 1632 & $\cdots \ldots \ldots$ & $\ldots \ldots \ldots$ \\
\hline Barley . . . . . . . . . . . . . & 1546 & $\ldots \ldots \ldots$ & $\ldots \ldots \ldots$ \\
\hline Buckwheat . . . . . . . . . . & 1234 & $\ldots \ldots \ldots$ & $\ldots \ldots \ldots$ \\
\hline Corn and cob meal $\ldots \ldots \ldots \ldots$ & 1418 & $\ldots \ldots \ldots$ & $\ldots \ldots \ldots$ \\
\hline Hominy chop .............. & 1680 & $\cdots: \cdots$ & $\ldots \ldots \ldots$ \\
\hline Dried beet pulp . . . . . . . . . . & 1380 & $\ldots \ldots$ & $\cdots \cdots \cdots$ \\
\hline \multicolumn{4}{|l|}{ Medium Protein Group } \\
\hline Wheat bran & 1190 & $\cdots$ & $\ldots \ldots \ldots$ \\
\hline Mixed wheat feed .............. & 1376 & $\ldots$. & $\because \ldots \ldots \ldots$ \\
\hline Standard wheat middlings . . . . . . . & 1376 & $\cdots \cdots$ & $\ldots \ldots \ldots$ \\
\hline Flour wheat middlings $\ldots . . . .$. & 1594 & $\ldots \ldots \ldots$ & $\ldots \ldots \ldots$ \\
\hline Cotton seed feed . ........... & 1018 & $\ldots \ldots$ & $\ldots \ldots \ldots$ \\
\hline Buckwheat feed (shuck in) .. & 1274 & $\ldots \ldots \ldots$ & $\ldots \ldots \ldots$ \\
\hline Pea meal .... & 1402 & $\ldots \ldots$ & $\ldots \ldots \ldots$ \\
\hline Cull Beans. . . & 1518 & $\ldots \ldots \ldots$ & $\ldots \ldots \ldots$ \\
\hline
\end{tabular}




\begin{tabular}{|c|c|c|c|}
\hline Food & $\begin{array}{c}\text { Total } \\
\text { NUTRIMENT IN } \\
\text { I ToN. IBg. }\end{array}$ & Price per ToN & $\begin{array}{l}\text { Cost of } 1 \text { LB. } \\
\text { OF TOTAL } \\
\text { NUTRIMENT }\end{array}$ \\
\hline \multicolumn{4}{|l|}{ High Protein Group } \\
\hline Malt Sprouts. & 1390 & $\ldots \ldots \ldots$ & $\ldots \ldots \ldots$ \\
\hline Linseed oil meal . . . . . . . . . . . . & 1554 & $\ldots \ldots \ldots$ & $\ldots \ldots \ldots$ \\
\hline Cottonseed meal. . . . . . . . . . . & 1612 & $\ldots \ldots \ldots$ & $\ldots \ldots \ldots$ \\
\hline Gluten feed . . . . . . . . . . . . & 1612 & $\ldots \ldots \ldots$ & $\ldots \ldots \ldots$ \\
\hline Breever's dried grains . . . . . . . . . & 1314 & $\ldots \ldots \ldots$ & $\ldots \ldots \ldots$ \\
\hline Distiller's dried grains (corn) . . . . & 1772 & $\ldots \ldots \ldots$ & $\ldots \ldots \ldots$ \\
\hline Buckwheat middlings . . . . . . . . & 1478 & $\cdots$ & $\ldots \ldots \ldots$ \\
\hline \multicolumn{4}{|l|}{ Roughage } \\
\hline Timothy biay. & 962 & $\ldots \ldots \ldots$ & $\ldots \ldots \ldots$ \\
\hline Red clover hay . . & 980 & $\ldots \ldots \ldots$ & $\ldots \ldots \ldots$ \\
\hline Mixed hay ................. & 982 & $\ldots \ldots \ldots$ & $\cdots \cdots \cdots$ \\
\hline Alfalfa hay . . . . . . . . . . . . . . & 1098 & $\ldots \ldots \ldots$ & $\cdots \ldots \ldots$ \\
\hline Corn silage . . . . . . . . . . . . . & 344 & $\ldots \ldots \ldots$ & $\ldots \ldots \ldots$ \\
\hline Corn fodder (ears on) $\ldots \ldots \ldots \ldots$ & 796 & $\ldots \ldots \ldots$ & $\ldots \ldots \ldots$ \\
\hline Corn stalks (dry) $\ldots \ldots \ldots \ldots \ldots$ & 684 & $\ldots \ldots \ldots$ & $\cdots \cdots \cdots$ \\
\hline Mangels . . . . . . . . . . . . . . & 140 & $\ldots \ldots \ldots$ & $\cdots \cdots \cdots$ \\
\hline$\ldots \ldots \ldots \ldots$ & 192 & $\cdots \cdots \cdots$ & $\cdots \cdots \cdots$ \\
\hline
\end{tabular}

\section{Forming a Ration for a Horse}

Object. To learn to form a ration for a horse with given foods at stated prices.

Materials. None.

Directions. Form a ration for a 1000-pound work horse, using any of the foods in Exercise 14. The ration should contain 22 pounds of dry matter with a ratio of $1: 7$. Approximately one-half of the dry matter should be grain, and the bulk of the ration should not exceed 30 pounds. What is the cost of the ration at prices given?

\section{Measurinct Grain}

Object. To determine the number of bushels of grain in a bin. Materials. A half-bushel measure; a half bushel of the grain to be measured; a sack; a tape or rule; scales. 
Directions. Measure the length, width, and depth of the bin. Determine the number of cubic feet in the bin. Fill the half-bushel measure with grain from the bin and draw a straight edge over, leaving the grain even with the top. This is called "struck measure." Empty two of these measures into a sack and weigh, allowing for weight of the sack. There are 2150.42 cubic inches in a bushel. We now have three factors of a ratio to find the fourth. The cubic contents of a bushel, the weight of a bushel, and the cubic contents of the bin, to find the weight of grain in the bin. Divide the weight of grain thus obtained by the number of pounds in a bushel of the grain which you are measuring, to get the number of bushels in the bin.

How does this compare with the rule? which is as follows: find the cubic contents of the bin in feet and there will be .8 as many bushels as cubic feet.

\section{Measuring Hay}

Object. To determine the number of tons of hay in a stack or mow.

Materials. Tape measure.

Directions. Measure the length, width, and depth of the mow, and compute the number of cubic feet, and divide the product by 350 . This will give approximately the number of tons in a stack or mow. The estimate will be only approximate. It will vary with the quality and compactness of the hay.

\section{Measuring Silage}

Object. To determine the number of tons of silage in a silo. Materials. Tape measure.

Directions. Compute the cubic contents of the silo in feet, and multiply the product by 40 , as there are approximately 40 pounds to the cubic foot. To get the tons, divide by 2000 . This estimate 
will only be approximate, as the weight of silage varies with the depth below the surface, with the amount of water in silage, and with the diameter of the silo.

\section{Scoring the Dairy Cow}

Object. To compare good and poor dairy cows.

Materials. A good and a poor dairy cow ; a score-card.

Directions. With the score-card in hand very carefully go over the animals and compare each point mentioned on the card. Note the udders especially, page 132.

\section{Measuring Dairy Cows}

Object. To see if there is any relation between form and function in dairy cows.

Materials. A dairy herd. Measure as in Exercise 3.

Directions. Cows of a triple-wedge form are more desirable. To possess this form they must be much larger around the body just back of the hips and in front of the udder, than they are around the heart. Measure several good producing cows, and several poor producing. Average the front measurements of the good producers ; then the hind measurements ; do likewise for the poor producing. Is there a greater difference between the fore and hind measurements in the good cows than between the fore and hind measurements of the poor cows? Take measurements suggested on page 133 .

\section{Forming Ration for Dairy Cow}

object. To learn to form ration for a dairy cow with given foods at stated prices.

Materials. None.

Directions. Form a ration for a 1000-pound dairy cow, yielding 15 pounds of milk per day, using any of the foods in Exercise 14. The ration should contain 24 pounds of dry matter with a nutritive 
ratio of $1: 5.5$. Approximately one-third of the dry matter should be grain, one-third, should be silage, and one-third should be hay. What is the cost of the ration with foods at prices given?

\section{Cost of MrLK}

Object. To determine the cost of milk production.

Materials. Dairy herd and a pair of scales.

Directions. Weigh the food consumed by a cow and the milk she yields one day each month during the lactation period. Multiply the food consumed and the milk yield that day by the number of days in the month. Keep this record from month to month. On weigh days take a sample of the milk and test for butter fat (see Exercise 27). Calculate the pounds of fat given for the month. Calculate the cost of food each month, using prices obtained from the local grain dealer. You have the food consumed, its cost, the milk flow, and the butter fat by months.

\section{Removing Horns}

Object. To remove horns without injury to the animal.

Materials. A calf under three weeks of age; a stick of caustic potash ; a pair of shears.

Directions. See page 153.

\section{Plans for a Cow Barn}

Object. To learn the general arrangement and space required in a cow barn.

Materials. Drawing materials.

Directions. Show ground plan, outside dimensions of barn, including silo, also dimensions and arrangements of stalls, feed rooms, milk room, and the like. Estimate the cubic space for each animal. How much silage space would you provide for each animal? 


\section{Rough Anatiysis of Milk}

Object. To become familiar with the constituents of milk.

Materials. Milk, two-quart fruit jar, cheese cloth, beakers, rennet, funnels, filters, thermometer, platinum or porcelain evaporating dishes, test tubes.

Directions. Place about one pint of milk in a two quart fruit jar. Heat to about $70 \mathrm{~F}$. Shake vigorously until lumps of a yellowish substance collect. This substance is butter. Some fat will remain in the milk and cannot be collected. Remove the fat by straining through cheese cloth. The milk which runs through is called skimmed milk, or milk serum.

Empty the skimmed milk into a convenient dish, such as a beaker. Heat to about $90 \mathrm{~F}$. and add one cubic centimeter of rennet, stir thoroughly for about 15 to 20 seconds. Let stand for about 10 minutes. Strain through three thicknesses of cheese cloth. The white material which remains on the cloth is casein or curd. Filter some of the material which goes through the cheese cloth through filter paper, so that it is clear. Boil for about one minute about 25 cubic centimeters of the filtrate in a test tube or beaker. The white flocculent precipitate is albumen. Filter the solution through a filter paper. The albumen will collect on the filter. Collect the filtrate and evaporate it to dryness in a platinum or porcelain dish. The substance which remains is principally milk sugar.

\section{Qdalitative Determination oi Milk Ash}

Object. To determine the ash of milk qualitatively.

Materials. Milk, graduated pipette, nitric acid concentrated, platinum or porcelain evaporating dishes, water bath.

Directions. Place in a platinum or porcelain evaporating dish 18 cubic centimeters of milk, add 5 cubic centimeters of concentrated nitric acid. Heat to dryness in a water bath. Burn to a gray ash over a low flame. Do not burn too rapidly. 
27. Test for the Per Cent of Fat by the Babcock Method

Object. To find the per cent of fat in whole milk.

Materials. Babcock tester, whole milk bottles, 17.6 cubic centimeter pipette, 17.5 cubic centimeter acid measure, sulfuric acid, two samples of whole milk of different per cents of fat.

Directions. Test the two samples of whole milk as directed, page 161 .

\section{Babcock Test of Skimmed Milk}

Object. To find the per cent of fat in skimmed milk.

Materials. Same as used in testing whole milk, except skimmed milk bottles must-be substituted for whole milk bottles. Samples of skimmed milk.

Directions. Test skimmed milk as directed in the above exercise, paying special attention to using extra acid (20 c.c.) and whirling an extra length of time.

\section{Babcock Test of Cream}

Object. To find the per cent of fat in cream.

Materials. Babcock tester, 17.6 cubic centimeter pipette, 17.5 cubic centimeter acid measure, cream test bottles, balances for weighing cream, sulfuric acid.

Directions. Weigh 18 grams of cream into a cream test bottle and proceed as in whole milk.

In the äbsence of a balance and cream test bottle, cream may be tested by emptying a 17.6 cubic centimeter pipette of the sample into two or more test bottles, dividing the amount about equally between the bottles, and filling the pipette with water once or twice, which is then in turn divided about equally between the test bottles. The fat in the cream is found by adding the readings obtained in each of the bottles.

Since the weight of a given measurement of cream depends on 
the percentage of fat contained in the sample, the former method is the more accurate.

30. Babcock Test of Whole Milk using Different Amounts of AcID

Object. To show the effect of different amounts of acid upon the sample in performing the Babcock test.

Materials. Same as previously given for testing whole milk.

Directions. Test a sample of milk in the ordinary way. Retest the same as follows: after measuring 17.8 cubic centimeters of milk into the test bottle, add sulfuric acid up to the base of the bottle neck. Run the sample seven minutes and then add enough water to bring the fat into the graduated neck, 'and then run the sample one minute. Then read the per cent of fat and note the effect of the extra acid upon the fat column.

\section{Effect of Dirt in the Keeping Qualities of Milk}

Object. To show the relation of dirt and dust to the keeping quality of milk.

Materials. Some fresh milk, glass bottles or test tubes.

Directions. Mix the milk thoroughly and divide into several lots and treat as follows: (1) Set aside at room temperature; (2) add a few hairs taken from the body of a cow ; (3) add a piece of cobweb carrying dirt; (4) add some hay dust; (5) expose for a few minutes in an open pail to the dust of the room after sweeping; (6) add two or three small pieces of hay.

Shake the samples to incorporate the dirt in the milk and set aside at room temperature and note time of curdling and odor and appearance of curd. Do any show bubbles of gas due to the gasproducing bacteria? Compare with the untreated sample. Any changes in the milk are due to the bacteria carried on the added dirt. 


\section{Study of the Kegping Quality of Milk}

Object. To show the effect of temperature on the keeping quality of milk.

Materials. Some fresh milk, sterile test tubes plugged.with cotton or some small glass jars or bottles, and a thermometer.

Directions. Sterilize six jars or bottles by thoroughly scalding them in boiling water. Thoroughly mix the milk and put about equal amounts in each test tube or jar. Hold one at each of the following temperatures: $45^{\circ}, 50^{\circ}, 55^{\circ}, 60^{\circ}, 70^{\circ}, 80^{\circ}$ for several hours. This can be done by putting the test tubes or jars in dishes of water and using ice for holding the lower temperatures and hot water for the higher ones. The different temperatures should be maintained for from five to eight hours. At the end of this period, place all the jars at the same temperature and note the time when each curdles. It is well to get the milk from several sources and run different series of samples. If the samples are held at the different temperatures during the day, and placed together at the close of school, some may curdle during the following night, but most of them will curdle during the next day, and enough data can be obtained to show a difference in the keeping quality.

\section{Pasteurization of Milk}

Object. To show the effect of heating upon the keeping quality of milk.

Materials. Some fresh milk from a clean stable and some from a dirty stable and some clean test tubes with cotton plugs.

Directions. Fill seven test tubes from each sort of milk to a depth of $1 \frac{1}{2}$ to 2 inches. Place one of each at room temperature. Heat a dish of water to $145^{\circ} \mathrm{F}$. Place the remaining tubes of milk in the water, and remove as follows:-

One of each kind of milk at the end of 1 minute One of each kind of milk at the end of 2 minutes One of each kind of milk at the end of 3 minutes 
One of each kind of milk at the end of 5 minutes One of each kind of milk at the end of 10 minutes One of each kind of milk at the end of 15 minutes One of each kind of milk at the end of 20 minutes

Cool all samples to a temperature of $70^{\circ}$ and leave standing at room temperature and note the changes in appearance during the next two or three days. This exercise may be repeated, using lower and higher temperatures.

\section{Study of Milk Bacteria}

Object. Study of milk bacteria under the microscope.

Materials. A compound microscope, some microscopic slides, some Fuchsin or methyline blue staining solution, and several samples of milk at different ages and degrees of cleanliness.

Directions. With a small wire loop or other instrument smear a small drop of milk on a small area of glass slide, being sure to spread at least a part of it very thin. Allow this to dry in the air, and then cover the smeared milk with a few drops of the staining solution. Allow this to act about one minute and then wash off till no more stain is removed. Examine under the microscope. If the field is too darkly stained, it can be cleaned by putting on a few drops of alcohol and washing off immediately.

\section{Preparation of a Starter Culture for Butter Making}

Object. Study of a starter.

Materials. Six one-quart milk bottles, one kettle or similar utensil, 8 to 12 inches deep, one cup, some clean, tough paper, some twine, one thermometer, several teaspoons, one culture of starter, one quart of good skimmed or whole milk. (Starter cultures may be obtained from dealers, whose advertisements appear in the dairy journals.)

Directions. 1. Divide the one quart of milk evenly into three 2 в 
bottles. Tie some paper over the top to prevent contamination. (Bottle caps are good.)

2. Fill the kettle or similar utensil about one-half full of water.

3. Place the three bottles, each containing one-third of a quart of milk, in the water. (Bottles must not touch the bottom if heated over a fire). Support the bottles to prevent them from tipping over. Wire or cord may be used.

4. Place on a stove or over a gas jet, or insert a steam jet. (Heat slowly to prevent breaking the glass.) Hold above $180^{\circ} \mathrm{F}$. for 30 minutes (the boiling temperature is not too high).

5. Cool at $90^{\circ} \mathrm{F}$. (To prevent breaking the glass, lower the temperature rather slowly.) Shake the bottle often or the milk in the center of the bottle will not be cooled sufficiently. To cool, let a stream of cold water flow into the kettle.

6. Loosen the covers but do not remove them. Open carefully the package of starter. Now remove a bottle cover or cap sufficiently to introduce the starter. (Pour in one-third of the commercial culture in each bottle.) Shake to distribute the lactic acid bacteria throughout the pasteurized milk. In shaking, use rotary motion to prevent contamination by the milk coming in contact with the cover.

7. Incubate at about $70^{\circ}$ to $85^{\circ}$. The temperature must be fairly constant. When a soft, custard-like curd forms, the starter is ripe. This will require from 12 to 24 hours.

8. When ripe, set in cool place $\left(50^{\circ}\right.$ or below) until time for examination.

\section{Study of Starter made in Last Exercise}

Object. To become familiar with a good starter.

Materials. Starter made at last exercise.

Directions. Without shaking the starter, inspect the curd for gas pockets. It should be perfectly free from gas pockets which indicate the presence of undesirable bacteria. Now shake well 
and pour some into a cup. With a teaspoon, dip some out. First smell it, and then put the entire spoonful into the mouth. It should have a pleasant sour taste and smell. (Often the first propagation is not so pleasant as the later ones, because of the presence of the original medium, which is usually disagreeable.)

Repeat the above exercise with these two exceptions: first, in the inoculation, instead of using the commercial culture, transfer from 2 to 10 per cent of your own newly made starter. Second, incubate at about $60^{\circ}$ to $75^{\circ} \mathrm{F}$. instead of the higher temperature in above Exercise, for the bacteria are now more active. It requires experience to regulate the amount of inoculation and the temperature to ripen the starter in the given time.

\section{Cottage Cheese Making}

Object. To acquaint the pupil with one of the uses of skimmed milk and buttermilk.

Materials. Thermometer, milk pan holding about three quarts, one milk pail, one-half yard of white cotton cloth, one quart skimmed milk, one quart buttermilk and one ounce salt. Use clean thermometer.

Directions. Pour the skimmed milk and the buttermilk into the milk pan. Heat to $90^{\circ} \mathrm{F}$. and leave undisturbed till firmly coagulated. Attach the cotton cloth over the top of the pail so that it will serve as a strainer. Pour the coagulated milk on the strainer. After the watery portion (whey) has drained off, the "curd" is left. Remove the strainer with curd in it from the pail top and place it on a table or board. Sprinkle one ounce of salt over the curd and work it in by kneading the curd with the hands. The cheese is then ready for eating. When sold, it is molded into small cylindrical forms and wrapped in parchment paper and tinfoil.

Sandwich cheese is made by adding chopped nuts to the cottage curd while the salt is being worked in. 
38. Weight of Dressed Carcass by Measurement

object. To determine the weight of the carcass by measuring the animal while alive.

Materials. A cow or steer soon to be slaughtered and a tape measure.

Directions. Measure the animal at the girth, and the length from point of shoulder to the quarters. Multiply the square of the girth in feet by the length in feet and by .25 and the answer should be the dressed weight in imperial stones. There are 14 pounds in a stone.

\section{Cuts of Meat}

Object. To learn the various cuts of meat, their location, and market value.

Materials. Access to butcher shop containing carcasses of beef, pork, and mutton.

Directions. Note the sides or quarters of each class, beef, pork, and mutton, as they hang on the hook. Note where the carcasses have been halved and quartered; methods of telling young carcasses from old ones; and methods of telling a good one from a poor one. Ask the butcher to locate the various cuts. If convenient, have him cut a few slices from each part. Make a careful study of each and compare one with the other. Ask the price and approximately the weights of each cut. According to the diagram, page 142, figure total weight of euts, 1, 2, 4, 5, 6, 7, 8, 9, and 11, as given by the butcher. Also figure the total selling price according to the price he gives you. In like manner, figure total weight of cuts $3,10,12,13$ and 14, and total selling price. Compare the two groups. Work a similar problem in pork and mutton (pp. 230, 282).

\section{WooL}

Object. To learn the various classes of wool.

Materials. Wool from two or more breeds of sheep and a magnifying glass. 
Directions. Examine the samples closely with naked eye; then with a magnifying glass.

\section{Classification of Wool}

Clothing $\left\{\begin{array}{l}\text { Fine } \\ \text { Medium Staple } 2 \text { inches in length or less, or unsound } \\ \text { Coarse }\end{array}\right.$

Delaine $\left\{\begin{array}{l}\text { Fine } \\ \text { Medium }\end{array}\right.$ Staple 2 or 3 inches in length

Combing $\left\{\begin{array}{l}\text { Fine } \\ \text { Medium Staple over } 3 \text { inches long, strong, and sound } \\ \text { Coarse }\end{array}\right.$

Condition and Quality of Wool

1. Crimp $\left\{\begin{array}{l}\text { Fine or close } \\ \text { Open or wavy } \\ \text { Uniformity }\end{array}\right.$

2. Soundness. Take a small lock and stretch evenly and gently till unsoundness is shown by giving away at $\operatorname{som} \theta$ part. Note point at which unsoundness appears.

Suggestions for study. Write to a fine wool, a coarse wool, and a long wool sheep breeder for samples of wool. The names and addresses of these breeders can be obtained from advertisements in agricultural papers.

\section{Forming a Ration for Sheep}

Object. To learn to form a ration for sheep with given foods at stated prices.

Materials. None.

Directions. Form a ration for 10 sheep using any of the foods in Exercise 14. The ration should contain 25 pounds dry matter with a ration of $1: 6$. Approximately one-half of the dry matter should be grain. What is the cost of the ration at prices given? 


\section{Plan for Sheep Barn}

Object. To learn the general arrangement and space required in a sheep barn.

Materials.' Drawing materials.

Directions. Show ground plan and arrangement of feed racks and feed room and the like. Figure the cubic space for each animal. How does this compare with the horse and cow?

\section{Age, Sex, and Vitality of Fowls}

Object. To determine age, sex, and vitality in fowls.

Materials. Several fowls of different ages, sexes, and constitutional vigor; suitable coops in which they can be displayed.

Directions. Examine the different fowls and note their age, as indicated by the wrinkled condition of the face, length of toe nails, beak, and spurs, cleanliness of shank from scales or roughness (p. 307). It is difficult to distinguish the age of fowls over two years old. Often hens just completing their molt look like pullets, and pullets which lay and molt in the fall look like hens.

Observe that the sexes differ in kind and abundance of plumage, and shape of feathers, in size of comb and spur, and in voice.

Grade the specimens from strong to weak, page 324 .

\section{EG̈g and Meat Trpes}

Object. To learn to distinguish the characteristics of egg and meat type fowls.

Materials. Several specimens of egg, meat, and general purpose fowls ; suitable coops; obtain fowls of different size, shape, and temperament from the same breed.

Directions. Study each individual, noting length of body, depth and width of abdomen, width of pelvic bones, alertness, body condition, and vitality in the egg type fowl, as contrasted to the 
square, deep breast, larger size and more sluggish attitude of the meat fowl.

\section{Making Materials for killing Chicken Lice}

Object. The preparation of a powder and a liquid for killing lice and mites.

Materials. One-fourth pint crude carbolic acid, three-fourths pint gasoline, and two and one-half pounds of plaster of paris or a multiple of these amounts, also one pint crude carbolic acid and three pints kerosene or a multiple quantity. One pan, one pail, mixing ladle, one mosquito mesh wire screen.

Directions. For the powder, mix the carbolic acid and gasoline together thoroughly. Sprinkle this mixture on the plaster of paris and stir until the whole become a homogeneous pinkish brown mixture. Spread out thin on paper until dry, screen and make fluffy, then box it for future use.

For the liquid lice killer, mix the crude carbolic acid with the kerosene in the formula of 1 to 3. Apply as soon as possible, preferably in the form of a fine spray.

\section{Killing Chicken Lice}

Object. To apply lice powders and liquid lice killers.

Materials. Access to a poultry house and flock. A good supply of both the lice powder and the liquid lice killer; a foot pump and pail or hand force pump; a large box with door at one end and at top; shovel; and several empty baking powder cans.

Directions. Quietly drive the fowls into the box, preferably by putting the open door of the box on the outside of the house just in front of the exit. Clean off the nests and droppings boards, and if the pen be badly infested, remove the litter. Thoroughly spray the roosts, droppings platform, nests, and wall near the roosts with the liquid. Take care to force the liquid into all crevices and cracks. 
If the house is badly infested, also spray the floor and entire wall area. Drive several nail holes into the top of the baking powder can and use it to shake the powder into the feathers. Thoroughly dust each fowl with the powder. One student should hold the fowl head downward and legs spread apart while another shakes the powder into the feathers, and with his free hand works it into the skin.

Every fowl should be treated. In order to kill the lice or mites which hatch out after the first application, a second should be made 10 days later.

\section{Poultry Houses}

Object. To make a working drawing of a poultry house for laying fowls.

Materials. Drawing paper; drawing board; scale rule; compasses; hard pencil.

Directions. Make a working drawing (showing only the important details) of a poultry house.

1. Cross-section view showing roosts, nests, wall, and floor construction and dimensions.

2. Front view showing windows, etc., and dimensions.

3. Ground plan showing interior arrangement.

4. Estimate square feet of floor space, cubic feet of air space, number of square feet of floor to each square foot of glass area, number of square feet of floor to each square foot of cloth area (p. 340).

\section{Coop For HeN with Chicks}

Object. To make a box coop with covered run for hens with chicks.

Materials. Hammer, nails, saw, square, one box at least 2 feet on each side and 18 inches deep, extra matched lumber and small pieces to use as cleats, wire or lath for the covered run.

Directions. Remove the top of the box. Saw diagonally through 
the heavy end boards from the top corner to a point 6 inches lower at the rear. Remove the top rear board to the level. Saw enough of the match boards a proper length, so that they will entirely cover this top opening and allow for small eaves. Fasten these boards together with cleats, making the lower cleat fit loosely against the rear side of the box. This will hold the cover in place and allow it to be removed at will. Make an opening in the lower front side in which to place a 7 inch $\times 9$ inch window glass. Fasten grooved guides below and above this opening to fit the window sash and allow it to be pushed open or shut. Bore four 1 inch holes in the front side just above the window. Make a convenient sized frame run and cover with fine mesh wire or cleats.

\section{Feed-Hoppers for Poultry}

Object. To make a force feed-hopper.

Materials. Hammer, crosscut and rip saws, pair of wire clippers, 2 pair light hinges, 1 pound $8 d$. nails, 2 hooks and eyes, 15 feet of No. 8 wire, 1 piece tin 6 inches wide and 5 feet long, 50 feet square-planed and matched lumber.

Directions. Square the ends of the 10 inch board and saw through the middle at a $45^{\circ}$ angle to give the bevel at the top. Fasten cleats on these ends extending from 1 inch inside the lower corner of the beveled end to within 3 inches of the bottom end and 6 inches of the front. Lay these ends on the floor 5 feet apart, front edge up. In this position nail the front boards to these cleats. Next, fasten a 5 inch board across the front at the bottom. Drive pieces of wire 8 inches long, $\frac{1}{2}$ inch into this bottom board 2 inches apart. Bend these wires back against the body of the hopper and fasten with a small staple. A door to close the fowls away from the feed can now be made the size of this area and hinged above the wires. Next, nail a board across the top at the back and hinge a door to this board, covering the rest of the top (Fig. 139). The hopper is now ready to be hooked to the side 
wall of the poultry house, resting on the floor of the pen or on a platform 1 foot above the floor and 18 inches wide. The tin is bent and securely fastened to the side of the wall and to the platform.

\section{Structure of the EgG}

Object. To study the structure of an egg.

Materials. One lens, and facilities for boiling eggs. Each pupil should be supplied with two eggs, if possible, one with a light shell, the other with a dark shell ; two saucers; one drawing pencil ; one box of colored lead-pencils; a knife.

An egg-tester can be made by placing a lamp in a box with a hole, slightly smaller than the egg, cut through the side. Or, the egg may be held up to a similar hole in the curtain of a darkened room. In either case, look through the egg toward the light.

1. Strength of the egg shell. - Let the student hold a hard-shelled egg between the clasped hands, the ends of the egg in the hollow of the hand, and try to break it.

Observe the great strength of the shell, due to the arrangement of the particles in an arch similar to the stones or bricks in the arch of a bridge.

2. The contents of an uncooked egg. - (a) Break a fresh, uncooked egg in a saucer by separating the shell in the middle.

Observe the "germinal disk," which appears as a light-colored spot usually to be found on the upper surface of the yolk.

The germinal disk contains the life principle of the egg. Being on the upper surface, it remains in close contact with the source of heat during natural incubation.

(b) Note the "chalaza," or the whitish cords of denser albumen on the sides of the yolk toward either end of the egg. These cords of denser albumen serve to keep the yolk properly suspended within the albumen. Thus the chick, which develops on the upper surface of the yolk, is protected from injury, if, through rough handling, it should come in contact with the shell. 
(c) Note the transparent, watery appearance of the albumen (white of the egg).

The albumen supplies in liquid form the food by which the chick grows within the shell.

(d) Examine the shell and notice the air-space usually found near the large end. Observe the two tough membranes best seen at the air-space where the membranes separate.

The air-space furnishes a readily available supply of fresh air to the embryo chick. The two membranes prevent the too rapid

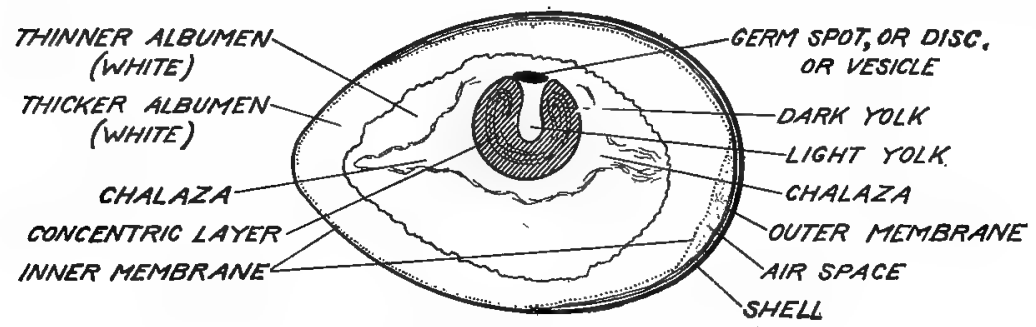

Frg. 152. - Section of an egg.

evaporation of moisture through the pores of the shell, but allow oxygen to enter the egg and carbon dioxid to pass out.

(e) By placing a section of the shell under the lens, indentations or pores in the shell may be observed.

These thinner parts permit the gases to pass through the shell more readily. If the pores of the shell are closed by oil, varnish, dirt, or broken egg, the chick will be smothered.

(f) Note the pigment of the shell, which gives to each egg its characteristic color.

Observe how the first eggs laid for a brood are more pronounced in color, and how the color pigment decreases with each egg that is laid, due to exhaustion of the supply.

3. The structure of a boiled egg. - Crack the large end of a hard-boiled egg carefully. Remove the shell, piece by piece, to avoid tearing the shell membrane. 
(a) Observe the air-space and the two membranes, which are separated with difficulty. Note that the outer membrane is the thicker and tougher.

(b) Cut the egg lengthwise through the middle. Observe the lighter-colored, flask-shaped center of the yolk, and the darker yolk arranged around it in concentric layers. Note the "germinal vesicle," or "germinal disk" at the upper part of the light yolk. Observe that the yolk is at one side and not in the center of the white of the egg. Note also that the germinal disk is on the upper side of the yolk. This is because the yolk is lighter in weight than the albumen and hence floats. The germinal disk on the surface of the white yolk is lighter than the dark yolk.

Snyder gives the chemical composition of the dry substance of the inside of the egg as : -

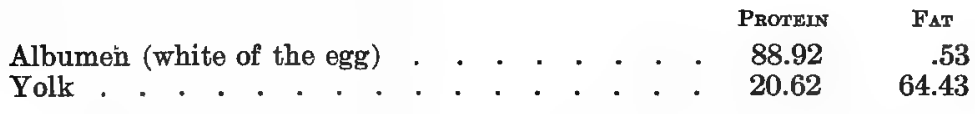

It will be seen that there is a large amount of fat in the yolk and almost no fat in the albumen. Fat is lighter than albumen, hence rises to the surface. This may be observed in practice by holding a fresh egg in front of an egg-tester and noting the tendency of the yolk to float upward.

This tendency of the yolk to float to the surface makes it necessary to turn eggs frequently when they are kept for hatching, otherwise the yolk will rise until the germinal disk comes in contact with the shell membrane. It will then become dry by evaporation and adhere to the membrane. If the egg is then turned the germ will be killed.

4. Make a drawing of the longitudinal section of the egg, showing: (a) The shell and its pores. (b) The two shell membranes turned back from the shell. (c) The air-space. (d) The three layers of albumen. (e) The vitelline membrane surrounding the yolk. $(f)$ The vitellus contained within the vitelline membrane. 
(g) The white yolk and the dark yolk showing its concentric layers. (h) The germinal disk. (i) The chalaza ("hammock cords").

\section{Preserving Eggs}

Object. To preserve eggs.

Materials. One pint " $\mathrm{N}$ " grade silicate of soda (waterglass); one two-gallon earthen jar; several dozen of fresh eggs.

Directions. Select clean, unwashed eggs. Wash out the jar in boiling hot water. Fill the jar with the eggs to within 2 inches of the top. Dilute the waterglass in nine times its bulk of water. Pour this mixture into the jar of eggs until all of the eggs are well covered. Cover the eggs with a plate to keep them below the level of the waterglass. Cover the jar and set in a cool cellar. Visit the jar every month to replace the water which has been lost through evaporation. 


\section{PART II \\ AGRICULTURAL LIBRARY}

The school should secure a complete set of the Farmers' Bulletins of the United States Department of Agriculture. These may be obtained from the Congressman of the district or by writing to the Secretary of Agriculture, Washington, D.C.

Write to your Congressman for such copies of the Yearbook of the Department of Agriculture as he may have for distribution, stating that they are for the school library.

Write to your State Experiment Station for copies of available bulletins and reports, and ask to be placed upon the mailing list.

Write to the State Board of Agriculture, asking whether it has publications for distribution.

Copies of a few good farm papers and country-life magazines are desirable for the reading-table.

The following books are recommended as among the best for Agricultural reference :-

Feeds and Feeding, by W. A. Henry, Madison, Wis.

Types and Breeds of Farm Animals, C. S. Plumb, Columbus, 0.

Breeding Farm Animals, F. R. Marshall, Columbus, O.

Physics of Agriculture, F. H. King, Madison, Wis.

The Cereals in America, T. F. Hunt, State College, Penn.

The Principles of Vegetable-Gardening, L. H. Bailey, Ithaca; N.Y.

The Principles of Fruit-Growing, L. H. Bailey, Ithaca, N.Y.

Principles of Soil Management, Lyon and Fippen, Ithaca, N.Y. 


\section{PART III}

\section{ADDRESSES OF AGRICULTURAL COLLEGES AND EXPERI- MENT STATIONS AND THE UNITED STATES DEPART- MENT OF AGRICULTURE}

When not otherwise indicated, the college and experiment station are at the same place. Any letter addressed to the "Agricultural College " or " Experiment Station," with proper post-office address will reach the institution.

Alabama -

College of Agriculture and Experiment Station, Auburn.

Canebrake Station, Uniontown.

Tuskegee Station, Tuskegee.

Alaska - Sitka.

Arizona - Tucson.

Arkansas - Fayetteville.

California - Berkeley.

Colorado - Fort Collins.

Connecticut -

State Station, New Haven.

Agricultural College and Storrs

Experiment Station - Storrs.

Delaware - Newark.

Florida - Gainesville.

Georgia - Experiment.

Hawaii -

Federal Station - Honolulu.

Sugar Planters' Station - Honolulu.

Idaho - Moscow.

Illinois - Urbana.

Indiana - Lafayette.

Iowa - Ames.

Kansas - Manhattan.

Kentucky - Lexington.

Louisiana - Baton Rouge.

Maine - Orono.

Maryland - College Park.

Massachusetts - Amherst.

Michigan - East Lansing.
Minnesota - St. Anthony Park, St. Paul.

Mississippi - Agricultural College.

Missouri -

College Station - Columbia.

Fruit Station-Mountain Grove.

Montana - Bozeman.

Nebraska - Lincoln.

Nevada - Reno.

Now Hamsphire - Durham.

New Jersey - New Brunswick.

New Mexico - Agricultural College.

New York -

State Station - Geneva.

College of Agriculture and

Cornell Experiment Station Ithaca.

North Carolina -

College Station - West Raleigh. State Station - Raleigh.

North Dakota - Agricultural College.

Ohio -

Experiment Station - Wooster.

College of Agriculture - Columbus.

Oklahoma - Stillwater.

Oregon - Corvallis.

Pennsylvania - State College.

Porto Rico - Mayaguez.

Rhode Island - Kingston. 
South Carolina - Clemson College. Virginia - Blacksburg.

South Dakota - Brookings.

Tennessee - Knoxville.

Texas - College Station.

Utah - Logan.

Washington - Pullman.

West Virginia - Morgantown.

Wisconsin - Madison.

Wyoming - Laramie.

Vermont - Burlington.

The United States Department of Agriculture is located at Washington, D.C. One may address the Secretary of Agriculture or write to one of the Divisions of the Department. The most important ones are as follows :-

Weather Bureau.

Bureau of Animal Industry.

Bureau of Plant Industry.

Forest Service.

Bureau of Chemistry.

Bureau of Soils.
Bureau of Entomology.

Bureau of Biological Survey.

Division of Publications.

Bureau of Statistics.

Office of Experiment Stations.

Office of Public Roads.

The most important addresses in Canada are :-

Dominion Department of Agricul- Agricultural.College, St. Anne de ture, Ottawa.

Ontario Agricultural College, Agricultural College, Winnipeg. Guelph. 


\section{PART IV}

AVERAGE WEIGHTS OF FEEDING STUFFS

As a rule under average farm conditions, it is not practicable to weigh each mess of food, nor is it necessary, as measuring is sufficiently accurate. The food from the measure should be weighed a few times at the beginning. To aid in approximating the weight of the various foods, the following table of weights and measures is quoted from Farmers' Bulletin No. 222 :

Average Weights of Different Feeding Stuffs

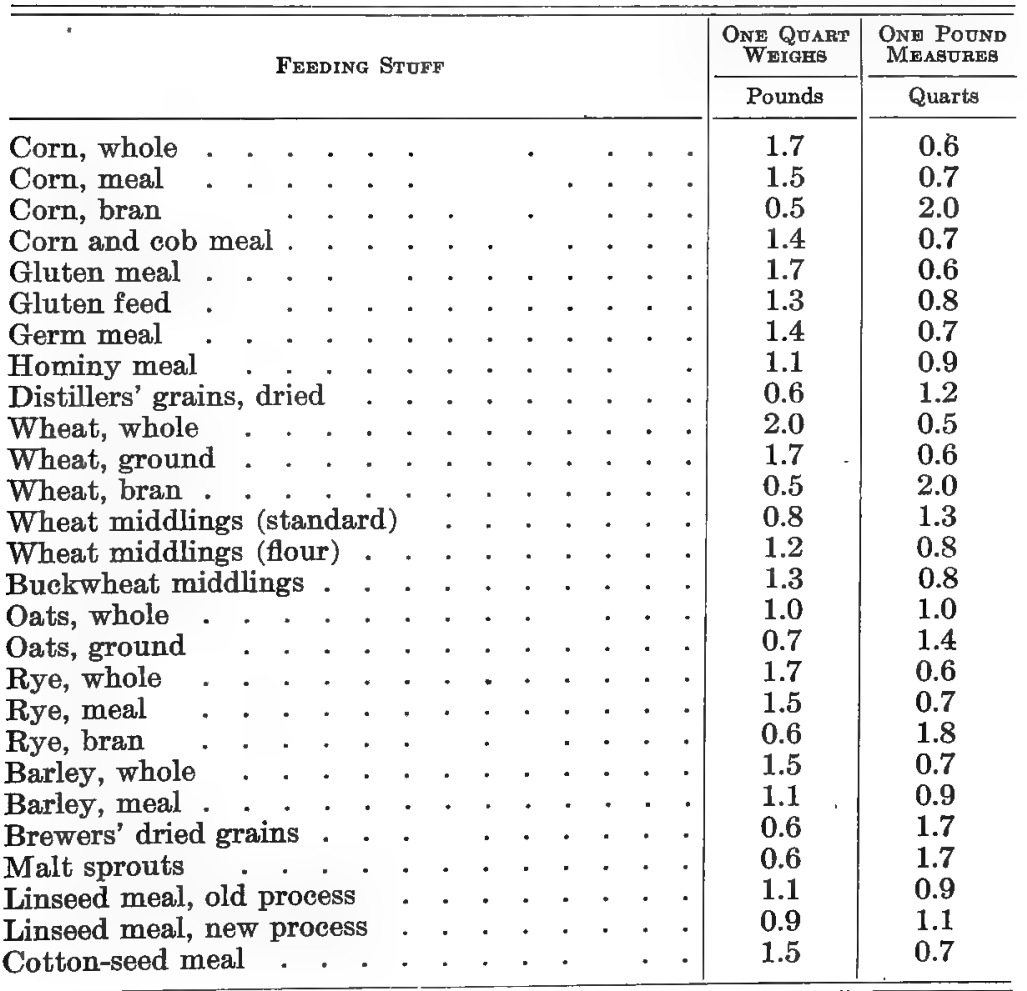




\section{PART V}

\section{ENERGY VALUES OF FEEDING STUFFS}

In calculating a ration for any class of farm animals on the energy basis; the energy value of each food must be known. The following table is from Farmers' Bulletin No. 346, United States Department of Agriculture.

Dry Matter, Digestible Protein, and Energy Valogs per 100 Podnds

\begin{tabular}{|c|c|c|c|c|c|c|c|c|}
\hline \multicolumn{6}{|c|}{ Femding Stofy } & $\begin{array}{c}\text { Total DRy } \\
\text { Matter }\end{array}$ & $\begin{array}{c}\text { Digestible } \\
\text { Protein }\end{array}$ & ENERGY VALUE \\
\hline \multicolumn{6}{|c|}{ Green fodder and silage: } & Pounds & Pounds & Therms \\
\hline Alfalfa . . . & 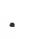 & . & & . & $\cdot \quad \cdot$ & 28.2 & 2.50 & 12.45 \\
\hline Clover - crimso & $n$ & . & • & & $\cdot$. & 19.1 & 2.19 & 11.30 \\
\hline Clover - red & & . & . & . & - & 29.2 & 2.21 & 16.17 \\
\hline Corn fodder $-\mathrm{g}$ & ree & & & . & & 20.7 & .41 & 12.44 \\
\hline Corn silage & . & . . & . & . &.$\quad \cdot$ & 25.6 & 1.21 & 16.56 \\
\hline Hungarian grass & & . & . & . &. & 28.9 & 1.33 & 14.76 \\
\hline Rape . . . & . & - & & . & $\cdot \quad \cdot$ & 14.3 & 2.16 & 11.43 \\
\hline Rye . . . & & & & . & . & 23.4 & 1.44 & 11.63 \\
\hline Timothy . . & & & • & - & $\cdot$ & 38.4 & 1.04 & 19.08 \\
\hline \multicolumn{9}{|c|}{ Hay and dry coarse fodders: } \\
\hline Alfalfa hay . & . & - & . & . &.$\quad$. & 91.6 & 6.93 & 34.41 \\
\hline Clover hay - re & & - & $\therefore$ & . & & 84.7 & 5.41 & 34.74 \\
\hline Corn forage, fiel & $\mathrm{d}$ c & ured & & . &.$\quad$. & 57.8 & 2.13 & 30.53 \\
\hline Corn stover & - & - & - & . & $\cdot \quad \cdot$ & 59.5 & 1.80 & 26.53 \\
\hline Cowpea hay . & . & . & . & . &.$\quad$. & 89.3 & 8.57 & 42.76 \\
\hline Hungarian hay & . & - & . & . &.$\quad$. & 92.3 & 3.00 & 44.03 \\
\hline Oat hay . & . & . & $\cdot$ & $\cdot$ & . $\quad$. & 84.0 & 2.59 & 36.97 \\
\hline Soybean hay & . & . & - & . & $\cdot \quad$. & 88.7 & 7.68 & 38.65 \\
\hline Timothy hay & 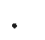 & . & . & . &.$\quad \cdot$ & 86.8 & 2.05 & 33.56 \\
\hline \multicolumn{9}{|l|}{ Straws: } \\
\hline Oat straw & ${ }^{\circ}$ & - & ${ }^{\circ}$ & - & . & 90.8 & 1.09 & 21.21 \\
\hline Rye straw & . & . & - & - & & 92.9 & .63 & 20.87 \\
\hline Wheat straw & . & . & . & . & .. & 90.4 & .37 & 16.56 \\
\hline \multicolumn{9}{|c|}{ Roots and tubers : } \\
\hline Carrots * : & $\cdot$ & - & - & . & - & 11.4 & .37 & 7.82 \\
\hline Mangel-wurzels & , & . $\quad$. & . & . & $\cdot$ & 9.1 & .14 & 4.62 \\
\hline
\end{tabular}


Dry Matter, Digestible Protein, and Energy Values peir 100 Pounds

Continued

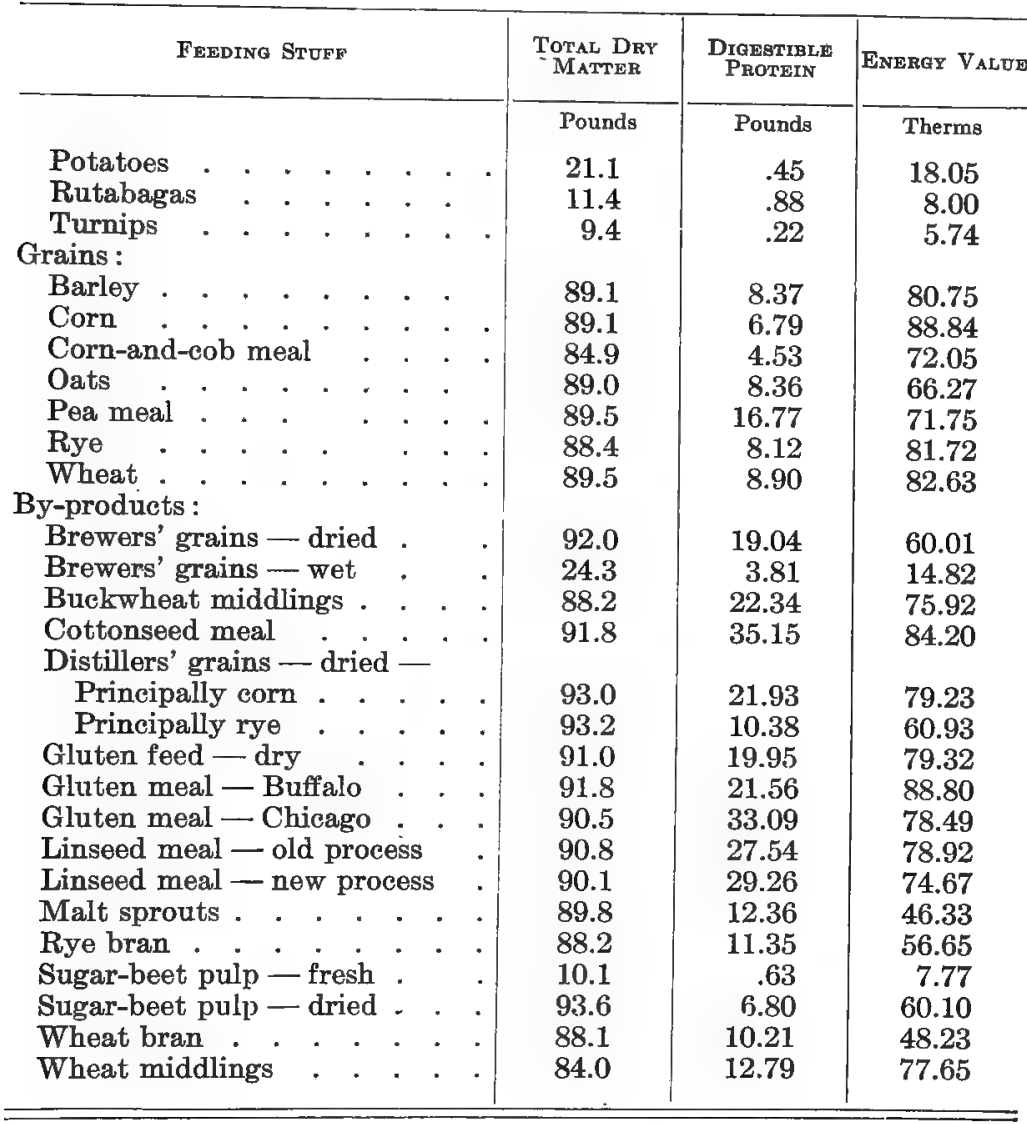




\section{PART VI \\ DIGESTIBLE NUTRIENTS IN FEEDING STUFFS}

In calculating a ration for any class of farm animals, the digestible nutrients of the foods must be known, as it is the digestible part only that is of use to the animal. The following table from Henry's "Feeds and Feeding," eleventh edition, gives a very complete list of American feeding stuffs and their digestible nutrients as well as the fertilizing constituents :-

Average Digestible Nutrients and Fertilizing Constituents

\begin{tabular}{|c|c|c|c|c|c|c|c|c|c|c|c|}
\hline \multirow{2}{*}{\multicolumn{5}{|c|}{ Name of FEed }} & \multirow{2}{*}{$\begin{array}{c}\text { TotaL } \\
\text { DRY } \\
\text { MAT- } \\
\text { TER } \\
\text { IN } 100 \\
\text { LBS. }\end{array}$} & \multicolumn{3}{|c|}{$\begin{array}{l}\text { Digegtible NUTRIENTs } \\
\text { IN } 100 \text { LBS. }\end{array}$} & \multicolumn{3}{|c|}{$\begin{array}{l}\text { Fertulzing Congtipd- } \\
\text { ents in } 1000 \text { Lise. }\end{array}$} \\
\hline & & & & & & $\begin{array}{c}\text { Crude } \\
\text { Protein }\end{array}$ & $\begin{array}{l}\text { Car- } \\
\text { bohy- } \\
\text { drates }\end{array}$ & Fat & $\begin{array}{l}\text { Nitro- } \\
\text { gen }\end{array}$ & $\begin{array}{l}\text { Phos- } \\
\text { phoric } \\
\text { Acid }\end{array}$ & Potagh \\
\hline $\begin{array}{r}\text { Concentro } \\
\text { Grains, seeds, and }\end{array}$ & the & ir ps & erts & & Lbs. & Lbs. & Lbs. & Lbs. & Lbs. & Lbs. & Lbs. \\
\hline Dent corn . & . & & & & .89 .4 & 7.8 & 66.8 & 4.3 & 16.5 & 7.1 & 5.7 \\
\hline Flint corn . & & & 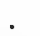 & & 88.7 & 8.0 & 66.2 & 4.3 & 16.8 & 7.1 & 5.7 \\
\hline Sweet corn & & & & & 91.2 & 8.8 & 63.7 & 7.0 & 18.6 & 7.1 & 5.7 \\
\hline Corn meal. & & & & & 85.0 & 6.1 & 64.3 & 3.5 & 14.7 & 6.3 & 4.7 \\
\hline Corn cob . & & 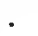 & 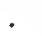 & . & 89.3 & 0.5 & 44.8 & & 3.9 & 0.6 & 6.0 \\
\hline Corn-and-cob m & eal & & & & 84.9 & 4.4 & 60.0 & 2.9 & 13.6 & 5.7 & 4.7 \\
\hline Gluten meal & & & & & 90.5 & 29.7 & 42.5 & 6.1 & 54.8 & 3.3 & 0.5 \\
\hline Gluten feed & $0^{\circ}$ & & & & 90.8 & 21.3 & 52.8 & 2.9 & 40.0 & 3.7 & 0.4 \\
\hline Hominy feed (cl & op & & & & 90.4 & 6.8 & 60.5 & 7.4 & 16.8 & 9.8 & 4.9 \\
\hline Germ oil meal & . & 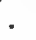 & 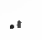 & 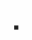 & 91.4 & 15.8 & 38.8 & 10.8 & 34.7 & 3.9 & 2.1 \\
\hline Corn bran . & . & & & & 90.6 & 6.0 & 52.5 & 4.8 & 17.9 & 10.1 & 6.2 \\
\hline Wheat . & . & . & & & 89.5 & 8.8 & 67.5 & 1.5 & 19.0 & 5.5 & 8.7 \\
\hline High grade flour & & & & & 87.6 & 10.6 & 65.1 & 1.0 & 19.2 & 5.7 & 5.4 \\
\hline Red dog flour & & & & & 90.1 & 16.2 & 57.0 & 3.4 & 29.4 & & \\
\hline $\begin{array}{l}\text { Flour wheat mic } \\
\text { Standard wheat }\end{array}$ & $\begin{array}{c}\mathrm{dli} \\
\mathrm{mi}\end{array}$ & $\begin{array}{l}\text { ngs } \\
\text { dd }\end{array}$ & ling & $\dot{g}$ & 90.0 & 16.9 & 53.6 & 4.1 & 30.7 & 12.2 & 9.6 \\
\hline (shorts) & . & - & 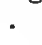 & 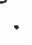 & 88.8 & 13.0 & 45.7 & 4.5 & 27.0 & 26.3 & 15.3 \\
\hline
\end{tabular}


Average Digestible Nutrients and Fertilizing Constitumats

Continued

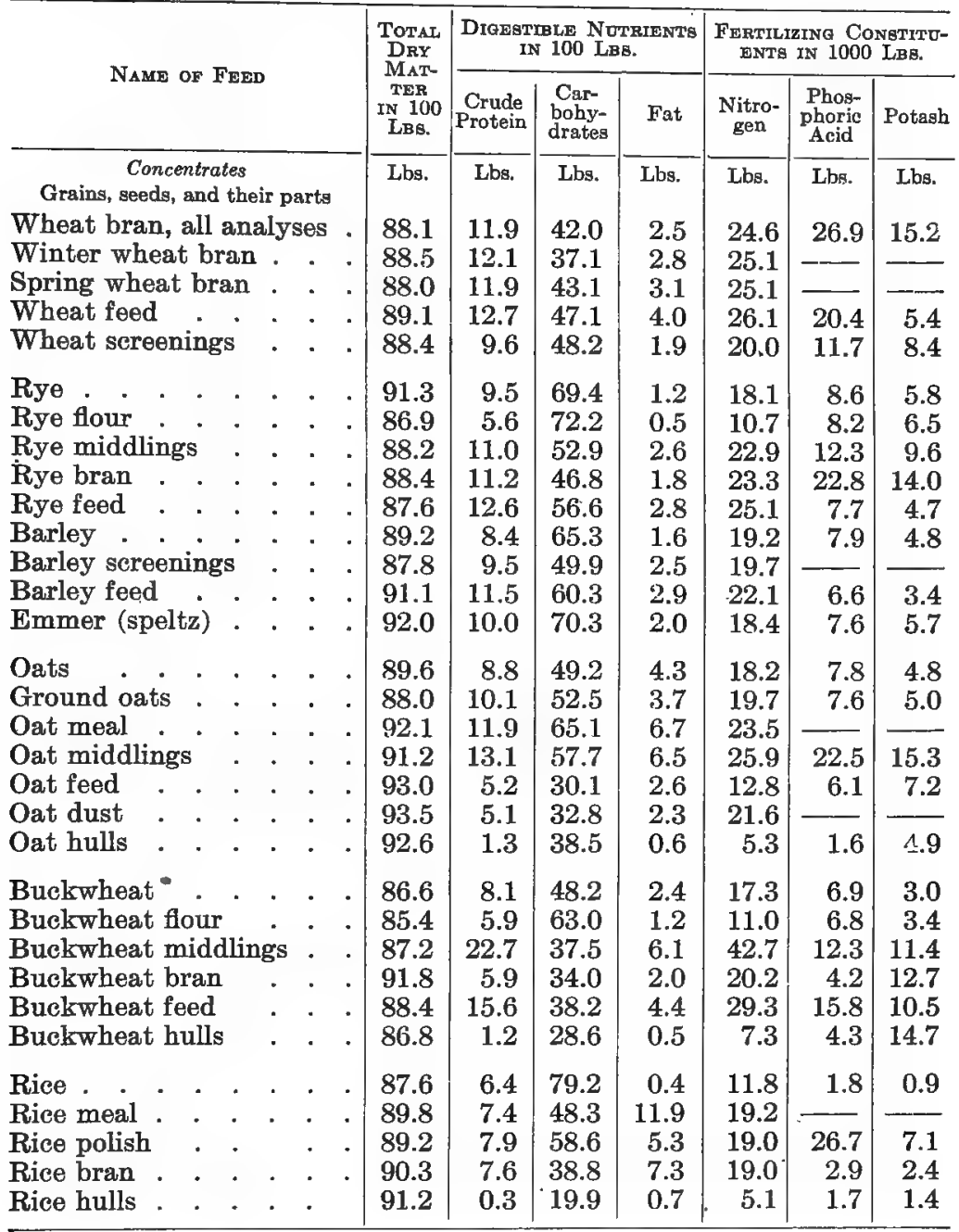


Average Digestible Nutrients and Fertilizing Constituents

Continued

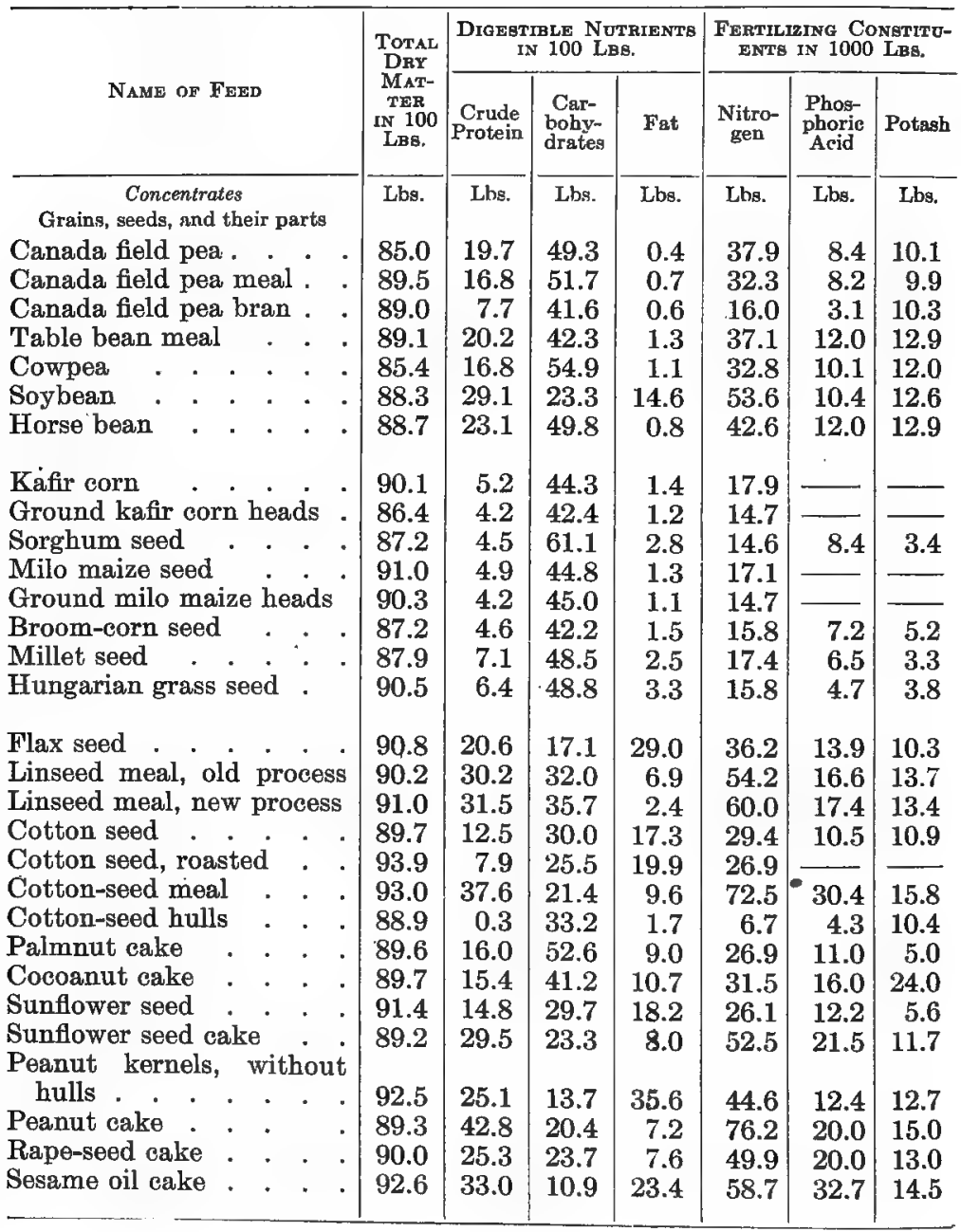


Average Digestible Nutrients and Fertilizing Constituents

Continued

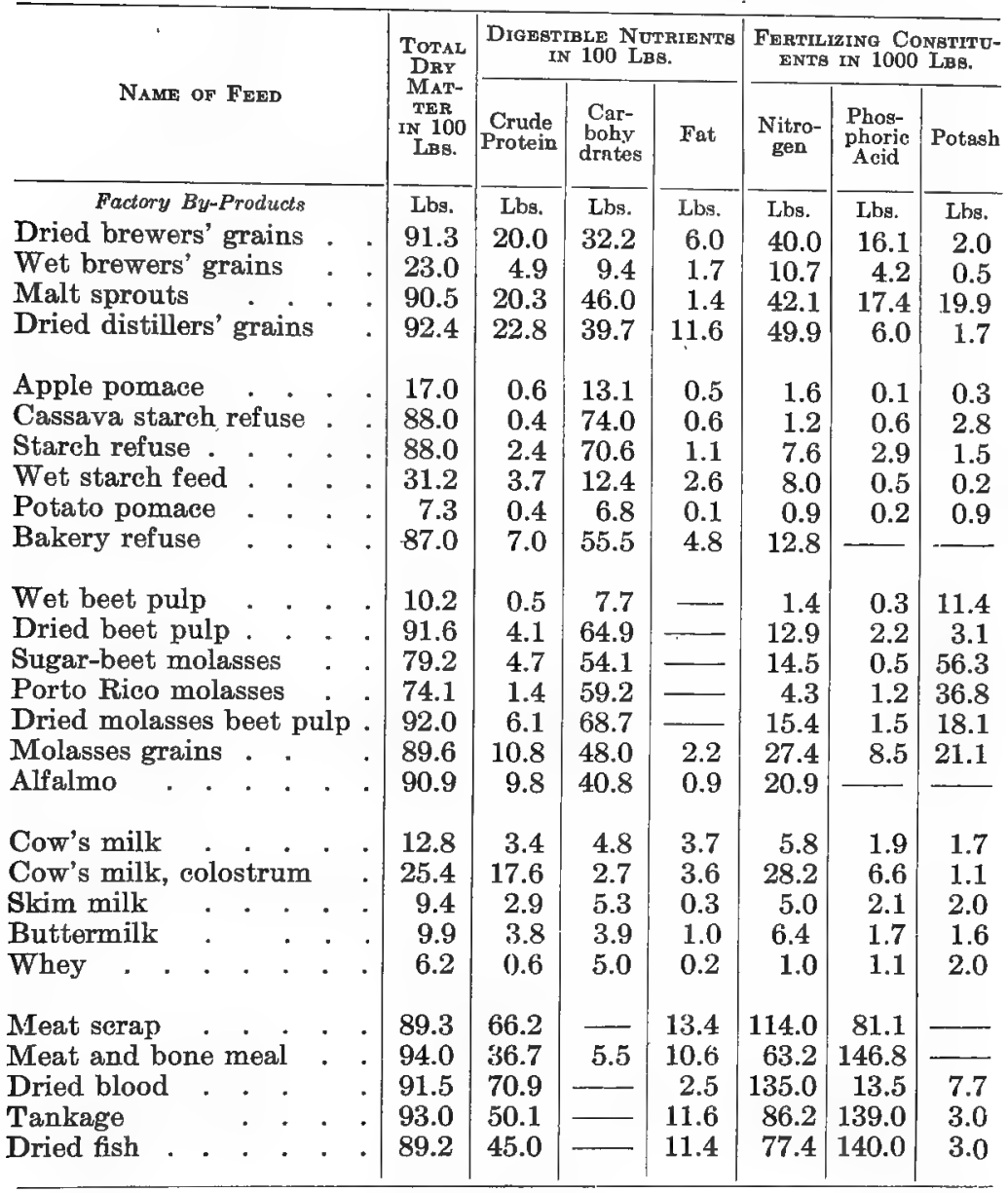


Average Digestible Nutrients and Fertilizing Constituents

Continued

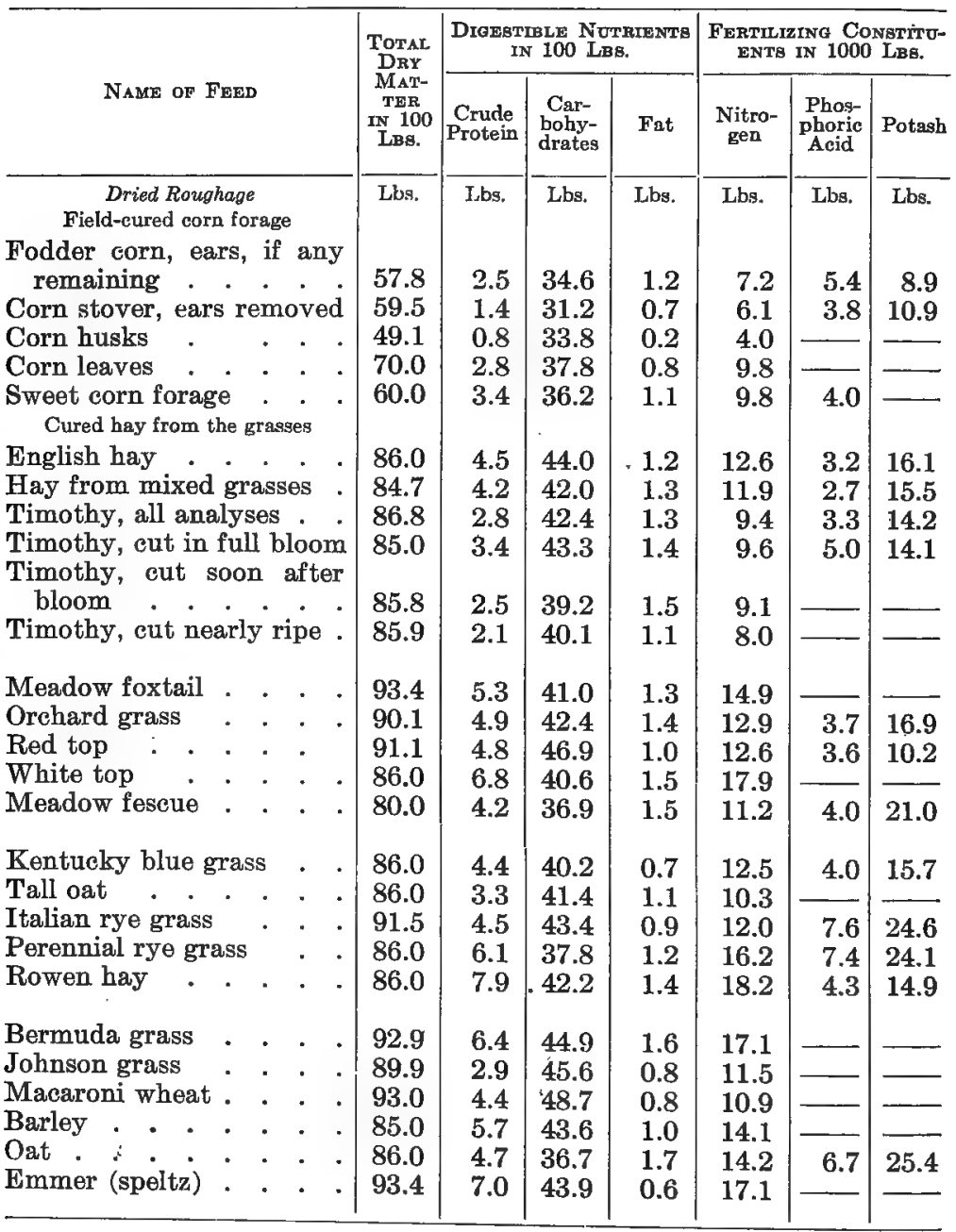


Average Digestible Nutrients and Fertilizing Constituents Continued

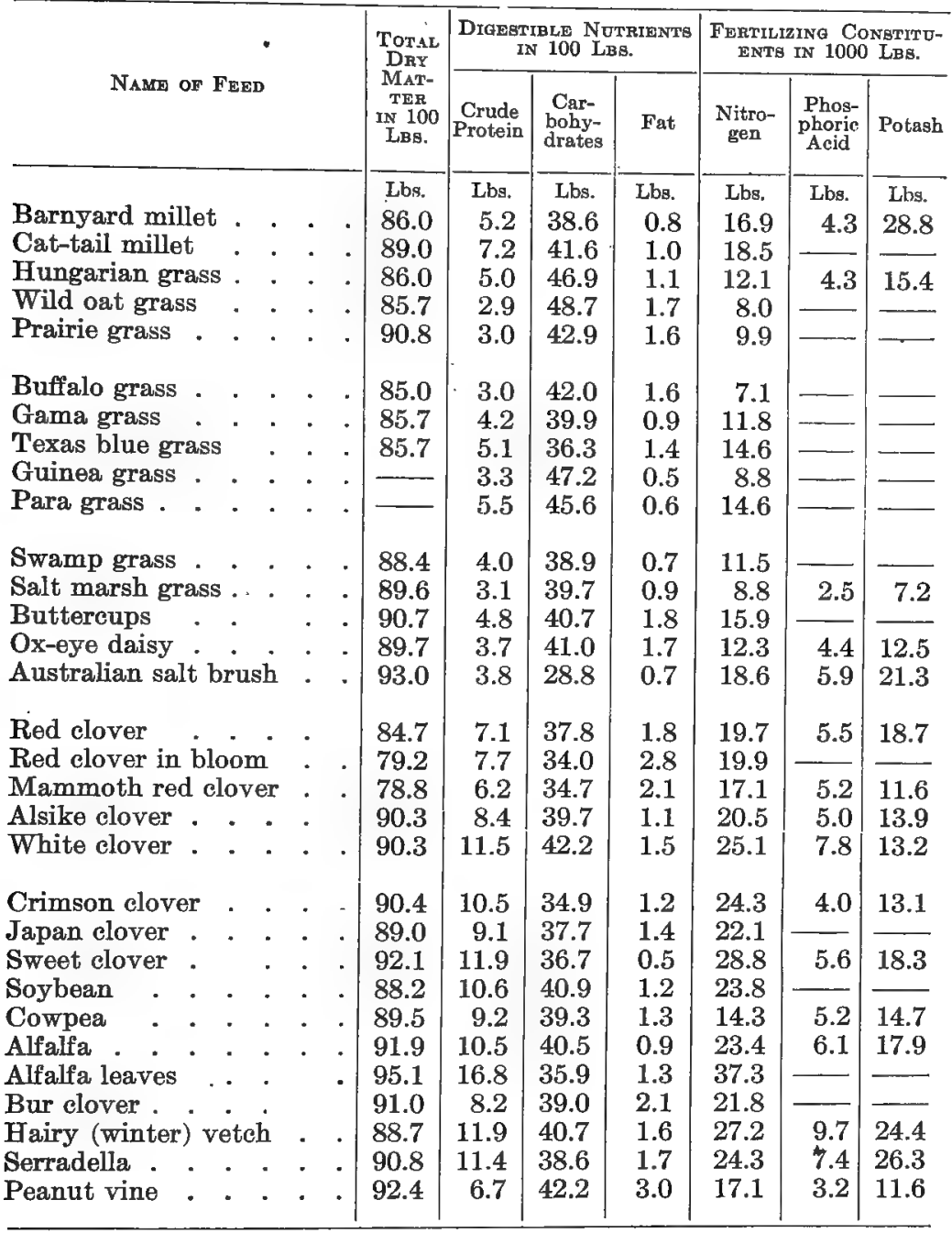


Ayerage Digestible Nutrients and Fertilizing Constituents

Continued

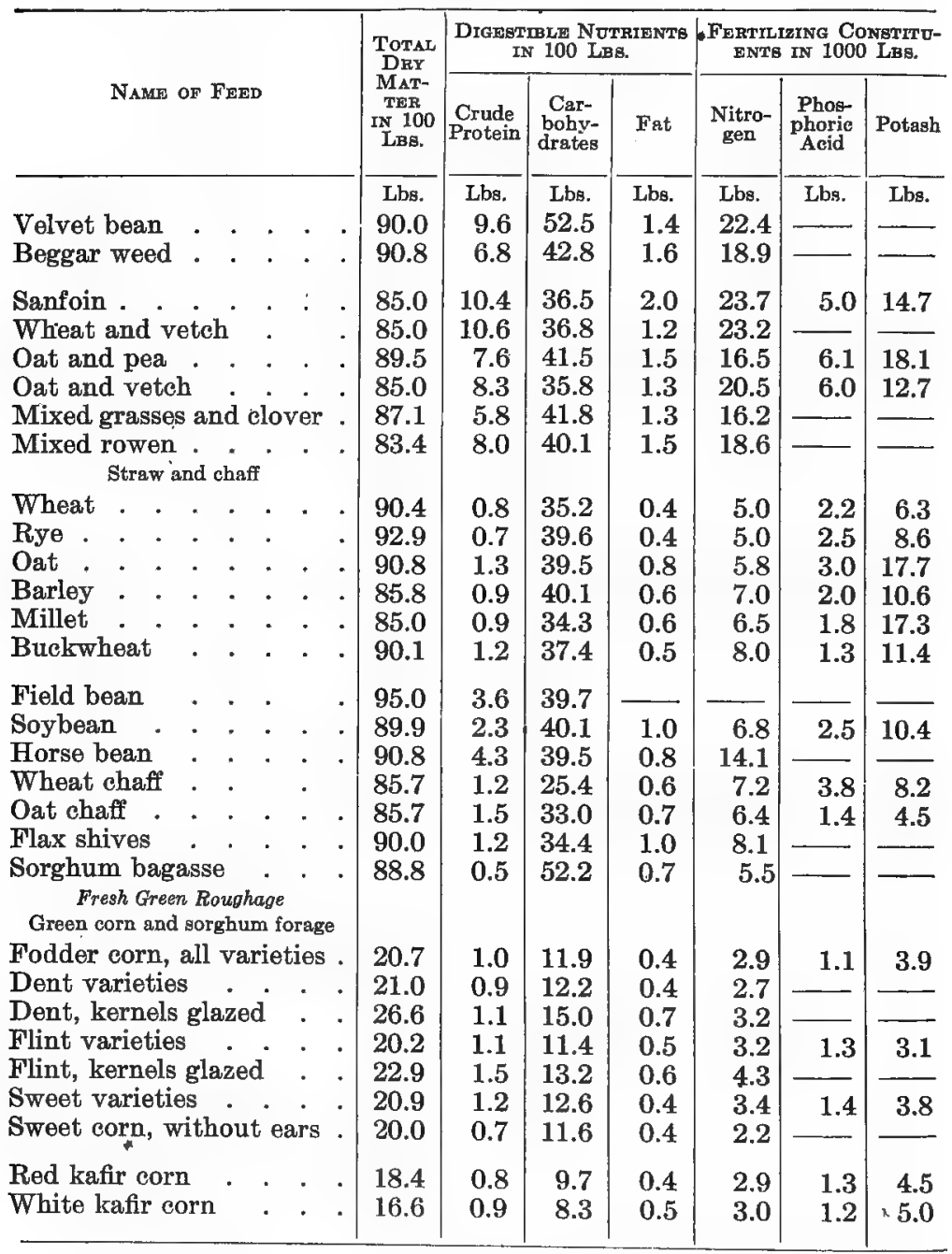


Average Digestible Nutrients and Fertilizing Constituents

Continued

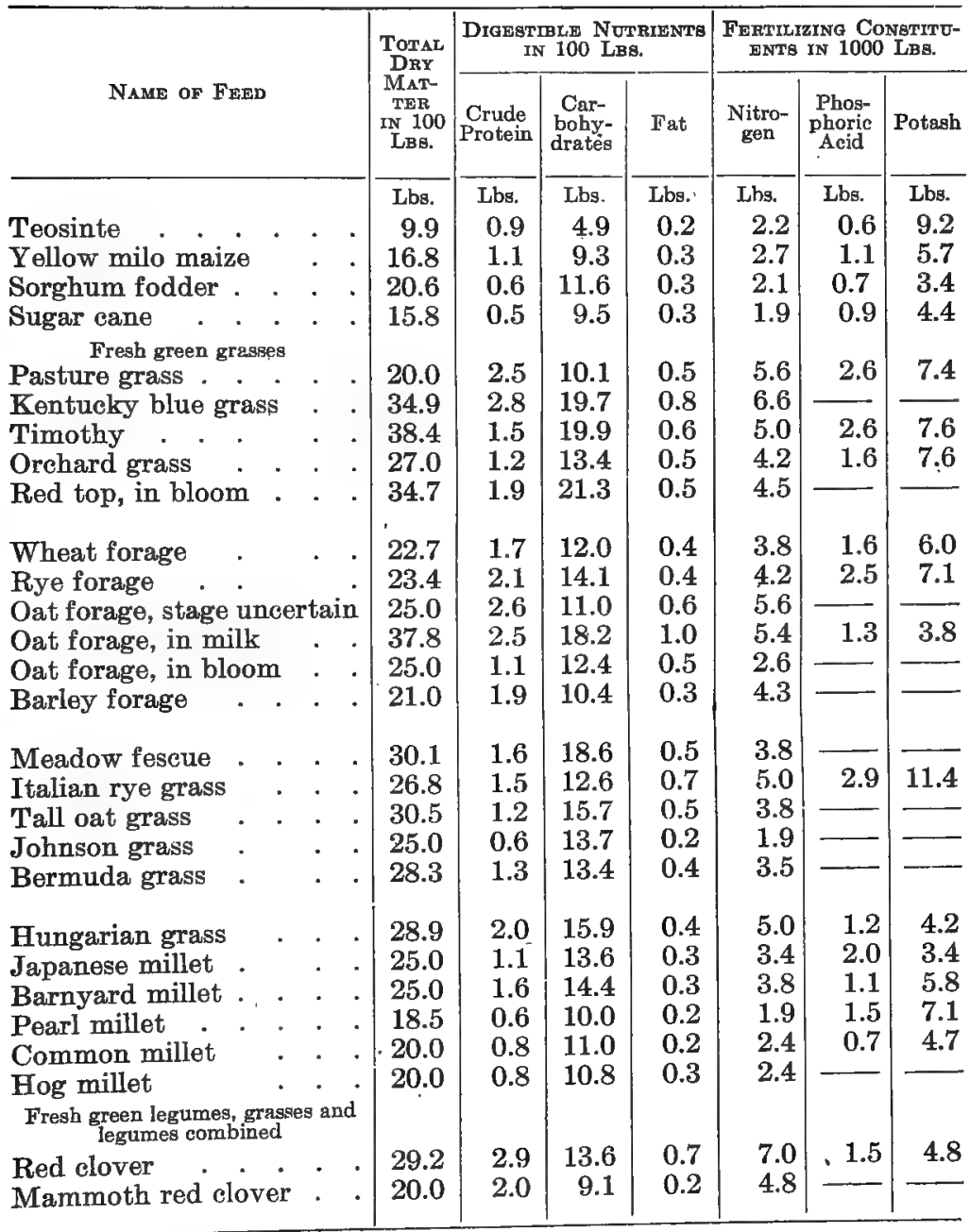


Average Digestible Nutrients and Fertilizing Constituents

Continued

\begin{tabular}{|c|c|c|c|c|c|c|c|c|c|c|c|}
\hline \multirow{2}{*}{\multicolumn{5}{|c|}{ NAME OF FEED }} & \multirow{2}{*}{\begin{tabular}{|c} 
TOTAL \\
DRY \\
MAT- \\
TER \\
IN 100 \\
LBB.
\end{tabular}} & \multicolumn{3}{|c|}{$\begin{array}{l}\text { DiaEgTIBLE NUTRIENTB } \\
\text { IN } 100 \mathrm{LBg} .\end{array}$} & \multicolumn{3}{|c|}{$\begin{array}{l}\text { FERTILIEING CongTITU- } \\
\text { ENTE IN } 1000 \text { Lss. }\end{array}$} \\
\hline & & & & & & $\begin{array}{c}\text { Crude } \\
\text { Protein }\end{array}$ & $\begin{array}{c}\text { Car- } \\
\text { bohy- } \\
\text { drates }\end{array}$ & Fat & $\begin{array}{l}\text { Nitro- } \\
\text { gen }\end{array}$ & $\begin{array}{l}\text { Phos- } \\
\text { phorid } \\
\text { Acid }\end{array}$ & Potash \\
\hline Alsike clover & & & & & $\begin{array}{l}\text { Lbs. } \\
25.2\end{array}$ & $\begin{array}{c}\text { Lbs. } \\
2.6\end{array}$ & $\begin{array}{l}\text { Lbs. } \\
11.4\end{array}$ & Lbs. & $\begin{array}{l}\text { Lbs. } \\
6.2\end{array}$ & Lbs. & $\begin{array}{l}\text { Lbs. } \\
20\end{array}$ \\
\hline Crimson clover & . & . & & & 19.1 & 2.4 & 9.1 & 0.5 & 5.0 & 1.2 & 4.0 \\
\hline Sweet clover . & . & . & . & & 20.0 & 2.5 & 8.4 & 0.4 & 6.1 & 2.4 & 6.7 \\
\hline Alfalfa & & & . & & 28.2 & 3.6 & 12.1 & 0.4 & 7.7 & 1.3 & 5.6 \\
\hline Spring vetch & & & . & & 15.0 & 1.9 & 6.6 & 0.2 & 4.3 & 1.0 & 4.5 \\
\hline Cowpea & . & & & & 16.4 & 1.8 & 8.7 & 0.2 & 3.8 & 1.3 & 4.6 \\
\hline Hairy vetch, wi & ate & & $\cdot$ & & 15.0 & 2.8 & 6.4 & 0.3 & 5.8 & 1.4 & 5.2 \\
\hline Hairy vetch, in & blc & om & & & 18.0 & 3.5 & 7.7 & 0.3 & 6.7 & & \\
\hline Soybean & . & & $\cdot$ & & 24.9 & 3.1 & 11.0 & 0.5 & 6.4 & 1.4 & 5.6 \\
\hline Serradella & . & & & & 20.5 & 2.1 & 8.9 & 0.4 & 4.3 & 1.6 & 5.5 \\
\hline Horse bean & 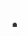 & & . & & 15.8 & 2.3 & 7.3 & 0.2 & 4.5 & 0.5 & 2.1 \\
\hline Velvet bean & 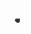 & & & & 17.8 & 2.7 & 8.4 & 0.4 & 5.6 & & \\
\hline Sanfoin . & 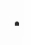 & & - & & 25.0 & 2.9 & 11.1 & 0.5 & 7.0 & 1.4 & 5.7 \\
\hline Canada field pe & & & & & 15.3 & 1.8 & 6.9 & 0.3 & 4.5 & 1.6 & 5.0 \\
\hline Canada field per & $a, i$ & a br & ud & & 15.0 & 2.6 & 6.8 & 0.3 & 5.0 & 1.1 & 4.4 \\
\hline Canada field pes & , i & bl & .00 & & 13.0 & 2.3 & 5.3 & 0.2 & 4.5 & 1.1 & 3.2 \\
\hline Canada field pea & i & po & d & & 16.0 & 1.9 & .7 .0 & 0.2 & 3.7 & 1.3 & 3.7 \\
\hline Barley and vetc & & & & & 20.0 & 2.1 & 6.5 & 0.3 & 4.5 & 2.0 & 5.7 \\
\hline Barley and peas & & & & & 20.0 & 2.1 & 9.1 & 0.4 & 4.5 & & \\
\hline Oats and peas & - & & $\cdot$ & & 20.3 & 1.8 & 10.2 & 0. & 3.8 & 1.5 & 5.0 \\
\hline Oats and vetch & & & . & & 20.0 & 2.3 & 10.0 & 0.2 & 4.8 & 1.4 & 3.0 \\
\hline Wheat and vetc & $h$ & $\cdot$ & ${ }^{\circ}$ & . & 20.0 & 2.6 & 10.3 & 0.3 & 5.4 & & \\
\hline $\begin{array}{r}\text { Mixed grass and } \\
\text { Roots and } T\end{array}$ & c] & ve & & & 25.0 & 2.3 & 14.6 & 0.5 & 4.6 & $\ldots$ & \\
\hline Potato . . & . & & - & & 20.9 & 1.1 & 15.7 & 0.1 & 3.4 & 1.6 & 5.8 \\
\hline Common beet & 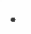 & & 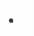 & & 11.5 & 1.2 & 7.9 & 0.1 & 2.4 & 0.8 & 4.8 \\
\hline Mangel & $\cdot$ & & $\cdot$ & & 9.1 & 1.0 & 5.5 & 0.2 & 2.2 & 0.9 & 3.8 \\
\hline Sugar beet & & & $\cdot$ & & 13.5 & 1.3 & 9.8 & 0.1 & 2.9 & 0.8 & 3.7 \\
\hline Flat turnip & - & . & • & . & 9.9 & 0.9 & 6.4 & 0.1 & 2.1 & 0.9 & 3.4 \\
\hline
\end{tabular}


Average Digestible Nutrients and Fertilizing Constituents Continued

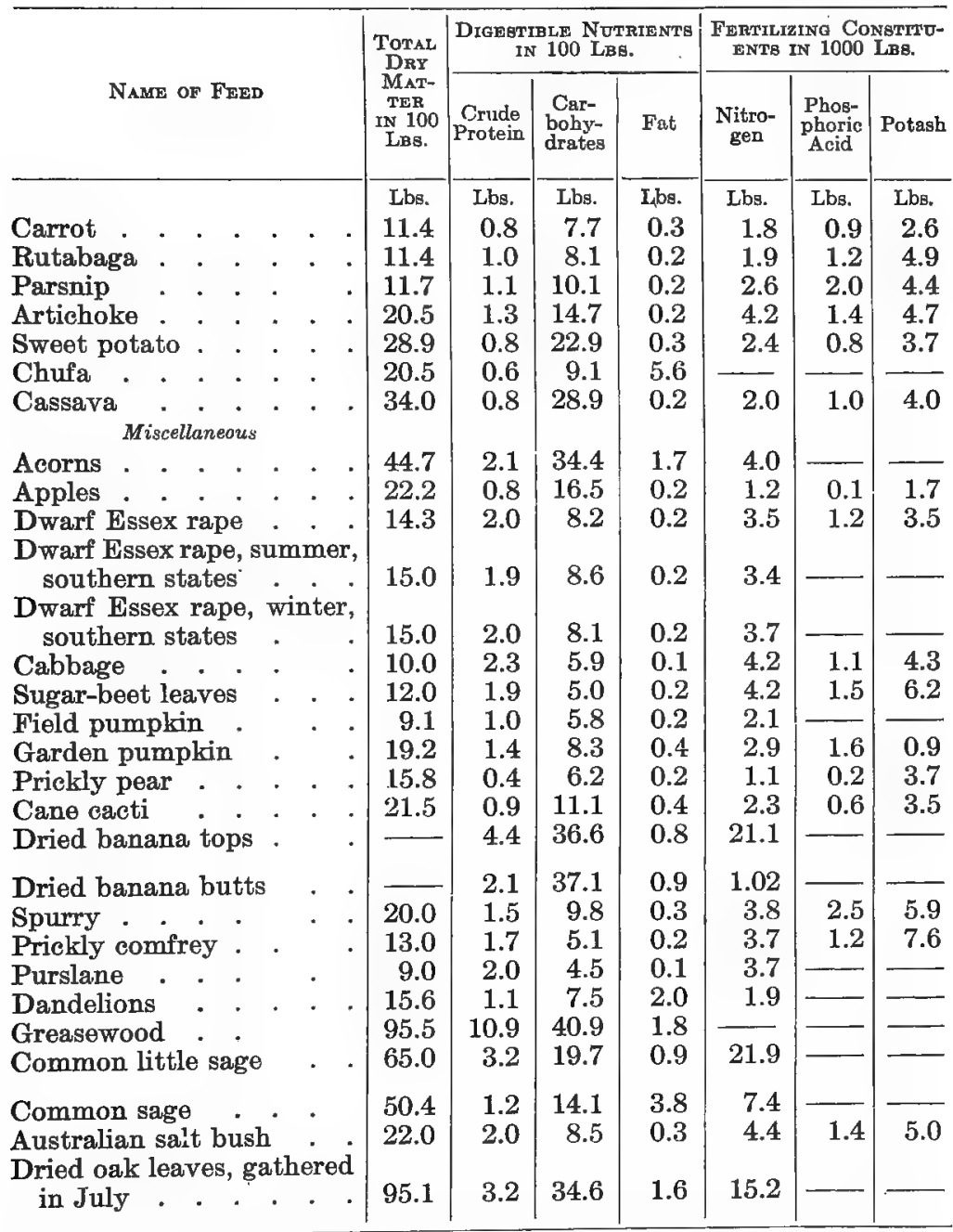


Average Digestible Nutrients and Fertilizing Constituents

Continued

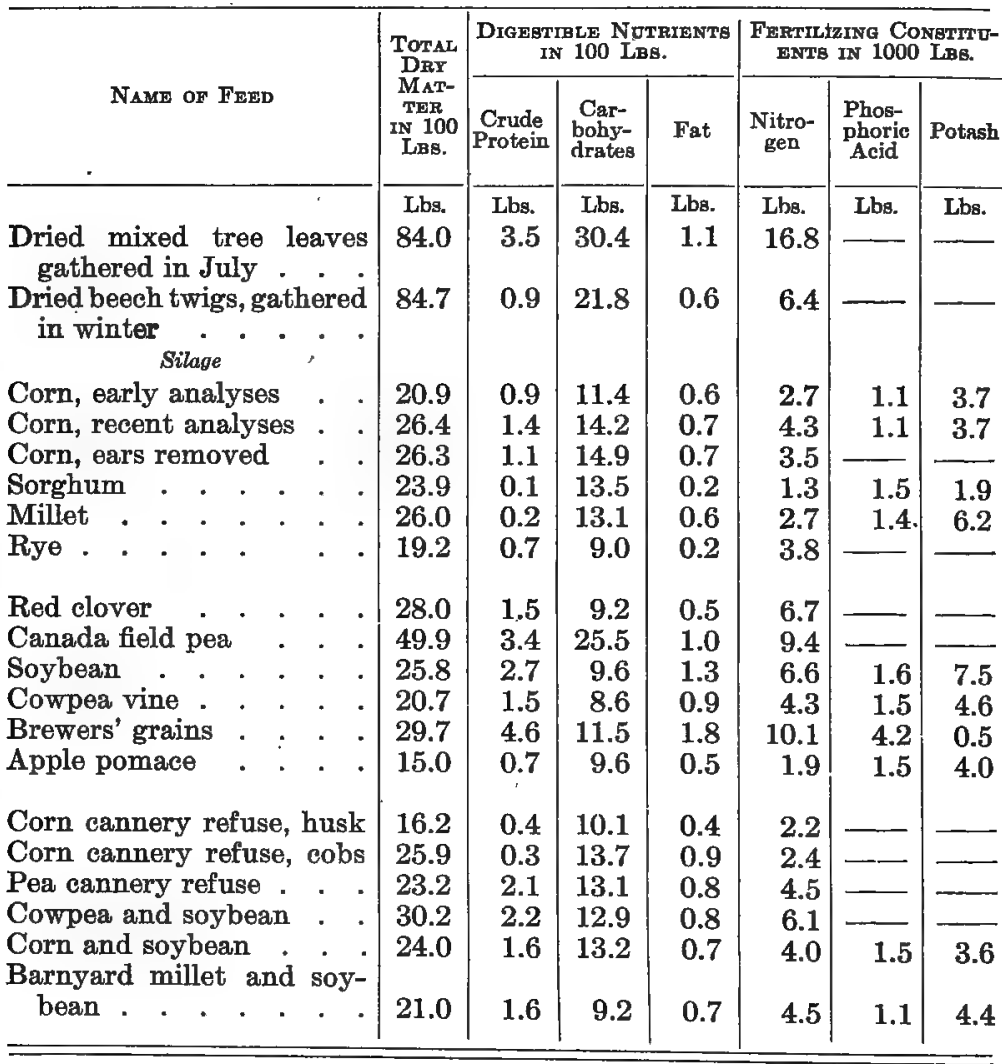




\section{INDEX}

Abdallah, 12.

Aberdeen Angus beef cattle, 123; compared with Shorthorn, 124; families, 124.

Adams, Seth, 200.

Adelaide of Beechlands, 110.

Age, of cattle, 130; of farm animals, 350 ; of fowls, 321 ; of horses, 34 ; of sheep, 223.

Agricultural library, 381.

Aguirre Merino, 200.

Alfalfa for swine, 289.

Amazonia, 12.

American bacon, 282.

American Merino fine-wool sheep, 199 ; compared with Delaine Merino, 202; compared with Rambouillet, 204; description, 200 ; fleece, 200.

American Saddle horse, 5, 10 ; compared with Thoroughbred, 11.

American track records, 8.

Andalusian fowl, 308 .

AndaIusian Jack, 31.

Anezah race, 9.

Angora goat, 219; fleece, 220.

Angus doddies, 124.

Animals, age of, 350 ; habits of, 349 .

Anna, 120.

Appenzell goat, 221.

Arabian horse, 5, 9; compared with Thoroughbred, 10 ; pony, 30.

Aralia DeKol, 113.

Armsby, Dr., 64.

Armsby's standard, 67 ; for beef cattle, 129 ; for dairy cattle, 145 ; for the horse, 71 .

Ash, 56; function of, 58 .

Astley, Richard, 262.

Atwood, Harvy, 265.

Auchenbrain Favorite Beauty 5th, 117. Auchenbrain White Beauty 2d, 117.

Ayrshire dairy cattle, 115; description, 116 ; records, 117.
Babcock test, for butter fat, 366; for cream, 366; for skimmed milk, 366 .

Baby-becf, 185 ; production, 185. -

Bacon, American, 282 ; English, 282.

Bacon-hog, 259 ; feeding, 291 ; judging, 281 ; sides, 281.

Bakewell, Robert, 25, 214.

Balanced ration, 65 .

Banostine Belle DeKol, 113.

Bantam fowl, 316 .

Barley Harvester, 20.

Barn, cow, 364; dairy, 166 ; horse, 357 ; sheep, 253,374 ; silo, 170 ; swine, 299.

Baron of Buchlyvie, 24.

Baron's Pride, 24.

Bates families of Shorthorns, 120.

Bates, Thomas, 120.

Beach, Munson, 261.

Beauty of Park Farm, 115.

Bedding, the horse, 86; for sheep, 255.

Bedouin tribes, 9.

Beef, baby-, 185 ; cuts of, 143 ; food required for, 178 .

Beef cattle, 119, 142 ; Aberdeen Angus, 123 ; Aberdeen Angus compared with Shorthorn, 124 ; Angus families, 124 ; age to feed, 175; baby-beef, 185.; breeding, 188; Butcher stock, 142; care and management, 188 ; condition, 139 ; coöperative grading-up, 188; cutters and canners, 142; detail characteristics, 140 ; fat steer, 141 ; feeding calf, 152; form, 139 ; form of feeder, 176; Galloway, 125; Galloway compared with Shorthorn, 126 ; general characteristics, 139; grain on pasture, 181; Hereford, 121 ; Hereford compared with Shorthorn, 122; how to turn to pasture, 181 ; influence of age, 175 ; judging, 137 ; market classes, 141 ; measurements, 133; method of summer 
feeding, 180; milkers and springers, 142; minor breeds, 126; quality, 139 ; roughage increases capacity, 180 ; salt, 190 ; sample rations, 185 ; score card, 137; self-feeder, 190; shade, 190; shelter, 191 ; Shorthorn, 119 ; stockers and feeders, 142; Texas and western range cattle, 142; uniformity, 140; veal calves, 143; water, 190; wintér equipment, 191; winter feeding, 179-183.

Beef cow, points of, 106.

Beef type, 107.

Belgian draft horse, 26 ; compared with Percheron, 27.

Belle Netherland Johanna, 113.

Bellfounder, 12.

Belmont Park course, 8.

Berkshire lard-hog, 260, 262; compared with Poland China, 263.

Berry, William, 202.

Big China hog, 261.

Bit, 97 ; uses, 93.

Bitting, harness, 94 ; the colt, 94.

Blackbird family, 124 .

Blackfaced Highland, 214, 218.

Black Suffolk swine, 267.

Black Top Spanish Delaine, 201.

Black tribe, 28.

Blankets, 86.

Blind horse, 38.

Boar, see Swine.

Booth families of Shorthorns, 120.

Booth, Thomas, 120.

Boulonnais horse, 23.

Bracelet, 120.

Brahma fowl, 310.

Breeding, cattle, 165, 188; horses, 82 ; poultry, 337; sheep, 246; swine, 296.

Breeds, of cattle, 105; of coach horses, 14 ; of draft horses, 20 ; of donkeys, 31 ; of horses, 3 ; of ponies, 29 ; of poultry, 307; of sheep, 197; of swine, 259.

Breton horse, 23.

Bridle-bit, uses, 93.

Brittany cattle, 114.

Broadhook, 120.

Broilers, 334.
Bronders, 340.

Brood mare, feeding, 76.

Buchan humlies, 124.

Bull, see Cattle.

Butcher hogs, 282.

Buteher stock, 142.

Butter making, starter, 369 .

Byerly Turk, 5.

Byfield hog, 261.

Calf, 152 ; feeding, 152 ; on skim milk, 153 ; ration, 155 ; removing horns, 153; veal, 143 ; see Cattle.

Cambridge Rose, 120.

Canada Experiment Station addresses, 383.

Captain Byerly, 5.

Carbohydrates, 57; function of, 59.

Carcass, weight by measurements, 372 .

Cart Horse, 25.

Cart, training, 96.

Catalonian Jack, 31.

Cattle, 105; Aberdeen Angus, 123; age of, 130; age by horns, 131; Ayrshire, 115; Ayrshire records, 117; baby-beef, 185; beef breeds, 119 ; beef type, 107; breeds of, 105 ; Brown Swiss, 118; care, 188; care and management, 157; dairy score card, 131; dairy type, 105; description of Ayrshires, 116 ; description of Guernseys, 114; description of Holstein-Friesians, 112; description of Jerseys, 110; description of Shorthorn, 121; Devon, 127; disease, 171; Dutch Belted, 118; feeding beef, 175 ; feeding calf, 152 ; feeding dairy, 144; French Canadian, 118; Galloway, 125; Guernsey, 113 ; Guernsey records, 115; Hereford, 121 ; habits of, 349 ; HolsteinFriesian, 111; Holstein-Friesian records, 113; how to turn to pasture, 181 ; Jersey, 108; Jersey milk records, 111; Jersey records, 110; judging, 130; Kerry, 119; major dairy breeds, 108; measurements, 133 ; Polled Durham, 126; Red Polled, 128; removing horns, 153, 364 ; sample rations, 154 ; Shorthorn, 
119 ; silage, 151 ; soiling, 149 ; Sussex, 128; teeth, 130; tuberculosis, 172; udder, 136; West Highland, 128; watering dairy cow, 147.

Cement floors, 169.

Charles II, 5.

Charles Kent mare, 12.

Check-rein, 98.

Cheese making, cottage, 371.

Cherry Blossom, 120.

Cheshire swine, 268; description, 269.

Chester White lard-hog, 260, 265; compared with Poland China, 266.

Cheviot sheep, 213; compared with Southdown, 213; weight, 204.

Chickens, amount to feed, 329; young feeding, 328 ; see Poultry.

Chinese hog, 262.

Cholera in swine, 302; prevention, 302.

Clark, A. C., 269.

Clay family of horses, 12 .

Clay, Henry, 263.

Cleveland Bay Coach horse, 15, 20; compared with the Hackney, 20.

Clipping the horse, 85.

Clydesdale draft horse, 23; compared with Percheron, 25.

Coach horse, breeds of, 14 ; Cleveland Bay, 20 ; French Coach, 16; German Coach, 18; Hackney, 14.

Cochin fowl, 310 .

Cock, see Poultry.

Colantha 4th's Johanna, 112-113.

Collar, fitting, 99 ; humane, 100 ; leather, 100 ; pneumatic, 100; sweeney, 100.

Colling Bros., 120.

Collings, Robert, 267.

Colt, bitting, 94 ; harnessing, 95 ; training, 90 ; see Horse.

Confidence, 15.

Cost of ration, 75 .

Cotswold long-wool sheep, 215; compared with Leicester, 216; fleece, 201.

Count Johanna, 18.

Cow, dairy points of, 104.

Creamelle Vale, 113.

Crisp Horse, 28.

Crisp, Mr., 28.

Crude fiber, 57.
Cruickshank, Amos, 120.

Cruickshank families of Shorthorns, 120.

Crupper 100.

Cunningham cattle, 116.

Curb, 40.

Curtis, F. D., 264, 270.

Curtis Victoria swine, 270.

Cutters and canners, 142.

Dairy barn, 166 ; silo, 170 ; ventilation, 167.

Dairy cattle, Ayrshire, 115; barn, 166 ; care and management, 157 ; constitution, 134; breeding and performance, 165 ; detail characteristics, 135 ; feeding, 144; feeding calf, 152 ; feeding the milking cow, 148; feeding standards, 144; food requirements for milk, 145; forming herd, 165; general characteristics, 133 ; Guernsey, 113; HolsteinFriesian, 111; inspection of Jersey, 109 ; Jersey, 108; judging, 131 ; measurements, 133 ; milk records, 160; milk signs, 137; milk veins, 137; milking, 158; minor breeds, 118; ration for, 363 ; sample rations, 154 ; score card, 131 ; silage, 151 ; soiling, 149 ; summer feeding, 148 ; temperament, 135 ; udder, 136 ; unit of improvement, 165; veal calves, 143 ; watering, 147 ; winter feeding, 150.

Dairy cow, form, 133 ; measuring, 363 ; points of, 104 ; quality, 134 ; scoring, 363.

Dairy herd, formation, 165.

Dairy Maid of Pinehurst, 115.

Dairy type, 105.

Daisy Grace DeKol, 113.

Dan Patch, 14.

Dark Horse, 20.

Darley Arabian, 5.

Darley, Mr., 5.

Davis Victoria swine, 220.

Daytholeum, 249.

Delaine Merino fine-wool sheep, 201; Black Top Spanish, 201 ; compared with American Merino, 202; Dickinson, 201 ; National, 201. 
Demi-Sang, 16.

Devon cattle, 127.

Dexter-Kerry, 119.

Dickinson Delaine, 201.

Dickinson, W. R., 201.

Digestible nutrients, 62.

Digestion, 60; coefficient of, 62 .

Digestive organs, 61 .

Dipping, sheep, 248; swine, 298.

Disease, of cattle, 171 ; of swine, 301 ; tuberculosis, 172.

Docking lambs, 251.

Dolly Bloom, 115.

Dolly Dimple, 114, 115.

Dominique fowl, 314 .

Donkeys, breeds, 31 .

Dorking fowl, 314.

Dorset-Horn mutton sheep, 212 ; compared with Southdown, 212.

Down-Cotswold sheep, 209.

Draft breeds of horses, 20.

Draft horse, Belgian, 26; Clydesdale, 23 ; French draft, 23 ; Percheron, 21 ; Shire, 25 ; weight, 50.

Drake, see Ducks.

Druce, Samuel, 209.

Duchess, 120:

Ducks, 317.

Dunlop cattle, 116.

Dunlop, John, 116.

Durham Ox, 120.

Duroc hog, 264.

Duroc-Jersey lard-hog, 260, 263 ; companed with Poland China, 264.

East Friesland horse, 18.

East Prussian horse, 18.

Eclipse, 5.

$\mathrm{Egg}$ production, amount to feed, 332 ; breeds described, 308; production feeding, 330; mineral matter, 332; type, 307.

Egg study, 378; chalaza, 378 ; compositión, 380 ; preserving, 381 ; structure, 378.

Egg-tester, 378.

Ellman, John, 205.

English bacon, 282.

English track records, 8 .

Epsom Derby course, 6; track record, 8.
Epsom Oaks course, 6 ; track record, 8. Ericas, 124.

Escurial Merino, 200.

Essex lard-hog, 260, 267; compared with Poland China, 267.

Estantes sheep, 199.

Ether extract, 58.

Ewe, see Sheep.

Experiment station addresses, 382 .

Fairholme, 120.

Farm animals, registration, 84 .

Farmer's Glory, 20.

Farm teams, sample rations, 79 .

Farms for beef production, 189.

Fat, 58; function of, 59.

Fat-steer, 141.

Fattening swine, 289.

Feed, digestible nutrients, 387 ; energy values, 385 ; hays, 358 ; measurement of, 384 ; mixing, 357 ; succulent, 151 ; weight of, 384 .

Feed-bunk, 189.

Feeders, 139; condition, 176; form of, 176; quality, 177; and stockers, 142; uniformity, 140 ; wintering, 179.

Feed-hoppers for poultry, 377.

Feeding, bacon-hog, 291; beef cattle, 175 ; for beef in summer, 179 ; breeding swine, 287 ; the brood mare, 76 ; calf, 152 ; dairy cattle, 144 ; the foal, 76; egg production, 330 ; green food for poultry, 328 ; the horse, 71 ; lambs, 239; lard-hog, 289; meat scrap for poultry, 327 ; the milking cow, 148; mules, 75 ; pigs, 286; poultry, 327; poultry for meat production, 333; principles, 54; regularity for the horse, 72; sheep, 232 ; sick horse, 89; soiling, 149; standards, 64; standards, dairy cattle, 144; swine, 284; variety for poultry, 330; work horse, 73; work-horse, method -of, 74; young chickens, 328.

Feed-lot, 191.

Feed-racks for sheep, 255.

Feet, care of, 87, 237.

Filly, see Horse. 
Financial Countess, 110.

Fine-wool sheep, American Merino, 199 ; Delaine Merino, 201; Rambouillet, 203 ; type, 198.

Fireaways, 15.

Fisherman, 14.

Fistulæ, 39.

Fleece, Amerioan Merino, 200; Hampshire, 201; Leicester, 201; Lincoln, 201 ; Oxford, 201 ; Southdown, 201.

Floors, cement, 169 ; for poultry house, 345.

Fly-nets, 101.

Foal, feeding, 76 ; weaning, 78 ; see Horses.

Foggathorpe, 120.

Food, 54; amount for the horse, 73; ash, 56; carbohydrates, 57 ; composition, 55; cooking, 286; crude fiber, 57; digestible nutrients, 62; digestibility, 60; digestibility of, 63; effect on milk, 145; ether extract, 58; for beef production, 178; for ration, 359; for swine, 285; fat, 58 ; function of, 58 ; function of carbohydrates, 59 ; function of fat, 59 ; function of protein, 59 ; grinding, 285; high protein group, 361 ; low protein group, 360 ; medium protein group, 360 ; milk and flavor, 146 ; nitrogen-free extract, 57 ; order of supplying to dairy cow, 146 ; order of supplying for the horse, 72 ; preparation for swine, 285 ; protein, 56 ; ration, 63; requirements for milk, 145; requirements for sheep, 233 ; requirements for work, 71; roughage, 361 ; soaking, 285 ; use, 54 ; water, 55.

Forage-rack, 192.

Fowls, see Poultry.

French Coach horse, 15, 16; compared with the Hackney, 18.

French draft horse, 23.

French horse classes, 17.

Friesland cattle, 111.

Frizzle fowl, 316 .

Gaited Saddle horse, 11.

Gaits of Saddle horse, 11.
Galliers, William, 122.

Gallipoli, 21.

Galloway beef cattle, 125; compared with Shorthorn, 126.

Game fowl, 316.

Gander, see Geese.

Geese, 319.

Gelding, see Horses.

German Coach horse, 15, 18.

Gerranton Dora 2d, 117.

Giant Lincolnshire Horse, 25.

Gilbert, M., 203.

Gilt, see Swine.

Glenanaar of the Glen, 115.

Goats, 219; Angora, 219; milk, 220. Gobbler, see Turkey.

Godolphin, 21; Barb, 5.

Goose, see Geese.

Grain, for calf, 155 ; for foal, 77 ; measuring, 361.

Grant, G. M., 124.

Gravesend course, 8.

Great Horse, 25.

Grit for poultry, 327.

Grooming the horse, 85 .

Guernsey dairy cattle, 113; description, 114 ; records, 115.

Guinea-fowls, 319 .

Guinea hog, 263.

Hackney Coach horse, 14, 15; compared with Cleveland Bay, 20; with French Coach, 18; with German Coach, 18; description, 15; pony, 30.

Hadban, 9.

Haecker's standard for dairy cattle, 145.

Hal family, 12.

Halter rope, 354.

Hambletonian 10, 12; family, 12 ; Rysdyks, 12 ; pedigree, 12.

Hamburg fowl, 308.

Hampshire lard-hog, 266; compared with Poland China, 267.

Hampshire mutton sheep, 208; compared with Southdown, 209; fleece, 201.

Hanoverian horse, 18.

Harlem Park course, 8. 
Harness, 97 ; bitting, 94; caring for, 101 ; fitting the collar, 99 ; fly-nets, 101 ; parts of, 351 ; rope halter, 352 ; splicing rope, 352 .

Harnessing the colt, 95.

Hays, 358 ; measuring, 362.

Hazel of Sand Hill, 117.

Heather Blooms, 124.

Heifer, see Cattle.

Hen, see Poultry.

Hereford beef cattle, 121; compared with Shorthorn, 122.

Herod, 5.

Hewer, John, 122.

Hewer, William, '262.

High-lawn Hartog DeKol, 113.

Hinny, 32 ; see Mule.

Hobbs, Fisher, 267.

Hog, see Swine.

Hog cholera, 302.

Hog-house; 299.

Hog lot, 301.

Hog-wallows, 301.

Holderness cattle, 119.

Holstein cattle, 111.

Holstein-Friesian dairy cattle, 111 ; description, 112; records, 113.

Holstein horse, 18.

Homdani, 9.

Hoof, growth of, 88; unsound, 39.

Horned-Dorset, 212.

Horns, removing, 153 ; 364 ; in estimating age of cattle, 131.

Horses, 2 ; action, 45 ; age estimating, 34 ; barn, 357 ; bedding, 86 ; blankets, 86 ; breeds of, 3 ; care, 81 ; care of feet, 87; care of teeth, 85 ; characters, 47, 50; clipping, 85; cost of ration, 75 ; curb, 40 ; defective hearing, 39 ; feeding, 71; feeding the brood mare, 76 ; feeding foal, 76 ; feeding sick, 89 ; fistulæ, 39; food required for work, 71 ; forging, 40 ; form, 45 ; grooming, 85 ; habits of, 349 ; heavy type, 4; height, 44; impaired vision, 38 ; judging, 34 ; light breeds, 4 ; measurements of, 44,350 ; order of supplying food, 72; overreaching, 40 ; points of, $2,47-50$; poll- evil, 39; quality, 46; ration, 68,361 ; regularity in feeding, 72 ; ring-bone, 39 ; salt for, 72 ; sample rations, 79 ; side-bone, 39 ; the score-card, 40 ; scoring, 350 ; scratches, 39 ; shoeing, 88 ; soundness, 351; spavin, 40; splint, 39; sweeney shoulder, 39 ; teeth, 36 ; temperament, 47; Thoroughbred, 4; thoroughpin, 40; treating sick, 89 ; types of, 3 ; unsound, 38 ; unsound hoof, 39 ; watering, 72 ; weight, 350 .

Horse-breeding, 82 ; coöperative, 82 ; soundness, 84 ; uniformity, 84.

Hot-house lambs, 238 ; winter quarters, 238.

Houdan fowl, 314.

House poultry, 340.

Hubback, 120.

Humane collar, 100.

Humphrey, David, 202.

Humphrey, William, 209.

Imp. Beauty of Park Farm, 115.

Imp. Princess of the Blicqs, 115.

Incubation, 338 ; artificial, 339 ; natural, 338.

Incubators, 339.

Indian pony, 31.

Indiana Victoria swine, 270.

Infantado Merino, 200.

Irish Grazier, 261.

Isabella, 120.

Italian Jack, 31.

Jacks, breeds, 31.

Jacoba Irene, 110.

Jarvis, William, 200.

Java fowl, 314.

Jean Armour, 117.

Jeffries, James, 265.

Jeffries, Thomas, 122.

Jelfon, 9.

Jersey dairy cattle, 108; butter-fat records, 111; description, 110; inspection, 109; records, 110.

Jersey-Red hog, 263.

Judging, cattle, 130 ; horses, 34 ; poultry, 321 ; sheep, 222 ; swine, 275. 
Keheilet Ajug, 9.

Kellner, Dr., 64 .

Kentucky Saddle horse, 11 .

King's system of ventilation, 167 .

Kühn, Dr., 64 .

Lamb, cuts of, 230; docking, 251; fall, 241; feeding, 239; hot-house, 238 ; spring, 239 ; winter, 238; see Sheep.

Lancaster, 120.

Langshan, 310.

Langwater Hope, 115.

Lard-hog, 259 ; feeding, 289 ; form, 275 ; hams, 280; judging, 275; weight and condition, 275 .

Large Yorkshire bacon-hog, 271; description, 272.

Large White swine, 271.

Lass 38th of Hood Farm, 110.

Lavender, 120.

Leghorn fowl, 308.

Leicester long-wool sheep, 214; compared with Cotswold, 216; with Lincoln, 217; description, 214; fleece, 201.

Library, 381.

Lice, killing materials, 375.

Lily of Willowmoor, 117.

Lincoln long-wool sheep, 217 ; compared with Leicester, 217; fleece, 201.

Lintock, 24.

Livingston, Robert, 200.

Loin hitch, 92.

Long-wool sheep, 214; Cotswold, 215 ; Leicester, 214; Lincoln, 217.

Lord Barrington, 262.

Lord Selkirk, 126.

Lord Western, 267.

McCombie, William, 124.

McDowell, James, 201.

Major Delmar, 14.

Majorca Jack, 31.

Mambrino, 12 ; family, 12.

Maltese goat, 221.

Maltese Jack, 31.

Maneghi, 9.

Mare, see Horse.

Mares, Royal, 5.
Market classes, of beef cattle, 141; of horses, 51, 52; of sheep, 230 ; of swine, 281.

Martin Boxer tribe, 28.

Mason, Charles, 267.

Matchem, 5.

Matie of Sand Hill, 117.

Mead, R. M., 201.

Measurements of horses, 44 .

Meat, cuts of, 372 ; breeds of fowls described, 310 ; type of poultry, 307.

Medora, 120.

Meire, Samuel, 206.

Merino sheep, 199.

Messenger, 11.

Mexican pony, 31.

Middle Yorkshire hog, 268, 270.

Milk, analysis, 365 ; ash, 365 ; bacteria, 369 ; cost of, 364 ; effect of food on composition, 145 ; food requirements for, 145 ; food and flavor, 146 ; for calf, 153 ; goat, 220 ; keeping qualities, 367 ; oil, 249 ; pasteurization, 368 ; per cent of fat, 366 ; records value of, 161 ; sampling, 162 ; sanitary, 157 ; utensils, 158.

Milk-bottles, 162.

Milkers and springers, 142.

Milk-house, 158.

Milking, 158; machines, 159.

Milk-records, 160 ; keeping, 160.

Milk-signs, 137.

Milk-testing, 161 ; associations, 164; apparatus, 163.

Milk-veins, 137.

Mimulus, 120.

Minorca fowl, 308.

Morgan horse, 5 ; family, 12.

Morris Park course, 8.

Moss Rose, 120.

Mule, 32 ; feeding, 75.

Mutton, cuts of, 230 .

Mutton sheep, 204, 214; Cotswold, 215; description of Southdown, 206; Dorset Horned, 212; Hampshire, 208; Lincoln, 217; Oxford Down, 209; Shropshire, 206; Southdown, 204; Suffolk, 210.

Mutton type, 198. 
Naptholeum, 249.

National Delaine, 201.

Neapolitan hog, 262.

Neff, William, 261.

Negrette Merino, 200.

Netherhall Brownie 9th, 117.

New York Victoria swine, 270.

Nitrogen-free extract, 57.

Nivernais horse, 23.

Nonpareil, 120.

Norfolk Thin Rind hog, 265.

Normandy cattle, 114.

Nosegay, 124.

Nubian goat, 221.

Nutrients, 62 ; digestible, 387.

Nutritive-ratio, 65,359 ; for poultry, 328.

Ohio Improved Chester White, 266.

Oldenburg horse, 18.

Old English Black Horse, 25.

Old Grannie, 124.

Olga 4th's Pride, 110.

One Eye, 12.

One Thousand Guineas course, 6.

Orange Blossom, 120.

Oriental Game fowl, 316.

Original Chester White hog, 265.

Original Shales, 15.

Orloff Trotter, 5.

Ornamental breeds of fowls, 308 ; described, 316.

Orpington fowl, 314.

Oxford, 120.

Oxford Down mutton sheep, 209 ; compared with Southdown, 210; fleece, 201.

Pacer, 11.

Pacing records, 14.

Packing hogs, 282.

Pasteurization of milk, 368 .

Pasture, 182; for beef, 189 ; for sheep, 234 ; for swine, 287.

Paular Merino, 200.

Pearly Exile of St. Lambert, 110.

Percheron draft horse, 21 ; description, 22 ; compared with Belgian, 27; with Clydesdale, 25; with Shire, 25 ; with Suffolk, 28.
Picardy horse, 23.

Picotee, 120.

Pig weaning, 287; feeding, 286; see Swine.

Plymouth Rock fowl, 314 .

Pneumatic collar, 100.

Points, of the beef cow, 106; dairy cow, 104; fowl, 306; horse, 2; pig, 258; sheep, 196.

Poitou, 31.

Poland China lard-hog, 260; description, 261.

Polish fowl, 316.

Polled Durhapn cattle, 126.

Poll-evil, 39.

Pony, Arabian, 30 ; breeds, 29 ; Hackney, 30 ; Indian, 31 ; Mexican, 31 ; Shetland, 30; Welsh, 30.

Pontiac Clothilde DeKol 2d, 113.

Pork, cuts of, 282.

Poultry, 307; age, 374; Andalusian, 308; Bantam, 316; Brahma, 310; breeding, 337 ; broilers, 334 ; brooders, 340 ; care, 337 ; Cochin, 310 ; Colony house, 341 ; comb, 324 ; comparative judging, 322 ; coop, 376; detail characters of fowls, 324 ; Dominique, 314 ; Dorking, 314; ducks, 317; egg production, 330 ; estimating age, 321 ; exercise, 330 ; feeding, 327 ; feeding for meat production, 333; feeding young chickens, 329; feed hopper, 346, 377 ; frizzle, 316 ; game, 316; general purpose breeds described, 314 ; geese, 319 ; grit and mineral matter, 327 ; guinea fowls, 319; Hamburg, 308; houses, 340; house, 376 ; Houdan, 314 ; improvement, 337 ; incubation, 338 ; incubators, 339 ; Java, 314 ; judging, 321 ; Langshan, 310 ; Leghorn, 308 ; lice-killing materials, 375 ; long house, 341 ; management, 337 ; meat breeds described, 310; Minorca, 308 ; nutritive ratio, 328 ; old, 321 ; ornamental breeds described, 316; Oriental Game, 316; Orpington, 314 ; parks, 346; Plymouth Rock, 314; points of the fowl, 306; Polish, 316; ranges, 346; Red Cap, 308; Rhode 
Island Red, 314; roasters, 334; sample rations, 334 ; sex, 374 ; scorecard, 323 ; score-card judging, 322 ; scratching-shed, 343 ; Silkies, 316 ; sorting uneven flocks, 330 ; Spanish, 308 ; Sultan, 316 ; symmetry, 324 ; turkey, 317; types of, 307,374 ; vitality, 374 ; wattles and ear lobes, 324 ; weight, 324 ; wings, 326 ; Wyandotte, 314 ; yards, parks, and ranges, 346 ; young, 321.

Poultry house, floors, 345 ; labor-saving appliances, 345 ; size, 341 ; windows, 344.

Price, John, 122.

Prides, 124.

Princess of the Blicqs, 115.

Productive ration, 63-64.

Protein, 56 ; function of, 59.

Pullet, see Poultry.

Pumpkins for swine, 288.

Quality in beef cattle, 139; in dairy cattle, 134 ; in hogs, 277 ; in sheep, 225.

Quarantine lot for swine, 302.

Queens, 124.

Races, running, 6.

Ram, see Sheep.

Rambouillet fine-wool sheep, 203 ; compared with American Merino, 204.

Ranges for poultry, 346.

Ratio, nutritive, 359.

Ration, 63; Armsby's method, 67 ; for calf, 154 ; for beef production, 186 ; for dairy cow, 154, 363; balanced, 65 ; computing, 65 ; cost of, for hor'se, 75 ; food for, 359 ; forming, 359 ; for horse, 68,361 ; individual, 73 ; maintenance, 63 ; sample for the horse, 78 ; sample for poultry, 334 ; sample for sheep, 244 ; for swine, 292 ; productive, 63-64; for sheep, 373 ; WolfLehman method, 66.

Records, of Ayrshire cattle, 117 ; Guernsey cattle, 115; Holstein-Freisian cattle, 113; Jersey cattle, 110.

Red Cap fowl, 308.

Red Polled cattle, 128.

Reed, Alexander, 201.
Registration of farm animals, 84 .

Rena Ross, 117.

Rhode Island Red fowl, 314.

Ring-bone, 39.

Roasters, 334.

Rooster, see Poultry.

Roots for swine, 288; and tubers, 152.

Rope, halter, 354 ; splicing, 352 ; whipping end, 357.

Rosaire's Olga 4th's Pride, 110.

Royal Mares, 5.

Russian hog, 261.

Rysdyks Hambletonian, 12.

Saanen goat, 221.

Saddle horse compared with Thoroughbred, 11; gaited, 11 ; gaits, 11.

Salt, 190; for the horse, 72.

Sanitary milk, 157.

Santa Anita course, 8.

Saratoga course, 8.

Schales, 15.

Schwargthal goat, 221.

Score-card, beef cattle, 137 ; dairy cattle, 131; horse, 40 ; method of using, 40 ; poultry, 323 ; sheep, 223 ; swine, 275 .

Scoring, rules of, 41 .

Scratches, 39.

Secret, 120.

Self-feeder, 190.

Seymour, Richard, 212.

Shadingfield tribe, 28.

Shales, 15.

Shammar race, 9.

Shearing sheep, 250; hand, 250; machine, 251.

Sheep, 197; American Merino, 199; barns, 253, 374; bedding, 238, 255; Blackfaced Highland, 218; breeding, 246; breeds of, 197 ; care, 246 ; care of feet, 237 ; changing pasture, 235 ; class $A, B$, and $C, 198$; cheviot, 213 ; constitutional vigor, 226 ; Cotswold, 215; cuts of mutton, 230; detail characters, 226; description of American Merino, 200, dipping, 248 ; dips, 249; docking lambs, 251 ; Dorset-Horned, 212 ; estima- 
tion of age, 223; examination of fleece, 229; exercise, 237 ; fattening, 238; fine-wool type, 198 ; feeding, 232 ; feed-racks, 255 ; food requirements, 233; general appearance, 223; habits of, 349 ; Hampshire, 208 ; hot-house lambs, 237 ; improvements, 246 ; judging, 222 ; Leicester, 214; Lincoln, 217; market classes, 230; method of . catching, 222; method of holding, 222; mutton type, 198; mutton, 204; Oxford Down, 209 ; pasture, 234 ; points of, 196; quality, 225; Ramboullet, 203 ; ration, 373 ; sample rations, 243 ; score-card, 223 ; shade for, 236; shearing, 250; Shropshire, 206 ; Southdown, 204 ; sown pasture, 236 ; Suffolk Down, 210; summer feeding, 234 ; tying wool, 251 ; uniformity, 226, 247 ; vigor, 226 ; weight and condition, 225; winter feeding, 237.

Sheepshead Bay course, 8.

Shetland pony, 30 .

Shields, 15 .

Shire draft horse, 25; compared with Percheron, 25.

Shoat, see Swine.

Shoeing the horse, 88.

Shorthorn beef cattle, 119; compared with Aberdeen Angus, 124; with Galloway, 126; with Hereford, 122 ; description, 121 ; families, 120.

Shoulder, sweeney, 39.

Shropshire mutton sheep, 206; compared with Southdown, 207.

Siamese hog, 262.

Side-bone, 39 .

Silage, 151 ; measuring, 362.

Silkies fowls, 316 .

Silo, 170 ; filling, 171.

Silver, L. B., 266.

Skimmed milk, test, 366 ; for calf, 153 ; for swine, 289.

Small Black swine, 267.

Small White swine, 267.

Small Yorkshire lard-hog, 267.

Soiling, 149; for swine, 287.

Sophie 19th of Hood Farm, 110.
Soundness, in horse breeding, 84; in horses, 351.

Southdown mutton sheep, 204 ; compared with Cheviot, 213, with Dorset-Horned, 212, with Hampshire, 209, with Oxford Down, 210, with Shropshire, 207, with Suffolk Down, 211 ; description, 206; fleece, 201. Sow, see Swine.

Spanish fowl, 308.

Spanish hog, 263.

Spavin, 40.

Splint, 39.

Spotswood Daisy Pearl, 115.

Spring lambs, 239.

Springers and milkers, 142.

Squashes for swine, 288.

Stables for sanitary milk, 157.

Stallion, see Horses.

Standardbred horse, 11; compared with Thoroughbred, 12 ; families, 12.

Steer, 141 ; see Beef cattle.

St. Leger course, 6 ; track record, 8.

Stockers and feeders, 142.

St. Mawes Poppy, 110.

Succulent feeds for dairy cattle, 151.

Suffolk Down mutton sheep, 210; compared with Southdown, 211.

Suffolk draft horse, 27 ; compared with Percheron, 28.

Suffolk lard-hog, 268.

Sultan fowl, 316.

Sussex cattle, 128.

Sweeney collar, 100.

Swine, 257 ; bacon-hog, 259 ; breeding, 296 ; breeds of, 259; care, 295: Cheshire, 269; Chester White, 265; description of Poland China, 261; diseases, 301 ; dipping, 298; DurocJersey, 263 ; fattening, 289 ; feeding, 284 ; food for, 285; Hampshire, 266 ; heavy, 282 ; hog cholera, 302 ; hog .lot, 301 ; hog-wallows, 301; house, 299; improvement, 295; judging, 275; lard-hog, 259; Large Yorkshire, 271 ; market classes, 281 ; Middle Yorkshire, 270; pasture for, 287 ; points of, 258; Poland China, 260; quality, 277; quarantine lot, 302; sample rations, 292; score- 
card, 275 ; selecting breeding stock, 296 ; soiling, 287 ; Tamworth, 272; uniformity, 298; Victoria, 270.

Tamworth bacon-hog, 272; compared with Large Yorkshire, 272.

Teeswater cattle, 119.

Teeth, cattle, 130; care of, 85 .

Temperament, in dairy cattle, 135 ; the horse, 47.

Testing milk, 161.

Texas and western range cattle, 142.

The Abbess of Torr, 117.

The Harvester, 14.

Therm, 67.

Thoroughbred horse, 4 ; compared with Arabian, 10, with Saddle horse, 11, with Standardbred, 12 ; description, 6 ; races, 6.

Thoroughpin, 40.

Todd Brothers, 265.

Todd, S. H., 265.

Todd's Improved Chester White, 265.

Toggenburg goat, 221.

Tompkins, Richard and Benjamin, 122.

Tormentor's Loss, 109.

Track records, 8 ; American, 8.

Training the colt, 90 .

Training-cart, 96.

Trakehnen horse, 18.

Transhumantes sheep, 199.

Trotter, 11.

Trotting records, 14.

Tuberculosis in cattle, 172 ; methods of infection, 172 ; prevention, 173.

Tubers and roots, 152.

Tuley, Joseph, 272.

Turkey, 317 ; described, 317.

Two Thousand Guineas course, 6.

Twynham, John T., 209.

Types of horses, 3.

Udder, 136.

Uhlin, 14.

Unsoundness of horse, 38 .
Veal calves, 143.

Ventilation of dairy barn, 167; King's system, 167.

Venus, 120.

Victoria, 120.

Victoria hog, 270; compared with Cheshire, 270.

Violet, 120.

Walk-trot-canter horse, 11.

Wallace, John, 261.

Warder's Lady, 110.

War Horse, 25.

Water, 56 ; function of, 58 .

Watering, the milking cow, 47 ; the foal, 78 ; the horse, 72 .

Waterloo, 120.

Water-tanks, 192.

Watson, Hugh, 124.

Webb, Jonas, 205.

Webster, Daniel, 263.

West Down sheep, 209.

West Highland cattle, 128.

Welsh pony, 30 .

White Heifer That Traveled, 120.

White Strawberry, 120.

Wild Eyes, 120.

Wiltshire-horned sheep, 208.

Winter lambs, 238.

Wolff-Lehman standard, 66; for dairy cattle, 144; for beef cattle, 179; for the horse, 71; for sheep, 233; for swine, 284.

Wool, 372 ; tying, 251.

Woodcrest Meta Vernon DeKol, 103.

Wright tribe, 28.

Wyandotte fowl, 314 .

Yards for poultry, 346.

Yeksa Sunbeam, 115.

Yorkshire horse, 20.

Zenoleum, 249.

Zambora, 14. 

$T^{\mathrm{HE}}$ following pages contain advertisements of a few of the Macmillan books on kindred subjects 



\title{
Warren's Elements of Agriculture
}

\author{
By G. F. WARREN, Professor of Farm Management and \\ Farm Crops, New York State College of Agriculture at Cor- \\ nell University
}

Cloth, I2mo, 456 pages, $\$$ r.ro net

Written by Professor G. F. Warren, who is in charge of the Department of Farm Management and Farm Crops in the New York State College of Agriculture, Cornell University, an authority on questions pertaining to practical agriculture.

Professor Warren is, moreover, a farmer. He grew up on a farm in the middle West and is living at the present time on a farm of three hundred and eighteen acres, which he supervises in connection with his work at the University.

The "Elements of Agriculture" is a text that does not "talk down" to the pupil. It gives agriculture rank beside physics, mathematics, and the languages, as a dignified subject for the course of study.

In Warren's "Elements of Agriculture " there is no waste space. It is written with the ease that characterizes a writer at home in his subject, and it is written in a style pedagogically correct. The author has been a teacher of high school boys and girls and knows how to present his subject to them.

Experts in the teaching of agriculture the country over have been unanimous in praise of the text. For instance:

\section{Mr. J. E. Blair, Supt. of Schools, Corsicana, Texas :}

"An examination of Warren's ' Elements of Agriculture ' convinces me that it is a book of uncommon merit for secondary schools as well as for the private student. It is thoroughly scientific in matter, and is written in an attractive style, that cannot fail to please as well as instruct."

\section{Supt. E. S. SmirH, Whiting, lowa :}

"I am very much pleased with Warren's 'Elements of Agriculture.' In my opinion it is the only book on the market that presents the work of agriculture suitably for high schools; too many books are too simple and do not give enough work; a book for high schools must be more than a primer."

\section{THE MACMILLAN COMPANY}

Publishers

64-66 Fifth $\Delta$ venue

Now York 


\section{RURAL SCIENCE SERIES}

Edited by L. H. BAILEY

On Selection of Land, etc.

Isaac P. Roberts' The Farmstead . . . . - \$1 50

On Tillage, etc.

F. H. King's The Soil . . . • . . . 150

Isaac P. Roberts' The Fertility of the Land $: \quad: \quad 150$

F. H. King's Irrigation and Drainage . . : : : 150

Edward B. Voorhees' Fertilizers . : . . . : 125

Edward B. Voorhees' Forage Crops : . . . : 150

J. A. Widtsoe's Dry Farming . : : : : : 150

L. H. Bailey's Principles of Agriculture : ! : : 125

On Plant Diseases, etc.

E. C. Lodeman's The Spraying of Plants - - - . 125

On Garden-Making

L. H. Bailey's Garden-Making - . • . . 150

L. H. Bailey's Vegetable-Gardening $: \quad: \quad \vdots \quad: \quad 150$

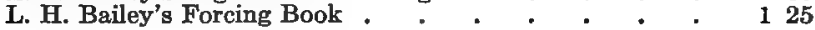

On Fruit-Growing, etc.

L. H. Bailey's Nursery Book . - . . . . 150

L. H. Bailey's Fruit-Growing . • : • : * : 150

L. H. Bailey's The Pruning Book : : : : : : 150

F. W. Card's Bush Fruits $\quad$ : : : : : : 150

On the Care of Live-stock

Nelson S. Mayo's The Diseases of Animals . . . . 150

W. H. Jordan's The Feeding of Animals : : : : 150

I. P. Roberts' The Horse

M. W. Harper's Breaking and Training of Horses : : 150

George C. Watson's Farm Poultry. . . • . . 125

On Dairy Work, Farm Chemistry, etc.

Henry H. Wing's Milk and Its Products . . . . 150

J. G. Lipman's Bacteria and Country Life : : : : 150

On Economics and Organization

I. P. Roberts' The Farmer's Business Handbook . . 125

George T. Fairchild's Rural Wealth and Welfare : : 125

H. N. Ogden's Rural Hygiene. . . . . : : 150

J. Green's Law for the American Farmer : : : : 150

\section{THE MACMILLAN COMPANY \\ PUBLISHERS 64-66 Fifth Avenue NEW YORK}




\section{Cyclopedia of American Agriculture}

Edited by L. H. BAILEY

Director of the College of Agriculture and Professor of Rurai Economy,
Cornell University.

With 100 full-page plates and more than 2,000 illustrations in the text; four volumes; the set, $\$ 20.00$ net; half morocco, $\$ \$ 2.00$ net; carriage extra

\section{VOLUME I-Farms}

VOLUNG II-Crope
VoLUME III-Animals

VOLUME IV-The Farm and the Community

"Indispensable to public and reference libraries... readily comprehensible to any person of average education."-The Nation.

"The completest existing thesaurus of up-to-date facts and opinions on modern agricultural methods. It is safe to say that many years must pass before it can be surpassed in comprehensiveness, accuracy, practical value, and mechanical excellence. It ought to be in every library in the country."-Record-Herald, Chicago.

\section{Cyclopedia of American Horticulture}

\section{Edited by L. H. BAILEY}

With over 2,800 original engravings; four volumes; the set, $\$ 20.00$ net; half morocco, $\$ 32.00$ net; carriage extra

"This really monumental performance will take rank as a standard in its class. Illustrations and text are admirable. . . . Our own conviction is that while the future may bring forth amplified editions of the work, it will probably never be superseded. Recognizing its importance, the publishers have given it faultless form. The typography leaves nothing to be desired, the paper is calculated to stand wear and tear, and the work is at once handsomely and attractively bound."-New York Daily Tribune.

\section{THE MACMILLAN COMPANY}

PUBLISHERS

64-66 Fifth Avenue
NEW YORK 


\title{
NEW EDITIONS OF STANDARD WORKS
}

\section{Farm Poultry}

By GEORGE C. WATSON, M.S.

Professor of Agriculture in the Pennzylvania State College

New edition revised and reuritten. Illustrated. Cloth, 12 mo. $\$ 1.50$ net.

This is one of the few books designed especially to help the practical farmer in the keeping of poultry. Published originally ten years ago, it contained the gist of the best accepted advice of the day, presenting only those facts that had been proved by experience and which were most capable of application on the farm. The volume has now undergone thorough revision, new ideas and teachings, so far as they safely apply to farm conditions, being incorporated. It is not a fancier's work. The plan of the original has been kept, but the new material in text and pictures is considerable.

\section{Milk and Its Products}

\author{
BY HENRY H. WING \\ Professor of Dairy Husbandry in Cornell University \\ New edition revised. With new illustration. \\ Cloth, 12mo. $\$ 1.50$ net.
}

Professor Wing has thoroughly revised his book, which since its publication has gone through thirteen large editions and has come to be recognized as the standard in its field. The matter relating to milk and its manufacture into butter and cheese has been rewritten in the light of the most recent practice. In addition a chapter has been added on the production of certified milk, a chapter containing complete directions for making simple bacteriological determinations, one on ice-cream and one containing a brief sketch of the leading breeds of dairy cattle.

\section{THE MACMILLAN COMPANY \\ PUBLISHERS \\ 64-66 Fifth Avenue \\ NEW YORK}















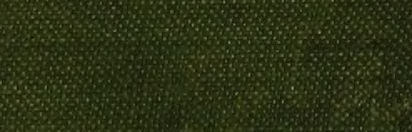

.

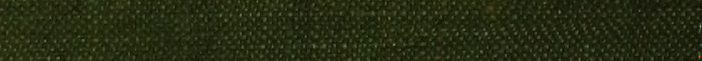

(6)

nontos

$\therefore$<smiles>C=CCCCCCC</smiles> 